José Carlos da Silva França

\title{
In situ, ex situ: O virtual como \\ elemento-chave entre o objeto de arte e \\ seus usuários
}

Programa de Pós-Graduação Interunidades

em Estética e História da Arte

São Paulo, 2018 
José Carlos da Silva França

\section{In situ, ex situ: O virtual como elemento-chave entre o objeto de arte e seus usuários}

Trabalho apresentado ao Programa de Pós-Graduação Interunidades em Estética e História da Arte (PGEHA) da Universidade de São Paulo como requisito para a obtenção do título de Doutor em Artes na Área de Concentração Estética e História da Arte

Universidade de São Paulo

Orientador: Profa. Dra. Lisbeth Rebollo Gonçalves

Programa de Pós-Graduação Interunidades

em Estética e História da Arte

São Paulo

Julho de 2018 
Autorizo a reprodução e divulgação total ou parcial deste trabalho, por qualquer meio convencional ou eletrônico, para fins de estudo e pesquisa, desde que citada a fonte.

Catalogação na Publicação

Serviço de Biblioteca e Documentação

Faculdade de Filosofia, Letras e Ciências Humanas da Universidade de São Paulo

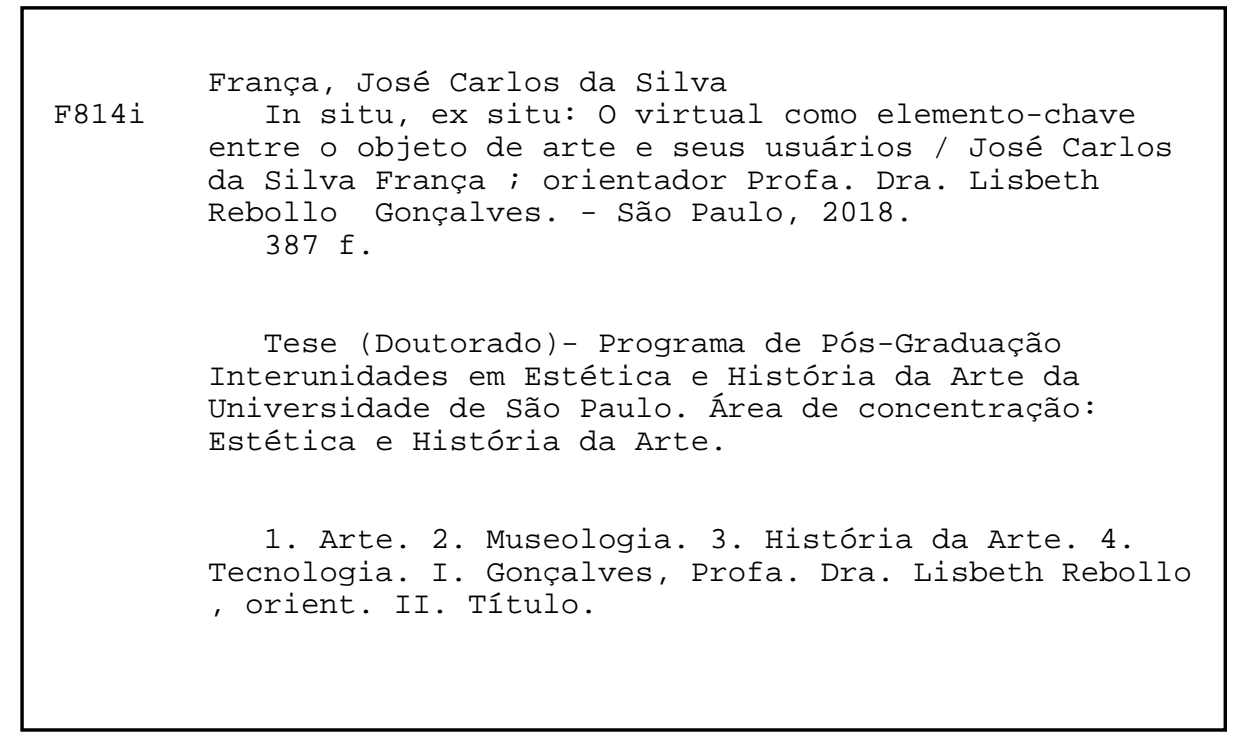


Nome: FRANÇA, José Carlos da Silva.

Título: In situ, ex situ: $O$ virtual como elemento-chave entre o objeto de arte e seus usuários.

Dissertação de Doutorado apresentada ao Programa de Pós Graduação Interunidades em Estética e História da Arte da Universidade de São Paulo para obtenção do título de doutor em Artes.

Área de Concentração: Estética e História da Arte.

Aprovado em:

Banca Examinadora:

Profa. Dra. Lisbeth Rebollo Gonçalves

Orientador

Prof. Dr.

Instituição:

Julgamento:

Prof. Dr.

Instituição:

Julgamento:

Prof. Dr.

Instituição:

Julgamento:

Prof. Dr.

Instituição:

Julgamento: 
Dedico estas linhas a Lélio e Irene França, os quais aguardavam, ansiosos, o momento desta defesa; mas que partiram - por caminhos diferentes, súbitos, dolorosos e inesperados - pouco antes deste momento se concretizar. Sem eles esta dissertação não existiria. 


\section{Agradecimentos}

Agradeço a todos os integrantes do PGEHA e do MAC-USP por sua dedicação e disponibilidade em todos os momentos onde uma dose de experiência se fez necessária.

À minha orientadora e minha co-orientadora: Muito obrigado pela paciência em sinalizar o caminho que trilhei como neófito. Sem a vossa visão ainda estaria no início da estrada, sem ideia do rumo a seguir.

Stephen Fry, Paul Springer and Tim Stephens: Thank you very much guys, you rock!

A todos os amigos e companheiros de jornada que dedicaram seu precioso tempo em comentários, análises, subsídios e estímulo, minha eterna gratidão. Gisele Franco, Nelsita Trimer e Victor França: Meu agradecimento a vocês pela presença em todos os momentos críticos.

Por fim, agradeço à Professora Ivette Claide Furlan Franco pela sua dedicada, amorosa e essencial tarefa de revisão do conteúdo. 


\section{Resumo}

Um breve olhar sobre o passado recente do museu e sua convivência com a tecnologia nas duas últimas décadas, irá trazer à tona um fato relevante: não se trata mais de questionar se as instituições de arte devem possuir presença virtual, mas sim quando. E se esta presença terá maturidade suficiente para que a experiência da recepção se torne tão ou mais valiosa do que o olhar e a sensação direta do espectador em três situações distintas: frente ao objeto de arte, na ampliação da experiência in situ da produção artística e na utilização de modelos e mecânicas ex situ (através de aplicativos conectados à Internet e nas situações de novos espaços híbridos, os quais fazem convergir tanto o real quanto o virtual).

A tecnologia traz ao universo da arte promessas de ampliação do espaço de atuação do museu através daquela. As expectativas geradas por tais promessas não se realizam de forma simples e natural.

Esta dissertação busca o estudo de procedimentos para a inserção do virtual como prolongamento do espaço do museu - e a subsequente geração de modelos de emissão de conteúdo via redes de comunicação. Sugere caminhos para tais modelos, diante de um espectador habituado ao uso de aparelhos de intermediação e recepção. Considera as diferenças de significação, para o espectador, entre a exposição no modelo tradicional e aquela que se baseia em um desdobramento virtual. Valida a inserção da tecnologia como parte deste processo, ao entender a exibição como um processo de mediação e ativação.

Os meios eletrônicos atuam no sentido de ativar as possibilidades de acesso remoto a contextos e conteúdos. Ao ser ativado virtual e remotamente, o museu ganha a possibilidade de preencher espaços outrora inexplorados.

O escopo da análise se dá no entendimento da relação entre a produção a ser exposta no modelo tradicional e aquela que ocorre através do mundo virtual.

Tendo o arcabouço teórico da estética da recepção como pano de fundo, busca refletir sobre os procedimentos a serem desenvolvidos quando da criação de experiências virtuais na configuração dos meios de acesso do público ao museu. Destarte, é possível colaborar com as disciplinas ligadas à Estética, História da Arte, Crítica da Arte e Arte-educação; pois todas elas têm, numa visão presente e futura, interesse em utilizar soluções que permitam disseminar conteúdo através dos meios eletrônicos.

Palavras-chave: arte. museu. tecnologia. virtual. imagem. estética. recepção. crítica. história. 


\section{Abstract}

A brief glimpse over the recent past of the museum and its relationship with technology will bring to view a significant fact: it is not a matter of questioning if they must have a virtual presence but when that should happen. Additionally, how strong and worthwhile will be that interaction? Will the remote experience be strong enough in order to overturn the one that happens right in front of the visitor? There are three situations where that assertive must be tested: right in front of the work of art, in the process of expanding the experience that results from the art production and the use of devices and networks (through applications connected to the Internet or navigating into new hybrid spaces, a convergence of both real and virtual worlds).

Considering the vacuum that exists, in the art domain, between the user reception and all the procedures that are necessary in order to make it effective, this study has the goal of investigating operational procedures, methodologies and techniques that may allow the inception of virtual models as an expansion of the museum physical space, and consequently their results: the generation of plataforms and models for sharing content from those virtual models, into an audience that is already used to deal with devices as their medium of reception. In bridging both the real and virtual worlds, this research aims to consider the different meanings, to the public, of a tradicional exhibit and its virtual counterpart. The insertion of technology as part of that workflow, when considering an exhibit as a process that acts as both activation and mediation.

The fact that the museum is able to get into the viewer's space without the need of physical transportation, thus filling spaces that were previously uncharted, is a major consideration in this study.

The search aims to the understanding of those relationships that arise when the traditional model of an exhibition - adopted by museums since their foundation - shares its space with virtual exhibits and data sharing via Internet and social networks.

It is the scope of this research to have a grounding on the Theory of Reception to reflect and suggest procedures, in order to enhance the virtual contexts that are going to be an essential part of the viewer's experience.

Keywords: art. museum. technology. virtual. image. aesthetics. reception. critique. history 


\section{Sumário}

1 INTRODUÇÃO $\ldots \ldots \ldots \ldots \ldots \ldots$

2 A RECEPÇÃO do OBJETO dE ARTE PELO USUÁRIO . . . . 16

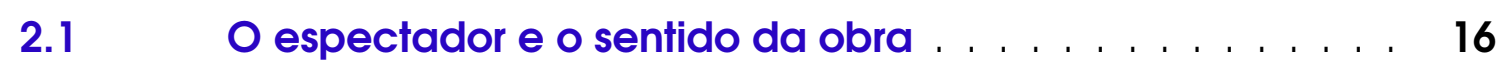

2.2 A experiência in situ transferida ao mediador eletrônico . 27

2.3 Da ambientação à virtualização . . . . . . . . . . . . 30

$2.4 \quad \mathrm{O}$ (relativamente) novo contexto . . . . . . . . . . 33

2.5 Características de uma nova configuração . . . . . . . 37

3 MODELOS TECNOLÓGICOS DISPONÍVEIS . . . . . . . . 41

3.1 A tecnologia como elemento integrador: uma introdução 41

3.1.1 Pressupostos ....................... 41

$3.1 .2 \quad$ Histórico . . . . . . . . . . . . . . . . . . . . . . . 42

3.1.3 Tecnologias experienciais . . . . . . . . . . . . 47

$3.1 .4 \quad$ O guia de áudio . . . . . . . . . . . . . . . . . 48

3.2 Tecnologias baseadas em dispositivos móveis . . . . . 50

3.2.1 Código QR (Quick Response) . . . . . . . . . . . . . . . . 52

3.2 .2 Realidade virtual ................. 56

3.2.3 Realidade aumentada . . . . . . . . . . . . . . . 58

3.2.4 Internet das Coisas (IoT) . . . . . . . . . . . . . 61

3.3 O avanço da conectividade . . . . . . . . . . 75

3.4 Adequação da tecnologia à museologia $\ldots \ldots \ldots$

4 CRITÉRIOS NO USO DA TECNOLOGIA . . . . . . . . . 85

4.1 Campo de atuação e sua conformidade . . . . . . . . 85

4.2 Os 4 critérios ligados à definição . . . . . . . . . . . . . 90 
4.2.1 Parcerias tecnológicas e geração de recursos . . . . . . . 91

4.2.1.1 Pressupostos . . . . . . . . . . . . . . . . . . . . . . . 91

4.2 .1 .2 Implementação . . . . . . . . . . . . . . . . . . 95

4.2 .2 Digitalização . . . . . . . . . . . . . . . . . . . . . . . . . . . 99

4.2.2.1 Pressupostos . . . . . . . . . . . . . . . . . . . . . . . . 99

4.2.2.2 Implementação . . . . . . . . . . . . . . . . 103

4.2.2.3 Gerenciamento do conteúdo . . . . . . . . . . . . . . . . 113

$4.2 .3 \quad$ Plataforma aberta $\ldots \ldots \ldots \ldots \ldots$

4.2 .3 .1 Pressupostos . . . . . . . . . . . . . . . . 118

4.2.3.2 Implementação . . . . . . . . . . . . . . . . . . . 124

4.2 .4 Internet e redes sociais . . . . . . . . . . 126

4.2 .4 .1 Pressupostos . . . . . . . . . . . . . . . . . . 126

4.2 .4 .2 Implementação . . . . . . . . . . . . . . . . . . . . 129

5 CONCLUSÃO . . . . . . . . . . . . . . . . . 139

$5.1 \quad$ Desafios e oportunidades . . . . . . . . . . . . . . 139

$5.1 .1 \quad$ O modelo tecnológico . . . . . . . . . . . . . . . . 142

5.1 .2 Simplicidade . . . . . . . . . . . . . . . . . . . . 144

$5.1 .3 \quad$ Etapas .......................... . . 145

5.1 .4 Planejamento ..................... . . 145

5.1 .5 Reprodutibilidade . . . . . . . . . . . . . . . . . 147

$5.2 \quad$ À guisa de conclusão $\ldots \ldots \ldots \ldots \ldots$

Referências . . . . . . . . . . . . . . . . . . . . 149

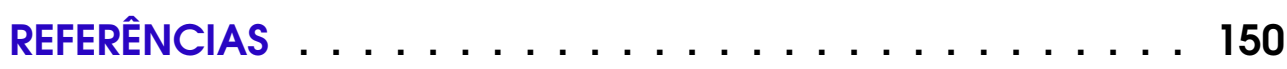

A GRÁFICOS E TABELAS . . . . . . . . . . . . . . . 159

B REPRODUÇÕES/TRANSCRITOS . . . . . . . . . . 165 
C ART IN AMERICA EM 01/10/2014 . . . . . . . . . . 166

D SIte DO tATE MUSEUM EM $18 / 04 / 2013 \ldots \ldots \ldots$

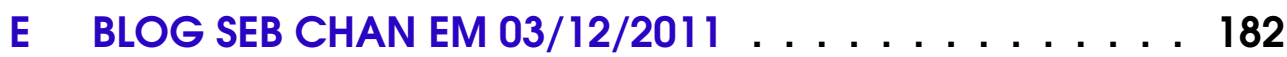

F KOVEN SMITH EM 11/04/2011 . . . . . . . . . . 191

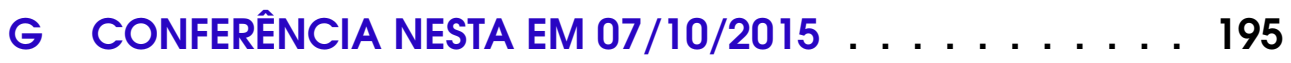

H GUIA DE PROCEDIMENTOS FOTOGRÁFICOS PARA REPRODUÇÃO DE OBJETOS MUSEOLÓGICOS . . . . . . . . . 260

I GLOSSÁRIO DE PADRÕES DE METADADOS . . . . . . 301

Lista de ilustrações . . . . . . . . . . . . . . . 320

Lista de tabelas . . . . . . . . . . . . . 321

J GLOSSÁRIOS E ÍNDICES . . . . . . . . . . . . . . . 322

Glossário . . . . . . . . . . . . . . . . . . . . . . 323

Siglas . . . . . . . . . . . . . . . . . . . . 380

Índice Remissivo . . . . . . . . . . . . . . . . . . 383 


\section{Introdução}

Um breve olhar sobre a relação entre o museu e o desenvolvimento da tecnologia baseada em computadores e redes, nas duas últimas décadas, irá nos trazer de imediato um fato relevante: não se trata mais de questionar se as instituições de arte devem possuir presença no mundo gerado pela eletrônica, mas sim quando.

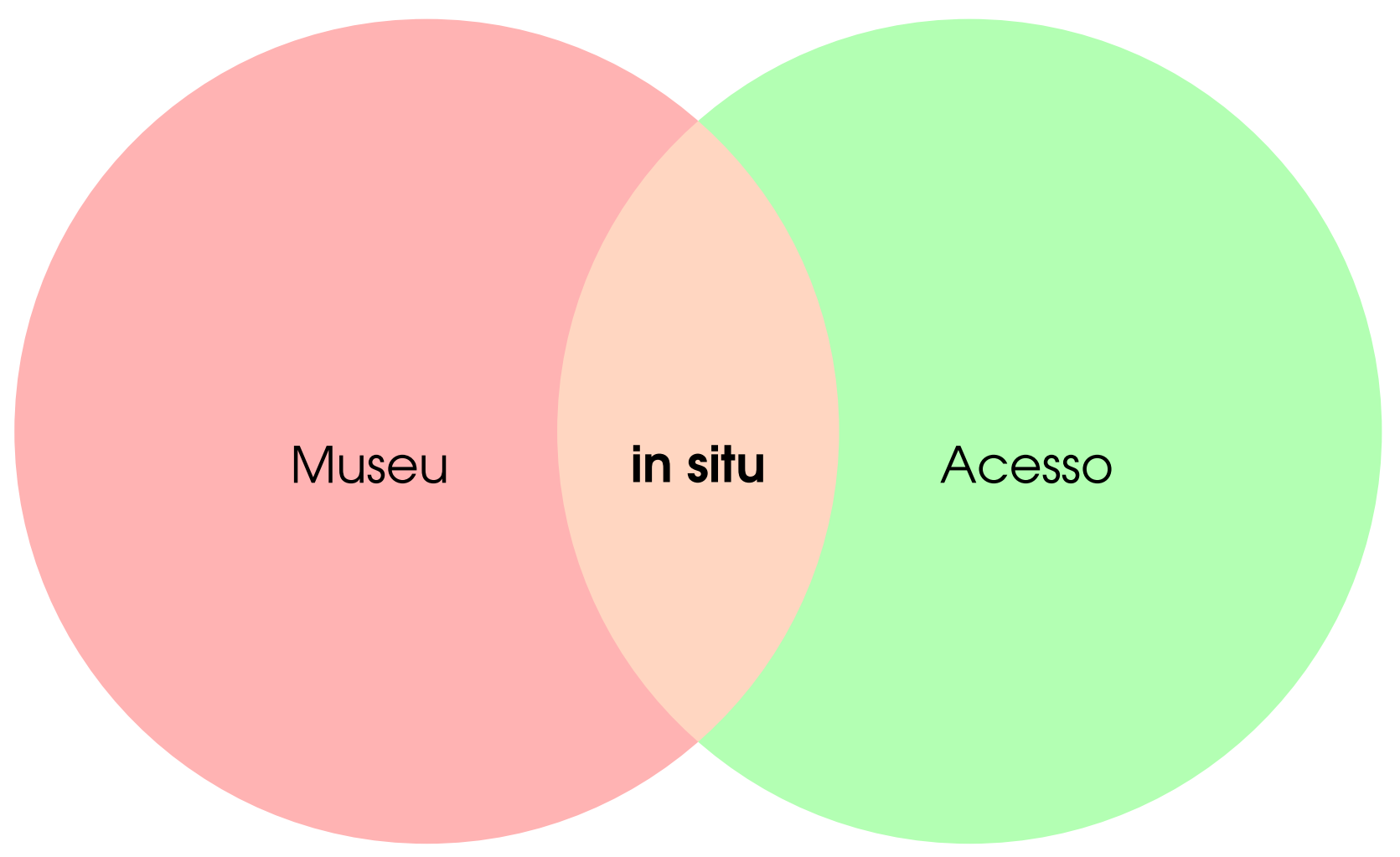

Figura 1 - Contexto clássico do expectador

Diferente do contexto clássico - onde o objeto de arte se apresenta de forma direta ao espectador, sem a necessidade de intermediação de 
artefatos eletrônicos - o contexto virtual gera, a partir de sua presença, uma nova e densa camada de informação - a qual, muitas vezes, se manifesta de forma invisível ao espectador - passível de múltiplos tipos de intervenção, formatação e interpretação. Onde a situação ideal surge da confluência entre os três atores.

\section{Museu}

\section{ex situ}

Acesso

Tecnologia

Figura 2 - Contexto virtual do expectador 
A partir do pressuposto de que o envolvimento de diversos setores do museu - os quais são fundamentais à sua existência e administração - necessitam, na contemporaneidade, de ferramentas que possibilitem interagir com um público que se faz conectado de modo cada vez mais precoce, surgem questões de alcance amplo e complexo.

Uma delas é: A inevitável presença virtual dos museus na vida do seu público terá maturidade suficiente para fazer com que experiência da recepção virtual ex situ se torne tão ou mais valiosa do que o olhar e a sensação direta do espectador in situ?

Acoplados à questão acima - e funcionando como requisito para a resposta - estão os contextos onde a presença da tecnologia pode se tornar agente de mudança:

- frente ao objeto de arte

- na ampliação da experiência da produção artística através de aplicativos conectados à Internet

- nas situações de novos espaços híbridos, os quais fazem convergir tanto o real quanto o virtual

- nos processos internos da instituição: catalogação, indexação, pesquisa, estudo, análise e compartilhamento de informações pertinentes ao objeto de arte

- na disponibilização daqueles processos internos ao público externo, sejam estes pesquisadores ou espectadores

Ao mesmo tempo em que tais situações impõem ação por parte do emissor, a tecnologia traz ao universo da arte mais promessas do que realidades, o que torna tais atributos desejáveis - mas não acessíveis de forma simples e natural. 
As possibilidades que a tecnologia apresenta aos participantes do processo de transição traz inúmeros desafios.

E dá origem a novas perguntas:

- Qual é o modelo tecnológico, em cada um dos quatro contextos acima, que representa a melhor relação entre os recursos existentes e a maximização de resultados?

- Qual deles será mais eficiente e rápido na implementação?

- Como será o fluxo de trabalho (workflow) dentro do museu quando da adoção da tecnologia e ao longo de sua vida útil (manutenção)?

- Qual é a garantia de que o modelo adotado não se tornará rapidamente obsoleto, inviabilizando assim o processo de virtualização de processos e acervos e gerando novo problema ao invés de soluções?

Os meios eletrônicos atuam no sentido de ativar a possibilidade de acesso remoto ao conteúdo outrora permitido apenas àqueles capazes de se locomover até ele. Ao ser ativado virtual e remotamente, o museu ganha a possibilidade de preencher espaços outrora inexplorados. Tal assertiva, porém, não ocorre de modo simples ou automático. As três questões acima se interpõem e se influenciam mutuamente; somente com respostas precisas a todas elas é que se pode considerar válido o caminho adotado rumo à virtualização.

A título de exemplo: uma das inúmeras variáveis que determinam a arquitetura de um projeto de tecnologia dentro do museu é o tipo de software a ser utilizado como fundação do edifício virtual. A existência de modelos e plataformas baseados em código aberto (open source), passiveis de utilização sem a necessidade de licenças de uso onerosas, decerto permite ampliar e democratizar a referida transição. Mesmo assim, os profissionais aptos a transformar o código binário em soluções eficientes 
existem em número reduzido e podem representar enorme dispêndio financeiro para a instituição.

que se pode depreender do exemplo é que não existe um caminho $100 \%$ seguro quando se trata de definir o modelo tecnológico a ser adotado para o Museu.

O objetivo deste trabalho é pesquisar a relação entre a produção a ser exposta no modelo tradicional e aquela que ocorre através da emissão virtual e do compartilhamento eletrônico, considerando para tanto o ambiente téorico ideal fornecido pelos estudiosos da Estética da Recepção; pois no campo eletrônico/virtual a ação do espectador/leitor/usuário é fundamental na construção tanto do contexto quanto do sentido:

Sendo assim, de acordo com sua posição histórica e experiências anteriores, o leitor vai conquistando, aos poucos, seu papel como produtor de sentidos. ${ }^{1}$

trabalho se divide em três capítulos principais:

1. Na primeira parte (Capítulo 2) se busca o entendimento das fundações do contexto virtual a partir da teoria desenvolvida pelos estudiosos da Estética da Recepção. Neste quadro se destacam duas frentes: de um lado, a busca do entendimento do papel do espectador, sua relação com o objeto de arte e seu papel como produtor de sentido; de outro, a atuação das ferramentas eletrônicas que incorporam a informação necessária para a atuação do espectador através dos intermediários eletrônicos

2. A segunda parte (Capítulo 3) estuda os modelos tecnológicos mais habilitados a interagir de forma eficiente com ambos museu e espectador, e como tal adequação pode se dar de forma adequada e viável

$1 \operatorname{COSTA}(2014$, p. 1) 
3. A terceira parte (Capítulo 4) expõe tais modelos, exemplificando a utilização de parâmetros e critérios de gestão do contexto virtual dentro de ambiente do museu

Devido à amplitude de possiveis soluções e desdobramentos, o escopo da dissertação é o estudo e análise de algumas das possibilidades que os museus têm à sua disposição, com ênfase naquelas que representem duas características principais:

1. Existir em formato de código aberto

2. Resiliência frente à obsolescência tecnológica

A partir do estudo do cruzamento destas características, se pretende contribuir para o entendimento das possiveis soluções e caminhos que podem ajudar o museu a definir sua trajetória no mundo virtual. 


\section{A recepção do objeto de arte pelo usuário}

\subsection{O espectador e o sentido da obra}

Enquanto nas ciências da computação o sentido do exposto pode ser rigorosamente codificado, na arte (seja como expressão ou cultura ${ }^{1}$ ) este só pode ser apreendido quando a compreensão pertence à própria percepção ${ }^{2}$. A experiência perceptiva e o entendimento do resultado da produção artística, assim como o ato de se fazer entender pelo espectador, são fatores prioritários em relação à sua historicidade ${ }^{3}$. Estes fatos impedem, desde o início, que se pense o objeto de arte apenas como fruto de codificação; mas sim como possibilidade de discurso ao receptor e sua consequente sensibilização, carregando em si ambivalência e ambiguidade.

1 "Existe a arte como expressão e a arte como cultura. A arte como expressão, como já disse, é a capacidade de os indivíduos interpretarem suas ideias através das diferentes linguagens e formas. A arte como cultura trabalha o conhecimento da história, dos artistas que contribuem para a transformação da arte."Meira (2005, p. 186)

2 Dufrenne (1970, passim)

3 "... it is true that that everyone who experiences a work of art incorporates this experience wholly within himself: that is, into the totality of his self-understanding, within which it means something to him. I go so far as to assert that the act of understanding, including the experience of the work of art, surpasses all historicism in the sphere of aesthetic experience." Gadamer (2004, p. 27) 
Apesar disto, a obra que adentra o museu necessita de procedimentos de classificação e indexação rigorosos, que agregam uma nova camada de significação e permitem sua integração ao acervo.

Ou seja: o objeto de arte carrega consigo, desde o momento em que é incorporado ao museu como patrimônio, informações precisas sobre sua procedência, autoria e história, além das especificidades técnicas ligadas ao suporte e material utilizados. Os procedimentos de catalogação deveriam incluir a produção de imagens da mais alta qualidade possível, mostrando a obra sob diversos ângulos. Também incluem, dependendo da antiguidade ou grau de importância histórica: radiografias, espectografias $^{4}$ e outros tipos de imagens técnicas, documentos e laudos de alta complexidade. Todo esse conhecimento incorporado à obra funciona como meta-informação e metadados ${ }^{5}$ (metadata ${ }^{6}$ ), elementos vitais não somente na arte, como também em qualquer processo contemporâneo ligado ao conhecimento. Desta forma se dá, na atualidade, a catalogação da produção artística no inventário do museu: através da informação inserida em camadas indiretas.

A partir do momento em que a obra se torna o núcleo de camadas de informação, as quais atingem o receptor antes mesmo de comprovada a existência física da mesma, se torna evidente que a admissão do conceito de arte como conhecimento absoluto em si mesmo, capaz

4 Derrick, Stulik e Landry (1999)

5 Metadados, ou Metainformação, são dados sobre outros dados. Um item de um metadado pode dizer do que se trata aquele dado, geralmente uma informação inteligível por um computador. Os metadados facilitam o entendimento das conexões e relações e a utilidade das informações dos dados.

<http://pt.wikipedia.org/wiki/Metadados> Acesso em: 20 mai. 2014

6 Metadata is data that gives information about other data. Descriptive metadata is information to help discover and identify a resource. Structural metadata describes the different parts of a resource (for example, title or abstract). Administrative metadata provides the information that helps to manage a resource, such as when and how it was created. There are a variety of metadata schemes and element sets that define what metadata should be included for different types of resources, these vary by discipline and environments. 
de chamar a atenção do receptor apenas pelos seus atributos visiveis, se torna comprometido:

\begin{abstract}
Quando a arte passa a se valer preferencialmente de linguagens denotativas que produzem mensagens como cópia ou reflexo da realidade, relega-se a um segundo plano a possibilidade de a obra comportar-se como uma pluralidade de significados. Nestes casos, ocorre a dominância da função referencial da linguagem ... que organiza os signos ao pôr em evidência o referente - o assunto ao qual a mensagem se refere. ... nestas situações, a obra de arte tende a comunicar. Ela se destaca como uma mensagem que transmite uma informação objetiva sobre a realidade, representando objetos, temas, assuntos (fora dela), e assim provoca o desvio da atenção do receptor para o objeto de que se fala e não para a obra em si mesma. Por conseguinte, não captura o receptor pelo que ela (obra) é em si mesma, mas pelo que ela referencia ${ }^{7}$.
\end{abstract}

O desvio da atenção do receptor pode significar que este se torna co-produtor da obra que contempla, desvinculado de qualquer responsabilidade ou necessidade de questionamento em relação à sua produção ${ }^{8}$. Dando assim ao espectador a conquista, de forma gradual, o papel de produtor de sentidos.

Ao se abordar o objeto de arte sob a lente da estética da recepção, e com o entendimento de que, no contexto aqui abordado: o vocábulo "texto" se abre à ambiguidade da representação não somente da palavra escrita mas também daquilo que se contempla nas artes visuais; e o vocábulo "leitor" representa o espectador frente a qualquer processo midiático,

O papel do leitor representa, sobretudo, uma intenção que apenas se realiza através dos atos estimulados no receptor. Assim entendidos, a estrutura do texto e o papel do leitor estão intimamente ligados. ${ }^{9}$

Uma vez estabelecido o papel fundamental do leitor/espectador, a sensibilidade deste na apreensão do conteúdo se torna o elemento-chave

7 Tavares (2003, p. 33)

8 "... art no longer bears the responsibility for its own philosophical definition." Danto (1998, p. 38)

9 Iser (1996, p. 75) 
para a eventual interpolação do espaço físico para o virtual, pois ambos são objetos que podem ser percebidos e apreendidos:

... a obra de arte espera a percepção que lhe faça justiça. Isso quer dizer que ela é, essencialmente, um objeto a ser percebido: ela encontra a plenitude do seu ser e o princípio mesmo do seu valor na plenitude do sensível. Agradar não é afagar a sensualidade, é, principalmente, satisfazer a sensibilidade. ${ }^{10}$

O entendimento do papel do espectador e sua relação com o objeto de arte se torna essencial para a criação de espaços virtuais, pois estes têm sua existência validada quando se dá a interação com o usuário. A partir da prioridade dada ao papel do espectador e da asserção de que "cada fruição é, assim, uma interpretação e uma execução, pois em cada fruição a obra revive numa perspectiva original" ${ }^{11}$, um museu virtual passa a representar novas categorias e perspectivas de percepção do objeto de arte. A ideia de fruição como elemento fundamental da recepção da obra e da experiência estética permite imaginar a transposição do ambiente físico para o eletrônico com a possibilidade de se enriquecer as interpretações e, consequentemente, aumentar as possibilidades de interpretação. Sua integração e complementaridade com a realidade do núcleo duro - o museu físico - traz ao espectador as duas pontas de um processo:

... um ciclo de alimentação recíproco entre o pólo da produção e o da recepção. Este modo não passivo de consumo da obra produz sempre variadas interpretações que, por sua vez, fomentam novos insumos, novas descobertas que então realimentam esse processo de recepção estética. $^{12}$

A recepção através dos meios eletrônicos implica na ativação em diversos níveis. Desde o acionamento físico do equipamento a ser utilizado pelo usuário até a sua efetiva participação através da interface disponibilizada,

10 Dufrenne (1972, p. 51)

11 Eco (1968, p. 40)

12 Tavares (2003, p. 41) 
... a mise en scène da exposição tem papel fundamental no processo comunicativo de seus conteúdos. A exposição pode ser entendida como um processo de comunicação, uma mediação. Nesse sentido, ela implementa informações culturais voltadas para o visitante, para seu receptor. Ela é, sempre, uma "ativação"13

Ao definir a exposição como uma "ativação", Gonçalves acaba por validar a inserção dos meios eletrônicos como parte deste processo. Pois estes atuam, justamente, no sentido de ativar a possibilidade de acesso remoto ao conteúdo outrora permitido apenas àqueles capazes de se locomover até ele. Ao ser ativado virtual e remotamente, o museu ganha e preenche espaços outrora inexplorados.

As obras de Jauss, Iser e Hall servem de âncora ao entendimento do processo de recepção.

As sete teses elaboradas por Jauss ${ }^{14}$ auxiliam no entendimento da recepção a partir da transição das paredes físicas para as eletrônicas.

\begin{tabular}{lll}
\hline Tese Descrição & Correspondência \\
\hline 1 & A historicidade da Literatura não & Uma das principais características \\
se dá pela cronologia das obras, & de um museu virtual é justamente \\
mas pelo diálogo dinâmico com & o diálogo dinâmico com a obra, a \\
a obra literária por parte de seus & partir da interface eletrônica. \\
leitores. & \\
\hline $2 \quad$ A experiência literária do leitor & O saber prévio se dá no presente, \\
pressupõe um "saber prévio" - & através do acesso aos metadados \\
conjunto de suas experiências, & e complementos da informação dis- \\
tanto de leitura quanto de vida, & poníveis ao longo da rede mundial \\
que desperta expectativas e aci- & de computadores (Internet). \\
ona uma determinada postura & \\
emocional. &
\end{tabular}

13 Gonçalves (2004, p. 18)

14 Jauss, Bahti e Man (1982) 


\section{Tese Descrição}

Diz respeito à distância estética - o afastamento ou nãocoincidência entre o horizonte de expectativas do leitor e o horizonte de expectativas suscitado por uma obra. Segundo essa tese, o caráter estético dos textos é determinado pelo público leitor, porque considera as diferentes épocas em que a obra foi lida (ampliação/acomodação do horizonte de expectativas).

4 Os sentidos de um texto são construídos ao longo da história. O tempo histórico do leitor influencia na construção desses sentidos para o texto. Só se pode compreender um texto quando se compreender a pergunta para a qual ele constitui uma resposta. A reconstrução do horizonte de expectativas (Erwartungshorizont) de uma obra é um aspecto fundamental para essa construção do sentido.

5 O lugar de uma obra na série literária não pode ser determinado apenas em razão de sua recepção inicial. Leituras posteriores modificam uma obra, pondo-a, historicamente, em um momento diferente daquele que foi produzida. Na Estética da Recepção, as obras literárias são consideradas um conjunto aberto de possibilidades, uma vez que podem adquirir novos sentidos a cada leitura, o que permite um constante reavaliar dos textos literários. Essa tese considera, portanto, o aspecto diacrônico da obra.

\section{Correspondência}

A capacidade de se atualizar constantemente as informações acerca da obra torna ambos objeto de arte e leitor abertos a múltiplas possibilidades. A possibilidade de acréscimo infinito de elementos informativos, metadados e relações cruzadas através de hiperlinks torna a obra permanentemente aberta, em um processo contínuo de acomodação e ampliação do horizonte de expectativas.

A expectativa da utilização de interfaces digitais para o acesso ao objeto de arte e informações correlatas se relaciona ao condicionamento do usuário por experiências similares já realizadas em outros quadrantes do conhecimento e pelo domínio, ainda que incipiente, da ferramenta eletrônica que dá acesso ao museu. $O$ indicador para determinar o horizonte de expectativas é a recepção do conteúdo virtual por parte do espectador.

A possibilidade de renovação constante de conteúdos e acréscimo de informações, anotações e comentários - característica presente nos meios eletrônicos - amplifica as possibilidades abertas ao leitor $e$ permite leituras renovadas a cada momento de acesso. O aspecto evolutivo (diacrônico) da comunicação eletrônica se revela mais ligeiro do que a capacidade de assimilação do leitor. 


\begin{tabular}{lll}
\hline Tese Descrição & Correspondência \\
6 & A história literária deve conside- & O aspecto sincrônico nos meios vir- \\
rar as sucessivas recepções da & tuais se mostra aparente no meio \\
obra (aspecto diacrônico) ao & utilizado no presente e nas possibi- \\
longo do tempo e em relação & lidades inerentes a este; enquanto \\
à recepção no momento de sua & a diacronia se mostra presente na \\
produção. Essa tese refere-se ao & constante evolução das possibilida- \\
corte sincrônico, no qual o ca- & des técnicas do meio (aumento \\
ráter histórico da obra literária é & de velocidade de acesso e pro- \\
visto pelo viés atual. Para melhor & cessamento, novas interatividades, \\
compreender a historicidade da & adição de novos conteúdos). \\
obra, há que se considerar o en- & \\
contro dos aspectos sincrônico & \\
e diacrônico. & \\
\hline Observa os aspectos diacrônico & Os efeitos sociais, éticos e psicológi- \\
e sincrônico e abarca a expe- & cos de uma sociedade conectada \\
riência cotidiana do leitor, rom- & a redes de informação e apara- \\
pendo com seu horizonte de & tos eletrônicos se fazem sentir de \\
expectativas, possibilitando uma & forma cada vez mais intensa no \\
visão crítica quanto à leitura da & presente; o efeito estético sobre \\
obra em questão e quanto à lei- & tal sociedade, aliado à experiência \\
tura de obras posteriores. Consi- & cotidiana do espectador na intera- \\
dera, além do efeito estético da & ção entre os mundos físico e virtual, \\
obra, também seu efeito social, & define o porvir do sucesso da recep- \\
ético e psicológico. & ção e experiência relacionadas aos \\
& museus virtuais. \\
\hline
\end{tabular}

Para Iser, a relação entre o leitor e o texto se dá através de interações. A parte ativa cabe ao leitor no ato da leitura - momento no qual participa no processo de criação textual e da criação do significado. A leitura é movida pelas reações e respostas do leitor. Tais reações são, em parte, geradas pelo repertório e estrutura do texto; são, porém determinadas pela subjetividade do leitor. Embora veja o leitor como criador ativo do sentido, confere ao texto um papel ativo, importante para contrabalançar as interpretações subjetivas ${ }^{15}$.

15 "The process of assembling the meaning of the text is not a private one, for although it does mobilize the subjective disposition of the reader, it does not lead to day-dreaming 
Iser classifica o texto como uma estrutura que permite ao leitor fugir do seu quadro de convenções ${ }^{16}$, iniciando assim uma conversação entre as partes, a qual não deve ser vista como unidirecional: o texto, ao invés de somente trazer a mensagem ao leitor, permite a este inserir suas próprias ideias no processo comunicativo ${ }^{17}$.

Além disso, Iser argumenta que a leitura não deve ser vista como um processo linear que se desenrola ao longo do tempo; mas sim como um processo recursivo, de auto-correção ${ }^{18}$ e de natureza cibernética ${ }^{19}$,

but to the fulfillment of conditions that have already been structured in the text" Iser (1980, p. 49-50)

$16 "$ "... a structure that enables the reader to break out of his accustomed framework of conventions..." Id., 1980, p. 50

17 "The literary text, then, exists primarily as a means of communication, while the process of reading is basically a kind of dyadic interaction ... (the reader) is bound to insert his own ideas into the process of communication" Ibid., p. 66-67

18 "Já disse que o homem e o animal têm uma sensibilidade cinestésica, por meio da qual mantêm um registro da posição e tensões de seus músculos. Para que qualquer máquina sujeita a um meio externo variado possa atuar de maneira efetiva é necessário que a informação concernente aos resultados de sua própria ação the sejam fornecidos como parte da informação com base na qual ela deve continuar a atual. Por exemplo, se estivermos manejando um elevador, não basta abrir a porta externa porque as ordens que tenhamos dado devam fazer o elevador estar diante dessa porta no momento em que a abrimos. É importante que o desengate para a abertura da porta dependa do fato de que o elevador se encontre realmente diante da porta; de outra maneira, algo poderia tê-lo detido e o passageiro despencaria no poço vazio. Tal controle da máquina com base no seu desempenho efetivo em vez de no seu desempenho esperado é conhecido como realimentação (feedback) e envolve membros sensórios que são acionados por membros motores e desempenham a função de detectores ou monitores - isto é, de elementos que indicam um desempenho. A função desses mecanismos é a de controlar a tendência mecânica para a desorganização; em outras palavras, de produzir uma inversão temporária e local da direção normal da entropia." Wienner (1968, p. 24)

19 Tentativa de compreender a comunicação e o controle de máquinas, seres vivos e grupos sociais através de analogias com as máquinas eletrônicas (homeostatos, servomecanismos, etc.). Estas analogias tornam-se possiveis, na Cibernética, por esta estudar o tratamento da informação no interior destes processos como codificação e descodificação, retroação ou realimentação (feedback), aprendizagem, etc. Segundo Wiener (1968), do ponto de vista da transmissão da informação, a distinção entre máquinas e seres vivos, humanos ou não, é mera questão de semântica.O estudo destes autômatos trouxe inferências para diversos campos da ciência. A introdução da ideia de retroação por Norbert Wiener rompe com a causalidade linear e aponta para a ideia de círculo causal onde A age sobre B que em retorno age sobre A. Tal mecanismo é denominado regulação e permite a autonomia de um sistema (seja um organismo, uma máquina, um grupo social). Será sobre essa base que Wiener discutirá a noção de aprendizagem.

<https://pt.wikipedia.org/wiki/Cibernética> Acesso em: 10 de dez. de 2015 
onde o novo conhecimento adquirido modifica o antigo e assim, de forma sucessiva e em camadas, a compreensão se torna mais ampla, tal qual uma câmara de amplificação 20 .

Enquanto Iser sugere a existência de um diálogo entre o texto e seu leitor, a interatividade do mundo virtual permite a adicionar extensões a este diálogo, através da participação de outros leitores e seus comentários e anotações, os quais passam a fazer parte indelével do objeto de arte e servir de referência para amplificação do entendimento. O potencial de interação permite ao processo que se torne participatório e comunitário, criando um sentido mais concretamente intersubjetivo. $\bigcirc$ papel ativo do leitor se potencializa e suas reações e respostas se tornam aceleradas devido à dinâmica do computador. no processo eletrônico, o diálogo entre o leitor e a informação fornecida pela máquina é obrigatório e prevalente.

museu virtual somente se justifica com a existência do diálogo traduzido em ação de troca informativa e participativa - comentários, anotações, compartilhamento e interatividade (Figura 3). Ao realizar tais operações, opera de forma plena e consolida o processo de recepção e interação preconizados por Iser.

Hall, em sua teoria da comunicação, sugere um modelo teórico de produção e disseminação de mensagens através de 4 estágios: produção, circulação, consumo e reprodução. O autor avança na ideia de que os espectadores têm papel ativo na decodificação das mensagens, pois se baseiam em seus próprios contextos sociais, sendo assim capazes de modificar, através da ação coletiva, a mensagem. Quando se decodifica a mensagem, se extrai o significado desta em termos simples de se entender.

20 "The reader's communication with the text is a dynamic process of self-correction, as he formulates signifieds which he must then continually modify." Ibid., p. 67 
Decodificar é, portanto, o entendimento através daquilo que já se sabe,

baseado na informação recebida. Significa obter, absorver, entender e,

eventualmente, utilizar a mensagem (Figura 3). Embora seus exemplos

utilizem como objeto a televisão, é possível extrapolar o modelo para

a tela dos artefatos computadorizados: o discurso eletrônico, enquanto

parte de uma rede, envolve o espectador e o torna, simultaneamente, emissor e receptor do conteúdo, tornando estes dois pólos diretamente

relacionados - momentos diferenciados no processo comunicativo ${ }^{21}$.

21 "The institutional structures of broadcasting, with their practices and networks of production, their organized relations and technical infrastructures, are required to produce a programme. Production, here, constructs the message. In one sense, then, the circuit begins here. Of course, the production process is not without its 'discursive' aspect: it, too, is framed throughout by meanings and ideas: knowledge-in-use concerning the routines of production, historically defined technical skills, professional ideologies, institutional knowledge, definitions and assumptions, assumptions about the audience and so on frame the constitution of the programme through this production structure. Further, though the production structures of television originate the television discourse, they do not constitute a dosed system. They draw topics, treatments, agendas, events, personnel, images of the audience, 'definitions of the situation' from other sources and other discursive formations within the wider socio-cultural and political structure of which they are a differentiated part. Philip Elliott has expressed this point succinctly, within a more traditional framework, in his discussion of the way in which the audience is both the 'source' and the 'receiver' of the television message. Thus - to borrow Marx's terms - circulation and reception are, indeed, 'moments' of the production process in television and are reincorporated, via a number of skewed and structured 'feedbacks', into the production process itself. The consumption or reception of the television message is thus also itself a 'moment' of the production process in its larger sense, though the latter is 'predominant' because it is the 'point of departure for the realization' of the message. Production and reception of the television message are not, therefore, identical, but they are related: they are differentiated moments within the totality formed by the social relations of the communicative process as a whole. At a certain point, however, the broadcasting structures must yield encoded messages in the form of a meaningful discourse. The institution-societal relations of production must pass under the discursive rules of language for its product to be 'realized'. This initiates a further differentiated moment, in which the formal rules of discourse and language are in dominance. Before this message can have an 'effect' (however defined), satisfy a 'need' or be put to a 'use', it must first be appropriated as a meaningful discourse and be meaningfully decoded. It is this set of decoded meanings which 'have an effect', influence, entertain, instruct or persuade, with very complex perceptual, cognitive, emotional, ideological or behavioural consequences. In a 'determinate' moment the structure employs a code and yields a 'message': at another determinate moment the 'message', via its decodings, issues into the structure of social practices. We are now fully aware that this re-entry into the practices of audience reception and 'use' cannot be understood in simple behavioural terms. The typical processes identified in positivistic research on isolated elements - effects, uses, 'gratifications' - are themselves framed by structures of understanding, as well as being produced by social and economic relations, which shape their 'realization' at the reception end of the chain and which permit the meanings signified in the discourse to 


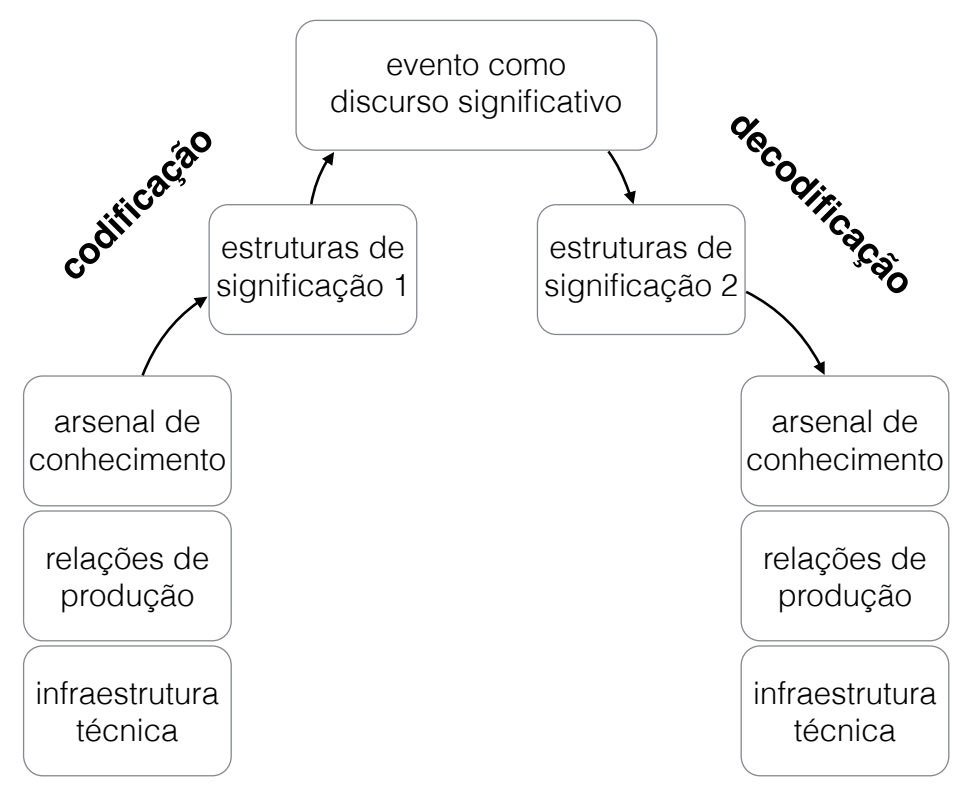

Figura 3 - Codificação/decodificação segundo Hall

Dentro das molduras conceituais definidas acima pela Estética da Recepção - e no escopo dos meios eletrônicos - a representação virtual, embora possa reproduzir o objeto de arte de forma cada vez mais realística e fiel, não é transparente em relação a esta representação pois necessita da mediação e articulação da linguagem em condições e relações reais. O código necessário para a geração de realidades virtuais cria o discurso inteligível e assegura o papel do receptor em frente à tela mutante e fluida do aparato tecnológico ${ }^{22}$. Fluidez esta,

be transposed into practice or consciousness (to acquire social use value or political effectivity)." Hall (1974, p. 92-93)

22 "Reality exists outside language, but it is constantly mediated by and through language: and what we can know and say has to be produced in and through discourse. Discursive 'knowledge' is the product not of the transparent representation of the 'real' in language but of the articulation of language on real relations and conditions. Thus there is no intelligible discourse without the operation of a code. Iconic signs are therefore coded signs too - even if the codes here work differently from those of other signs. There is no degree zero in language. Naturalism and 'realism' - the apparent fidelity of the representation to the thing or concept represented - is the result, the effect, of a certain specific articulation of language on the 'real'. It is the result of a discursive practice." lbid., p. 95 
geradora de um novo ambiente de interação e protocolos sociais e culturais. Que não se relacionam à ideia de evolução, mas de um ciclo infinito e auto-alimentador, baseado na informação disponibilizada em formato eletrônico. O chamado "novo ambiente sociocultural", tema de Santaella, define o ". . a afluxo avassalador dos signos, para a exacerbada dilatação que rende ao infinito das bordas difusas do ciberespaço e para as novas órbitas de circulação das linguagens agora inexoravelmente atreladas aos corpos em movimento ... "23.

É dentro deste panorama - simultaneamente ordenado e caótico que se dá a passagem do museu concreto, núcleo duro institucional, para a esfera virtual.

A "dilatação do presente"24 e a multidimensionalidade proporcionadas pela tecnologia, juntamente com o campo ampliado de possibilidades abarcado pela arte 25 , se transformam em padrão de conduta e ação, determinantes do sentido. E tudo isto necessita se encaixar no formato de recepção no qual o espectador se ache confortável.

\subsection{A experiência in situ transferida ao medi- ador eletrônico}

Embora a experiência direta seja considerada essencial no entendimento do objeto de arte, tanto na contemporaneidade quanto nos

Santaella (2007, p. 26)

24 Meira (2010, p. 1301)

25 "Em um campo ampliado de possibilidades, as manifestações artísticas dos últimos 50 anos, transgridem a filiação estética que compõe a história da arte, e, nos obrigam a repensar conceitos. As formas complexas de arte descrevem uma dilatação do presente" Id., 2010, p. 1301 
modelos tradicionais de manifestação artística ${ }^{26}$, o inevitável potencial de persuasão advindo dos meios eletrônicos pode gerar possibilidades inovativas e disruptoras, amplificando a noção da produção in $\operatorname{situ}^{27}$ e levando o local do evento a coincidir com aquele em que o espectador se encontra no momento do acesso à informação através dos meios eletrônicos.

Apresentam-se como parâmetros comparativos entre a exposição tradicional - o museu - e aquela proposta pelas novas ferramentas eletrônicas, a ligação intrínseca do saber com o imaginário, exposta por Didi-Huberman (1998), assim como a afirmação de Walter Benjamin sobre uma trama singular de espaço e de tempo ${ }^{28}$. $\bigcirc$ mundo dos fenômenos reais, tal como é percebido na contemporaneidade pelos sentidos, tem demonstrado que a objetivação da coisa em si - o objeto de arte enquanto conteúdo e conceito - é transformada na relação com o espectador $^{29}$. Mas esta transformação não se dá, necessariamente, dentro do espaço tradicional:

Enquanto o local de exposição constituía um meio em si para os artistas conceituais, hoje ele se tornou um local de produção entre outros. Agora não é tanto uma questão de analisar ou criticar esse espaço, e sim de situar sua posição dentro de sistemas de produção mais amplos, com os quais é preciso estabelecer e codificar relações. ${ }^{30}$

Situar a produção artística em sistemas mais amplos implica sua inserção nos protocolos de emissão e recepção contemporâneos. A utilização da tecnologia e dos meios virtuais se torna, assim, o prolongamento

\footnotetext{
26 (MEIRA, 2010; MICHAUD, 2003, passim)

27 "A produção de uma experiência in situ se torna primordial no fazer artístico, onde as transações e relações descrevem a essência; o procedimento e a postura substituem as propriedades." (MEIRA, 2010, p. 1301)

28 (BENJAMIN, 1996, Acesso em 20 mai. 2014)

29 "Transformation became the spectator's rather than the artist's role... In transforming what is present in the gallery - which resists transformation - we are becoming the creator, painlessly." O'doherty (1999, p. 99)

30 Bourriaud (2009, p. 82)
} 
natural de um processo que inclui todos os canais possíveis à disposição da civilização

Onde nenhum deles é mais o centro ou define a órbita dos demais:

É o socius, ou seja, a totalidade dos canais que distribuem e repercutem a informação, que se torna o verdadeiro local de exposição para o imaginário dos artistas dessa geração. O centro de arte ou a galeria são casos particulares, mas fazem parte de um conjunto mais amplo: a praça pública. ... Dessa forma, não se trata de opor a galeria de arte (local da "arte separada", portanto, mau) a um espaço público idealizado como local do "bom olhar" sobre a arte, o olhar dos transeuntes, ingenuamente fetichizados tal como antes se idealizava o "bom selvagem". A galeria é um local como os demais, um espaço imbricado num mecanismo global, um acampamento de base indispensável a qualquer expedição. Um clube, uma escola ou uma rua não são lugares melhores, são simplesmente outros lugares para mostrar a arte. $^{31}$

Dada a capacidade inerente aos meios eletrônicos de aglutinar, indexar e relacionar canais, o papel principal do museu virtual é agregar e coordenar tudo aquilo que esteja vinculado à informação do objeto de arte. Além disso o museu virtual necessita ampliar a ideia de "mostrar a arte" exposta por Bourriaud e considerar a participação efetiva do público na construção do significado ${ }^{32}$. Na afirmação de que ". . o ambiente tecnocultural emergente desperta o desenvolvimento de novas espécies de arte, ignorando a separação entre emissão e recepção, composição e interpretação"33 se encontra a chave da continuidade do papel do museu como local de possíveis diálogos entre passado, presente e futuro.

\footnotetext{
31 lbid., p. 82-83

32 "The whole meaning of the experience lies in the act of doing it. The work is your act." Brett (1994, p. 61 apud Lygia Clark)

33 Lévy (2007, p. 107)
} 


\title{
2.3 | Da ambientação à virtualização
}

\author{
A transferência de papéis entre a experiência in situ e o mediador \\ eletrônico aponta em direção às dinâmicas virtuais - dentro e fora do \\ espaço do museu:
}

\begin{abstract}
"As operações artísticas instaladas no campo ampliado articulam diversas práticas discursivas em uma ordem de simultaneidade, em forma de montagem, em uma organização de valores estéticos próprios à comunidade de indivíduos a qual a obra se dirige. Nos "deslocamentos", as experiências contemporâneas trazem a sensibilidade, e a imaginação retratando o "atraído" a fabricar sentido. Na qualificação do olhar aproximado, os desafios das novas ordens, do espaço e do tempo, desenham o campo das forças que ali operam, considerando a natureza das ações, levantam a questão do lugar do valor artístico contemporâneo. O entrecruzamento de vários elementos presentes no processo de interação e nos vínculos estabelecidos, indicam as qualidades da troca." 34
\end{abstract}

É crescente o papel dos novos mecanismos de interação, os quais se caracterizam pela via de mão dupla, onde a recepção ocorre a par com a emissão de comentários e imagens, as quais acabam por gerar novos modelos de representação e entendimento do universo midiático do museu.

Dada a dissolução de fronteiras entre a fotografia, a música e a palavra dentro do universo digital, o mesmo processo tende a ser emulado pelo modelo artístico dentro do museu:

Essa arte da pós-produção corresponde tanto a uma multiplicação da oferta cultural quanto - de forma mais indireta - à anexação ao mundo da arte de formas até então ignoradas ou desprezadas. Pode-se dizer que esses artistas que inserem seu trabalho no dos outros contribuem para abolir a distinção tradicional entre produção e consumo, criação e cópia, ready-made e obra original. Já não lidam com uma matéria-prima. Para eles, não se trata de elaborar uma forma a partir de um material bruto, e sim de trabalhar com objetos atuais em circulação no mercado cultural,

34 Ferreira e Cotrim (2006) 
isto é, que já possuem uma forma dada por outrem. Assim, as noções de originalidade (estar na origem de (...) ) e mesmo de criação (fazer a partir do nada) esfumam-se nessa nova paisagem cultural, marcada pelas figuras gêmeas do DJ e do programador, cujas tarefas consistem em selecionar objetos culturais e inserí-los em contextos definidos. ${ }^{35}$

Museu passa a representar outros papéis além dos tradicionais:

... poderíamos dizer que o museu de arte hoje é, simultaneamente, uma tradição, um espetáculo, um lugar político, uma promoção social, uma arena para processos de ação socio-cultural, uma especulação, uma coorporação(sic), uma experiência, bem como alegoria ou metáfora para a explanação, criação e manutenção de outras dimensões de conhecimento. O museu se configura assim como complexidade, grandeza modelada por múltiplas dimensões. ${ }^{36}$

Também passa a conviver com uma sociedade onde "o modelo visual dominante parece ser a feira ao ar livre, o bazar, o mercado aberto, reunião efêmera e nômade de materiais precários e produtos de diversas proveniências. A reciclagem (um método) e a disposição caótica (uma estética), enquanto matrizes formais, suplantam a vitrine e a organização em prateleiras"37.

Por fim, sua oferta cultural se dá para um público "inteligente e potencialmente subversivo: o usuário das formas."

Diante do processo de multiplicação quase infinita de fontes e matrizes proporcionado pelo universo digital, e sua miscigenação em formas híbridas (onde o novo, o original ou o belo não mais representam

35 Bourriaud (2009, p. 8)

36 Grossmann e Mariotti (2011, p. 1)

37 Bourriaud (2009, p. 26-27)

38 "A cultura DJ nega a oposição binária entre a enunciação do emissor e a participação do receptor, que esteve no centro de muitos debates sobre a arte moderna. O trabalho de um DJ consiste na concepção de um encadeamento em que as obras deslizam umas sobre as outras, representando ao mesmo tempo um produto, um instrumento e um suporte. Um produtor é um simples emissor para o produtor seguinte, e agora todo artista se move numa rede de formas contíguas que se encaixam ao infinito. O produto pode servir para fazer uma obra, a obra pode voltar a ser um objeto: instaura-se uma rotação, determinada pelo uso dado às formas." Ibid., p. 41-42 
fatores de diferenciação) ${ }^{39}$, o Museu tem a opção (como alternativa de sobrevivência) de aceitar a transformação que acontece diante de si e utilizar, a seu favor, os novos modelos.

A participação cada vez maior dos mundos virtuais nas práticas ligadas ao museu requer novas formas de integração com os visitantes ${ }^{40}$. A questão da captura fotográfica (Instagram ${ }^{41}$ ) e do auto-retrato ao lado de obras de arte conhecidas ou famosas (selfie ${ }^{42}$ ) é um dos fatores ligados à reação receptiva do público e representa apenas um modelo de inserção de novos formatos de registro dentro de um processo de apreensão e recepção clássicos do objeto artístico.

Ambientação e virtualização podem ser descritos como diferentes modelos de ativação do espectador (Tabela 11).

39 "Todas essas práticas artísticas, embora muito heterogêneas em termos formais, compartilham o fato de recorrer a formas já produzidas, mostram uma vontade de inscrever a obra de arte numa rede de signos e significações em vez de considerá-la como forma autônoma ou original ... Dizendo ainda que a pergunta artística não é mais: "O que fazer da novidade?" e sim; "o que fazer com isso?" Ibid., p. 12-13

40 The relationship of digital technology to museum practices is a field that continues to grow and acknowledge the potential of development. Development that will require new understandings related to museum content travelling across contexts, participatory methods suitable to designing digital technology into museum communication and new forms of relationships with visitors and citizens. Stuedahl e Lowe (2013, p. 303)

41 Rede social online de compartilhamento de foto e vídeo que permite aos seus usuários tirar fotos e vídeos, aplicar filtros digitais e compartilhá-los em uma variedade de serviços de redes sociais, como Facebook, Twitter, Tumblr e Flickr. Uma característica distintiva é que ela limita as fotos para uma forma quadrada, semelhante ao Kodak Instamatic e de câmeras Polaroid, em contraste com a relação a proporção de tela de 16:9 agora tipicamente usado por câmeras de dispositivos móveis. Os usuários também são capazes de gravar e compartilhar vídeos curtos com duração de até 15 segundos. O Instagram foi criado por Kevin Systrom e Mike Krieger e lançado em outubro de 2010. O serviço rapidamente ganhou popularidade: estimativas não-oficiais afirmam existir aproximadamente 100 milhões de usuários ativos (abril de 2012).

<http://pt.wikipedia.org/wiki/Instagram> Acesso em: 20 mai. 2014

42 A selfie is a self-portrait photograph, typically taken with a digital camera or camera phone held in the hand or supported by a selfie stick. Selfies are often shared on social networking services such as Facebook, Instagram and Twitter. They are usually flattering and made to appear casual. Most selfies are taken with a camera held at arm's length or pointed at a mirror, rather than by using a self-timer. A selfie stick may be used to widen the angle of view, such as for group selfies.

<https://en.wikipedia.org/wiki/Selfie> Acesso em: 18 fev. 2015 


\title{
2.4 | O (relativamente) novo contexto
}

\author{
A transferência ou compartilhamento de processos outrora confina- \\ dos a quatro paredes institucionais para um mediador eletrônico atende \\ alguns dos anseios e expectativas sobre o futuro do museu:
}

\begin{abstract}
Um museu do século XXI, seja criado agora ou não, será aquele que se comprometer com aspectos da cultura contemporânea. Não se trata apenas de assimilar as novas técnicas e tecnologias mas de estruturar políticas culturais inovadoras e estimulantes. ... A finalidade última do museu é trazer algum tipo de benefício às pessoas e provocar mudanças em suas vidas, e não ser simplesmente uma casa de custódia para obras de arte ou um centro erudito. Isto implica num constante questionamento de suas funções e propósitos. $^{43}$
\end{abstract}

O caminho, no entanto, possui obstáculos inerentes à função do museu ao longo de um considerável período da história:

\begin{abstract}
O privilégio da conservação sobre a fruição (ou de uma função sobre um propósito), é um aspecto que caracteriza o museu desde o século XIX e ainda se encontra presente nos dias atuais. $O$ processo de reificação que leva o museu a encarar a obra como sendo o objeto na sua materialidade, coloca a preservação do 'objeto único' acima da fruição e da experiência, revive o conceito de aura, do sagrado, daquilo que é apenas para se ver à distância e com respeito. A rigidez que se impõe, impossibilitando qualquer ação que não seja 'adequada', tolhendo o percurso de qualquer caminho que não esteja previsto e impedindo qualquer comportamento que não seja o de contemplação, mostra o quanto o museu precisa caminhar e repensar suas relações com as obras contemporâneas e com o público. Por que não criar réplicas para manuseio quando as obras solicitam uma participação do público? Desta forma não se subtrai a possibilidade lúdica da obra e a experiência do público. Mas para que isto ocorra é preciso que o museu se veja não mais como um reino do olhar e da contemplação, mas um espaço de experiências onde o "momento-arte" possa ocorrer. ${ }^{44}$
\end{abstract}

\footnotetext{
43 Filho (2005)

44 lbid.
} 
Alguns teóricos como Lévy são otimistas em suas enunciações a respeito dos espaços virtuais ${ }^{45}$. Na prática, porém, o caos em que se transformaram as redes sociais na rede mundial de computadores (Internet) - verdadeiros campos de batalhas virtuais em prol de causas obscuras e posições políticas perigosas e mínimo incremento vertical na informação 46 - mostra a necessidade de se contar com a mediação daqueles que, efetivamente, possuem o conhecimento necessário em cada especialidade ligada à prática museológica. De um lado o conhecimento especializado, do outro a transgressão típica da contemporaneidade; eis aqui os dois pontos que necessitam de equilíbrio e representação equalizada no mundo virtual. Tanto a transgressão quanto a especialização necessitam de fontes de informação ágeis e confiáveis, e que possam permitir a utilização e transformação do patrimônio cultural humano em sua plenitude:

Em nossa vida cotidiana, convivemos com ficções, representações e formas que alimentam um imaginário coletivo cujos conteúdos são ditados pelo poder. A arte apresentanos contra-imagens. Diante dessa abstração econômica que desrealiza a vida cotidiana, arma absoluta do poder tecnomercantil, os artistas reativam as formas, habitandoas, pirateando as propriedades privadas e os copyrights, as marcas e os produtos, as formas museificadas e as assinaturas de autor.

Se essas "recargas" de formas, essas seleções e retomadas hoje representam uma questão importante, é porque elas convidam a considerar a cultura mundial como uma caixa de ferramentas, como um espaço narrativo aberto, e não como um relato unívoco e uma gama de produtos acabados.

45 "O ciberespaço poderia abrigar agenciamentos de enunciação produtores de sintomas políticos vivos que permitiriam aos coletivos humanos inventar e exprimir de modo contínuo enunciados complexos, abrir o leque das singularidades e das divergências, sem por isso inscrever-se em formas fixadas de antemão." Lévy (2007, p. 67)

46 ... nos meios de comunicação conhecemos a maioria das noticias, ouvimos debates sobre a esfera pública, e, às vezes, participamos dessa conversa mediante os programas de rádio com telefone aberto e os bate-papos virtuais. Ao mesmo tempo em que os partidos políticos reduziram sua credibilidade e capacidade de representação dos interesses públicos, os meios de comunicação ocupam os lugares de intermediação e deliberação social. A vídeo-política substitui os comícios e a militância partidária. Diários e rádios, muito menos a televisão, informam melhor que no passado, e a mais cidadãos, atos de corrupção e violações de direitos humanos, ou difundem explicações sobre crises ecológicas ou políticas. O acesso cada vez mais amplo à Internet contribui para que múltiplos setores se conectem de forma imediata com informações antes restritas e com frequência as discutam em blogs. "Canclini (2008, p. 22) 
Em vez de se ajoelhar diante das obras do passado, usálas. ${ }^{47}$

Aqui se encontra a maior barreira: ao mesmo tempo em que os museus ao redor do mundo são confrontados com novos desafios e possibilidades inéditas relacionadas aos meios digitais, a tecnologia e os modelos adotados por estas Instituições para a emissão de conteúdos virtuais se apresentam, de modo geral, aquém do desejado. Diversas tentativas de inserir o museu no mundo virtual foram (e ainda são) motivo de frustração (Apêndice F)

A insuficiência dos meios eletrônicos disponiveis ao museu ocorre paralela à democratização da produção imagética, ou seja, a possibilidade dos participantes terem acesso a ferramentas e processos outrora restritos àqueles denominados "artistas" e "fotógrafos profissionais". Onde se propicia, segundo Santaella (2005), o surgimento de novos ambientes socioculturais ${ }^{48}$, através dos

instrumentos de composição de imagens e de transmissão que provocam um curto-circuito - até certo ponto - no sistema tradicional de exposição. O museu se torna então uma "tela de exibição do virtual, o ponto de emergência do organismo difuso e reticular da criação"49

Diante deste contexto, se dá ao objeto de arte a possibilidade de reprodução e acessibilidade infinitas, através da utilização destas ferramentas e processos, agora universais. Onde a mercadoria, agora sem custo visível, indica mudança significativa no modelo e estatuto ontológico outrora válido.

\footnotetext{
47 Bourriaud (2009, p. 110)

48 Santaella (2005, p. 24)

49 Cauquelin (2005, p. 152) e Boissier (1991)
} 
A combinação de reprodutibilidade e acessibilidade transparece naquilo que Krauss denomina a circunstância de que, agora, a tecnologia só pode ser vista através do fato inegável de sua obsolescência ${ }^{50}$.

O espectador carrega, em seu aparelho, um ícone da experiência usufruída frente à obra (quando o museu lhe permite o registro), enquanto o virtual lhe traz, através das redes, a possibilidade de interagir com uma imagem desta em resolução mais alta e informativa, além de informações subjacentes e fundamentais à ampliação do entendimento.

A fluidez trazida pelos meios eletrônicos à arte e, especificamente, à fotografia, gera modelos híbridos que se incorporam às coleções e exposições. Cabe ao museu aproveitar tal maleabilidade em sua missão de divulgar o conhecimento. No campo da fotografia, por exemplo,

\begin{abstract}
... as tecnologias digitais libertaram as imagens de seus suportes materiais, dotando-as de uma fluidez e uma maleabilidade inéditas. O que se vê, já a partir do final da década de 1960, são imagens híbridas resultantes de um diálogo entrecruzado de técnicas e saberes, tais como pintura, escultura, fotografia, vídeo, cinema, teatro, literatura, jornalismo, moda, design, ciência e computação para citar apenas algumas entre múltiplas possibilidades. ${ }^{51}$
\end{abstract}

A fluidez existente no objeto de arte contemporâneo passa a ter sua representação através do conteúdo virtual, em um processo de simbiose onde o conhecimento é conduzido de forma quase autônoma através das redes e dos aparelhos dos espectadores.

O virtual passa a ter seu papel definido: Tal como em um espetáculo52, chamam a atenção do espectador para o inusitado da obra, da qual decorre um modelo de engajamento, o ativar o outro. Os sentidos elásticos instigam os processos de significação; como um lugar de acolhimento, são da ordem de um conhecimento relativo e subjetivo.

\footnotetext{
50 Krauss (1999)

51 Costa (2013, Acesso em: 10 set. 2014)

52 Guy (1992, passim)
} 
Não se trata de trazer ao espectador um modelo inflexível, mas de oferecer a oportunidade de experimentação e criação de significado ${ }^{53}$ em uma estrutura de múltiplas configurações ${ }^{54}$. Mesmo que estas soem, em determinados momentos, como ruído 55

\section{5 | Características de uma nova configura- ção}

O papel ativo do leitor/receptor, aliado ao contexto de transição definido acima, determina alguns critérios para que as situações de recepção e emissão possam ocorrer e faz desejável a integração de diversos componentes que, muitas vezes, caminham isolados no percurso do objeto de arte.

As principais características que passam a existir neste quadro são:

53 "Não se trata mais de impor um acervo de idéias e estruturas acabadas ao espectador, mas de procurar pela descentralização da "arte", pelo deslocamento do que se designa como arte, do campo intelectual racional para o da proposição criativa vivencial; dar ao homem, ao indivíduo de hoje, a possibilidade de "experimentar a criação", de descobrir pela participação, esta de diversas ordens, algo que para ele possua significado. Não se trata mais de definições intelectuais seletivas: isto é figura, aquilo é pop, aquilo outro é realista tudo isto é espúrio! O artista hoje usa o que quer, mais liberdade criativa não é possivel. O que interessa é justamente jogar de lado toda essa porcaria intelectual, ou deixá-la para os otários da crítica antiga, ultrapassada, e procurar um modo de dar ao individuo a possibilidade de "experimentar", de deixar de ser espectador para ser participador. Ao artista cabe acentuar este ou aquele lado dessas ordens objetivas." Oiticica (1986, p. 111)

54 "Obras móveis, mutáveis, com múltiplas configurações, que, se movimentam criando infinitas combinações, se abrem para a ação do sujeito, obras que, abandonando o repouso da escultura tradicional, se tornam objetos relacionais." Meira (2008, p. 47 apud Lygia Clark)

55 "Subcultures represent "noise" (as opposed to sound): interference in the orderly sequence which leads from real events and phenomena to their representation in the media. We should therefore not underestimate the signifying power of the spectacular subculture not only as a metaphor for potential anarchy "out there" but as an actual mechanism of semantic disorder: a kind of temporary blockage in the system of representation." Hebdige (1979, p. 90) 
1. A integração deve se abstrair dos modelos e paradigmas tecnológicos do presente, pois estes se modificam rapidamente ${ }^{56}$

2. O espectador deve ser capaz de interagir e responder aos estímulos gerados pelo objeto de arte ${ }^{57}$

3. A intervenção do público se torna instantânea ${ }^{58}$ e direta - através de comentários, anotações, compartilhamentos ou mera observação e gera nova dimensão de intervenção no objeto artístico

4. As áreas distintas da historiografia e da crítica de arte passam a contar com a possibilidade de trabalharem juntas, como emissários de conteúdo a ser incorporado pelo espectador e seus aparelhos ${ }^{59}$. A curadoria permanente por parte dos profissionais de todas as áreas relacionadas à museologia é fundamental para a sobrevida de um projeto de museu virtual.

5. A obra se torna fluida, porquanto origem de todo o processo e também seu produto final, atuando simultaneamente como elemento significativo e conteúdo

56 "Como as competências em informática evoluem constantemente e têm como objetivo ser um produto de marketing, a dificuldade (com) que nos deparamos, enquanto interlocutores de uma coleção museológica, é a da escolha de um programa. É sempre difícil saber qual o programa mais adequado." Meira (2007, p. 59)

57 "The relationship of digital technology to museum practices is a field that continues to grow and acknowledge the potential of development. Development that will require new understandings related to museum content travelling across contexts, participatory methods suitable to designing digital technology into museum communication and new forms of relationships with visitors and citizens." Stuedahl e Lowe (2013, p. 303)

58 "As novas tecnologias permitem o fluxo de informações praticamente instantâneo, a comunicação globalizada, onde o fenômeno de mundialização ganha grande sedução, criou comunidades on-line onde enxergar o mundo e as produções culturais vindas do além, tornam-se acontecimentos possiveis: poder ter acesso visual a diferentes formas de pensamento estético é realmente interessante. O acesso ainda que virtual a culturas pouco visitadas, regionais, pouco difundidas e reconhecidas é de grande valia." Meira (2007, p. 60)

59 "Uma indexação pensada e aprimorada com constantes revisões revela-se extremamente necessária para as áreas de Fundamentos, Critica e História da Arte. A colocação em cena para a sociedade de um evento, por exemplo, seu testemunho como competência legítima de representação cultural: o seu sentido histórico, sua identidade artística, social e ideológica, é de responsabilidade e deve ser arbitrada por um Historiador de Arte." Ibid., p. 57 
6. O conteúdo virtual deve possuir qualidades intrínsecas tão relevantes quanto a obra em si60

Tais características se manifestam em uma matriz de quatro estados:

Figura 4 - Os 4 momentos da recepção

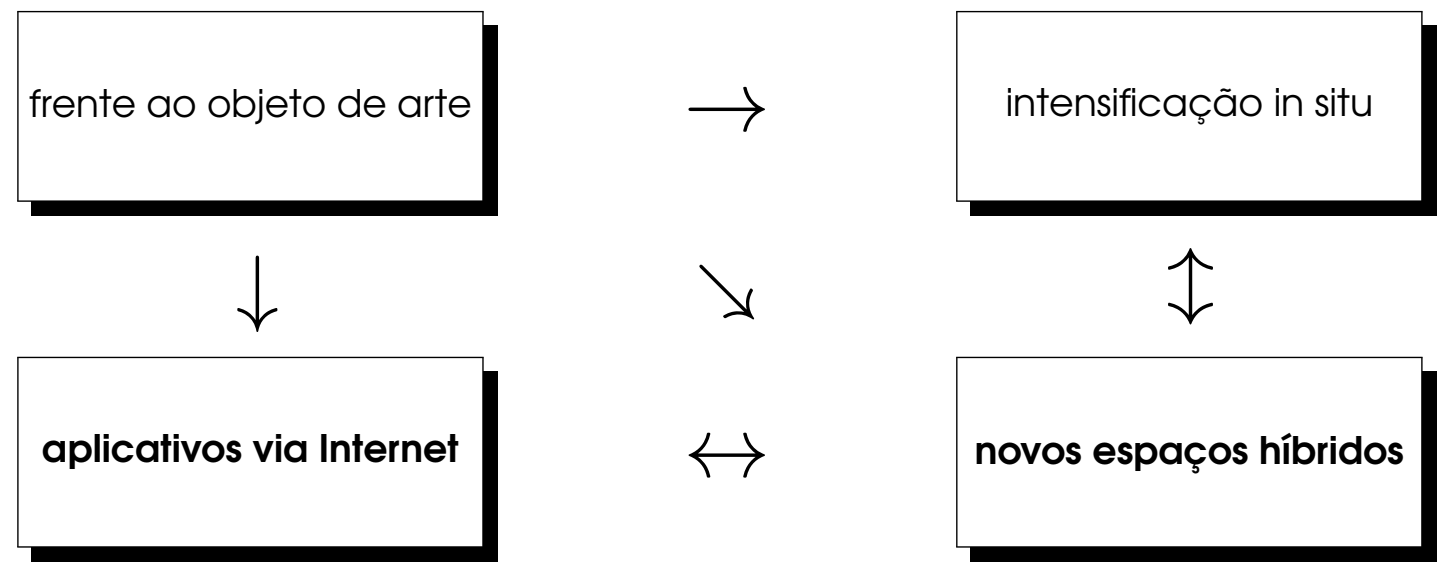

Em relação ao acesso pela Internet, porta de entrada virtual do museu, existem quatro questões fundamentais (Figura D):

1. Existe um caminho rápido e óbvio para se localizar as informações principais relativas ao museu físico (endereço, horários de funcionamento, taxa de admissão etc.)?

2. É possivel acessar de forma clara e compreensivel as informações sobre exibições e eventos sem cair em um labirinto de links de navegação - e ao mesmo tempo adquirir ingressos online se desejado?

3. O acervo se encontra bem representado e acessivel, com ferramentas de pesquisa e navegação simples de se utilizar e excelentes reproduções fotográficas dos objetos de arte?

$60 "$ "... é facilmente previsível que os museus do futuro se organizarão em torno de instalações de realidade virtual que permitam explorar suas coleções de maneira mais envolvente, enriquecedora, e mesmo mais inteligente. Serão exposições virtuais on-line, com obras quase vivas, que ocuparão o lugar das velhas e empoeiradas obras de arte e objetos de coleções tradicionais?" lbid., p. 65 
4. É possivel interagir com os 3 itens acima se o idioma do website não for nativo ao leitor?

A título de referência, os 8 objetivos da estratégia digital do museu Smithsonian (elaborada em 29 de julho de 2009) ${ }^{61}$ são:

\begin{tabular}{ll}
\hline Mission & $\begin{array}{l}\text { Prioritize Web and New Media programs in proportion to } \\
\text { their impact on the mission }\end{array}$ \\
\hline Brand & Strengthen brand relationships throughout the Smithsonian \\
\hline Learning & Facilitate dialogue in a global community of learners \\
\hline Audience & $\begin{array}{l}\text { Attract larger audiences and engage them more deeply } \\
\text { in long-term relationships }\end{array}$ \\
\hline Interpretation & Support the work of Smithsonian staff \\
\hline Technology & Develop a platform for participation and innovation \\
\hline Business & $\begin{array}{l}\text { Increase revenue from e-commerce fundamentals and } \\
\text { Model }\end{array}$ \\
\hline Web 2.0 perspectives \\
\hline
\end{tabular}

O capítulo seguinte aborda os modelos tecnológicos existentes, utilizados como ponte para a recepção do objeto de arte pelo espectador e para a interpolação dos espaços físico e virtual.

$61<$ https://smithsonian-webstrategy.wikispaces.com/Executive+Summary+and+ Moving+Forward> Acesso em: 20 jan. 2016 


\title{
3 | Modelos tecnológicos disponíveis
}

\author{
3.1 A tecnologia como elemento integrador: \\ uma introdução
}

\subsection{1 | Pressupostos}

\begin{abstract}
Users are changing. For the first time in history, users interact freely and comfortably with two realities: the physical and the virtual. We think of users as real people, in a real, tangible world, just as we have always thought of libraries as real buildings, with real books and journals - a very physical, tangible reality. But users are now sometimes, for all intents and purposes, virtual people, interacting with virtual services and virtual and digitized libraries and materials. Increasingly, as users learn to navigate the virtual world on their own, they also wish to navigate the physical world self-reliantly. ${ }^{1}$
\end{abstract}

Como definir o museu virtual em relação aos seus pressupostos tecnológicos? Segundo Nicholls, Pereira e Sani (2012), este consiste em uma coleção de objetos digitais logicamente relacionados, em diversos tipos de suporte; os quais, pela possibilidade de criar conexões e diversos pontos de acesso, acabam por transcender os métodos tradicionais de comunicação e interação com os espectadores. Pelo fato de não ocupar um espaço físico determinado, podem ser disseminados ao redor do mundo.

1 Lincoln (2002, p. 11) 


\subsubsection{Histórico}

There is no reason anyone would want a computer in their home.

(Ken Olsen², 1977)

Computers in the future may weigh no more than 1.5 tons $^{3}$. (Popular Mechanics, 1949)

De acordo com Christensen (201 1), a utilização da tecnologia como elemento amplificador da experiência do visitante - e mecanismo de acessibilidade do objeto de arte ao grande público - tem como um de seus marcos iniciais o surgimento da Galeria Boydell Shakespeare, aberta em Londres em 1789. A tecnologia empregada pela galeria para imprimir gravuras em tons monocromáticos permitiu disponibilizar o objeto de arte ao público e abrir novos canais com aquele. Possibilitou à audiência interatividade e possibilidade de "aquisição" de objetos de arte: atividades que se repetem do mesmo modo através das tecnologias do presente ${ }^{4}$.

O fato mais importante deste exemplo histórico parece ser a forma com que a tecnologia gera mobilidade em relação à obra exposta no museu, ao diminuir a distância entre o original e sua cópia, seja esta eletrônica - como no presente - ou em uma gravura monocromática como no exemplo citado acima ${ }^{5}$.

<https://en.wikipedia.org/wiki/Ken_Olsen> Acesso em: 23 jul. 2017

<https://en.wikipedia.org/wiki/ENIAC> Acesso em: 23 jul. 2017

4 "The Boydell Shakespeare Gallery can be regarded as an early milestone in the history of art museology. The very concept of making works of art accessible to the general public in an exhibition is of direct significance in itself. However, what makes the gallery important in the argumentation of this article is that already here in an early phase of the history of curating there is a new technology, and it is this technology that creates an opening in the exhibited object or work of art and its relation to an audience. Stipple engraving as it was employed by Boydell in the 1790s made it possible for the public to experience and own the work of art physically, and this is an ancestor of the museum visitors' participation of later times, when it is simply other technologies that are used, e.g., interactive, digital ones (...)" Christensen (2011, p. 9)

5 " (...) The Boydell Shakespeare Gallery is quite an early example of how exhibition technologies change the relationship between the work of art and an audience, but it 
Ao mesmo tempo em que o mundo presencia um período acelerado de invenções colocadas à disposição do público a partir do século XVIII, o museu absorve as tecnologias disponíveis, integrando-as em seu repertório de possibilidades.

A fotografia é um exemplo basilar: Seu surgimento permite o desenvolvimento de novas e fascinantes possibilidades para a exibição interativa de objetos de arte; ao mesmo tempo em que se criam novos mecanismos para registro, arquivo e documentação.

Merece destaque o surgimento (paralelo à fotografia e do mesmo co-inventor desta) do diorama6 - o qual traz aos museus (notadamente

is also an example of how the museum exhibition has taken part in the development of technologies, as a new stipple engraving technology was applied, tested and passed the test with flying colours. First of all, the original and unique work of art was made accessible in the public and commercial gallery. Secondly, reproductions were sold from the museum. Already, here one notices a change in the art institution, which in this early bourgeois period was on its way, moving away from noble and aristocratic patronage and going in the direction of the anonymous mass market. Here there is a parallel to the development of the prose genre, the novel. It too developed in the cross-current of a new and literate middle-class readership and the availability of the technology of a cheap printing press. The novel was mass media, and the difference with the Boydell prints is that a novel is not based on an auratic origi- nal, but only on a manuscript. The poignant point about the business model and overall concept of the Boydell Shakespeare Gallery is that it combined the exhibition of original art with a mass audience and a new technology into commercial distribution of the unique and original. The very accessibility of the work of art in the Boydell Shakespeare Gallery, at 52 Pall Mall in London, was enormously and qualitatively extended when the gallery visitor could have relatively cheap reproductions of the oil paintings at home. It was technology that made the mobility of the work of art possible, for it was the technique of stipple engraving that bridged the gap between original and copy." Id., 201 1, p. 11

6 Diorama é um modo de apresentação artística tridimensional, de maneira muito realista, de cenas da vida real para exposição com finalidades de instrução ou entretenimento.

O termo 'diorama' foi inventado por Louis Daguerre em 1822, para um tipo de display rotativo. A palavra significa literalmente: 'através daquilo, o que é visto' do grego di'através' + orama 'o que é visto, uma cena'.

O primeiro diorama foi criado por Daguerre e Charles Marie Bouton, sendo exposto em Londres em 29 de setembro de 1823. O significado 'réplica de uma cena em pequena escala, etc.' surgiu em 1902.

Num diorama, a cena de fundo, que pode ser uma paisagem, plantas, animais, eventos históricos, etc., é pintada sobre uma tela de fundo curvo, de tal maneira que simulem um contorno real. A tela colocada na obscuridade e iluminada de maneira adequada dá uma ilusão de profundidade e de movimento, dando a impressão de tridimensionalidade. O assunto principal, é pintado ou esculpido de tal forma que cria uma perspectiva falsa, modificando com cuidado a escala dos objetos para reforçar a ilusão de realismo. Todas estas técnicas são modos de apresentar uma vista realística 
àqueles ligados à história natural ${ }^{7}$ ) um novo meio interativo de representação que perdura até os dias atuais ${ }^{8}$.

A invenção da fotografia, no entanto, parece absorver todas as atenções, ao gerar enorme reação social e cultural. Segundo Walsh (2007),

Photography was a much bigger and more immediate sensation in its time than the advent of the World Wide Web in our own. Daguerre's achievements were announced at the Institut de France on August 19, 1839, with speeches, pomp, and ceremony intended to etch the date as an historic day. In the next couple of years, hundreds of "first photographs" of, among other things, the moon, followed. Within a decade, photographic technology had spread around the globe. A variety of competing methods for taking, developing, and reproducing photographs sprang up overnight, each providing its own special qualities and advantages, including long and short exposure times. These included Talbot's calotype (later talbotype) method, and collodion glass negative systems, as well as the daguerreotype. $^{9}$

O autor afirma que a fotografia não parece ter em seu início, conforme se acredita, status secundário em relação a outros modos de expressão artística, e que a definição precisa da relação entre esta e o modelo cultural dominante ainda depende de muitos estudos e avaliações $^{10 ;}$ vai além dos paradigmas estabelecidos ao afirmar que a pintura, na verdade, influenciou a fotografia mais do que o contrário ${ }^{11}$

de uma cena grande em um espaço reduzido.

<https://en.wikipedia.org/wiki/Diorama> Acesso em: 18 jul. 2017

7 <http://www.amnh.org/exhibitions/permanent-exhibitions/ biodiversity-and-environmental-halls/milstein-hall-of-ocean-life/promos/ for-educators/dioramas/> Acesso em: 18 jul. 2017

8 <http://eu.oheuaqui.com/2uc3lkb> Acesso em: 18 jul. 2017

9 Walsh (2007, p. 21)

10 "One myth of photography is of a poor, misunderstood medium that struggled for decades for recognition as art form, finally achieving that high status in the late twentieth century. In fact, the status of photography - nearly always the focus of one aesthetic controversy or another - varied throughout the nineteenth and early twentieth century. At different times and locations, photography's prestige both increased and declined, depending in part on other streams of the culture."Walsh (2007, p. 21)

11 "Another set of assumptions, frequently taught in the history of nineteenth-century art, is that photography exerted certain formal influences on how art was executed, composed, and framed. Some scholars have pointed out, however, that Western painting had begun to look like photography some years before photography existed. 
Desta forma a fotografia dá origem a um novo conceito de museu, o qual transforma de tal modo a exibição do objeto de arte, que qualquer modelo anterior não é nem mesmo lembrado:

Finally, photography helped give rise to an entirely new kind of art museum, the postphotographic museum. This model became so dominant in modern culture that it eventually absorbed and transformed the older idea of an art museum. Nowadays, we tend to forget there was ever a pre-photographic museum. But it was through the postphotographic museum that photography not only influenced art that came after its invention but also the entire history of art that came before it. ${ }^{12}$

Os chamados "museus pós-fotográficos" surgem para criar novas coleções, e não somente abrigar aquelas existentes, tendo enfoque e função educacionais. Um dos pioneiros no uso educacional do acervo, o Museu de South Kensington - posteriormente denominado Victoria and Albert Museum (V\&A) - fez da fotografia um dos componentes principais de qualquer mostra. Seus catálogos impressos e suas coleções fotográficas do acervo geraram tal expectativa que, ao redor de 1860, a demanda superava a oferta Os museus da América do Norte, surgidos em sua quase totalidade após a invenção da fotografia, seguem de perto o exemplo do Museu de South Kensington ${ }^{13}$.

Desta forma a fotografia, ao permitir múltiplos usos (incluindo aqueles estritamente técnicos como o raio-X, fotografia infravermelha e fotografia ultravioleta) - e ter seu espaço garantido dentro do museu - acaba por se incorporar tanto ao fluxo interno (registro, arquivo e documentação) quanto ao externo (exibições de fotógrafos ou artistas que a utilizam

\footnotetext{
In fact, much of the refinement of photographic equipment consisted of making sure that camera lenses would capture photographs that fit into established Renaissance ideas of linear perspective." Walsh (2007, p. 22)

12 Walsh (2007, p. 24)

13 Walsh (2007, p. 27)
} 
como meio de representação). Tal fluxo se torna, de fato, o modelo de funcionamento para os museus de arte ${ }^{14}$.

Tendo como participante ativo em seu contexto a tecnologia, resta ao museu acompanhar de perto a evolução daquela nos processos de captura e armazenamento da imagem; as quais trazem, em seu bojo, mudanças estruturais que representam ampliação de possibilidades de geração, uso e compartilhamento. Em seu formato original (análogo, baseada em componentes químicos e substrato físico), a fotografia foi largamente utilizada para a criação de livros e catálogos; em seu formato contemporâneo (digital, baseada em códigos binários) passa a ocupar espaço em bases de dados e seu uso é fluido e múltiplo, tanto do lado do artista quanto da instituição ${ }^{15}$.

14 "As we have seen, this complex system of photography, acquisition, conservation, publication, and circulation became the established system for the post-photographic museum, and it became the model for all art museums. The educational and evangelical system developed by Cole in the 1850s and 60s has itself become the basic paradigm of the modern educational art museum. Coupled with the development of academic art history, itself a discipline developed and taught largely with photographs and printed books, photography became the main means by which art is understood, interpreted, and evaluated." Walsh (2007, p. 29)

15 "In marketing, photos are used on posters, in brochures and on websites, and photographic reproductions of exhibits are available for sale in museum shops. Here postcards are a classical medium, but there may also be mugs, refrigerator magnets or tea towels. At the other end of the hierarchy of taste, the photographic work (of art) may be an exhibit in its own right, which paradoxically does not allow itself to be reproduced if it is on loan to another museum, as the art photo is the original. If it is away on loan, it is only supplanted in its home exhibition with a sign with verbal print. An oil painting in the same situation is often depicted with a small photo on the sign. Both in the museum shop and when the photo becomes the primary and independent exhibited work, the relationship between copy and original is stressed. And in this connection, it may be remarked that when a photo is reproduced, the unstable history of photography belonging or not belonging to the institution of art is also stressed. It was this very ability of the photographic technology to be reproduced and to reproduce that became an obstacle to its recognition as an independent art form. A definition of art that stresses originality tends to exclude photography because of its technological ability to be (re)produced in many copies. Only when photography was included in the art institution could it be exhibited in museums and galleries in its own right, and not just as an exhibition technology." Christensen (201 1, p. 12-13) 


\subsection{3 | Tecnologias experienciais}

Quando o museu armazena o conhecimento em bases de dados, passa a permitir a exibição de seu acervo sem a necessidade de ocupação de espaço físico, criando para si novas possibilidades de interação com o público. O ato de se conectar bases de dados e exibições cria relações entre a mostra e seus arquivos, os quais passam a ser acessiveis por parte do público via museu ou Internet. Uma das possiveis vantagens deste acesso - categorizada como "tecnologias experienciais" - é permitir a visualização indireta de documentos raros que necessitam temperatura e umidade específicos e não permitem o toque ou a exposição prolongada à luz de uma exibição ${ }^{16}$. De acordo com Kowal (2006),

\footnotetext{
"Experiential technologies", a limited type of virtual reality system, are here defined as digital multimedia presentations designed to mimic a particular 'real-life' experience. Computer models and animation suggest movement through space and interaction, and various embodiments of the technology have been employed to impressive effect in many arenas, including simulating the action of books...

... identifying the Silicon Graphics Demo Book in 1993 as one of the first, "true 3-D book(s)": an interactive, virtual 3-D book with animated page-turning. ${ }^{17}$
}

As pesquisas pioneiras sobre o tema são publicadas por Card et al. (2004) e Chu et al. (2004), tendo os últimos compilado, efetivamente, um novo modelo funcional de software de visualização de livros ${ }^{18}$.

Os primeiros exemplos em larga escala no uso das tecnologias experienciais surgem - sob o nome Turning the Pages (TTP) - na British

16 "A simple and efficient example of the possibility of visitors gaining access to material that is not exhibited are programmes such as "Turning pages", where the visitor to the museum on a touchscreen can browse through and read fragile manuscripts and early books." Christensen (2011, p. 12)

17 Kowal (2006, p. 222-223)

18 O software de visualização desenvolvido pelo grupo pode ser obtido em <http://www. nzdl.org/html/open_the_book/downloads.html> Acesso em: 19 jul. 2017 
Library em $1997^{19}$ e no MOMA em 200220. Tal modelo será posteriormente adotado por diversas instituições ${ }^{21}$.

\subsubsection{O guia de áudio}

Próximo elemento no rol de tecnologias de exibição não está vinculado diretamente ao objeto de arte ou à sua reprodução mecânica, mas sim à informação e comunicação que orbitam em torno daquele.

Christensen (2011) utiliza a terminologia "paratexto"22, baseada na pesquisa tipológica de Genette (1997) e no conceito de "ancoragem" de Barthes (1977, p. 156), aqui traduzido como metadados ${ }^{23}$.

Trata-se do sistema de guia de áudio. Uma tecnologia simples, popular e largamente utilizada, a qual cria um método eficiente de transmissão de metadados aos visitantes. A navegação pelo sistema permite diversas possibilidades e se dá de forma simples e direta. O número

19 <http://www.bl.uk/onlinegallery/virtualbooks/> Acesso em: 20 jul. 2017

$20<$ https://www.moma.org/interactives/exhibitions/2002/russian/> Acesso em: 20 jul. 2017

21 <http://ttp.onlineculture.co.uk/clients/> Acesso em: 19 jul. 2017

22 "Anchorage: a verbal text that anchors and controls the reading of an image is called an anchoring text. It is placed in close proximity to the image. It is practically impossible to find an image without an anchoring text. The reason is that images are polysemic, i.e., they contain so many codes that a sender must necessarily lead the reader's perception of the image in the intended direction with the help of the anchoring text.

Paratexts are texts that are placed around the main text and which add extra meaning to it. The main text is called the hypotext. There are different types of paratexts each with its own designation:

- Peritexts are paratexts that are physically connected to the hypotext without being an integral part of it. This is for instance a book's title printed on its cover.

- Epitexts are paratexts removed from the hypotext. This is for instance a review of a book in a newspaper.

- Autographic paratexts have been made by the producer of the hypotext himself. For instance, a director's spoken commentary of a film on a DVD.

- Allographic paratexts have been made by someone other than the producer of the hypotext. For instance a review in a magazine of a film."

Christensen (2011, p. 17)

23 Esta dissertação utiliza, desde o início, o termo "metadados", considerando-o intercambiável e adequado tanto à conceituação de ambos autores quanto aos propósitos da tese. (N. A.) 
de visitas guiadas por áudio foi estimada em 35 milhões em 2006; em alguns casos a porcentagem de visitantes utilizando o sistema supera os 50\% Tallon (2006, p. 1). Em algumas exibições específicas (tais como o projeto Experience Music Project em Seattle 24 e as mostras do artista David Bowie $^{25}$ e da banda Pink Floyd ${ }^{26}$ no V\&A) a presença do guia de áudio é fundamental para o entendimento e participação do espectador.

A utilização pioneira de um sistema de áudio se dá em 1952 no Museu Stedelijk, Amsterdam27. Denominado Short Wave Ambulatory Lectures, o equipamento utilizava um circuito fechado de transmissão de rádio via ondas-curtas, o qual era alimentado por um gravador de fita e propagado através de repetidoras instaladas no teto das galerias. As narrativas estavam gravadas em quatro idiomas - holandês, francês, inglês e alemão - e podiam ser ouvidas através de um receptor de rádio portátil com fones de ouvido, carregado pelo visitante ao longo do percurso. Devido às restrições da tecnologia analógica da época, todos os visitantes ouviam o mesmo trecho de áudio simultaneamente; o que ocasionava, devido aos itinerários previamente fixados, a formação de grupos caminhando pelas galerias em completa sincronicidade, como que guiados por uma força invisível.

A partir deste primeiro exemplo e em compasso com a evolução da tecnologia, o sistema se torna cada vez mais sofisticado. Em 1970, durante a exibição em 7 museus diferentes nos EUA dos tesouros de Tutankamon, mais de três milhões de espectadores utilizaram um aparelho

$24<$ http://www.mopop.org/?gclid=COHehP_il9UCFYIKOwodAQcFBQ> Acesso em 21 jul. 2017

25 <http://www.vam.ac.uk/content/exhibitions/david-bowie-is/about-the-exhibition/> Acesso em: 21 jul. 2017

26 <https://www.vam.ac.uk/articles/inside-the-pink-floyd-their-mortal-remains-exhibition> Acesso em: 21 jul. 2017

27 <http://www.stedelijk.nl/en?gclid=CPjEl8nDI9UCFc-6Gwodg6YHSg> Acesso em 21 jul. 2017 
Sony Walkman, alimentado por fita cassete (K7). Em 1993, já contando com a possibilidade de utilização das duas principais características da tecnologia digital (acesso a sistemas não-lineares e acesso aleatório à informação) o Museu do Louvre cria o guia de áudio do seu acervo permanente, permitindo aos visitantes percorrer um itinerário personalizado e ajustável. Até o final do século XX o sistema havia sido adotado por praticamente todos os grandes museus do planeta. É interessante observar que o guia de áudio foi a única tecnologia dedicada a visitantes adotada de forma unânime pelos museus.

No contexto contemporâneo surgem, paralelamente àqueles elaborados pelas instituições, infindáveis guias não-oficiais, baseados em podcasting ${ }^{28}$, desenvolvidos por estudantes e entusiastas e livremente distribuídos pela Internet aos visitantes interessados.

\section{2 | Tecnologias baseadas em dispositivos mó-}

\section{veis}

As tecnologias baseadas em dispositivos móveis evoluem de meros guias de áudio para diversas outras categorias, cada uma delas possuidora de funcionalidades específicas. Jogos interativos, por exemplo: Em 2013 o

28 Podcasting é uma forma de publicação de arquivos de mídia digital (áudio, vídeo, foto, etc.) pela Internet, através de um feed RSS, que permite aos utilizadores acompanhar a sua atualização. Com isso, é possivel o acompanhamento e/ou download automático do conteúdo.

A palavra "podcasting" é uma junção de iPod (marca do aparelho de midia digital da Apple Inc. de onde saíram os primeiros scripts de podcasting) ou a sigla para Personal On Demand (numa tradução literal, algo pessoal e sob demanda), e broadcasting (transmissão de rádio ou televisão). A série de arquivos publicados por podcasting é chamada de podcast. O autor de um podcast é chamado podcaster.

<https://pt.wikipedia.org/wiki/Podcasting> Acesso em: 22 jul. 2017 
Victoria and Albert Museum (V\&A) ${ }^{29}$ criou o programa Games Designer in Residence ${ }^{30}$, o qual permitiu ao artista contemplado desenvolver a criação de jogos digitais inspirados no acervo da Instituição.

Embora não haja uma designação abrangente, é possivel pensar em três características que englobam todos os sistemas existentes:

Móvel Não dependem de localização específica e estão disponíveis o tempo todo

Digital Suas funcionalidades se baseiam em um sistema eletrônico e binário

Pessoal Existe uma relação direta e única entre o visitante e o meio, tendo o visitante como controlador do processo

Para que seja validado como modelo tecnológico baseado em dispositivos móveis, todas as características acima devem estar presentes.

A matriz abaixo exemplifica as diferentes combinações que caracterizam modelos já existentes:

29 The Victoria and Albert Museum (often abbreviated as the V\&A), London, is the world's largest museum of decorative arts and design, housing a permanent collection of over 4.5 million objects. It was founded in 1852 and named after Queen Victoria and Prince Albert.

<https://en.wikipedia.org/wiki/Victoria_and_Albert_Museum> Acesso em: 02 ago. 2017

$30<$ http://eu.oheuaqui.com/2iOLbUp> Acesso em 30 jul. 2017 


\begin{tabular}{|c|c|c|c|}
\hline móvel & digital & pessoal & $\begin{array}{c}\text { a interação não se diferencia dos } \\
\text { terminais multimídia fixos, } \\
\text { descaracterizando a mobilidade }\end{array}$ \\
\hline móvel & digital & pessoal & $\begin{array}{c}\text { a interação se restringe às legendas } \\
\text { da obra }\end{array}$ \\
\hline móvel & digitat & pessoal & $\begin{array}{c}\text { a interação se transforma no } \\
\text { catálogo da exibição }\end{array}$ \\
\hline móvel & digital & pessoat & $\begin{array}{c}\text { o processo se restringe ao guia } \\
\text { humano ou tutor }\end{array}$ \\
\hline
\end{tabular}

Tabela 3 - Tecnologias baseadas em dispositivos móveis: diferenciação

\subsection{1 | Código QR (Quick Response)}

Alguns dos primeiros experimentos de transmissão de informações ao espectador via código QR (Quick Response Code) ${ }^{31}$ em museus se

31 O QR Code (ou Quick Response Code) é um símbolo bidimensional (2-D), criado e registrado em 1994 pela empresa Japonesa Denso-Wave (subsidiária da Toyota Motor Corporation), com o objetivo de permitir e facilitar, de forma rápida e eficiente, o processo de catalogação dos componentes para automóveis.

A sigla QR deriva do termo Quick Response (ou Resposta Rápida) e está associada ao fato destes códigos poderem ser lidos e decodificados eletronicamente, em grande velocidade, através de equipamentos de leitura.

Os códigos QR contém informação nos eixos vertical e horizontal, daí o termo bidimensional. Devido a esta característica os códigos QR possibilitam armazenar centenas de vezes mais dados do que os tradicionais códigos de barras.

A informação contida nestes códigos pode ser facilmente lida através de um leitor QR instalado no dispositivo do espectador.

São utilizados por inúmeras organizações e empresas nos mais diversos setores de atividade e o tipo de informação codificada pode ser bastante variado. Permitem armazenar diferentes tipos de dados, incluindo caracteres alfabéticos, números, símbolos, binários e caracteres do alfabeto japonês. Enquanto o tradicional código de barras pode ter no máximo 20 dígitos, um código QR pode armazenar até 7.089 caracteres. Estes caracteres podem ser combinados em um símbolo de grande porte ou então divididos em até 16 símbolos. Alguns dos tipos de uso mais frequentes são:

- texto simples

- URLS

- mensagens SMS 
dão no Powerhouse Museum em Sidney, Australia em 2008 32 , e no Mattress

Factory em Pittsburgh, EUA em 200933. Tais experiências tinham como objetivo melhorar a habilidade do visitante em obter, de forma simples e rápida, informações adicionais sobre o objeto exposto. O código QR era, frequentemente, posicionado ao lado - ou dentro - da legenda da obra.

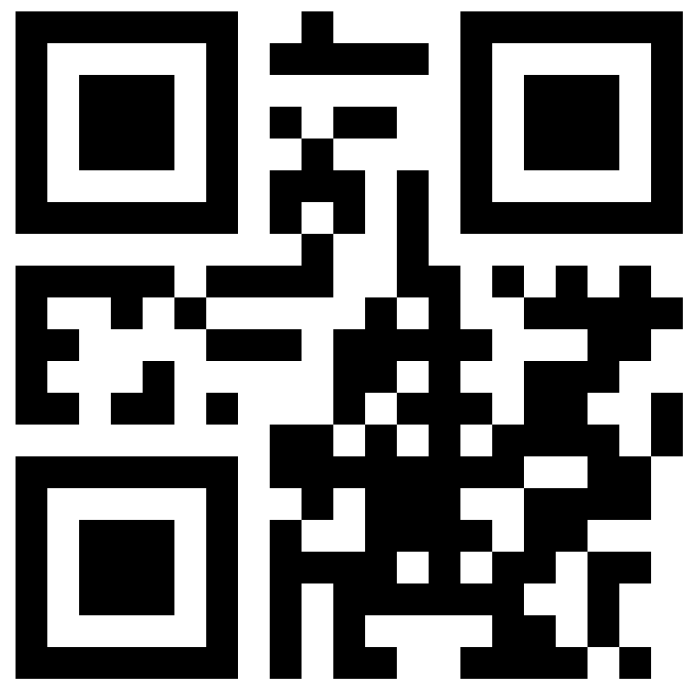

Figura 5 - Exemplo de código QR

- cartões de visita eletrônicos (vCard)

- endereços de e-mail

Após a popularização do uso dos códigos de barras, os códigos 2-D surgem para responder à necessidade de se armazenar mais informação, mais tipos de caracteres e menor espaço de impressão.

Apesar da marca registrada, os códigos QR podem ser utilizados livremente por qualquer indivíduo ou organização sem a necessidade de licenças ou taxas.

Isto estimulou sua utilização em diversas e inovativas formas, e o seu uso comercial e institucional se generalizou em várias partes do mundo.

Com o corrente avanço da tecnologia e a massificação da Internet nos dispositivos móveis, os códigos QR são em grande parte utilizados para ações de marketing. Mostraram-se eficazes na promoção interativa de marcas e produtos junto ao público, pois são capazes de ligar o universo físico ao mundo online.

Dada a facilidade de utilização dos leitores QR nos dispositivos móveis, é bastante simples decodificar e converter um código QR em um endereço na Internet e redirecionar o utilizador para conteúdos específicos, campanhas publicitárias ou perfis de empresas em redes sociais. É comum, na atualidade, se encontrar códigos QR associados a promoções, descontos e ofertas de toda espécie. <http://www.qrcode.com/en/faq.html> Acesso em: 31 jul. 2017

$32<$ http://eu.oheuaqui.com/2y90w43> Acesso em 18 set. 2017

33 <http://canada.pch.gc.ca/eng/1443184597449> Acesso em 01 ago. 2017 
Erarta - maior museu de arte privado da Rússia - utilizou códigos QR para fornecer aos visitantes, além das informações adicionais, opções para a aquisição de reproduções de arte de forma direta, através do telefone celular ${ }^{34}$.

Brooklyn Museum (EUA) compartilhou com seu público as questões relativas à utilização do recurso através de uma página na Internet ${ }^{35}$.

Alguns dos museus de grande porte que adotaram o código QR como parte do conteúdo educativo foram:

- Smithsonian Museum

- British Museum

- Getty ${ }^{36}$

- LACMA $^{37}$

- Cleveland Museum of Art ${ }^{38}$

- American Museum of Natural History

- Victoria and Albert Museum (V\&A)

- National Museum of China ${ }^{39}$

O aumento no uso de tais códigos como ferramentas de marketing no setor comercial gerou, da parte dos museus, interesse em experimentar a tecnologia. Diversas bibliotecas, por exemplo, adotaram os códigos como ferramenta promocional, a fim de divulgar seus endereços informativos na Internet e seus calendários de eventos. Outras utilizam o código como

$34<$ https://www.tnooz.com/article/cuddling-up-to-qr-codes-in-the-contemporary-art-world/ $>$ Acesso em 01 ago. 2017

35 <https://www.brooklynmuseum.org/community/blogosphere/2011/10/20/ qr-code-conundrum/> Acesso em 01 ago. 2017

36 <http://blogs.getty.edu/iris/project-switch-a-small-experiment-yields-big-lessons/> Acesso em 01 ago. 2017

37 <http://www.lacma.org/eeg-ar-things-we-have-lost> Acesso em 01 ago. 2017

38 <http://namp.americansforthearts.org/2011/01/19/what-on-earth-is-a-qr-code> Acesso em 01 ago. 2017

39 <http://www.rcip-chin.gc.ca/sgc-cms/nouvelles-news/anglais-english/?p=6664> Acesso em 01 ago. 2017 
atalho da versão para dispositivos móveis de seus websites. A biblioteca de Contra Costa County disponibiliza, para seus membros, códigos dentro de cartazes em transporte público, permitindo àqueles efetuar download de livros em áudio enquanto viajam. A Universidade de Bath e a Biblioteca da Universidade de Ryerson fornecem códigos em seus catálogos online que permitem localizar o ítem físico no acervo, assim como obter guias de áudio. Inúmeros outros usos são frequentes em diversas instituições ao redor do mundo 40 .

Embora exista enorme ênfase na disseminação no uso dos códigos QR por parte de diversos autores e pesquisadores ${ }^{41}$, a progressão do seu uso por parte dos visitantes se dá em escala bastante conservadora: uma pesquisa efetuada na Universidade de Bath em maio de 2009 mostra que apenas $12.6 \%$ sabiam o que era um código QR, embora $93 \%$ deles possuíssem um telefone celular com câmera integrada ${ }^{42}$. No início da primeira década do século XXI, diversos pesquisadores e estrategistas do setor de marketing decretaram a obsolescência de tal tecnologia, considerando sua utilização apropriada apenas em contextos muito específicos:

\begin{abstract}
QR Codes work well for one-off, consumer-to-business interactions where the consumer directs the flow of information. For instance, they are successfully implemented as a mobile airline boarding pass, coupon, or alternate payment method. The app creates the QR Code and the purpose is clear to the consumer. QR Codes are also appropriate for a highly-engaged user group to collect points or clues toward a goal. Only those who are fanatically engaged with your brand, or participating in an event or conference, are going to take the time to play along. ${ }^{43}$
\end{abstract}

Isto, no entanto, parece não ter ocorrido e, embora sua utilização não seja predominante ou paradigmática, sua presença e utilidade na transmissão de informação parece ter espaço garantido no futuro, graças

40 Schultz (2013, p. 3-5)

41 <http://onlineqrcodegenerator.com/223/qr-codes-in-museums/> Acesso em 01 ago. 2017

42 Walsh (2010, p. 57)

43 <https://www.inc.com/eric-v-holtzclaw/qr-codes-dont-bother-five-reasons.html> Acesso em 02 ago. 2017 
à utilização em aplicativos móveis de mensagens como o Snapchat, WhatsApp Messenger, Kik Messenger e, em toda a China, o WeChat44.

Um exemplo recente de seu uso dentro do museu está na mostra do Wrather Museum denominada African American History Month em $2016^{45}$.

\subsection{2 | Realidade virtual}

A principal finalidade de qualquer dispositivo de realidade virtual é a criação de experiências imersivas, ao permitir que o espectador possa se transportar para outro local ou vivenciar ações inexistentes no universo visivel sem precisar, necessariamente, se mover grandes distâncias .

A experiência imersiva se realiza através de um dispositivo móvel - aqui denominado controlador, acoplado a um processador capaz de executar o software. A integração com o usuário pode se dar através de um computador, smartphone ou console de jogos eletrônicos. Além disso, se deve utilizar algum tipo de equipamento que permita a integração dos sentidos àquilo que é gerado via software. Estes componentes atuam em conjunto para gerar em frente aos olhos do usuário um novo ambiente. Esta atuação é capaz de interagir com a percepção, de modo a simular uma experiência real.

O componente principal dos periféricos de realidade virtual está na visão estereoscópica: captação e sobreposição de duas imagens bidimensionais ligeiramente diferentes, que são interpretadas pelo córtex visual como uma única imagem via computação gráfica tridimensional (3D), a qual se assemelha ao modo como a informação vinda do universo visivel, através do efeito denominado estereoscopia, é processada. Para

\footnotetext{
$44<$ http://eu.oheuaqui.com/2ujWt2V> Acesso em 02 ago. 2017

$45<$ http://eu.oheuaqui.com/2ujghU2>
} 
que o efeito seja convincente, é necessário que a imagem vista na tela em frente aos olhos possua uma cadência (frame rate) mínima de 60 quadros por segundo.

Outro ponto importante para a simulação da realidade é o movimento. O dispositivo acoplado à cabeça irá acompanhar a orientação desta e, consequentemente, o campo de visão, gerando assim visões e imagens relativas ao ponto de vista do usuário visão. Isto é possível pela existência de um sensor denominado Unidade de Medição Inercial (IMU), estruturado em três componentes principais: um acelerômetro, um giroscópio e um magnetômetro, responsáveis por fornecer a orientação do dispositivo em relação ao horizonte e ao solo.

Alguns dispositivos, a fim de melhorar as informações de rastreamento posicional e de movimento fornecidas pelo IMU, contam com câmeras de rastreamento. Estes equipamentos localizam marcadores posicionados nos objetos e, através do uso de luz infravermelha ou refletores, conseguem determinar, com precisão, sua posição no ambiente.

Historicamente, a utilização do termo virtual como referência à integração entre o existente e o imaginário parece surgir em 1938, em um texto de Artaud (1958):

Theatre also takes gestures and develops them to the limit. Just like the plague, it reforges the links between what does and does not exist, between the virtual nature of the possible and the material nature of existence ${ }^{46}$

Desde 1959 o mesmo termo é utilizado nas ciências da computação para significar algo que não existe fisicamente, mas aparece aos sentidos por meio do software.

46 Artaud (1958, p. 16) 
Durante a década de 70 surge o termo realidade artificial, criado pelo artista interativo Myron Krueger $47,48,49$ em 1973 e posteriormente consagrado pelo pesquisador Jaron Lanier ${ }^{50}$ em 1987; seu aparecimento na literatura se dá em 1982, na novela de ficção científica Judas Mandala, de Damien Broderick ${ }^{51}$ ).

Desde então a evolução neste campo ocorre de forma constante e incremental, com avanços significativos e novas possibilidades surgindo a cada ano.

\subsection{3 | Realidade aumentada}

A finalidade do modelo virtual denominado realidade aumentada $(A R)^{52}$ é permitir a fusão entre o universo visivel e informação estruturada eletronicamente, criando uma camada virtual sobre o mundo real.

O efeito é gerado pela superposição de vídeos ou gráficos e a captura, projeção ou visualização do universo circundante em tempo real.

$47<$ https://en.wikipedia.org/wiki/Myron_W._Krueger> Acesso em 23 jul. 2017

$48<$ https://www.wired.com/201 1/05/augmented-reality-myron-krueger-artificial-reality-lab-1985/ $>$ Acesso em 24 jul. 2017

49 <http://www.inventinginteractive.com/2010/03/22/myron-krueger/> Acesso em 24 jul. 2017

$50<$ https://en.wikipedia.org/wiki/Jaron_Lanier> Acesso em 23 jul. 2017

$51<$ https://en.wikipedia.org/wiki/Damien_Broderick> Acesso em 23 jul. 2017

52 La realidad aumentada (RA) es el término que se usa para definir la visión de un entorno físico del mundo real, a través de un dispositivo tecnológico, es decir, los elementos físicos tangibles se combinan con elementos virtuales, logrando de esta manera crear una realidad aumentada en tiempo real. Consiste en un conjunto de dispositivos que añaden información virtual a la información física ya existente, es decir, añadir una parte sintética virtual a la real. La realidad aumentada es diferente de la realidad virtual porque sobre la realidad material "del mundo físico" monta una realidad visual generada por la tecnología, en la que el usuario percibe una mezcla de las dos realidades, en cambio en la realidad virtual el usuario se aísla de la realidad material del mundo físico para "sumergirse" en un escenario o entorno totalmente virtual.

<https://es.wikipedia.org/wiki/Realidad_aumentada> Acesso em: 08 ago. 2017 
Para se obter tal efeito é necessário existir uma câmera ou outro dispositivo que permita a interpretação e criação de um objeto virtual. Por meio deste dispositivo, será transmitida a imagem que vai ser combinada com a animação. Neste momento entra em ação o software ou aplicativo inteligente capaz de interpretar o sinal transmitido pela câmera. A fotografia capturada será projetada com uma imagem em 3D previamente incluída no aplicativo responsável pela renderização das ilustrações.

A diferença entre realidade virtual e realidade aumentada se dá pelo fato de que, nesta, imagens 3D são sobrepostas a ambientes reais. Enquanto a realidade virtual se esforça para permitir a total imersão do usuário em um ambiente 3D, a realidade aumentada traz elementos do mundo virtual para o universo visível. A tridimensionalidade se locomove até o universo do espectador, e não o contrário.

Seu impacto na arte contemporânea se torna cada vez mais presente ${ }^{53}$. A fronteira entre o real e o virtual pode se tornar difusa, e a recriação de um objeto de arte pode se tornar mais realista do que a própria realidade exposta: No exemplo de implementação realizado na igreja de Sant Climent de Taüll na Catalunha, Espanha ${ }^{54}$, é possivel recriar o espaço em diferentes períodos históricos e visualizar cada um destes períodos de forma absolutamente realista.

Com a adoção, por parte dos artistas, das técnicas e dispositivos de realidade aumentada para criar seus trabalhos - como ocorre, atualmente, no Museu de Arte Moderna de San Francisco (SFMOMA) 55 - é lógico se pensar que, devido à necessidade de se exibir tais trabalhos, os museus

$53<$ https://www.apollo-magazine.com/augmented-reality/> Acesso em 23 jul. 2017

$54<$ http://eu.oheuaqui.com/2tzNoXY> Acesso em 23 jul. 2017

55 <https://www.sfmoma.org/watch/playsfmoma-augmented-reality-game-jam/> Acesso em 23 jul. 2017 
acabem por adotar as tecnologias por eles utilizadas como parte de seu repertório e as utilizem em outros contextos.

fato de uma instituição secular como o British Museum adotar uma parceria com uma gigantesca empresa de tecnologia ${ }^{56}$ parece indicar a importância deste novo modelo de exibição. E o fato de que, enquanto a telefonia celular se mantiver como parte integrante da vida contemporânea (e, consequentemente, do público do museu) a realidade aumentada e suas camadas virtuais continuarão a permear todos os aspectos sociais e de consumo, incluindo o consumo de arte.

Antes mesmo da expressão Realidade Aumentada surgir ou se expandir como expressão corriqueira, já se criavam experimentos pioneiros que exploravam a superposição de camadas de contextualização:

Em 2010 o Museu Andy Warhol ${ }^{57}$ Iançou um aplicativo de realidade aumentada denominado Warhol Layar ${ }^{58}$, o qual permite aos usuários encontrar locais, nos arredores de Pittsburgh e New York City, que se relacionem com a vida do artista e também acessar informações sobre o próprio local.

Em 2009 a exibição House of Words ${ }^{59}$, realizada na casa-museu do consagrado escritor e lexicógrafo Samuel Johnson 60 , apresentou uma instalação denominada Interactive Work-table and Escritoire, a qual permitia ao público interagir com o famoso dicionário produzido por Johnson, adicionando a este novos vocábulos e verbetes e publicando tais adições imediatamente na Internet. Todo o processo se dá através de tecnologia

\footnotetext{
$56<\mathrm{http}$ ://www.britishmuseum.org/learning/samsung_centre.aspx> Acesso em 23 jul. 2017

$57<$ https://www.warhol.org/> Acesso em 23 jul. 2017

58 <http://eu.oheuaqui.com/2iM8TR6> Acesso em 23 jul. 2017

$59<$ https://www.creativereview.co.uk/the-house-of-words/> Acesso em 23 jul. 2017

$60<$ https://en.wikipedia.org/wiki/Dr_Johnson\%27s_House> Acesso em 23 jul. 2017
} 
avançada mas de fácil utilização por parte do espectador. As instruções passadas ao usuário são:

- Escreva uma palavra ou frase que você tenha inventado, ou

- uma palavra ou frase que seja especial e/ou particular para sua familia, ou

- uma palavra ou frase que, segundo você, deveria ter um sentido diferente do convencional

Através de uma caneta-tinteiro acoplada a um sistema de gravação, o usuário faz as adições que deseja e, ao colocar a pena de volta no tinteiro, o sistema gera a informação necessária para transmitir o que foi escrito para a Internet e também para um monitor instalado no mesmo local $^{61}$. Desta forma (e pelo fato de se lidar com um modelo tecnológico bastante amigável) a audiência, através da utilização de tecnologias digitais, se envolve em um processo de construção de significado ligado diretamente ao objeto de arte, tornando-se co-autora de uma obra produzida em 1755. Tal modelo de participação permite ao objeto exposto sair do passado e ser atualizado no presente, criando assim relevância na contemporaneidade e transformado a visita ao museu em ato engajado e fonte de experiência, gerando desta forma a conexão entre o passado e o presente 62 .

\subsubsection{Internet das Coisas (loT)}

O espaço museológico convive, há muito tempo, com sensores de toda espécie. Sua função inicial era ligada à preservação física do acervo:

61 Christensen (2011, p. 23-25)

62 Id. 2011 , p. 25 
controlar as condições de luminosidade, temperatura e umidade, além

de funcionar como parte do sistema de segurança da instituição.

O avanço, relativamente recente, na miniaturização e barateamento de sensores permite, segundo Chianese e Piccialli (2014, Prefácio), o aparecimento da Internet das Coisas (Internet of Things ou loT) ${ }^{63}$. Com sua rápida expansão e aplicação em diversos setores da atividade humana a utilização de sensores e sinalizadores no ambiente do museu ganha, além de maior flexibilidade em relação ao seu uso tradicional conforme Londero, Fairbanks-Harris e Whitmore,

There are many environmental monitoring challenges in cultural heritage requiring custom measurements that can be performed inconspicuously and viewed remotely. ${ }^{64}$

novas possibilidades em relação ao virtual:

Recent innovations in exhibition content enable new ways to connect. For the smartphone-owning $81 \%$ of adults, there's no better time to be exploring the ways museums communicate information. By downloading an app, visitors can add a layer of data to the existing surroundings through Internet of Things (loT) technology, connecting the physical and the virtual for the first time. The Internet of Things, an inter-networking of physical devices currently including smartphones, vehicles, and buildings, is growing exponen-

63 A loT é definida como uma infraestrutura de rede global que interconecta objetos, física e virtualmente, com o objetivo de compartilhar dados e informações para concluir determinadas tarefas. Essa infraestrutura inclui e envolve a Internet e as redes de comunicação, necessitando de identificação única de objetos, sensores e capacidade de conexão, como base para o desenvolvimento independente de serviços e aplicações. Ela é caracterizada pelo alto grau de captura autônoma de dados, transferência de eventos de rede, conectividade e interoperabilidade. , compartilhem dados e informações para concluir determinadas tarefas. A base para o funcionamento da loT são sensores e dispositivos, que tornam a comunicação entre as "coisas" possível. Além disso, é preciso um sistema de computação para analisar os dados recebidos e gerenciar as ações de cada objeto conectado a essa rede. Casagras (2011, p. 10)

Humans in modern times live in a highly connected world, and in 2015 more individuals were becoming aware of the Internet of Things (loT) - a vast network of physical objects with embedded microchips, sensors, and communications capabilities that link people, machines, and entire systems through the Internet. Networking firm Cisco Systems, which is credited with having coined the term Internet of Things, estimated in 2011 that 50 billion connected devices will exist by 2020 but that more than 99 <https://eu.oheuaqui.com/2mfvCme> Acesso em: 25 set. 2017

64 Londero, Fairbanks-Harris e Whitmore (2016, p. 166) 
tially, with experts predicting the introduction of 50 billion objects by 2020.65

A possibilidade de interação entre o dispositivo móvel do visitante e sensores ao longo do espaço físico do museu cria possibilidades inéditas para a exposição de conteúdo e desenvolvimento de narrativas. Este modelo era, anteriormente, apenas um conceito teórico.

Em janeiro de 2016 o estúdio de criação Squint/Opera implementou um aplicativo que atua como um guia virtual em Savoy Place, no centro de Londres. O edifício recebeu sinalizadores minúsculos e ocultos, movidos a bateria e que possuem um alcance que varia de 1 a 20 metros. O aplicativo instalado no dispositivo móvel entra em ação quando se aproxima de algum dos sinalizadores, interagindo com estes. Ao se realizar o contato, o aplicativo baixa a informação pertinente àquele ponto de referência e expõe ao usuário, instantaneamente, informações relevantes à localização. O dispositivo móvel se torna, desta forma, um guia personalizado e customizado para o visitante.

A possibilidade de interação granular e bastante detalhada dentro do espaço do museu permite, pela primeira vez na história daquele, exibir conteúdo físico ou digital e reagir ao visitante em tempo real, além de colher informações analíticas preciosas sobre a trajetória do visitante e seus interesses. O museu pode ter a informação precisa de qual sinalizador (e, consequentemente qual local, obra ou exibição) é o mais popular para o seu público, quanto tempo o visitante lá esteve e qual foi seu próximo itinerário, gerando possibilidades infinitas de interatividade e aprimoramento da experiência.

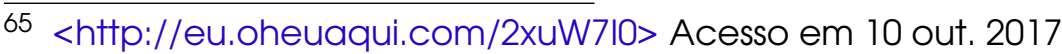


A coleta, com grande precisão, de dados relativos aos visitantes, permite planejar as próximas exibições com maior segurança em relação a resultados e expectativas:

For a more personalised experience there's an opportunity to use loT both ways and enable exhibits to react to the users that they come into contact with. The capture of this information could enhance the guests experience even after visiting the museum. Knowing what drew your attention during the exhibit would mean the app could deliver a perfect further reading list. Crucially, all the data about what's working, and what isn't, is collected in the background and can form part of the procurement process when the space is updated. 66

Os sensores utilizados para esta finalidade se baseiam nas tecnologias RFID (Identificação por Radiofrequência) ${ }^{67}$, Bluetooth e sua variante

66 <http://eu.oheuaqui.com/2zc9mQ6> Acesso em 10 out. 2017

67 RFID é uma sigla que vem do inglês e significa Radio Frequency Identification (Identificação por Radiofrequência). Trata-se de um sistema de captura de dados que utiliza o sinal, frequência, de rádio para realizar tal tarefa. Apesar de ser considerada uma tecnologia nova que surgiu na década de 80 quando o MIT iniciou estudos na criação de tecnologias baseadas em ondas de rádio e que servissem de referência ao desenvolvimento de novas aplicações de rastreamento e localização de produtos, um dos primeiros sistemas passivos de RFID surgiu durante a Segunda Guerra Mundial quando os aviões eram detectados à longa distância por radares, porém não se sabia se eram aeronaves amigas ou inimigas. Os alemães então descobriram que se seus pilotos girassem o avião enquanto retornassem à base, eles modificariam o sinal que seria refletido de volta aos radares. Isso os identificava como pilotos alemães. Mais tarde, os ingleses, sob o comando de Watson-Watt, projetaram o primeiro identificador ativo. Um transmissor era colocado em cada avião britânico e estes quando recebiam sinais das estações de radar no solo, transmitiam de volta um sinal de resposta, que identificava a aeronave como amiga. Nos RFIDs o princípio é o mesmo. Um sinal é enviado a um transponder, que é ativado e reflete de volta o sinal(passivo) ou transmite seu próprio sinal (ativo). A partir de então estudos e pesquisas na área de radiofrequência começaram a ser realizados e mostraram como essa energia poderia ser utilizada para identificar objetos remotamente. Começou assim o uso dessa nova tecnologia para identificar objetos em movimento. Isso foi uma vantagem em relação ao sistema de código de barra que necessita do objeto parado e de um leitor a laser. Utilizando um método de etiquetas (tags) inteligentes (etiquetas eletrônicas com um microchip instalado) que são postas nos objetos, estes passaram a ser rastreados por ondas de rádio através de uma resistência de metal ou carbono que funciona com antena, trocando informações com o sistema (computador) através de seus EPCs (Eletronic Product Code) ou Código Eletrônico do Produto. O RFID designa qualquer sistema que usa radiofrequência como método de identificação, porém o mais comum é o que utiliza microchip para armazenar a informação desejada. <http://eu.oheuaqui.com/2xuoTJ5> Acesso em: 10 out. 2017 
Bluetooth Low Energy (LE) ${ }^{68}$ e NFC (Near Field Communication ou Comunicação por Campo de Proximidade) ${ }^{69}$, representando gastos de aquisição muito menores em relação às gerações anteriores de dispositivos.

A partir de um investimento relativamente pequeno - quando comparado aos projetos que envolvem AR ou realidade virtual - é possível se conectar ao visitante, melhorar a experiência deste e personalizar o conteúdo exibido:

Ultimately, the combination of a popular technology, visitors being motivated to download a genuinely useful and informative app and real-time analytics is a potential game changer for museums. For a relatively small investment they can connect, enhance, personalise and understand more about their visitors - at least $81 \%$ of them. ${ }^{70}$

68 Bluetooth Low Energy ou, simplesmente, Bluetooth LE (também há a sigla BLE, mas ela é menos usada), é uma variante da tecnologia Bluetooth. Trata-se de uma especificação que faz a tecnologia consumir uma quantidade muito pequena de energia elétrica em relação às outras versões. Acessórios médicos portáteis, smartwatches e pulseiras inteligentes são exemplos de dispositivos que, por serem muito compactos, usam baterias de baixa capacidade. Assim, toda economia de energia é válida. O Bluetooth LE veio para atender justamente a essa necessidade. Para consumir menos energia, - Bluetooth LE utiliza várias técnicas. Uma delas é a redução na velocidade de transferência de dados, que normalmente não passa de $1 \mathrm{Mb} / \mathrm{s}$ : essa taxa costuma ser suficiente, pois o volume de dados é baixo. Pela mesma razão, um módulo Bluetooth LE também pode ficar a maior parte do tempo em "modo de descanso": como não há muitos dados a serem transmitidos, uma conexão de poucos milissegundos consegue dar conta de enviar ou receber todas as informações necessárias. Outra técnica é a redução do alcance da comunicação: o Bluetooth LE trabalha bem com distâncias de até 30 metros, mas o gasto de energia cai drasticamente se um dispositivo estiver bem perto do outro.

69 Comunicação por Campo de Proximidade, Near Field Communication ou NFC é uma tecnologia que permite a troca de informações sem fio e de forma segura entre dispositivos compativeis que estejam próximos um do outro. Ou seja, logo que os dispositivos estejam suficientemente próximos, a comunicação é estabelecida automaticamente, sem a necessidade de configurações adicionais. Estes dispositivos podem ser telefones celulares, tablets, crachás, cartões de bilhetes eletrônicos e qualquer outro dispositivo que tenha um chip NFC.

<https://pt.wikipedia.org/wiki/Near_Field_Communication> Acesso em: 10 out. 2017

70 <http://eu.oheuaqui.com/2y42Pt7> Acesso em 10 out. 2017 


\section{Linha do Tempo: Realidade Virtual}

\begin{tabular}{|c|c|}
\hline 1935 & $\begin{array}{l}\text { Stanley G. Weinbaum's escreve o conto Pygmalion's Spectacles, } \\
\text { o qual descreve um sistema de realidade virtual baseado em } \\
\text { óculos especiais e gravações holográficas que incluem aromas } \\
\text { e toque }\end{array}$ \\
\hline 1939 & $\begin{array}{l}\text { O visualizador estereoscópico View-Master é lançado no } \\
\text { mercado }\end{array}$ \\
\hline 50 & $\begin{array}{l}\text { Morton Heilig cria o conceito de Teatro Experiencial, que } \\
\text { engloba todos os sentidos do espectador em relação ao que } \\
\text { ocorre na tela ou palco }\end{array}$ \\
\hline 959 & $\begin{array}{l}\text { Ciência da Computação define realidade virtual como aquilo } \\
\text { que aparece aos sentidos por meio de software }\end{array}$ \\
\hline 962 & $\begin{array}{l}\text { Morton Heilig constrói o Sensorama, um protótipo daquilo que } \\
\text { denominou Experience Theatre: um modo de envolver o } \\
\text { espectador através da cinestesia. Exibia cinco filmes de curta } \\
\text { duração, acompanhados de ativação dos sentidos (visão, som, } \\
\text { aromas e toque) }\end{array}$ \\
\hline 1968 & $\begin{array}{l}\text { Ivan Sutherland, com a ajuda de Bob Sproull, cria o primeiro } \\
\text { Head Mounted Display, ou óculos/capacete de realidade } \\
\text { virtual (HMD) para utilização em simulações imersivas }\end{array}$ \\
\hline & Myron Krueger cria o têrmo realidade virtual \\
\hline
\end{tabular}


1978 O Massachusetts Institute of Technology (MIT) cria um sistema de hipermídia e realidade virtual denominado Aspen Movie Map, o qual simula uma caminhada pela cidade de Aspen, Colorado, em 3 modos distintos: verão, inverno e polígonos

1980 Atari, Inc. lança o videogame Battlezone, o qual utiliza gráficos em 3D para situar o jogador em um universo virtual ATARI funda um laboratório de pesquisas em realidade virtual, fechado dois anos depois Jaron Lanier e Thomas Zimmerman, ex-funcionários da ATARI, criam a VPL Research, empresa de tecnologias ligadas à realidade virtual Artificial Reality Lab: iniciativas pioneiras de Myron Krueger Disneylândia oferece a seus visitantes o Star Tours, simulador de vôo imersivo baseado na série Star Wars, fruto da colaboração entre o produtor George Lucas e Walt Disney Imageneering Virtual World Entertainment inaugura o primeiro centro BattleTech em Chicago, baseado no sistema SIMNET de treinamento simulado em rede, através de cabines que funcionam como um CONSOLE imersivo e interativo Electronic Visualization Laboratory cria a primeira sala imersiva, denominada Cave Automatic Virtual Environment (CAVE), a qual permitia aos espectadores visualizar seus próprios corpos em relação a outras pessoas presentes no recinto 
Sega Enterprises, Ltd. anuncia o lançamento do capacete Sega VR e o console de jogos Mega Drive. Utiliza tela de LCD no visor, fones de ouvido estéreo e sensores inerciais capazes de detectar e reagir aos movimentos da cabeça A revista Computer Gaming World prevê a disponibilidade em massa de sistemas de realidade virtual em 1994 Louis Rosenberg cria, em um laboratório militar norte-americano, o sistema Virtual Fixtures, o qual utilizava um exoesqueleto da parte superior do corpo, permitindo ao usuário uma experiência física de realidade virtual em 3D bastante convincente para a época O videogame DOOM é lançado pela id Software, introduzindo ao público a modalidade de jogos denominada first-person shooter e estabelecendo o modelo de múltiplos participantes como a categoria dominante em jogos de computadores Surge uma linguagem específica para objetos virtuais: Virtual Reality Modelling Language (VRML)

O têrmo realidade virtual surge pela primeira vez na literatura de ficção científica, através do conto Judas Mandala de Damien Broderick

Apple Inc. lança o modelo de visualização em 360 graus denominado QuickTime Virtual Reality

1995 Nintendo lança, no Japão, o consOle The Virtual Boy 


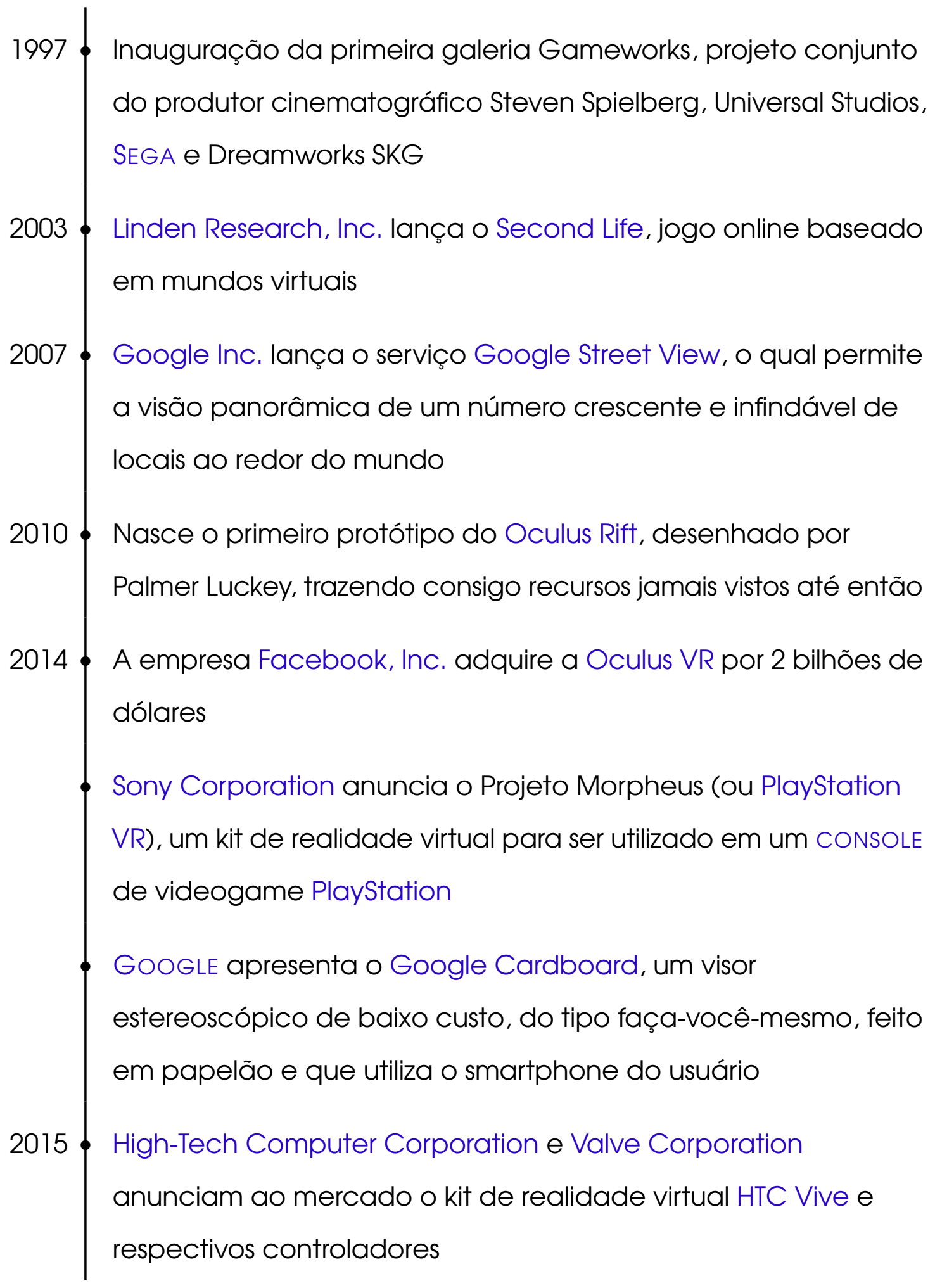




$2016\left\{\begin{array}{l}\text { Disney Studios e Museu Salvador Dali inauguram a exibição } \\ \text { Disney e Dali: Arquitetos da Imaginação, onde o espectador } \\ \text { pode, através da utilização de um HMD, literalmente adentrar a } \\ \text { obra do pintor. Mesmo para aqueles que se encontram } \\ \text { distantes do museu é disponibilizado, pela Internet, um } \\ \text { aplicativo que permite a mesma experiência imersiva }{ }^{71} \\ \text { O Smithsoniam Museum, em parceria com a empresa de } \\ \text { tecnologia Autodesk, lançam um modelo virtual do módulo } \\ \text { espacial Columbia (Apollo 11), permitindo sua visualização } \\ \text { interna nos mínimos detalhes através de mecanismos 3D } \\ \text { executados no próprio navegador }\end{array}\right.$

71 <http://eu.oheuaqui.com/2tH2yLl> Acesso em 23 jul. 2017

$72<$ https://3d.si.edu/apollo 1 lcm/> Acesso em 24 ago. 2017 


$2017\left\{\begin{array}{l}\text { Existem pelo menos } 230 \text { empresas dedicadas ao } \\ \text { desenvolvimento de produtos relacionados à realidade virtual. } \\ \text { FACEBOOK, por exemplo, possui } 400 \text { funcionários dedicados ao } \\ \text { desenvolvimento do seu óculos VR; do mesmo modo, GOOGLE, } \\ \text { APPLE, Amazon.com, Inc., Microsoft Corporation, SoNY, Samsung } \\ \text { Group - e tantas outras - possuem equipes dedicadas } \\ \text { exclusivamente ao desenvolvimento de tecnologias } \\ \text { relacionadas ao tema }\end{array}\right.$


FIGURA 6 VPL Data Glove (1987)

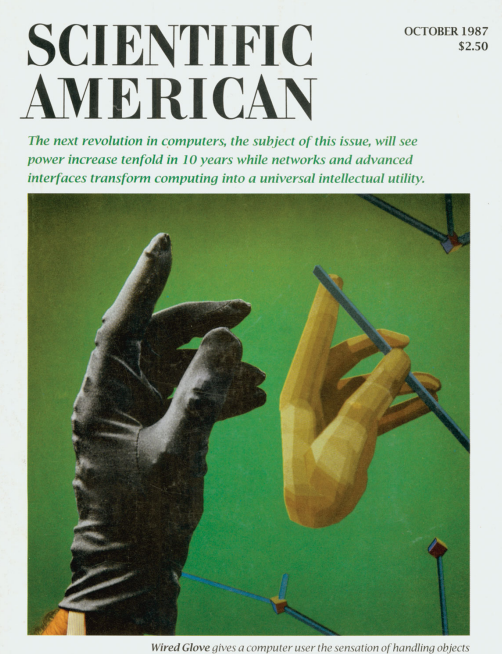

FIGURA 7 Sensorama (1962)

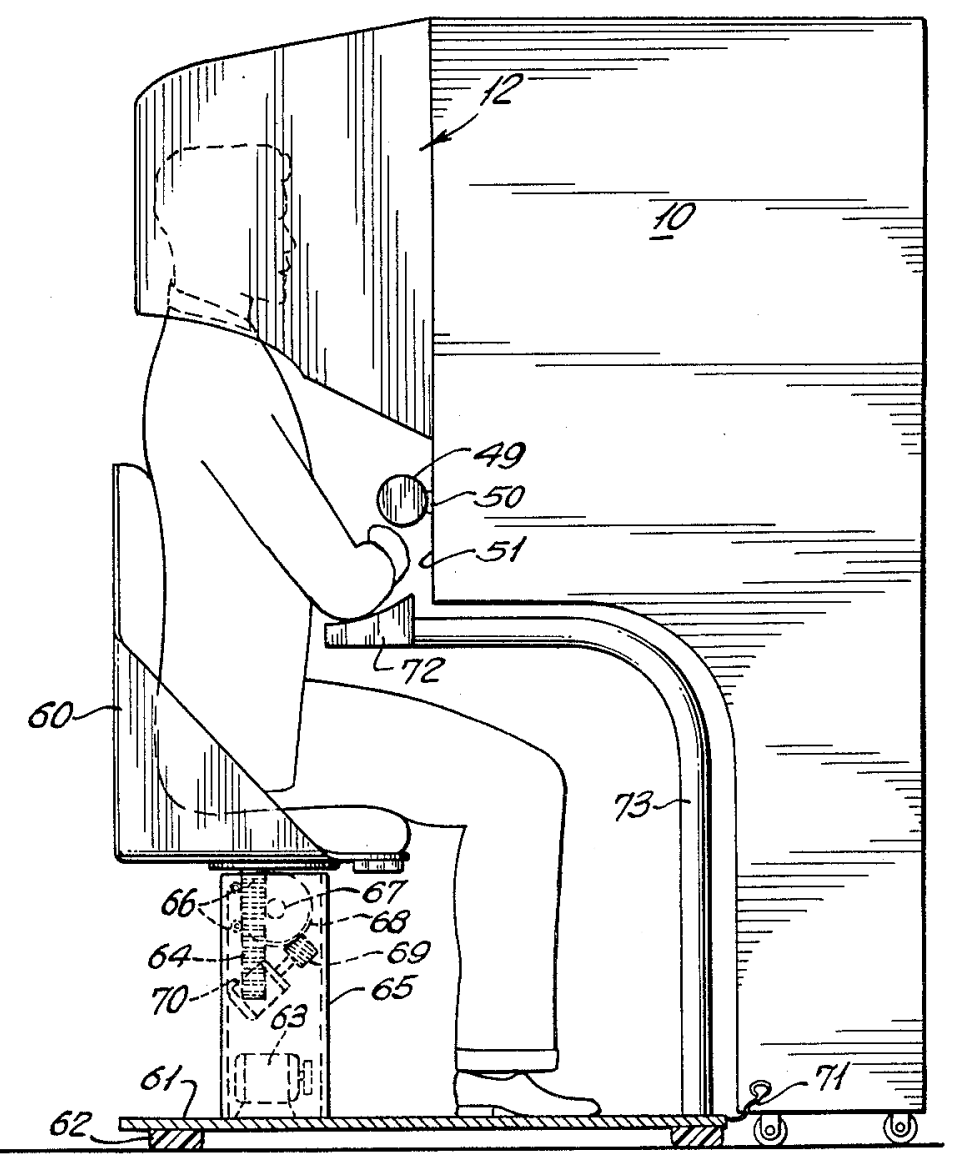


FIGURA 8 Viewmaster 3D modelo $G$ (1962)

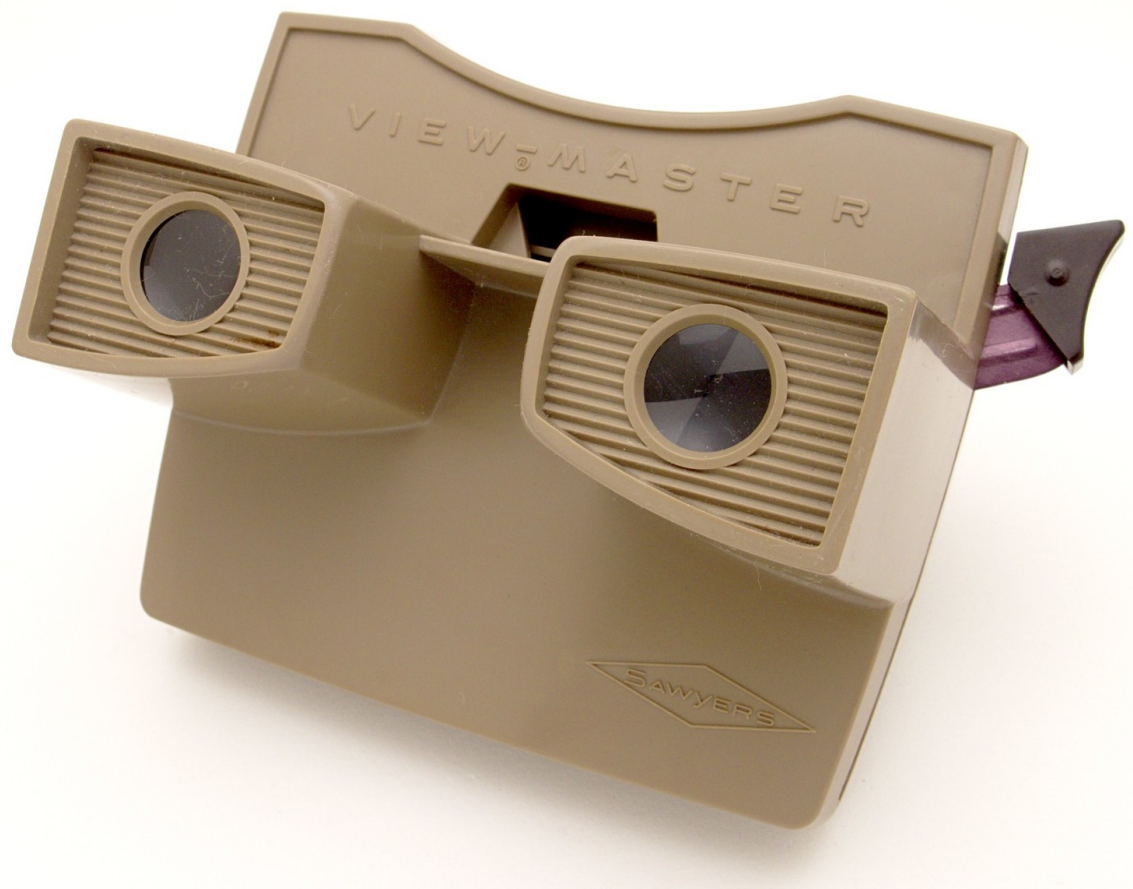

FIGURA 9 Viewmaster Virtual Reality Viewer (2015)

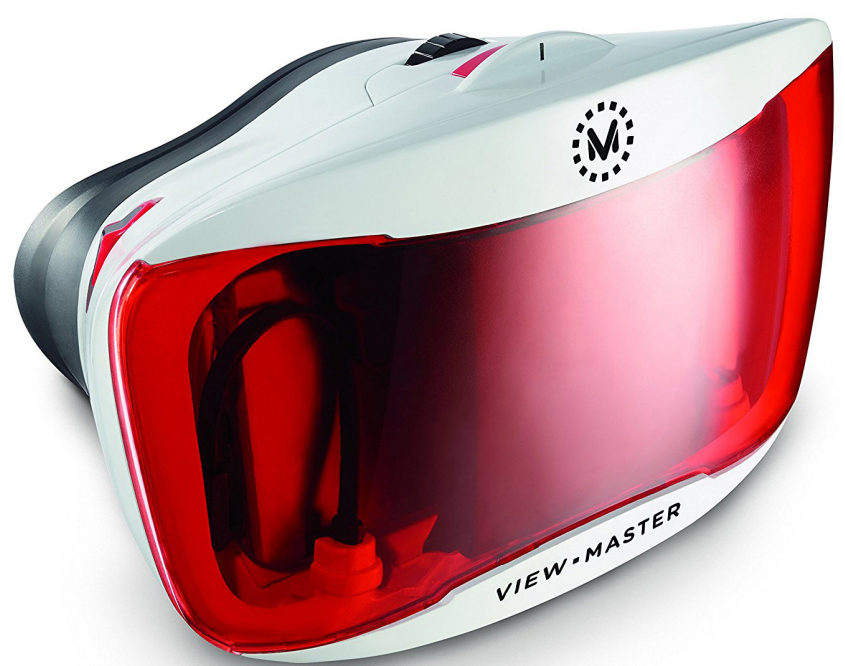


FIGURA 10 Sony Playstation VR HDM (2014)

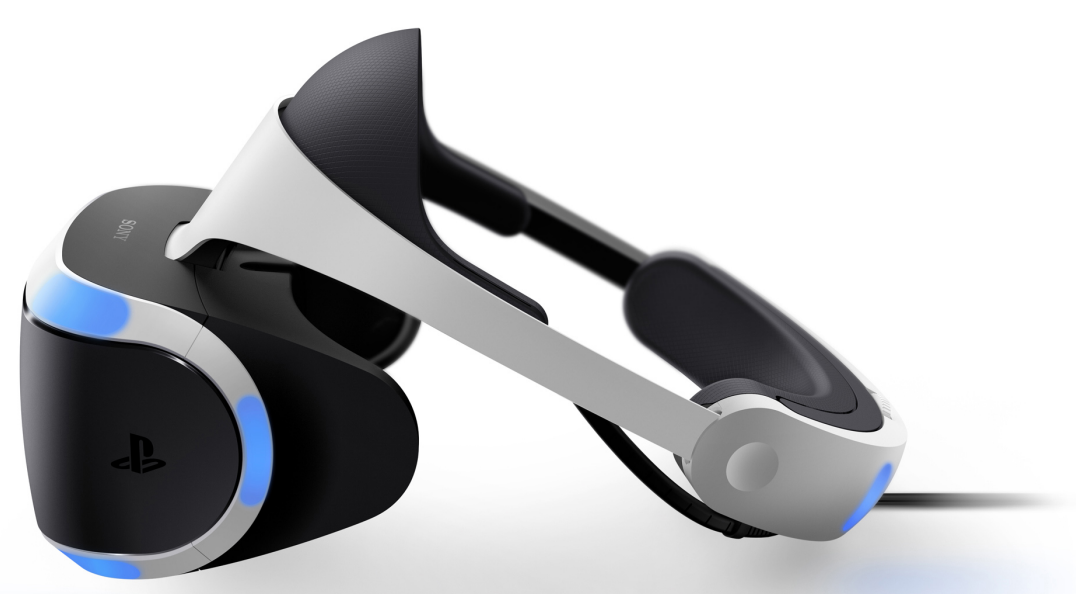

FIGURA 11 Google Cardboard (2014)

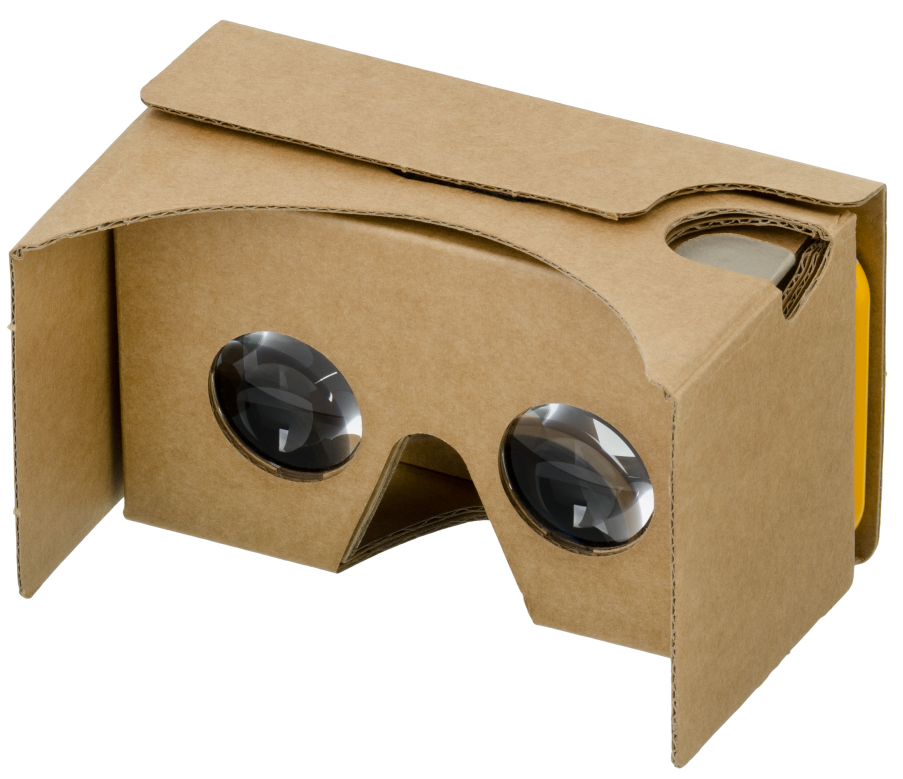




\subsection{O avanço da conectividade}

Ao longo da evolução dos sistemas de áudio guiado e dos dispositivos de realidade virtual e aumentada, surgem novas e inesperadas mudanças: Um período em que tecnologia, museus e expectativas dos visitantes se modificam, assim como o entendimento de cada uma destas variáveis.

À medida em que os museus e o resto do mundo adentram a era digital, a Internet se torna cada vez mais popular. Em 2016, 47\% dos habitantes do planeta possuem conectividade, divididos em $81 \%$ da população dos países desenvolvidos e $40 \%$ nos países em desenvolvimento ${ }^{73}$.

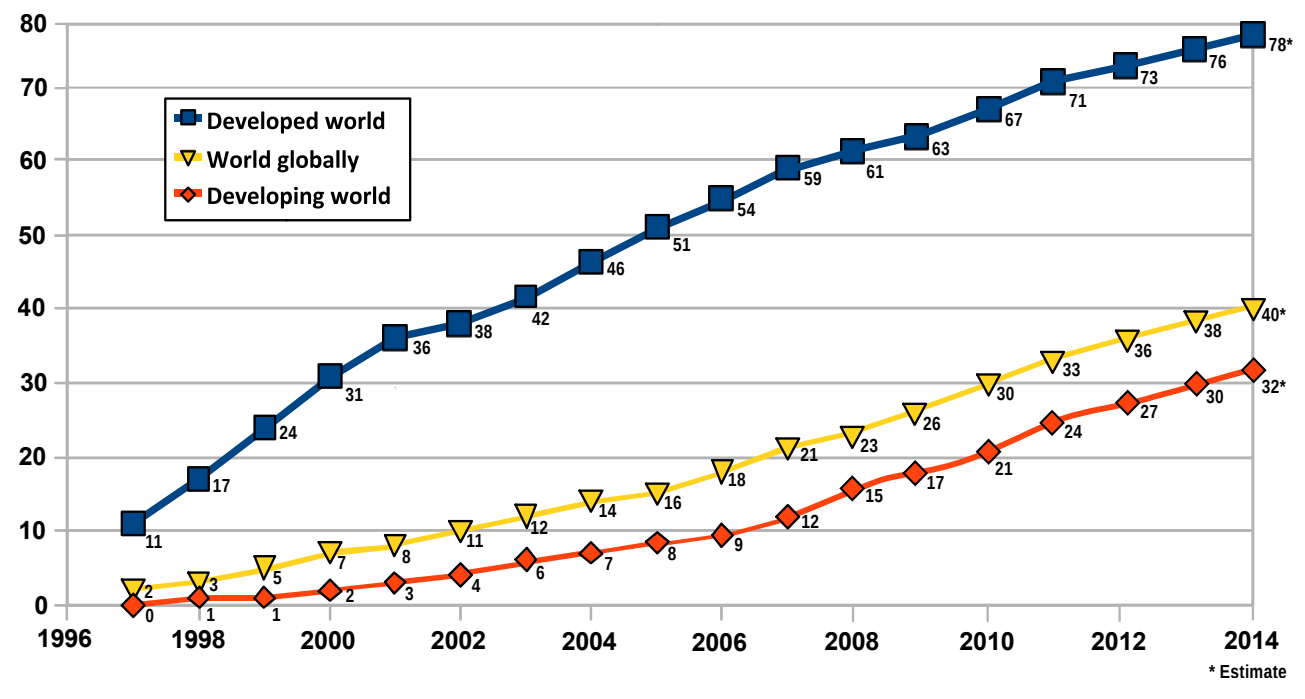

TABELA 5 Uso global da Interne†

A possibilidade de obter acesso a um maior número de fontes de dados determina mudanças nas atitudes da sociedade, como um todo, em relação a como, onde e por quê obter informação:

73 <https://en.wikipedia.org/wiki/Global_Internet_usage> Acesso em 21 jul. 2017 
What was possible before 1993 and what is today possible are two entirely different propositions. The instantaneous retrieval of information globally, in authoritative and systematic ways, is transforming the experience of the original object as well as the prefatory and subsequent experiences of learning about it. ${ }^{74}$

A influência e impacto deste processo sobre o museu se torna cada vez mais significativo. A Internet fornece a inércia social necessária para inovação não apenas no aspecto tecnológico como também nas metodologias, práticas e filosofia. A postura anterior do museu, dedicada a fornecer informação autoritativa ao visitante através de legendas, textos e guias de áudio começa a ser substituída por múltiplas perspectivas inclusive aquela do espectador.

A difusão da telefonia celular - a qual atinge, em 2013, 93\% da população planetária ${ }^{75}$ - forma a massa crítica necessária para, de acordo com a teoria da difusão da inovação de Rogers (2010), permitir a utilização do dispositivo em toda e qualquer atividade onde isto seja viável, pois este passa a ser o canal de comunicação do usuário com o mundo à sua volta; tornando-se, desta forma, um novo item dentro do rol das tecnologias baseadas em dispositivos móveis (vide Tabela 3) à disposição do museu.

\footnotetext{
74 Anderson (1999, p. 129)

75 <http://blog.cartesian.com/the-rise-of-mobile-phones-20-years-of-global-adoption> Acesso em 21 jul. 2017
} 


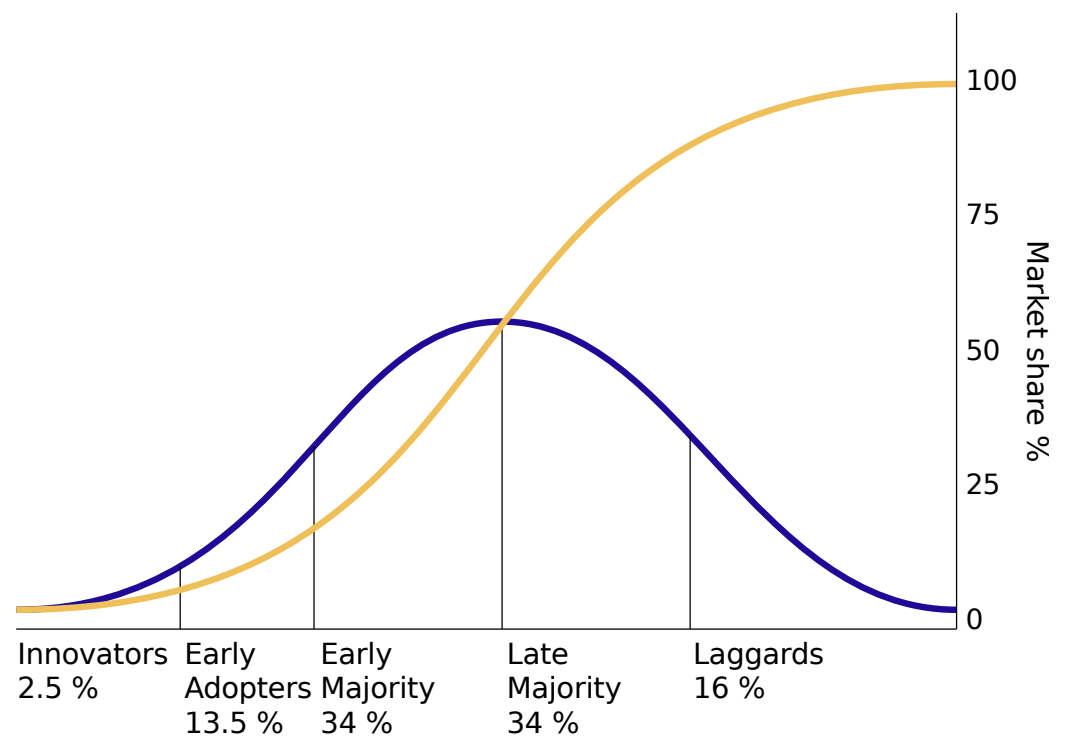

TABELA 6 Teoria da Difusão da Inovação

O momento contemporâneo traz o desafio da onipresença da Internet e sua capacidade de gerar padrões referenciais em relação à existência no mundo físico ou mesmo abstrato ${ }^{76}$.

A possibilidade de acesso a instrumentos de captura, edição e transformação de conteúdo transforma cada usuário em um potencial produtor cultural, curador ou historiador de arte:

With relatively little fanfare, the advent of inexpensive digital imaging, the spread of the World Wide Web, and the ability of these two technologies to quickly and easily alter, publish, and distribute photographic images, has radically changed the old, post-photographic hegemony...

... Once, the expense and complexity of making quality art museums and publishing them helped confine the discourse on art to a privileged circle of museums, art scholars, and elite publishers. Now that discourse is available to anyone with access to modern computer networks. On the World Wide Web, anyone can be a museum curator or art historian, promoting his or her own view of the meaning of art, borrowing images from museum Web sites, from hundreds

76 "Today we are in the era of the post-Internet art museum. Once, art historians said "it's not in my books or slide library, thus it must not be important." Now, their students tend to say 'It's not on the Internet. It must not exist'." Walsh (2007, p. 31) 


\title{
3.4 Adequação da tecnologia à museologia
}

\begin{abstract}
"(There is a) tension between the responsibility for heritage and the desire to break new ground; too little respect for heritage and the past is destroyed, too much; you threaten the future."

(Deborah Bull ${ }^{78}$, diretora de parcerias culturais do King's College, Londres no simpósio NESTA, 2015, v. Apêndice $G$ na página 195) ${ }^{79}$
\end{abstract}

\begin{abstract}
"Any attempt to augment an encounter with artwork using technological means invariably raises questions about the values we assign to certain modes of viewing. After all, isn't visiting a museum inherently tied to a very deep, very primary real-life experience? The promises and pitfalls of new technologies are forcing museums to rebalance their traditional mandates to care for a collection of physical objects while enabling scholarship and providing the wider public an opportunity to engage with works of art."

(Sarah Hromack e Rob Giampietro, Art in America, v. Figura C na página 167)
\end{abstract}

77 Art museums, now major presences on the Web themselves, have yet to respond directly to these technological changes with shifts in their basic philosophy towards the display and interpretation of works of art. For the most part, despite the transfer of masses of art-related material to electronic media, the uses museums make of digital photography to interpret and assess art remain similar if not identical to those made of "analog" photographs in the late nineteenth century. Online material and other digital publications produced by art museums still closely resemble printed catalogs and exhibition brochures, with a few technological flourishes rather than a fundamental change in approach. But the new museum Web sites are only the first manifestation of the post-Internet museums. Now fully engaged in a new electronic world, art museums are being pressured to move in new, yet-to-be-defined directions, as they were by photography one hundred and fifty years ago. Like photography when it appeared on the scene, digital technology is, simultaneously, a new art medium, a new way of interpreting and publicizing art, and a distinct challenge to art itself. A new South Kensington Museum may already be in operation, either in the physical world or in virtual space, for one era in museum history has surely ended while another has only begun." Walsh (2007, p. 31-33)

78 <http://www.nesta.org.uk/users/deborah-bull> Acesso em: 17 jul. 2017

79 <http://eu.oheuaqui.com/2v97LIA> Acesso em: 17 jul. 2017 
Com o avanço dos recursos tecnológicos disponíveis ao museu, o processo gerador da reação in situ do espectador se move do contexto histórico do objeto de arte em direção ao ex situ, o mundo contemporâneo ${ }^{80}$. As tecnologias utilizadas para exibição e interação dentro do museu passam a servir como ferramentas para a negociação efetuada entre dois universos: um deles do visitante e o outro do objeto de arte. O curador atua como mediador, responsável pela dosagem do grau de participação permitido ao espectador.

À medida em que as exibições veiculadas pelo museu se tornam digitais, virtuais, interativas e mediadas por dispositivos móveis, o potencial de participação do público se torna maior ${ }^{81}$. No exemplo da instalação Interactive Worktable and Scritoire (v. na página 60) o visitante pode negociar diretamente seu presente com o passado relacionado ao objeto exposto, pois o livro é atualizado e fisicamente modificado através de recursos tecnológicos e interativos ${ }^{82}$.

Merece destaque o fato de que a utilização da Internet das Coisas (Internet of Things ou loT) no contexto do museu pode, na opinião de Mighali et al. (2015, p. 550), trazer melhorias significativas na experiência cultural dos seus visitantes e gerar novos modelos de narrativas experienciais.

Um dos principais desafios dos museus na contemporaneidade é manter e aumentar o número de visitantes, além de atrair audiências mais jovens. Uma queda no número de visitantes é considerada como ponto negativo, tanto em têrmos financeiros quanto em relação ao impacto educacional sobre a população. Embora tal queda possa ser atribuída a

\footnotetext{
80 Christensen (2011, p. 26)

81 Christensen (2011, p. 27)

82 Embora o objeto original se mantenha intacto. (N. A.)
} 
um sem-número de variáveis, um fato a ser destacado é a competição frequente entre aquilo que o museu oferece e os produtos oferecidos pela indústria do entretenimento, pois ambos são modelos narrativos ${ }^{83}$, com a missão de criar e propagar o denominado storytelling 84 .

storytelling se apresenta como um dos fatores mais importantes dentro das novas doutrinas museológicas ${ }^{85}$ - as quais trouxeram a prática através dos guias de áudio, vídeos e a ênfase na organização temática e diferentes perspectivas e interpretações culturais.

O avanço dos modelos baseados em storytelling, aliados ao desenvolvimento tecnológico, dão origem ao storytelling digital interativo. Este combina a participação do espectador com a geração automática de narrativas, a fim de criar uma experiência mais pessoal e baseada no uso de dispositivos móveis. Na ausência de equivalentes em língua portuguesa, será utilizado o neologismo educational entertainment (edutainment) ${ }^{86}$, o

83 "Narrativa é uma exposição de fatos, uma narração, um conto ou uma história. As notícias de jornal, história em quadrinhos, romances, contos e novelas, são, entre outras, formas de se contar uma história, ou seja, são narrativas. As narrativas são expressas por diversas linguagens: pela palavra (linguagem verbal: oral e escrita), pela imagem (linguagem visual), pela representação (linguagem teatral) etc."

<https://www.significados.com.br/narrativa/> Acesso em: 08 Ago. 2017

84 "Storytelling é uma palavra em inglês, que está relacionada com uma narrativa e significa a capacidade de contar histórias relevantes. Em inglês a expressão tell a story significa contar uma história e storyteller é um contador de histórias."

<https://www.significados.com.br/storytelling/> Acesso em: 08 Ago. 2017

O têrmo storytelling será utilizado no lugar de seu correspondente em português (narrativa), pelo fato de ser o vocábulo preferido tanto nos textos sobre museologia em língua inglesa quanto pelo universo empresarial (de modo geral) e da propaganda e do marketing (em particular). (N. A.)

85 Danks et al. (2007, p. 104)

86 The process of entertaining people at the same time as you are teaching them something, and the products, such as television programmes or software, that do this.

<http://dictionary.cambridge.org/dictionary/english/edutainment> Acesso em: 08 ago. 2017

Educational entertainment (also referred to by the portmanteau neologism edutainment) is a concept designed to educate through entertainment. Most often it includes content intended to teach but has incidental entertainment value. It has been used by academia, corporations, governments, and other entities in various countries to disseminate information in classrooms and/or via television, radio, and other media to influence viewers' opinions and behaviors.

<https://eu.oheuaqui.com/2meTDKp> Acesso em: 08 ago. 2017 
qual define um tipo de experiência mais engajada, adaptativa e lúdica para o espectador.

No caso do guia de áudio - precursor de um modelo narrativo Christensen (2011) compara a narração com a trilha sonora de um "filme" criado pelo visitante ao se movimentar no espaço do museu:

What narrative devices does the audio guide use in its communication of significance?

This question may be advantageously rephrased as: Is the audio guide the soundtrack of the visitor's museum film? ${ }^{87}$

Dois exemplos de grande sucesso no uso do storytelling digital interativo - British Museum e Museu Salvador Dali - utilizam a realidade aumentada (AR) como recurso principal. No caso do British Museum, a experiência vivenciada por uma criança, frente à exibição, se transforma em um quebra-cabeça, através do uso de um aplicativo instalado em um dispositivo móvel. O aplicativo, denominado A Gift for Athena, premia o jovem visitante quando este encontra determinadas estátuas no espaço do museu (através da sugestão destas por meio de contornos), encaminhando-o para a próxima etapa da experiência.

A utilização do storytelling atinge um novo patamar através do Projeto CHESS (Cultural Heritage Experiences through Socio-personal interactions and Storytelling) ${ }^{88}$, patrocinado pela União Européia, com o principal objetivo de desenvolver modelos e plataformas para jogos e realidade aumentada que possam atender, simultaneamente, às necessi-

87 Christensen (2011, p. 18)

88 CHESS (Cultural Heritage Experiences through Socio-personal interactions and Storytelling) is a project, co-funded by the European Commission, that aims to integrate interdisciplinary research in personalization and adaptivity, digital storytelling, interaction methodologies, and narrative-oriented mobile and mixed reality technologies, with a sound theoretical basis in museological, cognitive, and learning sciences.

The principal objective of CHESS is to research, implement and evaluate both the experiencing of personalized interactive stories for visitors of cultural sites and their authoring by the cultural content experts.

<http://www.chessexperience.eu/> Acesso em: 03 ago. 2017 
dades de todo e qualquer museu 89 . O projeto se baseia nos dados relativos ao perfil do visitante, os quais são comparados e relacionados a personas pré-determinadas, representadas por descrições dos vários perfis relativos à base de dados dos visitantes do museu. Tal base é gerada através de pesquisas, análise dos visitantes e observações etnográficas. O visitante, inicialmente, preenche uma pesquisa - e desta forma é encaixado em uma das personas existentes. Esta identificação irá influenciar de forma decisiva a experiência interativa gerada pelo PROJETO CHESS.

A partir deste momento, a experiência do espectador passa a ser NÃO-LINEAR e se enquadra nos ditames conceituais da estética da recepção (v. section 2.1). O sistema se adapta, constantemente, às preferências do visitante: analisando, por exemplo, o tempo dispendido em frente a determinados objetos de arte ou o desempenho em jogos e desafios propostos. Baseado neste monitoramento o sistema gera a customização e adaptação da narrativa, tornando assim a experiência in situ mais relevante e dinâmica através de redirecionamentos e ajustes no roteiro.

O fato de permitir que roteiros interativos possam ser criados por curadores - ao invés de programadores e desenvolvedores de TI - oferece aos museus a oportunidade de recriar, constantemente, as experiências disponiveis aos visitantes, ampliando assim o fluxo potencial de expectadores e oferecendo experiências mais ricas e completas. As experiências iniciais do sistema se dão no Museu da Acrópole em Atenas, Grécia, onde a tecnologia foi utilizada para trazer à vida um conjunto de esculturas e ruínas através do uso da realidade aumentada (AR) (caso similar ao da igreja de Sant Climent de Taüll, v. subsection 3.2.3 na página 59); e também 
na Cité de I'Espace (um parque temático em Toulouse, França) ${ }^{90}$ - onde foi utilizado para dar vida às emoções dos vôos espaciais e à concepção do universo.

O avanço da tecnologia dentro do museu parece ocorrer na continuidade de um processo iniciado após a II Guerra Mundial nos museus de maior porte, o qual define a emergência de um novo modelo - onde os curadores se tornam membros de uma equipe composta de cientistas e museólogos, tendo designers a assistir a definição visual da exibição, educadores a desenvolver as estratégias relacionadas aos estudantes e público em geral, cientistas da informação para a coleta e análise dos dados gerados (antes, durante e depois da mostra) e até mesmo estrategistas de marketing para promover o museu e seu acervo. Nota-se, de forma perceptivel, a mudança de paradigma entre um modelo destinado a servir pesquisadores, para aquele voltado à inclusão do grande público. Como resultado de tal inovação os museus ganham novo tipo de popularidade e atraem um número cada vez maior de visitantes incluindo-se nesta contagem um número significativo de turistas. $\bigcirc$ que leva muitos dos governos que abrigam museus de destaque a reconhecer a contribuição destes na economia do país ${ }^{91}$. Segundo Gonçalves (2005),

o campo de atuação da instituição museu renovou-se no decorrer dos anos e tornou-se muito mais amplo, desenvolvendo, principalmente a partir da segunda metade do século XX, mecanismos de aproximação com a sociedade ${ }^{92}$

Todos os profissionais envolvidos no processo destinado a gerar exibições cada vez mais sofisticadas e atraentes ao público dependem, em larga escala, de recursos ligados às tecnologias dominantes na contemporaneidade. E o desafio se torna, cada vez mais, adequar os recursos

$90 \quad<$ http://www.cite-espace.com/> Acesso em: 24 ago. 2017

91 <https://www.britannica.com/topic/history-of-museums-398827> Acesso em: 24 ago. 2017

92 Gonçalves (2005, p. 8) 
humanos e verbas disponíveis àquilo que possa ser desenvolvido de modo a permitir tanto longevidade quanto atratividade.

As escolhas que caracterizam a passagem e integração transparente entre o in situ e o ex situ são dificeis e demandam estudos específicos para cada caso. A única certeza unânime parece estar relacionada, como visto, à inevitável obsolescência dos processos envolvidos ( seção 2.4 na página 35). O capítulo seguinte aborda os principais modelos, parâmetros e critérios envolvidos em tal processo. 


\title{
4 | Critérios no uso da tecnologia
}

\section{1 | Campo de atuação e sua conformidade}

\begin{abstract}
Quando musealizamos objetos e artefatos com as preocupações de documentalidade e de fidelidade, procuramos passar informações à comunidade; ora, a informação pressupõe conhecimento (emoção/razão), registro (sensação, imagem, ideia) e memória (sistematização de ideias e imagens e estabelecimento de ligações). ${ }^{1}$
\end{abstract}

Para a consolidação do entendimento da utilização da tecnologia dentro do espaço do museu é importante, de início, definir o campo de atuação em consonância com a definição do que seja o museu.

No Brasil, de acordo com a Lei n 11.904 de 14 de janeiro de 2009, que instituiu o Estatuto de Museus,

Consideram-se museus, para os efeitos desta Lei, as instituições sem fins lucrativos que conservam, investigam, comunicam, interpretam e expõem, para fins de preservação, estudo, pesquisa, educação, contemplação e turismo, conjuntos e coleções de valor histórico, artístico, científico, técnico ou de qualquer outra natureza cultural, abertas ao público, a serviço da sociedade e de seu desenvolvimento. $^{2}$

1 Guarnieri (2010, p. 205)

2 <http://eu.oheuaqui.com/2BofRQH> Acesso em: 30 ago. 2017 
Esta dissertação utiliza a conceituação adotada pelo estatuto do International Council of Museums (ICOM - Conselho Internacional de Museus) $)^{3}$ :

O museu é uma instituição permanente e sem fins lucrativos, a serviço da sociedade e do seu desenvolvimento e aberta ao público; a qual adquire, conserva, pesquisa, comunica e exibe, de forma tangivel e intangível, a herança e o patrimônio cultural da humanidade e tudo que a cerca, com os propósitos de educação, estudo ou fruição. ${ }^{4}$

Cada uma das colunas da Tabela 7 - as quais funcionam, respectivamente, como adjetivo, verbo e substantivo - apresenta um desafio em relação às soluções mais adequadas para o modelo tecnológico.

3 O International Council of Museums (ICOM - Conselho Internacional de Museus), criado em 1946, é uma organização não-governamental internacional, sem fins lucrativos, que se dedica a elaborar políticas internacionais para os museus. Possui mais de 27000 membros de 150 países, 114 Comitês Nacionais e 30 Comitês Internacionais.

Suas principais atividades são:

- Cooperação e intercâmbio profissional

- Difusão de conhecimentos e aumento da participação do público em museus

- Formação de pessoal

- Prática e promoção de ética profissional

- Atualização de padrões profissionais

- Preservação do patrimônio mundial e combate ao tráfico de bens culturais <https://eu.oheuaqui.com/2mdhSIM> Acesso em: 29 ago. 2017

4 According to the ICOM Statutes, adopted by the 22nd General Assembly in Vienna, Austria on August 24th, 2007:

"A museum is a non-profit, permanent institution in the service of society and its development, open to the public, which acquires, conserves, researches, communicates and exhibits the tangible and intangible heritage of humanity and its environment for the purposes of education, study and enjoyment."

<http://icom.museum/the-vision/museum-definition/> Acesso em: 29 ago. 2017 


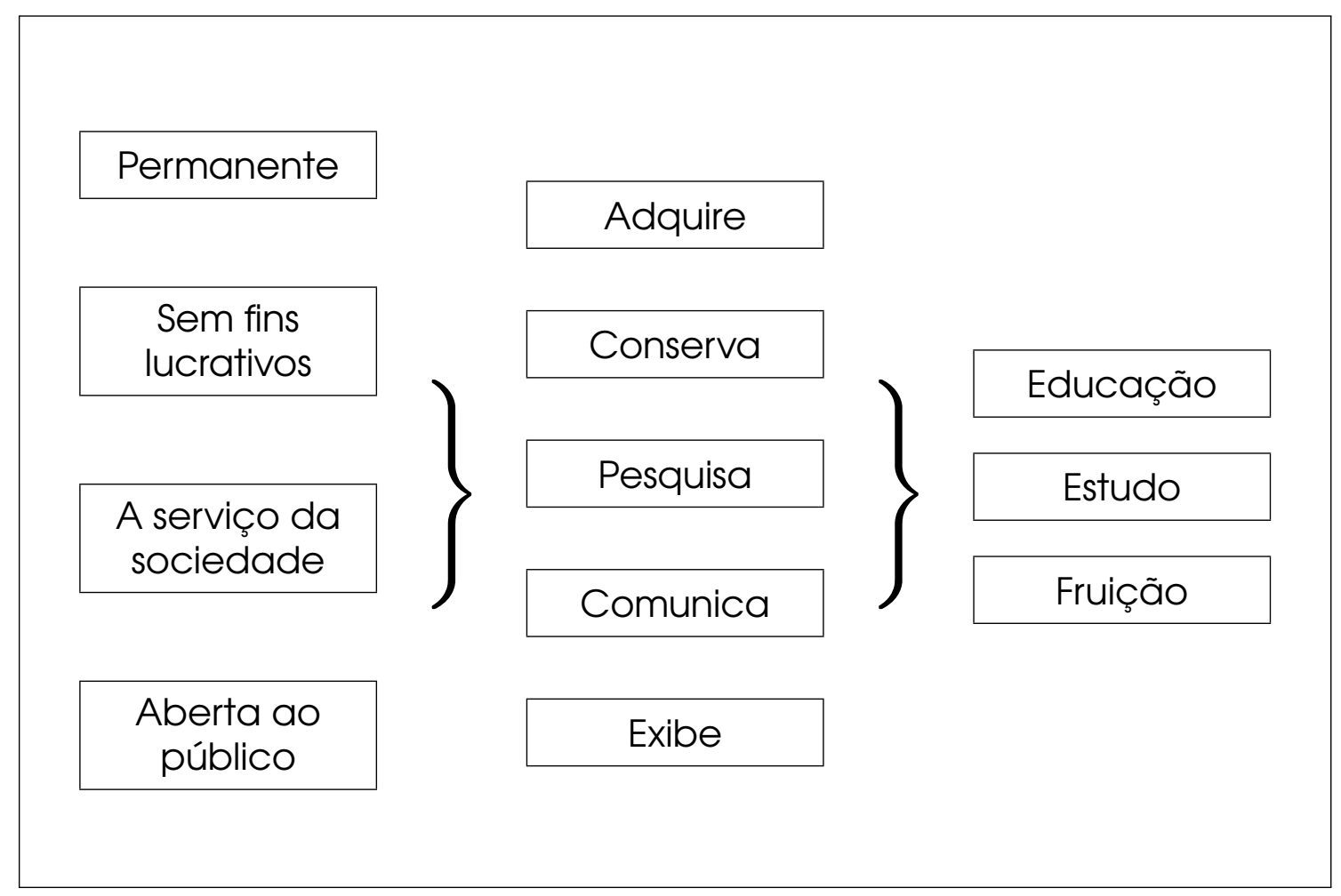

TABELA 7 Conceito de Museu segundo ICOM

As complexas interrelações entre os itens da definição e os temas de importância para a tecnologia podem ser melhor compreendidas quando visualizadas graficamente (Figura 12). 


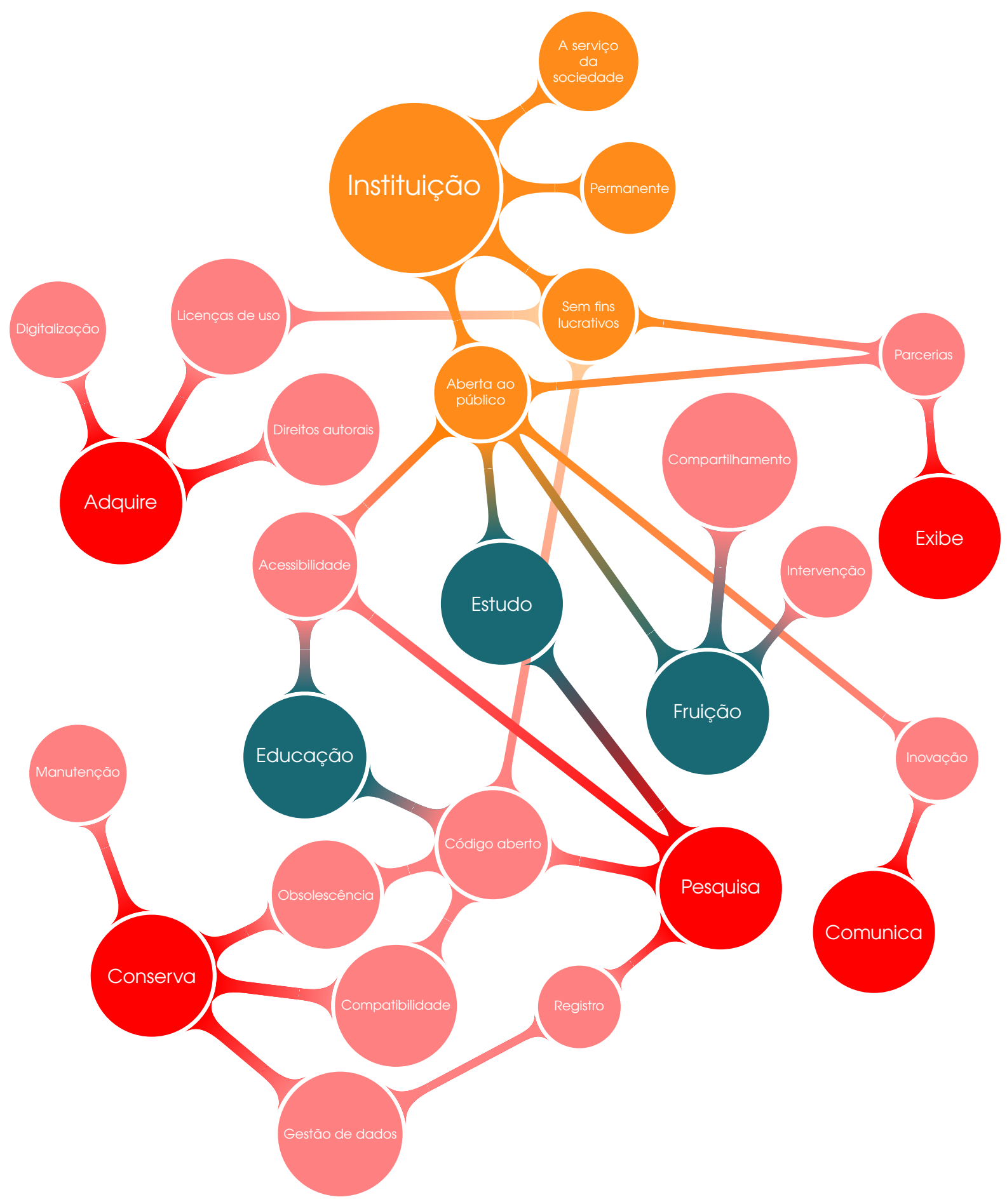

FIGURA 12 Conceito de Museu e sua relação com temas pertinentes à tecnologia 
Os temas de importância, tomados como base para a definição de critérios, foram compilados na Tabela 8, através de um modelo Mapa de calor (Heat map) ${ }^{5}$.

\begin{tabular}{|c|c|c|c|c|}
\hline & Permanente & $\begin{array}{l}\text { Sem fins } \\
\text { lucrativos }\end{array}$ & $\begin{array}{l}\text { A serviço da } \\
\text { sociedade }\end{array}$ & $\begin{array}{c}\text { Aberta ao } \\
\text { público }\end{array}$ \\
\hline Adquire & \multicolumn{4}{|c|}{ Parcerias tecnológicas e geração de recursos } \\
\hline Conserva & \multicolumn{4}{|c|}{ Digitalização } \\
\hline Pesquisa & \multicolumn{4}{|c|}{ Plataforma aberta } \\
\hline Comunica & \multicolumn{4}{|c|}{ Internet e redes sociais } \\
\hline Exibe & \multicolumn{4}{|c|}{ Museu virtual } \\
\hline
\end{tabular}

TABELA 8 Critérios tecnológicos aplicados à definição de Museu

A partir desta compilação é possivel entender, de forma pontual, os critérios relativos a cada um dos itens relacionados ao papel do museu e avaliar os modelos de gestão e implementação tecnológicas que, atuando juntos, trarão como resultado o "museu virtual", assim definido por (SCHWEIBENZ, 1998):

The "virtual museum" is a logically related collection of digital objects composed in a variety of media, and, because of its capacity to provide connectedness and various points

5 Os mapas de calor permitem que os visualizadores compreendam com mais facilidade a distribuição e a intensidade relativa de pontos de dados em um mapa. Em vez de colocar um marcador em cada localização, os mapas de calor usam cores para representar a distribuição dos dados.

A melhor forma de entender um mapa de calor é pensar em uma tabela ou planilha a qual contém cores ao invés de números, com uma transição correspondente (ou gradiente) entre estes extremos. Os mapas de calor são bastante apropriados para visualizar grandes quantidades de dados multidimensionais e podem ser utilizados para identificar grupos de linhas com valores similares, conforme elas são mostradas nas áreas de cor similar.

<http://datavizproject.com/data-type/heat-map> Acesso em: 25 set. 2017 
of access, it lends itself to transcending traditional methods of communicating and interacting with the visitors being flexible toward their needs and interests; it has no real place or space, its objects and the related information can be disseminated all over the world. ${ }^{6}$

Os 4 critérios expostos na Tabela 8 serão abordados, separadamente, nas próximas seções deste capítulo.

\title{
4.2 Os 4 critérios ligados à definição
}

\begin{abstract}
As Ciências da Informação se ocupam da perenidade da informação, dos acervos e das memórias e dos seus usos em contextos sociais e organizacionais. Como realinhar seus pressupostos para um contexto mercadológico informatizado e midiatizado em constante transformação, onde se reconfigura aceleradamente uma pluralidade de discursos, narrativas, linguagens e imagens? ${ }^{7}$
\end{abstract}

A análise, em separado, de cada um dos critérios ligados à definição de Museu, visa responder às oportunidades trazidas pelas tecnologias digitais e à mudança das expectativas dos visitantes, ao mesmo tempo em que busca prevenir investimentos onerosos em plataformas técnicas que se tornem impopulares ou obsoletas. Considera tais critérios como essenciais ao planejamento e enfatiza a importância da flexibilidade e colaboração durante o processo de desenvolvimento, qualidades estas que aumentam a sustentabilidade em um mundo incerto.

Schweibenz (1998, p. 191)

Marteleto (2007, p. 23) 


\title{
4.2.1 | Parcerias tecnológicas e geração de recursos
}

\subsubsection{1 | Pressupostos}

It is essential to recognise the ecologies within what are too often seen as distinct parts of the cultural world, above all between the publicly-funded and commercial sectors, but also including amateur arts and co-production. Culture is an organism not a mechanism, messier and more dynamic than linear models allow. The non-profit cultural sector contributes research and development for commercial cultural providers, while public funding enables them to take risks with creative content and ideas. There is a continual exchange of talent, finance, and content and ideas. ${ }^{8}$

A presença ativa do público nas atividades do Museu - sejam estes in situ ou ex situ - reflete um novo modelo de participação; onde aqueles que apreciavam a arte de forma apenas estática em um momento anterior, passam a fazer parte do evento de todas as formas possiveis. A tecnologia atua como mediador neste processo, ao facilitar e permitir tal participação em escala inédita.

A dimensão social contemporânea do Museu em relação ao seu público é exposta por (AURELIANO; COAN; FILHO, 2016):

\begin{abstract}
Contrária à antiga concepção de museu que colocava seus acervos em primeiro plano, o museu tem hoje como função primordial, servir à sociedade. Os museus se ampliaram em tipologias e quantidade e têm se tornado espaços de troca de experiências. Enquanto equipamentos públicos e culturais, se propõem a zelar pelo bem estar da comunidade, proporcionando espaços socialmente inclusivos e atuando como fonte confiável de conhecimento e informação. Ali também pode a sociedade alinhar seus valores, reverberando em decisões mais conscientes, tanto no âmbito local quanto global. ${ }^{9}$
\end{abstract}

(MARTINS et al. , 2017) relatam como a intermediação tecnológica acaba por se tornar a ferramenta ideal para tal iniciativa:

8 Crossick e Kaszynska (2016, p. 99)

9 Aureliano, Coan e Filho (2016, p. 3728) 
Não é mais um experimento a mediação museológica por meio de tecnologias. Estas já se encontram presentes em diversos espaços museais espalhados pelo globo, contribuindo para a indústria museológica. A Ciência da Informação complementa a experiência em dois processos centrais, sendo um responsável pelo recolhimento de dados e sua gestão na contribuição ao objeto da museologia: o acervo. O outro ponto recai sobre a atuação da gestão dos dados transformados em informação para a produção de conhecimento pelo público-visitante e na contribuição da materialização da experiência museológica destes espaços. ${ }^{10}$

(CROSSICK; KASZYNSKA, 2016) destacam o fato em seu relatório sobre arte e cultura:

Cultural experience has been significantly affected by the growth of digital technologies, which not only provide new ways for people to connect with cultural institutions but also new ways to experience commercial culture, for example through downloading and streaming music and film. The distinction between producer and consumer has become less clear with the rise of co-production and user generated content. ${ }^{11}$

Pode-se dizer que o público - ao atuar como participante ativo colaborador e também voluntário, se torna parceiro do processo cultural, gerando o chamado consumidor colaborativo:

(... ) o termo consumo colaborativo passou a ser utilizado academicamente em 2011 pelos autores americanos Botsman e Rogers. Segundo estes, o consumo colaborativo é uma forma de acomodar os desejos e as necessidades dos consumidores de uma maneira mais sustentável e atraente com menor ônus para o indivíduo.

(... Estas culturas, subculturas, grupos e comunidades mesclam os interesses pessoais às atividades de consumo $(\ldots,)^{12}$

\begin{abstract}
A fim de tornar a participação do público efetiva, é necessário esforço no sentido de conhecê-lo cada vez melhor. Como enfatiza a página do Instituto Brasileiro de Museus (IBRAM) ${ }^{13}$ na Internet:
\end{abstract}

10 Martins et al. (2017, p.60)

11 Crossick e Kaszynska (2016, p. 40)

12 Rohden et al. (2015, p. 12)

13 O Instituto Brasileiro de Museus (IBRAM) é uma autarquia federal, dotada de personalidade jurídica de direito público, com autonomia administrativa e financeira, 
Um museu sem seu público não está completo. Pode-se conhecer quem é esse público estudando vários aspectos de sua composição - se é principalmente de turistas, de moradores do entorno, de jovens, de escolares, de idosos; se é um pequeno número ou se é volumoso... Esses são apenas alguns de tantos outros (que) envolvem a caracterização do público. Ter a instituição aberta à visitação recebendo as pessoas e fazendo conhecidos os universos de seu acervo - é o aspecto mais importantes do projeto Museus \& Público, que visa estudar justamente os fatores e características das relações existentes entre os museus e seu público. Somente recebendo os visitantes é que essa relação pode se estabelecer e, assim, ser estudada. ${ }^{14}$

Os voluntários são um bom exemplo da comunidade de um museu que pode desempenhar papel crucial no funcionamento em diversas frentes:

- na incorporação de novos registros ou a revisão daqueles já existentes em um sistema de gestão de coleções

- participação em projetos de pesquisa científica cidadã

- participação em campanhas de crowdsourcing (contribuição colaborativa ou colaboração coletiva) ${ }^{15}$

vinculada ao Ministério da Cultura. Possui sede e foro em Brasília e conta com uma representação no Rio de Janeiro, podendo estabelecer escritórios ou dependências em outras unidades da federação. Foi criado a partir da Lei no. 11.906, sancionada pelo ex-Presidente da República Luiz Inácio Lula da Silva em 20 de janeiro de 2009. que desmembrou do Instituto do Patrimônio Histórico e Artístico Nacional a Diretoria de Museus e as Unidades Museológicas. I Instituto Brasileiro de Museus é o órgão responsável por desenvolver e aplicar a Política Nacional de Museus, bem como pela melhoria dos serviços do setor, tendo como objetivos, por exemplo, o aumento de visitação e arrecadação dos museus, o fomento de políticas de aquisição e preservação de acervos e a criação de ações integradas entre os museus brasileiros. O instituto também é responsável pela manutenção dos museus e casas históricas federais.

<https://eu.oheuaqui.com/2CYqy08> Acesso em: 10 jan. 2018

$14<\mathrm{http} / / /$ www.museus.gov.br/acessoainformacao/acoes-e-programas/

museus-e-publico/> Acesso em: 10 jan. 2018

15 The act of giving tasks to a large group of people or to the general public, for example, by asking for help on the internet, rather than having tasks done within a company by employees: Crowdsourcing means that work once done in-house, from design and research to customer support, can now be farmed out, cutting costs and tapping new expertise.

<https://dictionary.cambridge.org/dictionary/english/crowdsourcing> Acesso em: 20 nov. 2017 
As campanhas de crowdsourcing são como a abertura de uma mostra ou espetáculo. O grau em que geram interesse e entusiasmo no início, é proporcional ao seu sucesso. Através delas o Museu está apto a se beneficiar da parceria de seu público e, simultaneamente, gerar recursos de forma precisa e pontual, na certeza de que está no caminho definido por seus espectadores. Isto representa um novo modelo de relacionamento com os visitantes, fazendo tênues as linhas entre aqueles que trabalham nos museus e aqueles que se beneficiam do processo.

Paralelo ao fenônemo do consumo colaborativo existe o interesse, por parte das empresas de tecnologia (mas não somente destas), em abranger tal público-alvo e a forte simbologia associada ao Museu; gerando parcerias que possam trazer ao espaço (físico ou online) da Instituição os equipamentos e expertise necessários para se criar a presença virtual, viabilizando assim tal iniciativa (v. o exemplo do British Museum, subseção 3.2.3). As corporações apoiam os museus por razões que incluem identificação de marca, marketing direcionado, divulgação local, responsabilidade corporativa, educação e conscientização pública ${ }^{16}$. Além disso, o montante investido é pequeno em relação aos benefícios em publicidade, divulgação da marca e fidelização de clientes. As empresas, adicionalmente, se tornam co-participantes em ações socialmente responsáveis e viabilizam a programação da instituição patrocinada.

Merece destaque a iniciativa ex situ do Google Art Project (v. subseção 4.2.2.1), a qual se manifesta no Brasil ${ }^{17}$ através do IBRAM.

Os museus estão posicionados de forma única para liderar mudanças. Ao contrário de outras grandes organizações, espera-se que os museus incorporem valores não comerciais e, portanto, vocalizar questões

\footnotetext{
16 Hossaini et al. (2017, p. 346)

17 <https://eu. oheuaqui.com/2melxWY>Acesso em: 10 jan. 2018
} 
que podem não ser apropriadas para uma empresa dirigida pelos acionistas. Os museus também possuem mecanismos para o desenvolvimento de práticas que podem ser traduzidas em demanda comercial por produtos sustentáveis ${ }^{18}$.

Tem portanto o Museu, em virtude da tecnologia, a possibilidade de suportar de forma eficiente os três principais âmbitos que geram ou otimizam sua receita:

- subsídios governamentais

- doações privadas

- receitas de bilheteria e crowdsourcing

Além disto existe a geração de eficiências operacionais, aptas a reduzir despesas.

\title{
4.2.1.2 | Implementação
}

\begin{abstract}
Museums around the world are looking at new business models to support their growth and ensure their long-term sustainability in the face of uncertain funding. Although new technology-supported innovations such as crowdfunding and content syndication are providing new forms of revenue, there are few changes in the overall business model of the museum sector. ${ }^{19}$
\end{abstract}

A função principal da tecnologia nos museus, no curto prazo, é melhorar a funcionamento de modelos comerciais que já existem. No entanto sua presença no espaço museológico pode, em um primeiro momento, provocar confusão e ofuscar benefícios existentes ou legados. Ou até mesmo resultar em decréscimo de receita, dados os investimentos, tempo e recursos necessários à sua utilização inicial. Além disso, sem

\footnotetext{
18 Hossaini et al. (2017, p. 330)

19 Hossaini et al. (2017)
} 
coordenação e estratégia precisas em relação à colaboração prestada pelo público, o processo de participação deste pode se tornar caótico ou anular quaisquer benefícios gerados.

Diante deste contexto, é fundamental a consciência de que a revisão e inovação nos processos e metodologias internos é tão fundamental quanto as próprias ferramentas empregadas.

Nas atividades de participação do público, doadores e patrocinadores, faz-se fundamental a utilização de registros e relatórios de forma consistente e ordenada. Sem tal controle não há como se avaliar o progresso obtido ou a direção a ser tomada. Os objetivos estratégicos do Museu devem se refletir em sua coleção de dados e em seus relatórios.

Para tanto, a utilização do Customer Relationship Management (Gestão de Relacionamento com o Cliente ou CRM) ${ }^{20}$ se faz praticamente obrigatória, pois permite rastrear, personalizar, manter e estreitar o engajamento e o relacionamento com visitantes, associados, doadores e outros agentes vinculados ao Museu. Através do CRM é possivel ter, em um só local, o controle da bilheteria, comércio físico e eletrônico, licenciamento de ativos, convites e relacionamento com o público em geral. É possivel estender a funcionalidade da plataforma às iniciativas de crowdsourcing.

A era digital acabou por criar novas oportunidades para que as pessoas desfrutem de conteúdo exclusivo do Museu; o qual costumava

20 Customer relationship management (CRM) is an approach to manage a company's interaction with current and potential customers. It uses data analysis about customers' history with a company to improve business relationships with customers, specifically focusing on customer retention and ultimately driving sales growth. One important aspect of the CRM approach is the systems of CRM that compile data from a range of different communication channels, including a company's website, telephone, email, live chat, marketing materials, and more recently, social media. Through the CRM approach and the systems used to facilitate it, businesses learn more about their target audiences and how to best cater to their needs.

<https://eu.oheuaqui.com/2mg7ekx> Acesso em: 10 jan. 2018 
ser acessado somente por uma visita a uma exposição. Na atualidade, os canais de acesso a este conteúdo passam a ser múltiplos e variados:

- mídias sociais

- aplicativos móveis

- site

- exposição

- programas públicos

- arte-educação

- recursos de aprendizagem

- loja do Museu

Parece inevitável, frente à era digital, um posicionamento do Museu mais voltado a tirar vantagem dos modelo gerenciais adotados pelo mundo corporativo. É importante, porém, que os gestores e responsáveis por tais medidas tenham em mente a diferença essencial entre uma entidade cultural e aquelas destinadas a gerar lucros para seus sócios e acionistas.

Surgem, aqui, duas questões importantes relacionadas à captação de recursos:

1. É possivel unificar tais experiências, de modo a fornecer ao público a agregação de todas elas de forma transparente?

(HOSSAINI et al., 2017) afirmam ser importante implementar no Museu o conceito denominado omnicanal (omnichannel) ${ }^{21}$; ou seja, fornecer ao

21 Omnichannel é uma tendência do varejo que se baseia na convergência de todos os canais utilizados por uma empresa. Trata-se da possibilidade de fazer com que o consumidor não veja diferença entre o mundo online e o offline. O omnichannel integra lojas físicas, virtuais e compradores. Dessa maneira, pode explorar todas as possibilidades de interação. Essa tendência é uma evolução do conceito de multicanal, pois é completamente focada na experiência do consumidor nos canais existentes de uma determinada marca. Como exemplo, há os aplicativos móveis, que combinam o layout do site com a temática interna das lojas físicas. De forma prática, isso propicia ao consumidor utilizar todos os canais disponibilizados pela organização e a quebra das barreiras entre o mundo físico e o digital. <http://eu.oheuaqui.com/2zktlGA> Acesso em: 10 jan. 2018 
público a modalidade de experiência única e contínua que o mundo empresarial tenta aplicar aos negócios na atualidade. Para eles, este processo pode converter visitantes em partes interessadas que adquirem consciência do papel vital que os Museus desempenham na comunidade 22 .

A estratégia omnicanal (omnichannel) é pertinente a esta dissertação; pois significa, em teoria, a integração entre o in situ e o ex situ . A aplicabilidade de tais conceitos conduz, de forma direta, ao modelo virtual (Item 4.2.1.2).

2. Esta unificação pode gerar receitas adicionais?

De acordo com (BINA, 2011 ), a mudança nas práticas administrativas dos gestores gera, de fato, resultados financeiros:

Pode-se constatar ser uma tendência (...) a mudança no perfil de atuação dos gestores dos museus que utilizam o marketing cultural e as novas alternativas estratégicas para financiamento de suas atividades. Consegue-se assim, através das ações patrocinadas, uma maior dinamização da área museológica, com o lançamento de livros e catálogos, montagem de exposições temporárias, modernização de suas estruturas físicas, aquisição de acervo, oferecimento de programação educativa, informatização do acervo museológico, dentre outros. ${ }^{23}$

Isto sugere o modelo virtual como elemento-chave entre o objeto de arte, usuários e aumento de receita.

\footnotetext{
22 Hossaini et al. (2017, p. 16)

23 Bina (2011, p. 8)
} 


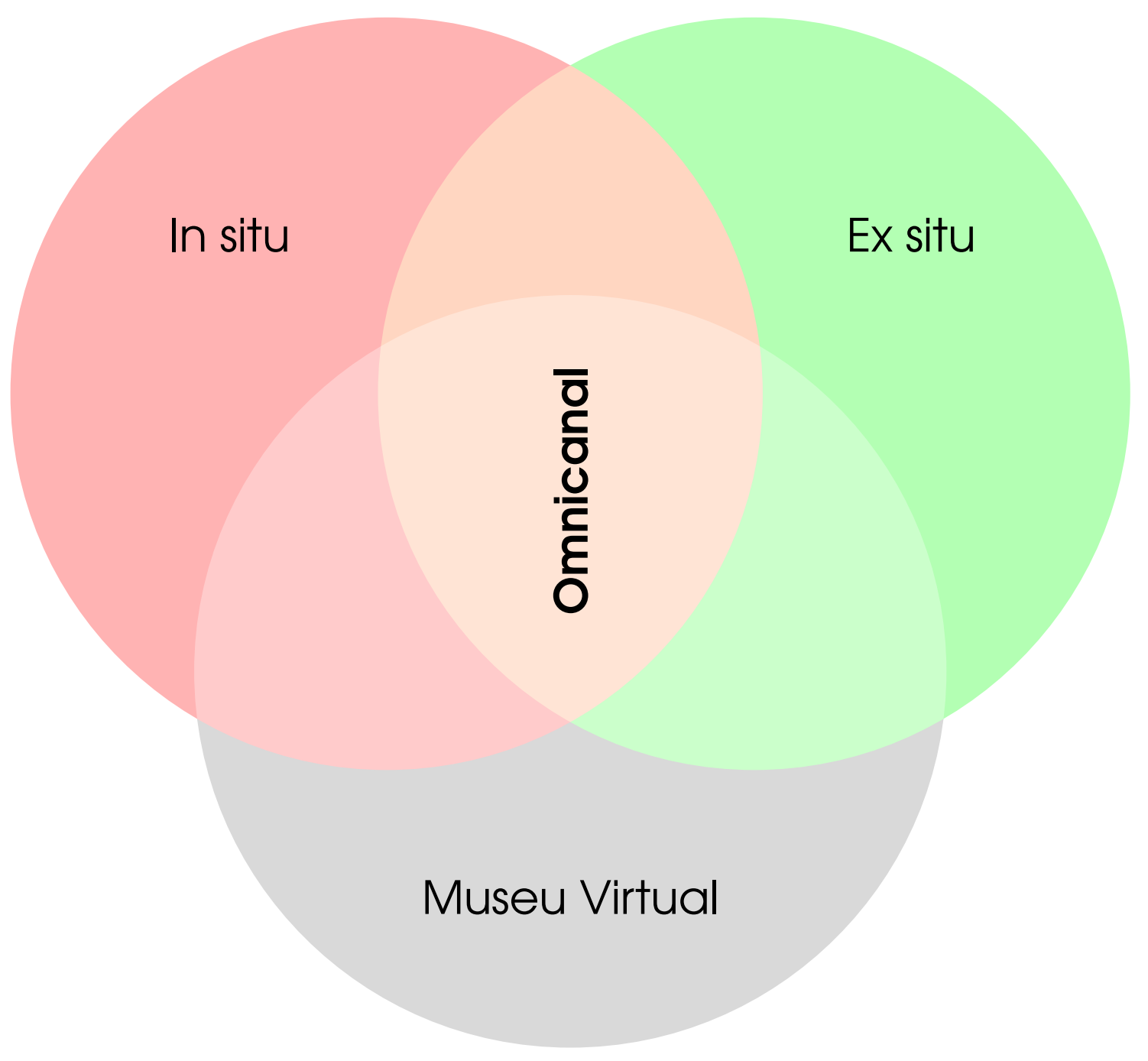

FIGURA 13 Confluência: Omnicanal, in situ e ex situ

\subsection{2 | Digitalização}

\subsubsection{1 | Pressupostos}

A produção de documentos que representem o acervo de modo fiel é o ponto-chave de um museu virtual ${ }^{24}$. Tal ação funciona, simultaneamente, como início de um processo e também como seu resultado final a ser disponibilizado ao público; o que demanda a máxima fidelidade

24 "The prerequisite for the virtual museum are digitized data." Schweibenz (1998, p. 191) 
possível (no contexto ex situ) em relação ao original, para que a promessa de aprofundamento da análise do objeto de arte possa, de acordo com (MEIRA, 2005), ser cumprida:

Os novos tratamentos da imagem trouxeram ao historiador de arte a ampliação das possibilidades de leitura da obra de arte, identificando muitas vezes conteúdos na imagem que outrora não se percebiam. A imagem de alta definição possibilitou um aprofundamento e maior esclarecimento aos estudos referentes à obra de arte, analises revolucionárias foram possiveis, da superfície ao suporte da pintura, da verificação de datas e atribuições, à identificação de assinaturas. A edição em tamanho incomum de detalhes de uma imagem permitiu um novo modo de análise e consulta (à) obra de arte, possibilitando a leitura de características não perceptiveis a olho nu. ${ }^{25}$

O documento digital também atua, de acordo com a definição de documentação museológica de (FERREZ, 1994), como elemento de acesso e recuperação da informação 26 .

A digitalização atua como elemento essencial neste processo:

Digitalizar implica, pois, uma série de atividades, nomeadamente, a seleção do que se pretende digitalizar de acordo com os critérios e prioridades fixadas, a identificação desses critérios e prioridades, bem como o propósito da digitalização, as necessidades, formas de acesso e usabilidade que condicionarão os requisitos técnicos de digitalização, o software e os equipamentos a utilizar, a par das competências, aptidões e número de recursos humanos requeridas, com consequências diretas no tempo, custo e qualidade do "produto final". Destas atividades resulta informação digital que fluirá nos circuitos organizacionais, podendo ser agregada a outra informação e que será descrita, armazenada, gerida, disponibilizada e usada no curto, médio e longo prazo. ${ }^{27}$

A tarefa era menos complexa enquanto o registro fotográfico tradicional e a palavra escrita eram os únicos meios de documentação 25 Meira (2005, p. 63-64)

26 "A documentação de acervos museológicos é o conjunto de informações sobre cada um dos seus itens e, por conseguinte, a representação destes por meio da palavra e da imagem (fotografia). Ao mesmo tempo, é um sistema de recuperação de informação capaz de transformar, como anteriormente visto, as coleções dos museus de fontes de informações em fontes de pesquisa científica ou em instrumentos de transmissão de conhecimento." Ferrez (1994, p. 1)

27 Pinto (2013, p. 19) 
existentes. No momento em que a tecnologia digital se insere no espaço museológico, a complexidade aumenta de forma significativa; pois não basta apenas efetuar o registro em um meio eletrônico - é necessário garantir que tal registro possa ser acessado no futuro, de forma eficiente e confiável, e sem perda de qualidade ou características intrínsecas. Além disso, existe o desafio contemporâneo de se documentar digitalmente aquilo que já nasce digital:

Caring for collections delivers a potent legacy. Systems, standards, and people come and go, but, whether physical or digital, the object delivers long-standing cultural resonance, which can be amplified through new technologies. Digitization strategies will evolve and improve with time - the needs of the object and associated conservation should always be at the forefront. Museum professionals should think creatively about collections and understand that processes and systems to manage collections are evolving within new processes for data capture, management, and display. Interpretation has become a fluid concept that is responding to digital immersion and the reorganization of society by crowdsourcing, personalization, and other digitally driven trends. Allied to this is the issue of contemporary collecting of ephemeral objects, either recorded or born digitally or "living objects" such as bio-art. Professionals will need to identify trends and strategies to deal with changing formats and how data is captured. ${ }^{28}$

Este processo necessita, além da produção de documentos de alta qualidade e fidelidade, a garantia de que sua catalogação e gerenciamento será adequada e apta a fornecer, a qualquer momento do presente ou futuro, a informação necessária sem dificuldades ou ruídos ${ }^{29}$.

28 Hossaini et al. (2017, p. 195)

29 "Digitizing cultural heritage collections involves opening up databases, previously the sole domain of the museum professionals, to end users. However, opening up databases makes the collections available but not necessarily accessible (Trant, 2006). Several studies report on a mismatch between museum documentation and end-users' information needs (e.g., Booth, 1998; Chaudhry \& Jiun, 2005; Stephenson, 1999; Trant, 2006). The mismatch can largely be explained by a specialist perspective and a collection management perspective on resource description, as museum documentation traditionally has been written for and by museum professionals and not end users. As a consequence of this mismatch the studies call for a supplementary (end) user oriented approach to virtual museums in general and to resource description of museum artefacts in particular." Skov $(2009$, p. 1) 
O aumento constante da qualidade de reprodução dos meios digitais torna a distância entre o objeto e sua réplica cada vez menor ${ }^{30}$. A quantidade de informação armazenada em um documento digital de alta resolução é superada apenas pela observação muito detalhada do próprio original. A utilização da realidade virtual (subseção 3.2.2), no entanto, pode permitir um nível de acesso muito maior ao objeto através de sua réplica, substituindo o contato direto (muitas vezes proibitivo) com o original (Nota de rodapé 60).

É importante levar em consideração um novo tipo de objeto museológico, fruto da era tecnológica. Denominado born digita/ ${ }^{31}$, traz novos paradigmas relacionados à autenticidade, acesso e outras características tradicionais relacionadas aos objetos físicos. A iniciativa Google Art Project ${ }^{32}$, por exemplo, requer de seus participantes a disponibilização de documentos em resolução extremamente elevada. Isto permite a qualquer visitante na Internet utilizar uma lupa sobre as obras de arte e descobrir detalhes que, eventualmente, passaram despercebidos aos especialistas. À medida em que imagens de alta resolução se tornam o padrão, é possivel imaginar um mundo onde o trabalho voluntário dos usuários da Internet se mescla àquele realizado por profissionais especializados (subseção 4.2.1.1).

Pensar criativamente sobre o acervo - e, simultaneamente, compreender que os processos e sistemas para gerenciar coleções estão evoluindo em novos processos de captura, gerenciamento e exibição de dados - é uma etapa primordial aos profissionais do Museu na era digital.

$30 "(\ldots)$ the lines between original and copy will blur as the quality of digital replicas increase. " Hossaini et al. (2017, p. 141)

31 "Born digital refers to objects that are created on a computer or another digital platform such as a digital camera." Hossaini et al. (2017, p. 139)

32 <https://www.google.com/intl/pt-BR/culturalinstitute/about/artproject/> Acesso em: 10 dez. 2017 
A interpretação tornou-se um conceito fluido que responde à imersão digital e à reorganização da sociedade por meio de crowdsourcing, personalização e outras tendências ligadas ao universo eletrônico.

Neste contexto, é necessário identificar tendências e estratégias para lidar com a mudança de formatos e como os dados são capturados.

\subsubsection{2 | Implementação}

O processo de conversão de objetos in situ em ativos digitais é realizado em 3 etapas ${ }^{33}$, conforme a descrição da Tabela 9.

Digitalização e inserção de metadados

\begin{tabular}{l} 
Checagem da qualidade e padronização dos documentos \\
produzidos \\
$\begin{array}{l}\text { Informação disponibilizada no sistema de gerenciamento } \\
\text { de conteúdo, base de dados e Internet }\end{array}$ \\
\hline
\end{tabular}

TABELA 9 Ełapas da conversão do acervo em ativos digitais

33 "The process of converting a museum's content into digital assets differs depending on the format of the original content. Legacy collections and archives require digitization, while contemporary digital content created on aging formats raises questions of preservation, storage, and access. Museum-created content such as learning resources, research and publications, and exhibition media require other considerations largely related to the channels that may carry them. For example, an exhibition video may need to be edited for length on website, and a teacher's guide accessed via mobile in a live exhibition is used differently than a printed pamphlet. The process of converting content resources to digital assets is done in three steps: digitization, databasing, and distribution." Hossaini et al. (2017, p. 137) 
O primeiro passo na criação de um banco de ativos digitais é avaliar os recursos de conteúdo existentes. Isto pode ser realizado através de uma auditoria de conteúdo.

Os tipos de conteúdo incluem:

- Coleções e documentação

- Arte digital

- Realidade virtual ou aumentada

- Mídia de exibição (e seus componentes, incluindo texto, imagens, gráficos, vídeo, interativos e coleções de exibição)

- Experiências e jogos móveis

- Recursos de aprendizagem

- Pesquisa e Publicações ${ }^{34}$

A digitalização do acervo pode vir a representar tarefa sobre-humana, pois o volume de objetos armazenados tende a ser significativo. A possibilidade de se automatizar o processo é diminuta, pois os tamanhos e formas são bastante variados.

Objetos em duas dimensões - pinturas, fotografias, desenhos, páginas de livros e manuscritos - não apresentam maiores dificuldades em relação à digitalização. A captura se faz, primordialmente, através de câmeras fotográficas digitais de alta resolução e scanners ${ }^{35}$; a possibilidade de automação é alta.

A digitalização através do scanner oferece vantagens quando o objeto possui texto que pode ser apresentado de forma independente em relação ao contexto tipográfico. A utilização de Reconhecimento

\footnotetext{
34 Hossaini et al. (2017, p. 137)

35 Dispositivo de entrada que permite enviar qualquer imagem ou texto em papel para o computador, podendo ser impresso ou modificado posteriormente.
} 
Óptico de Caracteres (Optical Character Recognition ou OCR) ${ }^{36}$ sobre o material digitalizado permite converter a imagem em texto que pode ser pesquisado, traduzido e acessado por qualquer perfil de usuário - inclusive os portadores de deficiência visual

É importante considerar a utilização do material eletrônico como fonte de pesquisa tanto para cientistas, pesquisadores e designers quanto para estudantes e o grande público. Em diversas situações será necessário um arquivo que possa sofrer ampliação considerável, ou até mesmo a produção de imagens específicas (raio-X, infravermelho, ultravioleta, tomografia, espectrografia ou microscopia eletrônica). Tais formatos adicionais agregam maior complexidade ao planejamento ligado à digitalização do acervo. A resolução de imagem ${ }^{37}$ utilizada deve ser a maior possível, a fim de garantir o uso deste documento em quaisquer situações presentes ou futuras.

A tecnologia de digitalização em três dimensões dos objetos do acervo (permitindo assim a visualização sob todos os ângulos) está disponível ao Museu, assim como os meios de se apresentar o material ao público.

36 Acrônimo para o inglês Optical Character Recognition, é uma tecnologia para reconhecer caracteres a partir de um arquivo de imagem ou mapa de bits sejam eles escaneados, escritos à mão, datilografados ou impressos. Dessa forma, através do OCR, é possível obter um arquivo de texto editável por um computador.

<https://en.wikipedia.org/wiki/Optical_character_recognition> Acesso em: $10 \mathrm{dez}$. 2017,

37 Resolução de imagem descreve o nível de detalhe que uma imagem comporta. $\bigcirc$ termo se aplica igualmente a imagens digitais, imagens em filme e outros tipos de imagem. Resoluções mais altas significam mais detalhes na imagem. A resolução de imagem pode ser medida de várias formas. Basicamente, a resolução quantifica quão próximas as linhas podem ficar umas das outras e ainda assim serem visivelmente determinadas. As unidades de resolução podem ser ligadas a tamanhos físicos (por exemplo, linhas por $\mathrm{mm}$, linhas por polegada etc.) ou ao tamanho total de uma figura (linhas por altura da imagem, também conhecidas simplesmente por linhas ou linhas de televisão). Ademais, pares de linhas são usados frequentemente em vez de linhas individuais. Um par de linhas é constituído de uma linha apagada e uma linha acesa adjacentes, enquanto "linhas" contam ambas as linhas apagadas e acesas. Uma resolução de dez linhas por mm significa cinco linhas apagadas alternando com cinco linhas acesas, ou cinco pares de linhas por $\mathrm{mm}$. As resoluções de lentes fotográficas e filmes são mais frequentemente citadas como pares de linhas por mm. <https://pt.wikipedia.org/wiki/Resolução_de_imagem> Acesso em: 10 nov. 2017 
No entanto, a escala requerida para tal empreitada ainda não pode ser preenchida de forma satisfatória pelos equipamentos e metodologias atuais. A evolução do processo, porém, caminha a passos largos e permite prever seu uso intensivo em um futuro próximo. O maior desafio da digitalização 3D é a preparação dos objetos para o processamento através da câmera, scanner ou qualquer outro dispositivo de captura. A utilização de equipamentos gerenciados por Inteligência Artificial (Al) ${ }^{38}$ - no momento limitados aos campos científico e industrial mas avançando em outros setores da atividade humana - pode permitir a criação e adaptação de plataformas que viabilizem seu uso dentro do Museu; e a posterior visualização, por parte do espectador, através de dispositivos HMD.

O modelo adotado na digitalização do acervo deve ser fartamente documentado através de um manual de procedimentos e, preferencialmente, a instalação física utilizada deve ser mantida sob manutenção e cuidados para que possa ser novamente ativada a qualquer nova aquisição ou demanda. O tempo e experiência necessários para se chegar à fórmula ideal de digitalização devem ser reaproveitados a todo custo, pois isto será a garantia de padronização e qualidade do processo ${ }^{39}$.

38 Inteligência artificial (por vezes mencionada pela sigla em português IA ou pela sigla em inglês Al - artificial intelligence) é a inteligência similar à humana exibida por mecanismos ou software. Também é um campo de estudo acadêmico. Os principais pesquisadores e livros didáticos definem o campo como "o estudo e projeto de agentes inteligentes", onde um agente inteligente é um sistema que percebe seu ambiente e toma atitudes que maximizam suas chances de sucesso. John McCarthy, quem cunhou o termo em 1956 ("numa conferência de especialistas celebrada em Darmouth Colege" Gubern, Román: O Eros Eletrônico), a define como "a ciência e engenharia de produzir máquinas inteligentes". É uma área de pesquisa da computação dedicada a buscar métodos ou dispositivos computacionais que possuam ou multipliquem a capacidade racional do ser humano de resolver problemas, pensar ou, de forma ampla, ser inteligente. Também pode ser definida como o ramo da ciência da computação que se ocupa do comportamento inteligente ou ainda, o estudo de como fazer os computadores realizarem coisas que, atualmente, os humanos fazem melhor.

<https://pt.wikipedia.org/wiki/Inteligência_artificial> Acesso em: 10 nov. 2017

39 "Creating and preparing digital reproductions of artworks requires careful attention to details noted above, as well as some specific concerns. Unlike typical photo reproduction, the colors within digital files of artworks should not be subject to 
A documentação existente sobre técnicas e processos de reprodução fotográfica de objetos museológicos é vasta; a aplicação prática de tais princípios, no entanto, demanda muito mais atenção do que a teoria parece demonstrar.

A utilização de procedimentos e práticas testados ao longo dos anos no segmento da fotografia são fundamentais para garantir a consistência dos documentos criados. Um exemplo de referência é o manual de práticas fotográficas digitais Universal Photographic Digital Image Guidelines (UPDIG) (Apêndice H).

Alguns tópicos relativos à digitalização necessitam ser ressaltados, pois funcionam como critérios. O primeiro deles é o tamanho mínimo da captura digital, a qual utiliza como unidade de medida o pixel (picture element) ${ }^{40}$, e que não deveria, em nenhuma hipótese, ser menor do que o tamanho de um monitor de alta resolução (1920 por 1080 pixels, v. Figura 14). Dada a possibilidade de se apresentar a imagem, atualmente, nas resoluções denominadas 4K (4096 por 2160 pixels) e 8K (7680 por 4320 pixels, v. Figura 15) e, no futuro próximo, se utilizar a surpreendente resolução 10K (10240 por 4320 pixels), a recomendação é que se produzam documentos que tenham, como padrão mínimo, a medida mais próxima da melhor resolução. A imagem deve contar, idealmente, com

interpretation or individual preference. The reproduction must produce the same perceived color (within physical limitations) as the original artwork."

<http://www.updig.org/guidelines/ir_fine_art.html> Acesso em: 10 dez. 2017

40 Pixel ou píxel (sendo o plural pixels ou píxeis) (aglutinação de picture e element, ou seja, elemento de imagem, sendo pix a abreviatura em inglês para pictures) é o menor elemento em um dispositivo de exibição (por exemplo, um monitor), ao qual é possível atribuir-se uma cor. De uma forma mais simples, um pixel é o menor ponto que forma uma imagem digital, sendo que o conjunto de pixels formam a imagem inteira. Em um monitor colorido, cada pixel é composto por um conjunto de 3 pontos: verde, vermelho e azul. Nos melhores monitores, cada um desses pontos é capaz de exibir 256 tonalidades diferentes (o equivalente a 8 bits) e combinando tonalidades dos três pontos é então possivel exibir pouco mais de 16.7 milhões de cores diferentes (exatamente 16.777.216). Em resolução de $640 \times 480$ temos 307.200 pixels, a $800 \times 600$ temos 480.000 pixels, a $1024 \times 768$ temos 786.432 pixels e assim por diante.

<https://pt.wikipedia.org/wiki/Pixel> Acesso em: 10 nov. 2017 
300 pontos por polegada (dots per inch ou DPI) ${ }^{41}$, para que possa ser utilizada no processo de impressão convencional sem perda de qualidade. A resolução e a quantidade de DPI da imagem irão determinar o nível de ampliação (detalhes) que esta pode disponibilizar ao público.

\section{K $7580 \times 4320$}

FIGURA 14 Resoluções de telas de vídeo e pixels correspondentes

41 Pontos por polegada (ppp; em inglês dots per inch ou DPI) é uma medida de densidade relacionada à composição de imagens, que expressa o número de pontos individuais que existem em uma polegada linear na superfície onde a imagem é apresentada. Também é comum encontrar referências a essa densidade pelo termo "resolução de imagem" ou simplesmente "resolução". A resolução é indicada pela composição da densidade horizontal e vertical, que podem ser iguais ou diferentes. De maneira geral, quanto maior o número de pontos por polegada, mais detalhada e bem definida é a imagem. 


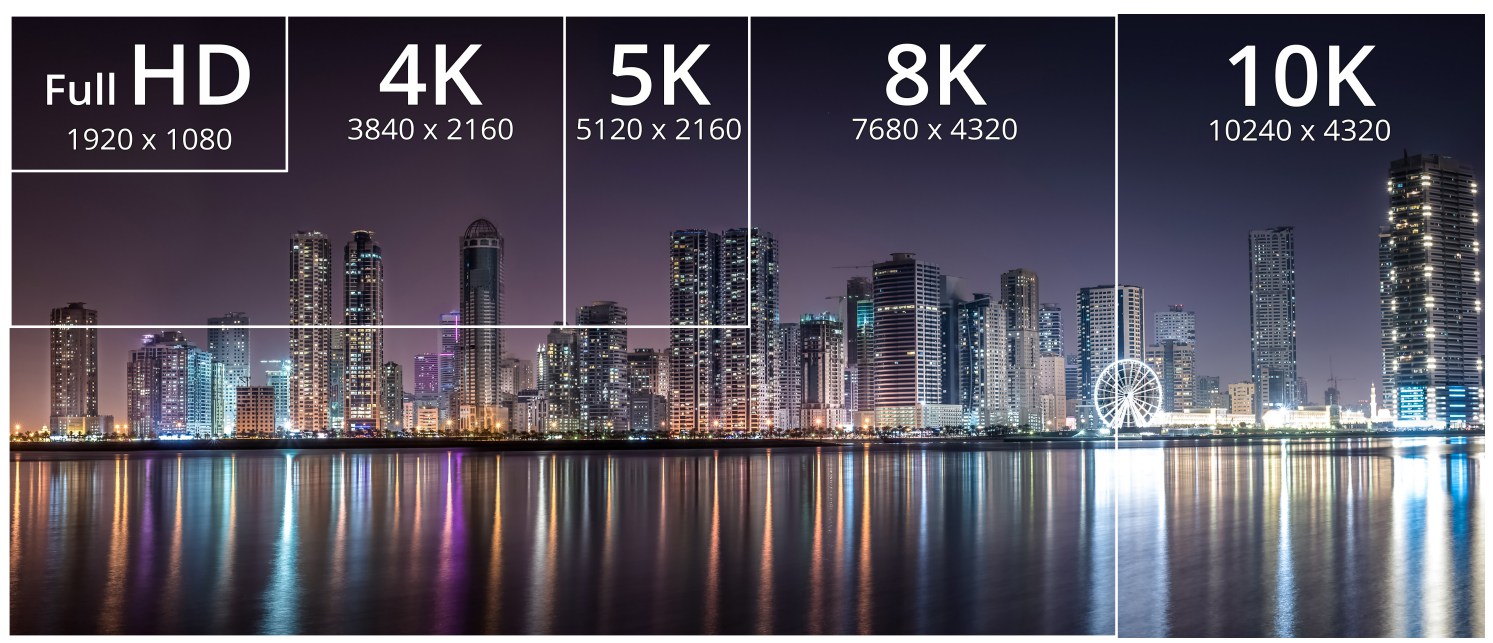

FIGURA 15 Imagem em diferentes resoluções de tela

O segundo ponto importante no processo de digitalização é o formato de arquivamento escolhido. A miríade de alternativas disponíveis torna confusa a escolha do formato de arquivo mais apropriado para as necessidades presentes e futuras. Para que o Museu possa garantir a longevidade de seus documentos e honrar o modelo de plataforma aberta (subseção 4.2.3.1), é importante considerar a utilização de formatos abertos $^{42}$.

Segundo (BODÊ; MANINI, 2013),

Uma das características específicas que tem sido apontada como extremamente importante para fins de preservação

42 Um formato aberto é uma especificação publicada para armazenar dados digitais, mantida geralmente por uma organização de padrões não-proprietária, e livre de limitações legais no uso. Um formato aberto deve ser implementável tanto em software proprietário como em software livre, usando as licenças típicas de cada um. Em contraste o formato proprietário é controlado e defendido por interesses particulares da empresa detentora de seus direitos. Os formatos abertos são um subconjunto do padrão aberto. O objetivo principal dos formatos abertos é garantir o acesso a longo prazo aos dados sem incertezas atuais ou futuras no que diz respeito às direitas legais ou à especificação técnica. Um objetivo secundário dos formatos abertos é permitir a competição, em vez de permitir que o controle de um distribuidor sobre um formato proprietário iniba o uso de um produto de competição. Os governos mostraram cada vez mais interesse em edições em formato aberto.

<https://pt.wikipedia.org/wiki/Formato_aberto> Acesso em: 11 dez. 2017 
por longos períodos é o acesso público à especificação do formato de arquivo, o que também é conhecido como uso de formatos abertos de arquivo. Como já abordamos anteriormente, todo formato de arquivo possui uma especificação, mas essa não é, necessariamente, de acesso público. As vantagens por trás da utilização de formatos de arquivo abertos se evidenciam ao se prever a necessidade de desenvolvimento de softwares para leitura desses documentos no futuro. O trabalho de desenvolvimento pode ser até mesmo inviável caso não se conheça os detalhes técnicos de determinado formato de arquivo. ${ }^{43}$

formato de arquivo que oferece, na atualidade, maiores vantagens de uso e mais se assemelha ao antigo filme fotográfico é o Digital Negative (DNG) ${ }^{44}$. Embora seja patenteado pela Adobe Systems Incorporated, seu uso é livre e a especificação é completamente aberta ${ }^{45}$. Sua habilidade em armazenar metadados é um diferencial importante para o arquivamento museológico e disponibilização de conteúdo ao público.

A partir do formato DNG é possivel criar um fluxo de trabalho que gere imagens em resoluções adequadas para:

- exibição na Internet

- impressão gráfica

- utilização em monitores e equipamentos de projeção

- disponibilização para a imprensa

43 BODÊ e MANINI (2013, p. 9)

44 Digital Negative (DNG) is a patented, open, non-free lossless raw image format written by Adobe used for digital photography. It was launched on September 27, 2004. The launch was accompanied by the first version of the DNG specification, plus various products, including a free-of-charge DNG converter utility. All Adobe photo manipulation software (such as Adobe Photoshop and Adobe Lightroom) released since the launch supports DNG.

DNG is based on the TIFF/EP standard format, and mandates significant use of metadata. Use of the file format is royalty-free; Adobe has published a license allowing anyone to exploit DNG, and has also stated that there are no known intellectual property encumbrances or license requirements for DNG. Adobe stated that if there were a consensus that DNG should be controlled by a standards body, they were open to the idea. Adobe has submitted DNG to ISO for incorporation into their revision of TIFF/EP.

<https://en.wikipedia.org/wiki/Digital_Negative> Acesso em: 11 nov. 2017

$45<$ https://helpx.adobe.com/photoshop/digital-negative.html> Acesso em: 11 dez. 2017 
De posse do arquivo digital, passa a ser fundamental a incorporação do maior número possivel de informações referentes ao objeto. A ausência desta etapa implica na existência de um documento sem nenhum vínculo ou possibilidade de acesso direto. Aqui entram em cena os METADADOS.

A documentação teórica e prática sobre os modelos existentes e sua implementação é vasta, controversa e merece enfoque específico. A utilização de metadados, na prática museológica, esbarra em dificuldades de toda espécie; o que dificulta a criação do modelo de plataforma aberta (v. Figura 17). Segundo (LIMA; SANTOS; SEGUNDO, 2016),

É no ambiente Web que está sendo disponibilizada, de forma digital, uma exponencial quantidade de recursos informacionais, nos mais variados tipos de fontes. No entanto, essas informações estão sendo disponibilizadas de forma não estruturada, dificultando a troca de dados e a comunicação entre sistemas e plataformas. ${ }^{46}$

A situação nos museus brasileiros merece atenção crítica pois, de acordo com (BEVILACQUA, 2016),

\begin{abstract}
Um dos fatores que impede a utilização de padrões de metadados nos museus de arte brasileiros é o fato de que a maioria dos padrões que existem e que estão em estágios avançados em países mais desenvolvidos não estão traduzidos para o português. Ou seja, há uma barreira de linguagem e também, pelo fato de os processos de informatização nos museus do Brasil serem de baixa qualidade, devido à ausência de padrões estabelecidos e aos baixos índices de duração dos mesmos, que não superam os dois anos de utilização, até serem substituídos por um novo projeto $^{47}$
\end{abstract}

Está fora do escopo desta dissertação a análise de tal fenômeno. Resta documentar os principais pontos a serem considerados em relação à utilização de metadados, quais sejam:

Tipos Existem três tipos de metadados ${ }^{48}$ :

\footnotetext{
46 Lima, Santos e Segundo (2016, p. 52)

47 Bevilacqua (2016, p. 14)

48 "There are three kinds of metadata:
} 
1. Descritivos - consistem em informação sobre o conteúdo e contexto dos dados

2. Estruturais - fornecem a informação a respeito da estrutura física dos dados ou sua criação

3. Administrativos - informação relacionada ao modo como estes dados podem ou devem ser gerenciados

Metodologias Foram criadas, ao longo do tempo, diferentes modelos para se criar e armazenar metadados. O documento Glossary of Metadata Standards, anexado ao apêndice desta dissertação (Apêndice I), funciona como fonte de referência para as múltiplas alternativas existentes.

O Embedded Metadata Working Group (EMDAWG) do Smithsonian Institution sugere que os ativos digitais incluam ${ }^{49}$ :

- título do documento

- direitos autorais e licenciamento

- fonte

- autor e informações de contato

- data

- descrição

- palavras-chave

1. Descriptive metadata consist of information about the content and context of your data. Examples: title, creator, subject keywords, and description (abstract)

2. Structural metadata describe the physical structure of compound data. Examples: camera used, aperture, exposure, file format, and relation to other data

3. Administrative metadata are information used to manage your data. Examples: when and how it was created, who can access it, software required to use it, and copyright permissions"

<https://eu.oheuaqui.com/2CkYlik> Acesso em: 14 dez. 2017

49 "The long-term goal, as established by the institutional strategic plan, to digitize all collections at the Smithsonian Institution, along with the increasing need to share data and increase access to collections, has made it essential to establish institution-wide metadata standards, including those for embedding metadata." <https://repository.si.edu/handle/10088/11123?show=full> Acesso em: 14 dez. 2017 
- identificador de trabalho

- título (legenda) ${ }^{50}$

\title{
4.2.2.3 | Gerenciamento do conteúdo
}

De posse do conteúdo, é necessário gerenciar seu armazenamento e distribuição eficientes. Segundo (PINTO, 2013),

Mais do que em qualquer outra época, hoje a Informação é vista como um valioso recurso de gestão, produzido, acedido e usado no âmbito dos processos organizacionais, afetando a arquitectura de processos, computacional e informacional da organização. É também memória organizacional que se pretende partilhar e usar como herança digital a partir dos múltiplos agregadores nacionais/internacionais. ${ }^{51}$

A gestão do acervo digital é tarefa inevitável no contexto de um museu virtual, exigindo decisões e planejamento que vão além das habilidades tradicionais da Instituição:

\begin{abstract}
Torna-se cada vez mais incontornável a convocação de uma abordagem sistêmica deste desafio plurifacético que é o "digital", seja qual for o ângulo a partir do qual o façamos (informacional, tecnológico, etc.). Um novo meio que à tradicional dimensão física dos acervos vinca a associação de uma dimensão lógica que condiciona e envolve os contextos e situações comportamentais relativos à produção, fluxo, armazenamento, gestão, transmissão e uso/reprodução de informação em todo o seu ciclo de vida, em qualquer contexto organizacional/humano e sem limitações físicas ou espaciais. ${ }^{52}$
\end{abstract}

50 <https://eu.oheuaqui.com/2CiGHKl> Acesso em: 14 dez. 2017

51 "Profissionais e investigadores, organizações/instituições e academia, instituições públicas e organizações privadas, terão que aprofundar o movimento de conscientização que lhes é exigido, acompanhando as iniciativas e produção normativa internacional, provendo ao desenvolvimento de políticas nacionais que garantam a qualidade e utilização futura da informação produzida no âmbito de projetos de digitalização, maioritariamente suportados financeiramente por entidades governamentais, a par do desenvolvimento de politicas sectoriais, da concepção e implementação de modelos, de normalização, de orientações e ferramentas que possam ser utilizadas pelas diversas organizações e instituições mas que abarquem e suportem todo o ciclo de digitalização e o integrem no ciclo de gestão da informação com vista (a) assegurar a qualidade, interoperabilidade, eficiência, eficácia e longevidade.

Pinto (2013, p. 28-29)

52 Pinto (2013, p. 10) 
A Figura 16 traz, a título de exemplo, o esboço utilizado para a configuração do sistema de gestão de conteúdo do Canadian Museum for Human Rights (CMHR).

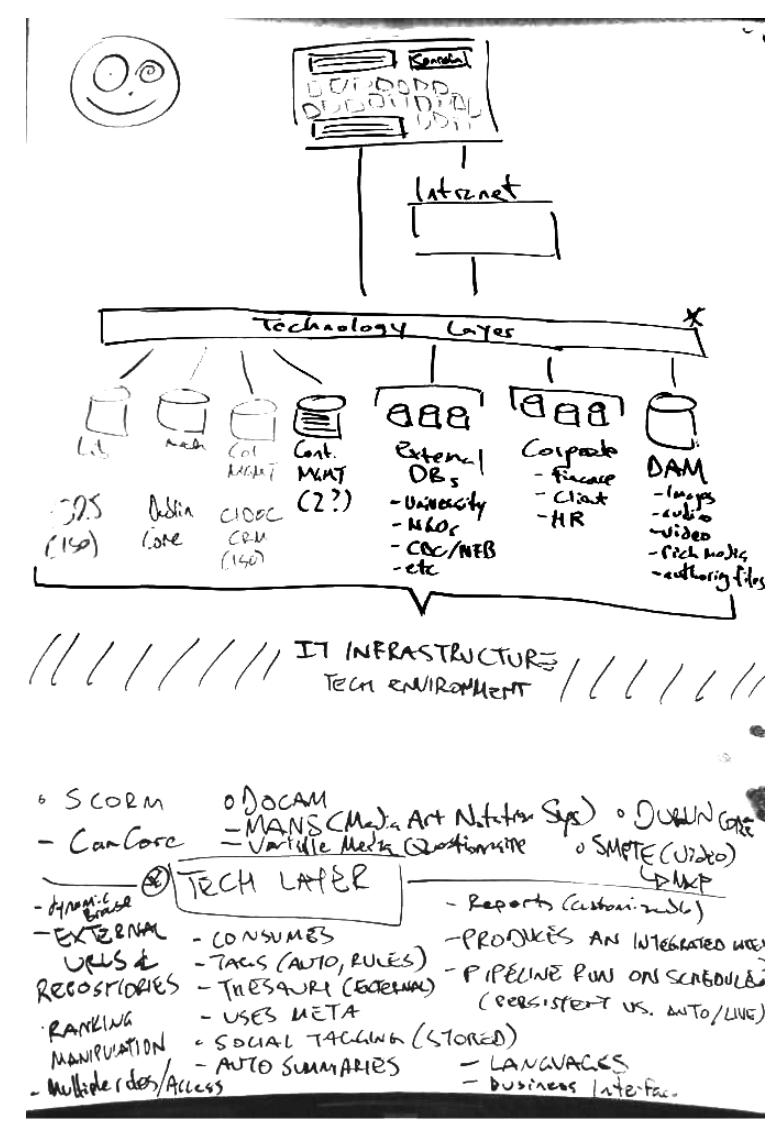

FIGURA 16 Escopo: Canadiam Museum of Human Rights

Neste quesito, o Museu tem a ganhar com a experiência adquirida pelo mundo corporativo em relação à gestão de documentos.

O termo Sistema de Gerenciamento de Conteúdo (Content Management System ou CMS) - também grafado como Enterprise Content Management System (ECMS) - se refere ao modelo utilizado para armazenamento e publicação de dados na web, redes e plataformas online; 
além de outras funções e ferramentas acessórias, tais como sistemas de gestão de acesso, cobrança e gerenciamento.

O CMS para um acervo físico ou digital é composto por uma base de dados (database), metadados, uma interface geral de configuração e administração, uma interface gráfica de usuário e Interfaces de Programação de Aplicação (Application Programming Interfaces ou APIs) ${ }^{53}$.

Pode ser definido através de 7 pré-requisitos estruturais, os quais se encontram especificados adiante ${ }^{54}$ :

1. Separação rigorosa entre conteúdo e apresentação

2. Metodologia baseada no paradigma "armazenar uma vez, referenciar frequentemente"

3. Distribuição dinâmica de conteúdo

4. Deve ser capaz de fazer "qualquer coisa"

5. Restrições do sistema através de regras de negócios e não de limitações técnicas

6. Modalidade completa e escalabilidade

7. Conformidade de padrões

53 Especificação de software que descreve como se comunicar com outro software. É a ferramenta para se criar a ponte entre aplicativos que, de outra forma, seriam incompativeis.

54 <http://eu.oheuaqui.com/2AKOrsz> Acesso em: 10 out. 2017

1. Strict separation of content from presentation

2. A "store content once and reference often" methodology

3. Dynamic delivery of content

4. Must be able to do "anything"

5. System constraints through business rules, not technical limitations

6. Complete modularity and scalability

7. Standards compliance

Hossaini et al. (2017, p. 174) 


\section{Separação rigorosa entre conteúdo e apresentação}

Os ativos digitais são armazenados na maior qualidade possível, em padrões e formatos aceitos por todas as partes envolvidas.

\section{Metodologia baseada no paradigma "armazenar uma vez, referenciar frequentemente"}

mesmo ativo digital pode ser utilizado em múltiplos contextos, garantindo assim uniformidade e economia de recursos. Mesmo que se utilizem tamanhos, formatos ou desenhos diferentes, o novo conteúdo será um derivativo daquilo que foi, anteriormente, armazenado e indexado.

\section{Distribuição dinâmica de conteúdo}

A informação armazenada no CMS, através da utilização de bancos de dados, é disponibilizada de forma instantânea e dinâmica e independe do modo ou da origem da requisição. Seja esta através da Internet, rede interna ou qualquer outro tipo de acesso, o sistema está apto a fornecer a informação requisitada e o contexto em que esta foi programada para ser exibida.

\section{Deve ser capaz de fazer "qualquer coisa"}

O sistema deve possuir flexibilidade para permitir a seus usuários e também a outros sistemas - executar todas as operações necessárias para que o acesso ao conteúdo seja sempre garantido, nas circunstâncias 
mais diversas. É rara a ocasião em que se conhece, de antemão, todas as peculiaridades de funcionais do Museu; isto implica em previsão de usos diversos no futuro, assim como possivveis evoluções e desdobramentos.

\section{Restrições do sistema através de regras de negócios e não de limitações técnicas}

A definição de Regras de Negócio (Business Rules) ${ }^{55}$ permite a inclusão de modelos de análise ou ação baseados em automação, permitindo assim flexibilidade no uso dos ativos digitais em circunstâncias variadas. Tais modelos e regras podem se aplicar ao gerenciamento de direitos autorais, direitos de uso específicos ou quaisquer outros requerimentos que se façam necessários dentro da lógica da Instituição.

\section{Modalidade completa e escalabilidade}

Content Management System (CMS) é um agregado de diferentes tecnologias que trabalham em uníssono. Para que as partes possam funcionar integradas, é necessário que trabalhem em padrões compativeis, principalmente em relação ao resultado entregue ao usuário ou público. Existem atualmente, no domínio da tecnologia, padrões sofisticados que

55 Regras de Negócio são declarações sobre a forma da empresa fazer negócio. Elas refletem políticas do negócio. As organizações com isto têm políticas para satisfazer os objetivos do negócio, satisfazer clientes, fazer bom uso dos recursos, e obedecer às leis ou convenções gerais do negócio. Regras do Negócio tornam-se requisitos, ou seja, podem ser implementados em um sistema de software como uma forma de requisitos de software desse sistema. Representam um importante conceito dentro do processo de definição de requisitos para sistemas de informação e devem ser vistas como uma declaração genérica sobre a organização. As regras de negócio definem como o seu negócio funciona, podem abranger diversos assuntos como suas políticas, interesses, objetivos, compromissos éticos e sociais, obrigações contratuais, decisões estratégicas, leis e regulamentações entre outros.

<https://pt.wikipedia.org/wiki/Regras_de_negócio> Acesso em: 04 jan. 2018 
permitem completa interoperabilidade e escalabilidade entre sistemas diversos. Cada um dos componentes do sistema deve possuir flexibilidade para se adaptar às necessidades presentes ou futuras, sem a necessidade de substituição ou reengenharia de toda a plataforma.

\section{Conformidade de padrões}

O Museu necessita de padronização, a fim de receber e compartilhar informações com outras Instituições e também com seu público (V. subseção 4.2.3.1). É natural que tal padronização faça parte do sistema de gerenciamento de conteúdo utilizado por aquele e seja requisito essencial de qualquer modelo de trabalho adotado.

\subsection{3 | Plataforma aberta}

\subsubsection{1 | Pressupostos}

Arquivos, bibliotecas e museus disponibilizam seus catálogos e/ou coleções digitais na Internet, tornando-os acessiveis a qualquer usuário, em qualquer lugar, a qualquer momento. Há, no entanto, grande dificuldade em tornar interoperáveis acervos hospedados em diferentes instituições, uma vez que esses acervos são dependentes de softwares específicos para publicar seus registros na Web. Os atuais softwares de gestão de catálogos - usados em arquivos, bibliotecas e museus - também não permitem que sejam feitos links para um registro específico, excluindo seus registros de toda a economia da Web, com base na publicação de conteúdos e de links entre eles. ${ }^{56}$

O modelo de plataforma aberta pressupõe a interligação de dados provenientes de fontes distintas, tais como arquivos, bibliotecas e museus. Qualquer conteúdo disponibilizado na Internet só poderá ser integrado e 56 Neto et al. (2013, p. 81-82) 
reutilizado pelos pares se estiver ancorado por sistemas que permitam alto grau de interoperabilidade.

A definição, metodologia de implantação e requisitos de uma plataforma aberta para o Museu abrange setores e questionamentos distintos, embora relacionados e interdependentes; cada um deles com necessidades específicas, e que podem ser divididos em três grupos principais:

- Gerenciamento de dados

- Acervo e exibição online

- Tecnologias de dados abertos (Open Data)

Para que o Museu possa cumprir com tais requisitos, é necessário que o vasto acervo de informações a ele vinculado como entidade física possa ser disponibilizado de forma remota a todos os interessados, tomando como modelo os princípios da Ciência Aberta (Open Science) ${ }^{57}$ :

- acesso público a dados de investigação

- trabalho de investigação cooperativo, incluindo a participação de não-cientistas

- uso de ferramentas colaborativas de difusão de conhecimento

A incorporação, pelo Museu, das ferramentas que permitem (pela primeira vez na história) disseminar o conhecimento - de forma global, coletiva e colaborativa - é fundamental para manter sua relevância, exposição e valor:

The big change that museums need to undergo to make themselves (and each other) useful and relevant in the 21 st Century is to make the collection a collective pursuit. Collaborative media makes the open source museum a feasible and viable option, technically simple and financially affordable. Such collaboration between different museums, and between museums and their audiences, has the poten-

57 <https://www.plataforma.edu.pt/plataforma/\#missao-e-objetivos> Acesso em: 14 nov. 2017 
tial to exponentially increase the accessibility and the value of their collections.

This is an argument for a reallocation of effort and resources to the idea of the open source museum, and to begin to concern ourselves as much with placing digital recording, conservation and collaboration at the heart of what we do -not at the periphery, where it exists now. ${ }^{58}$

Para que isto ocorra na prática é necessário o aperfeiçoamento constante das práticas ligadas ao processo. Segundo (MARTINS et al., 2017),

\begin{abstract}
O acesso e compartilhamento da informação possibilitado pelas tecnologias da informação e comunicação (TIC's) ocorre desde o desenvolvimento de sua difusão por meio da emergência dos dispositivos computacionais, eletrônicos, redes de distribuição e processamento de dados. Simultaneamente há o aumento da importância da informação como recurso estratégico nas instituições, que tem exigido dos profissionais da informação o aperfeiçoamento na recuperação da informação. ${ }^{59}$
\end{abstract}

Para Hossaini et al. (2017) o conteúdo não deve ser bloqueado em bancos de dados proprietários. Em vez disso deve ser liberado, isto é, gerenciado por padrões que permitam que seja dimensionado, servido e reutilizado em qualquer plataforma digital.

A solução mais orgânica para tais demandas, baseada nos exemplos seguidos pelas Instituições, implica na adoção de tecnologias e programas de computador baseados em código aberto (open source). Desta forma, o código-fonte (source code) ${ }^{60}$ está disponível para download,

$58<$ https://medium.com/the-many/the-open-source-musuem-6df96fdaedb3> Acesso em: 19 nov. 2017

59 Martins et al. (2017, p. 55)

60 Código-fonte (source code em inglês) é o conjunto de palavras ou símbolos escritos de forma ordenada, contendo instruções em uma das linguagens de programação existentes, de maneira lógica. Existem linguagens que são compiladas e as que são interpretadas. As linguagens compiladas, após ser compilado o código fonte, transformam-se em software, ou seja, programas executáveis. Este conjunto de palavras que formam linhas de comandos deverá estar dentro da padronização da linguagem escolhida, obedecendo critérios de execução. Atualmente, com a diversificação de linguagens, o código pode ser escrito de forma totalmente modular, podendo um mesmo conjunto de códigos ser compartilhado por diversos programas 
revisão e modificação por qualquer interessado. O gerenciamento da informação, dentro deste modelo, permite que esta seja dimensionada, servida e reutilizada em qualquer plataforma digital.

Tal procedimento se mostra benéfico em diversos aspectos:

- não existe custo de aquisição

- possui, muitas vezes, qualidade superior ao seu correspondente proprietário

- a acesso ao código assegura maior garantia de longevidade dos dados e aumenta as chances de reutilização a longo prazo

- os processos aplicados aos conteúdos do acervo são transparentes e conhecidos, e não dependem da existência de terceiros

- através da utilização de licenças de uso público apropriadas os pesquisadores, alunos e membros da comunidade podem adicionar recursos, corrigir erros e personalizar para usos especiais; todas as modificações e adições ao software devem ser lançadas sob esta mesma licença, garantindo desta forma que, quando terceiros alterem o código, suas modificações e adições também serão abertas, de modo que toda a comunidade se beneficie

A tecnologia de código aberto reflete a ambição do museu de democratizar a tecnologia e os conteúdos e serviços que aquela pode gerenciar, ao mesmo tempo em que incentiva padronização ampla e aberta. ${ }^{61}$

Ao adotar padrões comuns, os museus ao redor do mundo podem vincular seus recursos para criar uma base de conhecimento universal.

Neste contexto, os museus devem se considerar parte de redes onde o conteúdo gerado por coleções, exposições, pesquisadores, programas

e, até mesmo, linguagens.

<https://pt.wikipedia.org/wiki/Código-fonte> Acesso em: 29 nov. 2017

61 Hossaini et al. (2017, p. 168) 
educacionais e visitantes está disponível globalmente através de qualquer canal digital ${ }^{62}$. O conteúdo não deve, portanto, ser bloqueado em bases de dados proprietárias, mas sim gerenciado por padrões que permitam que seja dimensionado, servido e reutilizado em qualquer plataforma digital. Tais padrões são a chave para o compartilhamento. De acordo com Skov (2009):

Standards help institutions to document their collections according to a commonly shared model. Therefore the application of standards aims to support a homogeneously description of museum artefacts facilitating easier access to cultural heritage collections both within a single institution and across institutions. ${ }^{63}$

A busca por padrões é enfatizada por (FERREZ, 1994) quando nos lembra

(...) da necessidade de se alcançar um sistema transparente, isto é, um sistema em que qualquer membro da equipe do museu e demais usuários (pesquisadores e público em geral) possam facilmente "acessar" para obter as informações que desejam, sem precisar passar pelos meandros de sistemas criados para uso exclusivo de um pequeno grupo e até mesmo de uma única pessoa. ${ }^{64}$

Isto já ocorre na prática65; sua adoção em massa pode vir a tornar invisiveis as especificidades existentes nas bases de dados espalhadas ao redor do mundo66. Iniciativas como o projeto OpenGlam (Galleries, Libraries, Archives and Museums) ${ }^{67}$ permitem a diversos museus ao redor do mundo que se juntem a projetos de dados abertos vinculados, onde os

\footnotetext{
62 Hossaini et al. (2017, p. 357)

63 Skov (2009, p. 43)

64 Ferrez (1994, p. 4)

65 <http://eu. Oheuaqui.com/2AMjnaa> Acesso em: 30 nov. 2017

66 "Memory is invisible, and what we call today technology will likely become largely invisible in the future" Anderson (1999, p. 132)

67 OpenGLAM (Galleries, Libraries, Archives and Museum) is an initiative coordinated by Open Knowledge that is committed to building a global cultural commons for everyone to use, access and enjoy. OpenGLAM helps cultural institutions to open up their content and data through hands-on workshops, documentation and guidance and it supports a network of open culture evangelists through its Working Group.

<https://openglam.org/faq> Acesso em: 10 nov. 2017
} 
participantes seguem padrões estabelecidos para estruturar seus dados e torná-los acessíveis aos interessados. Isso torna mais fácil para os museus encaminhar e educar visitantes não apenas em seus próprios ativos, mas também para ativos em outros locais.

Por fim, o conceito de plataforma aberta também chama para si as tecnologias que permitem o acesso universal ao conteúdo e experiências vinculadas ao Museu, através da adequação de elementos chave ligados à comunicação entre as partes:

Idioma Em um ambiente multilíngue, as opções de tradução são a forma básica de garantir a acessibilidade para todos. O idioma fácil de ler garante que o conteúdo seja acessivel a pessoas com deficiência intelectual.

Tamanho do texto As opções para aumentar o tamanho do texto são úteis para pessoas com deficiências visuais.

Legendas de vídeo $\bigcirc$ texto está presente na tela em todos os momentos (legendas abertas) ou se disponibiliza texto que pode ser lido com um decodificador específico (subtítulo fechado) para suportar pessoas com deficiência auditiva.

Transcrição Disponibilidade do conteúdo em um arquivo de texto, permitindo assim o acompanhamento do conteúdo de áudio.

Descrição de áudio $\bigcirc$ áudio de uma pessoa especialmente treinada que lê nomes de títulos e descreve informações visuais é adicionado a uma trilha sonora de vídeo quando há pausas. Isto pode incluir um menu falado, acessivel através do dispositivo utilizado pelo visitante.

Visita sensorial Representações em braile e tridimensionais de exposições de museus permite passeios de toque para pessoas com deficiências visuais. 
Tecnologia assistiva Como exemplo, pode-se ter o recurso de um leitor de tela através de um sintetizador de fala.

\subsubsection{2 | Implementação}

O modelo de implementação - representado visualmente na Figura 17 - consiste em 2 pólos principais - acervo e dados - interligados pela mesma plataforma, e acessiveis através de 3 compartimentos.

O primeiro deles representa os índices ou metadados, os quais permitem que se obtenha a semântica do objeto museológico e possibilita associações e conexões com outros objetos tanto através de máquinas quanto de seres humanos.

O segundo está ligado à simbologia de intercomunicação entre sistemas eletrônicos distintos através das API, as quais atuam como tradutoras entre diferentes modelos tecnológicos, possibilitando a comunicação entre plataformas incompativeis de modo transparente e sem atrito.

O terceiro deles é o signo: a representação visual, auditiva, sensorial etc. do conteúdo físico do acervo.

A somatória dos três elementos, trabalhando em conjunto, possibilita a disponibilização, no maior grau possivel, da experiência ligada ao Museu e seus objetos.

Cabe ao Museu produzir informação em 3 frentes distintas:

1. Através da digitalização dos objetos de arte na maior qualidade possivel (subseção 4.2.2.2)

2. Na inserção de metadados e outras informações de catalogação na base de dados da Instituição 


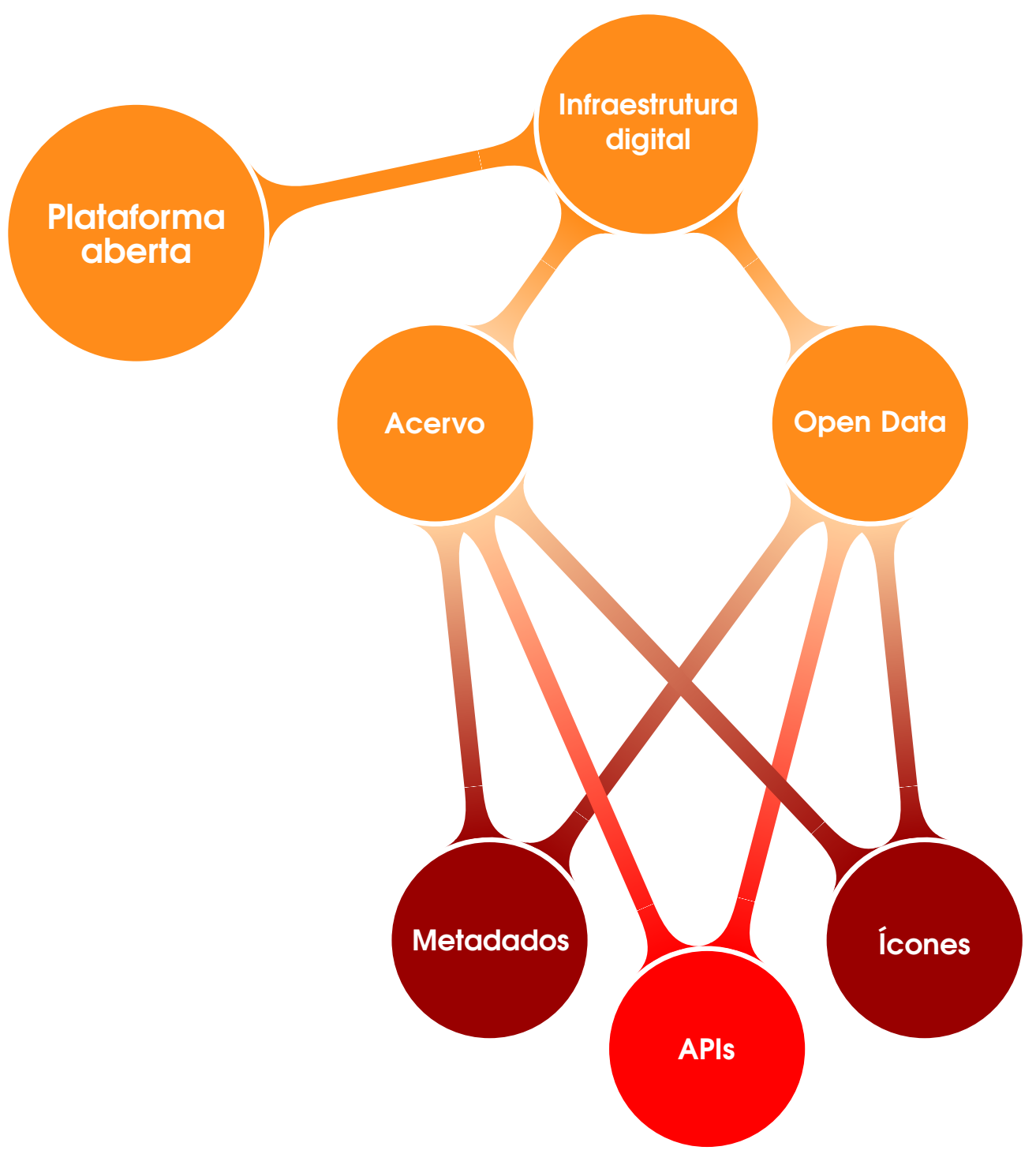

FIGURA 17 Plataforma aberta, relações e interdependências

De posse da informação, é necessário cuidar de seu gerenciamento de forma adequada.

A Associação de Gerenciamento de Dados (Data Management Association ou DAMA) define o gerenciamento de dados e informações como "o desenvolvimento, execução e supervisão de planos, políticas, programas e práticas que controlam, protegem, entregam e aumentam o valor dos ativos de dados e informações". 
O modelo de gerenciamento de conteúdo está abordado na subseção 4.2.2.3 na página 113.

\subsection{4 | Internet e redes sociais}

\subsubsection{1 | Pressupostos}

(...) o início da década de 2010 é marcado pelas redes sociais, notadamente o Twitter e o Facebook, em que as pessoas se identificam com seus dados reais, se expõem com foto e tudo, e usam os sistemas para se manterem conectadas aos amigos, familiares, colegas de trabalho e demais conhecidos. A interação é contínua, ao longo de vários momentos do dia, seja pelo celular ou outro computador móvel. Um evento interessante é motivo para tuitar e tornar a notícia compartilhada com todos, e basta um só minutinho. A foto tirada na praia é compartilhada na rede social. O SMS entrega a mensagem que divulgaram na sua rede de relacionamentos. Eu estava no ciberespaço naquele instante em que estava lendo a mensagem na tela do meu celular? Nem havia percebido. Não há mais uma clara fronteira entre o digital e o real. ${ }^{68}$

As redes sociais representam um canal importante entre o Museu e seus espectadores, tanto atuais quanto potenciais. Funcionam como ferramenta para enviar conteúdo ao público e também como plataforma para obter retorno e gerar conteúdos, comunidades e conversações. Através das mídias sociais o Museu cria oportunidades significativas para atingir e atrair novos públicos e, também, envolver as comunidades existentes em modelos que vão além da presença física.

fato de se ter um espectador que acessa, cada vez mais, as redes sociais através de dispositivos móveis (v. seção 3.2), possibilita afirmar que estes serão o principal canal de comunicação para tais redes em quase

68 Costa e Pimentel (201 1, p. 8) 
todo o mundo; consequentemente o vínculo entre o Museu, dispositivos móveis e redes sociais parece ser um fato consolidado.

Pode-se afirmar, portanto, que necessidade de se atrair ou ampliar a visitação pública aos museus depende da habilidade destes em abarcar os aspectos relativos às mídias sociais. Pode ser, na maior parte, um processo lento e complexo, e que depende de inovação em diversas frentes onde o museu, tradicionalmente, se comporta de modo conservador ( $\mathrm{V}$. seção 2.3).

If the role of the museum, the reason it exists, is to tell the story of the history of humankind to all of humankind, then you need a way of doing that act of telling. In simple terms, the Internet is that way. Sometime in the next twenty or thirty years all of the world will get access to the Internet. Four billion people are expected to be online by 2020 alone. When that happens, the museum will be uniquely enabled to do the very thing it was set up to do. Its digital strategy is therefore the things it needs to do to go along that path to Internet-facilitated universalism. ${ }^{69}$

Os primeiros experimentos com mídias sociais em museus ocorreram através de instalações imersivas, onde os visitantes produziam selfies e se encaixavam no contexto do objeto de arte. Em 2013 o centro Pompidou, em Paris, permitiu aos visitantes tirar fotos de si mesmos sentados no sofá em forma de lábio (inspirado no rosto de Mae West) criado por Salvador Dali. Um ano depois o Museu Dali ${ }^{70}$ em São Petersburgo, Flórida, instalou uma cabine fotográfica que permitia aos visitantes sobrepor seus retratos àquele de Gala - musa de Dali - olhando para o Mediterrâneo. Tais iniciativas podem vir a se tornar repetitivas ou enfadonhas para o público, sendo preferivel se pensar em iniciativas mais duradouras e ligadas a plataformas como o Instagram, realidade aumentada ou tecnologias específicas. Existem, no entanto, impedimentos de ordem financeira que impedem o desenvolvimento de tais customizações.

\footnotetext{
69 Hossaini et al. (2017, p. 4)

$70<$ http://thedali.org/> Acesso em: 05 jan. 2018
} 
Alguns museus utilizam análises e comentários das comunidades da Internet para decidir a melhor maneira de apresentar o acervo. Em 2009, o Museu de Arte de Cleveland ${ }^{71}$ utilizou as redes sociais para rastrear e analisar as jornadas dos visitantes em torno de uma de suas galerias. Descobriu que, longe de seguir o caminho preferido dos curadores através da coleção, ler textos interpretativos e seguir os links e caminhos estabelecidos por aqueles, os visitantes se moviam de forma aparentemente aleatória, dependendo do seu interesse naquele momento. A resposta do museu foi abrir o Gallery One ${ }^{72}$ : um espaço interativo com versões digitais de cada peça da coleção; com isto, o público se tornou o guia.

Seria este o prelúdio de um futuro onde os museus sucumbem ao populismo e o número de visitas e acessos à galeria desempenha papel decisivo em relação àquilo que deve ser exposto? Para Alex Espinós, fundador da agência de consultoria e marketing digital La Magnética, sediada em Barcelona, as mídias sociais permitem que se faça exatamente o contrário:

If you have an exhibition about an artist that is slightly offtopic you can focus on specific communities online. ${ }^{73}$

Os museus possuem um rico conteúdo exclusivo, perfeitamente adaptável aos canais de mídia social; estes, por sua vez, oferecem ao Museu a oportunidade de se envolver com aqueles que não o visitarão no mundo físico.

$71<\mathrm{http}$ ///www.clevelandart.org/about/about-the-museum/history-and-mission> Acesso em: 05 jan. 2018

$72<$ https://eu.oheuaqui.com/2AyaPzu> Acesso em: 05 jan. 2018

73 <https://eu.oheuaqui.com/2AwI9XD> Acesso em: 05 jan. 2018 


\subsubsection{2 | Implementação}

Para os museus, é importante ter em mente que as mídias sociais são, provavelmente, uma das melhores formas de alcançar pessoas que não se conectam de nenhuma outra maneira. Para muitos a mídia social pode ser a única maneira de se conectar com o Museu e, portanto, deve ser vista não apenas como uma ferramenta de marketing para levar as pessoas à experiência concreta do museu (ou seja, uma visita à localização física), mas como um experimento per se. No caso do público denominado Geração Y ou geração do milênio (millenials) ${ }^{74}$, a utilização das mídias sociais é praticamente obrigatória. Uma pesquisa realizada junto ao público norte-americano ${ }^{75}$ mostra que, pela primeira vez, a descoberta da arte se dá através das redes sociais e não pela visita a museus e galerias ${ }^{76}$.

As mídias sociais são diferentes das exposições, na medida em que sua comunidade espera poder compartilhar conteúdo - e o compartilhamento de conteúdo é o cerne do seu sucesso. ${ }^{77}$

A adoção, pelo Museu, de práticas voltadas às redes sociais, implica em investimento significativo de tempo e recursos humanos para que surjam resultados significativos. Cada um dos mecanismos sociais

74 A geração Y (também chamada geração do milênio ou geração da internet), é um conceito em Sociologia que se refere, segundo alguns autores, como Don Tapscott, à corte dos nascidos após 1980 e, segundo outros, do início da década de 1980 até meados da década de 1990, sendo sucedida pela geração Z. Essa geração desenvolveu-se numa época de grandes avanços tecnológicos e prosperidade econômica, e facilidade material, e efetivamente, em ambiente altamente urbanizado, imediatamente após a instauração do domínio da virtualidade como sistema de interação social e midiática, e em parte, no nível das relações de trabalho. Se a geração $X$ foi concebida na transição para o novo mundo tecnológico, a geração $Y$ foi a primeira verdadeiramente nascida neste meio, mesmo que incipiente. <https://pt.wikipedia.org/wiki/Geração_Y> Acesso em: 05 jan. 2018

75 Invaluable (2016)

76 A recent study in the United States found that millennials discover art through social media rather than visiting museums-although the opposite is true for baby boomers.

Hossaini et al. (2017, p. 46)

77 Hossaini et al. (2017, p. 48) 
existentes - ou por surgir - possui suas especificidades, as quais precisam ser compreendidas e administradas. Os museus que desejam envolver pessoas através da publicação de seu conteúdo em mídias sociais devem considerar cuidadosamente os requisitos de cada uma das plataformas escolhidas. De acordo com (HOSSAINI et al., 2017),

Each social media platform has a slightly different function and works with different media, and it is important that once museums decide to use a particular platform they research and observe the conduct and activity of that community to act accordingly. On the whole, however, museums can consider social media as a program or channel (...) that provides digital content, supports conversation, and facilitates or drives action. ${ }^{78}$

As principais plataformas sociais ${ }^{79}$ são:

- Instagram

- YouTube 80

- FACEBOOK

- Linkedln 81

- Twitter $^{82}$

78 Hossaini et al. (2017, p. 45)

79 No Ocidente, ao final de 2017

80 YouTube is an American video-sharing website headquartered in San Bruno, California. The service was created by three former PayPal employees - Chad Hurley, Steve Chen, and Jawed Karim - in February 2005. Google bought the site in November 2006 for US\$ 1.65 billion; YouTube now operates as one of Google's subsidiaries. <https://en.wikipedia.org/wiki/YouTube> Acesso em: 06 jan. 2018

81 Linkedln is a business - and employment-oriented social networking service that operates via websites and mobile apps. Founded on December 28, 2002, and launched on May 5, 2003, it is mainly used for professional networking, including employers posting jobs and job seekers posting their CVs. As of 2015, most of the company's revenue came from selling access to information about its members to recruiters and sales professionals. As of April 2017, Linkedln had 500 million members in 200 countries, out of which more than 106 million members are active. Linkedln allows members (both workers and employers) to create profiles and "connections" to each other in an online social network which may represent real-world professional relationships. Members can invite anyone (whether an existing member or not) to become a connection. The "gated-access approach" (where contact with any professional requires either an existing relationship or an introduction through a contact of theirs) is intended to build trust among the service's members.

<https://en.wikipedia.org/wiki/Linkedln> Acesso em: 06 jan. 2018

82 Twitter é uma rede social e um servidor para microblogging, que permite aos usuários enviar e receber atualizações pessoais de outros contatos (em textos de até 280 
- Snapchat83

A partir das peculiaridades e pontos fortes de cada uma delas é possível criar uma política de divulgação e utilizar os ativos mais adequados a cada um dos contextos

A Tabela 10 descreve as características específicas de cada uma delas.

\begin{tabular}{l|l}
\hline Instagram & Imagens de impacto \\
\hline YouTube & Vídeos que promovam engajamento \\
\hline Facebook & Histórias e narrativas de cunho pessoal e emotivo \\
\hline Linkedln & Informações ligadas ao mundo profissional e corporativo \\
\hline Twitter & Imagens e textos rápidos e inteligentes \\
\hline Snapchat & Vídeos e fotos impactantes e de curta duração \\
\hline
\end{tabular}

TABELA 10 Características das diferentes redes sociais

caracteres, conhecidos como "tweets"), por meio do website do serviço, por SMS e por softwares específicos de gerenciamento. As atualizações são exibidas no perfil de um usuário em tempo real e também enviadas a outros usuários seguidores que tenham assinado para recebê-las. As atualizações de um perfil ocorrem por meio do site do Twitter, por RSS, por SMS ou programa especializado para gerenciamento. $O$ serviço é gratuito pela internet, entretanto, usando o recurso de SMS pode ocorrer a cobrança pela operadora telefónica. O twitter foi criado em Março de 2006 por Jack Dorsey, Evan Williams, Biz Stone e Noah Glass e foi lançado em Julho de 2006 nos EUA. A ideia inicial dos fundadores era que o Twitter fosse uma espécie de "SMS da internet" com a limitação de caracteres de uma mensagem de celular. Inicialmente chamada Twttr (sem vogais), o nome da rede social, em inglês, significa gorjear. A ideia é que o usuário da rede social está "piando" pela internet. Desde sua criação, o Twitter ganhou extensa notabilidade e popularidade por todo mundo. Algumas vezes é descrito como o "SMS da Internet". Jack Dorsey é o atual CEO da empresa. <https://pt.wikipedia.org/wiki/Twitter> Acesso em: 06 jan. 2018

83 Snapchat é um aplicativo de mensagens com base de imagens, criado e desenvolvido por Evan Spiegel, Bobby Murphy e Reggie Brown, estudantes da Universidade Stanford. Com o aplicativo, usuários podem tirar fotos, gravar videos, adicionar textos e desenhos à imagem e escolher o tempo que a imagem ficará no visor do amigo de sua lista. Com a nova atualização é possivel iniciar uma conversa com texto ou vídeo com seus amigos, mesmo sem ativar sua câmera para conversar. O tempo de cada snap é de 1 a 10 segundos, e após aberto, a imagem ou vídeo somente poderá ser vista pelo tempo escolhido pelo remetente. A imagem é excluída do dispositivo e também dos servidores. Também é possivel adicionar filtros nas fotos, salvar as fotos tiradas no app no computador e anexar arquivos ao bate-papo dentro do Snapchat. <https://pt.wikipedia.org/wiki/Snapchat> Acesso em: 24 ago. 2017 
São pontos centrais, relacionados a todas as mídias sociais, a centralização de processos ao redor do usuário (tornando este o núcleo de transformação institucional) e o fato da mídia social dar suporte a tal centralização utilizando um modelo de ativação que se baseia em 3 princípios:

Desintermediação Remoção dos elementos "mediadores" nos museus, a fim de colocar o especialista em diálogo mais próximo com o público Informalização Compartilhamento do conhecimento através de conversas informais, e não através de publicações acadêmicas

Participação $\bigcirc$ público desempenha um papel ativo e definido no produto, conteúdo ou serviço digital.

Além disso, dois conceitos são importantes para a compreensão ampla do processo: bridging e bonding; ambos criados por (PUTNAM, 2001). Bridging refere-se à conexão com pessoas que são diferentes entre si (redes dentro de um grupo heterogêneo), enquanto bonding se refere ao fortalecimento de uma conexão com pessoas que são semelhantes (rede social de um grupo homogêneo). São formas de fortalecer o capital social - ou seja, os recursos adquiridos através de relacionamentos com os outros.

O ponto comum para obtenção de sucesso em todas as redes sociais é a capacidade de arregimentar seguidores através da amplificação de ambos bridging e bonding, fazendo com que seguidores se atraiam em um ciclo contínuo.

Tendo como objetivo o aumento do número de seguidores e tomando como exemplo a plataforma Twitter pode-se afirmar, de acordo com (ESPINÓS, 2015), que o caminho mais importante para o Museu 
ampliar sua base de seguidores é através de recomendações. $\bigcirc$ modelo segue três etapas distintas:

A new user signs up on Twitter and is asked about the topics he or she is interested in. After setting a location and choosing "museums" or "culture" among their topics of interest, Twitter presents the new user with a list of museums' profiles to follow. After choosing several museums, other museums are going to show as suggested Twitter accounts to follow.

Secondly, the Twitter algorithm continuously offers account holders new profiles to follow based on their past behavior-that is, who they follow, mention, favorite, and retweet.

Thirdly are mentions or retweets. When a museum's follower mentions the museum in a tweet or retweets a post, this follower's followers can see this interaction and may choose to follow the museum from which the post originates.

autor afirma que os três mecanismos acima citados acabam por gerar entre $70 \%$ a $90 \%$ de novos seguidores para os museus.

mecanismo subjacente a este processo é denominado fechamento triádico (Tabela 10).

A idéia subjacente do fechamento triádico se baseia no seguinte princípio: Se duas pessoas em uma rede social têm um amigo em comum, então há uma maior probabilidade deles, também, se tornarem amigos no futuro $^{84}$. É a forma orgânica como as pessoas se conhecem. As chances destas duas contas sociais se conectarem podem ser pequenas, mas são

84 "We were really interested in this question and studied it further. The mechanism that underlies the three main sources of new followers is called triadic closure. Triadic closure works in a similar fashion across most social media-including Facebook or Linkedln, although some details may differ.

The underlying idea of triadic closure is quite simple: if two people are connected through a third person, chances are they too will be connected in the future. It is the way we have gotten to know many of our acquaintances and friends in the "real world." The chances that these two people or two Twitter accounts connect may still be small, yet they are much higher than those of two random users among the half a billion Twitter users or 1.4 billion Facebook users.

If a museum is connected with another museum (mutual following) or if they share a significant number of followers, it is likely Twitter will suggest the first museum to the followers of the second one. For instance, a user that follows several contemporary art museums is going to get other contemporary art museums as recommendations."

Espinós (2015) apud Hossaini et al. (2017, p. 55) 
muito maiores que as de dois usuários aleatórios entre o meio bilhão de usuários do Twitter ou 1,4 bilhões de usuários do FACEBOOK.
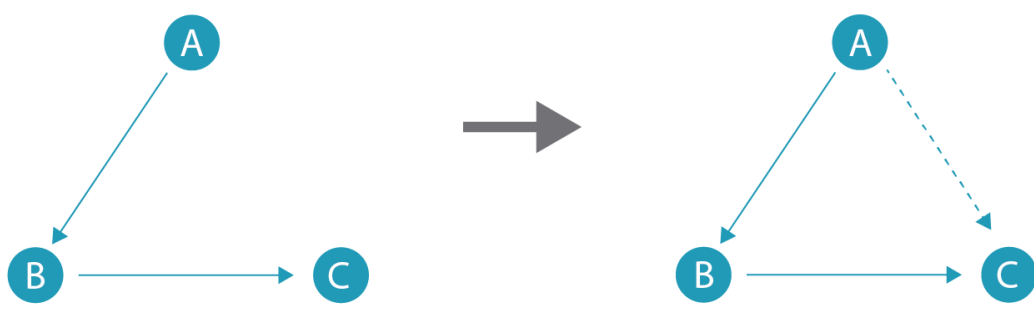

FIGURA 18 Fechamento triádico

As redes sociais conduzem à agregação; a qual, por sua vez, caminha em direção à consolidação de seu público online.

A implementação, com sucesso, da estratégia de divulgação em redes sociais, depende de planejamento e análise de resultados. A manutenção de iniciativas em redes sociais é um desafio que precisa ser planejado como qualquer outro programa. As métricas e metodologias baseadas em Key Performance Indicators (Indicadores-chave de desem- 
penho ou $\mathrm{KPI})^{85}$ geram a informação necessária para se quantificar e planejar resultados nas plataformas utilizadas ${ }^{86}$.

Os KPI devem incluir, minimamente, as seguintes análises:

- Alcançar novos públicos que não são atendidos por outros canais

- Envolver o público existente de maneiras novas e sustentadas

- Ganhar contribuições da comunidade

- Catalizar conversas importantes e relevantes

- Aumento do engajamento com outros canais

Os índices recomendados por (HOSSAINI et al. , 2017) são:

- Characteristics of web visitors such as unique visits, volume of target demographics, user satisfaction ("did you find what you were seeking?"), and engagement metrics such as dwell time.

- Subscriptions to newsletters and other online campaigns.

- Social media engagement measured by likes, friends, fans, shares, comments and other indicators.

- Media coverage reported by absolute number of mentions, links into your digital properties, and online referrals.

85 Indicadores-chave de desempenho (em inglês Key Performance Indicator, KPI, ou Key Success Indicator, KSI), são ferramentas de gestão para se realizar a medição e o consequente nível de desempenho e sucesso de uma organização ou de um determinado processo, focando no "como" e indicando quão bem os processos dessa empresa estão, permitindo que seus objetivos sejam alcançados. Existem diferentes categorias de indicadores, que podem ser indicadores quantitativos, indicadores qualitativos, principais indicadores, indicadores de atraso, indicadores de entrada, indicadores de processo, indicadores direcionais, indicadores acionáveis e indicadores financeiros. KPIs são "veículos de comunicação", pois permitem que o corpo de gestores de uma organização comuniquem aos seus liderados o quão eficiente um processo é e como está seu desempenho ao longo de um período determinado. De posse dessas informações, cabe ao gestor e equipe traçarem planos de ação para o atingimento de determinadas metas ou até mesmo valer-se dos KPls para saberem se estão ou não no caminho certo. O passo mais difícil na construção de um KPI talvez seja a definição da meta que se deseja alcançar. Isso porque o executivo precisa saber exatamente onde quer chegar e o que é relevante ao seu processo. Por exemplo, um executivo de vendas não precisa controlar todos os indicadores da área de gestão de recursos humanos pois estaria gastando parte de seu tempo e energia em algo que não é o que gera valor à sua função. Isso pode parecer meio óbvio, mas um grande erro das organizações como um todo é o emprego de tempo e esforço em atividades que não são relevantes.

<https://eu.oheuaqui.com/2CWdOHj> Acesso em: 07 jan. 2018

86 Hossaini et al. (2017, p.54) 
- Conversions of digital touchpoints into a user journey that deepens engagement through a visit, membership, purchase, social sharing or other museum-defined outcome.

- Trading income that is a definitive outcome of higher engagement.

- Retention rates of staff and volunteers measured by length of service. ${ }^{87}$

É preferível escolher, de início, apenas dois ou três KPI. O excesso de informações no início do processo pode levar à chamada paralisia por análise. As práticas recomendadas para este processo são:

Frequência É importante efetuar a análise, juntamente com a equipe, em horários regulares e predeterminados; este processo é rápido e pode ocupar alguns poucos minutos de outra reunião.

Treinamento É necessário criar oportunidades de treinamento em estatística e métrica para os integrantes do Museu; mesmo para aqueles que possuam experiência no tema

Consistência Medições consistentes em períodos regulares são fundamentais para avaliação de tendências; neste caso, a consistência supera a precisão.

Perfis Estudos qualitativos regulares são fundamentais para validar o que os dados quantitativos estão dizendo; a orientação voltada para análise de dados mas centrada no visitante exige, além da coleta, interação direta com aqueles.

Por fim, cabe lembrar a necessidade de planejamento e da colaboração especializada em quaisquer ações que potencializem o contato com um público vasto e, muitas vezes, imprevisível. As competições e promoções, por exemplo, são uma das atividades virtuais que os museus podem adotar, a fim de mostrar a seu público o compromisso com as mídias sociais, e

87 Hossaini et al. (2017, p. 342-343) 
que consideram seus seguidores como parte de uma comunidade. É uma

forma de valorizar e encorajar o envolvimento profundo e ativo com o

museu entre um amplo espectro de pessoas que podem ou não encontrar

a mesma diversão visitando o edifício físico.

Por fim, é importante lembrar que a mero aumento do número de seguidores nas redes sociais não trará, de forma automática, benefícios imediatos à Instituição. Soa apropriada, como fechamento, a reflexão de (MATOS, 2013):

A utilização das redes sociais pelos museus, enquanto instituições que têm uma missão muito específica, tem suscitado um interessante debate a nível internacional e uma intensa profusão de estudos, académicos e não só, sobre o tema. O debate, revelador da dificuldade que os museus encontram nesta matéria, centra-se na(s) forma(s) de abordagem às redes sociais por parte de instituições que não se enquadram naquilo que os 'gurus' desta área definem como a participação das grandes corporações, ou seja a promoção de marcas ou produtos, mas sim uma interação entre instituição e público que as beneficie mutuamente e contribua para a evolução da sociedade. Ou seja o museu deve utilizar as redes sociais como mais uma plataforma, um meio, para cumprir a sua missão e políticas, de acordo com o que está inscrito na definição de museu do ICOM. Mas como o tem feito?

Alguns museus centram-se na promoção das suas atividades, serviços, coleções, etc. Outros procuram uma maior interatividade com o público através de perguntas, debates ou através de programas específicos de participação em projetos concretos do museu (documentação de coleções, classificação de exposições, etc.). Outros ainda centramse na promoção e divulgação de conteúdos provenientes de utilizadores das redes sociais, tendo por base um tema (ou evento, por exemplo) relacionado com o museu, dando todo o destaque aos utilizadores. A existência de um catálogo da coleção on-line tem permitido em alguns casos experiências interessantes nesta matéria, através de interações diretas com a própria coleção. Enfim, são inúmeras as formas encontradas pelos museus para utilizar a enorme audiência disponivel no Facebook, Twitter, Flickr, Pinterest, Google+, Linkedin, Foursquare ou a que tiver sido criada entre o tempo em que escrevi este texto e a sua publicação. Mas como o devem fazer?

As redes sociais, tal como outras formas de contato e interação com o público dos museus, devem ser enquadradas no âmbito da missão e políticas definidas pelos responsáveis dos museus considerando, como não podia deixar de ser, as particularidades inerentes a este tipo de 
ferramentas interativas. $O$ museu deve compreender $\mathrm{O}$ âmbito específico de cada uma das redes que tem à sua disposição, conhecer o seu funcionamento, o fim para que são criadas e conhecer as motivações de quem as usa. O Twitter tem um universo de utilizadores e objectivos distintos dos que tem o Linkedin ou o Flickr. Duas redes muito semelhantes, como o Facebook ou o Google+ por exemplo, terão resultados de interação distintos. Por outro

lado, o museu deve ter previamente definida uma estratégia de utilização das redes sociais (mesmo quando o que pretende se resuma apenas à promoção das suas atividades), inserida na sua política de comunicação, à qual deve corresponder um planeamento onde estejam previstos os recursos (humanos e financeiros) necessários para corresponder às expectativas que cria a partir do momento em que usa uma rede social. A estratégia e plano de utilização das redes sociais, por seu turno, devem capacitar o museu e a sua equipa na persecução dos objetivos traçados inicialmente. Um trabalho que representa bem mais do que a autorização administrativa para abrir e começar uma conta em nome do museu, mas que, na minha opinião, tem obrigatoriamente que ser feito com antecedência. E porquê a estratégia e planificação prévia?

A resposta resume-se numa palavra: avaliação. Ou seja, perceber qual é exatamente o contributo das redes sociais para que o museu possa cumprir o que está definido na sua missão. Um valor que, na minha opinião, não se pode medir unicamente na quantidade de 'seguidores' que a instituição tem nas redes sociais e que deve ter principalmente em conta o contributo destas novas tecnologias para adicionar significado às três vertentes (ou às relações existentes entre elas) desta equação: Museu, Coleções e Público. Sem definir estratégia e plano o que poderemos avaliar?

Por isso, creio que não é preciso ser-se especialista para criar um blogue, abrir uma página no facebook ou ter uma conta no twitter, mas precisamos muito de especialistas que nos orientem sobre como aproveitar e optimizar os recursos disponíveis a favor da nossa instituição e dos nossos objectivos. Mas claramente o problema também está nas instituições, que nem sempre reflectem sobre estas questões. Por isso, antes de aderir a todas as aplicações disponiveis na internet é necessário pensar numa estratégia concertada e humanizada, definida a partir de questões basilares: porquê, para quê e para quem? ${ }^{88}$

88 Matos (2013, p. 09-10) 


\section{5 | Conclusão}

\section{1 | Desafios e oportunidades}

A partir do diálogo entre texto e leitor e a ênfase no papel do espectador trazido pelo arcabouço teórico da Estética da Recepção (Tabela 2.1), se adiciona o potencial - trazido pelos meios eletrônicos - de aglutinar, indexar e relacionar informação (seção 2.2) relativa ao objeto de arte. Tendo como elemento-chave a participação efetiva do público e seu papel ativo na construção de significados - e levando em conta que tal participação ocorre, na atualidade, pela intermediação realizada através dos dispositivos móveis (seção 3.2) - é natural que surjam intermediações baseadas em tais ferramentas. O Museu funciona, per se, como ferramenta de comunicação; embora dependente, até o passado recente, de instalações físicas e, sempre que possivel, edifícios monumentais. Os meios oferecidos por uma civilização digital oferecem a oportunidade destes se tornaram transferiveis e transportáveis, ampliando

desta forma seu alcance e efetividade. À medida em que os acervos se tornam digitalizados, os objetos de arte se transformam em dados e os 
registros se tornam metadados (subseção 3.1.4). Existe aqui a oportunidade única, para os museus, de explorar e expandir tais recursos digitais.

É dentro deste cenário que se pretende, à guisa de conclusão, estabelecer alguns dos vínculos entre o usuário e seus mecanismos de acesso ao ambiente virtual, os modelos adotados pelo Museu para disponibilizar seu acervo (através das inúmeras possibilidades trazidas pela tecnologia) e as metodologias e ferramentas necessárias a esta consecução.

A passagem de um modelo de mão única baseado na experiência in situ para um contexto ex situ de múltiplos canais exige de todos os envolvidos no processo o entendimento dos caminhos possiveis, assim como a capacidade de tomar decisões que possam se justificar, em diversas instâncias, ao longo do tempo.

É razoável se considerar que o acervo represente um recurso amplamente inexplorado e potencialmente valioso para educadores, estudantes e público em geral, e não somente como parte de uma visita ao Museu. Também é razoável estabelecer proporções entre os recursos humanos e financeiros dispendidos para que tal acervo aumente seu âmbito de influência e o efetivo retorno de tal empreendimento.

A partir de tais considerações se chega à afirmação de que as experiências virtuais não podem se basear apenas em tecnologia; pois esta muda tão rapidamente que é praticamente impossivel acompanhála todo o tempo. O investimento de tempo e recursos em equipamentos corre o risco de se tornar ineficaz e desatualizado rapidamente. Todas as apostas em grande escala, neste contexto, se mostram perigosas; a abordagem mais eficaz, portanto, é aquela experimental em pequena escala - e, principalmente, gradual. Assim, ao invés de se conceber tais dispêndios, é preferível pensar no investimento em experiências digitais 
baseadas em conteúdo - as narrativas que o Museu deseja fornecer sobre seu acervo, seu lugar e suas histórias. As exposições virtuais passam a representar narrativas (seção 3.4); e os museus de hoje têm uma enorme gama de ferramentas à sua disposição para criá-las e, ao mesmo tempo, pedir aos seus visitantes que compartilhem e participem de tais histórias.

A chave, portanto, é transformar a intemporalidade de tais experiências em investimentos duradouros através da tecnologia e do uso da narrativa e do storytelling; pois estes parecem sobreviver muito bem à obsolescência, além de gerar o necessário envolvimento emocional com seus participantes.

O desafio que aqui se apresenta é fazer o Museu abraçar três conceitos principais, os quais podem representar ruptura com suas práticas e tradições:

Desintermediação Eliminação das barreiras entre os especialistas e o público do Museu

Informalidade Mudança no modelo de comunicação formal e tradicional Participação do Público Criação de canais físicos e virtuais para o diálogo entre todos os participantes, sejam estes internos ou externos (seção 2.1)

Todas estas mudanças simultâneas tornam o modelo existente incerto e instável; mas o que se pode depreender neste processo de desintermediação, informalidade e participação é o caminho potencial para um futuro novo e mais sustentável. Se o escopo aqui se apresenta correto, então a atual ameaça para os museus tradicionais é a forma com que apresentam o conhecimento que possuem e os canais de distribuição que priorizam. Há um longo caminho a ser trilhado e uma das diretivas mais importantes 
deste processo é muito simples: tratar os canais de participação do público com o máximo de seriedade.

\subsection{1 | O modelo tecnológico}

Pode-se afirmar que a tecnologia digital melhora, acelera e compartilha a capacidade e potencial dos museus em armazenar, analisar e disseminar suas informações e conhecimento acumulado.

Não faltam opções ao Museu para criar sua presença virtual. Desde a utilização de códigos QR (subseção 3.2.1) à criação de modelos grandiosos baseados em realidade aumentada ou virtual (subseção 3.2.2 e subseção 3.2.3), é possivel contar com uma enorme paleta de escolhas tecnológicas. Muitas delas irão, eventualmente, se traduzir em custo significativo e retorno abaixo do esperado.

A conclusão em relação aos investimentos, portanto, é que existem riscos significativos relacionados às tecnologias adotadas. E que, desta forma, se evitem projetos que possam representar sangria nos recursos financeiros ou demasiado comprometimento em tempo e recursos humanos. Não se deve buscar modelos de hardware ou soluções específicas enquanto não se contextualizar um modelo teórico focalizado em 2 eixos: conteúdo e experiência do visitante. A solução mais próxima do ideal é aquela que atende ambos requisitos.

Sob o ponto de vista técnico, a opção que atende ao requisito acima se baseia na utilização de código aberto (open source) (subseção 4.2.3.1) em todos os fluxos e etapas do processo de virtualização. É imperativo que se descartem soluções que possam criar dependência técnica e financeira em relação a fornecedores externos, assim como 
quaisquer alternativas que possuam segredos industriais, patentes e outros impedimentos de ordem técnica e jurídica que não permitam a disseminação e uso livres e adequados às múltiplas situações. Não é possível conciliar a definição do que seja um Museu - em sua essência aberto ao público (seção 4.1) - com mecanismos e tecnologias que sejam secretas ou opacas.

Muitas vezes, tal compromisso com a transparência irá acarretar pressões por parte de possíveis patronos e patrocinadores. Cabe ao Museu possuir assertividade e articulação em seu posicionamento, a fim de preservar sua liberdade e compromisso com o futuro.

É possivel se iniciar o caminho ex situ através de práticas simples e de custo insignificante. $O$ cerne da jornada rumo ao mundo virtual se localiza em frente àqueles que hoje são responsáveis pelo universo in situ, e se traduz na organização da informação, processos de catalogação e indexação precisos e eficientes (Figura 1) e a utilização de plataformas e processos que não funcionem como armadilhas para a obsolescência ${ }^{1}$. Ou seja, qualquer solução ligada aos processos de base deve contar com a utilização de código aberto em todas as suas ramificações. Cabe ao Museu estar cercado de consultores que não possuam vínculos ou interesses localizados em relação a determinadas empresas ou soluções, pois isto irá significar a adoção de soluções mais custosas ou ineficientes. Na verdade o Museu tem, à sua disposição, milhares de especialistas prontos a colaborar (a custo zero) nas decisões mais acertadas, através

1 "...so-called systems integration industry often relies on and promotes difficult-to-use, expensive, and unreliable systems to propagate a business model we call the Broken Box model. In this model software and hardware systems are locked out with proprietary technology that the museum doesn't have access to for maintenance and repair or the system uses a proprietary software base that the client cannot control or maintain. The business goal of the Broken Boxers is to create the necessity for long-term maintenance and content contracts with large institutions and to keep those institutions from developing internal capacity." Hossaini et al. (2017, p. 332) 
de fóruns e consultas via Internet. Além disto, e se considerando que todos os processos e metodologias estejam alinhados e estruturados, é possivel contar com o próprio público em diversas tarefas relacionadas à indexação.

\subsection{2 | Simplicidade}

As soluções simples e duradouras contemplam aquilo que, embora recente em relação à história do Museu, já possui considerável massa crítica dentro dos curtos períodos e fases da tecnologia. A resiliência inerente ao museu ao longo dos séculos - e sua capacidade de se adaptar às mudanças de contexto - deve estar presente como paradigma em todo o processo de planejamento.

O website do Museu (Figura D) pode ser considerado elemento essencial na busca de soluções; não devendo, em hipótese alguma, ser negligenciado. O apelo contemporâneo no sentido de tornar o navegador mais importante do que aplicativos esparsos e dificeis de se manter representa uma oportunidade valiosa. O website deve portanto funcionar, no dispositivo móvel, como o controle remoto do visitante.

Em relação ao aprendizado e arte-educação, a simplicidade também traz dividendos imediatos. É mais efetivo, por exemplo, que um programa de tela sensivel ao toque se concentre, inicialmente, em garantir a aprendizagem afetiva do conteúdo básico - ao invés de um mergulho profundo no tema.

Do mesmo modo, a interação com o espectador e o conteúdo gerado por este pode se dar tendo como ponto de partida declarações predeterminadas - ao invés de entradas abertas que exigem moderação. 


\subsubsection{Etapas}

O primeiro passo em uma experiência virtual é a identificação de três pontos-chave:

- objetivos temáticos

- experiência do visitante desejada

- objetivos de aprendizagem

Estes pontos devem ser definidos antes de qualquer decisão sobre os meios apropriados de expressão, independentemente do uso da tecnologia.

Em seguida, cabe a criação de equipes interdisciplinares para apoiar o projeto desde o início - pois é importante que haja diversidade de representação e que os membros do time inicial defendam seus pontos de vista em relação a conteúdo, design e operações; garantindo que, desta forma, um conjunto equilibrado de prioridades e necessidades seja representado e entendido - o que dará origem a resultados mais efetivos.

Por fim, é essencial ser realista em relação ao envolvimento com a experiência digital. Gerar para o visitante uma experiência que seja ambas cognitiva e emocionalmente envolvente é, muitas vezes, um exercício de restrição. É tentador sobrecarregar a experiência com conteúdo ou complexidade pelo simples fato de que a tecnologia pode lidar com isso.

\subsection{4 | Planejamento}

Neste ponto a dissertação contempla mais perguntas do que respostas. Pois cada caso, embora relacionado aos demais, possui características únicas que demandam respostas customizadas. 
O desejo de introduzir novas tecnologias nos museus existentes requer planejamento e metodologias aptas a julgar o mérito dos projetos. As oportunidades associadas às tecnologias digitais estão acopladas à mudança das expectativas dos visitantes. Todo cuidado é pouco no sentido de evitar investimentos onerosos em plataformas técnicas que se tornem impopulares ou obsoletas. Deve aqui se enfatizar a importância de ambas flexibilidade e colaboração ao longo do processo de desenvolvimento. Não é possível, simplesmente, replicar modelos funcionais utilizados no passado e utilizá-los, intactos, na metodologia associada ao mundo digital. Merece consideração o fato de que a maior parte dos investimentos digitais exigem inovações em gestão e, ao invés de diminuir esforços dispendidos, os aumentam significativamente.

Ao iniciar o planejamento de qualquer projeto virtual, cabe ao Museu identificar seus objetivos para o projeto e fazer a avaliação dos recursos necessários para atingir esses objetivos. A consulta a fornecedores externos pode ser vital para se obter apoio na avaliação da viabilidade do orçamento, da disponibilidade da tecnologia e do plano de manutenção a longo prazo.

Algumas das perguntas cabíveis nesta etapa são:

- Que tipo de experiência digital queremos ter?

- Quais são os resultados que queremos ver?

- Qual é o nosso público-alvo para esta experiência?

- Temos a equipe e experiência para fazer isso internamente, ou precisamos de ajuda externa (ou seja, um consultor ou produtor externo)?

- Quem servirá na equipe de desenvolvimento?

- O orçamento é adequado?

- Caso contrário, onde os fundos podem ser adquiridos? 
- Os visitantes serão cobrados por essa experiência?

- Os visitantes serão obrigados a ter seus próprios dispositivos, ou estes serão fornecidos?

- A experiência é satisfatória para as pessoas que desejam usar dispositivos móveis?

- Existe um plano para lidar com a falha do equipamento?

- Quais são os custos a longo prazo (manutenção, atualização etc.)?

- A tecnologia está disponível ou precisamos de um produto personalizado?

- Temos o conteúdo exigido internamente, ou isso precisará ser fornecido em outro lugar?

- Existem preocupações (que devemos estar cientes) em relação à segurança, privacidade, direitos autorais e ética?

Estimativas conservadoras afirmam existir mais de cinquenta e cinco mil museus no mundo, espalhados em 202 países $^{2}$, principalmente na Europa e nas Américas, e o número continua crescendo à medida em que a Ásia e a África desenvolvem seus museus. Para grande parte deles a tecnologia pode ser o diferencial entre a relevância e a obscuridade.

\subsection{5 | Reprodutibilidade}

Ainda existe uma clara diferença entre exposições digitais em meios digitais - como por exemplo em um website (ex situ) - e objetos físicos em uma coleção (in situ); mas os avanços diários na tecnologia modificam, pouco a pouco, tal equilíbrio. Dada a crescente produção artística que nasce diretamente digital, novas questões surgem em relação à reprodutibilidade inerente à tecnologia e sua capacidade de gerar uma cópia 
idêntica ao original; pois não existem critérios objetivos que definam o que seja um "original" digital em relação à sua réplica digital. Também não existe, neste contexto, nenhuma "aura" a ser atrofiada (seção 2.4). As novas questões surgidas são:

- Se o museu cria uma cópia idêntica do objeto de arte, pode esta substituir o original?

- Se positivo, em que momento isto deveria ocorrer?

- Como se gerenciam, neste cenário, direitos autorais e autenticidade da obra?

\section{2 | À guisa de conclusão}

O Museu se caracteriza como entidade que coleta e exibe contêineres, os quais se mostram diferentes para cada contexto ou cultura; enquanto eles próprios são o grande recipiente. O desafio que se colocou, desde o surgimento do primeiro destes recipientes na história humana, foi o modelo de exibição, no espaço disponível, de tal conteúdo ao seu público (in situ). E cada época soube aproveitar os recursos existentes ao seu dispor.

Os museus possuem, na contemporaneidade, a oportunidade sem precedente de atender (e participar de forma ativa) de um mundo digital com fome de experiência. As exposições e mostras no espaço físico (in situ) atuam como o início de um processo que se expande por uma enorme rede capilar, a qual abrange o trabalho documentado de artistas, curadores, designers, educadores, historiadores, críticos e demais integrantes da máquina museológica. A oportunidade dada ao Museu de digitalizar e promover acesso não somente às suas coleções - 
como também às pesquisas, relatórios, interpretações, catálogos e outros documentos ligados ao processo (ex situ) - permite a conexão daquele com o restante do globo terrestre de forma direta. A resposta do público também se concretiza de forma direta através destes mesmos instrumentos. É possivel ao Museu adotar modelos de compartilhamento, crowdsourcing e outras estratégias do mundo digital para ampliar a abrangência de seu acervo e escopo educacional em comunidades que, anteriormente, jamais teriam acesso a tais recursos. Através das redes sociais é possivel criar eventos ao vivo que permitem ao seu público conversar diretamente com artistas, curadores e outros especialistas. Ao adotar padrões comuns e universais, baseados em software de código aberto, o Museu acaba por vincular seus recursos ao objetivo maior de criar uma base de conhecimento universal, alcançando de tal forma a integração entre o in situ e o ex situ e funcionando, verdadeiramente, como elemento-chave entre o objeto de arte e seus usuários. 


\section{Referências}

ANDERSON, M. L. Museums of the future: The impact of technology on museum practices. Daedalus, JSTOR, v. 128, n. 3, p. 129-162, 1999. Disponivel em: <http://ftp.columbia.edu/itc/anthropology/schildkrout/ 6353/client_edit/week14/anderson.pdf>. (2 ocorrências, pp. 76 e 122)

ARTAUD, A. The Theatre and Its Double, trans. Oneworld Classics Limited, 1958. ISBN 978-1-84749-078-0. Disponível em: <http://eu.oheuaqui.com/ 2†A9GsL>. (p. 57)

AURELIANO, L. G.; COAN, S.; FILHO, E. R. Panorama da sustentabilidade nos museus. Blucher Design Proceedings, v. 2, n. 9, p. 3725-3737, 2016. Disponivel em: <https://eu.oheuqqui.com/2mcwxnE>. (p. 91)

BARTHES, R. Rhetoric of the image. na, 1977. Disponivel em: <https://faculty. georgetown.edu/irvinem/theory/Barthes-Rhetoric-of-the-image-ex.pdf>. (p. 48)

BENJAMIN, W. Petite histoire de la photographie. Études Photographiques, Études photographiques, n. 1, nov 1996. Disponivel em: <http: //etudesphotographiques.revues.org/99>. (p. 28)

BENJAMIN, W. The work of art in the age of mechanical reproduction. (S.I.): Penguin UK, 2008.

BEVILACQUA, G. M. F. Museus como serviços de informação. Seminário Serviços de Informação em Museus, p. 11-17, 2016. (p. 111)

BINA, E. D. Investimento financeiro em museus: experiência brasileira. In: ICOM - PORTUGAL. 2011. Disponível em: <https://eu.oheuaqui.com/ 2meoala>. (p. 98)

BODÊ, E. C.; MANINI, M. P. Formatos de arquivo para preservação de documentos digitais. 2013. Disponivel em: <http://enancib.ibict.br/index. php/enancib/ixenancib/paper/viewFile/3120/2246>. (2 ocorrências, pp. 109 e 110)

BOISSIER, J.-L. Machines à communiquer faites oeuvres. Qu'est-ce la communication, Paris, 1991. (p. 35) 
BOURRIAUD, N. Esthétique relationnelle. Dijon: Les Presses du Réel, 2000. (p. 159)

BOURRIAUD, N. Pós-produção: como a arte reprograma o mundo contemporâneo. São Paulo: Martins Fontes, 2009. (4 ocorrências, pp. 28, 29,31 e 35)

BRETT, G. Lygia clark: in search of the body. Art in America, v. 82, p. 56-63, 1994. (p. 29)

CANCLINI, N. G. Imaginários Culturais da Cidade: informação, espetáculo e desconhecimento. In: ITAÚ CULTURAL. Enciclopédia Itaú Cultural de Arte e Cultura Brasileiras. São Paulo: Itaú Cultural, 2008. p. 15-31. ISBN 978-85-7979-060-7. (p. 34)

CARD, S. K. et al. 3book: a scalable 3d virtual book. In: ACM. CHI'04 Extended Abstracts on Human Factors in Computing Systems. 2004. p. 1095-1098. Disponível em: <https://pdfs.semanticscholar.org/ba13/ 511 ble5ccf396a8ec5997e98998f7f3d2bbb.pdf>. (p. 47)

CASAGRAS, R. the inclusive model for the internet of things report. EU Project, n. 216803, p. 16-23, 2011. (2 ocorrências, pp. 62 e 352)

CAUQUELIN, A. Arte contemporânea: uma introdução. São Paulo: Martins Fontes, 2005. (p. 35)

CEIA, C. E-Dicionário de Termos Literários. 2015. Disponível em: <http://www.edtl.com.pt/business-directory/6479/ horizonte-de-expectativas-erwartungshorizont-/>. (p. 342)

CHIANESE, A.; PICCIALLI, F. Designing a smart museum: When cultural heritage joins iot. In: IEEE. Next Generation Mobile Apps, Services and Technologies (NGMAST), 2014 Eighth International Conference on. (S.I.), 2014. p. 300-306. (p. 62)

CHRISTENSEN, J. R. Four steps in the history of museum technologies and visitors' digital participation. Mediekultur: Journal of media and communication research, v. 27, n. 50, p. 23, 2011. Disponível em: <https://tidsskrift.dk/index.php/mediekultur/article/viewFile/2982/4612>. (8 ocorrências, pp. 42, 43, 46, 47, 48, 61, 79 e 81)

CHU, Y.-C. et al. Realistic books: A bizarre homage to an obsolete medium? In: IEEE. Digital Libraries, 2004. Proceedings of the 2004 Joint ACM/IEEE Conference on. 2004. p. 78-86. Disponível em: <http://researchcommons.waikato.ac.nz/bitstream/handle/10289/1339/ 04-CYC-DB-IHW-Realisticbooks. pdf? sequence=1\&isAllowed=y>. (p. 47)

COSTA, A. M. Nicolaci-da; PIMENTEL, M. Sistemas colaborativos para uma nova sociedade e um novo ser humano. Sistemas colaborativos. PIMENTEL, M.; FUKS, H.(Orgs.). Rio de Janeiro: Elsevier, 201 1. Disponível em: 
<http://sistemascolaborativos.uniriotec.br/wp-content/uploads/sites/18/ 2017/09/SC01-SociedadeHumano.pdf>. (p. 126)

COSTA, H. Palavras da Curadora. São Paulo, 2013. Disponível em: <http://www.mac.usp.br/mac/EXPOSI\%C7OES/2013/fronteiras_incertas/ curadora.htm>. (p. 36)

COSTA, M. H. M. d. S. Estética da recepção e teoria do efeito. Universidade de Maringá, 2014. Disponível em: <https://abiliopacheco.files.wordpress. com/2011/11/est_recep_teoria_efeito.pdf>. (2 ocorrências, pp. 14 e 344)

CROSSICK, G.; KASZYNSKA, P. Understanding the value of arts \& culture: The AHRC Cultural Value Project. Taylor \& Francis, 2016. Disponível em: <http://www.ahrc.ac.uk/documents/publications/ cultural-value-project-final-report/>. (2 ocorrências, pp. 91 e 92)

DANKS, M. et al. Interactive storytelling and gaming environments for museums: The interactive storytelling exhibition project. In: SPRINGER. International Conference on Technologies for E-Learning and Digital Entertainment. 2007. p. 104-115. Disponível em: <http: //barmonger.org/speciale/Referencer/Interactive\%20Storytelling\% 20and\%20Gaming\%20Environments\%20for\%20Museums\%20-\%20The\% 2OInteractive\%20Storytelling\%20Exhibition\%20Project.pdf>. (p. 80)

DANTO, A. C. The end of art: A philosophical defense. History and theory, Wiley Online Library, Middletow, v. 37, n. 4, p. 127-143, 1998. (p. 18)

DERRICK, M. R.; STULIK, D.; LANDRY, J. M. Infrared Spectroscopy in Conservation Science: Scientific tools for conservation. 1999. Disponivel em: <https://www.getty.edu/conservation/publications_resources/pdf_ publications/pdf/infrared_spectroscopy.pdf>. (p. 17)

DIDI-HUBERMAN, G. ○ que vemos, o que nos olha. São Paulo: Ed. 34, 1998. Prefácio de Stéphane Huchet; tradução de Paulo Neves. ISBN 9788573261134. (p. 28)

DUFRENNE, M. Is art language? Philosophy Today, v. 14, n. 3, p. 190-200, 1970. (p. 16)

DUFRENNE, M. Estética e Filosofia. 3. ed. São Paulo: Editora Perspectiva, 1972. (Coleção Debates). (p. 19)

ECO, U. Obra Aberta: Forma e Indeterminação Nas Poéticas Contemporâneas. (S.I.): Perspectiva, 1968. (p. 19)

ESPINÓS, A. Museums on Twitter: Three case studies of the relationship between a museum and its environment. 2015. Disponivel em: <https://eu.oheuaqui.com/2CQ6Og5>. (3 ocorrências, pp. 128, 132 e 133) 
FERREIRA, G.; COTRIM, C. Escritos de artistas: anos 60/70. In: _. Rio de Janeiro: Zahar, 2006. cap. Discursos, Advertência, Deslocamento, Inserções em circuitos ideológicos, p. 142-149. (p. 30)

FERREZ, H. D. Documentação museológica: teoria para uma boa prática. Cadernos de Ensaio, n. 2, p. 64-74, 1994. (2 ocorrências, pp. 100 e 122)

FILHO, D. d. L. O museu no século xxi ou o museu do século xxi? Revista do Fórum Permanente: espaço aberto ao pensamento coletivo, 2005. Disponível em: <http://www.forumpermanente.org/revista/edicao-0/ textos/o-museu-no-seculo-xxi>. (p. 33)

GADAMER, H.-G. Truth and Method. 2. ed. London: New York: Continuum, 2004. (p. 16)

GENETTE, G. Paratexts: Thresholds of interpretation. (S.I.): Cambridge University Press, 1997. v. 20. (p. 48)

GONÇALVES, L. R. Entre cenografias: o museu e a exposição de arte no século XX. (S.I.): EDUSP, 2004. (p. 20)

GONÇALVES, T. L. Apostila de museologia I. (S.I.), 2005. (p. 83)

GROSSMANN, M.; MARIOTTI, G. O museu de arte hoje. São Paulo: Hedra, 2011 . Disponivel em: <http://www4.unirio.br/museologia/textos/o_museu_ dearte_hoje.pdf>. (p. 31)

GUARNIERI, W. R. C. Textos e contextos de uma trajetória profissional. São Paulo: Pinacoteca do Estado, Secretaria de Estado da Cultura, v. 1, 2010. Disponível em: <http://eu.oheuaqui.com/2x5oa0C>. (p. 85)

GUY, D. La société du spectacle. Galiimard, Paris, 1992. (p. 36)

HALL, S. The television discourse-encoding and decoding.: Encoding and decoding in television discourse. In: . (S.I.): Hutchinson, 1974. p. 128-138. (2 ocorrências, pp. 24 e 26)

HEBDIGE, D. Subculture and style. (S.I.): Routledge, 1979. (p. 37)

HOSSAINI, A. et al. Manual of Digital Museum Planning. (S.I.): Rowman \& Littlefield Publishers, 2017. ISBN 9781442278967. (19 ocorrências, pp. 94, 95, $97,98,101,102,103,104,115,120,121,122,127,129,130,133,135,136$ e 143)

INVALUABLE. American Attitudes Toward Art. 2016. Disponível em: <http://www.adamjamesbutcher.com/wp-content/uploads/2014/11/ American-Attitudes-Toward-Art-Survey_Invaluable-2.pdf>. (p. 129)

ISER, W. The act of reading: A Theory of Aesthetic Response. (S.I.): JHU Press, 1980. (p. 23) 
ISER, W. O ato da leitura: uma teoria do efeito estético. São Paulo: Editora, v. 34, 1996. (p. 18)

JAUSS, H. R.; BAHTI, T.; MAN, P. D. Toward an aesthetic of reception. (S.I.): University of Minnesota Press Minneapolis, 1982. v. 2. (p. 20)

KOWAL, K. C. Mercator, hands-on: the use of "experiential"technology for atlases. e-Perimetron, v. 1, n. 3, p. 221-229, 2006. Disponível em: <http://www.e-perimetron.org/vol_1_3/Kowal.pdf>. (p. 47)

KRAUSS, R. E. Reinventing the medium. Critical Inquiry, University of Chicago Press, Chicago, v. 25, n. 2, p. 289-305, 1999. (p. 36)

LÉVY, P. (A) Inteligência coletiva: por uma antropologia do ciberespaço,. (S.I.): Edições Loyola, 2007. (2 ocorrências, pp. 29 e 34)

LIMA, F. R. B.; SANTOS, P. L. V.; SEGUNDO, J. E. S. Padrão de metadados no domínio museológico. Perspectivas em Ciência da Informação, v. 21, n. 3 , p. 50-69, 2016. Disponível em: <http://portaldeperiodicos.eci.ufmg.br/ index.php/pci/article/viewFile/2639/1789>. (p. 111)

LINCOLN, Y. S. Insights into library services and users from qualitative research. Library \& information science research, Elsevier, v. 24, n. 1, p. 3-16, 2002. Disponível em: <http://www.sciencedirect.com/science/ article/pii/S0740818801001074>. (p. 41)

LONDERO, P.; FAIRBANKS-HARRIS, T.; WHITMORE, P. M. An open-source, internet-of-things approach for remote sensing in museums. Journal of the American Institute for Conservation, Routledge, v. 55, n. 3, p. 166-175, 2016. Disponivel em: <http://dx. doi.org/10.1080/01971360.2016.1217671>. (p. 62)

MARTELETO, R. M. O lugar da cultura no campo de estudos da informação: cenários prospectivos. Contemporaneidade, p. 13, 2007. Disponível em: <http://www3.eca.usp.br/sites/default/files/form/ata/pos/ppgci/ publicacoes\%20-\%20informacaoContemporaniedade(1).pdf\#page=13>. (p. 90)

MARTINS, C. et al. O uso da informação nos museus. Biblos, v. 30, n. 2 , p. 52-63, 2017. Disponivel em: <https://www.seer.furg.br/biblos/article/ viewFile/5606/4436>. (3 ocorrências, pp. 91, 92 e 120)

MATOS, A. Estamos ligados?: Museus e redes sociais. n. 21, p. 09-10, 2013. Disponivel em: <http://icom-portugal.org/multimedia/info\%20ll-21_ Jun-Ago 13.pdf>. (2 ocorrências, pp. 137 e 138)

MEIRA, S. M. Museus virtuais. In: FEA/USP. $2^{\circ}$ Contecsi - Congresso Internacional de Gestão da Tecnologia e Sistemas de Informação. São Paulo: FEA/USP, 2005. v. 2, n. 2005, p. 186. (2 ocorrências, pp. 16 e 100) 
MEIRA, S. M. Museus virtuais: Uma nova dimensão de divulgação de artes visuais? Revista MVSEV, Revista MVSEV, Porto, Portugal, v. 15, p. 19-33, 2007. (p. 38)

MEIRA, S. M. A anti-aesthetica contemporânea. In: Metáforas da Arte. São Paulo: MacUsp, Programa de Pós-Graduação em Estética e História da Arte, 2008. p. 47. (p. 37)

MEIRA, S. M. As novas relações da estética. In: XXX Colóqio do Comitê Brasileiro de História da Arte. Rio de Janeiro: Museu Nacional de Belas Artes, 2010. p. 1300-1308. (2 ocorrências, pp. 27 e 28)

MICHAUD, Y. L'art à l'état gazeux, essai sur le triomphe de l'esthétique. Pluriel art, Hachette, Paris, p. 169, 2003. (p. 28)

MIGHALI, V. et al. Innovative iot-aware services for a smart museum. In: ACM. Proceedings of the 24th International Conference on World Wide Web. (S.I.), 2015. p. 547-550. (p. 79)

NETO, A. L. dos S. et al. Tecnologias de dados abertos para interligar bibliotecas, arquivos e museus: um caso machadiano. Transinformação, SciELO Brasil, v. 25, n. 1, 2013. Disponível em: <http://www.scielo.br/pdf/tinf/v25n1/a08v25nl>. (p. 118)

NICHOLLS, A.; PEREIRA, M. P.; SANI, M. LEM. The learning museum. Report. Vol. 1: The virtual museum. 2012. 92 p. Disponivel em: <http://online.ibc.regione.emilia-romagna.it///libri/pdf/LEM_reportl_ theVirtualMuseum.pdf>. (p. 41)

O'DOHERTY, B. Inside the white cube: the ideology of the gallery space. (S.I.): Univ of California Press, 1999. (p. 28)

OITICICA, H. Situação da vanguarda no brasil (proposta 66). In: Aspiro ao grande labirinto. Rio de Janeiro: Rocco, 1986. p. 110-112. Disponível em: <http://openlibrary.org/books/OL233851 1M/Aspiro_ao_grande_labirinto>. (p. 37)

PINTO, M. M. Gestão de documentos e meio digital: um posicionamento urgente e estratégico. Gestão do conhecimento, da informação e de documentos em contextos informacionais, 2013. Disponivel em: <https://repositorio-aberto.up.pt/bitstream/10216/70837/2/77026.pdf>. (2 ocorrências, pp. 100 e 113)

PUTNAM, R. D. Bowling alone: The collapse and revival of American community. Simon and Schuster, 2001. Disponivel em: <https://books. google.com.br/books?hl=en\&lr=\&id=rd2ibodep7UC\&oi=fnd\&pg= PA 13\&dq=bowling+alone+putnam+book\&ots=G5EcpYoiWO\&sig= aPMAvqs 19z3XSVvQ2vOAeYNkxQg\#v=onepage\&q=bowling\%20alone\% 20putnam\%20book\&f=false>. (p. 132) 
ROGERS, E. M. Diffusion of innovations. Simon and Schuster, 2010. Disponivel em: <https://books.google.co.uk/books?hl=en\&lr=\&id=v1ii4QsB7jlC\&oi= fnd\&pg=PR 15\&dq=everett+rogers\#v=onepage\&q=everett\%2Orogers\&f= false>. (p. 76)

ROHDEN, S. F. et al. Consumo colaborativo: economia, modismo ou revolução? Desenvolve: revista de gestão do Unilasalle. Canoas, RS. Vol. 4, n. 2 (jul. 2015), p. 9-24, 2015. Disponível em: <https: //www.lume.ufrgs. br/bitstream/handle/10183/148056/001001183.pdf>. (p. 92)

SANTAELLA, L. Da cultura das mídias à cibercultura: o advento do pós-humano. Revista FAMECOS: mídia, cultura e tecnologia, v. 1, n. 22, 2005. Disponivel em: <http://www.followscience.com/content_uploads/ 57412e380b1b24829609ce395256b901/803/da_cultura_das_midias_a_ cibercultura_o_advento_dos_pos_humano.pdf>. (p. 35)

SANTAELLA, L. Linguagens líquidas na era da mobilidade. (S.I.): Paulus, 2007. (p. 27)

SCHULTZ, M. K. A case study on the appropriateness of using quick response (qr) codes in libraries and museums. Library \& Information Science Research, Elsevier, v. 35, n. 3, p. 207-215, 2013. Disponível em: <https: //ora.ox.ac.uk/objects/uuid:e9033b5e-d4ca-40c2-a1b4-8edd833f481e/ datastreams/bin8d92aca7-6a25-4b6d-af40-65291daa925b>. (p. 55)

SCHWEIBENZ, W. The"virtual museum": New perspectives for museums to present objects and information using the internet as a knowledge base and communication system. ISI, v. 34, p. 185-200, 1998. Disponível em: <http://eu. oheuaqui.com/2gPOZ6f>. (3 ocorrências, pp. 89, 90 e 99)

SKOV, M. The reinvented museum: Exploring information seeking behaviour in a digital museum context. Royal School of Library and Information Science, 2009. Disponivel em: <http://vbn.aau.dk/files/77302501/ MetteSkovThesis.pdf>. (2 ocorrências, pp. 101 e 122)

STUEDAHL, D.; LOWE, S. Design experiments with social media and museum content in the context of the distributed museum. Nordes, v. 1, n. 5, p. 118-119, 2013. (2 ocorrências, pp. 32 e 38)

TALLON, L. On audio tours. Engage Review, v. 18, p. 1-7, 2006. Disponível em: <http://www.engage.org/downloads/1AA029E3_18.\%20LO\%C3\%AFc\% 20Tallon.pdf>. (p. 49)

TAVARES, M. Fundamentos estéticos da arte aberta à recepção. ARS (São Paulo), scielo, v. 1, p. 31 - 43, 12 2003. ISSN 1678-5320. Disponível em: <http://www.scielo.br/scielo.php?script=sci_arttext\&pid= S1678-53202003000200003\&nrm=iso>. (2 ocorrências, pp. 18 e 19) 
WALSH, A. Qr codes-using mobile phones to deliver library instruction and help at the point of need. Journal of information literacy, v. 4, n. 1 , p. 55-65, 2010. Disponível em: <https://ojs.lboro.ac.uk/JIL/article/view/ LLC-V4-I1-2010-1/1975>. (p. 55)

WALSH, P. Rise and fall of the post-photographic museum: Technology and the transformation of art. Theorizing digital cultural heritage, p. 29, 2007. Disponivel em: <http://mitpress.universitypressscholarship.com/view/10. 7551/mitpress/9780262033534.001.0001/upso-9780262033534-chapter-2? print=pdf>. (5 ocorrências, pp. 44, 45, 46, 77 e 78)

WIENNER, N. Cibernética e sociedade. (S.I.): Ed. Cultrix São Paulo, 1968. (p. 23) 


\section{A Gráficos e tabelas}

\begin{tabular}{|c|c|}
\hline Ambientação & Virtualização \\
\hline $\begin{array}{l}\text { As ambientações contemporâ- } \\
\text { neas no espaço do museu, res- } \\
\text { ponsáveis pela visualidade e va- } \\
\text { lor cultural - desde a escrita de } \\
\text { seu conceito (projeto de curado- } \\
\text { ria) à mise en scène (solução ou } \\
\text { produto) - se inserem na cultura. } \\
\text { A forma relacional da arte con- } \\
\text { temporânea, descrita nos anos } \\
90 \text { como uma teoria da forma } \\
\text { por Bourriaud (2000), demonstrava } \\
\text { que a prática artística teria se } \\
\text { encaminhado a criar situações } \\
\text { com uma experiência vivencial. } \\
\text { Como nas interações humanas, } \\
\text { configura relações intersubjetivas } \\
\text { de maneira a tornar a arte um } \\
\text { lugar de encontro, de ligação e } \\
\text { de convivência com o sensivel. } \\
\text { Os sistemas e estratégias escolhi- } \\
\text { dos pelos artistas hoje sinalizam } \\
\text { outros sentidos na cadeia inten- } \\
\text { ção - enunciação - interpreta- } \\
\text { ção ao tomar ações e histórias } \\
\text { visíveis, como figuração de con- } \\
\text { ceitos. A encenação das formas }\end{array}$ & $\begin{array}{l}\text { A experiência física de se ob- } \\
\text { servar o objeto de arte tem se } \\
\text { tornado cada vez mais mediada } \\
\text { pela tecnologia, com tendência } \\
\text { à intensificação, dado o aumento } \\
\text { constante do acesso à Internet } \\
\text { pelos aparelhos. Embora os mu- } \\
\text { seus criem, muitas vezes, defini- } \\
\text { ções problemáticas em relação } \\
\text { à experiência ou interação do } \\
\text { espectador com o objeto de arte } \\
\text { - e procurem reforçar tais prescri- } \\
\text { ções através do projeto, da arqui- } \\
\text { tetura, textos e materiais didáticos } \\
\text { e também pelo posicionamento } \\
\text { específico da obra no contexto } \\
\text { espacial - é necessário se levar } \\
\text { em conta o papel mutante da } \\
\text { tecnologia na experiência e frui- } \\
\text { ção da obra. Ao se aceitar tal } \\
\text { papel, o entendimento em rela- } \\
\text { ção à recepção e emissão da } \\
\text { arte em espaços físicos e virtuais } \\
\text { adquire mais nuanças e a visão } \\
\text { do processo se torna mais crítica } \\
\text { e precisa. }\end{array}$ \\
\hline
\end{tabular}
de arte contemporânea ativa o espectador a significar o simbólico nos vestígios expressos espacialmente. A cenografia ambiental em situações arte envolve e mergulha o observador numa quasesensação que inquieta-o a com- 
Timeline: Virtual Reality

$1935\left\{\begin{array}{l}\text { Stanley G. Weinbaum writes the short story Pygmalion's } \\ \text { Spectacles, describing a system of virtual reality based on }\end{array}\right.$ special glasses worn by the user, with holographic recordings that included smell and touch

Market launch of the View-Master stereo viewer

Morton Heilig creates the concept of Teatro Experiencial - taking into account all the spectator's senses in relation to what happens on the screen or stage

The science of Computing defines virtual reality as what appears to the senses by means of software

Morton Heilig builds his Sensorama, a prototype of what he called Experience Theatre: a way of involving the spectator through kinaesthesia (awareness through movement). He showed five short films, accompanied by activation of the senses (vision, sound, smell and touch) Ivan Sutherland, with the help of Bob Sproull, creates the first HMD a virtual reality eyewear/helmet assembly for use in immersive simulations Myron Krueger creates the term virtual reality

1978 The Massachusetts Institute of Technology (MIT) creates a system for hipermedia and virtual reality, named Aspen Movie Map, simulating a walk through the city of Aspen, Colorado, in three different modes: summer, winter and polygons 
1980 Atari, Inc. launches the videogame Battlezone, which 3D graphics to place the player in a virtual universe

ATARI founded a virtual reality research laboratory; it was closed two years later

Jaron Lanier and Thomas Zimmerman, former employees of ATARI, created VPL Research, a company to operate in technology related to virtual reality

Artificial Reality Lab: pioneering initiatives of Myron Krueger

Disneyland offered its visitors Star Tours, a flight simulator based on the Star Wars - the result of a collaboration between the producer George Lucas and Walt Disney Imageneering Virtual World Entertainment opened the first BattleTech in Chicago, based on the SIMNET system of network simultaneous training, using cabins functioning as an immersive and interactive console Electronic Visualization Laboratory created the first whole-room immersive display, called Cave Automatic Virtual Environment (CAVE). This enabled spectators to see their own bodies in relation to the other people present at the location Sega Enterprises, Ltd. launched the Sega VR and the Mega Drive console. This used an LCD screen in the visor, stereo headphones and inertial sensors able to detect and react to movements of the head 
Computer Gaming World magazine predicted mass availability of virtual reality systems by 1994 In a US military laboratory, Louis Rosenberg created the Virtual Fixtures, system, which used an exoskeleton of the upper part of the body, enabling the user to have a physical experience of virtual reality in 3D that was very convincing at that time Launch of the videogame DOOM é lançado pela id Software, by id Software, introducing what came to be known as first-person shooter games, and establishing the multiple-participant model as the dominant category in computer games

Emergence of a specific language for virtual objects: Virtual Reality Modelling Language (VRML)

First appearance of the term virtual reality in science fiction, in Damien Broderick's short story Judas Mandala Apple Inc. launches the 360-degree visualisation system called QuickTime Virtual Reality

In Japan, Nintendo launches the The Virtual Boy console Inauguration of the first Gameworks Gallery, a joint project of film producer Steven Spielberg, Universal Studios, SEGA and Dreamworks SKG based on virtual worlds 


\begin{tabular}{|c|c|}
\hline 2007 & $\begin{array}{l}\text { Google Inc. launches Google Street View, giving panoramic } \\
\text { views of an endlessly increasing number of locations around the } \\
\text { world }\end{array}$ \\
\hline 2010 & $\begin{array}{l}\text { First prototype produced of Oculus Rift, designed by Palmer } \\
\text { Luckey, with previously unprecedented resources }\end{array}$ \\
\hline 2014 & $\begin{array}{l}\text { Facebook, Inc. acquires Oculus VR for } 2 \text { billion dollars } \\
\text { Sony Corporation announces the Morpheus Project (or } \\
\text { PlayStation VR), a virtual reality kit to be used in a console of the } \\
\text { videogame PlayStation } \\
\text { GooGLE presents Google Cardboard, a low-cost do-it- } \\
\text { yourself-style stereo viewer, made out of cardboard and using } \\
\text { the user's smartphone }\end{array}$ \\
\hline 2015 & $\begin{array}{l}\text { High-Tech Computer Corporation and Valve Corporation } \\
\text { announce their virtual reality kit HTC Vive and its related control } \\
\text { devices }\end{array}$ \\
\hline 2016 & $\begin{array}{l}\text { Disney Studios and the Salvador Dali Museum open the } \\
\text { exhibition Disney and Dali: Architects of the Imagination, in } \\
\text { which the spectator, using an HMD, can literally enter the } \\
\text { painter's works. Even for those located far away from the } \\
\text { museum, an application is made available on the Internet giving } \\
\text { the same immersive experience }\end{array}$ \\
\hline
\end{tabular}

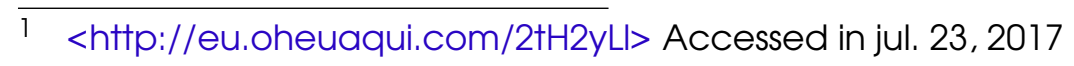


Smithsoniam Museum, in partnership with Autodesk, launch a high-resolution 3D scan of the command module Columbia (Apollo 11). This highly detailed model, allows anyone with an Internet connection to explore the entire craft including its intricate interior $^{2}$

Magic Leap, a mysterious company developing a revolutionary virtual reality model through fields of light projected directly onto the human retina, is valued at 4.5 billion dollars

The Rosa Parks Experience at the National Underground Railroad Freedom Center is a new virtual reality experience that brings history to life. Visitors wear Samsung Gear VR devices and sit on augmented bus seats, where they see, hear, and feel a virtual experience through the eyes of Rosa Parks on December 1, 1955 There are at least 230 companies dedicated to development of products related to virtual reality. FACEBOOK, for example, has 400 employees working on development of its VR wearable glasses; and Google, Apple, Amazon.com, Inc., Microsoft Corporation, Sony, Samsung Group - and many others have teams exclusively dedicated to development of technologies related to this area 


\section{B | Reproduções/Transcritos}




\section{Art in America em 01/10/2014}

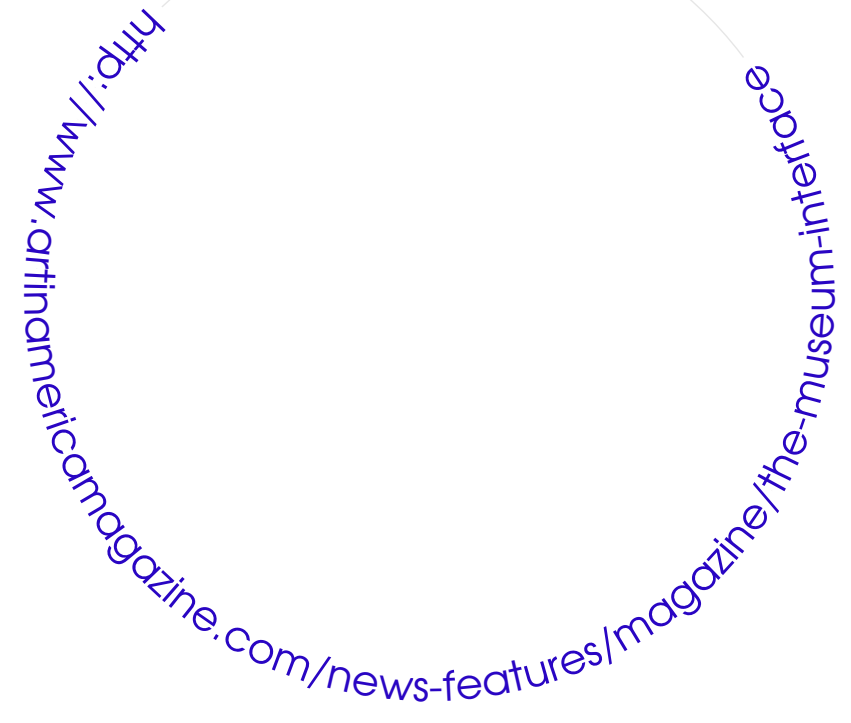




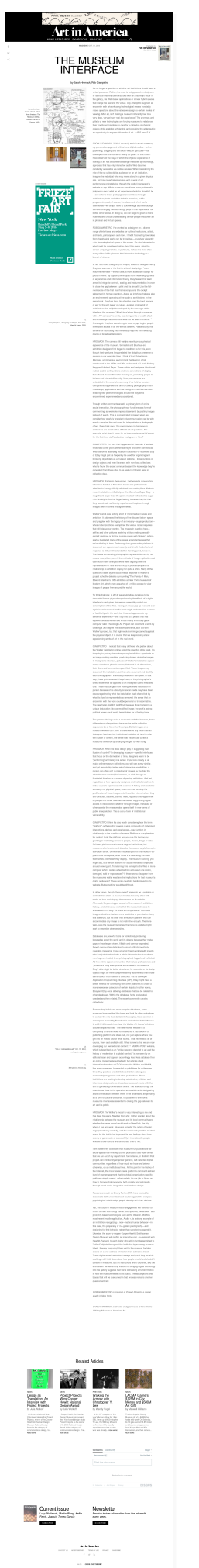

\section{The Museum Interface}

\section{by Sarah Hromack, Rob Giampietro}

It's no longer a question of whether art institutions should have a virtual presence. Rather, the onus is being placed on designers to facilitate meaningful interactions with art that might occur in the gallery, via Web-based applications or in new hybrid spaces that merge the real and the virtual. Any attempt to augment an encounter with artwork using technological means invariably raises questions about the values we assign to certain modes of viewing. After all, isn' $\dagger$ visiting a museum inherently tied to a very deep, very primary real-life experience? The promises and pitfalls of new technologies are forcing museums to rebalance their traditional mandates to care for a collection of physical objects while enabling scholarship and providing the wider public an opportunity to engage with works of art. - R.G. and S.H.

SARAH HROMACK While I currently work in an art museum, my personal engagement with art and digital media - online publishing, blogging and the social Web, in particular - has developed over the course of nearly 20 years. In that time, I have observed the ways in which the 
physical experience of looking at art has become increasingly mediated by technology, a process that has only intensified as the Web became constantly accessible via mobile devices. When considering the role of the so-called digital audience for an art institution, I imagine the individual who may never stand in a given physical site, yet may nevertheless engage with a work of art, performance or installation through the digital interface of a website or app. While museums sometimes make problematic judgments about what an art experience should or shouldn't be - and enforce those pedagogical prescriptions through architecture, texts and other didactic materials, public programming and, of course, the placement of art works themselves - we simply have to acknowledge and even accept the ever-changing role technology plays in that experience, for better or for worse. In doing so, we can begin to glean a more nuanced and critical understanding of how people encounter art in physical and virtual spaces.

ROB GIAMPIETRO I've worked as a designer on a diverse range of interfaces and websites for cultural institutions, artists, architects, philosophers and more. I find it fascinating how ideas from the physical world can be translated - crudely or elegantly - to the metaphorical space of the screen. I'm also interested in what could be considered native about this space, what the screen uniquely provides. In particular, I share the view of so many of the field's pioneers that interactive technology is a branch of cinema

In his 1955 book Designing for People, industrial designer Henry Dreyfuss was one of the first to write of designing a "man-machine interface" - in that case, a more accessible cockpit for pilots in WWII. By applying techniques from the emerging fields of ergonomics and information theory, Dreyfuss and his team aimed to integrate controls, seating and instrumentation in order to close the gap between a pilot and his aircraft. Like the full-room scale of the first mainframe computers, the cockpit subsumed 
its human operator - it was an interface that was also an environment, operating at the scale of architecture. In the same book, Dreyfuss turns his attention from the hard lessons of war to the soft power of culture, evoking another bit of architecture that might be reshaped by the new logic of the interface: the museum. "A half-hour's tour through a museum with a TV camera," he wrote, "can bring to life a wealth of art and knowledge that could otherwise not be seen in months." 1 Once again Dreyfuss was aiming to close a gap, to give people immediate access to all the world's artwork. Paradoxically, his scheme for facilitating this immediacy required the mediating device of broadcast television.

HROMACK The camera still weighs heavily on our physical experience of the museum. Surrealist and Bauhaus-era exhibition designers first began to condition us for this, even though their gestures long predated the ubiquitous presence of screens in our everyday lives. I think of Kurt Schwitters's Merzbau, an immersive environment the German artist constructed in the 1920s and '30s, or the work of László Moholy-Nagy and Herbert Bayer. These artists and designers introduced radical spatial configurations and new conventions of display that altered the conditions for viewing art, prompting people to behave and interact differently. Now, our cameras are embedded in the smartphones many of us hold as constant companions; by presenting and circulating photography in still-novel ways, applications such as Instagram and Vine are also enabling new phenomenologies around the way art is encountered, experienced and considered.

Though written comments are still a primary form of online social interaction, the photograph now functions as a form of commenting, as we make implied statements by posting images instead of words. This is a complicated prospect when we consider how woefully prevalent miscommunication can be with words - imagine the vast room for inter- 
pretation a photograph offers. If we think about this phenomenon in the museum context we are faced with a difficult set of questions. For example, what does it mean for us to encounter an artist's work for the first time via Facebook or Instagram or Vine?

GIAMPIETRO I'm sure that happens a lot! I wonder if we fast-forwarded a few years wether we might find other commercial Web platforms absorbing museum functions. For example, Etsy or Ebay might just as frequently be used for organizing and browsing object data as a museum website. I know curators of design objects and even librarians with non-book collections who've found the expert communities and the knowledge they've generated from these sites to be useful in filling in gaps in collection data.

HROMACK Earlier in the summer, I witnessed a conversation wherein a handful of New York-based arts professionals admitted to having willfully refrained from seeing Kara Walker's recent installation, A Subtlety, or the Marvelous Sugar Baby - a magnificent larger-than-life sphinx made of refined white sugar - in Brooklyn's Domino Sugar factory, because they felt that they had already sufficiently experienced the piece through images seen in others' Instagram feeds.

Walker's work was nothing short of monumental in scale and ambition. It addressed the history of the disused factory space and grappled with the legacy of an industry - sugar production - whose labor practices exemplified the vicious racial inequities that still plague our country. The images in question here - selfies and other pictures featuring visitors making sexually explicit gestures or striking juvenile poses with Walker's sphinx-starkly illustrated many of the issues around art access that we're alluding to here. Technology has given us the platform to document our experiences instantly and at will; the behavioral response is still unrefined and often hair-triggered, 
however. The issues surrounding photographic representation are by no means new, either, even if the methods of image replication and distribution have changed: we've been arguing over the representation of race and ethnicity in photography and its relationship to exhibition display for quite a while. Many of the questions raised by the social media response to Walker's project echo the debates surrounding "The Family of Man," Edward Steichen's 1955 exhibition at New York's Museum of Modern Art, which drew a quarter of a million people to view images of people from around the world.

To think that now, in 2014, we would allow ourselves to be dissuaded from a physical experience by the effects of a digital interface is sad, given that we can ostensibly control our consumption of the Web. Seeing an image pop up over and over again in various social media feeds might make me feel a sense of familiarity with the work, but it cannot approximate my sensorial experience - and I say this as a person that has experienced augmented and virtual reality in military-grade computer labs! The Google Art Project can document a work by creating a 360 degree interactive panorama, as it did with Walker's project, but that high-resolution image cannot supplant the physical object. It is crucial that we keep looking at and experiencing works of art in the real world.

GIAMPIETRO I noticed that many of those who posted about the Walker installation online noted the specifics of its scent. It's tempting to portray the contemporary installation - spectacle as an image-making machine, producing dozens of similar images. In Instagram's interface, pictures of Walker's installation appear stamp-sized on a phone's screen, flattened in all dimensions, their likers and commenters quantified. These images may document the installation, but they also document and identify each photographer's individual presence in the space. In that way, these 
pictures assert the primacy of the photographer's direct experience as opposed to an Instagram user's mediated one. Those discouraged from visiting Walker's installation in person because of its ubiquity on social media may have been discouraged not by what the installation itself offered but by what its flood of representations removed: the sense that an encounter with the work could be personal or transformative. The new hyper-visibility is difficult because it can transform a unique installation into commodified image; the work's lasting political power could easily be mistaken for a fleeting trend.

The person who logs on to a museum's website, however, has a different sort of experience because the entire collection appears to be at his or her fingertips. Digital images on a museum website can't offer transcendence any more than an Instagram feed can, but institutional websites do tend to offer the illusion of control, the sense that visitors can curate a museum's collection by arranging images to their liking.

HROMACK What role does design play in suggesting that illusion of control? In developing museum - specific interfaces that focus on the delineation of time, designers seem to be "performing" art history in a sense: if you look closely at all major online museum collections, you will see a very similar, and yet remarkably limited set of interactive possibilities. A person can often sort a collection of images by the date the artworks were created, for instance, or click through an illustrated timeline as a means of parsing art history. And yet, regardless of how vigorously designers and institutions strive to imbue a user's experience with a sense of history and academic accuracy - of physical space, even - no one can stop the proliferation of those images onto the wider Internet where they are collected, stacked, starred, liked, reposted and regrammed by people into other, unknown narratives. By granting digital access to its collection, 
whether through images, metadata or other assets, the museum also opens itself to new forms of public interpretation. This is a true form of institutional vulnerability.

GIAMPIETRO I think it's also worth considering how the term "platform"software that powers a wide community of networked interactions, devices and experiences - may function in relationship to the question of access. Platform is a euphemism for control: build the platform and you rule the territory by granting or restricting access to people, places, things or data. Software platforms are to some degree institutional, but museums also function and describe themselves as platforms, in a broader sense. Sometimes this description of the museum-as-platform is conceptual, other times it is describing the walls themselves and the art they display. The museum building, you might say, is a certain platform for social interaction organized around viewing art. Transferring this concept to the Web is more complex: what if certain artworks from a museum are stolen, damaged, sold or repossessed? If these works disappear from the museum's walls, what are the implications for that museum's digital audiences? These works could still be displayed on its website. But something would be different.

In other cases, though, there doesn't appear to be a problem or contradiction at all - a museum hosts a traveling show with works on loan and displays those works on its website. Afterward, they are logged as part of the museum's exhibition history. And what about works that the museum chooses to write about on a blog? Or show as comparisons? You could imagine situations that are more restrictive or permissive along this spectrum, but it's clear that a museum platform that can accommodate any image is not restrictive enough. The more wall - less the museum becomes, the more its website might start to resemble other websites. 
Databases are powerful tools for collectively producing knowledge about the world and its objects because they make gaps in knowledge evident, fillable and comma-separated. Expert communities dedicated to visual artifacts inevitably resemble museums. I have an artist friend working with insects who has just stumbled onto a whole Internet subculture where rare bugs are traded, bred, photographed, logged and trafficked. Ad-hoc online expert communities that include professionals and "prosumers" may even provide some benefits to museums: Etsy's data might be better structured, for example, or its design objects might be more comprehensively documented than those same objects in a museum's collection. Via its developer Application Programming Interface (API), Ebay might have a better method for connecting with other platforms to create a more networked collection of certain objects. In other words, Ebay and Etsy excel at being databases that can be related to other databases. Within the database, facts are isolated, checked and then related. The expert community curates collectively.

Even as they build ever-more complex databases, some museums have resisted this trend and look for other metaphors to explain the role their digital interfaces play. Most common is a metaphor favored by French critic and scholar André Malraux. In a 2012 Metropolis interview, the Walker Art Center's Andrew Blauvelt explained that, "The new Walker website is a completely different model for museums. It has become a publishing platform and ideas hub, not just a place where you get info on how to visit or what to visit. That information is, of course, there and available still. What is new is that we are now developing our own editorial content." 2 MOMA's POST website, which is described as an "online resource devoted to art and the history of modernism in a global context," is overseen by an editorial team and appears accordingly less like a database than an online magazine 
populated with full articles about international modern art. 3 Of course, the Walker and MoMA, like many museums, have acted as publishers for quite some time: they produce and distribute exhibition catalogues, membership magazines and other publications. These institutions are seeking to develop scholarship, criticism and interviews designed to be shared across social media with the aim of generating conversation online. The interface brings the operator as close to the operation as possible while designating a site of mediation between them. If we understand art primarily as a form of cultural discourse, it's possible to envision a museum's interface as essential to closing the gap between its art and its public.

HROMACK The Walker's model is very interesting to me and has been for years. Reading from afar, I often wonder about the relationship between the museum and its local community and whether the same model would work in New York, the city where I live and work. Museums consider the notion of public engagement very carefully, and the social web provides an ideal space for the institution to project its own feelings about how openly or generously or successfully it interacts with people-whether those notions are functionally true or not.

I am not entirely convinced that museum-run publications-as-socialspaces-the Whitney Stories publication and video series that we run out of my department, for instance, or MoMA's Post project-can unilaterally engender genuine, self-selected digital communities, regardless of how much we hope and believe otherwise, on an institutional level. At this point in the history of the Internet, the major social media platforms command a sheer level of user engagement that individual, organization-specific platforms simply cannot, unfortunately; it's our job to figure out how to harness that monopoly, both socially and technically, through smart social integration and interface design. 
Researchers such as Sherry Turkle (MIT) have worked for decades to both understand and caution against the complex psychological relationships people develop with their devices.

Yet, the future of museum visitor engagement will continue to mimic current technology trends: smartphones, "wearables" and proximity-based technologies such as the iBeacon. MoMA's most recent mobile application, Audio +, is a strong example of an institution recognizing a now - natural human behavior - in this case, the propensity of in - gallery photography and designing for that behavior rather than sanctioning against it. Likewise, the soon-to-reopen Cooper Hewitt, Smithsonian Design Museum will proffer an interactive pen, co-designed with Hewlett-Packard, to each visitor who will in turn be permitted to "collect" objects throughout the institution by scanning museum labels, thereby "capturing" their visit to the museum for later access on a web address printed on their admission ticket. These digital experiments don't always work, and they certainly challenge still-held ideas about how people should and shouldn't behave in museums. But art institutions aren't churches, and the enthusiasm we see among visitors for bringing digital technology into the gallery suggests that we're witnessing a transformation in how the museum relates to its public. The assumptions and biases that will be overturned in that process remains another question entirely.

ROB GIAMPIETRO is principal at Project Projects, a design studio in New York.

SARAH HROMACK is director of digital media at New York's Whitney Museum of American Art. 
D | Site do Tate Museum em 18/04/2013

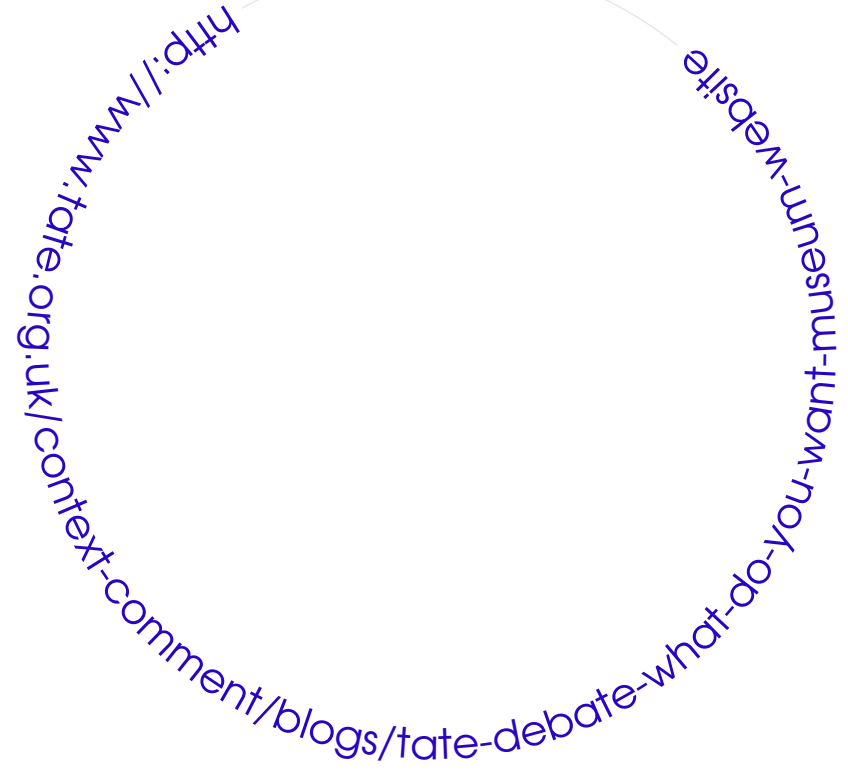




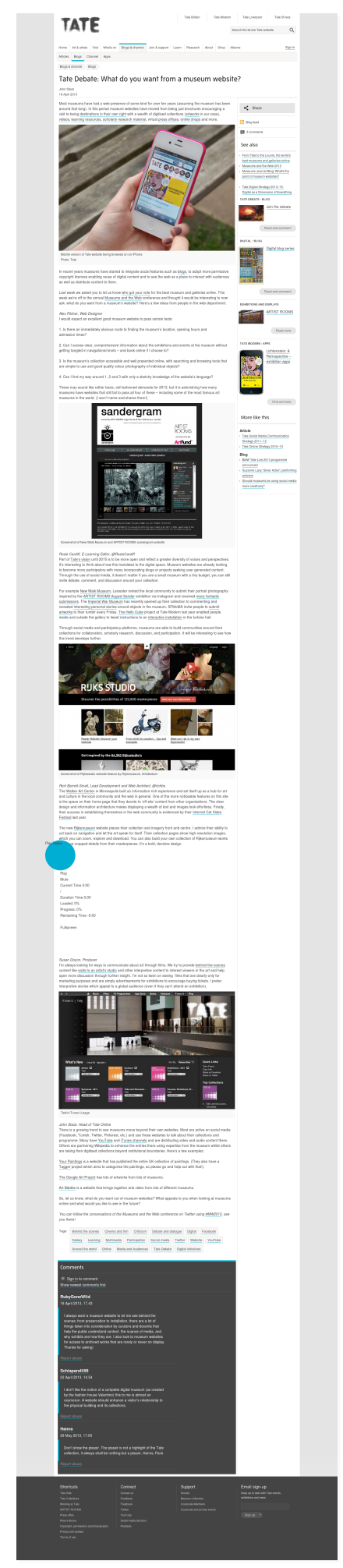

\section{Tate Debate: What do you want from a museum website?}

\section{John Stack}

Most museums have had a web presence of some kind for over ten years (assuming the museum has been around that long). In this period museum websites have moved from being just brochures encouraging a visit to being destinations in their own right with a wealth of digitised collections (artworks in our case), videos, learning resources, scholarly research material, virtual press offices, online shops and more.

In recent years museums have started to integrate social features such as blogs, to adopt more permissive copyright licences enabling reuse of digital content and to see the web as a place to interact with audiences as well as distribute content to them.

Last week we asked you to let us know who got your vote for the best museum and galleries online. This week we're off to the annual Museums and the Web conference and thought it would be interesting to now ask: what do you want from a museum's website? Here's a few ideas from people in the web department:

Alex Pilcher, Web Designer 
I would expect an excellent good museum website to pass certain tests:

1. Is there an immediately obvious route to finding the museum's location, opening hours and admission times?

2. Can I access clear, comprehensive information about the exhibitions and events at the museum without getting tangled in navigational knots - and book online if I choose to?

3. Is the museum's collection accessible and well presented online, with searching and browsing tools that are simple to use and good quality colour photography of individual objects?

4. Can I find my way around 1, 2 and 3 with only a sketchy knowledge of the website's language?

These may sound like rather basic, old fashioned demands for 2013 , but it is astonishing how many museums have websites that still fail to pass all four of these - including some of the most famous art museums in the world. (I won't name and shame them!)

Rosie Cardiff, E-Learning Editor, @RosieCardiff

Part of Tate's vision until 2015 is to be more open and reflect a greater diversity of voices and perspectives. It's interesting to think about how this translates to the digital space. Museum websites are already looking to become more participatory with many incorporating blogs or projects seeking user generated content. Through the use of social media, it doesn't matter if you are a small museum with a tiny budget, you can still invite debate, comment, and discussion around your collection.

For example New Walk Museum, Leicester invited the local community to submit their portrait photography inspired by the ARTIST ROOMS August Sander exhibition via Instagram and received many fantastic sub- 
missions. The Imperial War Museum has recently opened up their collection to commenting and revealed interesting personal stories around objects in the museum. SFMoMA invite people to submit artworks to their tumblr every Friday. The Hello Cube project at Tate Modern last year enabled people inside and outside the gallery to tweet instructions to an interactive installation in the turbine hall.

Through social media and participatory platforms, museums are able to build communities around their collections for collaboration, scholarly research, discussion, and participation. It will be interesting to see how this trend develops further.

Rich Barrett-Small, Lead Development and Web Architect, @richbs

The Walker Art Center in Minneapolis built an information-rich experience and set itself up as a hub for art and culture in the local community and the web in general. One of the more noticeable features on this site is the space on their home page that they devote to 'off-site' content from other organisations. The clear design and information architecture makes displaying a wealth of text and images look effortless. Finally, their success in establishing themselves in the web community is evidenced by their Internet Cat Video Festival last year.

The new Rijksmuseum website places their collection and imagery front and centre. I admire their ability to cut back on navigation and let the art speak for itself. Their collection pages show high-resolution images, which you can zoom, explore and download. You can also build your own collection of Rijksmuseum works and save cropped details from their masterpieces. It's a bold, decisive design.

Susan Doyon, Producer 
I'm always looking for ways to communicate about art through films. We try to provide behind-the-scenes content like visits to an artist's studio and other interpretive content to interest viewers in the art and help open more discussion through further insight. I'm not so keen on seeing films that are clearly only for marketing purposes and are simply advertisements for exhibitions to encourage buying tickets. I prefer interpretive stories which appeal to a global audience (even if they can't attend an exhibition).

John Stack, Head of Tate Online

There is a growing trend to see museums move beyond their own websites. Most are active on social media (Facebook, Tumblr, Twitter, Pinterest, etc.) and use these websites to talk about their collections and programme. Many have YouTube and iTunes channels and are distributing video and audio content there. Others are partnering Wikipedia to enhance the entries there using expertise from the museum whilst others are taking their digitised collections beyond institutional boundaries. Here's a few examples:

Your Paintings is a website that has published the entire UK collection of paintings. (They also have a Tagger project which aims to catagorise the paintings, so please go and help out with that!).

The Google Art Project has lots of artworks from lots of museums.

Art Babble is a website that brings together arts video from lots of different museums.

So, let us know, what do you want out of museum websites? What appeals to you when looking at museums online and what would you like to see in the future? 


\section{E Blog Seb Chan em 03/12/2011}

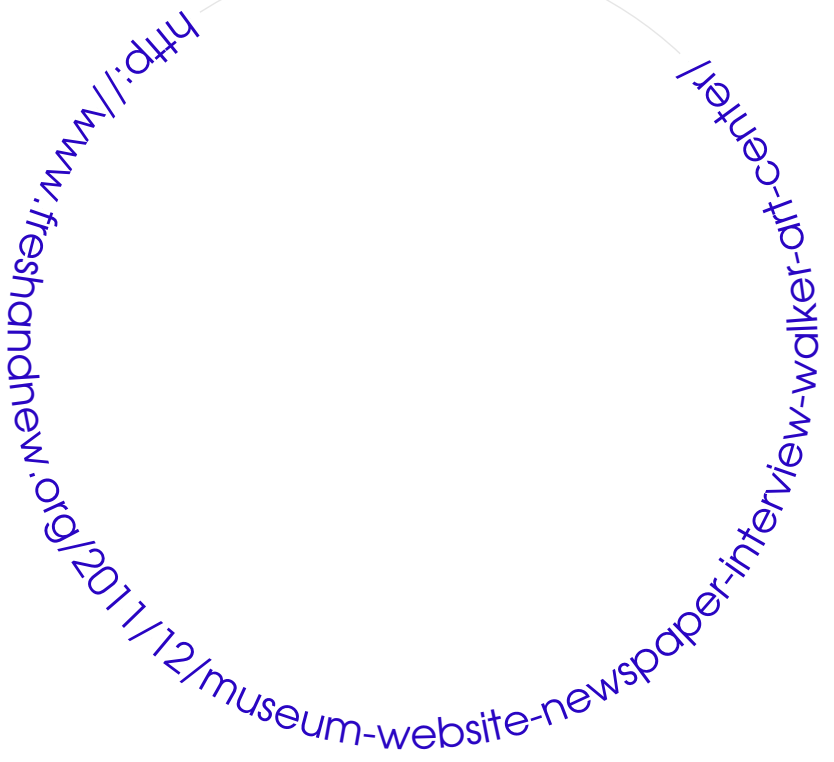




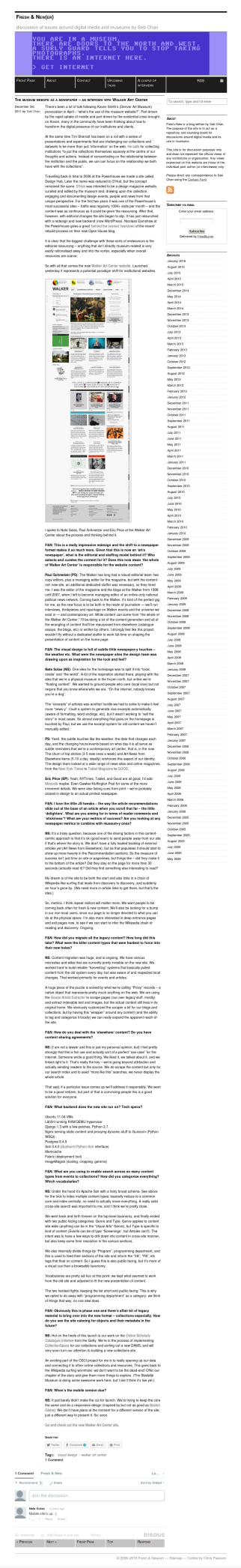

\section{The museum website as a newspaper \\ (an interview with Walker Art Center)}

There's been a lot of talk following Koven Smith's (Denver Art Museum) provocation in April - "what's the use of the museum website?". Part driven by the rapid uptake of mobile and part driven by the existential crisis brought on Koven, many in the community have been thinking about how to transform the digital presence of our institutions and clients.

At the same time Tim Sherratt has been on a roll with a series of presentations and experiments that are challenging our collections and datasets to be more than just 'information' on the web. He calls for collecting institutions "to put the collections themselves squarely at the centre of our thoughts and actions. Instead of concentrating on the relationship between the institution and the public, we can can focus on the relationship we both have with the collections".

Travelling back in time to 2006 at the Powerhouse we made a site called Design Hub. Later the name was reduced to D'Hub, but the concept remained the same. D'Hub was intended to be a design magazine website, curated and edited by the museum and, drawing upon the collection, 
engaging and documenting design events, people and news from that unique perspective. For the first two years it was one of the Powerhouse's most successful sites - traffic was regularly 100K+ visits per month - and the content was as continuous as it could be given the resourcing. After that, however, with editorial changes the site began to slip. It has just relaunched with a redesign and new backend (now WordPress). Nicolaas Earnshaw at the Powerhouse gives a great 'behind the scenes' teardown of the recent rebuild process on their new Open House blog.

It is clear that the biggest challenge with these sorts of endeavours is the editorial resourcing - anything that isn' $\dagger$ directly museum-related is very easily rationalised away and into the vortex, especially when overall resources are scarce.

So with all that comes the new Walker Art Center website. Launched yesterday it represents a potential paradigm shift for institutional websites.

I spoke to Nate Solas, Paul Schmelzer and Eric Price at the Walker Art Center about the process and thinking behind it.

F\&N: This is a really impressive redesign and the shift to a newspaper format makes it so much more. Given that this is now an 'art/s newspaper', what is the editorial and staffing model behind it? Who selects and curates the content for it? Does this now mean 'the whole of Walker Art Center' is responsible for the website content?

Paul Schmelzer (PS): The Walker has long had a robust editorial team: two copy editors, plus a managing editor for the magazine, but with the content-rich new site, an additional dedicated staffer was necessary, so they hired me. I was the editor of the magazine and the blogs at the Walker from 1998 until 2007, when I left to become managing editor of an online-only national political news network. Coming back to the Walker, it's 
kind of the perfect gig for me, as the new focus is to be both in the realm of journalism - we'll run interviews, thinkpieces and reportage on Walker events and the universe we exist in - and contemporary art. While content can come from "the whole of the Walker Art Center," I'll be doing a lot of the content generation and all of the wrangling of content that'll be repurposed from elsewhere (catalogue essays, the blogs, etc) or written by others. I strongly feel like this project wouldn't fly without a dedicated staffer to work full-time on shaping the presentation of content on the home page.

F\&N: The visual design is full of subtle little newspaper-y touches - the weather etc. What were the newspaper sites the design team was drawing upon as inspiration for the look and feel?

Nate Solas (NS): One idea for the homepage was to split it into "local, onsite" and "the world". A lot of the inspiration started there, playing with the idea that we're a physical museum in the frozen north, but online we're "floating content". We wanted to ground people who care (local love) but not require that you know where/who we are. "On the internet, nobody knows you're a dog".

The "excerpts" of articles was another hurdle we had to solve to make it feel more "news-y". I built a system to generate nice excerpts automatically (aware of formatting, word endings, etc), but it wasn't working to "sell the story" in most cases. So almost everything that goes on the homepage is touched by Paul, but we use the excerpt system for old content we haven't manually edited.

PS: Yeah, the subtle touches like the weather, the date that changes each day, and the changing hours/events based on what day it is all serve as subtle reminders that we're a contemporary art center, that is, in the now. 
The churn of top stories (3-5 new ones a week) and Art News from Elsewhere items (5-10 a day, ideally) reinforces this aspect of our identity. The design team looked at a wide range of news sites and online magazines, from the New York Times to Tablet Magazine to GOOD.

Eric Price (EP): Yeah, NYTimes, Tablet, and Good are all good. I'd add Monocle maybe. Even Gawker/Huffington Post for some of the more irreverent details. We were also taking cues from print - we're probably closest in design to an actual printed newspaper.

F\&N: I love the little JS tweaks - the way the article recommendations slide out at the base of an article when you scroll that far - the little 'delighters'. What are you aiming for in terms of reader comments and 'stickiness'? What are your metrics of success? Are you looking at any newspaper metrics to combine with museum-y ones?

NS: It's a tricky question, because one of the driving factors in this content-centric approach is that it's ok (good even) to send people away from our site if that's where the story is. We don't have a fully loaded backlog of external articles yet (Art News from Eleswhere), but as that populates it should start to show up more heavily in the Recommendation sections. So the measure of success isn't just time on site or pageviews, but things like - did they make it to the bottom of the article? Did they stay on the page for more than 30 seconds (actually read it)? Did they find something else interesting to read?

My dream is of the site to be both the start and also links in a chain of Wikipedia-like surfing that leads from discovery to discovery, and suddenly an hour's gone by. (We need more in-article links to get there, but that's the idea.) 
So, metrics. I think repeat visitors will matter more. We want people to be coming back often for fresh \& new content. We'll also be looking for a bump in our non-local users, since our page is no longer devoted to what you can do at the physical space. I'm also more interested in deep entrance pages and exit pages now, to see if we can start to infer the Wikipedia chain of reading and discovery. Ongoing.

F\&N: How did you migrate all the legacy content? How long did this take? What were the killer content types that were hardest to force into their new holes?

NS: Content migration was huge, and is ongoing. We have various microsites and wikis that are currently pretty invisible on the new site. We worked hard to build reliable "harvesting" systems that basically pulled content from the old system every day, but was aware of and respected local changes. That worked primarily for events and articles.

A huge piece of the puzzle is solved by what we're calling "Proxy" records - a native object that represents pretty much anything on the web. We are using the Goose Article Extractor to scrape pages (our own legacy stuff, mostly) and extract indexable text and images, but the actual content still lives in its original home. We obviously customized the scraper a bit for our blogs and collections, but by having this "wrapper" around any content (and the ability to tag and categorize it locally) we can really expand the apparent reach of the site.

F\&N: How do you deal with the 'elsewhere' content? Do you have content sharing agreements?

NS: (I am not a lawyer and this is just my personal opinion, but) I feel pretty strongly that this is fair use and actually sort of a perfect "use case" for the internet. Someone wrote a good thing. We liked it, we talked 
about it, and we linked right to it. That's really the key - we're going beyond attribution and actually sending readers to the source. We do scrape the content but only for our search index and to seed "more like this" searches, we never display the whole article.

That said, if a particular issue comes up we'll address it responsibly. We want to be a good netizen, but part of that is convincing people this is a good solution for everyone.

F\&N: What backend does the new site run on? Tech specs?

Ubuntu 1 1.04 VMs LibVirt running KVM/QEMU hypervisor Django 1.3 with a few patches, Python 2.7. Nginx serving static content and proxying dynamic stuff to Gunicorn (Python WSGI). Postgres 8.4.9 Solr 3.4.0 (Sunburnt Python-Solr interface) Memcache Fabric (deployment tool) ImageMagick (scaling, cropping, gamma)

F\&N: What are you using to enable search across so many content types from events to collections? How did you categorise everything? Which vocabularies?

NS: Under the hood it's Apache Solr with a fairly broad schema. See above for the trick to index multiple content-types: basically reduce to a common core and index centrally, no need to actually move everything. A really solid cross-site search was important to me, and I think we're pretty close.

We went back and forth forever on the top-level taxonomy, and finally ended with two public-facing categories: Genre and Type. Genre applies to content site-wide (anything can be in the "Visual Arts" Genre), but Type is specific to kind of content (Events can be of type "Screenings", but Articles can't). The intent was to have a few ways to drill down into 
content in cross-site manner, but also keep some finer resolution in the various sections.

We also internally divide things by "Program", programming department, and this is used to feed their sections of the site and inform the "VA", "PA", etc tags that float on content. So I guess this is also public-facing, but it's more of a visual cue than a browsable taxonomy.

Vocabularies are pretty ad-hoc at this point: we kept what seemed to work from the old site and adjusted to fit the new presentation of content.

The two hardest fights: keeping the list short and public-facing. This is why we opted to do away with "programming department" as a category: we think of things that way, no one else does.

F\&N: Obviously this is phase one and there's affair bit of legacy material to bring over into the new format - collections especially. How do you see the site catering for objects and their metadata in the future?

NS: Hot on the heels of this launch is our work on the Online Scholarly Catalogue Initiative from the Getty. We're in the process of implementing Collectionspace for our collections and sorting out a new DAMS, and will very soon turn our attention to building a new collections site.

An exciting part of the OSCl project for me is to really opening up our data and connecting it to other online collections and resources. This goes back to the Wikipedia surfing wormhole: we don't want to be the dead-end! Offer our chapter of the story and give them more things to explore. (The Stedelijk Museum is doing some awesome work here, but I don't think it's live yet.)

F\&N: When's the mobile version due? 
NS: It just barely didn'† make the cut for launch. We're trying to keep the core the same and do a responsive design (inspired by but not as good as Boston Globe). We don't have plans at the moment for a different version of the site, just a different way to present it. So: soon. 
F Koven Smith em 11/04/2011

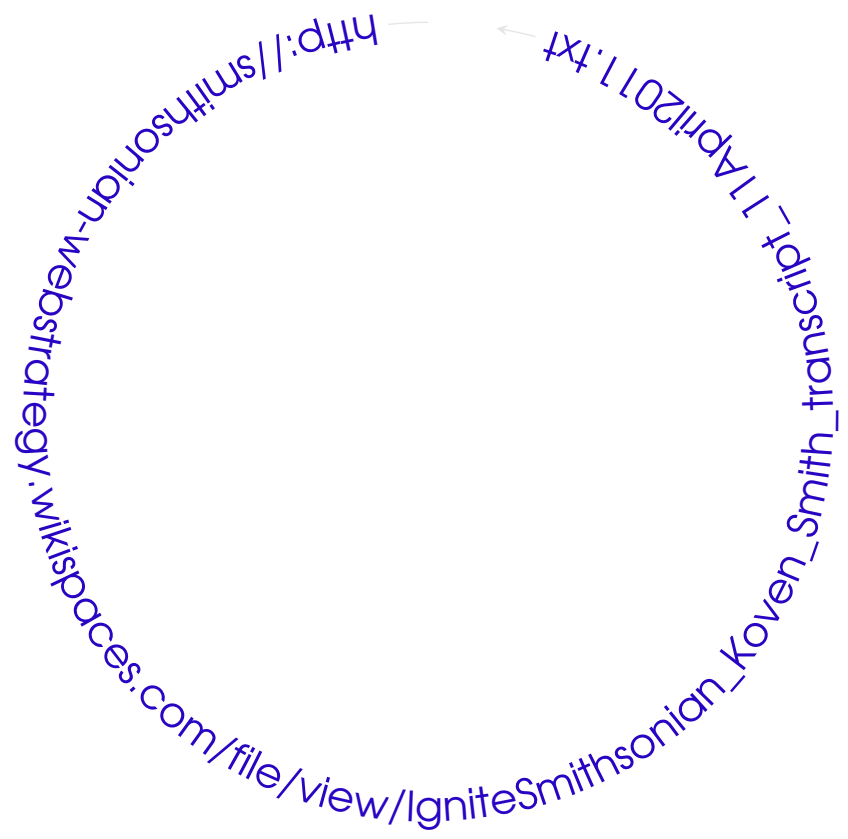


Transcript of Koven Smith's Ignite Smithsonian talk.

Presented 11 April 2011 at the Smithsonian Institution.

Project homepage:

http://smithsonian-webstrategy.wikispaces.com/lgnite+Smithsonian

Transcription done by Sue Cairns, courtesy of Koven Smith

Date this transcription was published: 6 May 2011

Yeah, I don't think I believe in museum websites anymore. I'm not really sure why we keep building them. We keep building them based on the same model over and over without really having any sense of whether that model even works now, much less if it ever worked.

Here's a good example from the J. Paul Getty Museum. Great, great museum website, except what I feel like we're doing basically is building a really kick-ass wagon when what we really need is the automobile. So what's another example of this phenomenon that I'm talking about? Another thing that I hate, if you ask. Online collections. Why do we do these? No one can explain to me exactly what we expect to get out of an online collection. It seems like we do it to satisfy ourselves as museums, but we really can never explain who are we serving with these. Who's using these? Oh, researchers-this is always the answer we get. It's good for scholarly research. This is a great example from the Indianapolis Museum of Art's collection page, which is a wonderful online collections site. However, how much research are you really doing here? You don't link to external sources, you don't get other things. So what we usually (come back to is) that, well, the collections online are good because they encourage people to come to the museum. 
However, this is a great quote from James Davis at Tate. Here's something you never hear people say - (the pictures on) Flickr (are) great, but we don't require people to come in to a physical building in order to see them. In fact, so here's what I'm thinking -basically once we get the locations, hours and maps out of the way, I'm not exactly sure what we're supposed to build for our museum websites. But it certainly to me feels like... what we really need to do here is disambiguate the physical visit from the digital experience completely so that we can actually allow our websites to sing.

And there's a whole new slew of technologies that make this possible. Facebook's Open Graph, RDFa, Linked Data, the Semantic Web. All these things that allow us to basically reach out into the world and grab content from wherever it may exist and put it together, onto our own sites. And this allows us to basically do what I would call agile content development? quick development, redevelopment, deployment, redeployment and coagulation of content in different forms. This allows us to basically create an experience that means limitless content, with limitless kinds of experiences. We're not any longer limited by the sort of arbitrary boundary of the physical museum wall, that we (currently) translate into the digital environment.

However, what this does mean...is that we actually have to focus on enabling experience online rather than simply focusing on producing content. In fact, I think this is one of the hardest realities that I think we in museums are going to have to face over the next few years. We've spent so long saying "content, content, content, we need to produce more content." No, what we actually need to do is enable access to content, whether that content's being produced by us, or produced by others. And so...what we need to do is answer questions that people are actually asking. However you may feel about content farms like eHow, wikiHow, 
whatever, what they do do very well is they find questions that people are actually looking for, and answer them directly and completely. And so...by combining content from lots of sources, we can actually really focus on what people want, and worry just exclusively about making that content that's unique to us.

And everybody asks when we say "Ok, well what if, if now we're just pointing to content that just exists out there and not producing it ourselves won't we lose our trust, won'† we lose our authority?' Sure we will! But we haven't actually earned that trust and authority in the digital domain yet. We actually earn that by creating accessibility and making ourselves a place that people got to again and again and again for content.

Yeah, what would the museum website of the future actually look like, based on these concepts? I have no idea. I don't know. I really don't.

We just had a whole great conversation at Museums and the Web (around this idea), and it's clear that everybody kind of recognises that the model is broken, but we don't know what it's (replacement) would look like. And so the key here is that we have to find a way to make ourselves meaningful in cooperation and in partnership with all these (social media platforms). In a world where all of these social media platforms exist, where in many cases our content is (already) there, that our website still means something. And so really the question we have to ask is "In a world where there is YouTube, where there's Facebook, exactly why would someone come to your museum website? What's the reason?" And so as soon as we can answer that, I think that we're going to build finally a website that makes sense ? at least to me, and hopefully to the rest of you. 
G Conferência NESTA em 07/10/2015 


\section{A MENDED DRAFT VERSION-FOR REFERENCE USE ONLY F R O L IVE S P E ECH - T O-TEXT T R A N C RIP TION}

Wednesday, 7th October 2015

Nesta Conference - Making Digital Work

This conference will have live subtitles by Stagetext. Please sit where you can see the text comfortably. Thank you.

ROSIE: Good morning, and welcome to Making Digital Work, sharing the learning from the $£ 7$ million Digital R\&D Fund for the Arts and to Birmingham, to the Library of Birmingham, and the Birmingham Rep who are kindly hosting us today.

The buildings are connected by the foyer. You may have already noticed. We will be working across both buildings. Lunch and breaks are in the Rep's Mezzanine area and the breakout sessions will be in the wonderful brand new Library of Birmingham, as indicated in your map.

We are delighted that you can join us today at Making Digital Work, as we share the opportunities and challenges arising from our increasing adoption of digital tools and technologies.

Digital technology is clearly fundamental to how arts organisations in England work now. $73 \%$ of arts and cultural organisations feel that digital technology has a major impact on their organisation's ability to fulfil its mission successfully. It has been proved that digital technology is improving access to bigger audiences, younger audiences and more diverse audiences.

Our key themes today: mobile, accessibility, data and business models, led by our theme champions, Tom Grinsted, Jo Verrent, Julie Freeman and Nicole Yershon.

Also we will be hearing from a host of fantastic speakers including representatives from a number of the projects supported by the Digital R\&D Fund for the Arts. There are 52 projects. We won't be hearing from all 52 but a significant proportion. They are here to share what has worked, what hasn't, to offer practical advice and take aways, their insights and hard won experience and learning. We will end this morning with a keynote speech from Deborah Bull, director of culture, King's College London, and at the end of the day we've got a final panel looking to what the future holds for digital.

Please take the opportunity to connect, explore, share and take away learning tools and advice. There will be plenty of opportunities to network and connect, although there won't be any audience Q\&A during the sessions. Instead, like a Ted talk, we will have a special Q\&A lounge and the speakers will be there during each break and you will have a chance for a one to one Q\&A session, with most of the speakers. You can speak to them over the breaks.

If you want to tweet please set your devices to silent but please join the conversation, using \#artsdigital. Please take the opportunity to meet the projects funded by the R\&D process, who will be available over the two breaks and lunchtime to show you their learning. They are here in the spaces outlined in your lanyard guide in the Rep and in the breakout spaces of the library.

In your lanyard you will find the programme, the themes, the schedules and helpfully a map with the location of all the speakers' lounges and breakout rooms. If you could check what breakout session you have signed up for and where that session is, I will be reminding you when each session commences.

The exits, the toilets, if you go out of here and to the right, the toilets are situated on the Mezzanine and the ground floor. There's no fire evacuation plan today so if you hear bells, essentially make your way to the fire exits and out of the building. 


\section{AMENDED DRAFT VERSION-FOR REFERENCE USE ONLY F R O L IVE S P E ECH - T O-TEXT T R A N C RIP TION}

In the catering area there are some of our publications. If you can't find one, you can download them from the website, and finally please join us for drinks after the whole day, at 5.20 until 7.00 in the book Rotunda in the Library of Birmingham. There are plenty of Nesta staff around today so if you are unsure of anything or need any assistance, please ask.

So it's probably appropriate that we kick off today with the chief executive of Nesta, Geoff Mulgan, who has had a rather astonishing career. Very early on, he was a TV and radio reporter for the BBC, so he is calm under pressure. Geoff - no, he really is! And also he knows brilliantly about timing because he has done all this sort of thing for live television, so Geoff, not to put you under pressure, but how do we get to the next level?

GEOFF: Okay, well, thanks very much, Rosie, and thank you all for being here. I am going to be very brief but I will say a little bit about how we've got here, what the fund was set up to do and maybe some thoughts about where it goes next. I really want to start by thanking all of you for being here in sunny Birmingham in this rather extraordinary building, which I hadn't actually been in, though I have walked past it many times during its gestation.

Did any of you hear Brian Eno's lecture on art a few days ago? A handful of you. He had this wonderful definition of art as "everything we don't need to do". Which I like, though of course if you think about it, it's wrong, because there are lots of things we don't need to do which aren't art but the proper traditional definitions of art describe it as a means of communication, an assemblage of sounds, light or words or touch which has an effect on us, and that's why it's kind of obvious that digital technologies which have the ability to reconstruct, to break down, to recombine information of any kind, it's not surprising they are having an absolutely profound effect on really every area of artistic - both creation, assumption and use and imagination. Behind this fund was in some ways a very simple idea. A question of: how can we help the arts make the most of that? How can we help them make the most not just of maturing technologies, like the ones many of you have either in - hopefully not in your hands, but probably in your pockets - you know, smartphones, laptops, and so on, but also waves of new technology which are already around us but will become much more mainstream in the next few years, like super-computers and machine learning from Deep Mind or a world covered with sensor where we all sense everything. How many people here own an Oculus Rift? I think about one. This is not yet in every household in the country but in the next couple of years it's fairly likely there will be a couple of million with virtual reality and all of this poses a great challenge for the arts: how to understand these technologies, how to adapt them, how to use them, how to combine them with the reinvention of art forms themselves, but even more important perhaps, how to use them to engage with audiences in different ways. How to raise money in different ways, how to get feedback from data. And we felt that this was a big challenge. In some ways not a new one.

I have in my possession a programme for the late 1960s of an ICA exhibition on computers and the arts. There have probably been thousands of projects on digital technology and the arts since the 1960s, maybe well before, but all of them have been individual projects, or individual exhibitions. There's nothing - never been anything systematic like a research and development programme of the kind which happens in almost every other sector.

If you are looking at health or education, or the military or retail or banking, you will find large-scale R\&D around digital technologies funded out of mainstream core budgets and helping to fuel the evolution of everything from drones to new ways of managing your bank accounts, and the arts is unusual in that it has never done that. It has had lots of bitty projects but nothing systematic. So that was the idea behind this fund, and we had great collaborators in the Arts Council and AHRC. As you can see and you will see today, an extraordinary explosion of creativity linking academics, arts organisations, tech innovators and I won't go through all of these numbers, you will see in the materials just how much has been done. The outcomes which have been achieved, the different strands 
which you are going to hear about, all of which I think have made huge progress compared to where we were a couple of years ago; how to make the most of mobile, so thousands of tourists now walking around our cities use things like talking statues to have a different relationship with the physical environment; things like iBeacons I think could transform almost every gallery and museum in the country.

We've got a lot of work underway on business models, and given what we know about the funding climate of the next few years, this is going to be important for everyone: how do you raise more money, whether it's investment or revenue or selling things in different ways, and again great examples of doing that well. Lots of innovation around accessibility, and this is perhaps one of the most exciting things digital technology can do, is take art forms which were pretty inaccessible and make them accessible to groups who were perhaps often a bit hard to engage or reach, and again we will hear some fantastic examples of that, which I hope will be copied very widely.

Then finally data. How to in some ways go with the grain of what is happening in so many other sectors, where the constant flow of feedback from your audience becomes part of how every organisation works. That is normal for the Facebooks and Googles. It's becoming normal even for others, even like the BBC and so on, but this is still pretty new territory for most arts organisations and it requires different skills, different methods, different ways of thinking. I just want to make one final point, which is really about what happens next. This was a one-off programme. It brought together a good collaboration of organisations. We think this programme has vindicated the premise that there was a huge amount of innovation waiting to be tapped and that the arts needed to do this kind of innovation as systematically as every other sector, so that we can make the most of what are almost certain to be wave after wave of new technologies like the Internet of Things or virtual reality, and so on.

The truth though is this is a little bit outside of the comfort zone. Most of the arts, and this is true of Nesta as of others, we are used to giving out grants for individual projects. The idea of a R\&D programme where you systematically mine the potential of new technologies, experiment, bring together new collaborations, measure what works, and then spread the results, so anyone else can borrow, copy, adopt, adapt the results, that is quite a new idea for this sector, and it's still not clear whether that's an idea many people accept, whether this approach actually has a future in this sector.

So my very final point is really to ask whether at some point today we think about what could or should happen next. Do we need, coming out of this fund, more resources for developing the really good ideas? A few months ago, we launched again with ACE, the Arts Impact Fund, which is providing some kinds of investment for really good, scalable projects, but again we don't really have the funding for scaling technology projects in the arts, the kind of things being proven by this fund, many of the ones which will be on show today.

We don't quite have any structured way of mining the potential of things like virtual reality, augmented reality, near field communication. All these new tools and technologies which are baffling at first, but may well just become part of daily life pretty quickly.

Finally, I think there is a case at least for creating for the arts some kind of open, shared capacity for systematic research and development. The BBC oddly has always had it. They have a research R\&D team who invent fantastic new technologies, some of which are then made open to others. They are trying to change their way of working at the moment, but I think there's perhaps a bigger prize of re-thinking how the UK could build on what they've done to create something very different in nature, so that the sort of work we are talking about today could become absolutely mainstream and, crucially, open, so anyone can get the benefit of all of the ideas. 


\section{AMENDED DRAFT VERSION - FOR REFERENCE USE ONLY F R O L IVE S P E ECH - T O-TEXT T R A N C RIP TION}

So that's all I really wanted to say. I hope today we will celebrate what has been achieved. I am sure we will be inspired. But I hope we can also think a little bit about what needs to happen next. How do we build on this, learn from the successes and from some of the failures that make this much more normal, because I don't think it's selfevident that the arts should be the only sector which doesn't do systematic digital R\&D. Thank you.

\section{[Applause]}

ROSIE: Thanks so much, Geoff. Now, Darren, follow that! Darren Henley really needs no introduction, but I will just quickly run through why he is here. He began as chief executive of the Arts Council England in April 2015 with a keynote speech in Hull.

DARREN: City of Culture 2017. Hope you will all be there!

ROSIE: But you spent 25 years in radio, leading Classic FM for the past 15 years as managing editor and then Managing Director, appointed OBE for services to music and your two independent government reviews into music education and cultural education published in 2011 and 2012 resulted in the creation of England's national plan for music education.

Do you feel, as Geoff implied, that the arts have been left out of the digital revolution and everyone else has steamed forward and, you know, we are lagging behind yet to actually build -

DARREN: I think the first great thing to say at a digital conference is you get constant feedback all the time. So Geoff went down very well with Twitter so I can now have something to compete with, but I think that - I don't subscribe to the view that the arts is left behind in some ways because I think there's huge entrepreneurialship and creativity and a lot of digital expertise in the arts but where this has worked really well is we've taken some of that expertise and crashed it into other areas as well and we are working with different people, groups and organisations that maybe arts organisations haven't traditionally worked with, so working with tech companies, with universities, I think that's where it's really exciting because there is that expertise and creativity in arts and cultural organisations but we need to find ways of surfacing that up all the time.

ROSIE: Have they been resistant or have they all been keen on it?

DARREN: No, I think one of the challenges for arts organisations, particularly if you are an individual artist or a small arts organisation, is having that digital expertise in-house so one thing we can do with Nesta when funding in the area of R\&D is to help people to have access to that so I don't think the people who run our arts organisations across the country are in any way resistant to creativity and doing things differently because that's in the DNA of an artistic person.

ROSIE: Of course, but it's easier for a Tate to do something than if you are a very small -

DARREN: Absolutely right. If you are a big organisation you are going to have that infrastructure and support, so I think one of the things we've got to do all the time is to find ways of getting smaller organisations and giving them the platforms, because we know in the tech world it's very often the small organisations that come up with the brilliant ideas who then go on to become big organisations.

ROSIE: But the platforms can sometimes be a bit woolly. We all understand the ability of digital to book tickets, or perhaps to have relays of live events, but something like The Space, The Space has been troubled, not quite sure it's lost its main team, and obviously we are going to be hearing from the new chief executive later on today, but what is it for? 


\section{AMENDED DRAFT VERSION-FOR REFERENCE USE ONLY F R O L IVE S P E ECH - T O-TEXT T R A N C RIP TION}

DARREN: So The Space, you know, has a great team in place now and for us it's taking the organisations we invest in and taking them to the wider platform. To work with someone like the BBC who have access into virtually every home in the country, it's really important that the Arts Council has a platform there that we can take the organisations that we invest in to the BBC's audiences. At the same time, we are working with Channel 4, with Canvas which will be a big new YouTube channel for the arts, so to get arts and culture out to as many people as possible.

ROSIE: And to really help the capacity of the sector?

DARREN: Definitely, and we are here to invest in arts and cultural organisations. That's what we do. As an Arts Council we don't actually create it ourselves, we work with people, through people in this room to take arts and culture to big new audiences and we want to make sure that arts and culture are part of absolutely everybody's lives. One thing that's interesting, working as I did in the media, these devices now are really important. If you are 15-24 this is how you consume your media so we can't have arts and cultural organisations not engaging because that's where there is a risk they will get left behind.

When I talk to people, there is a huge appetite for development and change and for developing knowledge and understanding.

ROSIE: Just a couple of the R\&D projects, which ones did you think were particularly innovative and engaging?

DARREN: There's lots. I really like the Steve Reich clapping one which is very simple but helps you to develop your music skills. I think that Connect Through Sound did really good stuff in terms of music education in saying this is something that will help you go to rural areas, and to take high quality music education to rural areas; and then I was interested in Fire Station in Windsor with what they are doing around booking tickets using models that have been developed in the airline industry. We learn and adapt to bring it inside.

ROSIE: Just a quick steer for anybody who may be applying or hoping for Arts Council hope. What are your priority areas?

DARREN: We are really interested in - we have five areas. One is about great art is central to what we do. The second is about taking great art to everyone, so we are really keen to have a wide geographical distribution. When I was speaking in Hull one of the first things we did was talking about widening our Lottery Fund that we spend outside of London so that's going up to $75 \%$ outside of London from a historical point of $65 \%$ out of London.

We want it to be for absolutely everybody across the country so that's very important for us as well and the diversity of people we are talking to is also absolutely vital and we are also interested in helping organisations to diversify their income streams as well so new business models is something we are also very excited about.

ROSIE: Do you worry you might be leaving older people behind, or in areas where there is internet poverty, you know, people that aren't connected, what about these people?

DARREN: I think that this, for a long time, will be complementary to the traditional ways of taking art and culture to people. I don't think we are going to at any moment be switching things off but yes, it is really important that we have a good broadband infrastructure across the country, it's very, very important that we do remember people who live in rural areas and I think actually technology could really help us there. One of the things is it's easier to work with people in urban conurbations simply because there's lots of people in one place but it's really important that we 


\section{AMENDED DRAFT VERSION-FOR REFERENCE USE ONLY F R O L IVE S P E ECH - T O-TEXT T R A N C RIP TION}

are taking arts and culture out to every part of the country and in my first 100 days in the job I travelled from Cumbria to Cornwall so I've seen everything in terms of size and scale and that's really important for us.

ROSIE: Is there a country abroad whose digital arts policy you admire?

DARREN: I think it's up for the taking still, at the moment. So I don't see why, working on projects like this and with a bit more long term thinking, we can't become the leader. I like the idea of England becoming the leader in this sort of area, and if we have a lot of expertise here, we have some real insight and innovation happening, and I think it's incumbent on organisations like the Arts Council to keep on backing these things, and to make these ideas bigger.

ROSIE: Darren Henley, thank you so much. Thank you. Very inspiring, thank you.

\section{[Applause]}

Right. Thanks so much. Now, if anyone is booked on to the - are you okay - the Business Models Masterclass with Mandy Berry and Rosie Ukleja, please make your way to room 101 before the next - no, it's nice, really! [Laughter]

Now, mobile audiences. Increasingly, as Darren said, we are using mobile devices to access information. What are the opportunities for the arts? To take us through our first theme, I would like to introduce Tom Grinsted. Tom is Group Product Manager for the suite of Guardian mobile tablet applications including the new Guardian app for Android and iPhones, The Guardian Observer daily editions, Apple News and Flipboard, with over a decade of experience specialising in mobile, Tom has worked with clients including London 2012, the Education Department, the Wellcome Trust and of course The Guardian.

Before we hear from Tom, here is a short film to tell you what it's all about. Can we run the film, please. Thank you.

[Video shown - no audio]

TOM: Hello, everyone, I'm Tom Grinsted. Not only am I following myself but I'm wearing the same shirt! [Laughter]

But I would like to just put you guys at ease, I do have more than one shirt. They just look all the same. I am a mobile champion, which is a really odd title, right? You will notice today I'm not wearing my cape and I think I speak to everyone when we should be happy that I'm not wearing my underwear on the outside but really this means I'm here to do some arm waving about mobile and what it means.

To start off with, I kind of want you guys to think about your relationships with your phones, so can you all get your mobiles out, please? If you think about doing this 15 years ago, I would have said can you all get your mobiles out, and most of you would have looked around and said I don't have a mobile.

Can you turn the screen on and face it towards me?

This is either going to work well or hideously depending on the quality of the phone camera I've got. Screen towards me, otherwise you are just going to look like loads of sinister faces.

Okay, that's going to be tweeted. Thanks very much. I say that, I mean it's going to be tweeted wi-fi-dependent so it's probably not going to be tweeted. [Laughter]

Yes, so when I think about what to talk to you guys about, I initially went to a place that most people instinctively go. I started thinking about all of the different ways that you can use your phone, I started thinking about how the technology has changed, I started thinking about talking about what you can do with it, and then I realised, you are 


\section{A MENDED DRAFT VERSION-FOR REFERENCE USE ONLY F R O L IVE S P E ECH - T O-TEXT T R A N C RIP TION}

going to hear a huge amount of stuff today about what you can do with mobiles, about genuinely inspirational projects from people who have been hugely innovative, so I don't really want to talk about what you can do with mobiles, what I want to do is talk about how it feels.

I was looking back - so Tom Watson, the founder of IBM - a vastly more connected and frankly more intelligent person than I am, confidently predicted apparently that there was a world market for maybe five computers by the year 2000. He was also really, really optimistic that, if we were lucky, computers would weigh less than 1.5 tons. [Laughter]

To put that into context of where we are now, the World Bank is predicting that by 2020 there will be over 4 billion computers worldwide, each weighing less than 150 grams. Obviously talking about smartphones. Well done, Tom. [Laughter]

In developed markets, like the UK, then we've already got to saturation point with adults of over $80 \%$ [inaudible] but I don't think it's possible for us to overestimate the effects that almost every adult walking around with what was a supercomputer by the 1970s standards is having. The effect is physical, it's mental and it's emotional so I kind of want to think about that emotional relationship for a minute.

Can you all put your hands up? That wasn't a difficult instruction. And keep them up. So, if I asked you, if hypothetically I asked you to turn to the person next to you and introduce yourself, could you put your hands down if that would make you really uncomfortable? Okay, that's great, most of you have your hands up. Can you turn to the person next to you and introduce yourself, please? [Laughter]

All right, all right, that's enough. Can you all put your hands up again? Now, hypothetically ... [...]

Now, hypothetically, if I ask you to turn to the person next to you and give them two air-kisses on the cheek - put your hands down if that makes you uncomfortable! [ Laughter ]

Okay, I am not going to ask you to do it! I suspect if I had done it first thing, a few more hands would have gone up! Put your hands up, please.

If I ask you to share the latest book to the stranger sitting next to you, will that make you uncomfortable? 50 Shades of Grey. I want to think about your relationship with your mobile phone. I want you to think about those fantastically incriminating e-mails that you sent; I want you to think hidden away is Tindr or Grindr, and I want you to think about the text history you have with your loved one. If I ask you to unlock your phone to the stranger next to you, and leave them with it for five minutes - put your hands down if that makes you comfortable! [ Laughter ].

There are three people .... . Thanks very much. You can put your hands down!

I want you to consider that for a second. Because I would posit the reason it makes you uncomfortable isn't just because of technically what is on it - or maybe you guys have incriminating stuff! [ Laughter ]. I guess the reason you don't want to do it is because the mobile phone in many ways is an extension of you. When someone gets a smartphone, they become habitualised to it. They get more and more used to it, and it reaches into their lives. In doing it, it extends them and enhances. Somebody was talking about sci-fi vision of the future, and I would argue that the smartphone guys - makes you guys in a meaningful sense a more advanced and more enhanced cyborg, and advanced human, more so than any. 
As an example, my mum used to be able to name, I think, all the kings and Queens of England since 1066 by rote, and there are some who say that's really smart to be able to do. Well, I can't do that, although, that's not true - I can I just outsource it! So not only can I name the kings and Queens of England back to 1066, I can name every king and Queen of the world back to the end of recorded history and do it more accurately and quickly than my mum ever could. The reason I can do that because if anyone asked me that question now, I would instinctively reach for my mobile phone and Google it.

Similarly, I am terrible with names and faces, absolutely terrible, so I apologise for people to whom they've introduced themselves, but, for me, the phone is a complete godsend, because, when trying to remember that person and putting a name to a face and trying not to look like an idiot, I can used LinkedIn. I've outsourced that, and in doing so, I feel closer to my phone, because my phone is enabling me to do something which I found socially awkward and embarrassing. This is what I mean about how the phone makes you think. Because we've become so used to it, we don't think about it in these terms, because, traditionally, and especially out of the technology sector, they are referred to as "tools". We don't think of them in biological ways, but I would argue, in a very meaningful way, your mobile phone becomes as close to a sixth sense as you can get.

Not only is it a view on to a world you can't see - a digital world -- the internet - it allows you to augment your physical world, allows you to enhance your understanding. Area that you are in, and it allows you to communicate and allows you to listen and to talk.

So what is this, if it is not like a sense? In fact, the only reason we don't think of it that way is you can put it down. You can't put down one of your other senses. Those of you who use mobile phones, and, if, like me, you kind of use them all the time, it is almost the last thing you touch before you go to sleep - depending on how your marriage is! And it is almost the first thing you touch when you wake up in the morning. It is there whenever you're conscious. So, for me, when I stop and think about it, my mobile phone makes me feel enabled. It makes me feel like I could do things that I could never have done before and that were frankly unthinkable only a few years ago.

As you might have guessed, and I am sure you guys know this, that is a phenomenal opportunity, and it is an opportunity that I don't think arts and heritage have really tapped yet. This fund was exactly about trying to tap into that opportunity, so we are going to hear now from three different speakers, and each one is talking about how they have grasped that opportunity and used mobile technology.

I am going to introduce each one, and because my whole schtick was about how mobiles make you feel, I am going to introduce them into how I think their products made me feel when I looked at them. We will start off with Andrew Burke who will present the Clapping app. For me, that app is all about helping you to feel fantastic, about helping you to feel music, help you feel a deeper connection with music. So, as it seems appropriate, can you please put yourself together a huge lap for Andrew. [Applause]

>>: Can you all hear me? I am Andrew Burke, the Chief Executive of the London Sinfonietta, which is a contemporary chamber ensemble, specialising in music by living composers, and we've championed that cause since 1968. I am here, really, in nine minutes to tell you as much as I can about this project, what we did with it and what we've learned from it, so if I am saying anything you know, please forgive me, especially if you're musically trained, I will assume some people need some background.

First of all, that's the first slide. This really described one of the first learnings. This project was a partnership, and, for a small arts organisation like ours, with a turnover of about 1.5 million, there's no way we would have achieved this without a partnership, and that has taught us about how to do our next one. We are very grateful, Nesta, and the 
Arts Council for funding, and our project partners, Touch Press, who helped us build it and Queen Mary's of London as well as individuals like Barbara - capacity is it the big challenge in doing these kind of projects.

Clapping music is a piece composed by an American composer, still alive - called Steve Reich, nearly 80 . He transformed music in the second half of the 20th century by making minimal music - not a title he invented. Basically, he was on tour with a lot of kit, uses a lot of percussion equipment, and he realised that if that didn't arrive at one of his gigs in Europe, he would be in trouble, and he saw a flamenco artist clapping and decided he would make his own version of a piece which he could perform on stage if his equipment didn't turn up. That's him on the right when he had hair! This piece is clapping music. For those of you who can read music, you will see straightaway what is going on. There is a short video in a second showing you what is going on. A rhythm that both people clap at the same time together in the first bar, and then you see the second bar where it says "clap 2", the second player rotates the rhythm by one note. He keeps on rotating it through each of the rotations until the piece comes back into sync with itself. Can I have the bit of video now, please. [ Video played ]

And so you can see the bottom rotates. In performance, it makes a really compelling experience. People are going to stare at these two percussionists watching what is going on, and when the two patterns align, it is very satisfying. I went to music university. Steve Reich was a big God for me. A couple of years ago, I sketched ideas how I can put this on mobile phone. I've been known to play mobile phone games on buses when travelling, so I thought this dead time could be improved, and instead I could improve my rhythm or something about music.

This project took a year to scope, a year to fund, and a year to make, so lesson is they take time. You can't rush them, these digital projects. That sketch turned into this idea with the colleagues I mentioned before, Touch Press, Queen Mary, and you can see the versions of the rhythm there, as the next pattern comes towards you. It is like Tetris in concept, the game, the lines come towards you, keep on coming towards you. You can download it, it is free, you can try it, and you'll get a better idea, and I can show you here what it does. It is a free download. We decided not to charge with it because of the complications of negotiating with the composer and the rights around that, but also to make sure that the app had its maximum reach and impact.

The other big development that surprised us, we were pleased we made this choice, and, in a way, the success, was to gamify this - gamify this piece of music. We did that by adding a high score protocol to how far you got through the game, and the app automatically generates screen shots at the end of your attempts which you can post, and, by posting them to our server, you can enter a competition.

Now, if you go to Classic Music app as a hashtag search, you will see around the world, people are submitting their high scores. Someone there submitting from Japan or Korea - I am not up on what that language is - but this is happening now quite a lot, and the competition element of it is what is motivating people to keep going and learn something in musical terms which is a dry and dusty thing, you know, improving your sense of rhythm.

We were surprised by the success we have had it. There's been 73,000 downloads in 97 countries so far, and no doubt because of Steve Reich. He's an iconic composer living today, and he has a lot of followers, and his piece, Clapping Music has become a very well-known piece of experimental music of its day and still fascinates people, so the idea you can actually try it, learn it, do it for yourself on your iPhone is something that's captivated the imagination of a lot of people.

We have also run a competition, as I mentioned, people were submitting their ideas - sorry, submitting their high scores, and people got quite addicted to it - like really seriously addicted. They wanted to get into the top ten. That was the top ten that ended our first competition. A chap called Wolfram Winkel came over to Germany, kept on 


\section{AMENDED DRAFT VERSION-FOR REFERENCE USE ONLY F R O L IVE S P E ECH - T O-TEXT T R A N C RIP TION}

entering about 30 or 40 times to make sure he was number one on the top of the competition leader board, an online magazine in America started their own $28 \mathrm{~K} \mathrm{club} \mathrm{-} \mathrm{in} \mathrm{other} \mathrm{words,} \mathrm{they} \mathrm{encourage} \mathrm{people} \mathrm{to} \mathrm{submit} \mathrm{their} \mathrm{high}$ scores and be part of the $28 \mathrm{~K}$ club. We even think about printing T-shirts saying they are in the club. The thing that convinced us about the success was people were fascinated about trying something on a mobile phone, but having a live iteration, come to a live event and be part of a real community. That was reassuring for us. We didn't want to make a purely digital experience but wanted people to meet.

These were our research questions that we submitted as part of our application. We wanted to see if gamifying a discipline makes people stick with it. It does. What impact did it have with people engaging further with other bits of our art form? We are still finding out about that. We have a concert on Saturday at London that we've encouraged the competition entrants to attend and we will see how many do turn up.

A few more slides to say what we learned. Things that we got right: partnership with the big name, partnership with Steve Reich helped. Frowned on how can you gamify this, but what is did was cause people to keep on learning, keep on engaging with the music discipline we've built into it. I am proud of the fact that we've made an experience that works really well on the mobile phone. It is not just a streaming of a live experience, it is actually a complete experience on the phone, and it is that fact that we encourage people to attend live. If we did things differently again, if the whole project from scratch, I would make sure we had more time and get iterations to go to our research team because the last time it was a bit of a rush. We really squeezed our research partners, and I apologise to them.

Future challenges: what do we do next? We are taking a big, deep breath, saying wow, that was great. What do we do next? The money and the time. Two big things that all organisations, not just ours, we consulted with big organisations and they said the same thing. Monetisation: is it really possible? The amount of capital you need to get these projects done. I don't know if we will find a way to earn money from the direct product.

However, there are opportunities in themselves: we are going to roll out this app in schools because kids like technology, and if we can get them to practise their sense of rhythm, that's good. We will build the community of people who build it and that's where the possible monetisation is, making people more loyal, invest in future projects we do. We want to enjoy the community out there loving this thing and make sure we get to our next digital project.

I have had my nine minutes. Thank you very much. [ APPLAUSE ]

TOM: We're going to move on quickly now to the Hidden Museum, and Zak is going to come on in a minute and talk about it. It feels like mobile technology is something you do on your own. If you look at the family section of the Guardian, a lot of people bemoan the fact that their kids, and adults, are using the phone on their own. What I loved about the Museum, is that turns it on its head.

ZAK: Good morning, everyone. I wanted to talk briefly around our game. A quick sort of aside mentioning what Tom mentioned around the emotion, one of the interesting things I find is I've got a one-year-old. Every time I feel I have my phone, I feel guilty I am on my phone constantly. It is one of those emotional personal things for me around mobile.

The project was called the Hidden Museum, and it was about how we could get more people to go around the museum, talk to each other and also use really cool technology to really enjoy their experience, and for us to find out a little bit more them. We know so little about the million or so visitors we get a year, so we thought this would be a really fantastic opportunity for us to do that. So we are really grateful to our partners, University of Bristol, and of course the fund. 
The project was at Bristol Museum and Art Gallery. It is on three different floors, a really large building, got amazing world-class collections, but the majority of people just stay on the bottom floor, so it is really scary when you see the people with 14 galleries, saying I just thought you had toilets, $\mathrm{Wi}-\mathrm{Fi}$, and a cafe. This project came along to see if we could scratch our own itch. We wanted people to explore the museum on their own. I call the project about poking the box. So we worked with a technology partner, Aardman, and stuff beyond our capability. One of the things that is difficult for us is to keep abreast of the latest technology, so we didn't: we passed it on to Aardman, so that's pretty good for us.

We also worked with the University of Bristol. Who can do research better than a university full of researchers, right? Instead of me going well, I can ask people, do they go upstairs, downstairs, the university was really fantastic with that, and a good thing about this project that has come out of it, is that Darren is now a full-time employee for us. We liked his research so much that we thought we actually needed a researcher, and he has come along, so, for me, one of the exciting things about the project has been that continuation of the partnership.

These are I beacons for those of you who have never seen these before. We put 150 of these around the building. As far as I know, we with one of the first people to litter litter the building with these pieces of technology. Our vigilant and caring staff immediately started to return them because they were suspicious devices in their mind, so, for anyone who does do I Beacons make sure you identify them individually, because if you end up with a pile of them on your desk, you will have no idea where they came from!

Our technology partner did this with iBeacons. If anyone of you what that means, let me know! They focus on the mechanics of iBeacons, they're little devices that emit Bluetooth. They don't do anything themselves. Your device will know where it is, and it can trigger it to do stuff. These were around. We found, for example, they go through floors, don't go through walls, you can be one foot from it, so it doesn't work. We had lots of head-scratching throughout the project to get it all to work.

This is again us trying to look at the various spaces, a big challenge of our building is that because it is not a brand new building with amazing $\mathrm{Wi}-\mathrm{Fi}$, it is an old building with lots of different really difficult challenges in terms of ergonomics of the design and took a long time to work out where to place them in the building. What I was hopeful for the project is that, putting them around the entire building, we would be able to see almost like a cookie-trail of where people went, so we could see if people went left, if they went right, for example, you know, and those sorts of things, which I think are really interesting. Now that I am responsible also for things like retail, and other bits and pieces where my Head of Transformation title comes in, it is financially useful for people know if they're anywhere near the cafe or the shops.

These are spread all across the building. We based used testing device, iPads for the public to do. We did Museum Takeover Day where we had lots of kids come in and try and destroy our beautiful iPads that were brand new. I am glad to say, they all came back, all safe, they all came back safe, and, actually, the interesting problem we had was that people were so engrossed in using the device in the early prototypes, they kept walking into things! It is quite scary that people will walk like lemmings following their device, so do make sure you get your risk assessment done to include people walking into walls!

The game itself, basically we involved the game because it turns out all the technology wasn't particularly brilliant, so you did things like you want to paint your own paintings, so you did this really clever stuff. Most people end up of course trying to chuck it across the room, hit their loved ones, so that didn't really work. 


\section{A MENDED DRAFT VERSION-FOR REFERENCE USE ONLY F R O L IVE S P E ECH - T O-TEXT T R A N C RIP TION}

What we did find, it was really interesting that people by designing the experience, people actually started talking to each other more, so we made sure that the hidden part of it included the fact that the device was just an enabler for them to go and experience something, so, for example, in our rear hall, hit by bomb damage, shrapnel on the wall no-one knows that - but the app tells them that and spent ages talking about that rather than using the device.

We chose group sizes for data around who is using the game, how long they would be here, and so we started identifying interesting insights into how long people are in the building because we don't know that sort of stuff. They can choose their own character and get stickers. They run around the galleries and have a good time, and couldn't find any photographs of people having such a great time as those characters there!

And then they would be able to enjoy themselves quite a lot. The reason it is partly called hidden as well is because there's lots of stuff, mainly around stories and parts of the collection that people just don't get an opportunity to see. Not everyone is as fortunate to me to find the curator saying, "I don't get it, can you please explain it to me?" That's been a really fantastic part of the project. To sum up, really, it has been such a great pleasure to use iBeacons in the museum, but maybe the idea of sensors being good for us to exploit in the future.

\section{[Applause]}

TOM: Great, thanks very much. I was fortunate to be project lead for a Nesta project when I worked at Imperial War Museum, so museums.

So we've looked at projects which have really been about extending the abilities of gallery space, or extending your feeling and abilities musically as well.

Now a slightly different tack and what I loved about this is how it feels to have a piece of technology on you which can help you in a way that most people never think of. How can you - how does it feel to have a piece of technology that helps you to be independent in spaces which most of us completely take for granted so we are now going to go on to UCAN with Mared, Megan and Jo.

MEGAN: Good morning. I'm Megan John and this is my colleague, Mared, from UCAN which is an arts organisation for blind and partially sighted young people which helps build confidence through drama and this is Jo Reid from Calvium who is our technical partner on the project.

Both Mared and I are registered blind, and over the past few years we've noticed how much technology has developed and what a difference it has made to our lives, especially mobile technology. We are both standing here, holding our iPhones. Apple is wonderful, with their accessibility features and it has helped us become so much more independent.

So our - although in UCAN we are confident performing on stage, as an audience member, although we love going to the theatre, we would never consider going independently because of the obstacles that would face us. So walking into a theatre, getting from the foyer to the box office can be a challenge, and then -

MARED: Or just finding the box office in the first place.

MEGAN: And then from the box office to a certain door, and then from the door to our specific seats, which is a maze. So the one thing that technology couldn't do to us was navigate us inside a building, and when asking our membership in UCAN, if we could create something for you, what would it be, it would be able to navigate inside unfamiliar buildings. So we created an app called UCAN GO. UCAN GO is a user-led indoor navigation app which allows people with sight loss to independently navigate arts venues with confidence. 
MARED: So naturally we are an arts organisation, and technology was not high on our list of things that we could do, so we needed a technology partner to create our dream and make it a reality. So we were really, really fortunate when we found Jo and the rest of the Calvium team that we then had this shared vision and this goal that we really wanted to create the best possible thing that was going to work for us.

It's all well and good having a user-led project, where people - the users are at its core, but we found that that's only going to work if the people that you are working with and collaborating with are actually going to listen to what you have to say and not only listen to it but then act on it and make it happen. So we found that this is a truly collaborative progress and a true collaboration from the beginning, because it was constant back and forth; we were the experts in what we can see and Jo and Calvium were the experts in the technology.

So in terms of user-led, we ran user testing workshops throughout the whole R\&D process with our membership. We have over 600 members all over Wales and we also created a Steering Committee of about ten people who we went back and forth with a lot to make sure that we were getting the best product that we possibly could have.

We think that we are the best people to do this because we have users at its core, but we also have the best technology project who have all this expertise behind them. And we would just like to thank Nesta and Arts Council Wales and the AHRC because without that we would never have been able to start this journey.

JO: So I'm going to go on to describe the solution that we collaboratively came up with and just to highlight some of the deliberate design decisions we made going through, and of course these decisions are a factor of many things. They are a factor of the iterative user testing that we took throughout it, so we tried our solution out at every stage with many of the UCAN members and our target audience, and wider. And also, as a process of learning together, we each shared and understood exactly how mobile made people who are visually impaired and want this confidence, how it unlocks their lives and how they can use it so the first decision was to make it a low vision aid. We deliberately want a solution that will work for everyone, and it will work for visually impaired people and our solution does.

So one of the ramifications of that is that we chose a heads-up landmark based approach, so low vision means you can see some things, and we wanted the app designed to be natural, so we know that people like the idea - again, independence was what our customers wanted. So something that wasn't like a white stick. Everybody walks around with mobiles now, so a solution that would work with a single ear piece in your ear, deliberate things that you can just easily follow the interface to lead you through step by step, so from here to the door, from the door to the foyer, from the foyer to front of house, is what was worked and was shown to be usable by everyone.

Maps are great. iBeacons are great. We've used them all in the past. What we knew is that because, again, for this particular project, we couldn't rely on a technology that the cleaners may have taken the iBeacon away or something might not work so our solution is designed for scalability so it works with what you have on your phone; it can work better if a venue decides to have iBeacons in there a wants to have maps and everything else, but if you have got low vision, maps are great if you can see at all. If actually as we learnt from our partners you have to zoom in so that all you see on the screen is three little bits of text, you can't construct a map in your head very easily, so the idea is that we create this landmark approach. Certainly again we learnt from the team they wanted the common colour contrast so that people can easily set so it's easy to see. We have the ability to dynamically route. We've mapped out the whole of the Millennium Centre and it takes into account your preference so if you are a female or you need wheelchair accessibility, you can be routed within the building so we really have developed the equivalent of a sat nav type system for indoors, and so also for scalability it blends a naturalistic overview approach, so before you go you can get an idea of what's there, so you know where you want to go from and where you want to plan your route, 


\section{A MENDED DRAFT VERSION-FOR REFERENCE USE ONLY F R O L IVE S P E ECH - T O-TEXT T R A N C RIP TION}

and then we use Siri for the automatic translation of the encoding we have of the building, into the directions, so it's scalable for any venue.

So it was great to work with these guys. We got there and we are excited about what the future holds.

MEGAN: Yes, so we had the problem and we were fortunate enough to be collaborating on creating the solution and I think that Mared and I have proven through this process how vital it is to have a user-led approach and have a user as part of the development phase because we now are showing that through mapping these two venues and having them in an app that has been created, that's scalable and that we want to keep building, that we are not only showing how we can use our expertise to create an app which is accessible for us but we are also creating employment for people who actually struggle in finding work.

So yes, we have two venues mapped on our app, but we obviously want to keep going and take over the world, so we would love to keep mapping arts venues.

MARED: We would like to go to more than two arts venues, if possible!

MEGAN: But as arts venues are a minefield for visually impaired people, so are many other buildings so our hope is that one day we can map everywhere, so UCAN GO is free to download from the app store for anyone who has a iPhone so please go ahead, have a look and if you have any more questions, please come and ask us. We are happy to answer anything. Thank you.

[Applause]

TOM: Thanks very much, guys. So we are coming to the end of the - well, we are actually at the end of the mobile session in here. I just kind of want to wrap up some of the things that you guys have seen and I will do it very, very quickly because, as you just saw, there are refreshments. Never good to be blocking drinks.

So I think what we've heard today has been - I don't know about you guys but I find them genuinely inspiring and they are a small selection of the kind of projects that the Digital R\&D Fund has undertaken. What I really love about the projects we've heard about is I see them all about using the technology to augment yourself in a really positive way. Now, whether that's augmenting your visit to a museum, it's augmenting your music skills or augmenting your independence in venues then really, sitting at the heart of this, it's about being hugely creative with the technology that we now all carry around with us. If you take one thing away from this it's really I hope a verve to do that yourselves, to look upon mobile as a huge opportunity. So please can you join me in giving one last round of applause to everybody who presented today.

[Applause]

ROSIE: Thank you very much to Tom Grinsted.

[Applause]

Right, now, we've got a half-hour break. Refreshments are served in the Rep Mezzanine. There's an opportunity to talk to this morning's speakers, who I think we all agree were absolutely wonderful, in the speakers' lounge on the ground floor of the Rep. If you are booked on the mobile masterclass presented by Zak Mensah who I nearly had an air kiss with, but then was denied - never mind - please make your way to breakout room 101 for a prompt 11.50 start. Please be back here in the studio theatre to talk about our next theme, accessibility, at 11.45. Thank you so much. 


\section{[Applause]}

\section{[Refreshment break]}

ROSIE: Right, welcome back. And now for our second theme of the day, accessibility. Now, as we've already heard from Mared, Megan and Jo, digital technology can really make a difference to accessibility. This theme is to look at how the arts can use technology to reach a public audience, particularly those with disabilities. Our champion for today is Jo Verrent, who believes that different is delicious, not divergent. She is the senior producer for Unlimited, the world's largest commissions programme for disabled artists, delivered by Shape and Artsadmin. Before Jo comes to talk to us, I would just like to have a brief film. Thank you, if you could run the film.

\section{[Video]}

>>: Access is about how you reach out to a much wider audience. A whole range of people. That's where creativity can really come to the fore ... [video audio not relayed] ...

JO: Hi, my name is Jo Verrent and I'm the accessibility champion, similarly no cape, but I do have a medically themed pen. [Laughter]

I've got 15 minutes to convince you that accessibility isn't dry, boring and an add-on to what you do; instead, it's a fundamental, intrinsic element and a fascinating one at that.

Access is usually thought of as being hideously dull and boring which is why you will see they carefully stapled us to the keynote so that you can't escape us, which I think is quite clever.

In order to convince you that access can be exciting, the first thing I'm going to do is to wow you with a little bit of a video. Roll video, please.

So I'm going to audio describe this as we go through. So we see coral, we see fish, we see blue sea, and we also start to get glimpses of Sue Austin, the artist, in her underwater wheelchair. And the text says, "First, she went underwater". You can see the chair that she scuba dives in. She is wearing a dress, her hair is flowing free, and she has the fins on her chair which give it additional stability within the water.

She is spinning with shoals of fish.

[Gentle music playing]

Surrounded by blue, spiralling. Here she is doing a full 360 -degree turn in her wheelchair, something she would never be able to do.

\section{[Sound problem]}

... not killing the artist became really, really important within this work.

Sue is fearless. I think anybody who wants to go, "Let's take the wheelchair underwater, into space", is really fearless. You can see the effort it takes on her face there. She is controlling the motorised trike at this point. Also we've worked out this is very weather-dependent. Costs increased when we had to keep flying her down to France to fly. Learning to fly in England, not particularly successful. There she is, she is crashing out there, but as you see, I will leave her playing in the background. So what has this fantastic work to do with access? 


\section{A MENDED DRAFT VERSION-FOR REFERENCE USE ONLY F R O L IVE S P E ECH - T O-TEXT T R A N C RIP TION}

Well, as you saw in the film, Sue has gained funding from the Digital R\&D Fund to look at how such immersive work can be created and displayed by everyone, for everyone, so their research looked at producing a commercially viable, robust system of integrated 360 -degree filming and installation so making sure this type of work can be created by anybody and also displayed anywhere so that small arts communities, educational communities don't need to miss out on the potential of digital.

They developed affordable head sets and technology that enabled them to really reach out to audiences that are currently excluded in a way that we don't often think about. People are excluded due to physical and psychological barriers from the idea of actually going into some of the big organisations, some of the bigger institutions. And the financial barriers that a lot of disabled and other people really experience, travelling - Sue lives in a very rural area and that's a key part of her practice. So access isn't just about captions and audio description although those things are really, really vital too. It can be much more than that. Access isn't even just about ensuring access to individual artworks.

It can be about seeing your reflection somewhere in the artwork that you consume. I think Sue gives a sense of freedom, liberation and transformation and they are not usually words that you associate with the concept of disability. Access is about involvement. It might mean access to participating in the arts, or access to the possibility even of becoming an artist yourself. I think ultimately, it's about access being seen as a fundamental aspect of humanity.

When we deny people access, we treat them as lesser. We say they aren't valued. We say they are not as important. They are not as human as everyone else. We deny them what we need. And this is what you do every single time you forget to put on captions, or you don't audio describe a piece of content, or you don't have time to Alt tag an image when you put it up on your website.

So now I bring you crashing down with a guilt trip and I am sorry about that but I will continue to do that right through the session. So let's go back to some of the motivational stuff. I tried to think who is out there that really inspired me because I think the best way to engage people is through inspiration.

I wanted to talk for a moment about a disabled artist called Simon Mckeown. This is from Motion Disabled. It's a work that took the unique movements of disabled people and using motion capture technology created avatars, moving avatars that showed those idiosyncratic movements as an object of beauty rather than an identity. This is one of the stills, and that's another from his. You can see it here displayed in gallery settings.

His work is really an anecdote to the whole eugenics campaign. He thinks that we are really trying to cut down on the numbers of disabled people that there are and he wants to show that we are just as vital and valid as everyone else.

His work is shown in galleries and you can see it there also projected outdoors. I was part of the first piece that was projected outdoors. That really worked. Not this one. This was part of in 2010 Motion Disabled was projected globally. 17 countries in 23 sites on the same day, which was December 3rd, which is the international day of disabled people, so he was able to galvanise a huge range of organisations behind him to make that happen and his work is really seen as an example of the creative case, quite often, as evidenced by the Arts Council, and that idea of using creativity and disability as a creative advantage rather than a barrier or a block.

His most recent work you can see there, projected onto the side of Cork College of Commerce, was part of Culture Night this year, Cork Ignite, and Cork Ignite was part of a series of three and it followed the model in the UK, 


\section{A MENDED DRAFT VERSION-FOR REFERENCE USE ONLY F R O L IVE S P E ECH - T O-TEXT T R A N C RIP TION}

Unlimited, that I'm the producer of. We fund disabled artists to create exceptional, extraordinary work, and a number of our commissions have used technology to increase access, often quite unconventionally.

This is Katherine Araniello who has a piece called The Dinner Party Revisited. She interacts with herself on screens during the performance but that's not what I want to talk to you about. Katherine has limited mobility and her ability to travel is compromised by access, so we wanted to see whether we could create another way for that work to tour. So when she performed, this is a photograph taken at the Southbank Centre in London, when she performed there, we also had a shadow performance somewhere else and she was live streamed to it, with an inflatable Katherine, with her face appearing on the inflatable Katherine. We wanted to see if she might be able to tour it virtually.

Wendy Hoose, another commission that we worked with, which is a piece that used captions in an innovative way. You can see them on the back there. They were used like a mobile phone, came up like text speak during the performance, and it's a piece very much about hooking up for sex via mobile phone apps, so it kind of really fitted the aesthetic of the piece which is when access he tends to work best.

We've got Richard Butchins, 213 Things About Me which is a piece about autism and within the soundscape of that he wanted to echo his own experiences of autism by having a much more fragmented soundtrack, and the Doorways Project which is a project by artist Bekki Perriman, which has a series of audio - it's just an audio track. Sometimes I think with digital we think we have to throw everything at a piece. It has to be on multichannels, all of the time, but actually her piece is about the stories of people who live on the street, and what she wanted to do was to really hone down to a single channel of information, an audio channel which really enabled people to focus on that content.

She used to sleep in doorways, so her unique insight into that experience is what makes that piece work.

Sometimes only the people themselves who have that experience can really shape and convey that material in a way that everybody can value, which I think is really, really important.

Another artist who does that for me is Jon Adams who describes himself as neurodiverse so his neurology, the way in which he interacts with the world is different from everyone else's and he explores hidden elements within society. A lot of his work is taken from smears or marks that he notices around him, and then he relays digitally, playing with perceptions of normal, inaccessible, hidden; and he repositions neurodiversity to me as something beautiful rather than odd.

That I take into my own work. This is a slide from Take Me To Bed. Never call a project Take Me To Bed. The amount of emails that I get -

[Laughter]

It's really, really a bad name. But you can see there, there's four bodies, not typical bodies, who move very slowly within the installation. It's in Sweden at the moment but again it's challenging that sense of normal, that sense of normal movement.

So access is about getting everybody involved. It's getting everybody represented and when I say everyone, I really mean everyone. Quite often, everyone doesn't mean anyone, and particularly within tech often a lot of work excludes people with learning disabilities, apart from Sprung Digi. Sprung Digi is a fantastic project led by Sarah Pickthall that focuses on the creativity of learning disabled people and increases their exposure and their access to technology. That's from one of their tech days. You can see the mass of wires there, as people get surprised, delighted and frustrated by the world that tech has to offer. And that work also, particularly with learning disabled 
people, highlights and addresses the isolation that a lot of disabled people experience. It's a way of enskilling people to break through some of those isolating factors that are becoming increasingly common with the age of austerity that's in front of us. Disabled people are really bearing the brunt of the cuts at the moment, and more and more services are going, so the vitality of people's art lives as well as their lives can be really enhanced by all of this.

Built on the work of companies like Heart $\mathrm{n}$ Soul that we will hear about in a minute, and one more example before my time is up, I wanted just to talk about Aidan Moseby's Periodic Table of Emotions. He has created a Periodic Table of Emotions where as a Twitter stream and local newspapers are running, the lights of different emotions light up according to how a city is feeling. So this is running in Dundee at the moment. So you are able to see whether people in Dundee are talking about being delighted or depressed. It's a fantastic way of gauging emotions. But enough about me. Next, you are going to hear about four very different projects that are looking at expanding access all in very, very different ways. Four projects that don't just bolt on access, but put disabled people really at the heart of that research, so look, listen and enjoy. But don't just leave it there. We are not interested in you sitting back and finding it all mildly informative. We are interested in what this might actually inspire you to do. So I'm going to be watching Twitter later, to see how what we are showing you can impact on the work that you do.

So first of all I'm going to introduce you to Justin Spooner, Lilly Cook and Richard Phoenix who all come from Heart $\mathrm{n}$ Soul, who are going to take us through the journey of SoundLab, and the way that digital music making doesn't have to be daunting; it can be fun, creative and empowering. Thank you.

\section{[Applause]}

JUSTIN: Hello, everyone. I am Justin Spooner, of those three. This is Lily Cook, and this is Richard Phoenix. We are going to use the next nine minutes to tell you about SoundLab. It was one of the funded projects from the R\&D fund. We were extremely lucky to get that award. We managed to spin it out over 18 months, rather than the standard 12 maybe it isn't a standard 12? Maybe it is a standard 18. And, basically, it was a project to try and discover which kind of digital music-making technologies could really be of use, and work for people with learning disabilities to make the kind of music that they wanted to make themselves.

What I am going to do is I am going to show you a video that gives you a bit of a flavour of that, because it is a super compressed way of getting a sense of it, but before that, I am going to tell you a mini anecdote: a while ago, Lilly and I went to Abbey Road. For some reason, when I think of Abbey Road, it doesn't come to my mind. Abbey Road Red, which is their research unit. We did a talk about SoundLab, and what was interesting about that session - and it still strikes me as unbelievable - is we were talking about technologies that help them express themselves, but there was dissent in the room, a significant number of people who were quite clear they didn't want music-making to become more accessible because what that would lead to is more bad music, and more bad music would be bad for music fans because they would have to wade through more bad music, and so on.

This actually, turned out to be just before we got on the stage, Lilly got up and told anecdotes about her making music, and it just dropped dead, total quietness in the room, and I had to apologise for destroying the party. The point we were making was, forget about professionalism, forget it being a career and think about people's individual expressivity. Think about your own ability to make something and how important it is to make something for you, and that is what SoundLab is about. I will give you a taste of it with this film.

[ Video shown ] [ Electronic Music ]

\# Sound ... \# 


\section{AMENDED DRAFT VERSION-FOR REFERENCE USE ONLY F R O L IVE S P E ECH - T O-TEXT T R A N C RIP TION}

>>: The opportunity to make new friends and an opportunity to work with different pieces of equipment I've not worked with before.

>>: Being around familiar people. SoundLab is safe.

>>: Sound laaab.

\section{[ APPLAUSE ]}

JUSTIN: Thank you. There, we ran one of those workshops - we ran 20 of the workshops in all shapes and sizes. Richard made the workshops they work, and he will explain to us this second how he did that.

RICHARD: It wasn't just me, but we wanted to talk a bit about I guess failing a lot, and it was the beginning I think maybe the way that it was those workshops ran. It was a bit more in the research mind set of user testing, and kind of like us going away and looking at a lot of things that were existed, and then taking them to a group of people like being okay, let's see what happens, and sort of quickly realised that that wasn't going to work, and that we basically we needed to do it together, we needed to learn with the people that we were trying to encourage to make music, and I always think my job is a mews facilitator, ultimately, to get rid of my job, to make independent music-makers, people who feel confident that they can make music, that they have the tools and resources to do so, so I think, you know, something like an iPad is an incredible tool to help people make music, and just trying to work out how we can sort of make that a possibility, and so, I guess, a large part of that is not necessarily me deciding what I think is going to be accessible, it is working with people to try and sort of figure out what works for them, and it is a very personal relationship, and things work perfectly for some people and then will be just not usable for somebody else.

I guess a good way of talking about the workshops is to talk to Lilly about it because she has been involved throughout the whole project, and I guess, yes, Lilly, you want to talk about how you've been involved with SoundLab and -

LILLY: I kind of got told about the SoundLab workshop, and, at this time, I knew nothing about it. I was like what do I do now? I didn't know Justin, I didn't know you at the time. I didn't know either of you, and I am just like, oh, and then I kick and back. It was so cool. I didn't know half of this existed, seriously. We've tried everything.

God knows what, I can't remember the names of what, because there's bloody loads of things! Yes, there's loads of reviews, things like the Feralini, and the round one, the what, you can really make music with this? After trying obviously like a couple of weeks, I sat there, and I went to Justin, like, I need something that doesn't make - I don't want to make the childish beats, that I haven't got the know-how to use the professional Mac software, so help me, and SoundLab has done that completely. Yes.

JUSTIN: An examples of the kind of music that you want to make, and we sort of go about working out what tools that we had that could help make that happen, and, yes, I think that's a really good point. It was about - we made a lot of like different diverse music over the project, and it was just about that sort of personal relationship, and supporting people to make the music that they wanted to make.

LILLY: I felt sorry for these guys, and I was like, "I don't like that song any more, let's change it to this one." Then the tempo changed. And I think it was the fin I should project, there's four different songs mixed in to one, because I couldn't decide which one to use! But, yes, it sounded okay in the end. It sounds quite good.

RICHARD: It has got a very heavy beat. 


\section{AMENDED DRAFT VERSION-FOR REFERENCE USE ONLY F R O L IVE S P E ECH - T O-TEXT T R A N C RIP TION}

LILLY: That's all I wanted!

RICHARD: If you want to know a bit more, you may have signed up, sign up to the masterclass - that session we're doing on accessibility just after lunch, and, also, keep your eye out for this flier, because we are running an event on at that November where we've got a whole dedicated day where we will be at Nesta where you can have a go at those technologies and get much more hands on than we can today. Thank you.

\section{[ APPLAUSE ]}

JO: I am pleased I've brought my medical pen because I've written it down because I want to play on things I don't have to remember the name of! Sometimes we really forget that actually it is about the immersion, it is about getting involved in stuff, it is not about listing endless reams of big important names of big important pieces of equipment. Fantastic, thank you.

Next, we are going to hear from Rachael Oliver who is the community engagement manager of Circus Starr. She's going to tell us about the Show and Tell app. It is an app that's got a real potential to unlock the whole world of arts and culture for an audience who really do often get left out, people on the autistic spectrum. Over to Rachael.

RACHEL: Hello, everybody. I am a bit of a project magpie. I came along when most of the hard work was done, so my predecessor, Cath Logan, was a Community Engagement Manager at the time, and also Therapy Box, and Tracey Piper Wright did all our research, and I've come along and inherited this baby, and I've got to take it forward, so, when I use the word "we" it is kind of a Royal we, so go I a long with me.

First of all, the project itself: what we wanted to do, we wanted to increase accessibility, and we obviously realised that there was a big explosion of mobile apps and smartphones everywhere and kids were using them. We also identified the fact that there was few arts programmes that really catered for children with autism. It is kind of apps that I am talking about, children that struggle with unknown situations, and I am shaking!

But it is basically a visual story format, so, what you get is a bank of images to our circus apps, the ring master does announcements, but also there are things in there that gives the child a bit of a preview what is coming, things like queuing up outside the tent, things like the generator outside the tent which might make a bit of a noise can be included.

But also, what was quite unique for us was we were supporting autistic children but within an entertainment setting, rather than a clinical or an educational kind of setting which was obviously quite different for us, and quite different for them as well.

Obviously, we went for the iDevices. It was basically because that was the preferred option for children and adults with autism, but also because of previous of our tech partners, Therapy Box. A bit of a background about us. Circus Starr has been touring for 28 years. We specialised in inclusive circus performances, so we have children from all walks of life with all sorts of challenges and barriers, so we have children who have been referred to us by social services, had difficult upbringings. We have children who have lost parents, children with disabilities who are not mobile who will come to us in this wheelchairs. It is come on, come all. Our shows are relaxed. Anything goes, basically. No-one is going to stare or bother if your child meltdowns, if you need time out. We positively encourage people to dance, get up, scream out, do whatever comes normally, and the great thing is that parents can relax and actually enjoy a shared family experience, which is quite rare for them. 
We had an awareness that the show was appealing to children with autism but then we realise that there were some children that were too anxious to step inside the tent. I mean, I've spoken to parents who have maybe turned up two or three years running who couldn't actually physically move from the car park through the tent doors. It was, you know, the child was too anxious about what might lay beyond those tent doors.

So, obviously, we were looking to build confidence. We wanted to give that child a sense of predictability of familiarising themselves with the unknown of kind of picking points thinking, "Yes, I've seen that on the app." And that's where we were going with it. We tested it on our autumn tour, we had a handful of users that were testing it and their parents. It was really great, got brilliant feedback. Everybody said that it increased the enjoyment. The surprising thing was that, when we were asking whether we thought this kind of technology could help get into other arts venues and cultural experiences, everybody concentrated on the more basic going shopping or, you know, the sort of more mundane day-to-day stuff which speaks volumes for how difficult it is for these families to make it out the door. Obviously, something that was pleasurable and a leisure activity wasn't quite at the forefront of their minds.

The other part of the app, two features, the Plan My Visit and the After My Visit. The After My Visit means the child can upload pictures and use it to recall and talk with their families, and our families really like doing that. One of the things we discovered on the way was the fact that it was I pods and iPhones, although we thought it was a great idea at the beginning actually restricted access because a lot of our families are from low income so they only have Android devices, so we want to look at increasing the accessibility of it.

The other slight criticism was that it needed a bit more fun in it. Obviously, we were looking at it was a tool to prepare children, but we were looking at a very wide age group. A lot of the children that come to our show can be anything from sort of two, three to teenage, and I think a lot of them were interested in playing Clash of Clans or Candy Crush, or whatever else was going, so it didn't meet their expectations there.

The insights, we had a lot of help from the National Autistic Society. Heather Wildsmith helped us, helped us with the text we included. It was about setting expectations in the right way. We have at the interval a popcorn machine, face painting, the usual things you would find at a circus, and they were all chargeable. We put you will have popcorn at the interval, have your face painted. She said, no, you need to say, "There will be popcorn." Not setting the expectation up that it was going to happen because it was then a family having to deal with a child that was upset because things hadn't gone the way they thought.

We also kind of got an awareness of what made us autism-friendly, and it is really kind of quite interesting for other organisations looking to appeal to that audience, because it was the ring master signposting the bits of the show. They really liked the obvious exaggerated emotions; there was no reading between the lines. Our circus is obviously in a round. You can see everything that is going to happen. There are not any big surprises.

One of the key challenges was the recruitment and the user-testing. Obviously, if you're dealing with a group of children who find it very stressful to be in unknown situations, you can't expect them to rock up to an office they've never been to, so a lot of time we were using after-school get-togethers, and that didn't always work because the children were tied or we didn't have enough time.

One minute left - oh, my goodness! The time issue was a big thing, both with the users, wanted to involve more, and also with the developers. We found face-to-face communication was better at getting their point across and theirs.

The future - my bit. We want to make it more available, and we want to put it on Android, but there are obviously cost implications, and we need to make it backwards-compatible as well because a lot of children inherit their friends 


\section{AMENDED DRAFT VERSION-FOR REFERENCE USE ONLY F R O L IVE S P E ECH - T O-TEXT T R A N C RIP TION}

that their parents. We want more involvement of the user in the design process but didn't bargain for the fact there would be ongoing maintenance, crashes, bug fixes, renewing the content - it is really important it is accurate so what they see is what they get.

Also, our key thing at the moment, I am really pushing for, is to create a template that we can then offer to other organisations that can use it in their own arts venues, for their shows to try and encourage that audience to come in and take a look. I will say one more thing. We did have a wonderful e-mail from an eight-year-old boy. The mother was absolutely astounded that he managed to make it through the whole hour and a half - completely mesmerised, but the fantastic was that was that she had attached this e-mail of a dozen pictures of different activities they tried throughout the summer on the fact she had built the confidence she could do that with her child. Obviously, it is opening doors, and we want it to open more. That's it. Thank you.

\section{[ APPLAUSE ].}

JO: Thank you so much. I really hope it gets to template stage, because I can think of a whole range of different projects that will benefit from that kind of introduction they do for those particular young people.

Next, we often talk in access about the fact that, when you make something accessible, it supports a range of people, but then you realise it supports a actually much wider range than the people you first intended it for. In some ways, our next project will talk more about that, so I am going to introduce Arwel Gruffydd, the artistic director of Theatre Genedlaethol. And Derick Murdoch, creative of Galactig who is going to talk about Sibwrd. [ APPLAUSE ]

ARWEL: [ Welsh spoken ] I hope I demonstrated to you in a few short sentences there, but for maybe a very small few of you in the audience, your disability in that you don't speak Welsh! [ APPLAUSE ]

We are the Welsh language national theatre, Theatre again and again Cymru, means "National Theatre Wales". We have two languages. Our sister company produces work in English and we produce work in the Welsh language. Wales has a total population of around 3 million. About 560,000 of those speak Welsh. Our disability was we couldn't reach the population of our own country. That was the task we needed to face head on. We needed to grow our audiences. In the past, we also needed to - we also needed to communicate our work to a wider audience, not only in Wales, but the UK and internationally as well, and also meet head on ambitions to tour internationally.

We, in the past, have used various traditional methods of communicating the dialogue of a theatre piece to an audience that doesn't speak the language of that theatre piece by methods such as simple sheets of sin opposition handed out to the audiences before the performance but uses devices such as Stagetext as we are seeing here, and various ways of surtitling. The problem with those, is, just handed a piece of paper before a performance is not an engaging way of bringing your audience on board, but, also, with surtitling, we found that audiences were playing a bit of a tennis match, looks at the actors, reading the - looking at the text and read actors.

We needed a more engaging way of involving the audience in the theatre piece so they could look at the performance going on and receiving the translation simultaneously.

In 2013, we produced two site-specific theatre pieces using headphones, so the first of which we just had the actors mic 'ed so the audience could hear what the actors were saying in the town. The second of which was halfway up a mountain in Snowdonia, it was a conventional play, but performed outdoors. Again, we gave microphones to the actors and used silent disco technology for the audience to have two channels, so the Welsh speakers would listen on channel A, the English speakers, or non-Welsh speakers would listen on channel B. On channel B, we interjected the dialogue of actors now and again with a short synopsis just to keep the audience informed, just to tell them what was 


\section{A MENDED DRAFT VERSION-FOR REFERENCE USE ONLY F R O L IVE S P E ECH - T O-TEXT T R A N C RIP TION}

going on. We talked to our digital partner, Galactig, about this idea, and, out of that evolved Sibwrd, which Derick might be able to tell you a bit more now.

DERICK: Sibwrd is based around a multilingual system. You can upload synopsis along with text to support that. They can also upload programme information, multilingually as well. The users download the Sibwrd app to the theatre, and they will connect to the Sibwrd Wi-Fi system. We decided not to rely on a building's Wi-Fi network or on 3G, so, instead, there is a Wi-Fi kit that you can take with you to theatres or site-specific dramas.

When the user connects to Sibwrd in the theatre, they can then download the programme to have a look at, and sit back and wait for the performance to begin. The audio is then triggered via remote application which is managed by a member of the production team. So we are going to show a small demo which should demonstrate how Sibwrd plays out.

ARWEL: This is a production of The lady of the Sea in Welsh.

[ Welsh spoken ]

"The steamer has arrived, bringing tourists to the town."

"Barry needs to hurry down to the quay to offer his services as hairdresser to the visitors and is also a dance teacher and leader of the local band."

[ Welsh spoken ]

ARWEL: So we discovered during the development of this technology various things. We discovered there by using focus groups that people actually required a bit more synopsis than we thought they might. We purposely set up the first half of the play where the audience received a lot of synopses, and then the second -- synopses, and the second act, they got it now and again. The overwhelming feedback was that people got lost and they needed more. With the second project we trialled this technology out on, the main learning that found there was that language is more than just language. With language comes cultural knowledge as well. This was a play about the protest movement around the Welsh language that grew in the 1960s. And so Welsh speakers in the audience actually had some cultural knowledge, and actually just translating the text for non-Welsh speakers was not enough. We needed to include in the synopses cultural context of what was going on, so dialogue within cultural context.

With Sibwrd, we were able to trial out another aspect of this technology where you can use actually more than one language at the same time. So we took it to Germany, a festival of minority language theatre companies, and there we were able to perform Sibwrd, but not only were we able to give the audience the synopsis in German, but also in English, and also in Sorbian which is a minority language spoken in eastern Germany.

Moving forward from that?

DERICK: Focus groups helped us understand users and tested technology at key points. We wanted it to be simple with enough scaffolding to enable them to use the app and then with any user interface should be to reduce the distance between the audience and the content. With mobile apps, user experience should be guessable, predictable, and physical.

Nailing the user experience was relatively simple, but what we discovered it was not just about the technology. There were many lessons learned early on about getting the user journey right, from arriving in the theatre to when the lights go down, one issue we had after lights went down was that users sometimes assumed the app wasn't working, 


\section{AMENDED DRAFT VERSION-FOR REFERENCE USE ONLY F R O M LIVE S P E E C H - T O-TEX T T R A N S R I P T I O N}

so one of the things we did was make sure that there was cues being triggered early on with audio right at the start of the production. The audience doesn't care about gimmicks and features, the most important thing is the performance.

I am going to skip past what we are doing next, and we can just talk about very quickly I will - we can talk -

ARWEL: Our next production which we premiered at the Edinburgh Fringe this year, we will be touring Wales with it in November, you can catch it at the Cardiff Dance Festival second week in November. Do come along and try out Sibwrd. An unintended consequence, in a way, of this project, was dealing with an access requirement that is more conventional in that we are now able to use this app in order to convey the text to those with hearing impairment, and, in the future, we are also developing it for visually impaired as well. Basically, what we've done is we've put that on to that, and also giving it an audio content. So, thank you very much.

\section{[ APPLAUSE ]}

JO: My November diary is now filling up. I've got to go to Nesta and now to Cardiff as well. Fantastic.

Our final presentation in this slot is Maria Oshodi, who is the chief executive of Extant, who is going to be telling us about Flatland, and again the real importance of keeping the ownership of work within the hands of disabled people; not doing things for people, but doing things with people. Maria.

MARIA: Thank you. Okay, right, so hello, everyone. As Jo said, I'm the Artistic Director at Extant, and Extant is the leading professional performing arts company of visually impaired artists. I'm here to talk about a Digital R\&D funded project called Flatland. I am going to give you a summary of the experience, the main goals and key learnings.

So Flatland was designed as a proof of concept piece to show that it is possible to create an immersive theatre experience using technology that is accessible to both visually impaired and sighted audience members. It aimed to challenge the status quo in arts and heritage where digital expansion or enhancement of cultural opportunities focuses mainly on the visual, and the use of screens as an interface. Instead, Flatland aimed to move theatre away from spectacle to a more embodied experience.

We wanted to use this as a specific example in order to influence wider applications.

The project was a collaboration between a multi-disciplinary team of visually impaired and sighted artists in this country and in Holland, and UK engineers based in the United States.

Together, we explored a range of innovative technologies to create an immersive, pitch black installation, inspired by the 19th century satirical novella, Flatland. It tells a story of a two-dimensional universe, populated by unusual geometric characters where the social systems are determined through the art of hearing and the art of feeling. Specifically, we developed a handheld haptic device - I think there's an image on the screen now of it. It's a kind of a cube which is sort of palm-sized, fits in the palm of your hand. The top sort of plain of the cube slides forward and swivels left and right and that is what guides the person.

So we developed this and a tracking system which guided audience members through the dark environment, and we created interactive set pieces that provided sensory experiences, including the use of e-textiles.

We also used sound effects and live actors and sought to integrate all of these elements within the dramatic narrative. Each performance enabled both independent navigation through a set of four multisensory scenes, and 


\section{A M E N D D D RAFT VERSION-FOR REFERENCE USE O L Y F R O L IVE S P E ECH - T O-TEXT T R A N C RIP TION}

group moments where audience members were brought together to test whether the technology could support a collective experience.

Each audience member was given the motors, a second generation haptic handheld prototype device which guided them through the Flatland world.

They used sensations fed to the audience member as they moved and is an extension of our first navigation device called the Haptic Lotus which was developed for our initial project, The Question in 2010.

As well as this, we used location tracking of audience members within the dark part of the installation, which works in a similar way to GPS, and linked this to the prototype device to provide us with navigational cues and also to set targets within the installation. I would like to show you a few minutes now of a film that has been made on Flatland, so if we can show that.

[Video]

>>: Flatland is a project by itself ... [video sound not relayed] ... uses haptic technology ...

>>: We are on the edge of a really exciting time in terms of performance, in terms of broadcast, because of what technology is now going to enable us to do so what we have to start doing now is playing with this stuff. We have to start playing with the really interesting junction between all the creative industries and technology, and I suppose the thing that attracted me about working on the Digital R\&D Fund, it's the best example I can see of a deliberate intervention to start playing through creative industries with technology ... [inaudible] ...

>>: I think it's part of a larger movement that is going on, which allows audiences to grow, to explore, so I wrote about Flatland in my video games column in The Guardian because it seems to me to share these important interesting points with video games.

>>: I'm very interested in the relationship that people have with this technology ... [video sound is indistinct] ...

>>: I was really pleased to come into the project and try to help.

>>: Maria and I had discussed the overlap between the project in its theatrical format but also the potential to use that technology within exhibitions, or museums, and other organisations and also it would be really useful as a tool ... so we thought there was a real opportunity to share that knowledge and experience. From a personal perspective I thoroughly enjoyed my haptic experience. It was a really interesting and intriguing exploration of a space ... I thoroughly enjoyed it. ... really freed up my own inhibitions slightly because I then felt more able to explore personally, which was really exciting.

MARIA: Thank you. Sorry, we would be here all day! Okay, so over 100 people, sighted, visually impaired and wheelchair users from a range of games, tech, arts and heritage sectors, were invited to the Flatland installation to explore this first hand, and to reflect with us on the success of this endeavour, and perhaps most importantly the Flatland installation highlighted for us how accessible technologies can be designed into an experience from the very beginning, rather than an afterthought.

The project also enabled us to explore how new technologies can play with the audience's engagement with their own senses, the environment and new ways of storytelling, and this in turn enabled us to develop ideas for what we think is a revolutionary new theatrical convention, although we still only just are beginning to engage with its rules of engagement, which are very, very embryonic at the moment. 


\section{A MENDED DRAFT VERSION-FOR REFERENCE USE ONLY F R O M LIVE S P E E C H - T O-TEX T T R A N S R I P T I O N}

So more specifically, what we learnt is that teams working at a distance need blocks of time in the same room with each other where they can creatively explore together to avoid prescribed thinking. Thank you. And if planning a similar project again, we would locate creative development time within the actual installation venue to create a holistic installation build, rehearsal and performance process.

We also learnt that for multisensory installations, fine-tuning is required to manage cognitive overload, ie to balance the attention required of an audience between listening and feeling, etc. If you provide too much of either stimuli, you risk one of them being ignored.

We also learnt that the distinction between creative team, technology and research partners is unhelpful. All are engaged in a deeply creative process. Tech in our context is not something that can be just pulled off of a shelf but is groundbreaking research that requires time. Similarly, research is ongoing, an ongoing process of reflection in which all partners share.

So to conclude, we aim to continue this dialogue for the arts and cultural gaming and tech, etc, sectors, and to facilitate this we've created Finding Flatland, which is a demonstration experience where we present some of the technology, navigational and environmental elements inspired by Flatland, and it's all available in a portable set-up, and we've got this throughout the day for all of you to experience and participate in, in room 104 upstairs, so we hope that you get a chance to visit it at some point today. Thank you.

[Applause]

JO: Fantastic. So I hope you will see that access isn't dull and boring; it can be incredibly fascinating. It's also absolutely vital and it's entirely your responsibility to make sure that everything that you can do is done to make everything that you do as accessible to as wide an audience as possible.

Can you thank all my speakers in this session? They've done a fantastic job, and on we go. Thank you.

\section{[Applause]}

ROSIE: Thank you. Thank you to a wonderful panel and thank you to Jo Verrent. Jo Verrent.

[Applause]

Who I forgot to say is a Cosmopolitan Woman of Achievement, so that's not bad.

Now, we are on to the keynote address, which is being given today by Deborah Bull. To introduce Deborah, who is going to speak about the risk of success, I would like to introduce Hasan Bakhshi, director of creative and digital economy, policy and research, Leicester.

HASAN: Thank you, Rosie. Yes, thank you, Rosie and good afternoon everyone. So as a charity whose mission is to support innovation for the benefit of all, research and development in all its forms is something we care a good deal about in Nesta. However, in the rain, and this is something that Geoff Mulgan alluded to earlier in his comments this morning, the received wisdom about R\&D, how R\&D happens, who does it and when does it lead to successful innovation, has been dictated almost exclusively by scientists and engineers. In fact, actually, one of the reasons for having the Digital R\&D Fund for the Arts in the first place was that funders wanted to improve our understanding of research and development as it happens in the arts and what funders can do to support it. 


\section{AMENDED DRAFT VERSION-FOR REFERENCE USE ONLY F R O L IVE S P E ECH - T O-TEXT T R A N C RIP TION}

So who better to reflect on the roles of R\&D, of risk-taking and experimentation than Deborah Bull? Deborah's illustrious career has included over 20 years with the Royal Ballet, including as principal dancer, director of the artists' development initiative, creative director of $\mathrm{ROH}$, which we will hear more about from Deborah, and then as creative director of the wider Royal Opera House; a critically acclaimed writer, broadcaster and thought leader, you will all be familiar with her current work as Director of Culture at King's College London. As this career biography makes clear, Deborah is one of those individuals who has succeeded at the highest level in a range of environments. She has crossed artistic, leadership and intellectual boundaries and we are delighted that she can join us this afternoon to share her thoughts on experimentation, so please join me in welcoming her to the lectern.

\section{[Applause]}

DEBORAH: Thanks. Thank you very much, Hasan, for an over-generous introduction, and it's a great pleasure to be part of this conference today and hear about all these really fantastic, innovative projects.

I'm going to start by doing something I very rarely do, which is hark back just for a moment to my years as a ballet dancer. I want to take you back with me to a moment on the Covent Garden stage and I'm dancing the Sleeping Beauty and I'm about to face one of ballet's most difficult challenges, the Beecher's Brook, if you like, of the ballet repertoire. The music is reaching its climax and I'm poised, centre stage on point, and the conductor holds the percussionist on an extended drum roll while 2,000 pairs of eyes wait for my next move which is to release my partner's grip and balance, unsupported, frozen in time and space, in the spotlight in the middle of Covent Garden. It's a moment that gets rehearsed over and over again in the studio, repeated failures leading on a good day to glorious success, and on a bad day it is excruciating. Ten years on, that simple move of one hand, from here to here, is probably the greatest risk I've ever had to take. I realise now that as a dancer I came to terms early on with the inescapable truth that there is no success without risk, and there's no risk without failure. Because making mistakes is how our brains learn. You see it as babies start to toddle, and you see it as little girls like I was start to learn to dance. The wobbles and the stumbles are the visible effects of the brain working out the most efficient way to send the most direct message to the muscles. If it doesn't get it right, it tries again, and when it works out that most direct pathway, it locks it in, and new network of neurons and synapses which is there for good so the risk and failure are integral to the eventual success.

Over the next 20 minutes, I want to talk to you a little bit about how that everyday familiarity with risk and failure has informed and shaped some of the work I've done beyond my dancing career. I want to look at some of the institutional challenges of developing environments that are open to risk and comfortable with failing, and I want to look at how attitudes to risk and failure are influenced by cultural conventions, our upbringing and the wiring of our brains.

Now, I spent most of my performing career in a large, long-established organisation, viscerally aware of the tension between the responsibility for heritage and a desire to break new ground. Too little respect, and the past is destroyed; too much, you threaten the future. Long term success and the security that comes with it seemed not to facilitate creativity and risk but actually to militate against it. At the same time, looking around me at the vibrant, independent dance sector of the 1980s and 1990s, I saw almost the reverse: individual artists, small scale companies, barely surviving from project to project yet consistently pushing boundaries and trying out new ideas. Throughout my career, in and around several large scale, long-established organisation, I've become increasingly aware of a conundrum which is this: large established organisations seem to have the scale, the resources and the track records to support risk-taking, but they struggle to find the necessary flexibility, the working environment or the culture. 
Individuals and companies working at the margins or even outside the systems seem to have the creative freedom but not the resources.

It was in response to that conundrum that I established a framework at the Royal Opera House to enable genuine and sustained collaboration between the institution and the individual, a mechanism to bring the risky fleet of foot and the imaginative thinking of creative mavericks inside the organisation while resources, skills, networks and knowhow would be shared out into the broader sector.

Opening up the organisation to independent creative artists might, I hoped, influence the culture of the organisation itself, and it was this ambition that led to the establishment of $\mathrm{ROH} 2$, a unit inside the Royal Opera House but with freedom from some of its organisational constraints, a mission to bring together different voices and approaches in order to stimulate new ideas and a specific remit to provide an arena for risk.

At the time, I was working largely on instinct. I had a clear vision of what the change needed to be. I had an idea of how we might do it and I had a passionate desire to make it happen, and over the years I became more and more curious about the why. As organisations become more established and more successful, why did it seem ever harder for them to take the kind of creative risks that brought them into being in the first place? I could see the obvious challenges: long term planning cycles, union agreements, fixed overheads creating pressure to maximise ticket income by repeating trusted formula rather than risking something new.

But it seemed to me that organisations accrued something else as they acquired history: they accrued unconscious shared beliefs and assumptions that silently infiltrated the decision-making process. Mental models that in reality were driving the business model.

Years later, when I read a work in 1957 on institutionalisation, I found a language that helped describe the things that I was observing. Selznick's references are the US Marine Corp and the San Francisco cable car.

He describes institutionalisation as a process that happens over time, reflecting its history, the people involved, the groups it embodies, the vested interests of those groups, and the way it has adapted to the environment.

In his theory, when organisations become institutionalised, they're prized for what they are rather than what they do. The more precise an organisation's goals, the more specialised what it does, the less opportunity, he says, there is for social forces to affect its development.

Crucially, in times of discussion we are having today, this can make them resistant to change. In his words, "Bowing to economic or technical considerations reluctantly and with regret."

Obviously, that's not any of us in the room, by the way! In Selznick's view, organisations should be expendable. He calls them instruments to achieve ends, and they should be readily cast aside when a more efficient tool becomes available.

Here, I really am dancing on some fine lines, because, to suggest to you that arts organisations are expendable and we placed by something more efficient is a bit too close for an argument to instrumentalism and won't make me many friends. He isn't talking about arts institutions, and, crucially, if he were, he wouldn't be describing as art as the instrument; he's talking about organisations. It is the systems he's talking about. I think what he's warning it is any tendency to value structures or operating models for their own sake rather than for what they achieve. He is reminding us also of the imperative to remain alive to changes in the external environment that might, if they're ignored, become toxic. 


\section{AMENDED DRAFT VERSION-FOR REFERENCE USE ONLY F R O L IVE S P E ECH - T O-TEXT T R A N C RIP TION}

Let me bring this to life to you with an example. When I was growing, knowledge lived in a series of books on the shelf, the Encyclopaedia Britannica. But, in 1990, it was a company with a 225-year-old history, it was a global brand, and its annual post-tax profits were $\$ 40$ million.

Five years later, its sales were down by 50 per cent, the sales force were slashed in half, and its 91 offices were reduced to 20. Its CEO and board were dismissed, and Encyclopaedia Britannica was up for sale. What did it get wrong? It failed to - it ignored Encarta, Microsoft's encyclopaedia, because it didn't align with its mental model in the world around it. In now what is regarded as a classic case of market blindness, the CEO dismissed the threat of personal computing as irrelevant to the operation that he was leading. "We are in the book-publishing business, not the computer business," he said.

There are four lessons to the story which applies to any organisation. Number one, that history counts for nothing if the market changes.

Number two, that fixed mental models about yourself and what you do can blind you to external events if they don't correspond you to your view of the world.

Number three, if a Microsoft comes along, well, it is probably game over.

Number four, the biggest contributor to future failure is past success. Which is worth thinking about.

So how might big successful established companies, who were themselves once pioneers - let's not forget - respond to the disruptors at the other end of the market? Do they compete against them or do they continue to focus on providing bigger and better for their existing customer base? After all, historically, that's what they've done, and it has been successful. And this, you may well recognise, is Clayton Christianson's Dilemma from his 1997 book. He points out that companies like Encyclopaedia Britannica leave the high road open to a new population to access something that was previously only available to a limited few, and this, of course, changes the shape of the market.

One possible response to the innovator's dilemma is to try to bring the innovators inside the tent, and that is what I was trying to do, I now realise, at the Royal Opera House when I set up ROH 2 in 2001. I hadn't read Christianson before and didn't realise I was building on the concept of Skunk Works, as "an enriched environment intended to help a small group of individuals design a new idea by escaping the routine organisational procedures."

Protecting the group from those organisational constraints, industry conventions, and those inhibiting mental models we've already talked about lets them think creatively, take risks and break the rules. At the opera house, the project groups came from both inside and out, and they worked across art forms, recognising that it is often at the boundaries between disciplines that true innovation occurs.

Our aim was not just to develop new ideas. I also wanted to influence the organisation's culture and its attitude to risk and failure, and so, in the core team we had both newcomers but some old hands too, and this was important because it allowed us to think like an outsider but with deep insider knowledge, and that made the team a more potent agent for longer-term change.

I was probably swimming a bit against the tide. It wasn't unusual in being an organisation that was more comfortable talking about success than failure, and when I shared my first board presentation with a colleague, she was absolutely horrified I intended to include the phrase, and, if I don't fail from time to time, I won't be succeeding. She said, "You can't say that to the board!". I said I am going to, and, of course, I did. I knew instinctively that if artists were going to create great art, they would need to take risks, and they would need, therefore, to be allowed to get it 


\section{AMENDED DRAFT VERSION-FOR REFERENCE USE ONLY F R O L IVE S P E ECH - T O-TEXT T R A N C RIP TION}

wrong, and I believed it was the responsibility of organisations that have a loyal audience base and the luxury of relative stability to support artists over an extended period, giving them the space to take risks and allowing them to fail.

If we avoided discussing those failures, we were depriving ourselves of the learning that contributes in the end to the eventual success.

So I have a nagging worry that, despite everything I've argued today about the importance of risk-taking and the value of getting things wrong, we are becoming as a society more and more focused on stress and less and less comfortable with risk and failure.

Why would that be the case? Well, one explanation comes from a group of academics in Stockholm, Michigan, and the London Business School. Using data from 42 countries, they explored how our belief in our ability to succeed, our fear of failure, and our attitudes to risk are contingent on our national culture.

They argue that a society that emphasises high performance leads people towards activities with the highest predicted economic outcome rather than activities that are more uncertain. In other words, the more society values high performance, the more a fear of failure prevents us taking risks. It seems that this may be a particular problem here in the UK, a PWC report recently compared attitudes to failure in the UK and the US included this quote:

"In the UK, a failure is a failure. In the US, a failure is someone who has tried."

We may be compounding all this by raising a generation of risk-averse children. There is an emerging consensus over researchers over the last 25 years that, far from giving them confidence, over-praising children actually leads them to become more cautious. Social comparison craze, "I.e., you're better than others" teaches children alone that winning alone is the goal. How do they maintain the number-one status? Well, of course, by avoiding risk. "If I don't try, I can't fail." The end result is they grow up unprepared to cope with failure.

It is not only damaging to their personal development, it is eventually damaging for the economy. As lan Livingstone said on the recent report on the business of creativity, understanding that failure is simply success work in progress will give young people the mind set to become job-makers, not just job-seekers.

But it may be that our brains are hard-wired to avoid failure. Research into how science research is carried out - and, yes, I did just say that, research into research! - found that the brain carefully edits reality. The part that part that perceives error can be overridden by a second part that suppresses those things that don't square with our view of the world. When those two areas of the brain activate together, we notice that something is wrong, but, simultaneously, we edit out the error message.

Essentially, our brains seek confirmation of what we already believe to be true, regardless of the facts. If the data contradicts the theory, what happens? The experiment is deemed a failure. Yet, in science, as in art, it is often the unexpected result, the experimental error, that unlocks the result, the puzzle.

Reassuringly this same research also showed that considers-disciplinary conversations forced the scientist to find new ways to express the problem, to revisit their assumptions, and to see the apparent failure in a new light, which is another good argument for collaborations across disciplines and for including the " $\mathrm{A}$ " of arts in esteem-based curriculum.

I learned from those very first ballet classes far too many years ago that, if I was ever going to succeed, I had better make failure my friend, because no dancer has ever managed a triple pirouette on the first time of trying. Failing 
again and failing better will make me the dancer I want to be, and it is not a new millennium. A millennium - "I err, therefore I am." Failure is one of the key drivers of evolution of the failure shapes our brain, our primary teacher, and it provides valuable knowledge that helps mankind advance, and, if you don't take risks, you can't fail.

I said earlier that the biggest contributor to future failure is past success. What I didn't say is that the reverse is also true. The biggest contribution to future success may just be the risks you take, and the failure that you learn from as you go along the way. Thank you.

\section{[ APPLAUSE ]}

>>: Thank you for that. We've only got about ten minutes or so, maybe slightly under, but I think best what we can do, even though it is billed as a conversation, is to raise maybe a few issues which hopefully we can explore with Deborah over lunch and myself will be around as well for those wanting to continue the discussion.

I am coming from the world of innovation studies, innovators' dilemma that you prescribed, is there anything distinctive about how it is played out in cultural institutions compared with institutions of other sectors?

DEBORAH: There are two things that come to find, and the first is about the people. We, me who work in arts organisations, that we put super human effort into what we do, and become very, very passionate about it. Selznick writes about the impact of this of the ability of an organisation to change, because we can become overly attached to the organisation as it is. That's one of the risks.

The other point is there's been a resistance - it comes back to that same argument, and I am going to make myself unpopular - but there's been a resistance to asking of a activities to create works for specific purposes other than the art itself, so, you know, we want to commission an X, a play, but we want to have that guy, so we can't tell him it has got to be for young people, or to attract older audiences, or to bring together local communities, I mean, he is an artist, right? He will speak from his heart, the idea will come, and he will give us the art. There has been a resistance. Again, one says these things as if they are generic. I know there are examples of organisations where that isn't true, but sometimes there has been this resistance to - a sort of sacrosanct nature of the art. We can't touch the art, we want to attract new audiences, but we can't touch the art.

Actually, if you were a business and you wanted to get a new market, a new purchaser, you would look at what you're selling, but there is this feeling that the art is sacrosanct, and so I think those things are particular perhaps to cultural organisations.

HASAN: That is a fundamental challenge organisations wanting to innovate. You mentioned the ROH 2 language, used the language "open innovation" and again coming from innovation studies one thinks of Procter \& Gamble and IBM, but here $\mathrm{ROH}$ was doing it, and how you overcome those challenges and resistances?

DEBORAH: When I arrived there, there were two bits of paper on my desk. One was a invitation for my annual appraisal on my first day, and the other was a head-hunter inviting me to apply for another job! It led me to think about who might have taken that job, and, in some ways, there would be lots of people who could have done it much better, but I had two things that stood me in really good stead: one was this really passionate vision - I am quite a deep - and a keep gut understanding of the organisation, a visceral understanding of it - so I had a passion for what it could do differently, and complete naivety about the organisational challenges. I really didn't know the - I mean, I didn't even see the minds, I just hopped over them. I think anybody with a deeper experience of working in big organisations would have been cautious. I kind of went where angels feared to tread because I didn't really know, I didn't really know I was overstepping boundaries, and I - so I had very good support from Tony Hall who really 


\section{AMENDED DRAFT VERSION - FOR REFERENCE USE ONLY F R O L IVE S P E ECH - T O-TEXT T R A N C RIP TION}

wanted to make the change and saw a way to do it, and I had a fantastic team, and I think that point, it is a strong point of having the old hands - so people who know the organisation but are with you on the change journey - and the fresh eyes.

I mean, the advice - who is it? - some famous business person, "Listen to your newcomers." Get their perception before they become the hold hands, because, actually, they can tell you things that are blindingly obvious but you've become so fixed in the way you're doing things.

I think there was, yes, there was a great openness from the sector to engage, and I think that probably was helpful that I was speaking initially as an artist, so that the, it never felt - it really didn't feel - or, sorry, the response was very rarely, if ever, a "Which box are you ticking now?" People genuinely saw the passion for -

HASAN: [ Inaudible ].

DEBORAH: I like to think so.

HASAN: This is another potentially very provocative point you made, and I've got this quote, this researcher Selznick, that organisations should really be expendable.

DEBORAH: Yes.

HASAN: Which was a striking statement, organisations instruments to achieve end. It aligns with our Digital R\&D Fund, the creation of the knowledge we were funding rather than projects per se, even though there's been amazing projects we've heard today. Do you think in the arts and cultural sector we should become more comfortable with the idea of churn?

DEBORAH: I think transformation is important. It is that issue of being alive to the external environment, and what are the needs of the nation? What are the needs of the sector, the art form? I like the idea of an ecology, and I like the idea of, you know, those things where you push down somewhere and it pops up somewhere else, so, that, actually, it is not about destroying and building, it is about moving skills, resources, networks, knowledge around the sector to where it is needed, to make the change, so I think there is something about being comfortable with transformation.

I was very struck $X$ years ago when, sort of in the same week, Viyella went down, Wedgwood went down, and went Woolworths has gone. We can't get stuck thinking any of us are here forever. Just as none of us as individuals are indispensable, I think probably the logic is that our organisations are not. What they do is different.

HASAN: Would you like to make predictions about what the next predictions of the next Wedgwood would be!

DEBORAH: No, I wouldn't! [ Laughter ]

HASAN: Before we finish, another important theme I picked up in your comments was this idea of innovation coming at the boundaries between different disciplines, and obviously, your current role in higher education institution, your experience of the Royal Opera House. Can you give practical examples where clashing of boundaries led to successful innovation?

DEBORAH: So you never quite know when the success might happen, of course, and I think immediately of the things we are doing at King's where we are bringing together artists with scientists, craft-makers with surgeons, who are 


\section{AMENDED DRAFT VERSION-FOR REFERENCE USE ONLY F R O L IVE S P E ECH - T O-TEXT T R A N C RIP TION}

repairing bits of the body are working with craft-makers to look at the where the innovations in techniques might go across the sectors. We are not going to know if they're successful until the first patent comes out.

Thinking back to the opera house, we were very fluid about how we interpreted that, so, one of my first projects, I basically was thinking about what is opera? Opera is story-telling through stage, through voice, and, actually, every culture does that, so we worked with Nitro who were a black theatre Co-op to invite successful black British composers who had never worked in the opera genre to come and work with us on opera and individual arias. You never know how those things are going to influence people's careers, but it was lovely to see Wallam, a talented composer, done fine without it, but when you see her doing a piece in the Last Night of the Proms it is nice to think you might have influenced the route of that journey.

We played around with formats, too. I am always amused that every good television programme, hey, it is miraculously an hour because it fits with the schedule, and every theatre is two and a half hours long but great ideas are sometimes 20 seconds or 20 minutes. I am very interested in the different between the analogue brain, my brain which is page down, and a brain of the person who has been brought up in the digital domain because they will see the world differently. We thought how does that translate into a theatrical experience? What would it look like if you created a real-world website where you went and clicked on, entered into the thing you found interesting and you moved on if not? No clear start or beginning. Of course, you have to open and shut the building, so we were playing a lot with formats, learning from other genres, and then putting together technology with composers, and word with dance - all sorts of things.

The first piece we did, which doesn't seem hugely innovative now, but Will Tuckett, who is a brilliant choreographer, had worked a lot in the standard ballet formats, and, you know, done well, but he was losing heart a bit. He came downstairs to the smaller space and did Wind in the Willows. He was frustrated about the "We are going to the shops dance" because how else do you know you're going to the shops? He thought, we will just say it. So what a brilliant idea. Now they go to the shops. Let's get on with the action. He invented this form of dance theatre - not musicals, not - and Willows, we which did on a shoestring three for four times, now they're doing it in the West End at Christmas. That feels like a bit of a success, but you wouldn't say the Wind In The Willows doesn't sound hugely wizzy and digital, does it?

HASAN: Nice art form innovation, cultural innovation coming together. I am conscious of the fact that lunch awaits. I should apologise to the tweets because Twitter has been noisy on my iPad. Thank you very much, Deborah. If you join me in thanking her for the time.

\section{[ APPLAUSE ]}

ROSIE: Hasan and Deborah, thank you so, from standing on one point to Encyclopaedia Britannica, you made risk sound essential. Thank you for a wonderful speech, and a wonderful conversation afterwards. Very inspiring. It is going to be a quick lunch. You need to be back here at 2.15. Lunch is served in the mezzanine, and, of course, you can talk to this morning's speakers, and the speakers' lounge in the ground floor of the Rep and Meet the Projects. We are back to talk about our next theme, which is data. If you're booked on to the accessibility masterclass, please make your way to Room 101 for a 2.20 start or 104 for the digital workshop.

\section{[ Lunch break ]}

This conference will have live subtitles by Stagetext. Please sit where you can see the text comfortably. Thank you. 


\section{AMENDED DRAFT VERSION-FOR REFERENCE USE ONLY F R O L IVE S P E ECH - T O-TEXT T R A N C RIP TION}

ROSIE: Okay, welcome back, everyone. You will be happy to know, I've got two exciting bits of news for an arts digital conference: the wi-fi is now working. You can access it like that; and the other thing is that \#artsdigital is trending, yay, so that's really cool.

Right, I suppose appropriately enough we are now getting onto our third theme which is data, and our champion Julie Freeman. Julie Freeman uses data to create kinetic sculptures, sound compositions and animations. Her artwork, which has been exhibited internationally, questions technology's impact on how we connect to and translate nature. She leads as the data's culture art programme at the Open Data Institute and is a co-founder of an organisation raising awareness of human rights through art. She is a TED Senior Fellow and a doctoral student.

JULIE: Hello, nice to see everyone.

[Microphone not relaying audio for speech-to-text.]

... we are in a world where data is available everywhere ... how we can make a difference by using it ... I want to show you a website now that indicates [inaudible] ... it's realtime and it monitors the amount of data that we are spewing out all the time through blog posts, through emails, through tweets and [inaudible] ... interesting indication of the amount of data that is being generated every second of every day. It makes us wonder what on earth we should do with this ever growing resource.

The next slide. So a snapshot of what the ODI wanted me to present ...

[No audio for speech-to-text]

... it's not magic. In fact, the opposite to that. You can't keep data in the cupboard, bring it out ten years later and say, "Look at the value of my data". That's not going to work either. The future of data is in realtime understanding. ... we know that data is not truth. A number cannot be truthful. ... I am going to show you just briefly examples of how we can use data to connect with people in a different way. This first work, a vending machine ... [indistinct audio] ... hours labour that traditionally we are kind of supposed to. In a digital economy we all work nearly all of the time because of our devices, and he made this huge, $3 \mathrm{mx} 5 \mathrm{~m}$ banner, so we've got data as knitting and this is someone in one of his workshops who has knitted it looks like a sleeve, I'm not sure, but she was really interested in how data and knitting came together so it's a really lovely project. It made data very tactile.

This is another piece by Fabio called The Obelisk. It's a beautiful piece, a light sculpture that flickers and changes, the opacity changes to form different light patterns. The data he is collating from different news feeds is all about crimes against humanity, so if there's a crime of aggression or there's something to do with war, the light flickers, and suddenly the piece of work changes from being something quite beautiful and abstract in the corner to something that is reminding us constantly that the world is very, very far away from peace.

This piece of work is the last piece I'm going to show. It's from Natasha who is our current artist in residence at the ODI. She is an interesting character, a photographic artist although I would argue she is also a performance artist as well. She made a piece of work called Married Man in which she went on 80 dates with married men that she found through a website and she took covert sound recordings and covert images of them, of the date, so just of their hands, of the table, of the debris that they had left after dinner, and this is the handbag that she used to do that with. It's a beautiful print that we've got up in the space at the ODI. One of the things that came out of this was people the staff at the ODI were like, "Well, we are pretty data savvy, can you tell us where the data is in this work?", and in fact with lots of our works, we have. People don't always see straight away where the data is. 


\section{A MENDED DRAFT VERSION-FOR REFERENCE USE ONLY F R O M L I E S P E E C H - T O-TEX T T R A N S R I P T O N}

We were lucky, some weren't so lucky, that within weeks of Natasha starting work at the ODI the Ashley Madison affair broke, and I don't know if anyone doesn't know about this, but it's a website where you can hook up with people who are married, a clandestine affair website, and they were hacked and the hackers pretty much put the data up there so you could search for email addresses of people who had been cheating on their partners or who were interested in playing that game.

All of a sudden Natasha's work, which is just a series of photographs, became very much about data, very much about the vulnerability of data and the vulnerability of people using digital technology and putting their information out there, and what that means in today's culture and society. It's a very powerful piece of work that was assisted by this leak of data that, you know, was quite serious and led to some really fatal things happening.

So we need to think about what data means, rather than just this kind of ever-expanding growth of blog posts and tweets and things like that, what else is the data that is out there? What is the data that is directly relevant to you and your organisation? If we click on another website here, that is again another example of a measurement of everything, and scroll down to the food section, I was looking at this as I was researching and I thought, "This is a really interesting website that gives us an awful lot of information". These figures here particularly took me: food. This number, if you look in the middle, people who died of hunger today, 18,522, 23 and rising quite quickly, more than one a minute. Above that, obese people in the world, which is also a number that is rising, nearly 540 million people.

I think these are two really powerful numbers, and if we move to the next slide what I found was that I was wondering who those people were. Why is this happening? What does this data mean? The data is without context and it doesn't fulfil me. It makes me feel awful. But it is not fulfilling me properly.

So it's not about - it's not oil, not magic, not truth, and it's not just about growth. It's about the context and the story that you tell with these numbers. I want to - ooh, sorry - I want to tell you a personal story. Today is 7th October. It's 20 years ago today that my Dad died. When I was building the presentation, I couldn't stop thinking about it. It's a remarkable - 20 years is such a long time. It's still a very powerful feeling. One of the things that I thought, it's like what is the data that reminds me of my Dad? Where is my Dad's data? Twenty years ago, there's not much out there. One picture I could find when I Googled for someone who had archived a magazine, but what I did remember was that he collected calculators. We didn't know this and when we cleared out all his stuff we found calculators everywhere, squirreled away in drawers and stuff, and it was really lovely, and it makes me smile to think about him and these calculators, and I thought: what is that data point? How many calculators did he have? I asked my Mum and she smiled and went, "I remember the calculators", she didn't know. Sorry. And my brother, he didn't know either. And I thought this is amazing. This is a piece of data I want to know. I am trying to remember my father, and to keep him alive, but I don't know the number. It's an unquantifiable value, and actually that is quite priceless.

So what is data? It's a mechanism. It's a mechanism to tell stories. It's a mechanism to communicate with people you might not have communicated with before. It's a way to contact people, audiences, performers. It's also a material, a really powerful material for artists to use in their artwork. And these artists aren't using it in a very literal kind of didactic way. They are using it as a way to reflect our society and our culture back to us.

It's also a memory. You know, data is a way of preserving what is alive and what has been alive, and the way that we can talk about that.

One of the things that is also important to remember is that it's not necessarily about the data we've got; it's about what we do with it. We know that data is changing the landscape in many, many ways. We can't quantify empathy. 


\section{AMENDED DRAFT VERSION-FOR REFERENCE USE ONLY F R O L IVE S P E ECH - T O-TEXT T R A N C RIP TION}

We can't quantify humanity and we shouldn't have to, we shouldn't need to, we shouldn't even be thinking about trying to do that. We should take the data and then we should act on it. If we know that there are people fleeing their countries because they need to get away because they are in fear of their own lives, we need not to be thinking about how we quantify that; we need to be just acting. We can make the world, the world of data, what we want it to be if we do it carefully. So I'm going to leave it there. And introduce three really amazing projects -

ROSIE: Deborah was talking about disruptive influences and I'm just going to be a small disruptive influence on your wonderful presentation because I forgot to introduce your film before you started speaking, so we are just going to have a small moment of disruption and we are going to have Julie's film which might actually be better after you have spoken than before. Who knows? It's not really your film, it's a sort of tee-up to what you are talking about and then we will bring on more guests. So if you could run the film, that would be great.

[Video shown without audio relay]

\section{[Applause]}

JULIE: We were truly disrupted by that. I would like to introduce Cimeon Ellerton and he is going to talk to us about his disruptive - no, he is not - his data aggregation tool, is what I want to say. Data aggregation tool. Cimeon, thank you.

CIMEON: Okay, hi everybody. Hopefully that's the little problem and then the rest of this is going to go swimmingly. We will see. So yes, my name is Cimeon, I am head of programmes at the Audience Agency and I want to talk to you about the project that was funded by the Digital R\&D Fund called Arts Data Impact. So data has become quite a loaded word over the last decade or so, I guess. At least certainly over time. It has moved out of the shadows as a purely technical term, something that researchers talk about and computer scientists and all of those sorts of people and, you know, it's something that we talk about every day in business and our lives, whether that's tweets, likes or the bottom line of finance.

But during this big data transition it has picked up quite a lot of baggage and hype, some positive and some negative, and it seems to have been particularly acute, I think, in the arts and our reactions to that have been quite mixed, I would feel.

So when we talk about data-driven decision-making, which was really the point of the Arts Data Impact project, it's greeted with amusement, indifference or even horror.

My colleague, Anthony Lilley, co-author of Counting What Counts was asked the following question after delivering a presentation on data-driven decision-making to senior leaders in the UK arts community, and that question as you see was: so you are telling us that a computer program should program my venue? And this isn't a silly question. I think we are all quite engaged with data but we are in the tent and there are plenty of people outside of the tent. So the portrayal of data in the media seems to be the sort of automated realtime analysis techniques employed in the truly big data domains such as finance or insurance, will maybe take all of our jobs. And of course, in reality, the scale and speciality of that data now available to us means that actually human interpretation is really more important than ever. So what do we know? We know that data does not equal truth. It's really crass to say, but my other colleague, Professor Paul Moore of the University of Ulster, who also co-wrote Counting What Counts, he reminds us that there is no objective truth in data, big or small, and it's always communicated through the lens of human interpretation. 


\section{AMENDED DRAFT VERSION-FOR REFERENCE USE ONLY F R O L IVE S P E ECH - T O-TEXT T R A N C RIP TION}

So our own and our organisation's values, knowledge and experience are really key to that interpretation and in this way data is always storytelling as we've heard already and we in the arts and culture sector really need to take control of the stories that we are telling because, if we don't actually have that data available to us usefully and in a way that we can interpret and analyse, with the skills and tools that we need in order to tell the right stories and to make sense of the data, then someone else is going to tell the story for us and possibly even take control of the means of production and distribution and communicating arts and culture.

Of course, it's really important to state here that there are people in arts and culture, and I am sure many of us are here, who "can do data". There are many people working with data every day, not least those often in marketing departments or development departments where perhaps they employ increasingly complicated procedures for measuring return on investment; there's an increasingly diverse marketing mix that they have to prove the value of; however, the reverential gap described in Professor Paul Moore's ethnographic study which is about to be published as part of the findings demonstrates that data literacy and what we came to describe as data-informed decisionmaking, which is perhaps a more palatable and more truthful description of the way data can be used than the kind of DDD or data-driven decision-making terminology - using that data literacy is really important to bring into a senior level in the organisations. Because even the best kind of data-driven tactical planning by some of those marketers or development officers is never going to achieve its full potential if the strategy itself is not data-driven, if the senior managers and the boards aren't really completely au fait and happy, if not interpreting the data themselves at least in understanding the interpretation that is presented to them.

So it was kind of out of that landscape that The Audience Agency brought together the project partners, Magic Lantern, University of Ulster, with the Barbican Centre, English National Opera to really look into those barriers to data-driven decision-making.

I was at a conference at the British Museum a while ago and there was much talk of the idea of data scientists being unicorns but as has already been said, data and the people who can interpret people are not magic, not mythical, they are not unicorns, they are among us. Arts Data Impact embedded the first ever artists in residence at these organisations and rather than taking a tools-based approach initially they asked the organisations what their actual issues were and turned those problems into challenges that could be answered by data tools, rather than the other way around.

So I'm going to very briefly talk about those tools. As I've said, it's not really - I don't have much time and it's not really about the tools, but the outcomes are really important, or the outputs rather for understanding the different directions that we took.

So the National Theatre, a big remit to look at theatre across the nation, and they wanted to understand what was being spoken about in social media, so we looked at Twitter. We think it's quite a groundbreaking tool because it's very difficult to get the data out of Twitter unless you have got loads of money and they actually sign off your business case, so essentially we developed a mechanism to actually start building a database of followers of cultural organisations in the Twittersphere and then apply learning to detect themes that are relevant to arts and culture or not, so they can have a really detailed and relevant understanding of their audience.

We looked at data storytelling. The English National Opera wanted to focus on the segmentation of their audiences and want to move just beyond what they would find out in their own box office systems so we used the big Audience Finder warehouse which I can tell you about another time, in order to see their audiences in a wider context and really it was a data storytelling tool and that has already had huge impact across the organisation in terms of developing a shared language, and what we really know is that actually the first step to changing the culture around 


\section{AMENDED DRAFT VERSION-FOR REFERENCE USE ONLY F R O L IVE S P E ECH - T O-TEXT T R A N C RIP TION}

data has really been about developing shared languages so that the programming team even can actually look at the results of this team, and not freak out and run away; they actually talk about who the audiences are for the different products that the English National Opera actually put on stage.

I'm nearly there. The Barbican were really interested in understanding membership and what we were able to do was to apply predictive analysis to their booker database. It does a really, really simple thing. It actually measures the likelihood of an audience member responding to an offer of membership, and so it doesn't require someone to even interpret any data. They just generate the list and they can send the right offer to the right people so that hopefully we grow the audiences. They are testing that right now, so I hope to come back and tell you exactly what the results are.

I am going to skip the next one because unfortunately I tend to talk too much and I've run out of time but if you want to find out about the other sorts of predictive analysis that we developed, then please do come and talk to me, but I think what's really important to say is that we worked from the problems up; we brought specialists and data scientists into the organisations and what we really looked at was the culture of the organisations around data, and that's what really made it work.

Thank you.

\section{[Applause]}

JULIE: I think it is really important that there's one of your slides that said, "Some of us do data." We can all do data, not just some of us. It depends on the tools we've got. I would like to introduce John Coburn, who is going to talk to us about novel interfaces for digital collections. I am hoping some of them will be about jelly! Maybe not.

JOHN: So I am John, I work at Newcastle, we have nine galleries and museums in our organisation. I will talk about data as cultural artefact, but, before I do, I will give context on the sector.

Over the last 15-plus years, we've sent a lot of money, multi-millions of pounds digitising objects, making digital replicates of objects that we keep. There is a common view that has been relatively little investment in tools that make this data available for a while, beyond a research audience. When I say a research audience, I don't just mean academic, I mean the person who wants to find the vase, or the school.

So, most museums have one of these, and it is not the only way of accessing the collections, but, for a while, this was the default way in to the greatest stuff in the world. Mitchell Whitelaw who is an artist and academic, this model of search, for him is ungenerous in that it withholds information and demands a query, and what we need within the sector is more generous interfaces that enable brows, enable us to discover the scale and complexity of our collections.

So, by way of contrast, when we talk about data as cultural artefact, this is maybe a very good example - a visually rich and content-rich record. This is maybe a less good example - Portrait of man by an unknown person.

So our project was a partnership with Newcastle university, and Microsoft Research. We were all very interested in new models of seven. We developed an R\&D interface which was about creating new and compelling experiences for a wider public. What we produced as well as the interface was a suite of tools which you stuck on which we are still refining that we are making available with the sector.

The methodology for developing the project was design-led research which the projects are today, usability at every stage. It was starting with a prototype and refining that as you go through the process, testing that with the public, 


\section{AMENDED DRAFT VERSION-FOR REFERENCE USE ONLY F R O L IVE S P E ECH - T O-TEXT T R A N C RIP TION}

and basically provoking from them what a final result should look like. Clearly, this is about designing a collections interface that was all about the user. It was much less about a space for a completion online.

It is a shame I can't demo the system for you. It is on our website. We developed - sorry, these were the design principles that informed the build of this following some early sector research. It needed to be these four things: immersive, simple -- that was only one 14th of half the available data, and we have 1.1 million objects in our collection.

It is set around infinite scroll but there is an intelligence in the system that responds to your every move. The more you over over artefacts, the more time you spent on them, the more related the content will be. We've minimised seven choices so we don't have drop-down lists and headers they understand. That represents the knowledge and the taxonomies of the museum. We have map views, a disparate collection, so a young woman there connects social history artefact with - we ...

We invited audience into this collection access through setting up what was actually very artificial binary search preference, one about audience, you know what they want to find, and one about audiences you don't know what they wanted to find. This is R\&D for some audiences, confuse, frustrate or make sense to them. We were essentially preparing that distinction.

So, a summary of the results following a month of testing - sorry for the text. We had a really high dwell time. I should say that we are treating these stats with caution, it was only a month of data, we would have liked more. The dwell time was on average high. We found that there was seventy per cent of the audience generally really responded well to this different presentation of artefacts, close to 30 per cent were just audiences who wanted much more control of the way they wanted to be in the system, so this different presentation was both the most liked and the least liked presentation. It was the feeling that was cited as both of these things..our report, which is submitted now, has been that separated common behaviours of engaged users, so, as well as rather than just saying engaged and not engaged, what we picked out are people who could be different types of engaged users. There are some who want to know about the artefacts, and that would be embodied in people who look at information, zoom in on the object. There are people who actually just want to be immersed in a load of data, and they don't really want to know all that much about individual objects.

Twice as many users who came to the system cited themselves as people they didn't know what they were looking for. They were giving publicity, we were not giving interface publicity, so it is in a state of development.

There has been sector interest in adopting this tool.

So I will quickly give you some insights. There are audience engagement insights. Differences between what an audience wanted from a collections interface. As I said, people saw this as a tool to get to artefacts. There were some people, though, who saw this as an experience, actually, it was a provocative experience that enabled them to warned through rich data, and it was the presentation of different data at the same time that was for them engage willing. Within this, given a number of people come to this after citing themselves as someone who doesn't know what they're looking for, it was the responsibility of our museum to provide more tools for the audiences who want to encounter the unfamiliar.

There are data insights we've gleaned. The collection the interface we've billed are generally objects in a catalogue. The interface should build on the strengths that you have -- of the data that you have available. We would like data that had more narratives and stories, and if they were in our collection, we would make focus on a story. 


\section{A MENDED DRAFT VERSION-FOR REFERENCE USE ONLY F R O L IVE S P E ECH - T O-TEXT T R A N C RIP TION}

We know that innovative tools can't do much with bad data, so incomplete data, audiences citing records where the key words were plain and not expressive enough, the objects were blur which. This, actually, is was -- blurry. It was a fault of the data, not the interface. With that, I've taken that back to staff and we've talked about the fact that really user experience should be emphasised as beginning at the point at think with data is entered and collected.

The design-led research, which we used, was not one that we ordinarily used within the museum. I don't know about you, but it was very time-consuming. It produced really complex and contradictory data that was, at times, difficult to respond to, but, actually, it was completely essential to be able to incrementally improve something that was about creating something of public value.

With that, it demanded that the organisation reflect on what is most important for them in 2015. Is it about duplicating what exists within the museum digitally or is it actually will using the data that best engages and provokes an audience?

So I will say thank you, but, before I do, I've written on my hand currently now we're in a position where we are releasing these tools to the sector, so if you are interested, you can either talk to me after this, we've stuck the code base and documentation as I've said, and we would love people to use this, adapt it, and do stuff with it. Thanks. [ APPLAUSE ]

JULIE: Thanks very much, John. It is really important in terms of opening up collections that we also open up the code and make everything open source. As John said, it is really time-consuming to do design-led research, so if everybody shares that research, then it will work out less time-consuming and more efficient in the future. It is such a brilliant project.

Now I want to introduce you to Joeli Brearley, who is from FutureEverything. She's going to talk about Arts API project. Thank you, Joeli.

JOELI: Okay, so, back in 2012, we were approached by Manchester Science Park, and they had a really, really interesting partnership deal and opportunity for us, and they were going to give us a brand new spanking office in their complex, three times the size of the office that we were currently in, and we could design it completely from scratch, and we were going to get really cheap rent. We thought, great, what a really brilliant opportunity. We asked them why they had offered this, why were they so keen to have us as part of their community at Mann chests Science Park, and they were really clear in their response. They said it was because of our network. They inherently knew that FutureEverything has a really extensive network, both in terms of location, and in terms of sector.

So this kind of got us thinking: we couldn't at that time, we know that we have a great network, we have really good relationships, but we couldn't demonstrate that, we couldn't articulate it, we couldn't interrogate it. What if we could? What new opportunities or doors might that open?

So this project isn't about your audiences - don't think about your audiences, this is about all the relationships that you have in order to get to the point of having an audience of having a programme.

So this was the hypothesis, this was where we started from, using social networking analysis, and data, can we create a tool for the arts that allows you to interrogate, articulate, and demonstrate your network? And, in doings, would this -- in doing so, would this create new opportunities for business modelling and support?

Now, I am not going to talk too much about the tool, actually, I am not going to give you a demonstration because I haven't got time, but I will tell you that this is what it now does. We've gone through the whole process, and the 


\section{A MENDED DRAFT VERSION-FOR REFERENCE USE ONLY F R O L IVE S P E ECH - T O-TEXT T R A N C RIP TION}

tool uses e-mail data from organisations, and it gives you a visualisation, an interactive visualisation of your network and your organisation's network. It has a clustering tool that allows you to analyse how well connected you are to different sectors, how well connected you are to different locations using algorithms from social networking analysis, it also allows you to understand how quickly information travels around your organisation and allows you to see some of the vulnerabilities. What happens if a person in your organisation leaves? What does that do to your network?

We talk a lot in the arts about relationships and networks, sort of pay lip service to it quite a bit. For FutureEverything, this is really fundamental to what we do. We act as a broker and an intermediary between different sectors, and, without that, we are nothing, so, to us, understanding our network is more important than understanding our audience, and I think that's the same for all the organisations, yet, currently, there's no tool to allow you really to do that.

So, if you want to know more information about the tool, if you're interested in it, please visit the website, and that shows you what it does and it gives you some example business models as well. Five minutes, okay.

So I am going to give you some of the learning from the project. Very quickly, collaboration isn't easy. You're working with.

You all have different challenges, objectives, cultures and ways of working. I remember John Knell saying to us early on in the project process, talk about what success looks like to you, and I wish I had listened more to that. We did talk about it but not properly enough, and if you don't talk about it, it will bite you in the bundle, I guarantee - bite you in the bum, I guarantee it.

Timelines: the process we would usually use for a project that is with one organisation organising it where you're not building technology is quite a linear process, and, actually, this was sort of backed up by Nesta, the mole stone process makes you think about this in quite a linear way. It doesn't work for R\&D technology projects, you've got to think about your dependables. You've got a technology partner there that is a commercial technology partner, paying them a lot of money to be part of this project, and, if you do your research and then you do your technology, you're not making the best use of them.

But, also, what we found was that the technology fed back into the research and vice versa, so you've got to work out what your dependables are, the minimum amount of - we used a new template which we called "blueprint, production, and evaluation" and started doing that two or three months in, but it meant we lost a lot of time. Iteration is key.

So, as I was saying with the technology feeding back into the data, when we started working with the technology, we realised and thinking about the data, we had always assumed that we would use lots of different data sets, but, actually, when it came to the crunch, none of those data sets would work, it is just e-mail data that worked for us now.

So, when we talk about data in the arts, we tend nearly to always focus on audiences. So, we are getting good, we get it, we get it is good to analyse data for audiences. But, actually, what this project was doing was it was just completely new, completely innovative, we were asking you to look at data in a completely different way. It was a different type of data, and it was a data source that you already use - so e-mail data, you're already generating this data, but lots of organisations were really, really scared when we said to them, "Okay, give us your e-mail data." They felt really weird about it. We couldn't at first understand why because this is your work e-mail. There is a really, really big question here that came up out to us at API about privacy, and who owns your e-mail? Do you only it? Do you 


\section{A MENDED DRAFT VERSION-FOR REFERENCE USE ONLY F R O L IVE S P E ECH - T O-TEXT T R A N C RIP TION}

only those messages you're sending because your work pay for the infrastructure and you have no idea what happens to this e-mail once you've written it and you've sent it? It could be intercepted by anybody, changed, adapted in any shape or form.

We kind of get this when we are talking about social media, when we're talking about Facebook, but do we get it when we are talking about our own personal communications.

If you have an e-mail client on your phone, then your e-mails are being used. They can be used by that organisation in any way that they feel like using them for their own benefit. So, are you willing to give up that feeling of privacy for the benefit of your own organisation? And we actually found that organisations weren't.

Lots of those organisations said to us the reap we are not willing to is because we feel morally and ethically uncomfortable with it.

Is that the case? Do you have a Facebook account? If you do, then you know, when you're putting pictures of other people up, you're going through that process already, and of actually, maybe it is not ethics, maybe you just - you haven't really grasped this whole world of data and online interaction.

So, there are some really, really big questions here that this raises. Do you still own something when you put it on line? What does privacy mean in a digital world?

The other thing that really struck me when we were doing this project is, with the arts, if you work in the arts, it is very personal to you, it is part of your identity. Deborah touched on this before. That is very clear in the way that we communicate. We will comfortably use our personal e-mail address to send a work e-mail and vice versa. You wouldn't get that at PriceWaterhouseCoopers. It wouldn't happen. If we are really going to harness data, do we need to professionalise? Do we need to think about how we are communicating?

I just do want to end, though, by saying that data is not a panacea, it is not going to answer all of your problems. The data that you use is only as good as the data set that you get it from, as we've talked about before. You have need humans, you know, people, that understand what they're doing to explain that data, to interact with that data for it to make sense, and you don't want such metrics to distract from other ways of knowing. Wisdom is only going to come from the old and the new, coupling those and marrying those properly. I was going to play a video, we did an art project called Smoke Signals using the data set that we had, and that is online. You can see it on artsapi.com.

\section{[ APPLAUSE ]}

JULIE: Really interesting project. I encourage you all to have a look at Arts API and encourage all of you to think about your e-mail usage. If we used it solely and concisely just for business, we would find that maybe we had fewer e-mails and more time to think about other stuff - just my personal e-mail hatred! So, yes, thank you all three of our speakers, all interesting projects, all online, and please do and have a look at them, and a round of applause for such three interesting speakers.

ROSIE: Thank you so much, Julie. That was wonderful. Now we are going to have a half-hour break, refreshments are going to be served as ever in the mezzanine. There's an opportunity to speak to the session speakers and the speakers' lounge on the ground floor of the rep and Meet the Projects. If you're booked into the masterclass make your way to room 1-01-or to Room 104 for a prompt - are we in the right mode? I've got 3.45? No, yes, this is please be back here to talk about business models, our next theme, at 3.30, and to hear about our panel talking about future digital. Thanks very much. 


\section{A MENDED DRAFT VERSION-FOR REFERENCE USE ONLY F R O L IVE S P E ECH - T O-TEXT T R A N C RIP TION}

[ Break ]

ROSIE: All right, everyone. Welcome back to our fourth theme of the day, which is a pretty crucial one: monetisation, how to make money out of this stuff? What is the best business model, and how can the arts tap into new distribution opportunities via digital to generate income?

To guide us through this very important session is Nicole Yershon, who has worked in the creative industries for 25 years. She joined Ogilvy in 2000 with the brief from a chairman to bring the agency into the 21st century. She overhauled the agency's broadcast and video editing facility making Ogilvy London the lead agency for digital assets. She's passionately driven new media right through the organisation. In 2008 she headed up Ogilvy London's innovation lab fuelling unprecedented creative campaigns. She is now the director of innovative solution, which is just a fantastic title. We will hear from her in a minute, but, first of all, let's see a short film. Can you run the film? Thank you.

[ Video shown - sound not relayed ]

"We are - e-commerce plug-in that allows artists to connect. Very quickly, we were getting interest from outside parties we didn't have previous relationships with.

The primary school is a rural school, they can find access to music provision difficult, and that's why we are testing new online methods of delivering music education.

>>: Our involvement is looking at the research and outcomes, actually building a model that can be used and rolled out to other musicians up and down the country.

>>: I believe there competition. I think for you, the creator of the business to survive, you need to be very clear about what it is you do. If you understand [...] then you build upon that."

NICOLE: Good afternoon, everyone. Thank you very much for having me here. Clicker working? Yes. Perfect!

I am going to talk about business models, and I'll put a few kind of film clips in there to reiterate a few bits and pieces.

So, change is inevitable. I don't know whether any of you have seen a really interesting clip that's on YouTube, about 12 minutes long, called "Humans Need Not Apply". It is interesting and sobering viewing. It is basically going to happen whether we like it or not. Uber was going to happen whether the taxi drivers liked it or not. They had something with Halo, they didn't quite push the boundaries with it. Uber came along, following up with Get. These things are going to happen, you can't put your head in the sand and pretend it is not or maybe l'll get another job before I have to deal with this thing.

But what is interesting with those companies is that they all are really looking at peer-to-peer, and I've been saying this for about ten or 15 years - it is all going to be about people, and we are all a brand, so therefore with Uber, the driver is going to rate you, if you're going to be mean or nasty, they're going to say you're not a very good passenger, and the driver is going to be rated, the same with Airbnb. This isn't Trip Advisor where people are paid to say something good or bad. This is about peer to peer, I think making people behave better, be decent, kind, honest. We are all a brand now, and, as they were saying, the session before, data is crucial.

Some of the things we've been doing at Ogilvy to allow for another business model, it is just entrepreneurial thinking, and I am lucky that management there have allowed me to do this for the last 15 years because it is disruptive, it is 


\section{AMENDED DRAFT VERSION-FOR REFERENCE USE ONLY F R O L IVE S P E ECH - T O-TEXT T R A N C RIP TION}

naughty, they say no, I do it anyway. It is not for the faint-hearted when you're looking at putting in new business models, especially if it is within creative industries and it is quite innovative.

Technology is touching everyone, not just the ad industry. Literally it started off with the music industry with Napster but has touched everyone. The collaboration we see is really important because you cannot know everything.

We did something with people that are our doorsteps with Silicon Roundabout where we went out to those new companies and we knew that we, as a big company, behind to collaborate with them and value their expertise and work with them in a collaboration, not tell them what to do. We say jump, they say how high? This is new territory. No-one knows whether some of these things can be done or not.

So we go and visit everybody, and one of the companies we saw was a company called It's Nice At, there were only three of them at the time, an innovative company, gave me an idea, made me think about doing a book for Rory Sutherland, because one of the business models we did to get money in the labs - so Labs isn't funded by Ogilvy, they pay three people's salary. They don't pay for all the shenanigans we get up to. The lesson we learned is we have to have a pot of money for us to experiment. If you keep asking the finance director they would continuously say no, so you had to find another way.

One of the ways that we found to get money into the lab was Rory Sutherland is a great speaker, so, in the very early days, I asked if I could act as his agent, and the money I could negotiate him to speak would come into our lab. He said yes, so Rory is one of our feeders into the pot, and then, then when we went on the Silicon Roundabout tour, we thought if we published a book from Rory looking at what he had done with Brand Republic and Spectator in those magazines, we could not only offer him to speak but offer the book to delegates at publisher's costs and the Labs were going to be the publisher. Not that we had ever published a book before! But, when you're looking at doing something for the first time, you've got to try it and fail and try it and fail. You don't see it as a failure but see it as learning. Now, the book gives us revenue into our labs R\&D.

You have just got to try it and fail and try it and fail until in the end you succeed, and not just see it as a failure but as learning.

So it's not run as a P\&L, a profit and loss for the company. Purposely kept it away from having to work for clients specifically so that if, say, I was attached to Dove or IBM for $50 \%$ of my time I wouldn't be able to be at venues like this, I wouldn't be able to look outside and bring in to 1800 people. So the Labs is purely an R\&D kind of pot of money, and there's just three of us in the organisation. It's more of a change agent. We make others within the organisation do the actual heavy lifting and the work. Because once they've done it once it means they can offer it again and again to clients.

So we published the book and then the next thing we did on our next tour was we did something with Animade, another little company that we saw on our second tour.

[Video]

>>: The single greatest improvement in customer satisfaction on the London Underground per pound spent came when they didn't add any extra trains nor change the frequency, they put dot matrix display boards on the platforms because the nature of a wait is not just dependent on its duration, but on the level of uncertainty you experience during that wait. Waiting 7 minutes for a train with a countdown clock is less frustrating and irritating than waiting four minutes knuckle-biting going, "When is this train going to damn well arrive?" 
Here is a beautiful example of a psychological solution deployed in Korea. Red traffic lights have a countdown delay. It's proven to reduce the accident rate. Why? Because road rage and general irritation are massively reduced when you can see the time you have to wait.

In China, not really understanding the principle behind this they applied the same principle to green traffic lights.

[Laughter]

Which isn't a great idea. You are 200 yards away, you realise you have got five seconds to go, you floor it.

NICOLE: So what we did with Rory, in his words, is we pimped him out. We found an asset that was really amazing and not just within one industry. He could work across many, many different industries, and then we were able to show management at Ogilvy by creating these two little films. All we wanted to do was sell more books and get people to our storytelling lab day so we used his voice-over with TED and got permission with them, and we spoke with Animade so there were three people involved, Animade, a producer and myself. Always keep it to small teams because more people end up costing more money and you go under the radar. It was three people, eight weeks, two films at minuscule cost but we spent quite a bit of money seeding it within that $£ 5,000$ and we managed to shift quite a few books to get some money into the lab pot.

That's Rory. So collaboration and partnerships and seeing where the marketplace is running is quite important and seeing how you can find an asset and then put it into not just books but also online, in lots of different places.

Need to get out of your comfort zone as well. No point going to any event where you know people or you know anything. You have got to go somewhere where you know nothing and no one. You are literally starting with a blank piece of paper and filling it up with loads of different ideas and it doesn't need to be in the same industry, so an example of that is we had one of our creative lab technologists go to Amsterdam, and he was tasked with two measures of success. You have got to be able to get some partnerships and also do a trend report to send back to the masses when you get back to London.

He found a great company there called Mind Play, who measures with a headset, he was doing something interesting with video endings where you could do something interesting with the video ending depending on how you felt about the character, so we brought him into our storytelling semester - we do them of a few weeks on one topic - so we attached him to a Lab lunch and our creative team were working on a brief and asked him, "Can you measure pleasure with this headset?", and he said I think so, but then labs will get involved, and then we worked with Birkbeck and we did something at Ravensbourne and although we didn't know if it was going to work, just in case it did, we needed to have that content, and this is the end result.

\section{[Video]}

>>: This newcomer brand wanted a bigger chunk of the chocolate market.

>>: Instead of just claiming to have the most pleasurable chocolate, this company wanted to prove it.

>>: Beyond Dark partnered with neurologists and technologists. To gather enough credible data, we would need 100 members of the public, hooked up to brain waving headsets which were set up to analyse pleasure for the very first time.

[Violin music] 


\section{A MENDED DRAFT VERSION-FOR REFERENCE USE ONLY F R O L IVE S P E ECH - T O-TEXT T R A N C RIP TION}

>>: The tests also proved Beyond Dark 15 to 20\% [?] more pleasurable than rivals. On Blue Monday, we released our happy news. The first ever pleasure scale made headlines.

>>: You have got chocolate bites, if you tuck into the chocolate -

>>: Ooh, she is ecstatic on the end.

>>: All this chatter pushed Beyond Dark from obscurity and a Beyond Dark fan base was born. The findings from the tests became the advertising.

At last, a brand could make emotional claims that were proven. Beyond Dark enjoyed a very pleasurable sales uplift, prompting speculation about where all this could lead us.

NICOLE: So the reason I do it that way round and tell the story is because, if I were to go to a Finance Director and say, "I need some money to send the lab technologists to Amsterdam for an event that was very random", he would say, "Yes, let me think about that for a moment. No."

So therefore we need to do it this way round to show that, had he not gone to Amsterdam, had he not met this random guy, had we not attached it to a semester of learning through our process to innovate, you would not have got that end result which picked up tons and tons of awards.

So it's very easy to ask for these things but you don't necessarily know where it's going to end so that's why the lab to be a bit entrepreneurial and not ask for permission, it's crucial. When we go to Amsterdam, it's not first class, it's a sleazy jet and airbnb. We are a little entrepreneurial unit really within Ogilvy.

Know your audience. So it's really important now, you cannot know everything about everything. My favourite saying is you don't know what you don't know, so you need to be looking at working with a load of startups. We do something with Collider, who are working with Mad Tech, an Incubator of all these new start-up companies, and we put money into the programme they run and they have ten cohorts twice a year, so 20 little companies, and we mentor those companies and our clients come in and say what problems they have and those companies are then able to have - whatever business model they are look to do, they are able to fix some of the clients' problems.

So it's always good to go to these incubators and accelerators, and you put in with the mentorship and you help these companies get something back, and there are times when you can actually then profit from these companies, where you put your own money in, or your organisation's money, and then it's a long term strategy, three years, five years, ten years down the line, you then might be able to get some money back. Hopefully, you know, you are investing in the future, especially us with Collider, with Mad Tech, so it's always good to have a little look around.

We test and learn a lot so even though when we first got something from - sorry, one minute - from Holition, it wasn't ready when we first had it. It wasn't ready for people, it wasn't ready to be released so we tested it in the lab probably for about six years and now they have the most beautiful iPad thing with L'Oreal where you put make-up on. You can see make-up on the iPad on your face but it's not on your face, it's on the screen.

We did the same with Holition with underwear and we managed to sell it into the guys at Geography who were Ogilvy's experimental team. They were doing something for Selfridges and for Triumph underwear and you could try it on without actually trying it on with this augmented reality. So beta testing something - it might not work now but as a long term thing, just keep going with it and testing and learning. 
Work with the right people. This is called the rough diamond and it works brilliantly. We are about five years into it and it has enormous success. More than happy to talk to people afterwards about it, but it basically is taking kids from age 14 who are in deprived areas of Hackney, Greenwich, Tower Hamlets, and showing them a space where they could work when they come into Ogilvy, and then we show them to be able to go on to further education, and these are kids that are failing at school because they are just not - you know, they can't sit there for eight hours in a day and be inspired by a lot of the teaching, so we route them through, then we will speed date them after two years at those schools and then hand-pick five or six of them as interns with us and then we will look to employ them.

Then measures of success. Very important, when you are doing business or when you are trying to be entrepreneurial: measure how success looks. Because it's not always financial. There are lots of other ways and means that you can determine success. So we have the six R's: so revenue, as long as with measure of pleasure you saw it will bring in some revenue with clients; reputation, so that's within the press or awards; recruitment of new diverse talent, that's through the rough diamond, or people wanting to work at Ogilvy because of the work that we have been delivering; retention of existing staff because they are starting to do really exciting work; relationships, that's the black book of all the people that we see like at Silicon Roundabout; and responsibility, that's giving back. So that's maybe my time with Nesta or stuff I do with Media Sound Box in Bristol. So I hope that's a quickfire 15 minutes just to give you a bit of inspiration as to different business models and thank you very much for your time.

[Applause]

I would like to introduce Mandy Berry who is our next speaker in this particular business module.

MANDY: Can I have the clicker? Thank you. Hi, everyone. So our live and digital project set out to test whether the concept of theatre for screen was something that could work and be viable for the small scale producer. At a time when those in the arts, arts organisations are facing unprecedented cuts in funding, alternative filmed media content, both in the UK and internationally, is experiencing stellar growth.

The market for large scale cinema events is increasing year on year, and by 2017 the global income for events similar is expected to reach nearly $£ 650$ million. However, these figures are largely led by some of the big, global players the Royal Opera House, the National Theatre, the Met Opera and others. We wanted to see if we could take inspiration from those people and type of organisations but find a way that could work for the smaller company.

So Miracle is a touring theatre company, based in Cornwall, touring largely in the southwest, taking its shows outdoors in the summer to beaches and cliff tops, parks and gardens, and indoors in the winter. We wanted to find new ways of finding much larger audiences and a network of rural and dispersed venues and also to earn new revenues but at the same time we wanted to stay true to the vision and the experience that makes Miracle something very special for our loyal audiences. So we explored four different ways of creating a digital version of our performances. The first was to do a live stream. The second was to do what we called As Live which in effect was the recorded version of the live stream, and then Made for Screen which we did in two ways. We made a performance without an audience so we could film from different angles and edit it. We also made a microbudget feature film. The equipment we used needed to be affordable. We needed the method of delivery to be user-friendly and the product to retain that kind of intimacy and spontaneity that you get with a small scale production and we wanted to find out if audiences would have an appetite for that kind of project, and very importantly we wanted to see if there was a way of building a viable business model.

Miracle Theatre worked with Golant Media Ventures to develop a model that would be both entrepreneurial and create very importantly an asset on the balance sheet. That's important in terms of having something that is 


\section{AMENDED DRAFT VERSION-FOR REFERENCE USE ONLY F R O L IVE S P E ECH - T O-TEXT T R A N C RIP TION}

investable in and in being able to raise loans, for instance, if you wanted to. We began by examining what Miracle really was, how did it do it what was the essence of Miracle and then we went on to use Canvas and then to create a business model template and to create a set of guidance that could be shared with others and that is available through Miracle Theatre and Golant Media Ventures for others to use.

It's important to see this as a profit-making activity, not a project; to see it as a venture. An investment is being made, at risk, and being the master, and the rights holders need to recoup that investment and obviously ideally to make a profit.

The master and the rights held in it are eligible to be accounted for as an intangible asset and then the master can appear as that on the balance sheet of the company, the organisation, the venture. Of course, the need for a very clear business model is really important because investors and other rights holders will want to have their share of the profits, and the way that that has been defined in the model will really affect and be very significant in who gets what.

We took theatre and film for our model in creating our business model template, but actually you could apply the same kind of core principles to it, to lots of other kinds of creative media. The live production that we used for the R\&D project was Waiting for Godot because that was the summer show that we had that year and the audience reactions were positive and it enabled people to see the work of theatre when you couldn't see it perhaps because of geographic reasons, timing, etc.

Technical issues for a small organisation in the kind of small venues we were using - and satellite distribution, really hard. We were using broadband, not costly satellite, and that doesn't really work for those kind of venues; and then the other versions, the Made for Screen and the As Live were more successful but the As Live not as successful as Made for Screen because it wasn't really live and didn't have the better production values.

Audience reactions to the true life story in Cornwall were particularly successful in its home territory of Cornwall. Tin was a collaboration set in a large part of the same locations as Poldark. The approach to making Tin was rapidly different to that of making Waiting for Godot so we created a green screen studio and during the final weeks of the production run we scheduled a 15-day shoot around the performances. We needed to work while we had got the actors, while everything was still hot and in people's mind, while we had the costumes, and so forth, and then we also used 1/12 models and some location shots and post-production was done by a local animation company. The result was an idiosyncratic 90 -minute feature film.

Tin cost around about $£ 100,000$ to do, very high cost for us and we achieved it with a hybrid model of funding, public funding and also investment funding where we are going to be sharing profits after we've recouped our costs.

We had to ensure that we had all the necessary rights in place to be able to exploit Tin, and we then had to decide how to distribute it. We decided to not go for the traditional route of going to film festivals, hoping for critical acclaim, securing distributors and sitting back and waiting for something that might take quite a long time to come to fruition; we decided to self-distribute, to do the guerrilla route and to use the enthusiasm of our local audiences and maybe earn some money and actually we did that really in some style. We had sell-out screenings in Cornwall's two cinema chains for not one, not two but for three weeks, and in Truro we outsold Fast and Furious at the box office; in fact, more than doubled it.

In the first two to three weeks, Tin reached 7,000 people and screenings are still continuing. It demonstrates the value that audiences place on culturally, locally produced content. 


\section{A MENDED DRAFT VERSION-FOR REFERENCE USE ONLY F R O L IVE S P E ECH - T O-TEXT T R A N C RIP TION}

This leaves questions: what happens after $R \& D$, where do you find the investment to take it forward and of course there are really good loan funds, things like the Arts Impact Fund but maybe we need venture funds as well.

We are being asked to be more entrepreneurial and commercial but also being asked to be open and share our learnings. Some might see that as difficult and their models might be seen as commercially sensitive. We think it should be public and shared.

Some might think those models really only work for the large players but we are learning that actually people are interested in the productions of smaller companies as well, and if the audiences have it and grow the cake, there will be enough for all of us.

We've taken risks but then we are a creative organisation and creativity always involves taking risks. We are applying risk to the whole of our business as a theatre company and we've learnt a lot and grown in confidence in doing it.

So the models for digital distribution for performance are new and many. There's no best way of capturing the performance. There's no best business model and perhaps being different to live theatre and to feature film, theatre for screen is perhaps a new art form in its own right, so really perhaps it's the Wild West out there but it's certainly, I think, all to play for in the future, for all of us. Thank you.

\section{[Applause]}

NICOLE: Thank you, Mandy. Our next speaker in this section is Jim Hinks. He is digital editor of Comma Press. I thought I would leave you with one snippet with each introduction, of advice that I think is quite important when you are looking at business models. It's not for everyone. Not everyone has that entrepreneurial hat or hunter mentality, so I would always suggest to find someone within your organisation. There's always one person that is just coming up with weird and wonderful plans and just give them a little more rope, just give them maybe not $100 \%$ of their day job, so that they could experiment and look to see other things that they could be doing. So it's not for everyone, not everyone has that hunter mentality, so others are left doing the day job which is great. But this area is a certain kind of individual. I always say: if it was easy, everyone would be doing it.

Okay, Jim, thank you.

JIM: Hello, I'm Jim, I work for Comma Press and we are independent publishers specialising in short stories. Our partners in this project are Function, an UX company, and MMU and the project is called Macguffin and it's a selfpublishing platform. I should say, I feel like a bit of a fraud being in this session because our project doesn't generate any revenue at all, and it's not really intended to. What it's really about is exploring some disruptive - apologies for the term - approaches to four key issues that are facing the publishing industry at the moment. And seeing if we can find new ways of doing them and also kind of build something that's quite fun and useful at the same time.

Those issues are: self-publishing, which is hugely on the rise at the moment; audio books; content discovery, so how do people find stuff to read and how can we match up the right content with the right reader; and consumer insights, so analytics. What can we learn from them in the industry and what can writers learn from consumer insight as well?

Probably the foremost of those topics is audio, which is increasingly important to the publishing industry. There's increased 4G coverage, so streaming content is more viable. It's better for accessibility, for blind and visually impaired readers, and it's also crucially future proof against wearables to some extent. The publishing industry has had its fingers burnt with kindle which took off and everybody had a lot of revenue from e-books and then as Kindle reader devices started to get more functionality, you could go on social media, e-books revenue started to fall. The 


\section{A MENDED DRAFT VERSION-FOR REFERENCE USE ONLY F R O L IVE S P E ECH - T O-TEXT T R A N C RIP TION}

industry believes that even if we've got driverless cars and stuff in future and wearable tech, then people will always want to listen to stuff while they are doing other stuff with their hands. So audio is a really kind of hot issue at the moment.

So what we want to do with this project is actually increase self-publishing writers to follow the lead of amateur podcasters, who have shown in recent years that technological barriers to entry have fallen away, so in the past you had to go into a studio and record your radio show, and now anyone with a decent microphone or indeed a smartphone and a quiet room and some practice can record near broadcast standard audio, so we thought: right, we will do that. We will build a publishing platform that has text and audio, so that's what Macguffin is. If you are a writer, you upload your story or your poem, the text of it, and you also upload an audio version in MP3, and end users can either read the text or stream the audio or toggle between them. It's an app as well.

The second innovation is content discovery. So we use something called a broad folksonomy model which means people can add tags, a bit like Twitter, to anyone else's content. This opens up some really good functionality so it means if you are a user - Macguffin builds into a really searchable database of crowd curated content - so if you are, let's say, a commuter and you have a 25-minute journey and you like crime, you can do a tag search for those two things and it will bring up all the results that match your search. It also means you can search for things thematically, so you might be a student studying poetry and you want to find some stuff about, I don't know, death, feminism and whatever it happens to be, and you can just filter through and find this stuff that's kind of been crowd curated. You can also make personal reading lists so if I add an unique tag to loads of content I can share that with people, kind of the way you used to make mixed tapes back in the day. So there you can see.

The third innovation is analytics so this is a real example. The analytics on Macguffin are open so anyone can see them. We don't want to kind of do nefarious things with your data; we want to let everyone use it and everyone benefit from it. So this is a story, you can see pins in the map where it's being read or people have given permission for us to collect the browser location data.

You see the completion rate isn't very good on this example, so not very many people getting to the end of this story, and crucially dropout points, so this shows - this is like - what's it called - our own pleasure scale. So it was a pleasure scale before for the chocolate and this is kind of our version of that, so the orange line is audio and the blue line is text, and you can see where people are dropping out as they go along.

This story is actually in three sections, so you can see that when people are dropping out it's when they are getting to the end of a particular section and this kind of flies in the face of conventional wisdom about narratology and short fiction, that if you give people different sections they feel they have achieved something, and it's tension and release and that will get them through the text, but this seems to show that it gives people permission to disengage. They think: I've got to the end of that bit now, I will just go and do something else.

So we are finding some quite interesting things. Also, the dropout rate at the start is really typical and we find that loads of people do that. They go, they read a few sentences, and then think, "This isn't for us", so we were a bit worried about that so we put a load of classic content on there, like classic short stories in the public domain, and their dropout rates are the same as well. It just seems that we are finding out about the way people browse literature.

I'm a bit short of time, so yes, I will scoot through some of the process stuff. We did a lot of lab testing because there's a lot of complex UX interactions, including tracking which is really useful so we can see where people are 


\section{AMENDED DRAFT VERSION-FOR REFERENCE USE ONLY F R O L IVE S P E ECH - T O-TEXT T R A N C RIP TION}

looking on the screen when they perform tasks, and we found people don't read onboarding copy ever; they just like big buttons. That's the take away from that.

What works well? We launched the website in July and I'm absolutely delighted with it. I think it works really well. Function, the tech company, did all the front end database and API work and did an amazing job. It's really stable, really usable. Feedback from users has been incredibly positive and we've had a load of really positive press, particularly in the publishing trade press, so that has been amazing. It's self-publishing, so it's unmoderated. People can post stuff up there and we were really worried about the content so we worked really hard to invite writers to put stuff on there and did a user survey recently and $69 \%$ of users thought the content was either good or very good so that's unusual for a self-publishing platform.

I've only got a minute left, so lots of things went well: privacy and data, we responded to users' needs. If anyone is doing anything to do with data, I can really recommend getting on the phone to the Information Commissioner's Office. They are really approachable, you talk through what you want to do. They flag up where they see there might be issues and it really gave us a lot of confidence to go forward with the project and also to build in things like an incognito mode and look into privacy issues, so that was a really useful thing to do.

What we would do differently: I'm not sure we would do apps. I think we might do a mobile-optimised website. I think we might take social media authentication out. People love signing in with Twitter and Facebook, but it's a pain and it has been about $30 \%$ of our effort.

One final thing to say because I have been told that time is up. I think it has been an amazing opportunity and it's really, really important to us to be able to do this because we are a non-profit press and we don't want to exploit people's data and do a lot of - some of the dodgy things that publishers are doing at the moment. Other people in this area are either conglomerate publishers or venture capital funded startups, and it's all about making a fast buck off people, so to give us the opportunity to join this global conversation, and actually say how can we use data in a way that is useful for readers and writers, has been a really great experience, so thank you.

[Applause]

NICOLE: Before I introduce the last speaker of this section, another little snippet that I've learned: any of your organisations that are quite big, when you start working with very small companies, really tiny SMEs, you've got to start acting a little bit differently and not pay them in the old-fashioned way that you used to, because otherwise they will go under. They have cash flow issues when they're that small and niche doing very specific, so you're going to have to work with your finance teams to make sure they get paid on time, perhaps even earlier than most other people who have larger companies, so I will now hand over to tone over to Tony.

>>: I am Tony Followell, Head of Media at the Royal Opera House. I am grateful to Nesta who funded our hybrid app at the Royal Opera House. We worked with King's College and Pop on the technology side. The hybrid app was wide-ranging and powerful for us, but it made the website for us responsive, with all of the benefits that comes from, and not just for making it available across platforms and devices, but also things like gee row location which we are able to plug into our growing cinema audience linking attendees with their local cinema, and also things like digital programmes which, thanks to the fund, we were able to develop, we did four of them initially, and, I am pleased to say, they're continuing with us, and that's a device we've been able to use to enhance the experience of both cinema and live stream audiences. 
Rob Greg was the expert behind the Hybrid app when that was developed. He has moved on now. I wanted to focus, if you will bear with me, on the live cinema and live-streaming benefits underpinned by that app and talk about the business model that applies to the Royal Opera House in those areas.

So a little bit of context first, if I may, and this is from a recent MTM survey which said that ninety per cent of arts organisations in the UK have produced live to digital, and, by that, it encompasses live cinema and live streaming work. Ninety per cent have already done something. 86 per cent want to do more.

26 per cent of UK audiences have watched live digital, and 30 per cent, seven per cent of the rest, would be interested in doing so. The big drivers for the audiences there are cost - it is generally cheaper than attending a stage show - and convenience..

I am going to talk through our ROH experience in cinema, home entertainment, TV, live-stream, a business model that works for us around those.

We tried very hard to connect the live stream relatively new activity for us, a live stream activity to the cinema activity - both global audiences, and try very hard to make those work together.

Our cinema slate is 12 titles per year, 1,600 cinemas or so, 40 countries around the world. The reach, particularly in the UK, is very, very important to us, of course, and now there are more people attending cinema relays around the world each season than there are attending performances at Covent Garden, so that is a measure much how worn the activity is, at least in terms of reach, how important the activity is.

Following the season, we have an in-house label who then produce DVDs from select titles across roughly half of those titles in the cinema, and also we've begun to put those out on BOD platforms, primarily digital theatre - iTunes, very difficult in an iTunes environment, in a vast ocean of material and difficult to see meaningful returns on the material we put in that environment.

Educational VOD opportunities, though, are relatively strong. There are a few of those platforms mentioned down at the bottom there.

I think the big challenge, though, is in the VOD area and that's what we are looking at at the moment. There is a huge gap we see, if many other do between the flat-lining, or, in most cases, dwindling physical media sales, and online take-up. We just haven't seen that take off yet, but we kind of know that it will, and it is just how to engage that audience, finding a business model that works around that is extremely difficult. Lots of examples, particularly in Europe, and elsewhere around the world, of large banks putting lots of money into creating players for institutions which then don't attract an awful lot of viewers, it has to be said. Even after five years, it still struggles sometimes to find enough eyeballs to make a business model around that.

Television side of things, so we operate a windowing system, the first three months or so, it is the titles sit in cinema, then, up to a year after that, it is the home entertainment DVD market, and then, beyond that generally speaking, TV, although there are some exceptions, quick turnaround titles for primarily the BBC.

We seem to be jumping about quite a lot. Live-stream: I was going to talk about at this point, so what we do, we use YouTube as our content management system, we have 800 films on there, 130,000 subscriptions to that. We are doing much more in the way of live stream activity. Now, much more regular events, large-scale events, and we treat them as promotional to the rest of the media activity, so promotional of the cinema relays, listening the live streams to the cinema relays that are coming up. Seventy pearls of our YouTube views come from outside the website, so 


\section{AMENDED DRAFT VERSION - FOR REFERENCE USE ONLY F R O L IVE S P E ECH - T O-TEXT T R A N C RIP TION}

they've been searched for or sent to those, to YouTube without having gone through the Royal Opera House website. 50 per cent of users are overseas, and the biggest age group is 18 to 34, so we are managing, there is plenty of evidence we are managing to grab a new audience out there.

We - the aims of the live streams is to cultivate that new audience, engage it, so lots of interaction solving the social media around live streams, and then migrate, so, from a live stream to your local cinema, wherever you are in the world, and bearing in mind that there may well be a future pay-per-view model that works around that.

The last big event we did in the live stream environment was World Ballet Day last week, and it linked together five of the world's biggest ballet companies in a mad 23-hour live stream. Here's a little film.

[ Video played ]

[ Music ]

>>: 350,000 live views to that live stream. As a result of world World Ballet Day, everybody assumed 1 October was World Ballet Day, so we have had to do it this year! There's been three subsequent views of the highlights of that material, so it is great generating the audiences around the live stream, then you've got that material to use in promotional context beyond that. We also trended on Twitter in the UK four minutes into our own section of that, so huge community engagement for around the world.

The big challenge for this and cinema is around data capture, and this is where the hybrid app has come in again around digital programmes. It is one way we've been able to try - no, jumping around quite a lot. I don't understand what has happened there.

Our digital programmes we create around each of the sip that relays, and now the live streams. They're AV-rich programmes, they develop and grow as you get towards the production, and actually they carry on growing after the production, so giving you reviews on social media of the performances, and telling you about products available around those.

And they're now free. We offer those free because data capture is of such value to us, and we want to enhance the audience experience through the digital programmes, that we offer them free against a promo code. They sign in, we get their data and we give them free content in return.

Thank you very much to Nesta and to King's, and to Pop for allowing us to first four of those. They're continuing, and, for the foreseeable future, and a firm place in our business model now.

There is just one last film which gives you an idea of some of the audience engagement on the day.

[ Video plays ]

[ Rhythmic music ]

>>: Thank you. [ APPLAUSE ]

ROSIE: Thank you so much to our panel. I think that was worth about, I don't know, 300 stroking of puppies or kittens, thank you very much, and thank you very much Nicole Yershon. [ APPLAUSE ] 


\section{A MENDED DRAFT VERSION-FOR REFERENCE USE ONLY F R O L IVE S P E ECH - T O-TEXT T R A N C RIP TION}

ROSIE: Now, we are going to discuss the future, having taken in all the information of the day, which has been quite mind-boggling, and so I would like to invite our panel to come up. I think you know who you all are. I will introduce you when you're up and sitting here on stage. So, can I have Andy, Anthony, Freya and David.

You're going there - marvellous. Right, thank you all. I'll just wait until everyone comes in.

To help us discuss what is next, the digital future looks like this, I would like to produce Professor Andy Miah, chair, Science Communication and Future Media, University of Salford, Manchester. Anthony Lilley, the interim CEO of The Space. Freya Murray, associate director of The Space, and David Watson, Head of Digital Hull 2017 City of culture.

To kick off, I would like to ask each of our panellists to speak for about two minutes on a burning issue that they think is going to come to the fore in the future. What digital future holds? I think let's say in the next year? If you say the next 20 - you know. What is the thing for you?

ANDY: If we can roll the film, it would be great. I wanted to put so that tomorrow images about the future. I was involved with a project over this last 12 months which made me realise how short 12 months really is to do anything at all, but these ideas about the future I think are situated for me in one of the indirect benefits or consequences of the project we are involved with which was around the nature of the collaboration. When we got funded for our project Daedlus, which is about drones, I was in arts school, and now in science school. There's a lot we can do to collaborate amongst sectors, departments, and my burning issue for the next year is to facilitate those relationships more effectively because, certainly working within a science school, we have technology coming out of our ears, budgets for it coming out of our ears, and, it is under-utilised. Many of the cool things that engineers, scientists are working on, I think can do much more and more work in connecting with arts organisations and artists. If there is one single thing that came out of our 12-month project trying to work on R\&D in a very challenging technology form, which is drones, which are inherently unstable device, but especially over the last 12 months, have gone through remarkable changes, is just being able to keep up with the change when you have big corporate entities being behind the technology as well. Being able to do that and allowing sectors to come together and take up some of the slack within the system where there are resources, both sort of technologies, but also human resources to help produce and develop projects, is the key issue for me, so, how I can work together with theatres, with all across the arts sector in both Manchester and Greater Manchester to build these bridges sounds almost like a cliche to say it, but it is come out of this one-year project, apparent how much pace there is to build more relationships within and across these institutions. We ended up with a project that did it involve immersive technology so this piece is built on Oculus Rift using the principles of drone flight to allow people to experience the eyes of aniridia malwas really an offshoot of the Nesta project, and, for me, it is a good example of how we can actually build into our work greater collaborative systems.

ROSIE: So it is less technology and more about trust and openness, and working alongside each other?

ANDY: Yes, it is about the geographic placement. I've been involved with people today where geography was crucial. It is ironic in the - getting together in physical space is crucial to allow us to realise projects.

ROSIE: Thank you. Anthony?

ANTHONY: I think probably, if we are looking at a timeline of a year, Rosy, for me, it is sort of - Rosie, it is about time we got rid of the world "digital" in these conversations in the sense there's a narrative of digital that's either about terrifying modernity that you must stop at all costs, so you sort of regulate Uber to protect taxi drivers, or there's a narrative of progress, means you've got to be on board at all costs inventing new things. I think the truth is more everyday than that now. We now have data, audience behaviours, creative behaviours and ways of working, that, 


\section{AMENDED DRAFT VERSION-FOR REFERENCE USE ONLY F R O L IVE S P E ECH - T O-TEXT T R A N C RIP TION}

when this project started - and I was literally there on the first day chairing the session - when this project started, it all seemed very far out, ways of working, collaborative, where there would be data. We were sort of positing things like apps, actually, which seems sort of antique as an idea, and so the notion that we frame everything as digital rather than as art first and foremost or the way in which the arts work I think has had its day.

ROSIE: Don't you think arts institutions big to small need to be guided still and encouraged to have a digital section, or to have a digital space within them?

ANTHONY: Over the last nine months, while I've been around at The Space trying to restructure and rethink what an intervention thereafter size can do, it is taught me more than anything that there are lots of arts institutions that are very good at that already but actually there is nothing inordinately special about the transformation that arts has gone on, is going on. I've worked in telly, computer games, worked in live cinema screenings, and they're all on that journey. It is just a form of strategy. It is just sort of knowing what you're trying to achieve, what you're willing to not do to get there. The hard bit is finding the germ of the idea. The idea is very seldom the technology. We could do an $R \& D$ fund about - all manner of things, and possibly we should, but, embedding the behaviours and the creativity in the way artists and art institutions work is going to deliver more value to society, so, you need a balance between the two.

ROSIE: Freya, you're very much worked in the cross-sector world. Would you concur with what Anthony has said?

FREYA: Yes, I think, absolutely, I think I have a big bugbear around the word "digital" and often when I am worked with artists on digital projects and I once made the mistake of calling calling one of them a digital artist and they nearly hit me. They said, "That doesn't divine me, those are the tools." We need to look at how - it is happening, but making it more kind of standard across the board, is how digital is just, is integrated, and it is seen very much as a tool across whether it is marketing, but looking beyond that into actually programming in the content creation, and I think partnerships, and like integrated partnerships are really key for that. One of the things I've just been producing for Sky Arts, partnership with the Arts Council, looking at creating new arts TV. We would like new Maverick TV that plays around with form and content, and we've been running speed-dating sessions between arts organisations and production companies, and it has been interesting. Some have sparked straightaway and some come away and say, "God, we just started talking completely different languages and then we found that commonality."

I think earlier today, I was speaking to someone, and they said about the thing is, it comes down to resource and capacity, and I think it has been floated around today that there can be all these opportunities, whether it is the space, the Nesta R\&D fund, Canvass, Sky Arts Amplify, but we need to practically address the resource and the capacity, and that will come with having more strategically sustained partnerships and a pooling of kind of skills and resources.

ROSIE: And also basically the technology. David, working in Hull, you know, Hull is in many ways a tableau rasa, a unique place because it has its own telecommunications set-up. Yet, there is a lot of internet poverty in Hull. It has high-speed broadband but many people in Hull don't have smartphones. What are the challenges for you in the next two years. These big moments where there is a deadline and you've got to get your act together by 1 January 2017?

DAVID: someone asked me about what the correlation is between 2012 when I did that job and this one. They're absolutely completely different. However, the one thing that 2012 had was lots of protocol that we could use as a starting point. 2017 doesn't -

ROSIE: From the Olympics committee? 


\section{A MENDED DRAFT VERSION-FOR REFERENCE USE ONLY F R O L IVE S P E ECH - T O-TEXT T R A N C RIP TION}

DAVID: yes, it has that Laser beam focus with everyone working to a deadline. There are many challenges to the job I am doing now, but it is a huge opportunity. We are not stuck with legacy systems. We can go out and collaborate and establish these partnerships, when City of Culture isn't just about what is in Hull, it is UK City of Culture showcasing the amazing things going on around the UK.

Content for me, creating it fast and delivering it to people is important, and not alienating the residents, and we are then trying to attract a huge audience around the world, and an extra million visitors, but it is about this partnership thing. I understand, and I've done my research about access to internet is probably the first thing I did in week one. Now I am working with the comms partners, do I give a mobile partner to give me vouchers for internet in I don't have time to take a problem and remain a problem, I have to find solutions, and be creative to do that.

ROSIE: As head of digital, are you more engaged with the sort of practical ticketing, information, you know, hot spots where you can hold up your phone to the Humber Bridge and have information about what a wonderful thing it is, or are you interested in perhaps taking something from the space that will be an art work someone can mews while they're walking through the Land of Green Ginger - a street in Hull.

>>: It is that core infrastructure we need to deliver, and, yes, it is ticketing and hot spots, and we need to start using I beacons properly. Making sure that we are remembering this is about the audience too. They're at the heart of everything we do. We need to service them properly, and this is one of the things that I've been talking about, is creating this digital culture, you know, and remembering the customer.

The other element is we are not adding on digital, it needs to be there from the beginning. It is part of my job going, "These are our opportunities." How do we add layers through digital at the start, and we are brainstorming, not just going to say we are going to live stream it - that is obviously part of the mix - but how can you push the boundaries and use all the stuff that is out there? I don't want to undersell what I am trying to do in a way. I am not trying to make new stuff all the time, people are doing amazing things already and using it in a different context.

ROSIE: How do you cope as a digital practitioner with the sort of in-built resistance to it from people, people who are grumpy about it, people who feel public money should not be spent on it because actually I prefer looking at things drawn with a pencil, and I want to see live art, and if I want to see something on a screen, I turn on my television? They accept television being digital and feel aggrieved that public money is being spent on it. Anthony? The space has come in for public - in the press, recently, the Sun had a big special -

ANTHONY: I noticed that! I had to introduce my children to what The Sun was, which is interesting. It is a -

ROSIE: The grumpiness?

ANTHONY: It is the same as having any subsidy for any cultural institution. I think it is wrong but it is an entirely legitimate position to take. The Space and the new strategy is about aiming to present some elements of the work that you commission from across the sector that are addressing the desire of people who may think that the height of innovation is watching something on the iPlayer, which is an innovation - it is quite recent, you know, on their iPad, which is also probably an innovation, so if I can commission the Royal Shakespeare Company and the Royal Ballet or stream something there or support a company doing that, I think that's a legitimate thing to do because it's part of the cultural tapestry, and, at the other end, there is an audience that doesn't come across with enough art. You either think it is a legitimate thing to do with public money or you don't. If you do think it is a legitimate thing to do and we are not engaging in public-service broadcasting with how to do that, we are in a much riskier situation than just sort of distributing the existing core product down the iPlayer or other platforms. 


\section{A MENDED DRAFT VERSION-FOR REFERENCE USE ONLY F R O L IVE S P E ECH - T O-TEXT T R A N C RIP TION}

ROSIE: Andy, do you have to be a diplomat in your world?

ANDY: I was very involved with the Olympics as well. Without a doubt, one thing historic about the space was the fact that a cultural programme was on the television. I mean, I turned on my TV, switched to the channel and there was The Space and content from it. Certainly the projects I am involved with which are dealing with people who are of limited economic means, who don't have smartphones, who wouldn't know what a beacon is if they stumbled over it, the TV, talking about being across all platforms but seem to neglect the television in the living room that isn't a smart television that people are relying on to get most their media content from. It is crucial to think about that because we focus so much on mobile but there is still a population that live a lot of their life through the television, and so designing for those audiences I think still is not only crucial but it is a matter of social justice, too.

ROSIE: Freya, I was very struck in Deborah's speech, she talked about her brain being analogue, and younger people's minds being digital, being used to being across, you know - my children are entirely converse - you know, I am okay with it, but when something goes wrong, I have to call one of them and they sort it out for me. Do you think this is something that artists have to engage with in dealing with people - a significant section of the population whose actually mind works differently because of digital?

FREYA: I think we can get hung up on we live in this digital world, everything has to be digital and we have to reach everybody. With everything we do, we have certain audiences, and what is going to be important is about being focused with it, and I also think, yes, we do, you know, young people are growing one lots and lots of devices, but I think there is also something about people wanting that kind of analogue breather as well, so they're not constantly looking at screens, so I think there's, yes, it is important to think, to kind of develop projects, and develop these platforms and the role the arts will play in that, but I don't feel the pressure that absolutely everything has to have a digital outlet because we should just look at it in terms of audiences, and who we are trying to reach as well.

\section{ROSIE: You're nodding at this}

>>: It is quite interesting, I think, because the proposition from when I joined 2017 was that everything would have a digital plane, and I had a problem with that. I think we should be using data to make decisions, in a way. This thing about it doesn't always have to be digital. I also don't want to tap stuff on just for the sake of it. I do think about we need to think about the way we serve people, and, yes, to a point they want it, we need to take each other to the places where they consume it, but that isn't always digital, or it is also I think bringing people into the fold in a different way. My analogy is the house. You all go to the living room but go into a different entrance. How do we get them from a different space. It is looking at it in a slightly different way and not putting everybody into that kind of pressure pot of everything has to be digital the time.

ROSIE: Andy, would you say that the role of university being innately uncommercial is different from the role that perhaps a television company has, or an advertising company? What is your role as chair in research?

ANDY: Yes, again, over this 12-month period with a technology partner, arts partner and research partner, we've seen what we do differently, and also where the overlaps are. Often universities are well placed to exploit those overlaps, and I don't think we do enough of it, frankly, and that's where there's considerable opportunity, but increasingly, universities are trying to find ways of connecting with non-academic sector, and to have an impact, to have influence to make a difference to what's going on in the arts sector or even the technology sector, health, whatever it might be, and I think in that aspect, they're lacking considerably in expertise, so, over the last five years, we've now gone through this assessment cycle in universities where our researchers have evaluated in part on the basis of our impact outside of university, but, actually, the expertise in doing that is quite limited in university. It is much more effective 
within an arts setting, so I've worked a lot with a effectively called -- a festival called "Abandon normal devices" but me, and the entourage around me thinking how to do that collaborative work with the public, how to reach the public, and produce activity and events with the public in mind. That is the crucial bridge that this fund for us has provided as a project.

ROSIE: So it is the arts world that is actually leading the way?

ANDY: I think it is, especially in terms of the public impact. I work with Fact in Liverpool. I think universities are not always very effectively linked into their local communities, whereas arts organisations tend to be much more, so I think there is a lot we can learn as an organisation to do that more effectively.

ROSIE: I asked earlier on Darren Henley the CEO of the Arts Council what country, if any, he admired and sort of aspired to. He said, "None, we are the leader." Do you concur with that? Do you represent the forefront of, or perhaps this audience, are we at the vanguard of digital?

FREYA: I don't think anyone is a leader in it yet, because, across the board, people are still finding - it is still very much at a development stage, and because technology is changing all the time, and people are consuming content in so many different ways, that I think there isn't a leader right now. There is an opportunity.

>>: If you look at patent applications around the world as one indication of innovation, then certainly we're not. The drone technology - one of the things -

ROSIE: Who is?

>>: China for drones, certainly, if you look at the patent applications over the last five years for drone technology, ninety per cent of them come out of China. So, I think, you know, that's only one measure, but, certainly, in terms of the economic underpinning of a particular technology, clearly, we're not at all. I think that's where, again, this was part of our project. We looked at the patent history around the technology relating to our subject to see how those patterns of growth are present, and it is clear one of the things we can do more, probably within the arts sector is think about routes from project to patent. I think that's an expertise that can perhaps most effectively be nurtured through that sort of collaborative project.

ROSIE: Do you have any examples?

>>: I don't know, it will be interesting to find out whether that data has been collected because that's one way that that can be harnessed.

>>: It's a really interesting and perplexing question, Rosie, about being a leader. Which is the world's best contemporary dance nation? I don't know the answer to that and I'm not sure that it's trackable and if it matters. So there is something about depth of engagement, something about cultural soft power. There has been that work recently about that, hasn't there, and there is certainly this work around technological innovation. I've seen many of the greatest things around art and culture coming out of this country and almost all of the worst, and I think that's how it should be. Isn't that what Deborah said earlier? I think that's how it should be. I'm unhappy when there isn't reach, I'm unhappy when groups just talk to themselves. There is a kind of theocracy of digital. That's why I'm anti the word. We don't have departments of paper anymore in universities. It's actually about how we operate in everyday lived experience increasingly, but once you build the wall, you have to defend the wall. If you are the digital specialist, you are kind of a shaman so you have to invent a way of keeping people away and one of the interesting things about the R\&D fund is how seldom that has happened or what has happened to overcome it. 


\section{A MENDED DRAFT VERSION-FOR REFERENCE USE ONLY F R O L IVE S P E ECH - T O-TEXT T R A N C RIP TION}

Fascinatingly, one of the things that has happened in the way we make work, and to bring things more close to each other over the last five years is the development of much more agile, creative production methodologies in software. They are literally called "agile". Lots of you will have used them in projects, I am sure.

I'm used to a waterfall process, being bombarded from above. You wrote a document and then explained why it wasn't that at the end. Now you have an agile methodology where you try and grow and learn. That's how you make and learn; that's what rehearsal is. It wasn't how you made software, and the two things coming together is a hidden and utterly crucial thing that makes it possible.

In agile methodology you talk about what you are going to do today, like in rehearsal, then you do them, show them to each other, like in rehearsal. I think we've slightly missed that actually in terms of bringing these things together. It certainly wasn't like that ten years ago.

ROSIE: I suppose one thing which is envisaging the future is what about the present? What will be lost? I'm a journalist and for journalists the digital impact has been like the arrival of the printing press, and there we all were with vellum and pens and paper and suddenly the printing press turns up and we are all yesterday and the internet has radically changed - newspapers going online, yes, printed papers still exist, but the whole - you know, it's like I'm a black cab driver and suddenly Uber has come along and I suppose the question is for art, will what one might call the old forms exist in parallel? Will it all go along happily, as it probably will with print and online, or will one - or certain forms just fall by the wayside and be eclipsed by a younger generation who think digitally?

Who would like to -

DAVID: I think if you are talking about art forms, everybody says [inaudible] is going to die but it hasn't luckily. It's this thing that Deborah Bull spoke about this morning: are you open to change with your business model? I think the director of English National Ballet says if you are a museum, it will die. If you keep the right attitude, it will not die; you can move forward at the right pace. You are never going to move all at the same time because that's unrealistic, but having that flair to be open and work with practitioners to help you do, because we can't do it all ourselves. This is why we don't have one sole person, the artistic person, the dancer, choreographer - we need lots of specialities to take us forward. So that is an interesting one.

If you look at history about when everyone says it's going to die, it's going to die - broadcast, it's going to die - it hasn't been the case because people like Deborah Bull are pushing -

ROSIE: Yes, and yet when she named Viyella, Woolworths, Encyclopedia Brittanica, those names sounded archaic.

DAVID: Yes, people used to say that about the Opera House. I used to work there, and actually they are probably one of the most innovative arts organisations, they are still doing great things, still leading and doing things like the $R \& D$ fund and still learning so as long as that appetite is there I don't think it will die.

ROSIE: Freya, what do you see for the future? Withering on the digital vine?

FREYA: I think there's always going to be an appetite for that. I used to produce various documentaries for Sky Arts and partnerships with so many different arts organisations and I always found it really interesting that dance was the most forward-thinking when it came to really looking at opportunities and how they could put what they were creating and experimenting with, put it into new platforms. I thought that was really interesting. Other forms were slightly more resistant to it and saw it purely as a marketing tool. 


\section{AMENDED DRAFT VERSION-FOR REFERENCE USE ONLY F R O M LIVE S P E E C H - T O-TEX T T R A N S R I P T I O N}

>>: I think that's probably where it was: let's get it out there, find the audiences and bring them with us, and that's probably why back then it was: let's be totally open so we don't become pre-historic.

ANTHONY: I was just thinking about what the analogue R\&D Fund for the arts is.

ROSIE: Core funding, basically.

ANTHONY: Yes, so isn't it that question that trumps it in the end? Most new technologies show the old technology up for what it wasn't good at and they make it get better at the thing it is good at, so cinema has been dead three times, and it's now become mostly about popcorn and being not in your house, in spite of the fact that some people, not all people, have surround sound, 60-inch screens and can probably make their own popcorn more cheaply, because there is something additional to it.

One of the great boon areas is the interaction between the live and the so-called digital because they are not in opposition. They are not different things. We did a commission with FKA Twigs at Manchester at the Festival this summer which was one of my first and so far only creative commissions -

ROSIE: I bet your kids thought that was cool.

ANTHONY: My kids are younger and would think it was cool if it was Rapunzel or something - sorry - but the two things were completely integrated and there were performances coming that I and others know about which are very integrated; live performers in 3D operas. I was part of one of those when I was at ENO. Lots are integrating.

But I'm more interested in - there's an old school thing going on in games where suddenly you can do a million selling title. A brilliant writer wrote something called 80 Days which is her version of Jules Verne, 80 Days Around the World in interactive form on an app and people who don't know they are engaging with a punk writer engage with a piece of art. So I'm interested in the way these worlds kind of cross fertilise. The people who usually present them as either/or have got skin in the tech and they want to tell you it will all be VR, you won't need theatres because VR is better than theatres; no, it's not. It's different to theatres.

ROSIE: So it's a parallel.

ANTHONY: It's a selling you things technology.

ANDY: I just want to defend digital because I think it is synonymous with a number of other ideas that it represents and it's those concepts that I think engage us, so one thing that has changed, why Encyclopaedia Britannica hasn't been as successful as Wikipedia is because people expect the participatory aspect of it. The agency we share in content.

ROSIE: And also the cinema, I went the other day and it was just so brilliant sitting in the theatre with my kids and going, "Oh no!", all of us.

>>: It's the interaction, the network. The digital is the foundation layer of it.

ROSIE: Well, as you say, it's the means, it's the pen, it's the paper.

ANTHONY: It totally is. I worked on James Graham's play Privacy at the Donmar last year and things we were doing which were very innovative in the context of a West End play were not in any way innovative for most of the techie, digital people. Being able to put an extract from Google Street View with everybody's house on the screen - of 


\section{AMENDED DRAFT VERSION-FOR REFERENCE USE ONLY F R O M LIVE S P E E C H - T O-TEX T T R A N S R I P T I O N}

course your house is on Google Street View, you know that implicitly, but my goodness you feel differently about it when it's 42-foot wide in a theatre.

ROSIE: Okay, final reflection. One last thing to think about that our audience can take away, one last thing to think about or one last thing that people should look out for.

ANDY: I guess not to get too distracted with the realtime economy; that there is more to life than just the present, which I think is what we often focus on with digital. Who is tweeting right now, live experiences; there's lots of other stuff that goes on.

ROSIE: Okay.

>>: Ooh, that's profound!

ROSIE: That is. Very, very good. I thought you were going to talk to us about Amazon.

>>: I'm completely tweeting what you just said.

>>: Already doing it.

ANTHONY: Yes, already doing it. Cimeon Ellerton earlier talked about a phrase that Professor Paul Moore uses, this reverential gap, that digital and artistic are different at different ends. They are not. That's true of all the digital projects I've ever done, whether it's television or whatever it is, you are actually just talking about people talking and collaborating in new ways and if they won't, then they are in trouble.

ROSIE: Okay, Freya?

FREYA: I think it does come back to this thing that people want to have great experiences and art provides that, both analogue and digital, and it will continue to do so. And I think there's going to be more and more interesting crossovers. That will continue to evolve but at the same time, as Anthony was saying earlier, they will run in parallel and that's fine as well, and it's being accepting of that and not trying to do everything.

ROSIE: Okay. David?

DAVID: I think probably the partnership element in collaboration, and I think about an attitude to instigating that kind of thing instead of waiting for it to come to you or huge events where you can just meet someone. I think if you have got an idea or the ambition, pick up the phone, email, social media, reach out.

ROSIE: Yes, yes. You can do it.

DAVID: And be more confident about what we can do. Everyone has the passion to do new things and experiment. The arts are extremely valuable otherwise we wouldn't do it but people do want to work with us and I think pushing that ourselves and being our own voice together is a good thing to do.

ROSIE: Thank you so much Andy, Anthony, David, Freya, thank you so much for your thoughts for the future. Thank you.

[Applause] 


\section{A MENDED DRAFT VERSION-FOR REFERENCE USE ONLY F R O L IVE S P E ECH - T O-TEXT T R A N C RIP TION}

Right, I'm just going to wind up. Right, we are just about to finish. If you could - I don't know if you have been given thank you so much, guys - I don't know if you have been given your evaluation forms. If you have, please fill them in as quickly as you can, so while you are in the moment. As Andy might say.

Thank you so much for being here today. I think - I hope you will agree - it has been a fascinating opportunity to see in depth a few of the R\&D projects, to see how artists and practitioners really are using digital to forge an exciting way forward in terms of access, in terms of business, in terms of data, monetising models, and today we've heard how the Arts Council is determined to use digital to drive forward its aims, particularly one to get the arts out of the magnet that is London, which I think is something that digital can do brilliantly.

And we've also been encouraged to think properly about risk in a riveting keynote address. How many puppy strokes was that? Loads.

Nesta is the organisation which has made this day possible, and it's my profound pleasure to invite Tim Plyming, Nesta's Director of Digital Arts onto the stage to close today.

\section{[Applause]}

TIM: Rosie, thank you very much indeed and thank you everyone for staying through to the end of the day. If you will allow me just to say a few minutes of thanks, I would greatly appreciate it. But thank you for staying through with us. I am reminded that we are in the middle of an industrial revolution at the moment and it is enormously exciting and at the end of today I'm more excited about it than I've ever been, and I've spent most of my working life working in that industrial revolution, and to give you a sense of how far we've come, in 2000 I was building the first ever website for Radio 2, and I was asked to go and speak to all of the presenters and explain what we were doing at a point where most of them hadn't got the internet and one particular presenter said to me: you are not going to have to worry about explaining any of this to me, I am an expert on technology. I've only got one question for you: where is the internet based? [Laughter]

And I said, "Well", and I'm not going to say his name and perhaps if you get me after for a drink then I might share it, and I said to this presenter, "It's not really based anywhere, the best way of thinking of it is all the computers in the world linked up together", and he said, "Yes, I know that, I know, but where is it based? Is it New York?" And I said, "Yes", and he went, "I thought so!".

[Laughter]

But we are still in the middle of that industrial revolution and it's an amazingly exciting place to be for the arts and cultural sector. I believe at the end of this three-year R\&D fund we are really only at the beginning of what could be an enormously exciting chapter. Look, two key principles really, at the heart of this fund when it was launched. One was the importance of sharing. Deborah Bull reminded us in her amazing keynote speech that the most interesting innovation happens between the sectors in that innovation space. This project for me, the two things that have stood out as really successful, beyond all of the experiments the 52 projects have made, is just to make the case and prove the value of sharing and collaboration. Because that's what this project really shouts out loud.

The second thing was that we asked all of the projects at the beginning of the process to be really generous, so this required a level of generosity that takes us slightly beyond the way that we sometimes work in a silo or mildly competitive - not perhaps always - just mildly competitive environment. So we asked people to work in a really generous way and at the end of this three-year process, which is where we are into at the moment, the thing that really strikes me is just the generosity with which people have embraced this process and I think both of those things 


\section{AMENDED DRAFT VERSION-FOR REFERENCE USE ONLY F R O L IVE S P E ECH - T O-TEXT T R A N C RIP TION}

are going to be really, really important in the next stage, in the next chapter for this industrial revolution. That sharing and collaboration, and that generosity that will be required.

Therefore, it really leads on to some thanks really, and I wanted to say some personal thanks to the projects. You have seen just a glimpse of 52 projects that have now completed and they are in the final stages of sharing what they are doing. We owe them as a sector an enormous thanks for the way that they have been embraced this process. It has been an enormous amount of risk for them. It has been them stepping out into the unknown, it has been an enormous amount of work. We have required from them an enormous amount of reporting, and we owe them, I think, as a sector, an enormous debt of thanks so some of those projects are represented in the room, and if not, they will hear applause, so perhaps we can give a round of applause to those 52 projects.

\section{[Applause]}

And I also wanted to thank those who have presented today. We wanted to make sure that they had run through what they were doing and had sent us all their stuff in advance and that was all on top of their day job, so the way that fairly seamlessly we've managed to present all of those projects is because those guys have really worked some very long hours in presenting. Our champions have been fantastic, giving us their time to both understand the projects, come and present today, write numerous articles for us, present videos. As ever, we asked them just to do a very small thing and then in traditional spirit of the art and cultural sector we then asked them to do another ten things on top of that and they were enormously gracious in the way that they did that. So to all of those who presented, and to our theme champions, perhaps we can give them a round of applause as well.

\section{[Applause]}

Also, a personal note of thanks to the brilliant digital R\&D team at Nesta who have worked on both this event and on numerous, a large amount of other things. The events team at Nesta led by Rebecca who have pulled the whole day together, our brilliant event - and to Rosie Millard who has brought her understanding of the sector and her brilliance in presenting both combined, so for those people as well perhaps a round of applause, thank you.

\section{[Applause]}

It has been an important collaboration between Arts Council England and the AHRC and my thanks to those partners who have been working with us, again a collaboration delivered across lots of different disciplines and organisations, and they've done that brilliantly, so we thank them for that.

Really, the final thing I wanted to do was to touch on what next really, because it is a question that we will have as we leave today. Do come and continue the conversation, share a piece of technology that you think is going to affect us over the next few years, over a drink. So there is some live music and a DJ, and plenty of alcohol and snacks up in the Rotunda, it's a beautiful space here within the Library at Birmingham, so as you head out of the door and turn left do come and join us for a drink. We will be very quickly editing films from all of the sessions today, which will be available on the main website for the fund, so you will find that at artsdigitalrnd.org.uk. Continue the conversation over Twitter. We have been trending for the last four hours, so continue that and share again on Twitter a piece of technology that you think is going to disrupt where we are at, at the moment.

Over the remainder of the year, we will be hosting some more events when we get a chance to presents some of the projects, so look out for those. Either follow us or look out for the hashtag \#artsdigital and we will share the final events for this year. 
AMENDED DRAFT VERSION - FOR REFERENCE USE ONLY

F R O M L IVE S P E C H - T O-TEXT T RA N S R I P T I N

Look, the last thing I wanted to do was to thank you so much for your interest in these projects, for being here today, for your warm and generous way that you have received the work that they've done. So a huge thanks to you. Do come and join us for a drink. Thank you.

[Applause]

[Conference ends]

For further information on live subtitling, see www.stagetext.org. 
H Guia de procedimentos fotográficos para reprodução de objetos museológicos 


\section{UPD|G universal photographic digital imaging guidelines

Photographers Guidelines

\section{Table of Contents}

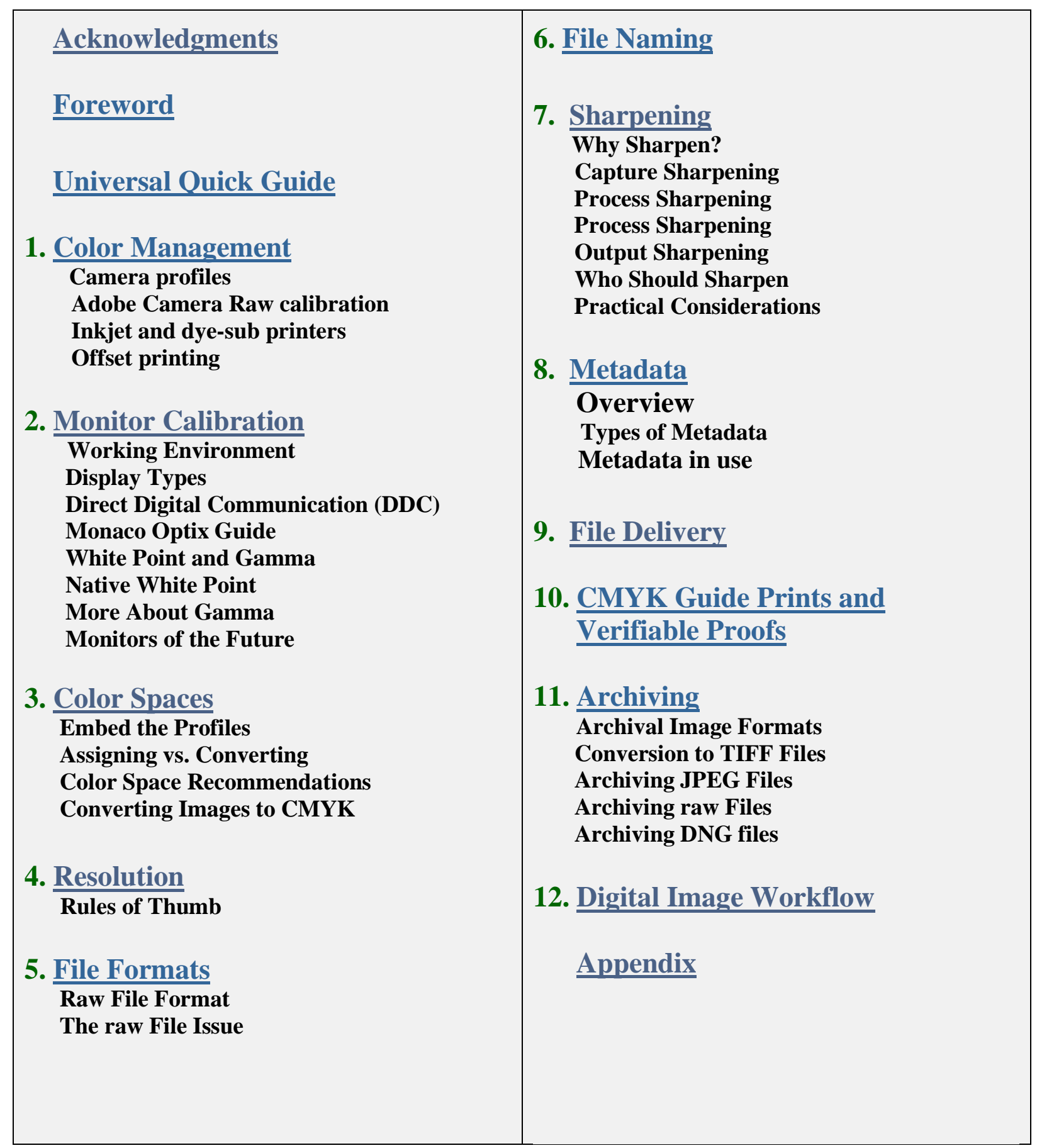




\section{Acknowledgments}

Managing Editor: Richard Anderson

Technical Editor: Michael Stewart

Contributing Editor: David Riecks

Contributing Editor: Peter Krogh

Copy Editor: $\quad$ Greg Smith

UPDIG Content Contributors:

\begin{tabular}{|l|l|}
\hline Andre Cornellier & Bob Marchant \\
Bob Croxford & Sam Merrell \\
Dennis Dunbar & Alan Newman \\
Kevin DePalmer & Michelle Alvarado Novak \\
Robert Edwards & Betsy Reid \\
Ken Fleisher & Stanley Rowin \\
George Fulton & Jeff Sedlik \\
Judy Herrmann & Ulrik Södergren \\
Reed Hoffmann & Tamra Stallings \\
Rick McCleary & Eddie Tapp \\
& Mike Upstone \\
\hline
\end{tabular}




\section{UPDIG Coalition Member Groups}

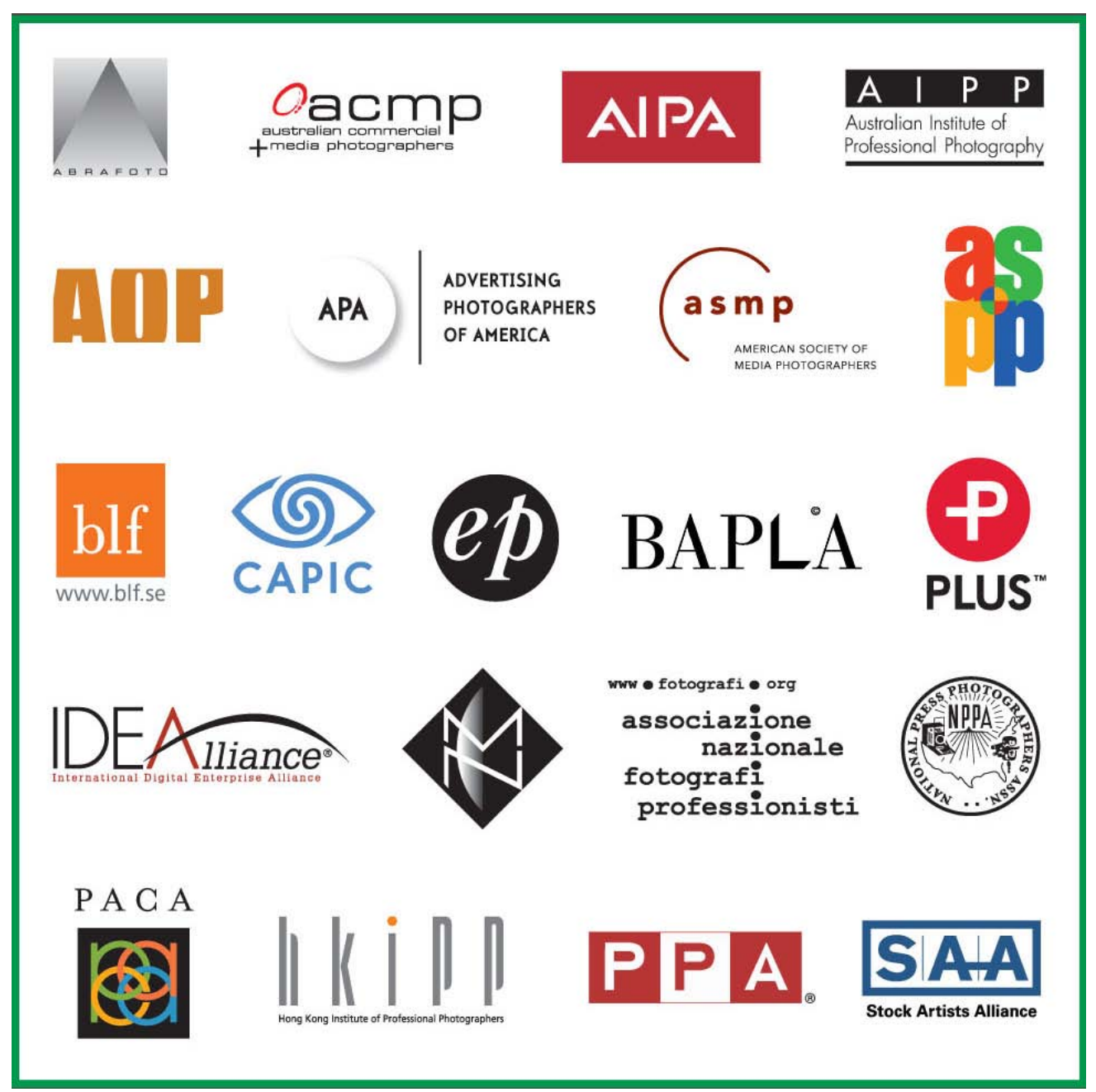

Advertising Photographers of America (APA)

Advertising and Illustrative Photographers Association (AIPA)

Australian Institute of Professional Photography (AIPP)

American Society of Media Photographers ( $\underline{\text { ASMP) }}$

American Society of Picture Professionals (ASPP)

Associação Brasileira dos Fotógrafos de Publicidade (ABRAFOTO)

Association of Photographers [UK] (OP $)$

Australian Commercial + Media Photographers (ACMP)

Australian Institute of Professional Photographers (

Canadian Association of Photographers and Illustrators in Communications (CAPIC)

Editorial Photographers (EP)

Hong Kong Institute of Professional Photographers (HKIPP)

International Digital Enterprise Alliance (IDEA)

Museum Computer Network (MCN)

National Association of Professional Photographers of Italy - TAU Visual (OOTOGRAFI)

National Press Photographers Association (NPPA)

Picture Archive Council of America (

PLUS (PLUS)

Professional Photo Companies and Photo Agencies Association [Sweden] (BLF)

Professional Photographers of America ( $\underline{\text { PPA }}$ )

Stock Artists Alliance ( $\underline{\text { SAA) }}$ 


\section{Foreword}

Vision Statement: The photography industry is undergoing great change. New ways of making and working with photographs are replacing older methods. The broad capabilities and efficiencies of digital capture and delivery have revolutionized the image marketplace. But in doing so they have exposed gaps in creative and quality control that frequently lead to confusion, inefficiencies, loss of quality and unnecessary expense. We recognize the need for worldwide imaging standards to facilitate reliable and repeatable image reproduction.

Film-based photography workflows relied on transparencies or prints to establish and share color and tonal information. Digital imaging lacks such tangible references. Integrated color management with accepted ICC workflows fills that void. After more than a decade of regular use and adjustment, ICC (also known as ICM) has proved itself a mature technology used by thousands of professionals. As the first link in the image supply chain, photographers must establish and adhere to the best practices of color management. And those who work with their photographs must follow the same standards in order to accurately reproduce those photographs.

The media for delivery and storage of images have also changed. Digital Asset Management offers a set of standards to replace film-based workflows. Our task is to identify terminology and workflow for image creation, image delivery, accurate reproduction and archiving. Implementing the standards and practices in these guidelines will enhance creative control and economic efficiency.

Mission Statement: The UPDIG Coalition is a global initiative of industry organizations working to identify, define and share best technical practices for reproducing, exchanging and archiving digital images.

The UPDIG Coalition brings together industry experts representing creators, distributors, users, technology providers and others dedicated to this mission.

The UPDIG Coalition collectively publishes and promotes the Universal Photographic Digital Imaging Guidelines.

\section{Objectives:}

1. Make digital imaging practices clearer and more reliable by developing standards for quality and terminology.

2. Develop web resources for imaging professionals that establish common digital imaging terms.

3. Demonstrate the creative and economic benefits of these guidelines.

4. Develop industry guidelines and suggested workflows for various types of image reproduction.

5. Establish consensus on these issues among professional photography trade organizations, image distributors, archives, printers, software developers and manufacturers.

\section{Standardization Goals:}

1. Color Management: ICC Workflow, Hardware Calibration, Guide Prints and Proofs.

2. File Delivery and Archiving: Naming Conventions, Resolution, Sharpening, Digital Workflow.

3. Metadata: embedded IPTC and XMP data, including PLUS Licensing Language.

4. Industry Terminology. 


\section{Quick Guide}

\section{Main Principles}

- Digital images should look the same as they transfer between devices, platforms and vendors.

- Digital images should be prepared in the correct resolution, size and sharpness for the device(s) on which they will be viewed or printed.

- Digital images should have embedded metadata that conform to the IPTC and PLUS standards, making them searchable while providing relevant rights and usage information - including creator's name, contact information and a description of licensed uses.

- Digital images should be protected from accidental erasure or corruption and stored carefully to ensure their availability to future generations.

\section{ICC Color Management}

ICC profile-based color management defines color information in standard terms necessary for proper reproduction of images. Monitors, printers, scanners, and ideally, cameras should be profiled. Working and output spaces - such as Adobe RGB, sRGB, SWOP CMYK, (etc.) should be embedded and preserved when opening files.

\section{Monitor Calibration}

Monitors should be calibrated and profiled with a hardware device. Visual calibration is not adequate for professional image editing. An accurate visual representation of the image is extremely important to the imaging process. Calibration standards range from:

- Gamma - 1.8 to 2.2 (or $\mathrm{L}^{*}$ ).

- White point $-5000 \mathrm{~K}$ to $6500 \mathrm{~K}$.

- Brightness levels - $80 \mathrm{~cd} / \mathrm{m}^{2}$ to $140 \mathrm{~cd} / \mathrm{m}^{2}$.

As a general calibration guideline, use gamma 2.2 and 6500K for both Windows and Mac. A white point of 5000-5500K is a common recommendation for offset printing. Set brightness levels in relation to the room's ambient lighting.

A calibrated and profiled monitor, in conjunction with good print profiles, will allow you to "soft proof” the intended output. A daylight (5000K/D50) light source at correct brightness is necessary to visually match monitor to print.

\section{Color Space}


Camera settings for color space can be critical when capturing TIFF or JPEG files. For raw image capture, it makes little difference how you set the in-camera color space, since you can set it just as effectively during postproduction. It's generally better to choose a large-gamut space such as Adobe RGB (1998), ECI-RGB or ProPhoto RGB - for JPEG and TIFF captures, and for image editing. It may be convenient to capture images in a narrow-gamut space, such as sRGB, if the pictures will not require color correction or tonal editing and you intend the images for web or sRGB lab prints. Note, however, you can convert a wide-gamut image to a narrow space such as sRGB, while a narrow-gamut image converted to a wide space will not (re)capture the colors of the wider gamut.

Offset printing requires image files saved in a CMYK color space, which has a very different and narrower gamut than digital image files captured in RGB color. A good CMYK conversion requires both expertise and knowledge of the specific press and paper type. Simple mode conversions in Photoshop are not recommended.

Photo lab prints often require the sRGB color space. However, some labs may have a specific color profile, either for embedding in the file or for use in soft proofing.

\section{Resolution}

Describe resolution of digital images either by pixel dimensions (width $\mathrm{x}$ height) for screen use or by physical size and resolution for print use. Express image resolution as pixels per inch (ppi), pixels per centimeter (ppc) or pixels per millimeter $(\mathrm{ppm})$. But note resolution is only relevant when paired with output size (e.g., 8x10 inches at 300 ppi). Here are recommendations for common uses:

- Inkjet prints: 180 to 360 (some say up to 480) ppi.

- Continuous-tone printing: 240 to 400 ppi.

- Offset printing: 300 ppi is often specified, but resolutions of 1.3- to 2-times the halftone screen ruling are considered safe. This means 195 to 300 ppi for a 150-line screen. Newspapers usually print with 85- to 100-line screens, requiring - at most images at 170 to 200 ppi.

\section{File Formats}

The best quality comes from capturing and editing in a raw file format. The advantages of raw file formats are: choosing color space when the file is processed; greater bit depth; the ability to adjust white balance, saturation, exposure (to a degree) and tonal characteristics; adjustable noise reduction; and correction for lens aberrations - all in a non-destructive manner. Raw files may be processed in a variety of software, from the camera maker's own to many third party products, and even by using the built-in raw processing of Apple and Windows operating systems. Converting raw files to DNG format is considered an excellent method for archiving raw files. DNG was designed as a more universal file format than camera-specific raw formats such as NEF or CR2.

File formats include: lossy compression types such as JPEG; lossless compression types such as LZW compressed GIF and TIFF, PSD and most raw file formats; and uncompressed types such as standard TIFFs. Some formats, such as JPEG2000 and HD Photo (JPEG XR), offer both lossy and lossless compressions. For the web, use JPEG. For printing, uncompressed TIFF is often preferred, although high-quality JPEGs (Level 10-12) can be visually indistinguishable from TIFFs, and some printers prefer their smaller file sizes. 


\section{Naming Files}

To avoid problems with files transferred across computing platforms, name files with only the letters of the Latin alphabet (A-Z, a-z), numbers, hyphens and underscores. Do not use other punctuation or symbols. Keep the full name to 31 characters or less, including its three-letter extension. Use file names that will not be duplicated. Multiple files with the same name cause problems for computers and people alike. Including the numeric date and the photographer's name is an excellent method for creating unique names.

\section{Sharpening}

Capture sharpening compensates for the loss of detail that occurs during any digital capture process. TIFF and JPEG capture allows for sharpening in camera or during postproduction. Sharpen raw files during postproduction. Do not sharpen heavily early in the image-editing process.

Process sharpening counters the loss of detail in the post-production process. Process sharpening is also used for creative effect. Perform it after color and tone correction, retouching, image sizing, etc. or for creative effect. The goal is an image that is acceptably sharp, but never oversharpened.

Output sharpening should be specific to the final output size and the output system (printing device, paper, ink, etc.) and applied only as a final step before output. It is important to communicate when delivering whether output sharpening has been applied.

\section{Metadata}

EXIF, IPTC, IPTC Core Schema and PLUS are the current standards for embedding metadata in image files. Embedded metadata should include creator and copyright information, as well as searchable keywords and license information. Including useful and relevant information in metadata adds value to an image.

\section{File Delivery}

Digital image files may be delivered on a variety of removable media, including hard drives, CD-Rs and DVD-Rs. Do not use adhesive labels on optical media, since they may separate and damage an optical drive. Printing directly on inkjet-writable or LightScribe media CD-Rs or DVD-Rs is a good way to provide information such as your copyright, usage license, file lists and disclaimers. For speed and convenience, deliver by FTP or e-mail. All image files should have embedded metadata. (For proprietary raw files, the safest route is to include the metadata in an XMP sidecar file.) Image file delivery should include ReadMe files.

NOTE: Provide a ReadMe file in PDF, HTML or TXT format with all files delivered for output. Such files should specify image size(s), color space(s), the copyright owner's contact information, any licenses granted, (or PLUS code) and if certain rights are being withheld, the words "other uses, reproduction or distribution are specifically prohibited." The ReadMe file should also include disclaimers noting recipients are responsible for following ICC-based, color-management workflows. 


\section{CMYK Guide Prints and Verifiable Proofs}

CMYK guide prints and verifiable proofs can serve as valuable reference points for digital files, especially if the recipient is unknown or the output profile generic. Creating CMYK guide prints and verifiable proofs that accurately represent offset CMYK printing requires knowledge of printer profiles and color management. Clearly convey the method used to produce the guide print.

\section{Archiving}

It is important to address the issue of who will archive digital image files. Basic decisions include what kinds of files will be archived and how the archives will be protected from format obsolescence and media failure.

\section{Digital Image Workflow}

No single workflow suits all photographers and all clients. A good digital workflow is the most efficient and automated way to get the job done. It should satisfy the clients' needs, embed necessary information (metadata), embed color profiles, and automate the archiving and backup of files. A good workflow saves time and protects against losing images and the work performed to optimize them. Many software packages can be part of a digital workflow. New programs appear regularly, some aiming to be all-in-one solutions. You will need to test to see which program or programs give you the right combination of metadata handling, efficiency, speed and image quality. 


\section{PHOTOGRAPHER GUIDELINES}

\section{ICC Color Management}

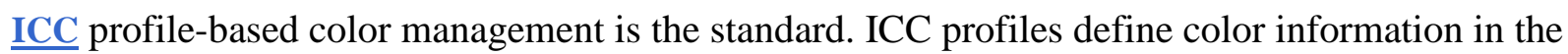
consistent terms needed for proper reproduction of images. All devices (scanners, printers, monitors, and ideally, digital cameras) should be profiled and profiles should be embedded in image files. Configure software, when opening files, to preserve embedded profiles, warn of mismatched profiles and warn of files with no embedded profiles.

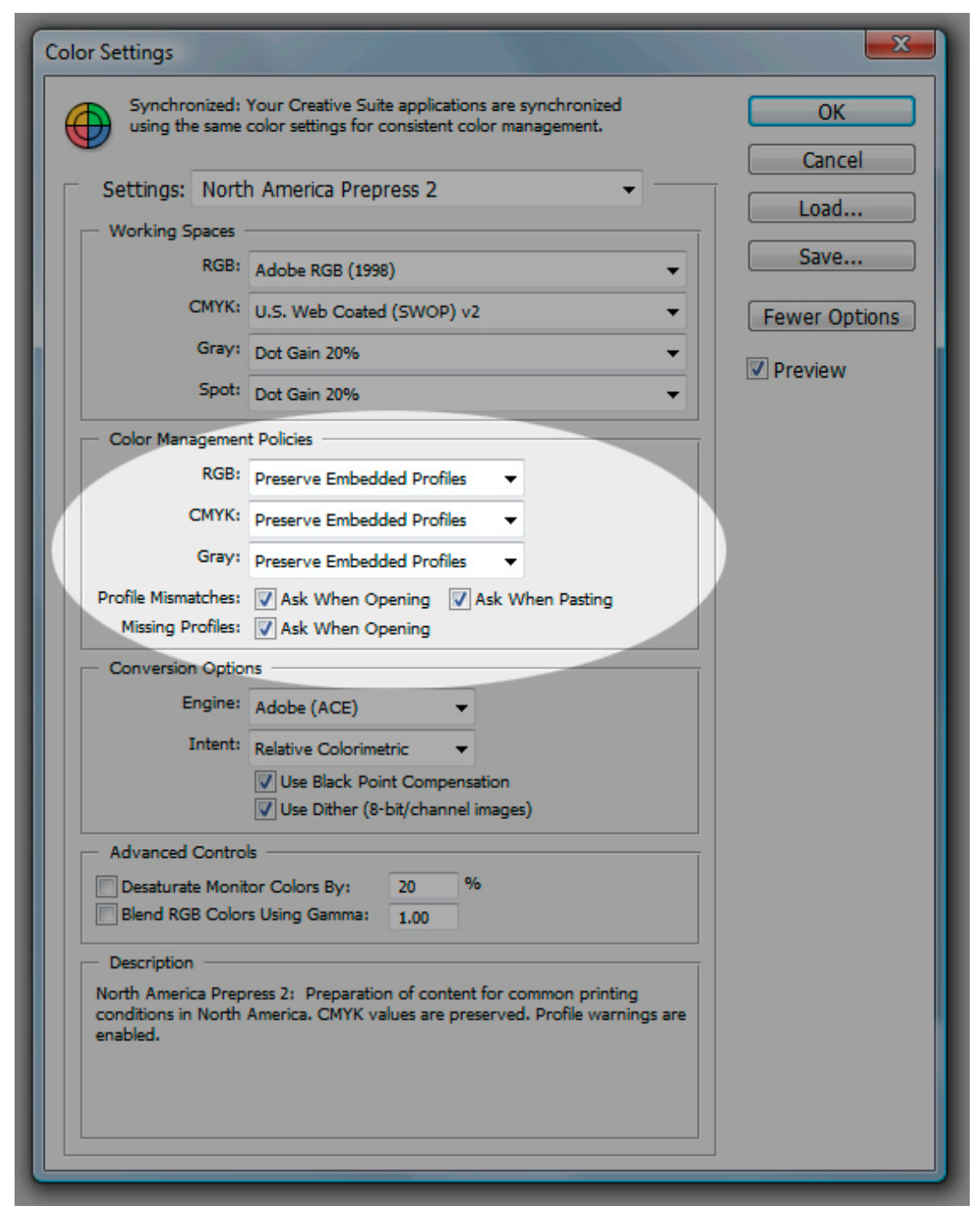

Photoshop CS3 Color Settings / Color Management Policies: "Preserve Embedded Profiles" turned on and "Ask When Opening and Pasting" checked for mismatches and missing profiles.

Camera profiles: Each camera, even compared to others of the same model, has unique characteristics. Although not so essential as monitor and printer profiles, camera profiles aid in reproducing accurate color. Used properly, they can offer more accurate color, a different color 
look and/or speed the workflow by saving time in post-processing. Profiling packages are

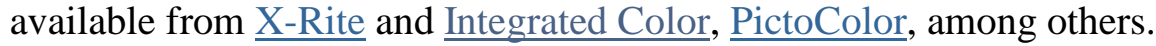

The issue with custom profiling cameras is the ability to apply that custom profile in raw processing software. Capture One Pro is the only commonly used raw Processor we have found that supports ICC camera profiles.

The DNG 1.2.0.0 specification formalizes the idea of a "camera profile" by expanding the colorhandling capability of Adobe's universal raw format in several important ways, related both to the handling of color tags - including proprietary and custom color spaces - and to the integrity of image data.

The new specification provides a structure for non-Adobe software to embed both Adobe Camera Raw profiles and custom color profiles in DNG files. Since other manufacturers' raw converters may use a variety of profiles, this should enhance interoperability and forward compatibility for all software using the DNG format.

Adobe has also opened its Camera Raw rendering for third parties to insert more profiles. This enables others to create profiles that match the look of in-camera conversions or to create new profiles that allow custom, highly styled conversions. Because a custom profile can be embedded in the DNG file, computers without that profile installed can now accurately render and display a custom look.

New metadata tags added in the specification define the use licenses of embedded profiles. Adobe has created a very broad license for its own profiles, and the revised DNG format permits other profile makers to tag their profiles as narrowly or openly licensed.

In addition, Adobe has added to the specification two new tags. Software can use these to verify that image data - including embedded raw files - are not corrupt. This allows development of tools that automatically review a collection of DNG files, ensuring with a high degree of accuracy the integrity of all image data.

Adobe Camera Raw calibration: $\underline{\text { ACR }}$ uses built-in or "base" camera profiles as a starting point for rendering raw files. These are actually a blend of two profiles, one for tungsten light and one for daylight. ACR blends the two according to the white balance of the raw file. Before Adobe developed the Looks Editor, the only method for customizing ACR raw rendering was to use the ACR Calibration Tab. It allows you to automatically adjust ACR's rendering based on your camera's response to a known color target, such as the GretagMacbeth 24 color checker.

The calibration process can be automated: Photograph the Macbeth 24 checker target, run Tom Fors'ACR Calibrator script, name and save the resulting calibration. The calibration can be applied to all the raw files of a particular camera model. Since Adobe Camera raw applies different camera profiles for daylight and tungsten lighting, you need to run at least two calibrations. We say "at least" because the calibration may also change incrementally for different ISO settings. A good guide to this technique can be found at the Visual Vacations site. Rags Gardner has a site with even more information on raw camera calibration using Adobe Camera Raw and scripts that work with other color targets. Lee Varis has suggested and explained another approach in his book Skin.

Inkjet and dye-sub printers: You can bring printers (including desktop and wide-format printers) into a color-managed environment via profiles. If working with the manufacturer's printer driver, turn off all color management and print a copy of the color target file. Next, 
measure the printed target with a spectrophotometer to generate a profile for accurate output on a particular paper or other medium. Repeat this process for each paper stock and ink type you use. If you do not own profiling software or a spectrophotometer, you can use one of several service providers, such as Chromix. Most RIP (raster image processor) software offers profiles for a wide variety of papers. Many RIPs will also allow use of custom profiles.

Offset printing: Three organizations in the United States have produced standards for the printing industry that allow for standardized CMYK profiles. They are: the SWOP Committee (Specifications for Web Offset Publications), covering web presses; GRACoL (General Requirements for Applications in Commercial Offset Lithography), which covers sheet-fed printing; and ANSI (American National Standards Institute), which has created a Newsprint standard CMYK profile. The three standards - SWOP TR001, and GRACol's DTR004, and ANSI's SNAP (Specifications for Newsprint Advertising Production) - if widely adopted, would ease worries about custom CMYK profiles.

In Europe, organizations such as FOGRA, ECI (European Color Initiative) and IFRA work on standardization of the printing industry. They have published general color profiles for several printing conditions. These profiles, based on the ISO 12647-2 standard, are available for download from ECI. Several larger print houses recommend them as CMYK profiles for their production. They also have garnered wide acceptance as proofing profiles.

If you have the expertise, it's best to provide the printer with CMYK image files embedded with the printer's custom CMYK profile. If the printer does not have a custom profile, it's best to consult with the printer or the client's production expert to determine the best color space for the delivered files. A standard Photoshop CMYK profile that matches the general press conditions SWOP Coated, GRACol, or SNAP - may suffice, particularly if the printer adheres to ISO, SWOP, GRACol or SNAP specifications. In this period of flux, communication is key. Profiles will also enable you to produce guide prints or aim prints (see section 10 CMYK Guide Prints and Verifiable Proofs) for clients, providing a printed reference for the press operator to target for color-matching purposes.

\section{Monitor Calibration}

Computer monitors must be calibrated and profiled before they can be part of a professional workflow. Accurate monitor calibration and creation of a display profile require a hardware device, such as the $X$-Rite EyeOne Display 2 or Color Vision Spyder 3 Elite. Another useful tool is a Profile Verification Kit (such as this one by Pixl Ltd). This is a digital file with an accompanying proof or print. After profiling your monitor, you view a comparison between the digital file, displayed in Photoshop (or other professional imaging software), and the proof print, as viewed under $5000 \mathrm{~K} / \mathrm{D} 50$ lighting, to indicate whether your monitor profile is accurate. If your work requires inkjet prints for display, you may do better to evaluate the images under 6500K/D65 lighting - and in some cases a dual-color viewing booth could be a useful investment.

Working Environment: No matter how good your monitor or how well you have it calibrated and profiled, you must ensure your work environment features subdued, neutral lighting that does not vary. Your computer desktop should be set to a neutral gray, and you should avoid having areas of bright color within your field of vision, or reflected in the monitor. This includes brightly colored clothing or brightly colored blinds, as any color reflected on the screen will likely influence your perception of the color displayed. If blocking off all windows in your editing room is not feasible or desirable, you can still achieve some measure of accuracy by creating a "daytime" profile and a "nighttime" profile, switching between the two. 
Display Types: The two most common types of display technology in use today are LCD and CRT. LCD (liquid crystal display) monitors are rapidly replacing CRT (cathode ray tube) displays. Production of professional-grade CRTs, such as the Sony Artisan, has ceased. LCD displays with LED backlighting show a very wide gamut that closely matches the Adobe RGB color space.

Calibrate CRT monitors before profiling, since they have hardware controls for their RGB amplifiers, as well as controls for black level and luminance. First, use the hardware device and software to adjust the RGB guns to the desired white point (often called color temperature, although this is a slightly different concept) and black point (if available on your display system). Next, profile the calibrated CRT. Color-savvy programs, such as Photoshop, then use the profile to display accurate color.

LCD displays often only have brightness controls, although some also have contrast settings, too. Some LCDs also have color temperature controls, but these actually only adjust the CLUT (color look up table. If the adjustment differs substantially from the native color temperature, this can cause reduced color gamut and banding. For that reason, when profiling an LCD, it is best to adjust only the brightness control and any contrast control, then let the profiling device set the desired white point through the display profile.

Direct Digital Communication (DDC): DDC allows adjustment of the display's brightness, contrast, white point and gamma through the profiling device and software. This will save time and improve precision when calibrating and profiling monitors. When shopping for a new monitor, its best to choose a DDC-compliant display if possible.

Monaco Optix Guide: Regardless of whether you use their product, Monaco has an excellent PDF manual that explains in detail how to calibrate and profile both CRT and LCD monitors.

White Point and Gamma: The purpose of monitor calibration and profiling is to create a situation where the image on your monitor closely matches the image as it will appear on a print, a proof, a press sheet - or, if your work is destined for the web, as viewed on the average uncalibrated PC or Mac monitor. Desired white points range from 5000K (yellow-red) to 6500K (bluer). The gamma correction may vary from 1.0 to 3.0, or be based on $\mathrm{L}^{*}$ gamma. The monitor's luminance may vary from $80 \mathrm{~cd} / \mathrm{m}^{2}$ to $140 \mathrm{~cd} / \mathrm{m}^{2}$. Adjust these settings based on viewing conditions. If comparing the monitor with proofs in a viewing booth, adjust to the best match. The correct luminance also depends on ambient light conditions. High-end color work should take place in ambient light controlled for color temperature, flare and luminance. For work in bright office or studio environments, you might need a luminance of more than 140 $\mathrm{cd} / \mathrm{m} 2$ to see shadow detail on your monitor.

There is no single standard for white point, gamma and luminance, because there is no standard for what you are trying to match. If you are working in pre-press, you will want to match press proofs and press sheets. For this, you may find a white point of $5000 \mathrm{~K}$ or $5500 \mathrm{~K}$ will give you the best match of monitor to proof or press sheet viewed under a $5000 \mathrm{~K}$ light. The appropriate luminance may be around $100 \mathrm{~cd} / \mathrm{m}^{2}$. If you are preparing files for ink-jet or Lightjet printing, you may find that a white point of $6000 \mathrm{~K}$ or $6500 \mathrm{~K}$ will give you the closest match, although you should always view the prints under the color temperature of the lighting where they'll be displayed. Once again, monitor luminance should match the appearance of the display prints in the viewing condition. Prepare image files for the web on a monitor calibrated and profiled to the sRGB standard gamma of 2.2 and white point of $6500 \mathrm{~K}$. This will be a compromise between the uncalibrated Mac gamma standard of 1.8 and the uncalibrated PC standard of 2.4. It is also a reasonable compromise between a prepress monitor calibrated to $5000 \mathrm{~K}$ and an uncalibrated PC 
monitor, which may be in the 7300K-9300K range. Modern LCD monitors usually have a native white point around $6500 \mathrm{~K}$.

Native White Point: Some argue for creating monitor profiles using native color temperature and native gamma, and let your eyes adjust to the difference between the monitor and the print or proof. Doing so will ensure you get the widest dynamic range the monitor can produce. It will also minimize artifacts, banding and posterization, which become more noticeable as you force a monitor (especially a standard, 8-bit monitor) farther from its native white point and gamma. If you do choose a custom white point and gamma, it is a good idea to evaluate the resulting profile with a utility such as Dry Creek Photo's Black Point Check and Grayscale Test. That stated, if your goal is matching your monitor to your prints, or more critically, a printer's proofs, choosing native white point is not the best practice. Minor banding is much less of an issue than failure to match print output.

More About Gamma: There are more choices for gamma than 1.8 and 2.2. Some calibration software allows you to choose a custom gamma. Other software allows you to edit the gamma curve, and one product, Integrated Color's ColorEyes Display, has " $\mathrm{L}^{*}$ gamma," which creates separate tonal curves for the shadow areas, midtones and highlights. It reportedly provides smoother transitions, and therefore more accurate color reproduction. If you are working in Adobe Photoshop, monitor gamma will not affect the appearance of image files, since Photoshop automatically corrects the gamma of the image as it is displayed on the monitor. Choosing a gamma has more to do with allowing your monitor to operate in its particular sweet spot, and avoiding loss of gamut, banding or posterization that may appear if you force it to run too far from its native gamma.

The LEDs are coming: The current TFT-LCD technology uses a white fluorescent backlight. NEC has produced a new type of LCD that uses red, green and blue LEDs (light emitting diodes) that combine to produce a white backlight. The advantages are a wider color gamut, greater dynamic range, and the ability to adjust the white point without compressing the color gamut. The NEC MultiSync LCD2180WG-LED was the first commercially available monitor of this kind. Although still very expensive as desktop displays, LED display technology has even emerged in some of the new Apple laptops.

\section{Color Spaces}

Camera settings for color space are critical when capturing TIFF or JPEG files. (Color space settings are largely irrelevant for raw files, since color space will be determined in the raw file processor.) Most professional digital cameras allow selection of the output color space for JPEG and standard TIFF, with usually two options: sRGB and Adobe RGB (1998). Capture photographs meant for high-end printing in a large-gamut space, such as Adobe RGB (1998). Capture photographs in the narrower-gamut sRGB color space if they are intended only for consumer-level printing or the web.

Embed the Profiles: All digital files should have embedded profiles (such files are called "tagged"), unless otherwise noted. Photoshop's color management policy should be set to "always preserve embedded profiles," and the "ask when opening" boxes should be checked to alert you to profile mismatches and missing profiles. When profile mismatches occur, you should elect to preserve the embedded profiles.

Assigning vs. Converting: Assigning profiles can change image appearance without changing the original image data. Assign when the original file has no embedded profile or the embedded profile is of dubious origin. Choose an appropriate profile with the help of the preview facility in Photoshop. While choosing the profile based on an image's appearance is necessarily a 
subjective decision, it enables a file to enter the workflow with a (hopefully well-chosen) definition of its intended color space.

Assigning a profile changes the appearance of an image but not its pixel values. Converting to a different color space does the opposite: It changes the pixel values while attempting to retain appearance. The purpose of converting is to transform the color space of the original file to the color space of the destination device as accurately as possible.

NOTE: Every imaging device describes color in its own way, based on its particular characteristics. We might say each device has its own "language" for color. Some languages have a large vocabulary, others a smaller one, and some contain words simply not available in others. To make translations possible among all the languages, we need a universal "reference language" with a huge vocabulary. This is the role of CIELab, which is a theoretical color space containing every color the human eye can perceive.

Continuing the analogy, ICC profiles are dictionaries that provide the CIELab equivalent for every word in a particular dialect - that is, for every color a specific device can represent. Embedding a profile in an image file is like sending the dictionary along with a written document: It gives the recipient information needed to understand all the words. It does not guarantee the recipient's language will have the words needed to translate the document perfectly, but if exact words don't exist, the recipient should be able to approximate the meaning with reasonable success.

Converting a file from one profile to another, in our analogy, is writing out a translation. And, as with human languages, something is always lost in translation. It is therefore advisable to minimize the number of conversions that are done.

Failing to embed a profile amounts to sending a document without revealing what language it was written in, forcing the recipient to guess. Computer programs don't guess, of course; they use a default setting and carry on blindly. A human operator, however, may try a number of different possibilities to see which one gives the most pleasing result. (This may or may not be the result that the sender intended.) This is done by assigning a profile to the image - instructing the program to act as though that profile had been embedded. Having settled on a profile, the human can then embed it to avoid further trouble.

We are indebted to the Institute of Quality Assurance's Digital special interest group for this explanation.

\section{Color Space Recommendations:}

a. Open-ended uses: When the final use of an image is not known, as with images created for stock photography or when the client will use the images in several media, it's best to supply a file in the Adobe RGB (1998) color space, with the profile embedded. The European printing and publishing industry is standardizing on ECI-RGB, an RGB profile with a slightly different gamut than Adobe RGB (1998). However, like Adobe RGB (1998), ECI-RGB contains the entire gamut of the standard CMYK profiles.

b. World Wide Web presentations: Convert images to SRGB and embed the sRGB profile before delivery.

c. Images prepared for screen and electronic presentations: PowerPoint and similar programs vary in their abilities to read color profile tags, so it is best to convert images to sRGB and embed the sRGB profile before delivery.

d. Display prints from professional digital color labs: A custom profile, obtained from the lab and used for your soft proofing, is the only way to have some assurance over final output. After adjusting your proof view, submit either an sRGB or (more rarely) Adobe RGB (1998) file with the profile embedded. If a lab does not have a custom profile, it's usually best to use the sRGB color space and embed that profile, though the inability to soft proof means less control over the output process. A better solution would be to find a lab that fully implements color management and provides custom profiles. 
e. Display prints from consumer digital-print vendors: There is a free database of ICC printer profiles for digital labs worldwide at the Dry Creek Photo site. The printers covered include models from Fuji Frontier, Noritsu, Agfa D-Lab, LightJet, Durst and Chromira, among others. Because most of these printers do not recognize embedded profiles, it is necessary to convert your files to their profiles, then save them with the profiles embedded. Converting to these profiles will give you the best color fidelity and allow you to soft-proof your digital files before committing them to print.

Labs that don't use profiles usually require conversion of submitted files to sRGB. Using the sRGB color space instead of a custom profile may yield less accurate color that doesn't take advantage of the full gamut such printers can produce. To avoid confusion on your end, it's still best to include the embedded profile, even if the lab will ignore it.

f. Offset printing: It's always best to begin by asking the printer or the client's production expert what file format, resolution and color space they prefer. RGB files contain many colors that cannot be reproduced by conventional CMYK printing. This can result in a printed piece different from the screen version or from the inkjet print of the file. There are three ways to avoid this confusion:

1. If the photographer has the necessary experience and knowledge to convert from RGB, digital images can be delivered as CMYK data. This can be the best solution, since the photographer knows how the image should look.

2. Accompany an RGB file with a cross-rendered guide print (see our page on guide prints and proofs) that includes only colors reproducible in CMYK.

3. Deliver files in both CMYK and RGB. This allows the photographer to make artistic decisions about color rendering, yet also gives the printer more tools to recover from mistakes the photographer may have made in converting RGB to CMYK. Ideally, convert CMYK image files from RGB using the printer's CMYK profile (see below), and embed it in the file. If you can't get the printer's exact CMYK profile, you can deliver an RGB master file with an embedded profile and a ReadMe file that explains, "For accurate color, choose to preserve embedded RGB profile when opening this (these) file(s)." But keep in mind there is less color variation between different CMYK profiles than different RGB profiles. Hence, if the printer assigns the wrong CMYK profile it will likely look better than assigning the wrong RGB profile. The printer also has the option to convert from a general CMYK profile, such as US Web Coated (SWOP) v2 to a more specific CMYK profile, - using either Photoshop>Edit>Convert to Profile, or more ideally, a device-link profile that can convert from one CMYK profile to another without having to go through the three-channel Lab color space used by Photoshop's conversion engine.

g. Inkjet and dye-sub printers: Choose a wide-gamut color space, such as Adobe RGB (1998) or ProPhoto RGB, for the source space. These printers have internal RGB-toCMYK conversion algorithms, so they should be profiled in RGB and you should not convert images to CMYK before printing with them. Although manufacturer-supplied profiles have greatly improved, using custom RGB profiles for the printer-paper combinations in the print space will provide the best quality and the best match to a profiled monitor.

NOTE: You can bring desktop and wide-format printers into a color-managed environment with the help of profiles. If working with the manufacturer's printer driver, turn off all color management and print a copy of the color target file. Next, measure the printed target with a spectrophotometer to generate a profile for accurate output on a particular paper or other medium. 
Repeat this process for each paper stock you use. Most RIP (raster image processor) software offers profiles for a wide variety of papers. Many RIPs will also allow use of custom profiles.

\section{Converting Images to CMYK:}

We strongly recommend all offset printers adopt the ICC standards. Currently, there is tremendous variation among offset printers, and nothing can be taken for granted. For many years, offset printers used a "closed loop" color-management approach. They scanned film on drum scanners with software that output directly to CMYK. The CMYK was targeted to a proofing device, the customer approved the proof and the press was adjusted until its output matched the proof. Color settings were built into the workflow, not applied to files. This meant printers could not offer custom CMYK profiles for digital files created outside their shops.

Today, with 60 to 80 percent of images intended for print arriving as digital files, offset printers are moving away from the closed-loop workflow. A single printed piece often includes digital image files from many different sources. It is increasingly likely an offset printer will have a CMYK profile that describes its proofing device's color space. As a general rule, an offset printer should be able to match the output of its proofing device.

Many times, digital image files must go to several different printers, or a project is photographed and delivered before a printer has been chosen. In such cases, it may be best to deliver RGB master files. These should always have embedded RGB profiles to ensure accurate color when they are converted to each printer's specific CMYK profile.

Send RGB image files (especially Adobe RGB [1998]) to a printer only if the shop has experience converting RGB files to CMYK - and then only if the printer will provide a "random" or a contract proof. If a printer has a clear understanding of ICC profiles and requests RGB, it's best to submit files in Adobe RGB (1998), or possibly, the narrower-gamut ColorMatch RGB. European printers may prefer ECI-RGB. If a printer cannot ensure preservation of the embedded profile before converting to CMYK, it is better to provide files converted to a general-purpose profile, such as SWOP Coated V2 CMYK, ColorMatch RGB or sRGB, with the appropriate profile embedded in the image file.

\section{Resolution}

Besides color profile issues, perhaps the biggest stumbling block to quality reproduction is inappropriate file resolution. Some digital cameras produce a native file that is marked as $x$ inches high by $y$ inches wide - at $72 \mathrm{ppi}$ (pixels per inch). This sometimes results in printers receiving files of the correct height and width but insufficient resolution. This mistake is so common printers recite a mantra that all files need to be 300 ppi when the image is sized to the final height and width to be printed. As a generalization, this is not bad. However, if you have good communication with a knowledgeable printer, you can use the more sophisticated standard of setting the file's resolution (expressed in pixels per inch) to 1.3 to 2.0 times the halftonescreen ruling (expressed in lines per inch) for the job.

Files of lower-than-optimum resolution will not deliver as much image detail and crispness as the output device can reproduce. Excessively high resolution, on the other hand, is wasteful of computer resources; the surplus data can only be discarded, yet the file will take longer to transmit, more memory to process and more disk space to store.

The resolution of digital images intended for computer displays is usually described by absolute pixel dimensions: width and height in pixels. For printing, width and height are often stated in inches, requiring a third value: of pixels per inch. (Outside the U.S., dimensions are stated in 
centimeters or millimeters, and resolutions expressed in pixels per centimeter [ppc] or per millimeter [ppm].) Beware: It's easy to confuse ppi with dpi (dots per inch), which refers to the resolution of a printing device, or with lpi (lines per inch), which describes a halftone grid or screen used for printing images on a press.

\section{Rules of Thumb:}

- Low-resolution images destined for computer displays (monitors) are best defined by pixel dimensions, such as 640 pixels wide by 480 pixels high.

- Inkjet printers normally work best with resolutions of 180 ppi to 360 (some say up to 480) ppi, such as $8 \times 10$ inches at 180 ppi.

- Continuous-tone printing (e.g., on film recorders or dye-sub printers) requires resolutions of 240 ppi to 400 ppi.

- $\quad$ The most commonly quoted offset-printing standard is 300 ppi. But resolutions of $1.3-2$ times the halftone screen for the project are considered safe. For example, if the images will be printed as 150-lpi halftones (common for magazine printing), the appropriate image file resolution range would be 195 ppi to 300 ppi. Newspapers print with coarse screens. A common newsprint resolution is 85 lpi, which works best with an image resolution of 170 ppi.

- Screen-display and electronic-projection image resolutions will vary substantially, depending on the native resolution of the projection device. It's important to obtain information about the native resolution of the screen or projector before delivering "screen resolution" images.

- The resolution of digital images intended for screen display and electronic projection is best described by absolute pixel dimensions: width and height in pixels. Example: $1024 \times 768$ pixels.

- Images should be cropped to the correct aspect ratio for intended use. Examples: $1024 \times 768$ is a 4:3 (1.33 to 1 ) aspect ratio, while widescreen $1920 \times 1080$ is a $16: 9$ (1.77 to 1 ) aspect ratio. Where cropping is undesirable because it will change the composition of the image, you should set the image size along the longest dimension. You can either accept that two borders (either the top and bottom or the left and right) will have bands of the background color, or you can add bands of black or another color to the image to fill out the screen.

- Determine whether the intended use of an image involves zooming or panning. If it does, deliver enough resolution to accommodate this intended use.

- The size of the image on a computer monitor is based on the physical size of the screen and the setting of the screen resolution. When sizing images for use on multiple computers, consider that a 600 x 400 -pixel image will almost fill an old 15-inch display set at $640 \times 480$ and will be very small on a 30-inch display set to 2560x1600.

- Size images delivered for projection specifically for the intended use whenever possible. Sizing images for the exact native resolution of the projector produces the best results. Undesirable effects, such as stretching, shrinking, pixelation and loss of sharpness can be caused by software and hardware rendering of unsized images. Besides these drawbacks, it's not useful to make the image larger (in terms of pixels) than the screen size, since it will take much longer to redraw. Size it too small, and the image quality will deteriorate. 


\section{Common Resolutions:}

o VGA (640x480) - Once the standard, now only used on small devices, such as graphics tablets.

- SVGA (800x600).

o XGA (1024x768) - By far the most common resolution for PowerPoint and projection video.

o SXGA (1280x1024).

o SXGA+ (1400x1050) - Newer projectors.

o Widescreen (1920x1080) - HDTV 1080i and 1080p.

A Guide to File Dimensions for Print:

Uncompressed file size requirements for print

\begin{tabular}{|l|l|}
\hline & RGB TIFF at 300 ppi (default for 150-line screen) \\
\hline Double page (A3) & $50 \mathrm{MB}$ \\
\hline Full page (A4) & $25 \mathrm{MB}$ \\
\hline Half page (A5) & $12 \mathrm{MB}$ \\
\hline Quarter page & $6 \mathrm{MB}$ \\
\hline Eighth page & $3 \mathrm{MB}$ \\
\hline Billboard & $48 \mathrm{MB}$ at $\mathbf{6 0 0}$ ppi (but 300 ppi is acceptable, i.e. 24 MB) \\
\hline
\end{tabular}

\section{Digital Capture Quality Parameters: Sensor Size and File Dimensions}

Sensor size and file dimensions offer only a rough guide to final printed quality. You can enlarge or reduce digital image files by interpolation in imaging software, which adds or removes pixels. RIP software and hardware can also interpolate during printing. Properly handled, interpolation can increase digital image files in size by as much as 400 percent. However, success depends on the qualities of the original file and the final output required. Note that increasing resolution through interpolation cannot add detail to a file. It may, however, prevent obvious pixilation, offering a smoother look.

\begin{tabular}{|l|l|l|l|}
\hline $\begin{array}{l}\text { Sensor Size } \\
\text { (megapixels) }\end{array}$ & Pixel Dimensions & $\begin{array}{c}\text { Approximate Doc. Size } \\
\text { at 300 ppi }\end{array}$ & 8-bit File Size \\
\hline $21.1 \mathrm{MP}$ & $5616 \mathrm{X} 3744$ & $12 \mathrm{X} 19$ inches & $60 \mathrm{MB}$ \\
\hline $17.5 \mathrm{MP}$ & $3413 \times 5120$ & $11 \times 17$ inches & $50 \mathrm{MB}$ \\
\hline $11.2 \mathrm{MP}$ & $2731 \times 4096$ & $9 \times 13$ inches & $32 \mathrm{MB}$ \\
\hline $6.3 \mathrm{MP}$ & $2048 \times 3072$ & $7 \times 10$ inches & $18 \mathrm{MB}$ \\
\hline
\end{tabular}


Stock-image distributors, magazine publishers or others requesting files may specify a certain minimum size for camera sensors used to generate image files. However, pixel quality trumps pixel numbers, so that a high-quality 6-MP sensor will often be sufficient for 95 percent of intended uses, while pictures from a 10-MP sensor in a point-and-shoot camera may not look good beyond 8x10 inches at 300 ppi, especially if used at an ISO exposure setting above 200. Although many publishers have standardized on 300 ppi for 150-line screens, the actual requirement is 1.3 to 2.0 times the line-screen resolution, so as a practical matter, smaller files can successfully work for a given final size.

\section{File Formats}

File formats vary widely. They include "lossless" compression types, such as LZW-compressed GIF and TIFF, PSD and most raw file formats, and uncompressed types, such as standard TIFFs. Some formats, such as JPEG2000 and HD Photo (JPEG XR), offer both lossy and lossless compressions. Although lossy compression at high compression rates can create visible artifacts, many call lower compression rates "visually lossless.” For the web, use JPEG. For printing, uncompressed TIFF is often preferred, although high-quality JPEGs are usually visually indistinguishable from TIFFs, and some prefer them due to file delivery and/or storage considerations.

Between capture and final output is an important intermediate step: the RGB master file. RGB master files are Photoshop (.PSD) or TIFF files, optimized in a large-gamut color space, such as Adobe RGB or ProPhoto RGB, at either the digital camera's native file size or interpolated to a larger size (consistent with any possible future use) by a raw-file-conversion program.

(We should mention there are some caveats to consider when choosing an extra-wide gamut space such as ProPhoto RGB instead of Adobe RGB. While the larger gamut does imply a wider range of image data preserved "down the line," it also implies bigger image transformations, possibly with bigger shifts in the color of the image, when it is converted to a narrow-gamut color space such as CMYK. In addition, an extra-wide color space necessitates the use of 16-bit image editing to avoid problems such as posterization or banding.)

Leave RGB master files unsharpened or sharpen only on a removable layer, since resizing for future uses is likely. Archive master files along with the raw files for a project.

Raw File Formats: Although you should capture images at the highest quality your workflow requires, the best quality clearly comes from capturing in a raw file format. The advantages of raw file formats include:

- The photographer can choose a different color space each time the file is processed.

- The file offers greater bit depth.

- The file captures the maximum dynamic range.

- The processing operation can adjust white balance, saturation, exposure (to a degree), tonal characteristics, highlight recovery, noise reduction and lens corrections, all in a non-destructive way.

- Many raw processors have sizing algorithms some say are superior to interpolation in Photoshop, since they are working with the actual pixel data captured by the camera's imaging sensor. 
- You can process raw files in a variety of software, from the camera maker's own tools to many third-party products, and even the built-in raw processing of Apple and Windows operating systems.

The Raw File Issue: While UPDIG advocates capturing raw format images whenever your workflow supports it, there are several potentially negative issues with raw file formats as opposed to capturing JPEGs or TIFFs. Most serious is the issue of proprietary, undocumented raw file formats becoming obsolete, unsupported, and eventually, inaccessible. (Luminous Landscape offers good analysis of this problem.) In addition, there are workflow problems associated with raw file formats. Proprietary raw files must be converted to another format or paired to sidecar files, before metadata can be safely added. If the raw files are converted to a standard format, such as TIFF or JPEG, they lose their ability to be non-destructively edited. If they are paired to sidecar files, they are harder to manage. And no cataloging software can read any color adjustment information contained in the sidecar files. Even proof-printing raw files, so your client can see your intended interpretation of the file, usually requires a batch conversion to another file format. There are several interesting possibilities for solving this problem:

- OpenRAW: The OpenRAW organization hopes to persuade camera makers to provide open documentation of their proprietary raw formats. Open documentation would improve the archiving outlook. At the same time, it would enhance the ability of thirdparty developers to create better raw file processors and more timely support for new cameras and their raw formats.

- DNG (Digital Negative): Another approach is Adobe’s open-architecture DNG file format. While Adobe characterizes DNG as an openly documented format, some people have objected that it can contain undocumented information, such as camera-maker notes, and can even contain encrypted data. Others object that it is not universally accepted and can be used by only a few kinds of software or cameras. DNG, however has several important positive features. According to the OpenRAW survey, Adobe Camera Raw has more than twice as many users as the closest competition. One reason is DNG's unique ability to combine the functionality of a standard raw file with the capability of safely accepting metadata. In addition, a DNG file can contain a full-size, color-corrected JPEG that is visible to cataloging software. These JPEGs can be used to make prints, or they can be copied and delivered to clients as high resolution files. And, although it makes for a large file to archive, a DNG file can contain the original proprietary raw file, which can be extracted and processed anew at a later time.

- New raw file handling software: Competing with the camera vendors' software, Adobe’s Bridge/Adobe Camera Raw, and such stand-alone applications as Bibble, Nikon's Capture NX and Phase One's Capture One are new types of "raw file handling" software. Examples include Apple's Aperture and Adobe’s Lightroom. These applications aim to be all-in-one solutions, handling everything from start to finish: ingesting files, browsing and selecting, rating, adding metadata annotations, cropping and image editing, printing, creating slide shows, and cataloging. Whether they prove to be indispensable tools will depend on how they develop and how universally they are adopted.

\section{Naming Files}

To avoid problems with files transferred across computing platforms, request file names that use only the letters of the Latin alphabet (A-Z, a-z), the numerals $0-9$, hyphens and underscores. Avoid other punctuation marks, accented letters, non-Latin letters, and other non-standard 
characters, such as $1: / *<>$ or brackets. On a local network or with rewritable media, limit the file name to 31 characters or less (including the three-letter file extension). Limit file names to 11 characters or less (including the three-letter file extension) when burning to optical media, since some computers don't support long file names. Use a single period (.) between the file name and extension.

Specify unique file names. Multiple files with the same name will cause problems for computers and people alike, and a newer file might automatically overwrite an older with the same name, or vice-versa. You may want to specify including the numeric date and/or the photographers name as part of the file name as a way to avoid duplicate names.

For a complete guide to file-naming protocol, see the Controlled Vocabulary web site.

\section{Sharpening}

Why Sharpen? To get the best quality out of any digital image, whether scanned from film or captured with a digital camera, you must compensate for the mathematically unavoidable loss of perceived sharpness that results from digitization. Likewise, whenever reproducing an image in a medium that relies on dots (whether the halftone dots of offset printing or the pixels of a computer monitor), there is additional, process-specific softening to anticipate and neutralize. Fortunately, there are good algorithms that perform the needed sharpening. For historical reasons, the sharpening process is often called "unsharp masking."

Capture Sharpening: Capture sharpening should compensate for softness introduced during capture. The goal should be the sharpest, clearest image for a client to view or use. If you are capturing in JPEG format and trying to minimize post-production time, you might try different in-camera sharpening settings. If you put quality ahead of speed - and especially if you may want large prints later - it is best to perform capture sharpening in post-production. If you are shooting raw Files, you may find that using the sharpening controls available in your raw processing program will work well for you. Adobe Camera Raw, for example, applies sharpening just to the luminance channel, which tends to minimize artifacts and noise issues. If you use another raw processor, you should test the effect of sharpening on a noisy file to determine whether the raw sharpening adds to the problem.

Noise: All digital capture involves some level of noise. There are three situations that require noise removal as part of the workflow:

a. When capturing at high ISO settings.

b. When capturing images where the highest possible quality is required, such as for stock or large prints (even at lowest ISOs).

c. When making long exposures with early-generation digital cameras that do not have built-in noise removal.

If noise issues with your files are more successfully corrected with a dedicated noise-removal program, it is best to sharpen after noise removal (that is, not in the raw processor). One exception might be the newer Bibble software that incorporates Noise Ninja into its raw processor.

Process Sharpening: Perform process sharpening at the end of whatever post-processing (editing, retouching, resizing, etc.) you apply to an image. Process sharpening corrects for the ways changes in size, color, tone and color space can affect sharpness. It also may involve the photographer's creative decisions about how sharp the image should appear, including 
sharpening selected areas for effect. This step may be left to the client if the photographer is delivering a quantity of images that are not being individually edited.

Output Sharpening: Output sharpening compensates for the characteristics of the final output device, and it is based on variables such as final size, intended viewing distance and reproduction technology (offset, inkjet, dye-sub, computer monitor, digital projection, etc.). Apply it as the final step before output. Once again, you may choose to use Photoshop controls such as Unsharp Mask, Smart Sharpen or one of the many third-party plug-ins. When creating a master file, you should save an unsharpened version, or save the sharpening on a layer, to allow new sharpening when repurposing and/or resizing an image file. You don’t want to guess whether a master file has been previously sharpened for output.

Who Should Sharpen? In principle, all sharpening should wait for final output. In practice, there are drawbacks to this approach: If you leave all sharpening decisions until the output stage, some photos may be rejected for apparent softness. In other cases, poor prepress work could lead to soft reproduction. If an image capture is sharp, you should show and deliver it sharp. Using three stages of sharpening is ideal, but it's not always practical. Photographers should deliver images with at least capture sharpening applied. If a photographer is editing or retouching images, he or she should also apply process sharpening. Photographers should only deliver images with output sharpening when doing the final pre-press work. If the client or printer will resize or repurpose the images, then the client or printer should be responsible for output sharpening. Clearly communicate this when delivering files with an included ReadMe file. Some photographers like to deliver a final image file with output sharpening on a layer. By toggling the layer on or off, the client or printer can either use or redo the output sharpening - depending on whether the files are resized, retouched or prepared for a different type of printer.

Practical Considerations: It's important not to over-sharpen at any stage. An image should always be able to tolerate additional sharpening. Mild over-sharpening imparts a surreal impression, while gross over-sharpening creates obvious halos around objects.

Which Sharpening Tool? Photoshop CS2 and CS3 each have a Smart Sharpen filter. These filters offer more control than Unsharp Mask because they can reduce sharpening amounts in highlight and shadow areas. Third-party plug-ins - such as Nik Sharpener Pro, Pixel Genius Photokit Sharpener, Focal Blade and others - allow you to fine-tune and automate the process. If possible, use a specialized sharpening plug-in, since the amount and method of sharpening depends on the final intended output, whether it is for web, continuous tone print, ink jet print, or offset printing. Set the image display at 50 percent for most print output, and at 100 percent for images intended for on-screen display. Other pixel magnifications - such as 33 percent, 66 percent or 200 percent - don't offer a true representation of the image, since Photoshop is interpolating the pixels to create these views. It's also important to remember the effects of sharpening appear different on your monitor than they will when ink hits paper, so make test prints - ideally on the same type of device that will be used for final printing.

Side Note: Accurately soft proofing of sharpening on a display is difficult. A sized print is the best way to proof sharpening. Truly accurate soft proofing can only be accomplished by matching screen resolution which is likely between 72ppi-117ppi with the image resolution. Only then is sharpening accurately displayed on screen at $100 \%$ size. Photoshop's preferences must also be set to the actual screen resolution. The soft proofed sharpening radius must then be multiplied by a factor which is determined by the actual printing resolution. A screen resolution of 100PPI and print resolution of 360 would yield a 3.6 times factor. Therefore a soft proofed sharpening radius of 1 pixel would need to be set to 3.6 pixels at print resolutions. This method of soft proofing sharpening is accurate, but not very practical in a high volume workflow. 


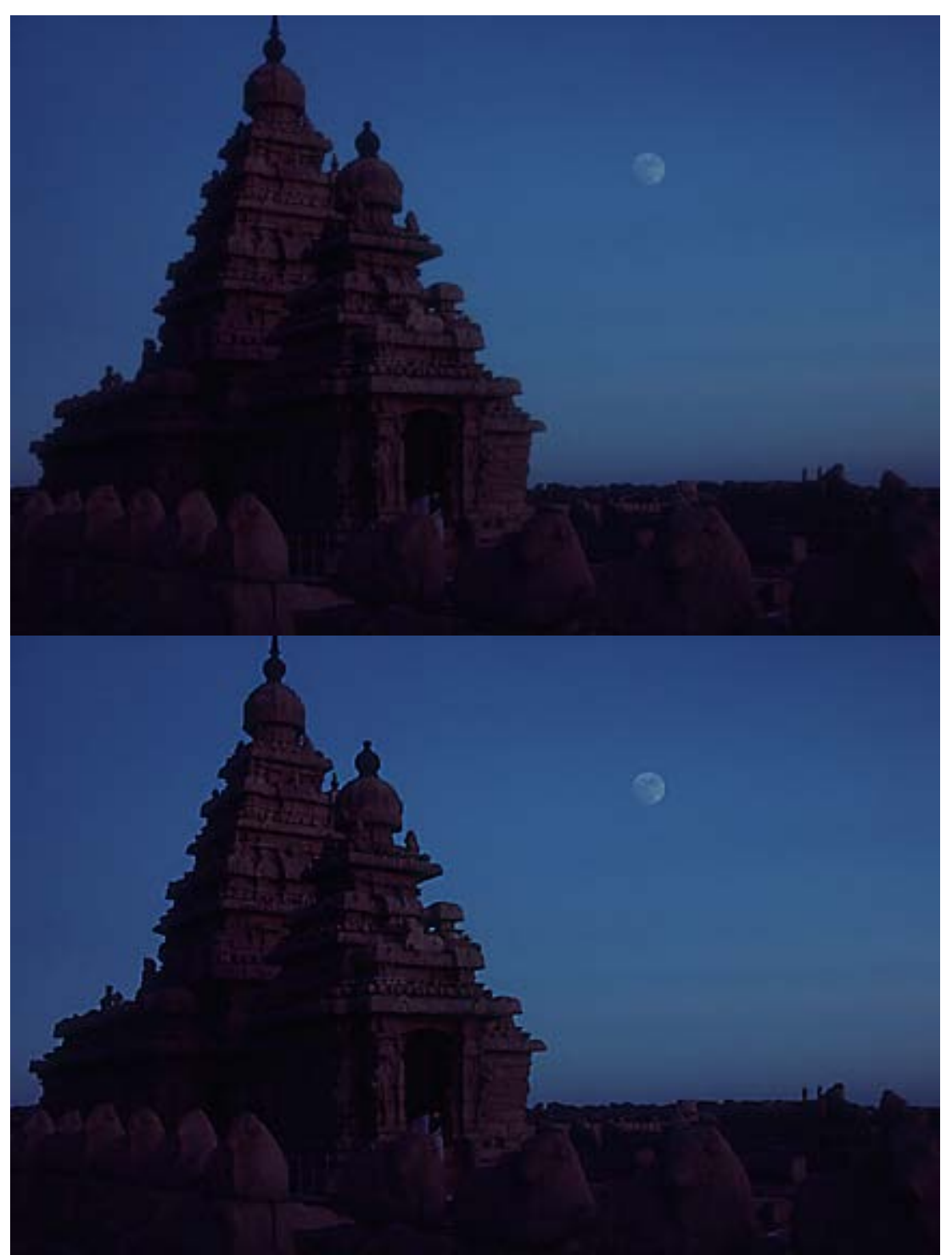

The Shore Temple of the Seven Pagodas; photo (c) 1985 by David Riecks, www.riecks.com.

In the sharpening example above, the first image is correctly sharpened for its size, the intended display medium (your screen) and the subject matter. The second image is over-sharpened, haloing the roof line with pale blue.

\section{Metadata}

\section{Overview}

Most digital image metadata is textual information embedded in an image file. Metadata has become an increasingly important attribute of a digital file, valuable for both creators and users of digital images. It offers a tool that can describe an image's technical characteristics, color profile, content, context, licensing terms, and perhaps most importantly, the identity and contact information for the rights holder.

The ability to readily identify and contact the rights holder for an image will likely become critically important if (when) proposed "Orphan Works" copyright exemptions become law. Bills introduced in the U.S. Congress, if passed, would affect all photographers by allowing anyone possessing an image to copy, modify, distribute, publish and otherwise use it for any purpose, 
after a reasonably diligent search fails to identify the rights holder. All images previously distributed without rights metadata may soon be vulnerable to unlicensed use as "orphaned" images. Embedding complete, accurate rights metadata will help protect images from unlicensed use. Many other countries are considering similar legislation.

Metadata can be embedded in standard file formats, such as TIFF and JPEG. You can also embed metadata in raw files, although this is only recommended for the Adobe DNG file format, since proprietary raw formats are neither standardized nor publicly documented. For now, with proprietary formats, it's best to attach metadata in a sidecar file. You can also save metadata in an image database, making sure the image file and its metadata reside in the same volume, folder or program, in order for the metadata to connect to the image file.

A variety of programs can read and write metadata. Programs like PhotoMechanic and ImageIngester can add metadata as files transfer from camera card to computer. Image editing programs (such as Adobe Photoshop), Image browsers, (such as Adobe Bridge), cataloging programs (such as Microsoft Expression Media (iView Media Pro), Extensis Portfolio and Canto Cumulus), and all-in-one programs (such as Adobe Lightroom and Apple's Aperture) can read, write and edit metadata. Some camera makers' processing software, such as Nikon's Capture $\underline{\mathrm{NX}}$, provide some basic (usually only legacy IPTC and not IPTC Core) metadata writing, as do some raw processors, such as $\underline{\text { Capture One. }}$

\section{Types of Metadata}

EXIF: All digital cameras include technical metadata, called EXIF data. This provides a host of information, such as the camera make and model, its serial number, the date and time of image capture, the shutter speed, lens used, the ISO speed setting, and often, other technical details, such as white balance and distance to the subject. Raw file processing software can use this information to more accurately render images.

ICC Color Profile Tags: Without a color profile tag, the person receiving an image file can only guess the color space used to create and edit it. Always embed an ICC profile in digital images.

IPTC: This includes user-supplied information. The earliest schema was the IPTC IIM (Information Interchange Module) model created by the newspaper industry in 1991 and incorporated into Photoshop in 1995. While considered a legacy format, it remains widely used and readable by most software that accesses metadata. The IIM format stores information separately but shares many fields with the XMP format. Referred to as the IPTC Core, or IPTC Core Schema for XMP, it includes the Description, IPTC Contact, Image, Content and Status panels that appear under the File > File Info menu in Photoshop.

XMP. The Extensible Metadata Platform or XMP is a specific type of extensible markup language used in PDF, photography and photo editing applications. Adobe introduced XMP in 1991. Adobe, IPTC and IDEAlliance collaborated to introduce in 2005 the IPTC Core Schema for XMP, which transfers metadata values from IPTC headers to the more modern and flexible XMP. Stock image distributors and other organizations have since created custom metadata panels that enhance metadata usefulness.

PLUS. The Picture Licensing Universal System is an integrated set of standards for communicating rights metadata associated with commissioned and stock images. The PLUS standards are developed, approved and maintained by the PLUS Coalition, an international, nonprofit umbrella association that includes publishers, designers, advertising agencies, photographers, illustrators, stock image distributors, artist representatives, museums, libraries, and standards bodies, such as UPDIG, IPTC, IDEAlliance and others. 


\section{Metadata in Use}

The type and amount of metadata photographers should embed in their images depends on who will receive the image files.

Stock image distributors can't function without metadata. They depend particularly on keywords. But photographers need to communicate with their stock distributors to know whether they should do all of the keywording, provide only limited keywording or perform no keywording. If the stock distributor prefers photographers do the keywording, ask for guidance. Captions, which are titles or explanations of images, should be foundations for the keywords that follow. Good keywords explain the who, what, where, when and how of a picture - important tools for finding specific image files.

You'll find an excellent guide to keywording on the Controlled Vocabulary web site.

In addition to the standard IPTC templates, stock image distributors may elect to create their own custom metadata panels - not only to capture additional data but also to organize it differently from the IPTC defaults. It's easy to install these XMP-based panels in Photoshop (see http://www.adobe.com/products/xmp/custompanel.html), and they offer a good way for stock image distributors to insert custom metadata into image files. Although often handled separately, photo releases can be stored in metadata by using a custom template. However, this custom metadata is not yet easily available or interoperable with most image database or cataloging software.

Magazines and publishers also depend on metadata, particularly caption, headline, author, contact information and usage rights. Image files with complete information can save magazines valuable time on deadline. Picture metadata can even provide additional reporting information, especially details such as GPS data and capture time.

Many publishers have rights-tracking software to verify they have all necessary licenses, have made all necessary payments, and conversely, can track licenses to others for using images they own. Good metadata reduces the cost of operating such systems.

Publishers who lack such software still may need to contact rights holders, perhaps for many years to come. They may need to defend themselves from lawsuits (libel, invasion of privacy, plagiarism, etc.) or undertake a regulatory compliance audit. If a publisher is sold, part of the buyer's “due diligence” includes ensuring its assets are untainted by legal clouds. Metadata reduces the need to rely on paper records.

For all of these reasons, photographers should determine magazine and publisher metadata needs, and when appropriate, install and populate custom metadata templates.

Publication designers can improve their workflow by organizing and categorizing pictures for metadata searches in browsers such as Bridge and digital asset management software such as Microsoft Expression Media/iView, Extensis Portfolio or Canto Cumulus. For example, if a design firm commissions a series of portraits, it is often critical to include the portrait subject's name in the Description and/or Headline fields. Other fields, such as Origin, can be equally important to a designer assembling a printed piece. The photographer should ascertain these metadata needs, or make the designer aware of how this custom metadata can improve the designer's workflow.

Web designers often have the same organizational and search needs as publications designers. But they have an additional responsibility to prevent metadata stripping. It is important for photographers to alert their web design clients to the importance of, and methods for, preserving metadata in images destined for the web. Unfortunately, in the initial release of Adobe Photoshop CS3, Save For Web (called Save For Web \& Devices in CS3) strips most metadata. 
Although it saves the file description and the creator's copyright notice by default, the feature changes the copyright status to Unknown. Beginning with the first CS3 update (Photoshop 10.0.1) it has become easier to discover how to include XMP metadata when using Save For Web. In the updated version, the Save for Web and Devices command includes the option to "Include XMP" in the main Save for Web dialog, where users will more likely find it. (In the first CS3 release, the option was buried in a sub-sub-menu.) When this option is enabled, all XMP data - including the creator copyright and contact info - is included in the optimized file, and the copyright status is preserved.

Regrettably, while easier to find than before, the option is not enabled by default. Users must discover it by clicking on a tiny triangle to open a fly-out menu (see illustration), and set it. Once set, however, it stays set.

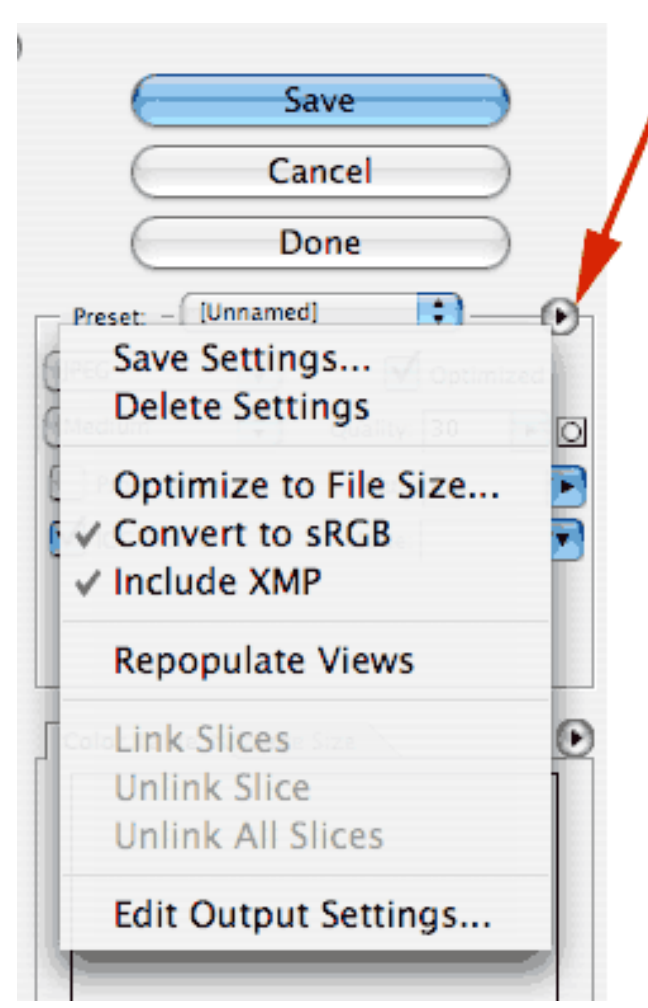

For most users, Photoshop CS3 will automatically request the upgrade from the Adobe web site and install it. If not, you can download the updater:

For Macintosh:

http://www.adobe.com/support/downloads/detail.jsp?ftp ID $=3774$

For Windows:

http://www.adobe.com/support/downloads/detail.jsp?ftp $\mathrm{ID}=3775$

Please note "include XMP" means just that. The new file will not include Legacy IPTC-format metadata.

Although many programs that read metadata recognize XMP, there are exceptions, including Apple Preview. This means web designers may still want to use "Save As" instead of "Save For Web \& Devices," particularly if their clients are photographers, since some magazine editors review photos in the Preview.

Photographers maintaining their own collections of commercial and personal work are realizing the workflow advantages of annotating archived files with descriptive metadata. In addition, rating, labeling and adding private metadata to pictures can help when categorizing, organizing and searching image file archives. Many photographers realize, after accumulating hard drives filled with image files, that relying on directory structure, dates and file names can lead to long, even fruitless, searches.

\section{File Delivery}

Digital image files may be delivered on removable media (removable hard drive, CD-Rs or DVD-Rs), or via FTP, web service or e-mail. If delivering files on CD-R, the recommended disc format is ISO 9660 or "Mac OS extended and PC (Hybrid) CD.” When delivering images on a DVD-R, make sure the recipient can read the chosen format, since there are several standards.

Do not use adhesive labels on optical media, since they may separate and damage an optical drive. Printing directly on inkjet-writable CD-Rs or DVD-Rs is a good way to provide information such as your copyright, usage license, file lists and disclaimers. 
Often speed and convenience requires delivery by File Transfer Protocol (FTP) or a web-based service. Although not a preferred method, e-mail delivery usually works if image files are small in number and size and if both sender's and recipient's internet service providers permit large attachments. E-mail delivery sometimes works better if the image files are first compressed using lossless compression software such as WinZip or Stuffit. Check to make sure the recipient can access your specific version of compressed files. Delivery by FTP or e-mail usually precludes delivery of a guide print (see next section), so always include a disclaimer that states, "Accurate viewing and reproduction depend on the recipient properly applying ICC color management."

It is important to provide a ReadMe file in PDF, HTML or TXT format with all files delivered for output. The accompanying file should specify image size(s), color space(s), the copyright owner's contact information, any licenses granted (or PLUS code), and for a limited license, the words "other uses, reproduction or distribution are specifically prohibited." The ReadMe file should also include disclaimers noting recipients are responsible for following an ICC-based color management workflow.

\section{CMYK Guide Prints and Verifiable Proofs}

Cross-rendered CMYK guide prints can serve as a valuable visual reference for digital files, especially if the recipient is unknown or the output profile generic. CMYK guide prints can be generated in two ways:

1) via the inkjet printer's own software driver

2) via a third-party software RIP

When printing via the printer driver, it is recommended that a custom ICC output profile be built for the inkjet printer. Though many printer manufacturers' profiles are very good for their own papers, a custom profile will help provide a more accurate CMYK guide print. When using a third-party proofing paper, a custom profile must be built.

When printing via a RIP, use a custom profile for the ink/paper combination used to create the CMYK guide print.

Verifiable proofs differ from CMYK guide prints in two important ways:

1) They are printed via a certified proofing system (SWOP, Fogra, etc.) Certified proofing systems combine RIP software, inkjet printers, inksets, and proofing paper. More information on SWOP-certified systems is available.

2) They contain an industry-standard target such as the 12647-7 Control Strip or the Fogra Media Wedge. By reading the target with a spectrophotometer, the recipient can verify the validity of the proof by confirming that the readings are within a certain tolerance.

A verifiable proof provides additional precision when indicating the color of digital files delivered to an offset printer.

Unless supplying a verifiable proof, photographers should include disclaimers stating that what they are supplying is a CMYK guide print for color reference only. Don't confuse CMYK guide prints or verifiable proofs with contract proofs. A contract proof is a guarantee by the offset printer that he will match the proof color on press. 
Since inkjet prints made from RGB editing spaces will have wider color gamuts than available from an offset press, CMYK guide prints must be "cross rendered" to more accurately predict the final CMYK printing. Cross rendering involves printing to the inkjet proofer using the final CMYK press profile as an intermediate space, thereby limiting the inkjet proofer's color gamut to the gamut of the final CMYK output space. If you use Absolute Colorimetric (or check the "simulate paper color" box in Photoshop CS3), you may more closely simulate the actual press sheet, since the whites will more closely match the duller white of the actual press stock.

Use a proofing paper that simulates the actual printing stock. Viewing conditions for guide prints and proofs should be consistent and ideally match the standards commercial printers use for viewing. A $5000 \mathrm{~K}$ light booth or Solux low-voltage system is recommended. The current ANSI standard for brightness is 2200 lux, which is roughly equivalent to f16 at 1/4-second at ISO 100 .

It's possible to create CMYK guide prints or even SWOP-certified proofs with inkjet printers. Photoshop's print dialog can be set to create a guide print. But more accurate SWOP proofs require a RIP. Epson offers professional printers with SWOP-certified ColorBurst RIPs.

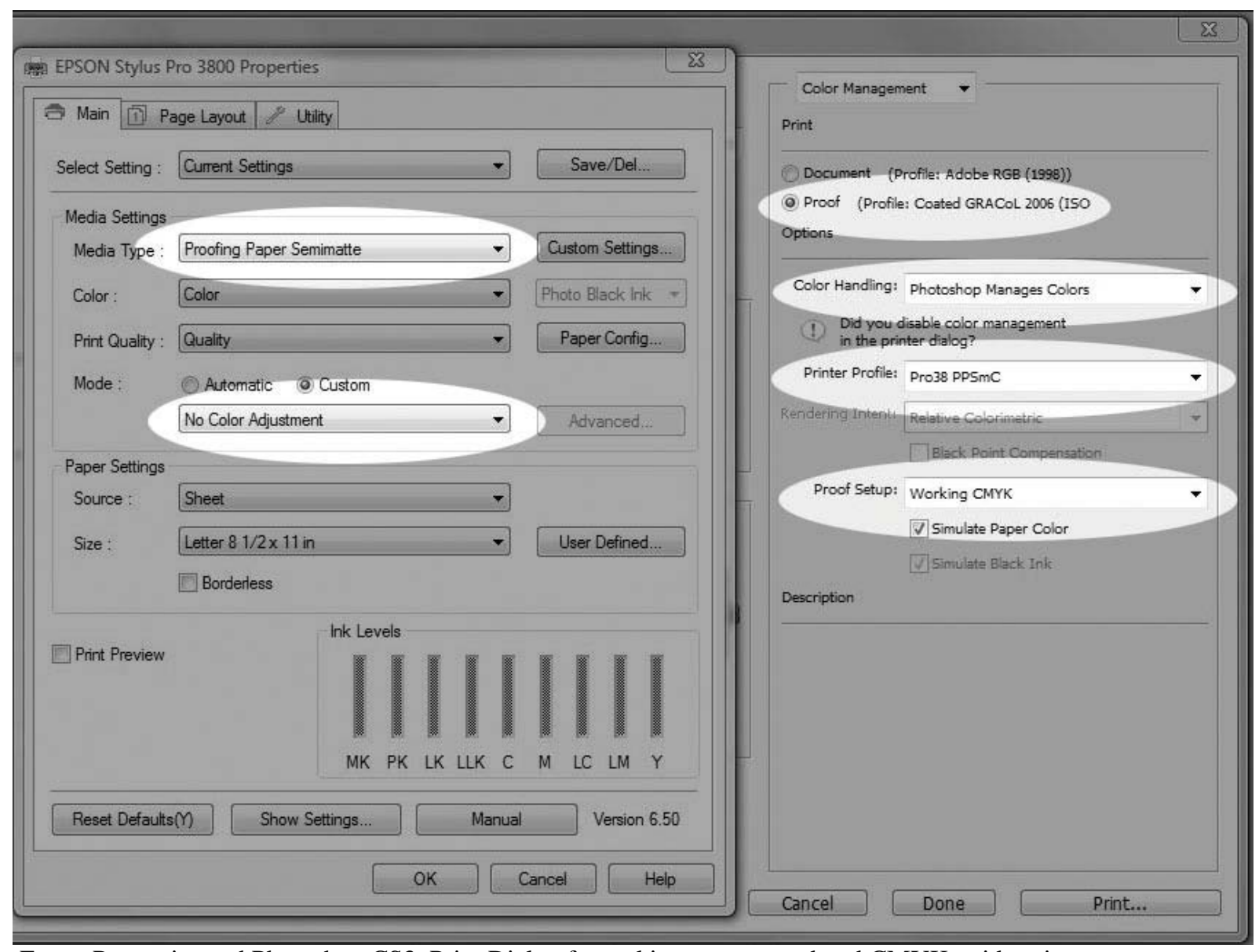

Epson Properties and Photoshop CS3 Print Dialog for making a cross rendered CMYK guide print. 


\section{Archiving}

It is important to address the issue of who will archive digital image files. Basic decisions include what kinds of files to archive, how to protect the archive from format obsolescence and media failure, and the choice of metadata scheme to facilitate searches.

Without careful filing, it can be hard to find a specific image. However, most image file formats (including all we recommend here) include space for metadata that facilitate cataloging and searching with a digital asset management programs (such as Extensis Portfolio or Expression Media). Embedding IPTC metadata in image files early in a workflow, paired with logical file numbering and naming conventions, speeds up cataloging and facilitates searching.

Storing multiple copies of image files on redundant hard drives is arguably the most convenient and least expensive solution to guard against data loss. Additional back-ups to CD-R or DVD-R media may be prudent. Note, however, that different brands and batches of CD-R and DVD-R media have different archival qualities. Use only media with high archival ratings; burn discs at lower speeds; do not use adhesive labels on discs; and write on discs only with non-solvent markers designed specifically for inscribing CDs and DVDs, writing only on the hub of the disc.

A prudent practice is to maintain a complete copy of your photo archive off-site. However, be aware of one potential problem with any type of online copy: If there is corruption in your primary copy and you have your system set to automatically clone it to the backup, you may corrupt the backup.

Over time, as operating systems change and new storage media emerge, you will likely need to migrate your digital image files. Most businesses and institutions have been slow to recognize the need for digital asset management, so it generally falls to photographers to maintain digital image archives. It's wise to discuss archiving responsibilities with clients to avoid losing image files.

Archival Image Formats: Archiving raw image files from Digital SLR cameras will likely be a key challenge in the long-term maintenance of a digital archive. Because each camera model creates a unique file type, it's likely some files will become unreadable in the future.

Photographers should develop a comprehensive strategy to confront this issue, accounting for the probable obsolescence of file formats and for the need for file format migration.

File format migration refers to the practice of converting image files to a different (newer) storage format. This might mean conversion to TIFF files, conversion to DNG files, or conversion to some future format not yet invented. Each choice holds certain advantages and disadvantages for image quality, storage needs, and workflow requirements.

Conversion to TIFF Files: By converting images to TIFF format, the photographer stores them in the most accessible file format. And because TIFF is an open standard, it should be readable for a very long time. TIFF also offers a workflow advantage: By converting to TIFF, you probably eliminate the need to reconvert the files again for many years, perhaps even for your lifetime. So images can be converted and archived with confidence they will be safely accessible long into the future.

There is a downside, however. TIFF files are much larger than raw files. Converting image files to 16-bit TIFFs can make the files up to 10 times larger than raw files and 15 times larger than compressed DNGs. This clearly increases the cost of file storage (assuming other costs stay the same). Although TIFF files have several compression options (LZW, ZIP, and JPEG), none is recommended due to the lack of universal support for a compressed TIFF format. This is especially important if you do not know exactly who will receive the file. Another downside to 
TIFF conversion is that it precludes the use of better raw converters surely coming in the future. Just as Photoshop CS3 converts raw files better than Photoshop CS2, it is likely the file conversion programs available several years from now will do an even better job.

Archiving JPEG Files: Conventional wisdom suggests the TIFF format holds a quality advantage over the JPEG format. This holds true only if the JPEG file is saved at less than 10 quality, using the Photoshop standard. Artifacts are either non-existent or insignificant at JPEG quality 10 or 12 . Higher bit-depth is really the only advantage of using TIFF over JPEG 10 or 12 (in terms of image quality). Some have argued that JPEG, because of the way it encodes data, compromises color. This is a misconception. When using the highest quality settings, there is no loss of color fidelity. Therefore, if JPEG files are saved at 10 to 12 quality, and if they do not require much pixel editing before use, archiving JPEG files is not a bad concept. And it can save a lot of space. For many picture archives, the economics of storing large numbers of files dominates all other considerations, and JPEG offers a feasible solution to the problem.

Archiving Raw Files: A photographer who chooses to archive raw files preserves the largest number of options for future file conversions. As software improves, new conversions of the image file might offer better color fidelity, better noise reduction or better upsizing interpolation.

This, too, has its downside. Raw files will likely require conversion to a more universal file format at some time in the future. For a single photographer, this may involve converting and recataloging hundreds of thousands of image files. If this conversion is not accomplished before that particular format becomes generally unreadable, then the conversion may simply never happen. And those images may be lost. Additionally, since raw files are proprietary, it may not be safe to alter these files. This means any work on these files, such as adding metadata or tonal adjustments to the image, should not be stored in the file itself. Instead, use either "sidecar" files or store these adjustments in a database. But the added files can become a file-management challenge that may present a serious roadblock in the future, as you try to include such work in a conversion file. Although some software can add metadata to raw files, there can be conflicts with Adobe Bridge not reading the processing information in the XMP file after metadata has been added by another program. Always test a backed-up image for anomalies before adding metadata to proprietary raw files.

Archiving DNG files: A raw file can also convert to DNG format, a documented, TIFF-based format created by Adobe. DNG can store the raw image data, metadata and a color-corrected JPEG preview of the image. The DNG file format provides a common platform for information about the file and adjustments to the image. Photoshop opens DNG in Adobe Camera Raw just as it does raw files, offering the full range of conversion options available with the original. Cataloging applications such as Expression Media and Extensis Portfolio can see metadata changes and image adjustments made in Camera Raw.

DNG will likely be readable long after most original raw formats become obsolete, simply because there will be so many more DNG images than those in any proprietary raw format. DNG also offers a lossless compression that can reduce the file size up to a third. In addition, DNG allows embedding the raw file itself, so it can be re-converted later if desired - although since this doubles the file size, embedding the original file may not be desirable.

There is, however, a downside to DNG: Conversion requires an extra step at the time of raw file processing. While this does not take terribly long, it is an extra process. Moreover, by converting a raw file to DNG, you currently preclude using the camera manufacturer's software for converting this file. If you like the conversions you get from the manufacturer's software more than the conversions you get from Photoshop, then DNG may not be acceptable. 
The DNG converter attempts to copy "Undocumented Maker Notes" to the metadata of the DNG file. These maker notes might include information that could be useful for converting the file at a later date (such as "dust reference" information, or information helpful in correcting chromatic aberration). By converting to DNG today, you may lose this data, since it is currently undocumented and it may not copy correctly.

\section{Archiving JPEG2000 (.jp2, .jpx, .jpf)}

Created by the Joint Photographic Experts Group committee in 2000, JPEG2000 is a waveletbased, image-compression standard. JPEG2000 offers a compression performance gain of around 20 percent compared to the standard JPEG. For lower or higher compression rates, the improvement can be somewhat greater. It has, however, notably higher computational and memory demands, which for most photographers means opening and closing JPEG2000 files takes more time. Unlike the standard, baseline JPEG, JPEG2000 does offer a fully lossless option. Improved compression options and performance, however, are not the main benefit of JPEG2000. The real achievement of JPEG2000 is "smart decoding." This feature enables a decoding application (or plug-in) to access and decode only the required portion of the code stream. This means a single JPEG2000 image can supply multiple, reduced-resolution versions of the original. These might include specific file sizes, and/or a high-quality, high-resolution view of a specific portion of the image. This makes JPEG2000 an excellent format if you require the ability to smoothly zoom, pan and rotate images. Creating compressed images that contain different quality levels allows master images in an archive to supply multiple derivatives, saving time and bandwidth. This makes an image archive much more efficient. In addition to this array of output options, JPEG2000 can handle very large images, at least up to a terabyte. JPEG2000, unlike standard, baseline JPEG, supports high-bit-depth (up to 16 bits per channel vs. 8 for standard JPEG) and high-dynamic-range images. JPEG2000 also underpins the MJ2 and JPM formats for motion images (each frame is a JPEG2000-compressed image) and compound images (images, graphics and text). These additional features make the JPEG2000 format a potentially valuable option for archiving film, video and historical materials.

JPEG2000 has not been widely adopted by photographers. Raw and DNG are viewed as better solutions for their specific needs. And JPEG2000 is not a good candidate to replace standard JPEG as a digital capture format, since the former requires far greater compression time. Still, photographers may want to become more familiar with JPEG2000 and be prepared to deliver in one of its variants, since many cultural heritage and digital preservation communities use it as the basis for their collections. Unlike photographers, these institutions are less concerned with improved rendering options over time. Their focus is preserving a specific rendering intent in the best way possible, with the most efficient storage and delivery options. JPEG2000 does these things well. The unanswered question is whether this "niche" adoption of JPEG2000 will ensure its long-term viability as an archival format. Some of the cultural institutions finding JPEG2000 to be the best current solution for their archiving needs include The Library of Congress, the Harvard University Library, Library and Archives Canada, Chronicling America website and the Google Library Project. For more information, see the Digital Preservation Coalition Technology Watch Report.

\section{Archiving HD Photo/JPEG XR}

Microsoft has thrown its hat in the ring of digital formats. Its technology was originally called Windows Media Photo, then renamed HD Photo, Microsoft is now working with the Joint Photographic Experts Group to make the format a JPEG standard, JPEG XR (for extended dynamic range). HD Photo has shown no compelling advantages over JPEG2000 for archival purposes. But HD Photo does have a faster compression algorithm compared to standard JPEG, and this offers some potential advantages as a digital 
capture format. Since the main drawbacks to the standard JPEG format are the 8-bit tonal depth limit and limited dynamic range, JPEG XR could provide a welcome step. Covered by Microsoft's Open Specification Promise, JPEG XR avoids problems associated with proprietary raw formats. The future of JPEG XR depends on camera makers offering it as a capture format. If and when this happens, then JPEG XR would become a potential archival format as well.

HD Photo is also the basis for the Microsoft Seadragon project and the related Photosynth photo viewing technology. These new technologies could also drive the adoption of HD Photo, since they both use HD Photo's ability to decode only the needed portions of an image, allowing for rapid screen draws as images are combined, zoomed, and panned. The latest Windows operating systems include full support for HD Photo.

NOTE: The archiving JPEG section is based on research and analysis by Ken Fleisher. Peter Krogh prepared the rest of this analysis of archival image formats. Peter offers a more in-depth discussion of these issues, as well as details related to the creation and maintenance of a digital archive, in The DAM Book: Digital Asset Management for Photographers (O’Reilly, 2006). It's available directly from the

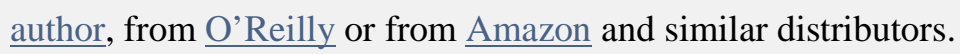

\section{Archiving 32Bit HDR Images}

HDR Imaging is a rapidly evolving field with very few set standards at this point. HDR image formats include: Radiance HDR, OpenEXR, JPEG-HDR, Windows WDP, TIFF LogLuv 24/32, Cineon DPX, TIFF float, PFM, and TGA. Radiance HDR and OpenEXR currently offer the most application support.

\section{Digital Image Workflow}

No single workflow suits all photographers or all clients. A good digital workflow is the most efficient and automated way to get the job done while capturing the most image information in the widest gamut for the widest possible uses in the future. It should satisfy the client's needs, embed necessary information (metadata), embed color profiles, save derivative files, archive and back up files. A good workflow saves time and protects against both loss of images and loss of work done to the images. Choosing the best software to achieve these aims is key. Because digital photographic imaging is relatively new, photographers must regularly explain to clients the trade-offs between quality and cost in different workflows.

A film-based workflow is simple: Photographers deliver film; designers or art directors decide how pictures will be used; offset printers and prepress houses handle conversion of the film to printing plates.

Digital cameras, along with scans from film by photographers and agencies, are replacing traditional workflows. While clients have been quick to embrace the speed and convenience of digital capture and delivery, they do not universally understand what is required to achieve the same quality levels delivered with film. With the exception of those involved in high-volume, quick-turnaround workflows, most photographers must decide how to handle file preparation. Some photographers want to avoid its distraction. Others embrace file preparation, because it allows powerful control over the reproduction of their images. Profiles and soft-proofing allow photographers to see how their files will look as display or press prints. Looking at soft proofs on calibrated monitors, those who embrace file preparation can deliver to printers files that will 
reliably (if not precisely) reproduce on paper the optimized images the photographers see on their monitors.

With some photographers embracing and others avoiding the details of file preparation, clients are understandably confused about who does this work and how much it costs. Many have tried preparing image files without first calibrating their monitors, yielding disastrous results. Some assume printers are accustomed to working with RGB files. However, a survey released in February 2005 by Printing Color Digest queried 800 offset printers and found only four accepted RGB files in their workflow. When you send an RGB file to an offset printer, the biggest risk is a pre-press worker will open it in the wrong RGB color space, altering the color, then lock in the mistake by immediately converting the file to CMYK. If the printer receives an untagged RGB file, and there has been neither communication with the printer nor the inclusion of a ReadMe file that indicates the file's color space, prepress will probably open the file in the shop's default RGB space. This may or may not be the space in which the file was optimized. Even when an image file is correctly tagged and its profile preserved, there may be problems if a printer uses a RIP for CMYK conversion. Most RIP software does not use black-point compensation, and without it, some conversions can appear flat and unsaturated (muddy).

The workflows below are general in nature. They aim to illuminate options and possibilities rather than offer step-by-step guides. The ideal workflow is a moving target. It varies based on the nature of the project, the photographer's capabilities, the client's needs, and perhaps most importantly, the overall budget and time constraints. Photographers should adopt and adapt workflows to fit project parameters:

- High volume, quick turnaround workflow.

- High volume, moderately quick turnaround workflow.

- Low volume, high quality workflow.

- High volume, high quality workflow.

\section{High Volume, Quick Turnaround Workflow:}

Examples: Most photojournalism, sports for newspapers and magazines, events and most public relations.

The focus is on speed, with tradeoffs in ultimate quality. Consequently, such workflows were the first to replace film with quick digital capture. Some issues and solutions include:

- High-quality JPEGs, captured in either Adobe RGB for print or sRGB for web, are suitable in many situations.

- Professional digital SLR cameras offer white-balance controls (with surprisingly accurate auto settings), in-camera sharpening and custom tone curves that can be applied at capture to generate JPEGs that are often adequate - if not optimal - for reproduction.

- Sometimes JPEGs must be reduced or compressed in the camera or afterward to meet transmission limits of bandwidth and time.

- News organizations and printers are expected to have staff trained to receive transmitted photos and prepare them for print, broadcast or web use.

- Software such as PhotoMechanic allows embedding IPTC data on the fly as image files transfer from memory card to computer, saving time and ensuring file recipients have all necessary captioning, cataloging and crediting information. 
- Increasing processing power, falling storage costs and growing bandwidth allow more photojournalists to consider raw workflows. New editing and batch processing software facilitates ingesting, optimizing and converting raw image files with ease and speed to meet most deadlines, while preserving all capture data for additional, higher-quality uses.

\section{High Volume, Moderately Quick Turnaround Workflow:}

Examples: Monthly magazines, institutional brochures, annual reports, web sites, and some types of advertising.

There is more focus on balancing competing needs for speed, quality and cost. This leads to many questions about who should do what. Some approaches and concerns include:

- Whether to capture raw files or high-quality JPEGs. A single assignment can generate thousands of images that could take many hours to process from raw files. If the photography is straightforward, the lighting is good (or at least not mixed), and the intended use is web, broadcast, newspapers or magazines printed on web presses, then JPEG capture may be fine. If the intended use is higher-quality, sheet-fed printing, if the lighting is mixed or requires a high ISO setting, if the final output will be full page or larger, or if there is a strong chance for higher-quality uses later, then capturing raw files provides the best quality.

- Presenting images to the client, art director or editor. Although there are many good image file browsers, including Photoshop's companion browser Adobe Bridge, speed and convenience often require posting a web gallery for editing. If not captured in sRGB, which is the default color space for most web browsers, copies of image files should be converted to that narrow-gamut space before posting to a web site. Usually, it's also best to reduce the resolution and compress the files to fit the viewer's screen and load quickly. Typically, proof images should be 500 to 1,200 pixels at their largest dimension (width or height), unless an editor or designer needs to see minute details. Using a DNG workflow, you can include an sRGB JPEG preview in the DNG file, which can be used for creating HTML proofs, eliminating the need to run a separate batch conversion for proofing.

- Delivering files for reproduction. Clients have two basic choices: 1) order optimized image files from the photographer; or 2) receive camera files and take responsibility for optimizing their reproduction. Either way, if good reproduction is the goal, someone who understands color correction, contrast enhancement and sharpening techniques will need to optimize the files. Some formats for file delivery include:

o Photographer delivers uncorrected, high-resolution JPEGs or TIFFs. At the very least, the photographer should embed and note the color space of the files, unless instructed otherwise by the printer. If the delivery method (bandwidth, size of media) can accommodate large files and the client has the needed software, hardware and expertise to deal with them, then 16-bit (48-bit RGB) TIFF files are probably best.

o Photographer delivers proprietary raw files. Although not recommended, this is now an option, since Photoshop's Adobe Camera Raw supports most camera raw formats. However, the photographer should include .XMP files (the small "sidecar" text files that describe how the raw file will be processed). Without them, the client won't likely know the photographer's intentions for color and tone. Working with raw files also requires high-end computer equipment, recent software, a color-managed workflow and a good understanding of digital photographic processing. 
o Photographer delivers DNG files. If the photographer makes corrections for color, exposure, etc., and then created DNG files with the full size JPEG preview option enabled, the recipient of the file will have the flexibility of a raw file and the intentions of the photographer. Until more raw processing software supports the DNG format, this limits conversion options primarily to Adobe Camera Raw and a few other programs, such as DXO Optics Pro and Silkypix Developer Studio. Other raw converter manufacturers, such as BibbleLabs, and Phase One, are adding support to read and write a DNG file. The same requirements as for proprietary raw files - high-end computers, current software, color-managed workflow -apply.

o Photographer delivers optimized, high-resolution TIFFs or JPEGs in an agreed RGB color space tagged with the appropriate color profile. Budget requirements along with the variance of exposure, contrast and color between images - dictate whether and how much the photographer optimizes each file, or whether he or she batch processes them. All should clearly understand the tradeoffs between cost and quality, along with the client's responsibility for adjusting final output. Some issues to consider include:

- Whether to deliver 16-bit TIFFs to allow the widest possible adjustment by others further along the workflow. Client must have storage space, knowledge and processing power for such files.

- Whether to sharpen the image before delivery. Sharpening is only appropriate for images delivered at final reproduction size and when the photographer fully understands the sharpening needs for the final use. If an image is sharpened, this should be noted in an accompanying ReadMe file, on the delivery medium (e.g., the CD-R label), on the delivery memo or on the border of the image. Sharpening a duplicated, composite layer within an image file (TIFF or PSD only) allows a client more resizing options.

- Whether, how much and when to compress images as JPEGs. JPEG files are handy when delivering many images or when delivery takes place with limited bandwidth or storage. But each time a file is saved as a JPEG, it loses image data and gains digital artifacts. The more a file is compressed, the more damage is done. When editing a JPEG file (whether created by the camera, scanner, or in post-processing), it's best to save the changed image as a TIFF or PSD (native Photoshop) file. Ideally, a photographer should only deliver JPEG files that are compressed slightly $(10,11$ or 12 quality), optimized and sized precisely for output.

o Photographer delivers an RGB master file. If the final use is offset printing, consider creating and archiving RGB master files. An RGB master file is used to create targeted CMYK files, which are sized, sharpened and profiled for the intended offset printer or press. The photographer can help ensure things go smoothly by delivering a "cross-rendered" guide print, as described in the earlier section on CMYK Guide Prints and Verifiable Proofs.

NOTE: RGB master files are Photoshop (PSD) or TIFF files, optimized in a widegamut color space (such as Adobe RGB, ECI-RGB or ProPhoto RGB), at either the digital camera's native file size or interpolated to a larger size (consistent with any possible future use) by a raw file conversion program. Leave them 
unsharpened, or sharpen only on a removable layer, since resizing for future uses is likely. Archive master files along with the raw files for a project.

\section{Low-Volume, High-Quality Workflow:}

Examples: High-end advertising, photo-illustration, portraits, high-end editorial, architecture.

High-resolution cameras capturing raw files, or high-quality film scans (usually from mediumor large-format film), are standard. Retouching, blending images and other special Photoshop procedures are common. Some photographers perform this work themselves, while others hire digital assistants or retouchers. Time and effort invested in postproduction often equals or exceeds that spent on image capture. Generally, post-production work yields an RGB master file (see footnote). How such files are prepared for final uses depends on the clients' production needs. (See the discussion of sharpening for more info.) In some cases, it's best to deliver several different file versions derived from an RGB master file, such as a high-resolution Adobe RGB file, a screen-resolution sRGB file and an CMYK file optimized for the expected press conditions, possibly sized and sharpened.

NOTE: RGB master files are Photoshop (.PSD) or TIFF files, optimized in a wide-gamut color space (such as Adobe RGB or ProPhoto RGB), at either at the digital camera's native file size or interpolated to a larger size (consistent with any possible future use) by a raw file conversion program. They should be left unsharpened, or be sharpened only on a removable layer, since resizing for future uses is likely. Master files should be archived along with the raw files for a project.

\section{High-Volume, High-Quality Workflow:}

Examples: Product and catalog photography.

Methods are often similar to low-volume, high-quality photography. However, to speed production, the large number of image files often requires help from a digital service bureau or pre-press house. Some studio workflows - particularly for catalogs - where all conditions can be carefully controlled, may benefit from a JPEG workflow.

Workflow Tools and the UPDIG Guidelines: Digital capture proved revolutionary in the sense that it provided options beyond film. Now that digital capture is such a large factor in creating photographs, a second revolution is occurring: the proliferation of software tools photographers can use to produce, edit, process and manage their digital image files. We are seeing a shift from Photoshop-style, pixel editing to metadata-based image editing. This shift depends on the nature of raw files themselves. Raw files are not image files in the same way that JPEG or TIFF files are. Raw files are unprocessed camera sensor data and do not become image files until decoded according to a set of instructions created by raw processing software in conjunction with user input.

Preserving Appearance: "Digital images should look the same as they transfer between devices, platforms and vendors.”

Unlike JPEG or TIFF files, which (if properly color-managed) always look the same as they transfer between devices, platforms and vendors, raw files will look different depending on the raw processor and the user's inputs.

The challenge, as UPDIG defines it, is to seek the emergence of a raw file processing ecology that will allow the photographer or image creator to fix a raw file rendering over applications and over time. As we discussed in the File Formats section, there are currently two ways to transfer a raw file's rendering intent: the use of some type of sidecar file (e.g., XMP, BIB), or the inclusion 
of a JPEG preview (the DNG approach). The trouble with sidecars is they are separate files and can get lost, deleted, overwritten or detached from their original raw files. Additionally, most cataloging software (those who do not consider Apple's Aperture or Adobe Lightroom to be effective cataloging solutions yet would say “all”) cannot read sidecar files. This hides the rendering intent from those programs. Even if other applications could read a variety of sidecar files, rendering intent would still very much depend on the rendering engine in use. Both the Mac OS and the new Windows Vista OS will have raw file rendering built in, but the rendering results probably will be different. The implication is that a raw or raw + sidecar would render differently depending on the OS, browser, or cataloging software. This type of subjective rendering is precisely what UPDIG was created to combat in the digital file realm. If we adhere to UPDIG principles, the DNG format is the only raw format that currently fixes rendering across applications and platforms, and hopefully over time, although that is by no means assured. All other raw file formats created so far operate in closed, proprietary systems, so fixed rendering requires conversion to another file format for proofing, cataloging and/or delivery.

Preserving Metadata: "Digital images should have metadata embedded that conform to the IPTC standards, making the images searchable, providing usage and contact information, and stating their creators or copyright owners."

Competing with fixed rendering and the safe insertion of rendering metadata in raw files is the need to insert the other kinds of metadata outlined above. The lack of standards among proprietary raw file formats raises questions of where to store this metadata, along with how other applications can discover and use it. Some proprietary raw processing software actually removes such metadata, creating a workflow problem and requiring reinsertion of this information in derivative files.

Adobe's DNG file format is the only raw file format that safely contains this kind of metadata without using a sidecar file. Those who want to use raw file processors that don't at least read DNG will have to continue to archive and manage proprietary raw files. They will need to store their metadata in sidecar files or database libraries. They must be mindful of the need to arrange their workflow so metadata is either preserved in the conversion to derivative files, or if necessary, added afterward to the derivative files. In addition, photographers whose work depends on processing thousands of files quickly may well settle on a different set of workflow software tools from those who seldom capture or process more than 30 or 40 image files per project. You should evaluate your software tools based on your needs (and the capabilities of your computer equipment) so you can make the correct compromises between perceived rendering quality, processing speed and ease of adding metadata.

Confusion surrounds the suitability of the emerging raw file handling software such as Apple's Aperture, Adobe's Lightroom and Nikon's Capture NX. Some people report these all-in-one programs unify and improve their workflow, while others complain they are slow, unstable, or unable to handle batch processing. Much of this conflicting information concerns whether a program is being used on dozens or thousands of files, and whether it is running on the fastest multi-core processors with 4+ GB of memory or on older hardware. It's no wonder a favorite phrase on digital photography forums is "your mileage may vary." 


\section{Appendix}

\section{ICC Color Management}

$\underline{\text { ICC International Color Consortium ICC White Papers }}$

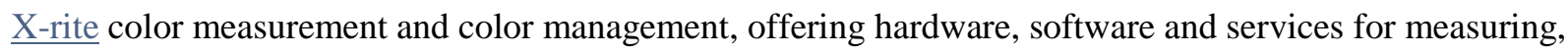
formulating and matching color including Color Checkers

Chromix Color Services, Color Think Software

SWOP Specifications Web Offset Publications

SWOP-certified systems This page lists the SWOP certified proofing systems

GRACoL General Requirements for Applications in Commercial Offset Lithography

FOGRA Graphic Technology Research Association

IFRA Global research and service organization for the news publishing industry.

ECI European Color Initiative

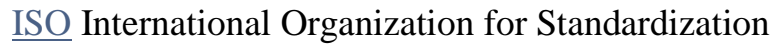

Dry Creek Photo Digital Imaging Resources for Photographers by Photographers

Colorremedies Color Management Essential Training

\section{Metadata}

EXIF.org - EXIF and related resources

Orphan Works Orphan works are basically works whose copyright owners cannot be located.

EXIF The specification uses the existing JPEG, TIFF Rev. 6.0, and RIFF WAV file formats, with the addition of specific metadata tags. It is not supported in JPEG 2000, PNG, or GIF.

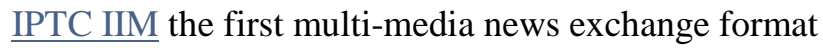

IPTC Core This page is about IPTC metadata to be used within Adobe's Extensible Metadata Platform framework.

XMP (Extensible Metadata Platform) a standard for metadata, created by Adobe Systems Inc.

PLUS standards An international non-profit initiative on a mission to simplify and facilitate the communication and management of image rights.

Controlled Vocabulary web site Recommendations for Limitations on Image Filenaming http://www.adobe.com/products/xmp/custompanel.html The custom File Info panel for XMP metadata allows you to define, create, and manage custom metadata properties using standard Adobe applications

\section{Software}

Bibble Professional Workflow and raw Conversion software for Windows, Mac OS X, and Linux Capture NX Nikon's software for simpler, more intuitive full-scale digital image processing and editing Capture One Raw workflow software from Phase One

Aperture Import, manage, and enhance your photos in one simple, integrated workflow

Microsoft Expression Media 2 is an extremely powerful and customizable image management software application for importing, annotating, organizing, archiving, searching and distributing your ever-growing collection of digital files.

HindSight Software for Professional Photographers including MetaMachine

PhotoMechanic Photo Mechanic is designed to work with groups of photos together in order to manage them.

ImageIngester double backup; naming; moving to folders; applying bulk metadata and Camera 
Raw/Lightroom settings; GPS tagging; converting to DNG; verifying; correlating multi-camera shoots. BreezeBrowser Used to download, browse, select, organize and post process their images, create web galleries and control cameras from a Windows PC.

Cumulus Digital Asset Management software and hardware

Portfolio Digital Asset Management software and hardware

DXO Optics Pro is a multi-award winning program running on Windows or Macintosh to automatically improve image quality.

Silkypix Developer Studio adjust the color, tone, and the white balance of the image can truly help you express your feelings through the photography.

DAM Useful Digital Asset Management and Workflow Software

\section{Adobe Software}

ACR (Adobe Camera Raw) Digital camera raw file support.

AcrCalibrator Tom Fors' calibration script for ACR. Visual Vacations ACR calibration tutorial

Lightroom Lightroom ${ }^{\circledR}$ software is the professional photographer's essential toolbox, providing one easy application for managing, adjusting, and presenting large volumes of digital photographs so you can spend less time in front of the computer and more time behind the lens.

\section{Monitor Calibration}

PDF manual how to calibrate and profile both CRT and LCD monitors

Gretag-MacBeth Eye-One Colorimeter

Color Vision Spyder 3 Elite Colorimeter

ColorEyes Display Color profiling software and hardware

Profile Verification Kit by Pixl Ltd.

\section{Black Point Check}

Grayscale Test

$\underline{\text { W }}$ cathode ray tube

W liquid crystal display

W white point

$\underline{\text { W }}$ color temperature

W color look up table

$\underline{\text { W }}$ gamma correction

W luminance

\section{File Formats}

DNG file format (Digital Negative) The public, archival format for digital camera raw data Luminous Landscape site A good analysis of the raw Flaw

OpenRAW Organization hoping to persuade camera makers to provide open documentation of their proprietary raw formats.

OpenRAW survey The 2006 raw Survey - A Report on the Experiences, Requirements, Belifs, and Preferences of Photographers and Imaging Professionals regarding raw Imaging Technology

\section{File Delivery}

YouSendIt Web file delivery service

SmugMug Online gallery and image sharing service

\section{Web Color}


http://www.northlight-images.co.uk/article_pages/web-browser-color-management.html* web browser color management

http://regex.info/blog/photo-tech/color-spaces-page2/* web browser color management

\section{Books}

The DAM Book: Digital Asset Management for Photographers, By Peter Krogh

Practical Color Management: Eddie Tapp

Real World Camera RAW: Broce Fraser and Jeff Schewe

Real World Color Management: Bruce Fraser, Chris Murphy, Fred Bunting

O’Reilly O'Reilly Media spreads the knowledge of innovators through its books, online services, magazine, and conferences

Peach Pit Essential resources for the creative community

\section{Blogs and Forums}

The Dam Forum

John Nack on Adobe

The Lightroom Journal

Photoshop News

\section{Consultants}

Peter Krogh- Digital Asset Management

Andrew Rodney- Color Management

Neil Barstow- Color Management

Chris Murphy- Color Management

David Riecks- Photo Metadata 
I Glossário de Padrões de Metadados 


\title{
GLOSSARY
}

\author{
$\mathrm{OF}$
}

\section{Metadata STANDARDS}

\section{Content: Jenn Riley \\ Design: Devin Becker}

Work funded by the Indiana University Libraries White Professional Development Award

$$
\text { Copyright 2009-2010 Jenn Riley }
$$

\section{(ㄷ) (1) 90}

This work is licensed under a Creative Commons Attribution-Noncommercial-Share Alike 3.0 United States License <http://creativecommons.org/licenses/by-nc-sa/3.0/us/>. 


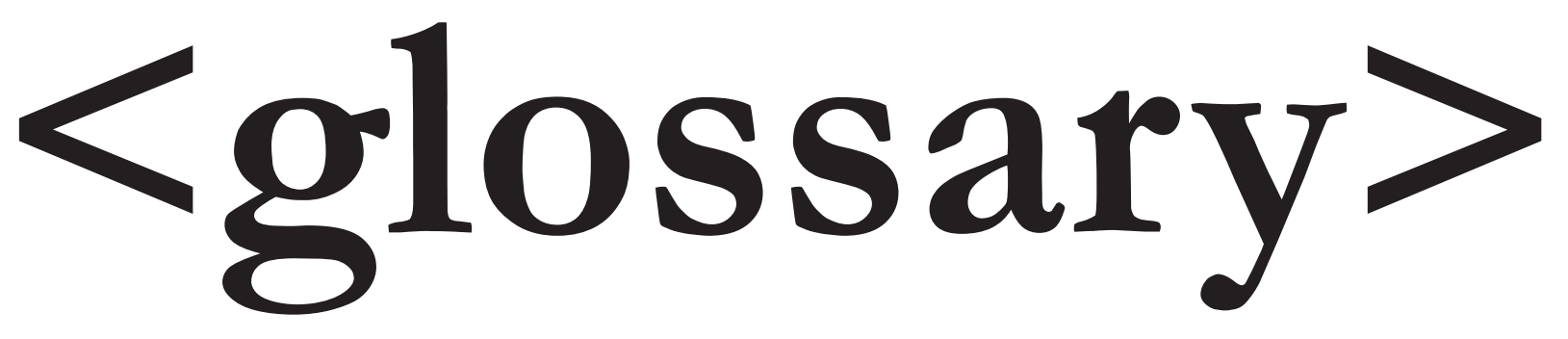

\section{AACR2}

Anglo-American Cataloging Rules, 2nd edition, Revised bttp://wmw.aacr2.org/

AACR2 is the primary content standard used in the library field in the US, Canada, the UK, and Australia. Its use is almost exclusive to libraries, although there have been calls for the archives and museum communities to adopt it for the description of "bibliographic" types of materials. While primarily focused on descriptive metadata, instructions exist that cover technical, rights, and structural metadata as well. AACR2 is scheduled to be replaced by RDA.

\section{AAT}

\section{Art \& Architecture Thesaurus}

http:/ / www.getty.edu/research/conducting_research/vocabularies/aat/

The AAT is one of a suite of controlled vocabularies maintained by the Vocabulary Program at the Getty Research Institute in Los Angeles. It focuses on generic terms for the description of works of art, architecture, and material culture. The AAT is organized hierarchically within seven facets: associated concepts, physical properties, styles and periods, agents, activities, materials, and objects. The vocabulary may be searched one term at a time freely on the web, and is available for license in bulk.

\section{ADL}

AES31-3-2008: AES standard for network and file transfer of audio - Audio-file transfer and exchange - Part 3: Simple project interchange (Audio Decision List) bttp:// wnw.aes.org/publications/standards/

The AES Audio Decision List (ADL) is a text-based file format and metadata standard for encoding the results of audio editing actions. The format records cuts, fades, the results of processing and filtering actions, and other edits to audio files made by a sound engineer. AES31-3 ADL support is included to some extent in audio editing software such as WaveLab and Pyramix.

\section{AES Core Audio}

AES-X098B: Descriptive metadata for audio objects Core audio schema bttp:/ / wmw.aes.org/standards/meetings/project-status.cfm

The AES Core Audio schema (in draft as X098B) is part of the Audio Engineering Society's suite of standards for descriptive metadata for audio objects, although the AES uses the term "descriptive" differently than the library community does. The scope of the AES Core Audio standard is wide, including analog originals, digitally reformatted copies, and native digital record- 
ings. The specification allows the capture of basic audio properties such as sample rate for digital files and groove width for physical discs. It also breaks audio objects down into "faces" (physical sides or directions for playback contiguously), "regions" (specific formats such as playing speed within a face), and "streams" (specific audio channels within a region). The AES Core Audio Schema and documentation are currently in draft status with no firm release date yet scheduled.

\section{AES Process History}

AES-X098C: Administrative metadata for audio objects

- Process history schema

http:// mww.aes.org/standards/meetings/project-status.cfm

The AES Process History standard is a data dictionary and XML Schema for recording information about processes that have been performed on an audio object over time. This includes but is not limited to transfer of audio between physical formats or from a physical format to a digital one. The standard provides elements to track extensive detail about device settings, signal chains, and even equipment serial numbers. AES-X098C is currently in draft status.

\section{AGLS}

Australian Government Locator Service

http:/ / wmw.naa.gov.au/records-management/create-capture-describe/ describe/AGLS/index.aspx

AGLS is an Australian government metadata standard intended for the description of government resources on the Web. It uses DCMI Terms properties, to which it adds a few additional properties such as function and mandate. AGLS can be expressed either in HTML or RDF/XML. AGLS usage guidelines frequently suggest appropriate controlled vocabularies for specific properties.

\section{Atom}

Atom Syndication Format

bttp:/ / tools.ietf.org/ html/ rfc4287

Atom is a syndication format for Web content in XML, allowing frequently updated information such as news feeds to be pushed to subscribed users. The most frequent use of Atom is to embedd an Atom-encoded news feed into an otherwise human-readable web page such as a news service or a blog.

The main alternative to Atom for syndicated content is RSS. Atom can also refer to a full Web publishing protocol in addition to the syndication format.

\section{BISAC}

Book Industry Standards and Communications bttp:// www.bisg.org/publications/product.php? $p=14$

BISAC is a subject vocabulary for books created by the publishing industry, specifically the Book Industry Study Group (BISG). It is arranged hierarchically and includes codes as well as textual labels for entries. BISAC is commonly used in bookstores, and has been seen in action in Google Book Search.

\section{CanCore}

bttp:// cancore.athabascau.ca/en/index.html

CanCore is a set of guidelines for the implementation of the IEEE LOM metadata standard. It arose from Canadian efforts on metadata for educational materials, and as such, its focus is on learning resources.

\section{CCO}

Cataloging Cultural Objects

bttp:// www.vrafoundation.org/ccoweb/

$\mathrm{CCO}$ is a content standard for the description of works of art, architecture, and material culture. It was developed in partnership between the Visual Resources Association and the Getty Foundation, and as such attempts to meet the needs of both the visual resources (frequently tied to libraries) and museum communities.

\section{CDWA}

Categories for the Description of Works of Art bttp:// wmw.getty.edu/research/conducting_research/standards/cdwa/

CDWA is a long-standing metadata standard from the museum community designed as a framework for the description of works of art and material culture. It is an extensive set of descriptive elements, including 532 categories and subcategories. Usage guidelines distinguish between data elements intended for display and those intended for indexing. CDWA defines only category labels and definitions - it does not define a specific syntax for encoding them, although the CDWA guidelines suggest a relational structure providing for easy re-use of authority records. CDWA is commonly implemented in museum management software.

\section{CDWA Lite}

Categories for the Description of Works of Art Lite bttp:/ / wmw.getty.edu/research/conducting_research/standards/cdwal cdwalite.btml

CDWA Lite is an XML representation of a subset of the full CDWA category set, explicitly designed for the 
sharing of descriptions of works of art and material culture via OAI-PMH. The OAICatMuseum OAI-PMH data provider software is designed to share CDWA Lite records in addition to Simple Dublin Core. There are ongoing efforts to harmonize CDWA Lite and MuseumDat into a new format called LIDO.

\section{CIDOC/CRM}

\section{CIDOC Conceptual Reference Model}

http:/ / cidoc.ics.forth.gr/

CIDOC/CRM defines concepts and relationships essential for the description of cultural heritage materials. Beyond the traditional descriptive information about physical objects, CIDOC/CRM also focuses on space and time information, including modeling of events that affect the physical objects held by cultural heritage institutions. CIDOC/CRM is strongly allied with the museum community. In addition to a textual document intended for human implementers, CIDOC/CRM is defined in a formal OWL ontology and in RDF. The CIDOC/CRM has been standardized as ISO 21127:2006.

\section{CQL}

Contextual Query Language

http:// wmw.loc.gov/standards/sru/specs/cql.html

CQL is a query language for information systems maintained at the Library of Congress. It operates using the concept of "context sets," allowing implementers to create new indexes, operators, etc., but still maintain common query parsing rules. CQL can be implemented at various conformance levels, and implementations are required to return diagnostics when a query feature is not supported. CQL is the query language most commonly used with the SRU search protocol. It attempts to be at once both simple and robust. The current version is 1.2 , which represents a name change from Common Query Language in CQL 1.1.

\section{DACS}

Describing Archives: A Content Standard

http:// www.archivists.org/governance/standards/dacs.asp

DACS is a product and publication of the Society of American Archivists, and thus reflects the descriptive priorities of the archival community. It replaces the older Archives, Personal Papers, and Manuscripts (APPM) content standard. It primarily focuses on the description of personal papers and institutional records. DACS is generally used in a multi-level description environment although it is possible to apply it for item-level description as well.

\section{DC}

\section{Dublin Core Metadata Element Set}

bttp:/ / www.dublincore.org/documents/dces/

Dublin Core is a widely misunderstood metadata standard. The Dublin Core Metadata Element Set (DCMES) is also known as Simple Dublin Core. Simple Dublin Core is a basic 15-element set designed to represent core features across all resource formats. It is standardized as ISO 15836-2003, ANSI/NISO Z39.852007, and IETF RFC 5013. The Dublin Core Usage Guidelines sometimes suggest (but do not require) specific content guidelines or controlled vocabularies. Simple Dublin Core is widely known as the baseline metadata format required for all resources shared via OAI-PMH. Encoding of the DCMES in HTML $<$ meta $>$ tags was popular in the early days of search engines, but today most search engines prefer to weigh page text and linking patterns more heavily then page creator-supplied structured metadata.

\section{DCAM}

Dublin Core Metadata Initiative Abstract Model bttp:/ / dublincore.org/documents/abstract-model/

The DCMI Abstract Model is a framework for the components of resource description and how they relate to one another. The structure of the DCAM is very similar to and inspired by the RDF model. The full model has three main sub-parts: the DCMI Resource Model, the DCMI Description Set Model, and the DCMI Vocabulary Model. These three work together to allow robust semantic relationships to be recorded between resources. The DCAM is a far cry from the 15 element set of simple Dublin Core that is familiar to many in the cultural heritage community, and represents a different and more robust approach to resource description. The DCAM is significantly more complex than the original simple Dublin Core, but offers a corresponding significant improvement in functionality and re-usability. Encodings of Dublin Core metadata in HTML, XML, and RDF all implement different subsets of the full DCAM.

\section{DDC}

Dewey Decimal Classification

bttp://mmw.oclcorg/dewey/

The Dewey Decimal Classification is primarily used in public libraries, and is currently in its $22^{\text {nd }}$ edition. Dewey divides knowledge into 10 primary classes, with further subdivisions possible in multiples of 10 . A process of "number building" is used to read the Dewey schedules and construct a potentially long number combining different intellectual aspects of a resource. 


\section{DIF}

\section{Discovery Interchange Format \\ bttp://gcmd.nasa.gov/User/difguide/difman.html}

DIF is an early metadata initiative from the Earth sciences community, intended for the description of scientific data sets. It inlcudes elements focusing on instruments that capture data, temporal and spatial characteristics of the data, and projects with which the dataset is associated. It is defined as a W3C XML Schema. DIF is fully compatible with the ISO 19115/TC211 geospatial metadata standard by providing places for elements from that standard.

\section{DIG35}

Digital Imaging Group 35

http:/ / www.i3a.org/technologies/metadata/

DIG35 is a metadata format for still images that grew out of industry work, specifically from the International Imaging Industry Association (I3A). DIG35 is divided into five blocks: basic image parameter metadata, image creation metadata, content description metadata, history metadata, and intellectual property rights metadata. DIG35 is defined primarily as a human-readable data dictionary, but a W3C XML Schema is also available.

\section{DTD}

Document Type Definition

bttp:/ / xmlfiles.com/dtd/

DTDs are mechanisms for defining XML languages, and serve as an alternative to W3C XML Schema and RelaxNG for this purpose. The DTD language dates back to SGML, but currently is also used for XML applications. DTD syntax is significantly simpler than W3C XML Schema, but lacks some more advanced functionality, such as strong data typing of element or attribute content.

\section{DwC}

\section{Darwin Core}

http:/ / www.tdwg.org/activities/darwincore/

Darwin Core is a "concept list" defining categories of information useful for the description of biological data - specifically, where organisms and species exist in time and space. The specification exists as a textual representation of the defined concepts and as an XML Schema. Darwin Core also provides extensions for curatorial, geospatial, paleontological, and interaction information. Darwin Core is managed under the auspices of Biodiversity Information Standards, a nonprofit devoted to promoting the sharing of biodiversity data.

\section{EAC-CPF}

Encoded Archival Context - Corporate Bodies, Persons, and Families

bttp:/ / eac.staatsbibliothek-berlin.de/

EAC-CPF is an XML representation of data about corporate bodies, persons, and families conformant to the model presented in the ISAAR (CPF) specification. In contrast to traditional library authority records for these entities that exist primarily to establish and justify controlled headings, EAC-CPF reflects its roots in archival description by focusing more on the context in which these entities operate. While EAC-CPF has a long development history, a significantly revised version was released in 2010, and as of yet the companion EAD standard has not had the opportunity to evolve to allow the two to be used in concert more effectively. EAC$\mathrm{CPF}$ is maintained by the Society of American Archivists in partnership with the Berlin State Library.

\section{EAD}

Encoded Archival Description

bttp:/ / wmw.loc.gov/ead/

EAD is a markup language for archival finding aids. It provides XML elements for strucutral and presentational data typically found in finding aid documents. While EAD is a markup language in the sense that it "flags" data structures as they appear in a pre-existing text, it is also the primary source of (semi-)structured descriptive metadata in archives.

\section{EML}

Ecological Markup Language http:/ / knb.ecoinformatics.org/software/eml/eml-2.0.1/

EML grew out of early metadata efforts from the Ecological Society of America. It is an extremely detailed specification that is intended to support the description of any type of ecological information, including raw data, published research papers, rights information, and research protocols. EML is defined as a series of W3C $\mathrm{XML}$ Schemas, and can wrap data packages together with metadata. At the highest level, EML models four primary entities: datasets, literature, software, and protocols, although not all are always applicable or are required for use.

\section{FGDC/CSDGM}

Federal Geographic Data Committee Content Standard for Digital Geospatial Metadata

http:// wnw.fgdc.gov/standards/projects/FGDC-standards-projects/ metadata/base-metadata/index_html 
The standard commonly referred to as FGDC (although FGDC is the maintenance agency, and CSDGM is the actual element set) is a large and early metadata standard for geospatial information created by agencies of the US federal government. The FGDC web site describes the scope of this standard as to allow users to "determine the availability of a set of geospatial data, to determine the fitness [of] the set of geospatial data for an intended use, to determine the means of accessing the set of geospatial data, and to successfully transfer the set of geospatial data."

The current production version of FGDC is 2.0, from 1998. Since this time, an international standard for geospatial information (ISO 19115) has emerged. Plans have been announced to create a US national geospatial metadata standard as a profile of ISO 19115, and to create version 3.0 of CSDGM as an implementation of that. This work has not yet been finalized.

\section{FOAF}

Friend of a Friend

http:/ / www.foaf-project.org/

FOAF is an RDF syntax for describing people, intended to be used on the Semantic Web. It includes features for encoding names, email addresses, personal interests, home pages, and various online identities. Although the language is focused on people, encoding traditional library authority files in FOAF is challenging due to its assumption that each individual has only one FOAF identity and its focus on online presence for current living persons.

\section{FRAD}

Functional Requirements for Authority Data bttp:/ / www.ifla.org/publications/ifla-series-on-bibliographic-control-34

FRAD is a companion document to the earlier FRBR conceptual model developed by IFLA. FRAD expands on FRBR by adding additional attributes to each of the Group 1, 2, and 3 entities; adding a new Group 2 entity (Family); and adding new entities intended to support the authority control process (Name, Identifier, Controlled Access Point, Rules, and Agency). Perhaps the strongest promise of the FRAD model is support for multi-lingual catalogs that can display to a user different forms of names for various entities depending on a user's location or language preferences.

In addition to expanded entities and attributes, FRAD defines a different set of user tasks for authority data than FRBR did for bibliographic data. Here, the user tasks are Find, Identify, Contextualize, and Justify. The final FRAD report was published by IFLA in 2009.

\section{FRBR}

Functional Requirements for Bibliographic Records bttp:/ / www.ifla.org/en/publications/functional-requirements-for-bibliographic-records

FRBR is a 1998 conceptual model of the biliographic universe, created in order to better understand the user tasks catalogs can and should support, and to suggest how bibliographic data might be viewed in support of these tasks. The most commonly known features of the FRBR report are its four user tasks (Find, Identify, Select, and Obtain) and the Group 1 Entities which categorize the products of intellectual and artistic endeavors (Work, Expression, Manifestation, and Item). The FRBR report has other features as well, including Group 2 Entities representing the creators of Group 1 Entities (Person and Corporate Body), Group 3 Entities which are the subjects of Works (Group 1 Entities, Group 2 Entities, plus Concept, Object, Event, and Place), and minimal standards for national bibliographic records.

The FRBR conceptual model has received a great deal of discussion in the cultural heritage community, but only in the very late 2000s have concrete implementations of the conceptual model into working systems begun to appear.

\section{FRSAD}

Functional Requirements for Subject Authority Data bttp:/ / www.ifla.org/node/1297

The FRSAD initiative is intended to provide a more complete conceptual model for FRBR Group 3 entities in their role serving as the subjects of FRBR Works. A draft of FRSAD for public comment was issued in early 2009. This draft abandoned the FRBR Group 3 entity structure (Concept, Object, Event, Place) in favor of conceptual entities (Thema) that are known by name tokens (Nomen).

\section{GEM}

Gateway to Educational Materials

bttp:/ / wnw.thegateway.org/about/documentation2/ schemas/index_ btmll

GEM is an RDF metadata vocabulary designed for the description of educational resources. The GEM model includes all the properties available in DCMI Terms, to which are added education-specific properties such as educational standards and pedagogical methods. The current version of GEM is 2.0.

GEM has also created a number of controlled vocabularies, including lists for audience level, assessment methods 
and instruments, and resource type. GEM Consortium members have access to the GemCat metadata creation tool, which produces GEM-compliant metadata.

\section{GILS}

Government Information Locator Service

bttp:/ / www.gils.net

GILS was an early metadata standard for the encoding of descriptive information for government records. It contained fields for the recording of creators, titles, identifiers, topical and geographic subjects, time periods, and access information. Usage of GILS has dropped off significantly in recent years.

\section{GML}

OpenGIS Geography Markup Language

http:// wmw.opengeospatial.org/standards/gml

GML is an element set intended for the description of geographic information, as well as providing for the creation of application schemas for more specific uses of GML. The GML schema is extremely detailed in its ability to describe sppatial and temporal features, topologies, and observation methods. GML is written in W3C XML Schema language, and is standardized as ISO 19136:2007.

\section{ID3}

bttp:// wmw.id3.org/

ID3 tags are data stored inside an MP3 audio file to assist with the identification of the content on the file. ID3v2 includes a number of predefined "frames" (essentially, fields) for use, including Album title, Composer, Date of recording, Original artist(s)/performer(s), and File owner/licensee. Images and other content files can also be embedded inside the ID3 chunk. ID3v2 also allows for user-defined frames. Most audio players, such as iTunes and Windows Media Player, can display ID3 tags to users and allow them to be edited.

\section{IEEE/LOM}

\section{Learning Object Metadata}

http:/ / ltsc.ieee.org/wg12/

The LOM standard is a "conceptual data schema" for the description of learning objects (by a broad definition of the term). LOM was developed and formalized through the IEEE and their Learning Technology Standards Committee. The stated purpose of LOM is to "facilitate search, evaluation, acquisition, and use of learning objects, for instance by learners or instructors or automated software processes." LOM data elements are grouped into nine categories: general, lifecycle, meta-metadata, technical, educational, rights, relation, annotation, and classification.

In addition to the conceptual data schema outlined in LOM documentation, a binding of the LOM model to XML has been creteated, and expressed in XML Schema language. Following the development of the DCMI Abstract Model, efforts have commenced to harmonize IEEE/LOM with this model.

\section{indecs}

$<$ indecs $>$ Metadata Framework

http:// wnw.doi.org/topics/indecs/indecs_framework_2000.pdf

<indecs> describes itself as a "model of commerce," operating under a simple basic premise: "People make stuff. People use stuff. People do deals about stuff." The basic entities of <indecs $>$ are as follows: Entities (something interesting) break down into Percepts (things percieved) which are further broken down into Beings and Things, Relations which are further broken down into Events and Situations, and Concepts.

$<$ indecs $>$ shares many common features with the FRBR model, but is different in that it focuses heavily on events that act on entities over time, an area FRBR avoids completely. While <indecs $>$ defines a robust conceptual model, it is unclear if many systems in either the cultural heritage or business communities have built systems that implement all or part of the model.

\section{ISAAR(CPF)}

International Standard Archival Authority Record for Corporate Bodies, Persons and Families http:/ / www.icacds.org.uk. /eng/isaar2ndedn-e_3_1.pdf

ISAAR(CPF) is a descriptive metadata model for contextual information in archives, covering the descriptions of corporate bodies, persons, and families; construction of access points for these entities; and documenting relationships among them, and between them and resources. The standard is intended to promote the sharing of archival authority records between institutions. Like the IDBD, ISAAR(CPF) is divided into several areas of description: identity, description, relationships, and control.

The first edition of ISAAR(CPF) was published in 1996, and the second edition was published in 2004. ISAAR $(\mathrm{CPF})$ is intended to be used with $\operatorname{ISAD}(\mathrm{G})$ for resource description. The EAC structure standard for archival authority data is intended to support the encoding of ISAAR(CPF)-compliant records. 


\section{$\operatorname{ISAD}(\mathrm{G})$}

International Standard Archival Description (General) bttp://www.ica.org/en/ node/30000

$\operatorname{ISAD}(\mathrm{G})$ is a statement of general principles for archival description, throughout the archival management process, and applicable to any type of material controlled archivally regardless of format or media type. $\operatorname{ISAD}(G)$ defines 26 elements of archival description, and defers to national or local rules for the structure of the values of those elements. The definitions of the archival description elements presented in $\operatorname{ISAD}(G)$ conform to the archival principle of respect des fonds and are structured to allow multi-level description. Like ISBD, $\operatorname{ISAD}(G)$ is organized into "areas" of description. These are: Identity Statement, Context, Content and Structure, Condition of Access and Use, Allied Materials, Note, and Description Control Areas.

\section{ISBD}

International Standard Bibliographic Description http:/ / www.ifla.org/publications/international-standard-bibliographicdescription

ISBD is a standard from IFLA designed to make bibliographic description more consistent across a wide range of applications. It serves two distinct functions: to define the selection and order of data elements to be recorded, and to prescribe punctuation to be used inside a bibliographic description. ISBD is divided into 8 "areas" of description: title and statement of responsibility; edition; material or type of resource specific; publication, production, distribution, etc; physical description; series; note; and resource identifier and terms of availability. The structure of AACR2 is strongly informed by the ISBD areas of information.

\section{ISO 19115}

Geographic Information - Metadata

http: / / wnm.iso.org/ iso/ iso_catalogue / catalogue_tc/ catalogue_detail.
btm?csnumber $=26020$

ISO 19115 is an international geospatial metadata standard which was built on the framework of the earlier US FGDC/CSDGM. Its initial version was released in 2003, and a revision was completed in 2009. Plans have been announced to create a US national geospatial metadata standard as a profile of ISO 19115, and to create version 3.0 of CSDGM as an implementation of that. This work has not yet been finalized.

\section{KML}

Keyhole Markup Language

http:/ / code.google.com/ apis/kml/ documentation/
$\mathrm{KML}$ is a markup language for geographic data used in the Google Maps and Google Earth services. It can be used to describe placemarks (single points), ground overlays, paths, and polygons. The language allows for 3-D spatial data, including altitude in addition to latitude and longitude. KML's relative simplicity and the availability of the Google Maps API have contributed to quick and fairly widesparead adoption of this language.

\section{LCC}

Library of Congress Classification

http:/ / www.loc.gov/catdir/cpso/lcc.html

The Library of Congress Classification is used primarily in academic libraries. It is divided into 21 basic classes, each of which start with one or more uppercase letters. Full class numbers use a mixture of letters and numbers, with subtopics offset by a period. Libraries typically append Cutter numbers at the end of LC class numbers to create a full call number for physical shelving of materials.

\section{LCSH}

Library of Congress Subject Headings bttp:/ / authorities.loc.gov

LCSH is a long-standing controlled vocabulary maintained by the Library of Congress, covering topical subjects, genres, and geographic places among other related areas of study. It is a precoordinated vocabulary, built upon the principle of literary warrant. Libraries can contribute new terms for consideration via the SACO initiative. Despite its function as a controlled vocabulary, LCSH is not a fully enumerated list, allowing the presence of "standard subdivisions" on explicitly authorized terms according to human-readable rules.

With the development of a new service, http://id.loc. gov, that makes Library of Congress-hosted vocabularies available to machine applications, LCSH and other vocabularies are now more readily available to applications outside the library community and especially outside the cultural heritage community.

\section{Linked Data}

\section{Linked Data}

bttp:// www.w3.org/DesignIssues/LinkedData.html

Linked data is a broad term that refers to a framework and a set of best practices for exposing data on the Semantic Web and making connections between resources. Linked data implementations are guided by four principles outlined by Tim Berners-Lee in 2006: 1) Use URIs as names for things, 2) Use HTTP URIs so that people can 
look up those names, 3) When someone looks up a URI, provide useful information, using the standards (RDF, SPARQL), and 4) Include links to other URIs. so that they can discover more things. One of the highest profile uses of linked data in the cultural heritage community is http://id.loc.gov, although that service does not systematically implement the fourth principle of linked data - linking to other things. The records at http:// id.loc.gov point to other records in the same service, but not to data elsewhere on the web. Additional information can be found at linkeddata.org.

\section{MADS}

Metadata Authority Description Schema

bttp:// www.loc.gov/standards/mads/

MADS is a companion to MODS, intended to encode authority data that is referenced by MODS bibliographic records. The structure and design of MADS are heavily influenced by the MARC Authority format. As such, it provides for the encoding of headings and cross references traditionally established by the library community, including personal names, corporate names, name/ title entries, title entries, subject, genres, and geographic places. While MADS allows for more of a complete description of an entity than MARC Authority does, it still retains a focus on documenting and justifying choice of headings. MADS elements use the same name as MODS elements whenever feasible. MADS is maintained by the Library of Congress, and its content is managed by the MODS/MADS Editorial Committee.

\section{MARC}

Machine Readable Cataloging

http://www.loc.gov/marc/

MARC was first developed in the late 1960s at the Library of Congress, and represented the first major attempt to encode bibliographic data in machine-readable form. MARC uses a mixture of fixed and variable fields to record information. The variable fields are themselves a mixture of coded and textual data. The MARC format is defined in ISO2709, which prescribes numeric field names that contain alphanumeric subfields. The MARC format in use in the US is known as MARC21. UNIMARC is a variant common in Europe. While there are five formats in the MARC21 suite, the Bibliographic and Authority formats are the most commonly used.

\section{MARC Relator Codes}

\section{MARC Relator Codes}

$$
\text { http:// www.loc.gov/ marc/ relators/relaterm.html }
$$

The MARC Relator Codes list is provided by the Library of Congress for use in specifying the role of an individual or group in connection with a resource. The list is expressed both in three-letter codes and in full Englishlanguage terms. Codes and terms from this list are commonly used in MARC and in MODS.

In cooperation with the DCMI community, the Library of Congress has developed a version of the MARC relator codes suitable for use in Dublin Core Application Profiles. These may be found at http://id.loc.gov/ vocabulary/relators.

\section{MARCXML}

MARC in XML

http:// wmw.loc.gov/standards/marcxml/

MARCXML, first released in 2002, is a representation of the ISO2709 MARC format in an XML syntax. MARCXML is designed to be fully interchangeable with MARC21 - records can be moved back and for the between the two formats without any loss of data. The MARCXML Schema, however, allows any 3-number field name and any alphanumeric subfield name, not restricting values to those defined in MARC21. MARCXML is primarily used as an intermediate step between MARC21 and other XML formats, as MARCXML can be converted to other XML formats with XSLT, which is not possible directly from MARC21.

\section{MathML}

Mathematical Markup Language

bttp:/ / wmw.w3.org/Math/

MathML is a W3C Recommendation for the low-level encoding of mathematical information, with the intention of representing this information on the Web. It is defined by an XML DTD. MathML elements exist both in support of presentation of mathematical data and for the content of the mathematical data itself.

\section{MEI}

Music Encoding Initiative

bttp:// wmw2.lib.virginia.edu/innovation/ mei/

MEI is a markup language for Western common music notation. It is strongly inspirted by the structure and design of TEI, and was developed in response to an identified need for a music notation format that facilitates research into the structure of musical corpora. In addition to the full notation encoding, MEI includes a header for bibliographic information about the notation file. MEI is developed and maintained as an XML DTD by Perry Roland at the University of Virginia. 


\section{MESH}

Medical Subject Headings

bttp://www.nlm.nih.gov/mesh/

MeSH is produced by the US National Library of Medicine for the description of biomedical journal literature, books, and other formats collected by the Library. It is also used for subject indexing in the PubMED database. The MeSH vocabulary contains a full syndetic structure of broader, narrower, and "use for" terms. The full vocabulary is available online for individual searches and downloads in XML and ASCII formats.

\section{METS}

Metadata Encoding and Transmission Standard http:// www.loc.gov/standards/mets/

METS is an XML metadata standard intended to package all the information needed to represent a complex object, including both primary files and metadata that describes them. It defines its own structure for representing files and the relationships between them, and allows embedding or referencing descriptive, technical, rights, source, and digital provenance metadata defined by other schemas. METS has various levels of support in digital asset management systems, including DigiTool, Greenstone, and the Archivists' Toolkit. This standard grew out of early work on representing complex digital objects by the Making of America II project. METS is maintained at the Library of Congress and through a volunteer Editorial Board.

\section{METS Rights}

METS Rights Declaration Schema

http:/ / www.loc.gov/standards/mets/news080503.html

METS Rights was developed by the METS Editorial Board as a simple and easy to implement rights schema, as an alternative or temporary solution before implementing a more comprehensive rights metadata format. It focuses on a simple structure for access and ownership rights for locally-controlled digital resources.

\section{MIX}

NISO Metadata for Images in XML Schema

http://wwm.loc.gov/standards/mix/

MIX is an XML representation of the Data Dictionary - Technical Metadata for Digital Still Images (ANSI/ NISO Z39.87-2006). As a technical metadata format for still images, MIX can be used to describe images born digitally such as those taken with digital cameras, and images that have been reformatted from analog originals such as scans of photographs or pages of text. The data dictionary on which MIX is based includes four basic areas of metadata: basic digital object information, basic image information, image caputure metadata, and image assessment metadata. The MIX XML Schema is maintained by the Library of Congress.

\section{MO}

Music Ontology

bttp:/ / musicontology.com/

The Music Ontology is a framework for the description of musical materials intended to push these descriptions to the Semantic Web. It is divided into three levels allowing incremental increases in complexity. Level 1 is for basic descriptive information such as tracks, artists, and releases. Level 2 adds the music creation workflow such as arrangement, performance, and recording. Level 3 adds support for complex events such as timelines and relationships between performances. The Music Ontology uses FRBR principles to separate a musical Work from its Manifestations. It is expressed in RDF/OWL.

\section{MODS}

Metadata Object Description Schema bttp://wmw.loc.gov/standards/mods/

MODS was developed by the Library of Congress Network Development and MARC Standards Office as a MARC-compatible metadata format expressed in XML and using language-based element names. MODS takes a similar approach to resource description as MARC, with some rearranging, removing, and adding of data elements. MODS is frequently used as a descriptive metadata structure standard inside METS metadata wrappers for storage or exchange of digital objects.

\section{MPEG-21 DIDL}

MPEG-21 Digital Item Description Language

http:// www.iso.org/iso/iso_catalogue/catalogue_tc/catalogue_detail. btm? csnumber $=41112$

DIDL is a component of the ISO/IEC 21000-2:2005 standard MPEG-21, and as such carries the same standarization weight MPEG-2, MPEG-4, and MPEG-7 carry. DIDL is a packaging format for digital objects, defining a data model for representing both content files and their metadata, and an XML wrapper format that conforms to the DIDL data model. The DIDL data model describes Containers, which can have Items, which group Components, which group individual datastreams called Resources. Descriptors apply to Containers, Items, or Resources. While MPEG21-DIDL is much less well known in the digital library community than METS, there are some high-profile implementa- 
tions, such as that at the Los Alamos National Laboratory Digital Library.

\section{MPEG-7}

MPEG Multimedia Content Description Interface

bttp:/ / www.chiariglione.org/mpeg/standards/mpeg-7/ mpeg-7.htm

MPEG-7, unline MPEG-1 and MPEG-2, is a standard for the description of the content of multimedia files, rather than a format for the multimedia files themselves. It is intended to provide structures for data both for human and machine users. The standard provides "description schemes" for a wide variety of uses. In addition to the high-level descriptions of content that will allow search and browse, there are description schemes for the creation process, rights information, technical information, user history, and low-level features such as color, lighting level, and sound timbre.

\section{MuseumDat}

http:/ / www.museumdat.org/index.php? $\ln =e n$

MuseumDat is a metadata structure standard for museums. It is based upon CDWA Lite, but while CDWA Lite has a heavy focus on works of art and material culture, MuseumDat also is appropriate for other types of museums such as technology and natural history. MuseumDat is defined in a W3C XML Schema. The current version is 1.0. There are ongoing efforts to harmonize CDWA Lite and MuseumDat into a new format called LIDO.

\section{MusicXML}

bttp:/ / www.recordare.com/xml.html

MusicXML is an XML encoding format for musical notation. It focuses on modern Western music notation, covering a full range of note types, accidentals, clefs, dynamics, and textual notations such as metronome markings and tempo indications. As such, MusicXML documents are extremely verbose and intended for machine processing rather than human consumption. MusicXML files can be structured by part or by measure. The format also includes a header for bibliographic information about the score. MusicXML is supported by many music notation software packages. The format was developed and is maintained by the company Recordare.

\section{MXF}

Material Exchange Format

bttp:/ / mxf.infol

MXF is a wrapper for a large set of formats for digital audio and video maintained by the standards body Society of Motion Picture and Television Engineers (SMPTE). The primary goal of the MXF wrapper and contained data formats is to exchange digital objects and their attendant metadata between audio and video devices such as cameras and video editing packages. In contrast to many standards emerging from the cultural heritage community, MXF focuses more heavily on low-level features of audio and video such as edit decision lists in video production, and less on high-level descriptive or preservation metadata.

\section{NewsML}

News Markup Language

http:/ / www.newsml.org/

The G2 version of NewsML is intentionally broad, covering textual news, articles, photos, graphics, audio, and video - the components that make up or express news items. Its data elements cover both factual information such as places and people but also higher-level conceptual information providing interpretation of events. NewsML is expressed both as a textual data model and an XML Schema.

\section{OAI-ORE}

Open Archives Initiative Object Re-use and Exchange http:/ / wmw.openarchives.org/ore/

OAI-ORE defines formats for the description and exchange of complex digital resources, which the framework calls Aggregations. Aggregations are then described by Resource Maps. Aggregations are groups of related content, whether different formats of the same content such as a PDF vs. a Word document, or content related by derivation such as a source data set and a paper written describing work done based on that data. OAI-ORE is explicitly designed to work with existing web technologies and therefore expose structured metadata to web-based applications. Serializations of the OAI-ORE model are available in Atom, RDF/XML, and RDFa.

\section{OAI-PMH}

Open Archives Initiative Protocol for Metadata Harvesting

bttp:/ / www.openarchives.org/pmb/

The Open Archives Initiative Protocol for Metadata Harvesting is a technology used to share metadata in a mostly automated way. "Data providers" set up servers where descriptions of resources are available using requests governed by the OAI-PMH protocol, and "service providers" collect metadata from multiple data providers and create value-added services on top of the aggregated 
data, such as cross-repository discovery. The protocol requires at a minimum a Simple Dublin Core record for every resource exposed, but also allows supplemental metadata formats as long as they are represented by a W3C XML Schema. The OAI-PMH protocol grew out of communities wishing to share pre-prints of scientific papers, but was quickly adopted by the larger cultural heritage community. While OAI-PMH is primarily about sharing metadata, some implementers have experimented with using it to share content as well, by providing links to thumbnail images or sharing full METS packages encapsulating or linking to full digital objects.

\section{OAIS}

Open Archival Information System bttp://public.ccsds.org/publications/archive/650x0b1.pdf

OAIS is known as a "reference model," defining concepts and responsibilities essential for ensuring preservation of digital information. The most well-known feature of OAIS is its categorization of information packages by their function. The Submission Information Package (SIP) is the content and metadata received from an information producer by a preservation respository. An Archival Information Package (AIP) is the set of content and metadata managed by a preservation repository, and organized in a way that allows the repository to perform preservation services. The Dissemination Information Package (DIP) is distributed to a consumer by the repository in response to a request, and may contain content spanning multiple AIPs. Preservation repository software frequently is described as "OAIS-compliant" to indicate a certain amount of functionality and standardization of features.

\section{ODRL}

Open Digital Rights Language

bttp:/ / odrl.net/

ODRL is a language for encoding rights management metadata, for abstract content and for specific manifestations (formats) of that content. ODRL is designed to record in a machine-readable way the information needed for Digital Rights Management (DRM) systems. The ODRL model defines Assets, Rights, and Parties, plus the relationships between them.

\section{ONIX}

Online Information Exchange

http:/ / www.bisg.org/what-we-do-21-15-onix-for-books.php

ONIX is a metadata standard for published material (essentialy books) that has emerged from the publishing industry. ONIX metadata is intended to accompany books throughout the supply chain, from production to retail distribution. ONIX is implemented as an XML Schema. Over 200 data elements are defined, with 31 identified as best practice to use. ONIX 3.0 was released in April 2009.

Some level of communication between the RDA and ONIX communities has occurred as part of the RDA development process. This interaction has the (as yet unrealized) potential for a greater level of partnership and data sharing between the publishing and library communities.

\section{Ontology for Media Resource}

Ontology for Media Resource

bttp:// wnw.w3.org/TR/2009/WD-mediaont-10-20090618/

The Ontology for Media Resource is a W3C Working Draft designed to provide a vocabulary for media resources, especially those on the Web. A "media resource" is defined as either a tangible, retrievable resource or the abstract work represented by a tangible thing. The Ontology defines a relatively small number of core properties in RDF, including properties for basic description, technical information, and user ratings. The specification also provides mappings to a wide variety of related standards.

\section{OpenURL}

ANSI/NISO Z39.88 - The OpenURL Framework for Context-Sensitive Services

bttp:/ / wnw.niso.org/ kst/ reports/standards?step=2\&gid=Eoproject_key $=d 5320409 c 5160 b e 4697 d c 046613 f 71 b 9 a 773 c d 9 e$

OpenURL is a technology that facilitates the discovery of full text content by users affiliated with an institution that provides access to licensed resources. An information service such as an abstracting and indexing database might support OpenURL by providing a link in each search result in an OpenURL format that includes among other things name/value pairs with appropriate bibliographic information to identify the located resource. Once constructed, OpenURLs are then sent to link resolvers run by individual institutions with which users are affiliatied, which check the bibliographic information about the located resource against a local database of licensed and open access resource. The user is then presented with a list of options for how to access different versions of the resource in print and in licensed databases.

SFX was the first mainstream OpenURL resolver used in libraries after it was purchased by Ex Libris. OCLC is the official OpenURL maintenance agency. 


\section{PB Core}

Public Broadcasting Core Metadata Dictionary

bttp:/ / www.pbcore.org/

PB Core is an extensive metadata structure supporting the description and exchange of media assets in the public broadcasting community, including both individual clips and full, edited, aired productions. Its elements are divided into sections focusing on intellectual content, intellectual property, instantiations, and extensions. PB Core is maintained under the auspices of the US Corporation for Public Broadcasting, and was influenced heavily by Dublin Core.

\section{PREMIS}

Preservation Metadata Implementation Strategies

bttp:// www.loc.gov/standards/premis/

PREMIS is a data dictionary and XML Schema for the encoding of information necessary to support the digital preservation process. Its data elements are divided into 5 categories, reflecting information on the PREMIS container, objects, events, agenda, and rights. A key feature of the PREMIS model is the definition of Objects as made up of Representations, Files, and Bitstreams. Also of note is the fact that PREMIS considers Objects immutable; if an action is taken on an Object that changes it, the result is a new but related Object.

PREMIS intentionally excludes format-specific technical metadata from its scope, assuming implementers will use other relevant standards for tracking this informatin. The Library of Congress is the official PREMIS maintenance agency.

\section{PRISM}

Publisher Requirements for Industry Standard Metadata

http://prismstandard.org/

PRISM emerged from the IDEAllance, a membership organization for the publishing industry and related companies focusing on topics such as information technology and digital content creation. The PRISM XML specification supports publishing and content aggregation workflows. As such, it provides a heavy focus on both descriptive and rights metadata. It re-uses some Dublin Core descriptive elements. The PRISM specification is formalized in XML DTDs and W3C XML Schemas, and in RDF. PRISM 2.1 was released in 2009.

\section{QDC}

Qualified Dublin Core

bttp:/ / wmw.dublincore.org/documents/dcmi-terms/
Qualified Dublin Core, also known as DC Terms, is an extension of Simple Dublin Core through the use of additional elements, element refinements, and encoding schemes. Qualified Dublin Core is seen in widely differing implementations, often using locally-defined refinements and encoding schemes. Some digital asset management systems such as CONTENTdm and DSpace operate on top of native Qualified Dublin Core models.

DC Terms is the basis for most recent activity in the Dublin Core Metadata Initiative, providing the fundamental properties that are used in description sets conforming to the Dublin Core Abstract Model (see DCAM).

\section{RAD}

Rules for Archival Description bttp:/ / wmw.cdncouncilarchives.ca/ archdesrules.html

RAD is the Canadian content standard for archival description. Its rules are based on archival principles such as respect des fonds and description reflecting arrangement. RAD contains chapters devoted to the description of several different types of resources, including moving images, sound recordings, and objects. Its structure is similar to that of AACR2. The most recent revision of RAD was issued in 2008 .

\section{RDA}

Resource Description and Access

http://rdaonline.org/

RDA is the planned replacement for AACR2 as the predominant content standard in the library community. It is intended to be useful beyond the library community as well. While primarily focused on descriptive metadata, some instructions exist that cover technical, rights, and structural metadata. RDA pushes the boundaries of a content standard, refering to sets of rules as "elements" which makes it closer to a structure standard than AACR2. Different communities will likely find either RDA's rules aspect or its data element aspect more interesting than the other. The standard is currently in draft; the initial version of RDA is scheduled for release in the summer of 2010. The initial release will have placeholders for several planned chapters.

\section{RDF}

Resource Description Framework bttp:// www.w3.org/TR/rdf-primer/

RDF is a meta-language for representing information, and serves as a key piece of the technical framework underlying Semantic Web activities. RDF defines its statements in "triples": the subject is what is being described, 
the predicate is an indication of what property of the subject is being described by the statement, and the object is the value of the property. The RDF Schema languages allows the definition of "classes" which meaningful groups of things to which resources can be connected. RDF can be represented in several different syntaxes, including XML and N3. As such, RDF is not an alternative to XML but rather operates at a slightly higher conceptual level.

\section{RELAX NG}

\section{RELAX NG}

bttp:/ / www.relaxng.org/

RELAX NG is a syntax for defining XML languages and serves as an alternative to DTDs and W3C XML Schema. It exists in both an XML syntax and a compact non-XML syntax, and the latter makes it a favorite among many developers. RELAX NG supports XML namespaces and external datatyping languages.

\section{RSS}

Really Simple Syndication

http://cyber.law.harvard.edu/rss/rss.html

RSS is a syndication format for Web content, allowing frequently updated information such as news feeds to be pushed to subscribed users. The most frequent use of RSS is to embed an RSS-encoded news feed into an otherwise human-readable web page such as a news service or a blog. An RSS feed is divided into "channels" for individual items, each of which have some required data such as title and description and some optional data such as publication date and category. RSS 2.0 allows enclosures, which support embedding of content and allow applications such as podcasting.

The main alternative to RSS for syndicated content is Atom. The RSS 2.0 specification calls for representation in XML, whereas the 1.0 specification represented information in RDF. RSS has also been known to stand for Rich Site Summary.

\section{SCORM}

Sharable Content Object Reference Model

bttp:/ / wmw.adlnet.gov/Technologies/scorm/default.aspx

SCORM was created as an effort of the Advanced Distributed Learning initiative of the US Department of Defense. The SCORM content aggregation model provides for the packaging and interoperability of metadata for e-learning materials. As such, it borrows elements from the LOM metadata standard.
The current version is SCORM 2004 4th Edition Version 1.1. The complete SCORM specifications include a description of a run-time environment and sequencing and navigation behavior in addition to the metadata specification in the content packaging description.

\section{Sears List of Subject Headings}

Sears List of Subject Headings

bttp:// www.hwwilson.com/print/searslst_19th.cfm

The Sears List of Subject Headings is a general-use controlled vocabulary for describing library collections, geared towards smaller public and school libraries. It includes topical, form, and geographic headings as well as proper names. Like LCSH, the Sears List uses a precoordinated structure, but its terminology is intentionally more generic and less specialized.

\section{SGML}

Standard Generalized Markup Language http:// wnw.iso.org/iso/catalogue_detail.htm?csnumber $=16387$

SGML is the precursor and current parent meta-language to XML. It is less strict in its structure than XML, including the ability to not require closing tags. Several metadata standards of interest to the cultural heritage community began as SGML languages and later migrated to XML, including EAD and TEI. HTML versions through HTML 4 are SGML languages, whereas XHT$\mathrm{ML}$ is an XML language. Currently, XML is favored over SGML for the development of new markup languages, largely due to XML's stricter structure.

\section{SKOS}

Simple Knowledge Organization System

bttp:// wmw.w3.org/2004/02/skos/

SKOS is a Semantic Web-driven method of encoding structured vocabularies in RDF. The RDF SKOS vocabulary focuses on describing concepts, which are represented by terms, and documenting relationships between concepts. SKOS-encoded data is a key building block in the Semantic Web's Linked Data movement. While SKOS can be used for encoding thesauri like those commonly used in the cultural heritage community, it fits less well for other types of controlled vocabularies common in this community such as name authorities. A high-profile use of SKOS in the cultural heritage community is the http://id.loc.gov service.

\section{SMIL}

Synchronized Multimedia Integration Language bttp://www.w3.org/TR/SMIL3/ 
SMIL is an early specification for describing and navigating multimedia files. It has existed for quite some time, with version 1.0 defined in 1998. The current version is 3.0 as a W3C Proposed Recommendation. SMIL 3.0 is represented in XML, and references media files (including audio, video, and still images) along with instructions on how to render them in parallel or in sequence to produce media playback for an end user. A large number of media players such as QuickTime and Windows Media support the SMIL format.

\section{SPECTRUM}

\section{SPECTRUM}

bttp:/ / www.collectionstrust.org.uk/ spectrum

SPECTRUM is a UK standard for museum documentation, maintained by the Collections Trust, a non-profit organization. SPECTRUM has a wide scope, including descriptive information for museum objects, reproduction management, acquisitions, and loan management. It is intended to prescribe data elements present in a museum management system, but does not provide a specific data encoding format. Version 3.2 was releaed in 2009.

\section{SRU}

Search and Retrieve via URL

bttp:// wmw.loc.gov/standards/sru/

SRU grew out of an initiative to define the "next generation Z39.50" in the library community. It is a Web Services-based protocol with response formats defined in XML. In contrast to bulk metadata harvesting technologies such as OAI-PMH, SRU is a federated search protocol, providing real-time search ability on remote services. SRU uses the CQL query language for remote searching. SRU is quickly gaining adoption in the cultural heritage community, although remove searching of library catalogs is still done much more frequently with Z39.50. SRU is maintained by a Steering Committee and Editorial Board, and documentation is hosted online by the Library of Congress.

\section{SWAP}

Scholarly Works Application Profile

http:/ / www.ukoln.ac.uk/ repositories/digirep/index/Scholarly_Works_ Application_Profile

SWAP is a DCMI-compliant application profile for the description of "scholarly works," which are defined loosely as eprints. SWAP is based on the FRBR conceptual model, and therefore differentiates between Works and their Manifestations. Descriptions of Manifestations are separated from descriptions of the Work itself. Basic descriptive information is included, as well as other in- formation particularly important to scholarly works such as granting agency and home page of the author.

\section{TEI}

Text Encoding Initiative

http:/ / www.tei-c.org

The TEI is an extensive markup language for textual materials. It is organized into "modules" - groups of markup elements that apply to different types of texts such as dictionaries and critical apparatuses, or features to be flagged within a text, such as names/dates/ people/places and tables/formulae/graphics. Elements in the TEI appear for both syntactic markup (pages, paragraphs, etc.) and semantic markup (names, places, etc.). TEI implementers typically use customized DTDs, W3C XML Schemas, or RelaxNG schemas to define the subset of the entire TEI language for use in a given project. The online Roma tool allows TEI implementers to generate these customized schemas for local use.

In addition to the markup defined for full texts, the TEI includes a header for metadata about the text itself. TEI was first released in 1994. The current version of the TEI is known as P5.

\section{TextMD}

Technical Metadata for Text

bttp:/ / www.loc.gov/standards/textMD/

The Technical Metadata for Text specification is an XML Schema for encoding the information needed to preserve and render text-based digital objects. TextMD covers features of text such as language, script, font, character encoding, and intended page direction and reading order. TextMD was originally developed at New York University, and is currently maintained by the Library of Congress.

\section{TGM I}

Thesaurus for Graphic Materials I: Subject Terms http:// wmw.loc.gov/ rr/print/tgm1/

TGM I is a controlled vocabulary for the description of subjects of visual (graphic) works. It is developed and maintained at the Library of Congress Prints and Photographs Division as a supplement to the Library of Congress Subject Headings, as greater granularity for image description is often needed beyond what LCSH provides.

The TGM I has been integrated together with the TGM II in order to form a unified vocabulary, but the two are still often discussed separately. 


\section{TGM II}

Thesaurus for Graphic Materials II: Genre and Physical Characteristic Terms

bttp:// wmw.loc.gov/ rr/print/tgm2/

TGM II is a controlled vocabulary for the description of genres for visual (graphic) works. Its scope is both genre in terms of physical form (Lantern slides) and content (e.g., Landscape photographs). It is developed and maintained at the Library of Congress Prints and Photographs Division as a supplement to the Library of Congress Subject Headings, as greater granularity for image description is often needed beyond what LCSH provides.

The TGM II has been integrated together with the TGM I in order to form a unified vocabulary, but the two are still often discussed separately.

\section{TGN}

Thesaurus for Geographic Names

http:/ / www.getty.edu/ research/conducting_research/vocabularies/tgn/

The TGN is one of a suite of controlled vocabularies maintained by the Vocabulary Program at the Getty Research Institute in Los Angeles. It focuses on geographic places, is organized hierarchicially, and contains coordinate data. It therefore is a prime candidate for use in applications where plotting resources on a virtual map is desired. The vocabulary may be searched one term at a time freely on the web, and is available for license in bulk. It is most frequently used by museums and other institutions focusing on the description of cultural objects.

\section{Topic Maps}

Topic Maps

bttp:/ / www.topicmaps.org/

Topic Maps are mechanisms for representing knowledge in a formal way. They can be used as a representation format for traditional knowledge organization structures such as indexes, glossaries, and thesauri, but can also be used for formalizing other types of knowledge organization structures. The Topic Maps model defines three aspects of the objects of description: their names (what they're called), occurences (specific instances of the abstract topic), and associations (the relationship between two topics).

The Topic Maps model is represented in XML via the XTM (XML Topic Maps) format. The Topic Maps framework is standardized as ISO/IEC 13250:2000. Topic Maps represent a powerful structure for knowledge organization but have not caught on heavily in the cultural heritage community at this point.

\section{ULAN}

Union List of Artist Names

bttp:/ / www.getty.edu/research/conducting_research/vocabularies/ulan/

The ULAN is one of a suite of controlled vocabularies maintained by the Vocabulary Program at the Getty Research Institute in Los Angeles. It focuses on proper names and associated data about artists, whether individuals or named groups. Many proper names appear in ULAN that do not appear in the LC/NACO authority file, and forms sometimes differ between these two vocabularies. The vocabulary may be searched one term at a time freely on the web, and is available for license in bulk.

\section{VRA Core}

Visual Resources Association Core Categories bttp:/ / www.vraweb.org/projects/vracore4 /

The Visual Resources Association Core Categories represent an early successful effort of a professional community to develop a metadata standard tailored to its own needs. VRA Core was originally built upon the Dublin Core base, adding features needed for the description and management of visual resources. It allows for the separate description of Images, Works, and Collections, reflecting the need of image repositories to manage data about the reproductions to which they provide users access separately from the metadata about works of art, architecture, and material culture themselves. The current version of this standard is VRA Core 4.0, which features two options for implementation: "unrestricted" which defines the VRA Core data elements, and "restricted" which enforces data contraints on certain elements to predefined vocabularies or date formats.

\section{VSO Data Model}

Virtual Solar Observatory Data Model

http://vso1.nascom.nasa.gov/docs/wiki/DataModel18

The VSO Data Model is an abstract model for solar data sets. It describes "elements," but these are meant generically rather than as specifications for explicit data fields in local systems. VSO elements are grouped into the following categories: observing time, target location, observer location, spectral range, physical/observable, data organization, wave mode sampling, and data source. The current version is VSO 1.8.

\section{XML}

eXtensible Markup Language

bttp://www.w3.org/XML/

$\mathrm{XML}$ is a meta-language for defining markup languages for specific purposes. XML languages tend to be either 
"data-centric," where XML elements are treated as structured data fields to be filled in, or "document-centric," where a document pre-exists and XML elements are used to flag specific features of the document.

The XML language itself is only one of a suite of XML-related technologies. Effective use of XML languages in information systems depends on many of these related technologies, including Xpath, XSLT, Xquery, and XML Schema language. XML grew out of and is an explicit subset of the earlier SGML specification, and provides tighter constraints on syntax intended to make machine processing of data easier.

\section{XML Schema}

\section{XML Schema}

$$
\text { bttp:/ / wnw.w3.org/XML/Schema }
$$

The XML Schema specification from the World Wide Web Consortium is often referred to as W3C XML Schema to differentiate it from other XML language definition standards. W3C XML Schema serves as an alternative to DTD and RelaxNG as a method for defining an XML language for a specific purpose. The W3C XML Schema language allows the specification of elements and attributes, the order in which elements can appear, cardinality of elements and attributes, data types for elements and attributes, and the use of elements and attributes from other namespaces. W3C XML Schema documents are themselves expressed in XML.

\section{XMP}

\section{Extensible Metadata Platform}

http:// www.adobe.com/products/xmp/

$\mathrm{XMP}$ is a metdata packaging format developed by Adobe with the primary purpose of embedding this metadata inside content files. The XMP data model is strongly influenced by RDF, and XMP encodings are in a constrained form of RDF/XML. Inside the basic XMP structure, standard schemas such as Dublin Core are defined for use, and XMP provides mechanisms for extending these standard schemas or creating new ones. Standard XMP schemas focus not only on descriptive metadata, but also metadata for management of the content.

\section{XOBIS}

XML Organic Bibliographic Information Schema

$$
\text { bttp:/ / xobis.stanford.edu/ }
$$

XOBIS was one outcome of the Stanford University Lane Medical Library's MEDLANE project. It is a model for "information objects and relationships," focusing more heavily on these relationships than do traditional bibliographic models. XOBIS shares many features in common with FRBR and the CIDOC CRM. The principal elements in the XOBIS structure are: Concept, String, Language, Organization, Event, Time, Place,Being, Object, and Work.

\section{XPath}

XML Path Language

bttp:/ / www.w3.org/TR/2009/REC-xpath-20090303/

XPath is a language for locating nodes within an XML document. It is used inside other XML technologies such as XSLT and XQuery.

\section{XQuery}

XML Query Language

bttp:// www.w3.org/TR/ xquery/

XQuery is a W3C-created query language to support the querying of native XML documents. It relies heavily on XPath 2.0 for the location of nodes within XML documents. Unlike many other XML technologies, XQuery is itself not expressed in XML. Its syntax is much closer to programming and scripting languages.

\section{XrML}

eXtensible Rights Markup Language

bttp:/ / www.xrml.org/

$\mathrm{XrML}$ is an XML language for the encoding of rights information. It is focused on the action of "granting" authorizations between Principals, Rights, Resources, and Conditions. Together these concepts make up a License.

\section{XSLT}

eXtensible Stylesheet Language Transformations bttp:// wnw.w3.org/TR/xslt

XSLT is one of a suite of XML-related standards from the W3C. This language is used to transform an XML document into a different XML document, or another structured document format. In the digital library and digital humanities communities, it is frequently used for mapping one metadata format to another, or for rendering a metadata record in (X)HTML for display to end users.

\section{Z39.50}

bttp:// wmw.loc.gov/ z3950/agency/

Z39.50 is a long-standing federated search protocol used by the library community to provide broadcast real-time 
searching of remote databases. It is most commonly used to retrieve MARC records from remote library catalogs, including OCLC's WorldCat, to facilitate copy cataloging and sharing of bibliographic records.

Arising out of standardization efforts begin in the 1970s, and first published as a standard in 1988, Z39.50 predates XML and Web Services architectures and as such is very different to implement than more modern information sharing protocols. The Z39.50 Next Generation initiative has among other things produced the SRU protocol and the CQL query language.

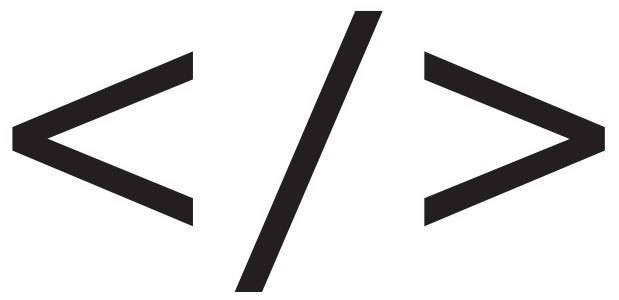




\section{Lista de ilustrações}

Contexto clássico do expectador . . . . . . . . . . . . . . . 10

Contexto virtual do expectador . . . . . . . . . . . . . . . . 11

Codificação/decodificação segundo Hall . . . . . . . . 26

Os 4 momentos da recepção . . . . . . . . . . . . . . . . . 39

Exemplo de código QR . . . . . . . . . . . . . . . . . . . . . 53

VPL Data Glove (1987) . . . . . . . . . . . . . . . . . . 72

Sensorama (1962) . . . . . . . . . . . . . . . . . . . 72

Viewmaster 3D modelo $G(1962) \ldots \ldots$

Viewmaster Virtual Reality Viewer (2015) . . . . . . . . . . 73 Sony Playstation VR HDM (2014) . . . . . . . . . . . . 74

11 Google Cardboard (2014) . . . . . . . . . . . . . 74

12 Conceito de Museu e sua relação com temas pertinentes à tecnologia . . . . . . . . . . . . . . . . . . . . . . . . . . 88

13 Confluência: Omnicanal, in situ e ex situ . . . . . . . . . . 99

14 Resoluções de telas de vídeo e pixels correspondentes . 108 15 Imagem em diferentes resoluções de tela . . . . . . . . 109

16 Escopo: Canadiam Museum of Human Rights . . . . . . . 114

17 Plataforma aberta, relações e interdependências .... 125

18 Fechamento triádico . . . . . . . . . . . . . . . . . . 134 


\section{Lista de tabelas}

Tecnologias baseadas em dispositivos móveis: diferenciação . . . . . . . . . . . . . . . . . . . . . . . . . . . . 52 Uso global da Internet . . . . . . . . . . . . . . . . . . 75 Teoria da Difusão da Inovação . . . . . . . . . . . . . . . . 77 Conceito de Museu segundo ICOM . . . . . . . . . . . . 87 Critérios tecnológicos aplicados à definição de Museu . 89 Etapas da conversão do acervo em ativos digitais . . . 103 Características das diferentes redes sociais ... . . . . 131 Ambientação versus Virtualização . . . . . . . . . . . . . . 159 


\section{J | Glossários e Índices}




\section{Glossário}

\section{Símbolos}

3D Gráficos que utilizam representações tridimensionais de dados geométricos (geralmente cartesianos), armazenados em um computador com o propósito de realizar cálculos e renderizar imagens bidimensionais.

<https://pt.wikipedia.org/wiki/3D_(computação_gráfica)> Acesso em: 25 jul. $201756,59,66,105,160$

A

Acesso aleatório Em ciência da computação, acesso aleatório é a capacidade de acessar um elemento arbitrário de uma sequência em tempo igual. O contrário é o acesso sequencial, onde um elemento mais distante leva mais tempo para ser acessado. Uma forma típica de diferenciar ambos é comparar um antigo rolo de pergaminho (sequencial: todo o material que antecede os dados desejados deve ser desenrolado) e um livro (aleatório: pode ser aberto imediatamente em qualquer página aleatória). Um exemplo mais moderno é comparar a fita cassete (sequencial: é necessário efetuar um avanço rápido pelas canções no início da fita para poder chegar às últimas) com o CD-ROM (acesso aleatório: é possível acessar diretamente a faixa desejada). 
<https://pt.wikipedia.org/wiki/Acesso_aleatório> Acesso em: 22 jul. 201749

Adobe A Adobe Systems Incorporated é uma companhia americana que desenvolve programas de computador com sede em San Jose, Califórnia. Foi fundada em dezembro de 1982 por John Warnock e Charles Geschke. Eles fundaram a Adobe após saírem do Xerox PARC para que pudessem desenvolver mais e comercializar a linguagem de descrição de página PostScript. A Adobe teve um papel importante na revolução da publicação em desktop quando a Apple Computer licenciou o PostScript para usar na linha de impressoras LaserWriter, o que ajudou a desencadear a revolução da edição eletrônica, em 1985. O nome da companhia, Adobe, vem de Adobe Creek, um riacho que corria próximo aos escritórios originais da empresa em Mountain View.

<https://pt.wikipedia.org/wiki/Adobe_Systems> Acesso em: 11 nov. 2017110

Al Inteligência artificial (por vezes mencionada pela sigla em português IA ou pela sigla em inglês Al - artificial intelligence) é a inteligência similar à humana exibida por mecanismos ou software. Também é um campo de estudo acadêmico. Os principais pesquisadores e livros didáticos definem o campo como "o estudo e projeto de agentes inteligentes", onde um agente inteligente é um sistema que percebe seu ambiente e toma atitudes que maximizam suas chances de sucesso. John McCarthy, quem cunhou o termo em 1956 ("numa conferência de especialistas celebrada em Darmouth Colege" Gubern, Román: O Eros Eletrônico), a define como "a ciência e engenharia de produzir máquinas inteligentes". É uma área de pesquisa da computação dedicada a buscar métodos ou dispositivos computacionais que 
possuam ou multipliquem a capacidade racional do ser humano de resolver problemas, pensar ou, de forma ampla, ser inteligente. Também pode ser definida como o ramo da ciência da computação que se ocupa do comportamento inteligente ou ainda, o estudo de como fazer os computadores realizarem coisas que, atualmente, os humanos fazem melhor.

<https://pt.wikipedia.org/wiki/Inteligência_artificial> Acesso em: 10 nov. 2017105

Amazon American electronic commerce and cloud computing company that was founded on July 5, 1994 by Jeff Bezos and is based in Seattle, Washington. The tech giant is the largest Internet-based retailer in the world by total sales and market capitalization. Amazon.com started as an online bookstore and later diversified to sell DVDs, Blu-rays, CDs, video downloads/streaming, MP3 downloads/streaming, audiobook downloads/streaming, software, video games, electronics, apparel, furniture, food, toys, and jewelry. The company also produces consumer electronics - notably, Kindle e-readers, Fire tablets, Fire TV, and Echo - and is the world's largest provider of cloud infrastructure services (laaS and PaaS). Amazon also sells certain low-end products like USB cables under its in-house brand AmazonBasics.

Amazon has separate retail websites for the United States, the United Kingdom and Ireland, France, Canada, Germany, Italy, Spain, Netherlands, Australia, Brazil, Japan, China, India, and Mexico. Amazon also offers international shipping to certain other countries for some of its products. In 2016, Dutch, Polish, and Turkish language versions of the German Amazon website were launched <https://en.wikipedia.org/wiki/Amazon.com> Acesso em: 26 jul. 2017 66,160 
API Especificação de software que descreve como se comunicar com outro software. É a ferramenta para se criar a ponte entre aplicativos que, de outra forma, seriam incompativeis. <http://eu.oheuaqui.com/2AKOrsz> Acesso em: 10 out. 2017 115, 124

Apple Apple Inc. (anteriormente Apple Computer, Inc.) é uma empresa multinacional norte-americana que tem o objetivo de projetar e comercializar produtos eletrônicos de consumo, software de computador e computadores pessoais. Os produtos de hardware mais conhecidos da empresa incluem a linha de computadores Macintosh, o iPod, o iPhone, o iPad, a Apple TV e o Apple Watch. Os softwares incluem o sistema operacional Mac OS X, o navegador de mídia iTunes; a suíte de software multimídia e criatividade iLife; a suíte de software de produtividade iWork; Aperture, um pacote de fotografia profissional; Final Cut Studio, uma suíte de vídeo profissional e produtos de software; Logic Studio, um conjunto de ferramentas de produção musical; o navegador Safari; e o iOS, um sistema operacional móvel. <https://pt.wikipedia.org/wiki/Apple> Acesso em: 25 jul. 2017 66, 160

Arte-educação Arte-educação, ensino de arte ou educação artística é uma disciplina educativa que oportuniza, ao indivíduo, o acesso à arte como linguagem expressiva e forma de conhecimento.

A educação em arte, assim como a educação geral e plena do indivíduo, acontece na sociedade de duas formas: assistematicamente através dos meios de comunicação de massa e das manifestações não institucionalizadas da cultura, como as relacionadas ao folclore (entendido como manifestação viva e em mutação, não limitada apenas à preservação de tradições); e sistematicamente na escola ou em outras instituições de ensino. A arte-educação tem um objetivo maior que a formação de profissionais dedicados a esta área de 
conhecimento: no âmbito da escola regular, busca oferecer, aos indivíduos, condições para que ele compreenda o que ocorre nos planos da expressão e do significado ao interagir com as artes, permitindo, dessa forma, sua inserção social de maneira mais ampla. Nesse sentido, os museus são uma ferramenta muito útil para a observação de uma forma mais condensada e intensa de diversas manifestações artísticas - sejam elas da contemporaneidade ou não.

No Brasil, a Lei de Diretrizes e Bases da Educação Nacional (LDB nž 9.394/96) estabeleceu, em seu artigo 26, parágrafo 2ž, que:

"O ensino da arte constituirá componente curricular obrigatório, nos diversos níveis da educação básica, de forma a promover o desenvolvimento cultural dos alunos"

"A arte é um patrimônio cultural da humanidade, e todo ser humano tem direito ao acesso a esse saber" De acordo com os parâmetros curriculares nacionais, a educação em arte propicia o desenvolvimento do pensamento artístico e da percepção estética, que caracterizam um modo próprio de ordenar e dar sentido à experiência humana: através da educação em arte, o aluno desenvolve sua sensibilidade, percepção e imaginação, tanto ao realizar formas artísticas quanto na ação de apreciar e conhecer as formas produzidas por ele e pelos colegas, pela natureza e pelas diferentes culturas (PCN-Arte-1997). <https://pt.wikipedia.org/wiki/Ensino_de_arte> Acesso em: 18 set. 2015 5

Atari Atari is a corporate and brand name owned by several entities since its inception in 1972, currently by Atari Interactive, a subsidiary of the French publisher Atari, SA (ASA).(1)(2)(3) The original Atari, Inc. founded in 1972 by Nolan Bushnell and Ted Dabney was a pioneer in arcade games, home video game consoles, and home computers. 
The company's products, such as Pong and the Atari 2600, helped define the electronic entertainment industry from the 1970s to the mid-1980s.

<https://en.wikipedia.org/wiki/Atari> Acesso em: 25 jul. 2017 66, 160

B

Base de dados $\mathrm{V}$. banco de dados, 115

Battlezone Jogo eletrônico para arcade da Atari lançado em 1980. 66, 160

Bluetooth Bluetooth é um padrão global de comunicação sem fio e de baixo consumo de energia que permite a transmissão de dados entre dispositivos, desde que um esteja próximo do outro. Uma combinação de hardware e software é utilizada para permitir que esse procedimento ocorra entre os mais variados tipos de aparelhos.

A transmissão de dados é feita por meio de radiofrequência, permitindo que um dispositivo detecte o outro independente de suas posições, sendo necessário apenas que ambos estejam dentro do limite de proximidade (via de regra, quanto mais perto um do outro, melhor).

Para que seja possivel atender aos mais variados tipos de dispositivos, o alcance máximo do Bluetooth foi dividido em três classes:

- Classe 1: potência máxima de 100 mW (miliwatt), alcance de até 100 metros;

- Classe 2: potência máxima de 2,5 mW, alcance de até 10 metros;

- Classe 3: potência máxima de $1 \mathrm{~mW}$, alcance de até 1 metro.

A Classe 2 é a mais utilizada; logo, a maioria dos dispositivos trabalha com alcance de até 10 metros. Há ainda a Classe 4, que é destinada a dispositivos que consomem pouca energia: sua potência é de 0,5 $\mathrm{mW}$; o alcance é de meio metro, aproximadamente. 
Esse índice sugere que um aparelho com Bluetooth classe 3 somente conseguirá se comunicar com outro se a distância entre ambos for inferior a 1 metro, por exemplo. Esta distância é suficiente para conectar um fone de ouvido a um telefone celular guardado no bolso da calça. É importante frisar, no entanto, que dispositivos de classes diferentes podem se comunicar sem nenhum problema, bastando respeitar o limite daquele que possui alcance menor.

A velocidade de transmissão de dados no Bluetooth é relativamente baixa: até a versão 1.2, a taxa pode alcançar, no máximo, 1 Mb/s (megabit por segundo). Na versão 2.0, esse valor passou para até $3 \mathrm{Mb} / \mathrm{s}$. Embora essas taxas sejam baixas, são suficientes para uma conexão satisfatória entre a maioria dos dispositivos. Todavia, a busca por velocidades maiores é constante, como prova a versão 5.0, capaz de atingir taxas de até $50 \mathrm{Mb} / \mathrm{s}$.

A história do Bluetooth começa em meados de 1994. Na época, a companhia Ericsson passou a estudar a viabilidade de desenvolver uma tecnologia que permitisse a comunicação entre telefones celulares e acessórios utilizando sinais de rádio de baixo custo, em vez dos tradicionais cabos. $\bigcirc$ estudo foi feito com base em um projeto que investigava o uso de mecanismos de comunicação em redes de telefones celulares, que resultou em um sistema de rádio de curto alcance que recebeu o nome MC-Link. Com a evolução do projeto, a Ericsson percebeu que o MC-Link poderia ser bem sucedido: seu principal atrativo era a implementação relativamente fácil e barata. Em 1997, o projeto começou a despertar o interesse de outras empresas que, logo, passaram a fornecer apoio. Por conta disso, em 1998, foi criado o consórcio Bluetooth SIG (Bluetooth Special Interest Group), formado pelas companhias Ericsson, Intel, IBM, Toshiba e 
Nokia (dezenas de outras companhias aderiram ao consórcio com o passar do tempo).

Bluetooth é uma tecnologia criada para funcionar no mundo todo, razão pela qual se fez necessária a adoção de uma frequência de rádio aberta e aceita em praticamente qualquer lugar do planeta. A faixa ISM (Industrial, Scientific, Medical), que opera à frequência de 2,45 GHz, é a que me mais se aproxima dessa necessidade, sendo utilizada em vários países, com variações que vão de 2,4 GHz a 2,5 $\mathrm{GHz}$.

Como a faixa ISM é aberta, isto é, pode ser utilizada por qualquer sistema de comunicação, é necessário garantir que o sinal do Bluetooth não sofra interferência, assimo como não a gere. $\bigcirc$ esquema de comunicação FH-CDMA (Frequency Hopping - Code-Division Multiple Access), utilizado pelo Bluetooth, permite tal proteção, pois faz a frequência ser dividida em vários canais.

O dispositivo que estabelece a conexão muda de um canal para outro de maneira bastante rápida. Esse procedimento é chamado "salto de frequência" (frequency hopping) e permite que a largura de banda da frequência seja muito pequena, diminuindo sensivelmente as chances de interferência. No Bluetooth, pode-se utilizar até 79 frequências (ou 23, dependendo do país) dentro da faixa ISM, cada uma "espaçada" da outra por intervalos de $1 \mathrm{MHz}$. <http://eu.oheuaqui.com/2xuYmel> Acesso em: 10 out. 2017 64,

Bluetooth LE Bluetooth Low Energy ou, simplesmente, Bluetooth LE (também há a sigla BLE, mas ela é menos usada), é uma variante da tecnologia Bluetooth. Trata-se de uma especificação que faz a tecnologia consumir uma quantidade muito pequena de energia elétrica em relação às outras versões. Acessórios médicos portáteis, smartwatches 
e pulseiras inteligentes são exemplos de dispositivos que, por serem muito compactos, usam baterias de baixa capacidade. Assim, toda economia de energia é válida. O Bluetooth LE veio para atender justamente a essa necessidade. Para consumir menos energia, o Bluetooth LE utiliza várias técnicas. Uma delas é a redução na velocidade de transferência de dados, que normalmente não passa de $1 \mathrm{Mb} / \mathrm{s}$ : essa taxa costuma ser suficiente, pois o volume de dados é baixo. Pela mesma razão, um módulo Bluetooth LE também pode ficar a maior parte do tempo em "modo de descanso": como não há muitos dados a serem transmitidos, uma conexão de poucos milissegundos consegue dar conta de enviar ou receber todas as informações necessárias. Outra técnica é a redução do alcance da comunicação: o Bluetooth LE trabalha bem com distâncias de até 30 metros, mas o gasto de energia cai drasticamente se um dispositivo estiver bem perto do outro. V. bluetooth, 64

Browser $\underline{V}$. navegador

C

Canadian Museum for Human Rights The Canadian Museum for Human Rights (CMHR) is a national museum in Winnipeg, Manitoba, located adjacent to The Forks. The purpose of the museum is to "explore the subject of human rights with a special but not exclusive reference to Canada, in order to enhance the public's understanding of human rights, to promote respect for others and to encourage reflection and dialogue."(5) It held its opening ceremonies on 19 September 2014. Established in 2008 through the enactment of Bill C-42, an amendment of the Canadian Museums Act, the Canadian Museum for Human Rights is the first new national museum created in Canada since 1967, and it is the first new national museum ever to be located outside the 
National Capital Region.

<https://en.wikipedia.org/wiki/Canadian_Museum_for_Human_Rights> Acesso em: 04 jan. 2018113

Cardboard Google Cardboard is a virtual reality (VR) platform developed by Google for use with a head mount for a smartphone. Named for its fold-out cardboard viewer, the platform is intended as a low-cost system to encourage interest and development in VR applications. Users can either build their own viewer from simple, low-cost components using specifications published by Google, or purchase a pre-manufactured one. To use the platform, users run Cardboardcompatible applications on their phone, place the phone into the back of the viewer, and view content through the lenses.

<https://en.wikipedia.org/wiki/Google_Cardboard> Acesso em: 26 jul. 2017 V. Google, 66, 160

Cibernética Tentativa de compreender a comunicação e o controle de máquinas, seres vivos e grupos sociais através de analogias com as máquinas eletrônicas (homeostatos, servomecanismos, etc.). Estas analogias tornam-se possíveis, na Cibernética, por esta estudar o tratamento da informação no interior destes processos como codificação e descodificação, retroação ou realimentação (feedback), aprendizagem, etc. Segundo Wiener (1968), do ponto de vista da transmissão da informação, a distinção entre máquinas e seres vivos, humanos ou não, é mera questão de semântica. $\bigcirc$ estudo destes autômatos trouxe inferências para diversos campos da ciência. A introdução da ideia de retroação por Norbert Wiener rompe com a causalidade linear e aponta para a ideia de círculo causal onde A age sobre $B$ que em retorno age sobre A. Tal mecanismo é denominado regulação e permite a autonomia de um sistema (seja um 
organismo, uma máquina, um grupo social). Será sobre essa base que Wiener discutirá a noção de aprendizagem.

<https://pt.wikipedia.org/wiki/Cibernética> Acesso em: 10 de dez. de 201523

Ciência Aberta A expressão ciência aberta (open science) faz referência a um modelo de prática científica que, em consonância com o desenvolvimento da cultura digital, visa a disponibilização das informações em rede de forma oposta à pesquisa fechada dos laboratórios. Atualmente a expressão também se refere a geração de materiais de pesquisa que são compartilhados abertamente, sem a necessidade de patentes.

<https://pt.wikipedia.org/wiki/Ciência_aberta> Acesso em: 20 nov. 2017

Console A video game console is an electronic, digital or computer device that outputs a video signal or visual image to display a video game that one or more people can play.

The term "video game console" is primarily used to distinguish a console machine primarily designed for consumers to use for playing video games, in contrast to arcade machines or home computers. An arcade machine consists of a video game computer, display, game controller (joystick, buttons, etc.) and speakers housed in large chassis. A home computer is a personal computer designed for home use for a variety of purposes, such as bookkeeping, accessing the Internet and playing video games.

There are various types of video game consoles, including home video game consoles, handheld game consoles, microconsoles and dedicated consoles. Although Ralph Baer had built working game 
consoles by 1966, it was nearly a decade before the Pong game made them commonplace in regular people's living rooms. Through evolution over the 1990s and 2000s, game consoles have expanded to offer additional functions such as CD players, DVD players, Blu-ray disc players, web browsers, set-top boxes and more.

<https://en.wikipedia.org/wiki/Video_game_console> Acesso em: 25 jul. 201756,66

CRM Customer relationship management (CRM) is an approach to manage a company's interaction with current and potential customers. It uses data analysis about customers' history with a company to improve business relationships with customers, specifically focusing on customer retention and ultimately driving sales growth. One important aspect of the CRM approach is the systems of CRM that compile data from a range of different communication channels, including a company's website, telephone, email, live chat, marketing materials, and more recently, social media. Through the CRM approach and the systems used to facilitate it, businesses learn more about their target audiences and how to best cater to their needs.

<https://eu.oheuaqui.com/2mg7ekx> Acesso em: 10 jan. 201896

Crowdsourcing The act of giving tasks to a large group of people or to the general public, for example, by asking for help on the internet, rather than having tasks done within a company by employees: Crowdsourcing means that work once done in-house, from design and research to customer support, can now be farmed out, cutting costs and tapping new expertise.

<https://dictionary.cambridge.org/dictionary/english/crowdsourcing> Acesso em: 20 nov. 2017 93, 96, 102 
Código-fonte Código-fonte (source code em inglês) é o conjunto de palavras ou símbolos escritos de forma ordenada, contendo instruções em uma das linguagens de programação existentes, de maneira lógica. Existem linguagens que são compiladas e as que são interpretadas. As linguagens compiladas, após ser compilado o código fonte, transformam-se em software, ou seja, programas executáveis. Este conjunto de palavras que formam linhas de comandos deverá estar dentro da padronização da linguagem escolhida, obedecendo critérios de execução. Atualmente, com a diversificação de linguagens, o código pode ser escrito de forma totalmente modular, podendo um mesmo conjunto de códigos ser compartilhado por diversos programas e, até mesmo, linguagens.

<https://pt.wikipedia.org/wiki/Código-fonte> Acesso em: 29 nov. 2017 120

Código QR O QR Code (ou Quick Response Code) é um símbolo bidimensional (2-D), criado e registrado em 1994 pela empresa Japonesa Denso-Wave (subsidiária da Toyota Motor Corporation), com o objetivo de permitir e facilitar, de forma rápida e eficiente, o processo de catalogação dos componentes para automóveis.

A sigla QR deriva do termo Quick Response (ou Resposta Rápida) e está associada ao fato destes códigos poderem ser lidos e decodificados eletronicamente, em grande velocidade, através de equipamentos de leitura.

Os códigos QR contém informação nos eixos vertical e horizontal, daí o termo bidimensional. Devido a esta característica os códigos QR possibilitam armazenar centenas de vezes mais dados do que os tradicionais códigos de barras.

A informação contida nestes códigos pode ser facilmente lida através 
de um leitor QR instalado no dispositivo do espectador.

São utilizados por inúmeras organizações e empresas nos mais diversos setores de atividade e o tipo de informação codificada pode ser bastante variado. Permitem armazenar diferentes tipos de dados, incluindo caracteres alfabéticos, números, símbolos, binários e caracteres do alfabeto japonês. Enquanto o tradicional código de barras pode ter no máximo 20 dígitos, um código QR pode armazenar até 7.089 caracteres. Estes caracteres podem ser combinados em um símbolo de grande porte ou então divididos em até 16 símbolos. Alguns dos tipos de uso mais frequentes são:

- texto simples

- URLS

- mensagens SMS

- cartões de visita eletrônicos (vCard)

- endereços de e-mail

Após a popularização do uso dos códigos de barras, os códigos 2-D surgem para responder à necessidade de se armazenar mais informação, mais tipos de caracteres e menor espaço de impressão. Apesar da marca registrada, os códigos QR podem ser utilizados livremente por qualquer indivíduo ou organização sem a necessidade de licenças ou taxas.

Isto estimulou sua utilização em diversas e inovativas formas, e o seu uso comercial e institucional se generalizou em várias partes do mundo.

Com o corrente avanço da tecnologia e a massificação da Internet nos dispositivos móveis, os códigos QR são em grande parte utilizados para ações de marketing. Mostraram-se eficazes na promoção interativa de marcas e produtos junto ao público, pois são capazes de 
ligar o universo físico ao mundo online.

Dada a facilidade de utilização dos leitores QR nos dispositivos móveis, é bastante simples decodificar e converter um código QR em um endereço na Internet e redirecionar o utilizador para conteúdos específicos, campanhas publicitárias ou perfis de empresas em redes sociais. É comum, na atualidade, se encontrar códigos QR associados a promoções, descontos e ofertas de toda espécie. <http://www.qrcode.com/en/faq.html> Acesso em: 31 jul. 201752

Código aberto Tipo de software cujo código-fonte é visivel publicamente. Algumas empresas comerciais como IBM, HP, Intel, Dell, entre outras, têm investido no software de código aberto, juntando seus esforços para a criação do Open Source Development Lab (OSDL), instituição destinada à criação de tecnologias de código aberto 13, 120, 142

D

DAMA DAMA (Data Management Association) is a not-for-profit, vendorindependent, international association of technical and business professionals dedicated to advancing the concepts and practices of information resource management (IRM) and data resource management (DRM). The vision of DAMA is to support an empowered global community of information professionals.

<https://en.wikipedia.org/wiki/DAMA> Acesso em: 10 nov. 2017125

Database $\underline{\text {. }}$ banco de dados

Difusão da inovação Diffusion of innovations is a theory that seeks to explain how, why, and at what rate new ideas and technology spread. Everett Rogers, a professor of communication studies, popularized the theory in his book Diffusion of Innovations; the book was first published in 1962, and is now in its fifth edition (2003).(1) Rogers argues that diffusion is the process by which an innovation is communicated over 
time among the participants in a social system. The origins of the diffusion of innovations theory are varied and span multiple disciplines. Rogers proposes that four main elements influence the spread of a new idea: the innovation itself, communication channels, time, and a social system. This process relies heavily on human capital. The innovation must be widely adopted in order to self-sustain. Within the rate of adoption, there is a point at which an innovation reaches critical mass.

The categories of adopters are innovators, early adopters, early majority, late majority, and laggards.(2) Diffusion manifests itself in different ways and is highly subject to the type of adopters and innovationdecision process. The criterion for the adopter categorization is innovativeness, defined as the degree to which an individual adopts a new idea.

<https://en.wikipedia.org/wiki/Diffusion_of_innovations> Acesso em: 22 jul. 201776

Diorama Diorama é um modo de apresentação artística tridimensional, de maneira muito realista, de cenas da vida real para exposição com finalidades de instrução ou entretenimento.

O termo 'diorama' foi inventado por Louis Daguerre em 1822, para um tipo de display rotativo. A palavra significa literalmente: 'através daquilo, o que é visto' do grego di- 'através' + orama 'o que é visto, uma cena'.

Primeiro diorama foi criado por Daguerre e Charles Marie Bouton, sendo exposto em Londres em 29 de setembro de 1823. O significado 'réplica de uma cena em pequena escala, etc.' surgiu em 1902.

Num diorama, a cena de fundo, que pode ser uma paisagem, plantas, animais, eventos históricos, etc. , é pintada sobre uma tela de 
fundo curvo, de tal maneira que simulem um contorno real. A tela colocada na obscuridade e iluminada de maneira adequada dá uma ilusão de profundidade e de movimento, dando a impressão de tridimensionalidade. O assunto principal, é pintado ou esculpido de tal forma que cria uma perspectiva falsa, modificando com cuidado a escala dos objetos para reforçar a ilusão de realismo. Todas estas técnicas são modos de apresentar uma vista realística de uma cena grande em um espaço reduzido.

<https://en.wikipedia.org/wiki/Diorama> Acesso em: 18 jul. 201743

DNG Digital Negative (DNG) is a patented, open, non-free lossless raw image format written by Adobe used for digital photography. It was launched on September 27, 2004. The launch was accompanied by the first version of the DNG specification, plus various products, including a free-of-charge DNG converter utility. All Adobe photo manipulation software (such as Adobe Photoshop and Adobe Lightroom) released since the launch supports DNG.

DNG is based on the TIFF/EP standard format, and mandates significant use of metadata. Use of the file format is royalty-free; Adobe has published a license allowing anyone to exploit DNG, and has also stated that there are no known intellectual property encumbrances or license requirements for DNG. Adobe stated that if there were a consensus that DNG should be controlled by a standards body, they were open to the idea. Adobe has submitted DNG to ISO for incorporation into their revision of TIFF/EP.

<https://en.wikipedia.org/wiki/Digital_Negative> Acesso em: 11 nov. 2017110

DOOM First-person shooter electronic game released in December 1993 that changed the direction of almost every aspect of personal com- 
puter (PC) games, from graphics and networking technology to styles of play, notions of authorship, and public scrutiny of game content. <https://www.britannica.com/topic/Doom> Acesso em: 25 jul. 2017 66, 160

DPI Pontos por polegada (ppp; em inglês dots per inch ou DPI) é uma medida de densidade relacionada à composição de imagens, que expressa o número de pontos individuais que existem em uma polegada linear na superfície onde a imagem é apresentada. Também é comum encontrar referências a essa densidade pelo termo "resolução de imagem" ou simplesmente "resolução". A resolução é indicada pela composição da densidade horizontal e vertical, que podem ser iguais ou diferentes. De maneira geral, quanto maior o número de pontos por polegada, mais detalhada e bem definida é a imagem. 107

\section{E}

Edutainment The process of entertaining people at the same time as you are teaching them something, and the products, such as television programmes or software, that do this.

<http://dictionary.cambridge.org/dictionary/english/edutainment> Acesso em: 08 ago. 2017

Educational entertainment (also referred to by the portmanteau neologism edutainment) is a concept designed to educate through entertainment. Most often it includes content intended to teach but has incidental entertainment value. It has been used by academia, corporations, governments, and other entities in various countries to disseminate information in classrooms and/or via television, radio, and other media to influence viewers' opinions and behaviors. <https://eu.oheuaqui.com/2meTDKp> Acesso em: 08 ago. 201780 
Erwartungshorizont Expressão de origem alemã (traduzida em inglês por horizon of expectation e en francês por horizon d'attente), que provém da fenomenologia de Husserl e da hermenêutica de Gadamer. Nesta perspectiva, o horizonte é, basicamente, o modo como nos situamos e apreendemos o mundo a partir de um ponto de vista subjectivo; o horizonte de expectativas é uma característica fundamental de todas as situações interpretativas, dizendo respeito a uma espécie de fatalismo que acompanhará qualquer ponto de vista face à visão que temos do mundo: quando interpretamos, possuimos já um conjunto de crenças, de princípios assimilados e ideias aprendidas que limitam desde logo a liberdade total do acto interpretativo; por outras palavras, quando lemos um texto literário, o nosso horizonte de expectativas actua como a nossa memória literária feita de todas as leituras e aquisições culturais realizadas desde sempre. Gadamer chamou à fusão do nosso horizonte individual com o horizonte do outro (texto ou pessoa individualizada) a compreensão (Verstehen). Este processo é conhecido por fusão de horizontes, fusão do horizonte do presente (do intérprete) com o horizonte do passado (inscrito no texto). Hans Robert Jauss, discípulo da hermenêutica de Gadamer, membro da Escola de Constance, e um dos mais inflexíveis dos críticos da estética da recepção, é o grande responsável pela divulgação da expressão nas décadas de 1970 e 1980. No seu ensaio nuclear, "A Literatura como Provocação" (1970), procurou ultrapassar os dogmas marxistas e formalistas que não privilegiam o leitor no acto interpretativo do texto literário e reforçou o conceito de horizonte de expectativas como impulsor da interpretação: "Uma obra não se apresenta nunca, nem mesmo no momento em que aparece, como uma absoluta novidade, num 
vácuo de informação, predispondo antes o seu público para uma forma bem determinada de recepção, através de informações, sinais mais ou menos manifestos, indícios familiares ou referências implícitas. Ela evoca obras já lidas, coloca o leitor numa determinada situação emocional, cria, logo desde o início, expectativas a respeito do 'meio e do fim' da obra que, com o decorrer da leitura, podem ser conservadas ou alteradas, reorientadas ou ainda ironicamente desrespeitadas, segundo determinadas regras de jogo relativamente ao género ou ao tipo de texto." (A Literatura como Provocação, trad. de Teresa Cruz, Veja, Lisboa, 1993, pp.66-67). Qualquer obra de arte literária só será efectiva, só será re-criada ou "concretizada", quando o leitor a legitimar como tal, relegando para plano secundário o trabalho do autor e o próprio texto criado. Para isso, é necessário descobrir qual o horizonte de expectativas que envolve essa obra, pois todos os leitores investem certas expectativas nos textos que lêem em virtude de estarem condicionados por outras leituras já realizadas, sobretudo se pertencerem ao mesmo género literário. $\bigcirc$ melhor indicador para determinarmos o horizonte de expectativas é a recepção da obra por parte do leitor. Uma crítica imediata ao conceito de horizonte de expectativas assim definido consiste no facto de se apresentar como uma espécie de instrumento único de análise estética de uma obra literária."

Ceia (2015, Acesso em: 13 fev. 2016) 20

Estereoscopia Estereoscopia (do grego "stereos", "firme, duro, sólido" + "skope", "ver", "observar") é uma técnica usada para se obter informações do espaço tridimensional, através da análise de duas imagens obtidas em pontos diferentes. É um fenómeno natural que ocorre em muitos animais com dois pontos de visão e também 
no ser humano, quando uma pessoa observa em seu redor uma cena qualquer. $\bigcirc$ facto de o ser humano ter dois olhos permite-lhe, através da estereoscopia ter a noção de profundidade espacial, com o objetivo de por exemplo ter a noção da distância a que se encontram os objetos. A estereoscopia humana é a análise de duas imagens da cena que são projetadas nos olhos em pontos de observação ligeiramente diferentes (distância pupilar), sendo que o cérebro funde as duas imagens no córtex visual, e nesse processo, o indivíduo obtém informações quanto à profundidade, distância, posição e tamanho dos objetos, gerando uma sensação de visão tridimensional.

A estereoscopia é também largamente usada em sistemas de vídeo e de processamento de imagem, para, por exemplo, com um número variado de câmaras de vídeo (duas ou mais), poder o sistema computacional associado calcular a posição 3D, o tamanho ou a velocidade dos objetos. Esta análise computacional é possivel através de processamento de imagem, pois são conhecidas as características intrínsecas das câmaras (distância focal, tipo de lente, etc.), as sua posições 3D no espaço e as suas orientações tridimensionais (vetor 3D em que estão alinhadas).

<https://pt.wikipedia.org/wiki/Estereoscopia> Acesso em: 27 jul. 2017 56

Estética da recepção A Estética da Recepção surge a partir das considerações teóricas realizadas por Hans Robert Jauss (1921-1997) em aula inaugural, em 1967, na Universidade de Constança. Na palestra, com o título de 0 que é e com que fim se estuda a história da literatura? Jauss faz uma crítica à maneira pela qual a teoria literária vem abordando a história da literatura, considerando os métodos 
de ensino, até então, tradicionais e propondo reflexões acerca dos mesmos. A conferência de Jauss é publicada, em 1969, com o título de A história da literatura como provocação à teoria literária, após a ampliação de algumas idéias pelo autor. COSTA (2014, Acessado em 15/06/2016) 14

Ex situ Expressão do latim que significa 'fora do lugar' ou 'fora do local', na tradução literal para a língua portuguesa. 5, 12

Extranet Parte da empresa que é extendida a usuários externos ("rede extra-empresa"), tais como representantes e clientes. Outro uso comum do termo Extranet se dá na designação da "parte privada" de um site, onde somente "usuários registrados" podem navegar, previamente autenticados por sua senha (login) $\underline{V}$. Internet

\section{$\mathbf{F}$}

Facebook Facebook é uma rede social lançada em 4 de fevereiro de 2004, operada e de propriedade privada da Facebook Inc. Em 4 de outubro de 2012, o Facebook atingiu a marca de 1 bilhão de usuários ativos, sendo por isso a maior rede social em todo o mundo. O nome do serviço decorre o nome coloquial para o livro dado aos alunos no início do ano letivo por algumas administrações universitárias nos Estados Unidos para ajudar os alunos a conhecerem uns aos outros. $\bigcirc$ Facebook permite que qualquer usuário que declare ter pelo menos 13 anos possa se tornar usuário registrado do site.

<https://pt.wikipedia.org/wiki/Facebook> Acesso em: 26 jul. 2017 66, $130,133,160$

Fita cassete A fita cassete ou compact cassette é um padrão de fita magnética para gravação de áudio lançado oficialmente em 1963. invenção da empresa holandesa Philips. Também O cassete era constituído basicamente por 2 carretéis, a fita magnética e todo o 
mecanismo de movimento da fita alojados em uma caixa plástica, isto facilitava o manuseio e a utilização permitindo que a fita fosse colocada ou retirada em qualquer ponto da reprodução ou gravação sem a necessidade de ser rebobinada como as fitas de rolo. Com um tamanho de $10 \mathrm{~cm} \times 7 \mathrm{~cm}$, a caixa plástica permitia uma enorme economia de espaço e um excelente manuseio em relação às fitas tradicionais.

O audiocassete ou fita cassete foi uma revolução difundindo tremendamente a possibilidade de se gravar e se reproduzir som. No início, a pequena largura da fita e a velocidade reduzida (para permitir uma duração de pelo menos 30 minutos por lado) comprometiam a qualidade do som, mas recursos tecnológicos foram sendo incorporados ao longo do tempo tornando a qualidade bastante razoável. Recursos como: novas camadas magnéticas (Low Noise, Cromo, Ferro Puro e Metal), cabeças de gravação e reprodução de melhor qualidade nos aparelhos e filtros (Dolby Noise Reduction) para redução de ruídos.

Os primeiros gravadores com áudio cassete da Philips já eram portáteis, mas no final dos anos 70 com a invenção do walkman pela Sony, um reprodutor cassete super compacto de bolso com fones de ouvido, houve a explosão do som individual.

<https://pt.wikipedia.org/wiki/Fita_cassete> Acesso em: 22 jul. 201749

Fluxo de trabalho $\underline{V}$. workflow, 13

Frame rate Cadência (frame rate), em audiovisual, é a medida do número de imagens ou quadros individuais que um determinado dispositivo óptico ou eletrônico processa e exibe por unidade de tempo. Em cinema, cada uma destas imagens é chamada de fotograma, e a cadência é medida em fotogramas por segundo (fps) ou quadros 
por segundo (qps). Em vídeo e demais mídias eletrônicas, as imagens individuais são chamadas de frames, e a medida da cadência é em frames por segundo (fps).

O termo se aplica igualmente em computação gráfica e sistemas de captura de movimento (motion capture). Nestes casos, utiliza-se muitas vezes a unidade Hertz (Hz ou oscilações por segundo), o que é coerente com o Sistema Internacional de Unidades, mas pode provocar confusão com a frequência de transmissão dos sinais eletrônicos necessários para gerar as imagens, que também é medida em Hertz. <https://pt.wikipedia.org/wiki/Cadência_(audiovisual)> Acesso em: 26 jul. 201756

\section{G}

Geração Y A geração Y (também chamada geração do milênio ou geração da internet), é um conceito em Sociologia que se refere, segundo alguns autores, como Don Tapscott, à corte dos nascidos após 1980 e, segundo outros, do início da década de 1980 até meados da década de 1990, sendo sucedida pela geração Z. Essa geração desenvolveu-se numa época de grandes avanços tecnológicos e prosperidade econômica, e facilidade material, e efetivamente, em ambiente altamente urbanizado, imediatamente após a instauração do domínio da virtualidade como sistema de interação social e midiática, e em parte, no nível das relações de trabalho. Se a geração $X$ foi concebida na transição para o novo mundo tecnológico, a geração $Y$ foi a primeira verdadeiramente nascida neste meio, mesmo que incipiente.

<https://pt.wikipedia.org/wiki/Geração_Y> Acesso em: 05 jan. 2018 128 
Google Empresa multinacional de serviços online e software dos Estados Unidos. O Google hospeda e desenvolve uma série de serviços e produtos baseados na internet e gera lucro principalmente através da publicidade pelo AdWords. A Google é a principal subsidiária da recém-criada Alphabet Inc.

<https://pt.wikipedia.org/wiki/Google> Acesso em: 26 jul. 2017 66, 160

H

Heatmap Os mapas de calor permitem que os visualizadores compreendam com mais facilidade a distribuição e a intensidade relativa de pontos de dados em um mapa. Em vez de colocar um marcador em cada localização, os mapas de calor usam cores para representar a distribuição dos dados.

A melhor forma de entender um mapa de calor é pensar em uma tabela ou planilha a qual contém cores ao invés de números, com uma transição correspondente (ou gradiente) entre estes extremos. Os mapas de calor são bastante apropriados para visualizar grandes quantidades de dados multidimensionais e podem ser utilizados para identificar grupos de linhas com valores similares, conforme elas são mostradas nas áreas de cor similar.

<http://datavizproject.com/data-type/heat-map> Acesso em: 25 set. 201788

Hipermídia Reunião de várias mídias num ambiente computacional, suportada por sistemas eletrônicos de comunicação. Hipermídia, diferentemente de multimídia, não é a mera reunião dos meios existentes, e sim a fusão desses meios a partir de elementos não-lineares. Uma forma bastante comum de Hipermídia é o Hipertexto, no qual a informação é apresentada sob a forma de texto interativo. As informações são acessadas pelo monitor de um computador, pela tela de um 
smartphone, entre outros dispositivos. O usuário é capaz de ler de forma não linear, ou seja, ele escolhe entre o início, o meio ou o fim do conteúdo. Segundo Bugay, a Hipermídia pode ser considerada uma extensão do Hipertexto, entretanto, inclui, além de textos comuns, sons, animações e vídeos.

<https://pt.wikipedia.org/wiki/Hipermídia> Acesso em: 26 jul. 201766

HMD A head-mounted display (or helmet-mounted display, for aviation applications), both abbreviated HMD, is a display device, worn on the head or as part of a helmet, that has a small display optic in front of one (monocular HMD) or each eye (binocular HMD). A HMD has many uses including in gaming, aviation, engineering, and medicine. <https://en.wikipedia.org/wiki/Head-mounted_display> Acesso em: 26 jul. $201766,105,160,360$

HTC HTC Corporation is a Taiwanese consumer electronics company headquartered in Xindian District, New Taipei City, Taiwan. Founded in 1997. HTC began as an original design manufacturer and original equipment manufacturer, designing and manufacturing devices such as mobile phones and tablets.

After initially making smartphones based mostly on Windows Mobile, HTC became a co-founding member of the Open Handset Alliance, a group of handset manufacturers and mobile network operators dedicated to the development of the Android mobile operating system. (5) The HTC Dream, marketed by T-Mobile in many countries as the T-Mobile G1, was the first phone on the market to run Android. HTC later shifted to marketing its own devices, including the HTC One series. In 2011, HTC ranked as the 98th top brand on Interbrand's Best Global Brands report. A September 2013 media report stated that HTC's share of the global smartphone market is less than 3 percent. 
While rising back to 7.2 percent in April 2015 due to its strong sales of recent devices, its stock price had fallen by 90 percent since 2011 , and the company experienced consecutive net losses. In 2016, HTC expanded into virtual reality hardware with the release of HTC Vive. <https://en.wikipedia.org/wiki/HTC> Acesso em: 26 jul. 2017 66, 160

HTC Vive Virtual reality headset developed by HTC and Valve Corporation. The headset uses "room scale" tracking technology, allowing the user to move in 3D space and use motion-tracked handheld controllers to interact with the environment with precision.

The HTC Vive was unveiled during HTC's Mobile World Congress keynote in March 2015. Development kits were sent out in August and September 2015, and the first Consumer version of the device was released on April 5th, 2016.

<https://en.wikipedia.org/wiki/HTC_Vive> Acesso em: 26 jul. 201766, 160

Hypertext Markup Language Linguagem de marcação utilizada para produzir páginas na Web. Documentos HTML podem ser interpretados

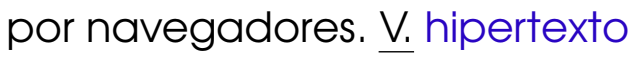

IBRAM O Instituto Brasileiro de Museus (IBRAM) é uma autarquia federal, dotada de personalidade jurídica de direito público, com autonomia administrativa e financeira, vinculada ao Ministério da Cultura. Possui sede e foro em Brasília e conta com uma representação no Rio de Janeiro, podendo estabelecer escritórios ou dependências em outras unidades da federação. Foi criado a partir da Lei no. 11.906, sancionada pelo ex-Presidente da República Luiz Inácio Lula da Silva em 20 de janeiro de 2009, que desmembrou do Instituto do Patrimônio Histórico e Artístico Nacional a Diretoria de Museus e as Unidades Mu- 
seológicas. O Instituto Brasileiro de Museus é o órgão responsável por desenvolver e aplicar a Política Nacional de Museus, bem como pela melhoria dos serviços do setor, tendo como objetivos, por exemplo, o aumento de visitação e arrecadação dos museus, o fomento de políticas de aquisição e preservação de acervos e a criação de ações integradas entre os museus brasileiros. O instituto também é responsável pela manutenção dos museus e casas históricas federais. <https://eu.oheuaqui.com/2CYqy08> Acesso em: 10 jan. 2018 92, 94

ICOM O International Council of Museums (ICOM - Conselho Internacional de Museus), criado em 1946, é uma organização não-governamental internacional, sem fins lucrativos, que se dedica a elaborar políticas internacionais para os museus. Possui mais de 27000 membros de 150 países, 114 Comitês Nacionais e 30 Comitês Internacionais.

Suas principais atividades são:

- Cooperação e intercâmbio profissional

- Difusão de conhecimentos e aumento da participação do público em museus

- Formação de pessoal

- Prática e promoção de ética profissional

- Atualização de padrões profissionais

- Preservação do patrimônio mundial e combate ao tráfico de bens culturais

<https://eu.oheuaqui.com/2mdhSIM> Acesso em: 29 ago. 201785

IMU An inertial measurement unit (IMU) is an electronic device that measures and reports a body's specific force, angular rate, and sometimes the magnetic field surrounding the body, using a combination of accelerometers and gyroscopes, sometimes also magnetometers. IMUs are typically used to maneuver aircraft, including unmanned 
aerial vehicles (UAVs), among many others, and spacecraft, including satellites and landers. Recent developments allow for the production of IMU-enabled GPS devices. An IMU allows a GPS receiver to work when GPS-signals are unavailable, such as in tunnels, inside buildings, or when electronic interference is present.

<http://eu.oheuaqui.com/2xhCMev> Acesso em: 25 jul. 201757

In situ Expressão do latim que significa "no lugar" ou "no local", na tradução literal para a língua portuguesa. Pode ser utilizada em dezenas de áreas do conhecimento, quase sempre assumindo a ideia de "local", "situação" ou "posição". 5, 12

In loco As expressões in situ e in loco são tidas como sinônimos. In loco também pode ser traduzida como "no lugar" ou "no próprio local". V. in situ

Instagram Rede social online de compartilhamento de foto e vídeo que permite aos seus usuários tirar fotos e vídeos, aplicar filtros digitais e compartilhá-los em uma variedade de serviços de redes sociais, como Facebook, Twitter, Tumblr e Flickr. Uma característica distintiva é que ela limita as fotos para uma forma quadrada, semelhante ao Kodak Instamatic e de câmeras Polaroid, em contraste com a relação a proporção de tela de 16:9 agora tipicamente usado por câmeras de dispositivos móveis. Os usuários também são capazes de gravar e compartilhar vídeos curtos com duração de até 15 segundos. Instagram foi criado por Kevin Systrom e Mike Krieger e lançado em outubro de 2010. O serviço rapidamente ganhou popularidade: estimativas não-oficiais afirmam existir aproximadamente 100 milhões de usuários ativos (abril de 2012).

<http://pt.wikipedia.org/wiki/Instagram> Acesso em: 20 mai. 201432 , 127,130 
Internet Rede de área alargada que é uma confederação de redes de computadores das universidades e de centros de pesquisa, do Governo, militares e comerciais, com base no protocolo TCP/IP. Proporciona acesso a sítios Web, correio eletrônico, sistemas de boletins eletrônicos, bases de dados, grupos de discussão, conteúdo multimeios etc. 20,33

\section{Internet-das-coisas $\underline{\mathrm{V}}$. loT}

Intranet Sistema parecido com a Internet, porém restrito aos funcionários de uma empresa $\underline{V}$. Internet

IoT A loT é definida como uma infraestrutura de rede global que interconecta objetos, física e virtualmente, com o objetivo de compartilhar dados e informações para concluir determinadas tarefas. Essa infraestrutura inclui e envolve a Internet e as redes de comunicação, necessitando de identificação única de objetos, sensores e capacidade de conexão, como base para o desenvolvimento independente de serviços e aplicações. Ela é caracterizada pelo alto grau de captura autônoma de dados, transferência de eventos de rede, conectividade e interoperabilidade. , compartilhem dados e informações para concluir determinadas tarefas. A base para o funcionamento da loT são sensores e dispositivos, que tornam a comunicação entre as "coisas" possivel. Além disso, é preciso um sistema de computação para analisar os dados recebidos e gerenciar as ações de cada objeto conectado a essa rede. Casagras (2011, p. 10)

Humans in modern times live in a highly connected world, and in 2015 more individuals were becoming aware of the Internet of Things (loT) a vast network of physical objects with embedded microchips, sensors, and communications capabilities that link people, machines, and entire systems through the Internet. Networking firm Cisco Systems, 
which is credited with having coined the term Internet of Things, estimated in 2011 that 50 billion connected devices will exist by 2020 but that more than 99

<https://eu.oheuaqui.com/2mfvCme> Acesso em: 25 set. 2017 62, 79

J

Jaron Lanier Jaron Zepel Lanier, norte-americano, nascido em 3 de maio de 1960, é um filósofo, escritor, cientista e artista visual ligado à ciência da computação. Pioneiro no campo da realidade virtual, deixou a atari em 1985. Criou, juntamente com thomas-zimmerman, a primeira empresa a comercializar luvas e óculos de realidade virtual.

<https://en.wikipedia.org/wiki/Jaron_Lanier> Acesso em: 22 jul. $2017 \underline{\text { V. }}$ VPL, 66, 160

K

Kik Messenger Kik Messenger, commonly called Kik, is a freeware instant messaging mobile app from the Canadian company Kik Interactive, available free of charge on iOS, Android, and Windows Phone operating systems. It uses a smartphone's data plan or Wi-Fi to transmit and receive messages, photos, videos, sketches, mobile webpages, and other content after users register a username. Kik is known for its features preserving users' anonymity, such as allowing users to register without providing a telephone number. The application logs user IP addresses which the company can use to determine location. As of May 2016, Kik Messenger had approximately 300 million registered users, and was used by approximately 40 <https://pt.wikipedia.org/wiki/Kik_Messenger> Acesso em: 24 ago. 2017 
KPI Indicadores-chave de desempenho (em inglês Key Performance Indicator, KPI, ou Key Success Indicator, KSI), são ferramentas de gestão para se realizar a medição e o consequente nível de desempenho e sucesso de uma organização ou de um determinado processo, focando no "como" e indicando quão bem os processos dessa empresa estão, permitindo que seus objetivos sejam alcançados. Existem diferentes categorias de indicadores, que podem ser indicadores quantitativos, indicadores qualitativos, principais indicadores, indicadores de atraso, indicadores de entrada, indicadores de processo, indicadores direcionais, indicadores acionáveis e indicadores financeiros. KPIs são "veículos de comunicação", pois permitem que o corpo de gestores de uma organização comuniquem aos seus liderados o quão eficiente um processo é e como está seu desempenho ao longo de um período determinado. De posse dessas informações, cabe ao gestor e equipe traçarem planos de ação para o atingimento de determinadas metas ou até mesmo valer-se dos KPIs para saberem se estão ou não no caminho certo. O passo mais difícil na construção de um KPI talvez seja a definição da meta que se deseja alcançar. Isso porque o executivo precisa saber exatamente onde quer chegar e o que é relevante ao seu processo. Por exemplo, um executivo de vendas não precisa controlar todos os indicadores da área de gestão de recursos humanos pois estaria gastando parte de seu tempo e energia em algo que não é o que gera valor à sua função. Isso pode parecer meio óbvio, mas um grande erro das organizações como um todo é o emprego de tempo e esforço em atividades que não são relevantes.

<https://eu. oheuaqui.com/2CWdOHj> Acesso em: 07 jan. 2018 134, 135,136 
$\mathbf{L}$

Linden Lab Linden Research, Inc., d/b/a Linden Lab, is a privately held American Internet company that is best known as the creator of Second Life.

<https://en.wikipedia.org/wiki/Linden_Lab> Acesso em: 26 jul. 2017 66, 160

Linkedln Linkedln is a business - and employment-oriented social networking service that operates via websites and mobile apps. Founded on December 28, 2002, and launched on May 5, 2003, it is mainly used for professional networking, including employers posting jobs and job seekers posting their CVs. As of 2015, most of the company's revenue came from selling access to information about its members to recruiters and sales professionals. As of April 2017, Linkedln had 500 million members in 200 countries, out of which more than 106 million members are active. Linkedln allows members (both workers and employers) to create profiles and "connections" to each other in an online social network which may represent real-world professional relationships. Members can invite anyone (whether an existing member or not) to become a connection. The "gated-access approach" (where contact with any professional requires either an existing relationship or an introduction through a contact of theirs) is intended to build trust among the service's members.

<https://en.wikipedia.org/wiki/Linkedln> Acesso em: 06 jan. 2018130

\section{M}

Magic Leap A US startup company that is working on a head-mounted virtual retinal display which superimposes 3D computer-generated imagery over real world objects, by projecting a digital light field into the user's eye, involving technologies potentially suited to applications 
in augmented reality and computer vision. It is attempting to construct a light-field chip using silicon photonics.

Magic Leap was founded by Rony Abovitz in 2010 and has raised 1.4 billion dollars from a list of investors including Google and China's Alibaba Group. In December 2016 Forbes estimated that Magic Leap was worth 4.5 billion dollars. As of June 2017, the company has not released a product to the market.

<https://en.wikipedia.org/wiki/Magic_Leap> Acesso em: 26 jul. 2017 66,160

\section{Mapa-de-calor $V_{\text {. heatmap }}$}

Mega Drive The Sega Genesis, known as the Mega Drive in most regions outside of North America, is a 16-bit home video game console which was developed and sold by Sega Enterprises, Ltd. The Genesis was Sega's third console and the successor to the Master System. Sega first released the console as the Mega Drive in Japan in 1988, followed by a North American debut under the Genesis moniker in 1989. In 1990 , the console was distributed as the Mega Drive by Virgin Mastertronic in Europe, by Ozisoft in Australasia, and by Tectoy in Brazil. In South Korea, the systems were distributed by Samsung and were known as the Super Gam*Boy, and later the Super Aladdin Boy. <https://en.wikipedia.org/wiki/Sega_Genesis> Acesso em: 25 jul. 2017 66

Metadados Metadados, ou Metainformação, são dados sobre outros dados. Um item de um metadado pode dizer do que se trata aquele dado, geralmente uma informação inteligível por um computador. Os metadados facilitam o entendimento das conexões e relações e a utilidade das informações dos dados. 
<http://pt.wikipedia.org/wiki/Metadados> Acesso em: 20 mai. 2014 $17,48,110,115,124$

Metadata Metadata is data that gives information about other data. Descriptive metadata is information to help discover and identify a resource. Structural metadata describes the different parts of a resource (for example, title or abstract). Administrative metadata provides the information that helps to manage a resource, such as when and how it was created. There are a variety of metadata schemes and element sets that define what metadata should be included for different types of resources, these vary by discipline and environments. $\underline{V}$. metadados, 17

Microsoft Empresa transnacional norte-americana com sede em Redmond, Washington, que desenvolve, fabrica, licencia, apoia e vende softwares de computador, produtos eletrônicos, computadores e serviços pessoais. Entre seus produtos de software mais conhecidos estão as linhas de sistemas operacionais Windows, a linha de aplicativos para escritório Office e o navegador Internet Explorer. Entre seus principais produtos de hardware estão os consoles de videogame Xbox, a série de tablets Surface e os Smartphones Microsoft Lumia, antiga Nokia. É a maior produtora de softwares do mundo por faturamento, e uma das empresas mais valiosas do mundo. <https://pt.wikipedia.org/wiki/Microsoft> Acesso em: 26 jul. 2017 66, 160

MIT Instituto de Tecnologia de Massachusetts (em inglês: Massachusetts Institute of Technology - MIT) é uma universidade privada de pesquisa localizada em Cambridge, Massachusetts, Estados Unidos. Fundada em 1861, em resposta à crescente industrialização dos Estados Unidos, o MIT adotou um modelo europeu universidade politécnica e salien- 
tou a instrução laboratorial em ciência aplicada e engenharia. Os pesquisadores trabalharam em computadores, radares e em sistemas de navegação inercial durante a Segunda Guerra Mundial e da Guerra Fria. A pesquisa de defesa pós-guerra contribuiu para a rápida expansão do corpo docente e do campus sob o comando de James Killian. O atual campus de 68 hectares foi inaugurado em 1916 e se estende por 1,6 quilômetro ao longo da margem norte da bacia do rio Charles. O MIT, com cinco escolas e uma faculdade que contêm um total de 32 departamentos, é frequentemente citado como entre as melhores universidades do mundo.

<https://eu.oheuaqui.com/2CYEgQK> Acesso em: 26 jul. 2017 66, 160

Myron Krueger Myron Krueger (born 1942 in Gary, Indiana) is an American computer artist who developed early interactive works. He is also considered to be one of the first generation virtual reality and augmented reality researchers.

<https://en.wikipedia.org/wiki/Myron_W._Krueger> Acesso em: 26 jul. 201766,160

\section{N}

NFC Comunicação por Campo de Proximidade, Near Field Communication ou NFC é uma tecnologia que permite a troca de informações sem fio e de forma segura entre dispositivos compativeis que estejam próximos um do outro. Ou seja, logo que os dispositivos estejam suficientemente próximos, a comunicação é estabelecida automaticamente, sem a necessidade de configurações adicionais. Estes dispositivos podem ser telefones celulares, tablets, crachás, cartões de bilhetes eletrônicos e qualquer outro dispositivo que tenha um chip NFC. 
<https://pt.wikipedia.org/wiki/Near_Field_Communication> Acesso em: 10 out. 201764

Nintendo Nintendo Co., Ltd.(a) is a Japanese multinational consumer electronics and video game company headquartered in Kyoto, Japan. Nintendo is one of the world's largest video game companies by market capitalization. (3) Founded on 23 September 1889(4) by Fusajiro Yamauchi, it originally produced handmade hanafuda playing cards. (5) By 1963, the company had tried several small niche businesses, such as cab services and love hotels. (6) The word Nintendo can be roughly translated from Japanese to English as "leave luck to heaven".(7) The company has created and released some of the best-known and top-selling video game franchises, such as Mario, The Legend of Zelda, and Pokémon.

<https://en.wikipedia.org/wiki/Nintendo> Acesso em: 26 jul. 201766 , 160

Não-linear Não linear refere-se a todas as estruturas que não apresentam um único sentido. Estrutura que apresenta múltiplos caminhos e destinos, desencadeando em múltiplos finais. Em Teoria Geral dos Sistemas diz-se que a não-linearidade é pressuposto de Sistemas Complexos e sua intricada rede leva a caminhos distintos e inimagináveis até mesmo para os criadores do sistema. Isto ocorre devido às interações entre dados e conexões que se tornam cada vez mais complexas, e estas geram realimentações que, por sua vez, realimentam o sistema tornando-o autorregulador. Em hipermídia, a não-linearidade é pressuposto fundamental do hipertexto.

<https://pt.wikipedia.org/wiki/Não_linearidade> Acesso em: 22 jul. 2017 V. acesso aleatório, 49, 82 
OCR Acrônimo para o inglês Optical Character Recognition, é uma tecnologia para reconhecer caracteres a partir de um arquivo de imagem ou mapa de bits sejam eles escaneados, escritos à mão, datilografados ou impressos. Dessa forma, através do OCR, é possivel obter um arquivo de texto editável por um computador.

<https://en.wikipedia.org/wiki/Optical_character_recognition> Acesso em: 10 dez. 2017, 104

Oculus Oculus VR is an American technology company founded by Palmer Luckey in June 2012 in Irvine, California, now based in Menlo Park. It specializes in virtual reality hardware and software products.

In March 2014, Facebook, Inc. CEO Mark Zuckerberg agreed to acquire Oculus VR for 2.3 billion dollars in cash and stock. In 2015, Oculus VR acquired Surreal Vision, a British startup focused on 3D reconstruction and mixed reality, stating that it could be possible for Oculus VR to develop products with the concept of telepresence.

<https://en.wikipedia.org/wiki/Oculus_VR> Acesso em: 26 jul. 2017 V. Oculus Rift, 66, 160

Oculus Rift Equipamento de realidade virtual para jogos eletrônicos, desenvolvido e fabricado pela Oculus. Basicamente, é um sistema visual do tipo Head Mounted Display, ou óculos/capacete de realidade virtual (HMD). O projeto está sendo desenvolvido pela Oculus VR que conseguiu 91 milhões de dólares de investidores, sendo que 2,4 miIhões de dólares foram levantados pelo site Kickstarter. A companhia foi fundada por Palmer Luckey e os coofundadores da Scaleform Brendan Iribe, Michael Antonov e Nate Mitchell. Depois o coofundador da Id Software John Carmack foi contratado como Diretor Técnico.

No dia 25 de março de 2014, a empresa foi comprada pela Facebook, 
Inc., tendo anunciado que manteriam o foco em desenvolver o mesmo tipo de produtos.

<https://pt.wikipedia.org/wiki/Oculus_Rift> Acesso em: 26 jul. 2017 66, 160

Omnichannel Omnichannel é uma tendência do varejo que se baseia na convergência de todos os canais utilizados por uma empresa. Trata-se da possibilidade de fazer com que o consumidor não veja diferença entre o mundo online e o offline. O omnichannel integra lojas físicas, virtuais e compradores. Dessa maneira, pode explorar todas as possibilidades de interação. Essa tendência é uma evolução do conceito de multicanal, pois é completamente focada na experiência do consumidor nos canais existentes de uma determinada marca. Como exemplo, há os aplicativos móveis, que combinam o layout do site com a temática interna das lojas físicas. De forma prática, isso propicia ao consumidor utilizar todos os canais disponibilizados pela organização e a quebra das barreiras entre o mundo físico e o digital. <http://eu.oheuaqui.com/2zkt|GA> Acesso em: 10 jan. 2018 97, 98

OpenGLAM OpenGLAM (Galleries, Libraries, Archives and Museum) is an initiative coordinated by Open Knowledge that is committed to building a global cultural commons for everyone to use, access and enjoy. OpenGLAM helps cultural institutions to open up their content and data through hands-on workshops, documentation and guidance and it supports a network of open culture evangelists through its Working Group.

<https://openglam.org/faq> Acesso em: 10 nov. 2017122

Open Science $\underline{V}_{\text {. Ciência Aberta }}$

Open source $\underline{V}$. código aberto 
Pixel Pixel ou píxel (sendo o plural pixels ou píxeis) (aglutinação de picture e element, ou seja, elemento de imagem, sendo pix a abreviatura em inglês para pictures) é o menor elemento em um dispositivo de exibição (por exemplo, um monitor), ao qual é possivel atribuir-se uma cor. De uma forma mais simples, um pixel é o menor ponto que forma uma imagem digital, sendo que o conjunto de pixels formam a imagem inteira. Em um monitor colorido, cada pixel é composto por um conjunto de 3 pontos: verde, vermelho e azul. Nos melhores monitores, cada um desses pontos é capaz de exibir 256 tonalidades diferentes (o equivalente a 8 bits) e combinando tonalidades dos três pontos é então possivel exibir pouco mais de 16.7 milhões de cores diferentes (exatamente 16.777.216). Em resolução de $640 \times 480$ temos 307.200 pixels, a 800 x 600 temos 480.000 pixels, a 1024 x 768 temos 786.432 pixels e assim por diante.

<https://pt.wikipedia.org/wiki/Pixel> Acesso em: 10 nov. 2017107

PlayStation PlayStation é uma série de consoles de videogame criada e desenvolvida pela Sony Computer Entertainment, abrangendo a quinta, sexta, sétima e oitava gerações de videogames. A marca foi lançada pela primeira vez em 3 de dezembro de 1994 no Japão. Dispõe de um total de seis consoles - sendo dois deles portáteis - um centro de mídia, um serviço on-line, uma linha de controladores e um palmtop, bem como diversas revistas especializadas.

<https://pt. wikipedia.org/wiki/PlayStation> Acesso em: 26 jul. 2017 V. Sony, 66, 160

PlayStation VR PlayStation VR, known by the codename Project Morpheus during development, is a virtual reality headset developed by Sony Interactive Entertainment, which launched on October 13, 2016. 
<https://en.wikipedia.org/wiki/PlayStation_VR> Acesso em: 26 jul. 2017 V. Sony, 66, 160

Podcasting Podcasting é uma forma de publicação de arquivos de mídia digital (áudio, vídeo, foto, etc.) pela Internet, através de um feed RSS, que permite aos utilizadores acompanhar a sua atualização. Com isso, é possivel o acompanhamento e/ou download automático do conteúdo.

A palavra "podcasting" é uma junção de iPod (marca do aparelho de midia digital da Apple Inc. de onde saíram os primeiros scripts de podcasting) ou a sigla para Personal On Demand (numa tradução literal, algo pessoal e sob demanda), e broadcasting (transmissão de rádio ou televisão). A série de arquivos publicados por podcasting é chamada de podcast. O autor de um podcast é chamado podcaster.

<https://pt. wikipedia.org/wiki/Podcasting> Acesso em: 22 jul. 201750

Projeto CHESS CHESS (Cultural Heritage Experiences through Socio-personal interactions and Storytelling) is a project, co-funded by the European Commission, that aims to integrate interdisciplinary research in personalization and adaptivity, digital storytelling, interaction methodologies, and narrative-oriented mobile and mixed reality technologies, with a sound theoretical basis in museological, cognitive, and learning sciences.

The principal objective of CHESS is to research, implement and evaluate both the experiencing of personalized interactive stories for visitors of cultural sites and their authoring by the cultural content experts. <http://www.chessexperience.eu/> Acesso em: 03 ago. 201781

$Q$

QR Code $\underline{\text {. }}$ código QR 
QuickTime VR QuickTime VR (also known as QuickTime Virtual Reality or QTVR) was an image file format developed by Apple Inc. for QuickTime. It allowed the creation and viewing of photographically-captured panoramas and the exploration of objects through images taken at multiple viewing angles. It functioned as a plugin for the standalone QuickTime Player, as well as working as a plugin for the QuickTime Web browser plugin.

<https://en.wikipedia.org/wiki/QuickTime_VR> Acesso em: 26 jul. 2017 V. Apple, 66, 160

\section{$\mathbf{R}$}

Realidade aumentada La realidad aumentada (RA) es el término que se usa para definir la visión de un entorno físico del mundo real, a través de un dispositivo tecnológico, es decir, los elementos físicos tangibles se combinan con elementos virtuales, logrando de esta manera crear una realidad aumentada en tiempo real. Consiste en un conjunto de dispositivos que añaden información virtual a la información física ya existente, es decir, añadir una parte sintética virtual a la real. La realidad aumentada es diferente de la realidad virtual porque sobre la realidad material "del mundo físico" monta una realidad visual generada por la tecnología, en la que el usuario percibe una mezcla de las dos realidades, en cambio en la realidad virtual el usuario se aísla de la realidad material del mundo físico para "sumergirse" en un escenario o entorno totalmente virtual.

<https://es.wikipedia.org/wiki/Realidad_aumentada> Acesso em: 08 ago. $201758,65,81,82$

Regras de Negócio Regras de Negócio são declarações sobre a forma da empresa fazer negócio. Elas refletem políticas do negócio. As organizações com isto têm políticas para satisfazer os objetivos do 
negócio, satisfazer clientes, fazer bom uso dos recursos, e obedecer às leis ou convenções gerais do negócio. Regras do Negócio tornam-se requisitos, ou seja, podem ser implementados em um sistema de software como uma forma de requisitos de software desse sistema. Representam um importante conceito dentro do processo de definição de requisitos para sistemas de informação e devem ser vistas como uma declaração genérica sobre a organização. As regras de negócio definem como o seu negócio funciona, podem abranger diversos assuntos como suas políticas, interesses, objetivos, compromissos éticos e sociais, obrigações contratuais, decisões estratégicas, leis e regulamentações entre outros.

<https://pt.wikipedia.org/wiki/Regras_de_negócio> Acesso em: 04 jan. 2018117

Resolução Resolução de imagem descreve o nível de detalhe que uma imagem comporta. O termo se aplica igualmente a imagens digitais, imagens em filme e outros tipos de imagem. Resoluções mais altas significam mais detalhes na imagem. A resolução de imagem pode ser medida de várias formas. Basicamente, a resolução quantifica quão próximas as linhas podem ficar umas das outras e ainda assim serem visivelmente determinadas. As unidades de resolução podem ser ligadas a tamanhos físicos (por exemplo, linhas por $\mathrm{mm}$, linhas por polegada etc.) ou ao tamanho total de uma figura (linhas por altura da imagem, também conhecidas simplesmente por linhas ou linhas de televisão). Ademais, pares de linhas são usados frequentemente em vez de linhas individuais. Um par de linhas é constituído de uma linha apagada e uma linha acesa adjacentes, enquanto "linhas" contam ambas as linhas apagadas e acesas. Uma resolução de dez linhas por mm significa cinco linhas apagadas alternando com cinco 
linhas acesas, ou cinco pares de linhas por $\mathrm{mm}$. As resoluções de lentes fotográficas e filmes são mais frequentemente citadas como pares de linhas por $\mathrm{mm}$.

<https://pt.wikipedia.org/wiki/Resolução_de_imagem> Acesso em: 10 nov. 2017105

RFID RFID é uma sigla que vem do inglês e significa Radio Frequency Identification (Identificação por Radiofrequência). Trata-se de um sistema de captura de dados que utiliza o sinal, frequência, de rádio para realizar tal tarefa. Apesar de ser considerada uma tecnologia nova que surgiu na década de 80 quando o MIT iniciou estudos na criação de tecnologias baseadas em ondas de rádio e que servissem de referência ao desenvolvimento de novas aplicações de rastreamento e localização de produtos, um dos primeiros sistemas passivos de RFID surgiu durante a Segunda Guerra Mundial quando os aviões eram detectados à longa distância por radares, porém não se sabia se eram aeronaves amigas ou inimigas. Os alemães então descobriram que se seus pilotos girassem o avião enquanto retornassem à base, eles modificariam o sinal que seria refletido de volta aos radares. Isso os identificava como pilotos alemães. Mais tarde, os ingleses, sob o comando de Watson-Watt, projetaram o primeiro identificador ativo. Um transmissor era colocado em cada avião britânico e estes quando recebiam sinais das estações de radar no solo, transmitiam de volta um sinal de resposta, que identificava a aeronave como amiga. Nos RFIDs o princípio é o mesmo. Um sinal é enviado a um transponder, que é ativado e reflete de volta o sinal(passivo) ou transmite seu próprio sinal (ativo). A partir de então estudos e pesquisas na área de radiofrequência começaram a ser realizados e mostraram como essa energia poderia ser utilizada 
para identificar objetos remotamente. Começou assim o uso dessa nova tecnologia para identificar objetos em movimento. Isso foi uma vantagem em relação ao sistema de código de barra que necessita do objeto parado e de um leitor a laser. Utilizando um método de etiquetas (tags) inteligentes (etiquetas eletrônicas com um microchip instalado) que são postas nos objetos, estes passaram a ser rastreados por ondas de rádio através de uma resistência de metal ou carbono que funciona com antena, trocando informações com o sistema (computador) através de seus EPCs (Eletronic Product Code) ou Código Eletrônico do Produto. O RFID designa qualquer sistema que usa radiofrequência como método de identificação, porém o mais comum é o que utiliza microchip para armazenar a informação desejada.

<http://eu.oheuaqui.com/2xuoTJ5> Acesso em: 10 out. 201764

\section{S}

Samsung Corporação transnacional que atua em diversos ramos da área de tecnologia da informação com sede em Seul, Coreia do Sul. Em 2015, o faturamento da Samsung foi de USD 177,365 bilhões, correspondente a 12,6

<https://pt.wikipedia.org/wiki/Samsung> Acesso em: 26 jul. 2017 66, 160

Scanner Dispositivo de entrada que permite enviar qualquer imagem ou texto em papel para o computador, podendo ser impresso ou modificado posteriormente. 104, 105

Second Life O Second Life (também abreviado por SL(1)) é um ambiente virtual e tridimensional que simula em alguns aspectos a vida real $e$ social do ser humano. Foi criado em 1999 e desenvolvido em 2003 e é mantido pela empresa Linden Lab. Dependendo do tipo de uso, 
pode ser encarado como um jogo, um mero simulador, um comércio virtual ou uma rede social. O nome "second life" significa em inglês "segunda vida", que pode ser interpretado como uma vida paralela, uma segunda vida além vida "principal", "real". Dentro do próprio jogo, o jargão utilizado para se referir à "primeira vida", ou seja, à vida real da t’pessoa, é "RL" ou "Real Life" que se traduz literalmente por "vida real".

<https://pt.wikipedia.org/wiki/Second_Life> Acesso em: 26 jul. $2017 \underline{\text { V. }}$ Linden Lab, 66, 160

Sega Empresa desenvolvedora de software para videogames, e uma antiga produtora de consoles. A companhia tem tido sucesso tanto no mercado de arcades quanto no de consoles caseiros, apesar de estar fora desse último setor desde 2001.

<https://pt.wikipedia.org/wiki/Sega> Acesso em: 25 jul. 2017 66, 160

Selfie A selfie is a self-portrait photograph, typically taken with a digital camera or camera phone held in the hand or supported by a selfie stick. Selfies are often shared on social networking services such as Facebook, Instagram and Twitter. They are usually flattering and made to appear casual. Most selfies are taken with a camera held at arm's length or pointed at a mirror, rather than by using a self-timer. A selfie stick may be used to widen the angle of view, such as for group selfies. <https://en.wikipedia.org/wiki/Selfie> Acesso em: 18 fev. 2015 32,127

Sensorama The Sensorama was a machine that is one of the earliest known examples of immersive, multi-sensory (now known as multimodal) technology. Along with five short films for it to display. It still functions today. 
<https://en.wikipedia.org/wiki/Sensorama> Acesso em: 25 jul. $2017 \underline{\text { V. }}$ $3 D, 66,160$

Sistema de Gerenciamento de Conteúdo Gerenciador para websites, portais e intranets, cujo objetivo é estruturar e facilitar a criação, administração, distribuição, publicação e disponibilidade da informação 114 ,

Smartphone Um smartphone (palavra inglesa que significa "telefone inteligente", ainda sem correspondente em português) é um telemóvel (celular, no Brasil) que combina recursos de computadores pessoais, com funcionalidades avançadas que podem ser estendidas por meio de programas aplicativos executados por seu sistema operacional (SO, ou OS - operating system), chamados simplesmente aplicativos ou apps (diminutivo de "applications"). Os sistemas operacionais dos smartphones permitem que desenvolvedores criem milhares de programas adicionais, com diversas utilidades, agregados em lojas online como o Google Play para Android, MS Windows Store para Windows Phone e a Apple App Store para iOS.

Geralmente, um smartphone pode possuir características mínimas de hardware e software, sendo as principais a capacidade de conexão com redes de dados para acesso à internet, a capacidade de sincronização dos dados do organizador com um computador pessoal, e uma agenda de contatos que pode utilizar toda a memória disponivel do celular, que pode ser interna (de origem), ou externa (expansivel, dependendo da capacidade do cartão de memória usado), o formato comum de cartão de memória em um smartphone é o microSD.

<https://pt.wikipedia.org/wiki/Smartphone> Acesso em: 25 jul. 201756 
Smithsonian Institution Instituto Smithsoniano (em inglês: Smithsonian Institution) é uma instituição educacional e de pesquisa associada a um complexo de museus, fundada e administrada pelo governo dos Estados Unidos. Com grande parte de seus prédios localizados em Washington, D.C., o instituto compreende 19 museus e sete centros de pesquisa, e tem 142 milhões de itens em suas coleções. <https://pt.wikipedia.org/wiki/Smithsonian_Institution> Acesso em: 14 dez. 2017112

Snapchat Snapchat é um aplicativo de mensagens com base de imagens, criado e desenvolvido por Evan Spiegel, Bobby Murphy e Reggie Brown, estudantes da Universidade Stanford. Com o aplicativo, usuários podem tirar fotos, gravar videos, adicionar textos e desenhos à imagem e escolher o tempo que a imagem ficará no visor do amigo de sua lista. Com a nova atualização é possível iniciar uma conversa com texto ou vídeo com seus amigos, mesmo sem ativar sua câmera para conversar. $\bigcirc$ tempo de cada snap é de 1 a 10 segundos, e após aberto, a imagem ou vídeo somente poderá ser vista pelo tempo escolhido pelo remetente. A imagem é excluída do dispositivo e também dos servidores. Também é possivel adicionar filtros nas fotos, salvar as fotos tiradas no app no computador e anexar arquivos ao bate-papo dentro do Snapchat.

<https://pt.wikipedia.org/wiki/Snapchat> Acesso em: 24 ago. 201755, 130

Sony Sony Corporation is a Japanese multinational conglomerate corporation headquartered in Tokyo. Its diversified business includes consumer and professional electronics, gaming, entertainment, and financial services The company is one of the leading manufacturers of electronic products for the consumer and professional markets Sony was 
ranked 113th on the 2016 list of Fortune Global 500.

Sony Corporation is the electronics business unit and the parent company of the Sony Group, which is engaged in business through its four operating components: electronics (AV, IT and communication products, semiconductors, video games, network services and medical business), motion pictures (movies and TV shows), music (record labels and music publishing) and financial services (banking and insurance). These make Sony one of the most comprehensive entertainment companies in the world. The group consists of Sony Corporation, Sony Pictures, Sony Interactive Entertainment, Sony Music, Sony Financial Holdings and others.

<https://en.wikipedia.org/wiki/Sony> Acesso em: 26 jul. 2017 66, 160

Sourcecode $\underline{V}$. código-fonte

Street View Google Street View é um recurso do Google Maps e do Google Earth que disponibiliza vistas panorâmicas de 360r̆ na horizontal e 290r na vertical e permite que os usuários (utilizadores) vejam partes de algumas regiões do mundo ao nível do chão/solo. Quando foi lançado, em 25 de maio de 2007, apenas cinco cidades americanas haviam sido incluídas. Desde então já se expandiu para milhares de localizações em alguns países como Estados Unidos, França, Austrália, Japão, Portugal e Brasil.

<https://pt.wikipedia.org/wiki/Google_Street_View> Acesso em: 26 jul. 2017 V. Google, 66, 160

\section{T}

Tecnologia Do grego tekne (técnica, arte, ofício) e logos (estudo), é um termo que envolve o conhecimento técnico e científico e a aplicação deste conhecimento através de sua transformação no uso de ferramentas, processos e materiais criados e/ou utilizados a partir 
de tal conhecimento.

Dependendo do contexto, a tecnologia pode ser:

As ferramentas e as máquinas que ajudam a resolver problemas;

As técnicas, conhecimentos, métodos, materiais, ferramentas e processos usados para resolver problemas ou ao menos facilitar a solução dos mesmos;

Um método ou processo de construção e trabalho (tal como a tecnologia de manufatura, a tecnologia de infraestrutura ou a tecnologia espacial);

A aplicação de recursos para a resolução de problemas;

O termo tecnologia também pode ser usado para descrever o nível de conhecimento científico, matemático e técnico de uma determinada cultura;

Na economia, a tecnologia é o estado atual de nosso conhecimento de como combinar recursos para produzir produtos desejados (e nosso conhecimento do que pode ser produzido).

Os recursos e como utilizá-los para se atingir a um determinado objetivo, para se fazer algo, que pode ser a solução ou minimização de um problema ou a geração de uma oportunidade.

<https://pt.wikipedia.org/wiki/Tecnologia> Acesso em: 15 jan. 201610

Tecnologia da Informação Pode-se definir Tecnologia da Informação (TI) como o conjunto de todas as atividades e soluções providas por recursos de computação que visam a produção, o armazenamento, a transmissão, o acesso, a segurança e o uso das informações. $\mathrm{Na}$ verdade, as aplicações para TI são tantas - e estão ligadas a tantas áreas - que há diversas definições para a expressão e nenhuma delas consegue determiná-la por completo. É a área da informática que trata a informação, a organização e a classificação de forma a per- 
mitir a tomada de decisão em prol de algum objetivo. A tecnologia da informação pode contribuir para alargar ou reduzir as liberdades privadas e públicas ou tornar-se um instrumento de dominação. TI refere-se, de modo geral, à coleção de recursos de informação de uma organização, seus usuários e a gerência que os supervisiona, inclusive a infraestrutura de Tl e todos os outros sistemas de informação em uma organização.

<https://pt.wikipedia.org/wiki/Tecnologia_da_informação> Acesso em: 24 ago. 201782

The Cave (Cave Automatic Virtual Environment) Uma espécie de teatro de realidade virtual, formado por um cubo de aproximadamente 3 metros quadrados, onde imagens eram projetadas para cercar os visitantes de sons e visões. Uma ou mais pessoas caminhavam livremente pelo espaço, utilizando óculos estereoscópicos, e seus movimentos eram rastreados - a fim de ajustar as imagens projetadas. O visitante, ao mesmo tempo, manipulava objetos tridimensionais através de um controle remoto com 3 botões. O campo de visão do espectador era preenchido com imagens, criando assim a sensação imersiva, ao mesmo tempo em que permitia a livre movimentação. O espaço podia ser utilizado por diversos visitantes simultaneamente, e suas sensações compartilhadas.

<http://eu.oheuaqui.com/2tYg3Br> Acesso em: 25 jul. 2017 66, 160

The Virtual Boy O Virtual Boy é um console portátil projetado por Gunpei Yokoi (pai de criações famosas como Game and Watch e Game Boy), que foi lançado em agosto de 1995 e se tornou o maior fracasso da Nintendo. Com um processador de 32 bits (o primeiro portátil da história a apresentar tal processador, seis anos antes do Game Boy Advance) e duas telas no formato de um óculos apoiado sobre 
um tripé, o portátil oferecia gráficos 3D, em uma tentativa de se aproveitar da moda de "realidade virtual" que assolava o mundo na época.

<https://pt.wikipedia.org/wiki/Virtual_Boy> Acesso em: 26 jul. 2017 V. , 66,160

Turning the Pages Turning the Pages is software technology for viewing scanned books on-line in a realistic and detailed manner. It was developed by the British Library in partnership with Armadillo Systems. The original version, first released in 1997, uses Adobe Shockwave. In January 2007 version 2.0 version was developed for Microsoft Vista using a browser-based Windows Presentation Foundation format. Features include page turns that are modeled on the actually deformation of different types of material (for example in a book with vellum pages, which is heavier than printed on paper, will appear to collapse under its own weight as it is turned). For certain books, such as the Sherborne Missal, the gold leaf catches the light as the book moves around.

The British Library has released a 'Turning the Pages Toolkit' for libraries around the world to put their collections online.

The Codex Leicester along with Codex Arundel was one of the first to be made available in the 2.0 format, with Bill Gates saying 'This is an innovative way to bring treasures - including mine - to a new audience'.

<https://en.wikipedia.org/wiki/Turning_the_Pages> Acesso em: 19 jul. 201747

Twitter Twitter é uma rede social e um servidor para microblogging, que permite aos usuários enviar e receber atualizações pessoais de outros contatos (em textos de até 280 caracteres, conhecidos como 
"tweets"), por meio do website do serviço, por SMS e por softwares específicos de gerenciamento. As atualizações são exibidas no perfil de um usuário em tempo real e também enviadas a outros usuários seguidores que tenham assinado para recebê-las. As atualizações de um perfil ocorrem por meio do site do Twitter, por RSS, por SMS ou programa especializado para gerenciamento. O serviço é gratuito pela internet, entretanto, usando o recurso de SMS pode ocorrer a cobrança pela operadora telefónica. O twitter foi criado em Março de 2006 por Jack Dorsey, Evan Williams, Biz Stone e Noah Glass e foi lançado em Julho de 2006 nos EUA. A ideia inicial dos fundadores era que o Twitter fosse uma espécie de "SMS da internet" com a limitação de caracteres de uma mensagem de celular. Inicialmente chamada Twttr (sem vogais), o nome da rede social, em inglês, significa gorjear. A ideia é que o usuário da rede social está "piando" pela internet. Desde sua criação, o Twitter ganhou extensa notabilidade e popularidade por todo mundo. Algumas vezes é descrito como o "SMS da Internet". Jack Dorsey é o atual CEO da empresa.

<https://pt.wikipedia.org/wiki/Twitter> Acesso em: 06 jan. 2018 130, 132,133

\section{V}

Valve Valve Corporation (também conhecida como Valve Software, e comumente referida como Valve) é uma empresa desenvolvedora de jogos eletrônicos e de distribuição digital norte americana com sede em Bellevue, Washington, Estados Unidos. Seu escritório subsediado em Luxemburgo para as regiões europeias, Valve S.a.r.l, foi aberto em 2012. Fundada em 1996 como Valve L.L.C. pelos ex-funcionários da Microsoft Gabe Newell e Mike Harrington, a empresa desenvolveu os jogos aclamado pelas críticas Half-Life, Counter-Strike, Portal, Day of 
Defeat, Team Fortress, Left 4 Dead e Dota 2. Também desenvolveu e faz a manutenção de Source, motor gráfico utilizado pela maioria de seus jogos, e a plataforma de distribuição de softwares Steam, que levou ao Steam Machine, uma linha de computadores pré montados rodando SteamOS.

<https://pt.wikipedia.org/wiki/Valve_Corporation> Acesso em: 26 jul. 201766,160

Victoria and Albert Museum The Victoria and Albert Museum (often abbreviated as the $V \& A$ ), London, is the world's largest museum of decorative arts and design, housing a permanent collection of over 4.5 million objects. It was founded in 1852 and named after Queen Victoria and Prince Albert.

<https://en.wikipedia.org/wiki/Victoria_and_Albert_Museum> Acesso em: 02 ago. 2017 45, 48, 50, 54

View-Master Invented by William Gruber and marketed by Harold Graves, View-Master was a successor to the stereograph viewer popularized in the 19th century by Oliver Wendell Holmes. But View-Master was an improvement over the traditional stereograph; it offered seven stereo views on each reel, compared with the stereograph's one view per card.

<http://www.3dstereo.com/vmhist.html> Acesso em: 25 jul. 201766, 160

Virtual Fixtures A virtual fixture is an overlay of augmented sensory information on a workspace in order to improve human performance in direct and remotely manipulated tasks. Developed in the early 1990s by Louis Rosenberg at the US Air Force, virtual fixtures was a pioneering platform in virtual reality and augmented reality technologies. 
<https://en.wikipedia.org/wiki/Virtual_fixture> Acesso em: 25 jul. 2017 66,160

VPL VPL Research was one of the first companies that developed and sold virtual reality products. It was founded by VR pioneer Jaron Lanier in 1985. VPL started in the corner of Lanier's cottage in the San Francisco Bay Area. "VPL" stood for "Visual Programming Languages", and Lanier said that the goal of the company was to create a visual programming language to bring programming to a mass audience. In 1990, VPL Research filed for bankruptcy and in 1999 all of its patents were bought by Sun Microsystems.

<https://en.wikipedia.org/wiki/VPL_Research> Acesso em: 26 jul. 2017 66, 160

VRML VRML (Virtual Reality Modeling Language, que significa: Linguagem para Modelagem de Realidade Virtual) é um padrão de formato de arquivo para realidade virtual, utilizado tanto para a Internet como para ambientes desktop. Por meio desta linguagem, escrita em modo texto, é possivel criar objetos (malhas poligonais) tridimensionais podendo definir cor, transparência, brilho, textura (associando-a a um bitmap). Os objetos podem ser formas básicas, como esferas, cubos, ovóides, hexaedros, cones, cilindros, ou formas criadas pelo próprio programador, como as extrusões. Além dos objetos, também é possivel acrescentar interatividade a estes por meio de sensores, podendo assim deslocá-los de posição, acrescentar luz, produzir um som quando o objeto é clicado ou o avatar simplesmente se aproxima dele, e abrir um arquivo ou página da Web, ou ainda outra página em VRML, quando o objeto é acionado. Não é necessário um software específico para a criação de arquivos VRML (embora existam), uma vez que os objetos podem ser todos criados em modo 
texto. Usualmente a extensão para esta linguagem é .wrl. Suplantado pela norma X3D, (1) que integra a linguagem VRML com XML e estende as capacidades de modelação e interação da norma VRML97.

<https://pt.wikipedia.org/wiki/VRML> Acesso em: 26 jul. 2017 66, 160

\section{W}

WeChat WeChat is a Chinese social media (instant messaging, commerce and payment services) mobile application software developed by Tencent. It was first released in 2011 and by 2017 it was one of the largest standalone messaging apps by monthly active users, with over 963 million monthly active users. It is widely known as one of the world's most innovative and versatile app and China's "App For Everything", with numerous unique functions and platforms ranging from payment to social media to services to shopping and more, that are equivalent to multiple Google Play or Apple Store's apps, but merged into one. <https://en.wikipedia.org/wiki/WeChat> Acesso em: 24 ago. 201755

WhatsApp Messenger WhatsApp Messenger é um aplicativo multiplataforma de mensagens instantâneas e chamadas de voz para smartphones. Além de mensagens de texto, os usuários podem enviar imagens, vídeos e documentos em PDF, além de fazer ligações grátis por meio de uma conexão com a internet. O software está disponível para Android, BlackBerry OS, iOS, Symbian, Windows Phone e Nokia. A empresa com o mesmo nome foi fundada em 2009 por Brian Acton e Jan Koum, ambos veteranos do Yahoo e está sediada na cidade estadunidense de Santa Clara, na Califórnia.

<https://pt.wikipedia.org/wiki/WhatsApp> Acesso em: 24 ago. 2017 55 
Workflow Seqüência de passos necessários para que se possa atingir a automação de processos de negócio, de acordo com um conjunto de regras definidas. O conceito de workflow foi concebido de acordo com a noção de processos, permitindo que estes possam ser transmitidos de uma pessoa para outra de acordo com algumas regras. $\bigcirc$ gerenciamento de workflow possui um conjunto de ferramentas para administração de monitoramento, para controlar aplicações clientes do workflow, as aplicações invocadas, ferramentas de processos dentre outras. Sistemas de workflow se inserem no contexto geral de software cujo objetivo é o suporte ao trabalho cooperativo, onde se enfatiza a interação entre usuários, e não apenas a interação usuário/sistema 13

\section{$\mathbf{Y}$}

YouTube YouTube is an American video-sharing website headquartered in San Bruno, California. The service was created by three former PayPal employees - Chad Hurley, Steve Chen, and Jawed Karim - in February 2005. Google bought the site in November 2006 for US\$ 1.65 billion; YouTube now operates as one of Google's subsidiaries. <https://en.wikipedia.org/wiki/YouTube> Acesso em: 06 jan. 2018130 


\section{Siglas}

\section{Símbolos}

3D tridimensional $\underline{V_{1}}$ 3D

A

Al Artificial Intelligence $\mathrm{V}$. Al

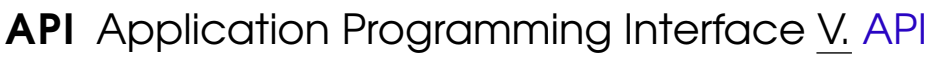

AR Augmented Reality V. realidade aumentada

C

CAVE Cave Automatic Virtual Environment V. The Cave (Cave Automatic Virtual Environment)

CHESS Cultural Heritage Experiences through Socio-personal interactions and Storytelling $\mathrm{V}$. Projeto CHESS

CMHR Canadian Museum for Human Rights $V_{\text {. }}$ Canadian Museum for Human Rights

CMS Content Management System V. Sistema de Gerenciamento de Conteúdo, 115, 116, 117

D

DAMA Data Management Association ‥ DAMA

DB database $V$. banco de dados

DNG Digital Negative $\underline{\text { V. }}$ DNG

DPI dots per inch $\underline{\text {. }}$ DPI 
DRM Digital Rights Management $\underline{\text {. }}$ Gestão de direitos digitais

E

ECMS Enterprise Content Management System ‥ Sistema de Gerenciamento de Conteúdo, 114

EMDAWG Embedded Metadata Working Group 112

$\mathbf{G}$

GLAM Galleries, Libraries, Archives and Museums V. OpenGLAM

GPL GNU Public License V. GNU Public License

H

HMD Head Mounted Display $\underline{\text {. }}$ HMD

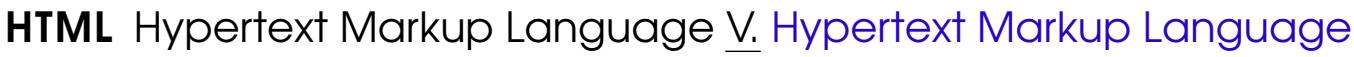

HTTP Hypertext Transfer Protocol … Protocolo de Transferência de Hipertexto

I

IA Inteligência Artificial V. AI

IBRAM Instituto Brasileiro de Museus V. IBRAM

ICOM International Council of Museums $\mathrm{V}$. ICOM

IOT Internet of Things $\mathrm{V}$. IOT

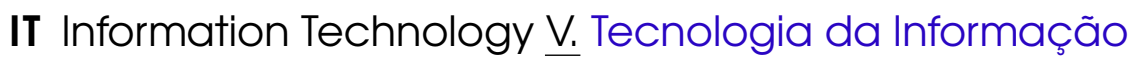

K

K7 Fita cassete V. fita cassete

KPI Key Performance Indicators V. KPI

M

MIT Massachussets Institute of Technology $\underline{\text {. }}$ MIT

$\mathbf{N}$ 
NFC Near Field Communication $\underline{\text {. }}$ NFC

0

OCR Optical Character Recognition V. OCR

$\mathbf{P}$

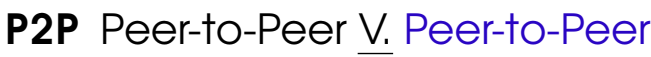

PPP pontos por polegada $\underline{V}$. DPI

Q

QTVR QuickTime Virtual Reality $\underline{\text {. }}$ QuickTime VR

$\mathbf{R}$

RA Realidade Aumentada V. realidade aumentada

RFID Radio-frequency identification V. RFID

T

II Tecnologia da Informação V. Tecnologia da Informação

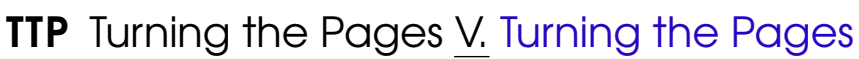

U

UPDIG Universal Photographic Digital Image Guidelines 107

V

V\&A Victoria and Albert Museum V. Victoria and Albert Museum

VPL VPL Research V. VPL

VRML Virtual Reality Markup Language V. VRML

W

WWW World Wide Web V. World Wide Web 


\section{Índice Remissivo}

$3 D, 56,59,67,68,70,106,161,162, \quad$ Battlezone, 67, 161

164

bluetooth, 64

A

acesso aleatório, 50

Bluetooth LE, 64

bluetooth-le, 64

Adobe, 110

British Museum, 81

Al, 106

C

aleatório, 50

Amazon, 71, 164

API, 115, 124

aplicativo, 63

Apple, 68, 71, 162, 164

Apple Computer, 68, 162

$A R, 58,60,65,81,82$

arte, 16

arte-educação, 5

Atari, 67, 161

aura, 148

Autodesk, 70, 164

B

banco de dados, 115

base de dados, 115

cadência, 57

Canadian Museum for Human

Rights, 114

Cardboard, 69, 163

CHESS, 81

cibernética, 23

Ciência Aberta, 119

ciências, 16

CMHR, 114

CMS, 114-117

código aberto, 13, 120, 142

código QR, 52

código-fonte, 120

computação, 16

computadores, 10 
console, 56, 67-69, 161-163

CRM, 96

crowdsourcing, 93, 95, 96, 103

D

DAMA, 125

Damien Broderick, 58, 68, 162

Data Management Association, 125

def-API, 124

def-IoT, 62, 79

def-NFC, 64

def-RFID, 64

difusão da inovação, 76

diorama, 43

Disney Studios, 70, 163

DNG, 110

DOOM, 68, 162

DPI, 108

E

ECMS, 114

edutainment, 80

eletrônica, 10

EMDAWG, 112

Erwartungshorizont, 21

espectador, 16

estereoscopia, 56

estética da recepção, 14 ex situ, 5, 12, 79, 84, 91, 94, 98, 140, $143,147,149$

$\mathbf{F}$

Facebook, 69, 71, 130, 133, 163, 164

fita cassete, 50

fluxo de trabalho, 13

frame rate, 57

G

Geração Y, 129

Google, 69, 71, 163, 164

guia virtual, 63

H

heatmap, 89

hipermídia, 67, 160

HMD, 66, 70, 106, 160, 163, 360

HMD (head-mounted display, ou capacete de realidade virtual), 66, 160

HTC, 69, 163

HTC Vive, 69, 163

I

IBRAM, 92, 94

ICOM, 86

id Software, 68, 162

IMU, 57 
in situ, 5, 12, 28, 30, 79, 82, 84, 91, millenials, 129

$98,103,140,143,147-149$

MIT, 67, 160

Instagram, 32, 127, 130

Museu Salvador Dali, 70, 81, 163

Instituto de Tecnologia de Massa-

Myron Krueger, 66, 160

chussets, 67,160

Inteligência Artificial, 106

Internet, 20, 92

IOT, 62, 79

N

não-linear, 50, 82

NFC, 64

IT, 82

Nintendo, 68, 162

J

Jaron Lanier, 67, 161

Judas Mandala, 58, 68, 162

\section{K}

Kik, 56

Kik Messenger, 56

KPI, 134-136

$\mathbf{L}$

Linden Lab, 69, 162

Linkedln, 130

0

OCR, 104

Oculus, 69, 163

Oculus Rift, 69, 163

Omnichannel, 97

omnichannel, 97, 98

Open Science, 119

open source, 120,142

OpenGLAM, 122

$\mathbf{P}$

percepção, 16

M

pixel, 107

Magic Leap, 70, 164

PlayStation, 69, 163

mapa de calor, 89

PlayStation VR, 69, 163

Mega Drive, 68, 161

Playstation VR, 69, 163

metadados, 17, 48, 110, 111, 115,

podcasting, 50

124

podcasts, 50

metadata, 17, 124

PPP, 108

Microsoft, 71, 164

produção, 16 
Projeto CHESS, 81, 82

Projeto Morpheus, 69, 163

Q

QuickTime VR, 68, 162

$\mathbf{R}$

$R A, 58,60,65,81,82$

Realidade Aumentada, 81

realidade aumentada, 58, 65, 81 , 82,127

realidade virtual, 65

redes, 10

Regras de Negócio, 117

resolução, 105

resolução de imagem, 105

RFID, 64

\section{S}

Samsung, 71, 164

scanner, 104, 106

scanners, 104

Second Life, 69, 162

Sega, 68, 69, 161, 162

selfie, 32,127

Sensorama, 66, 160

sensores, 63

Sistema de Gerenciamento de

Conteúdo, 114

smartphone, 56
Smithsoniam Museum, 70, 164

Smithsonian, 112

Smithsonian Institution, 112

Snapchat, 56, 131

software, 13

Sony, 69, 71, 163, 164

source code, 120

Squint/Opera, 63

Street View, 69, 163

\section{$\mathbf{T}$}

tecnologia, 5, 10, 12, 13, 27, 28, 33, $35,36,42,43,46,48-50,54,55$, $60,75,82,83,91,94,95,101$, $105,120,123,140,147,159$ Tecnologia da Informação, 82 tecnologias, $36,38,48,50,60,61$, $64,76,79,83,117,127$ tecnologias experienciais, 47 Teoria da Difusão da Inovação, 76 The Cave, 67, 161 The Cave (Cave Automatic Virtual Environment), 67, 161

The Virtual Boy, 68, 162

Thomas Zimmerman, 67, 161

TI, 82

Twitter, 130, 132, 133 
U

Unidade de Medição Inercial (IMU), 57

UPDIG, 107

V

Valve, 69, 163

Valve Corporation, 69, 163

Victoria and Albert Museum, 45,

$$
49,51,54
$$

View-Master, 66, 160

Virtual Fixtures, 68, 162
Virtual Reality Modelling Language (VRML), 68, 162

VPL, 67, 161

VPL Research, 67, 161

VRML, 68, 162

W

WeChat, 56

Whatsapp, 56

WhatsApp Messenger, 56

workflow, 13

Y

YouTube, 130 